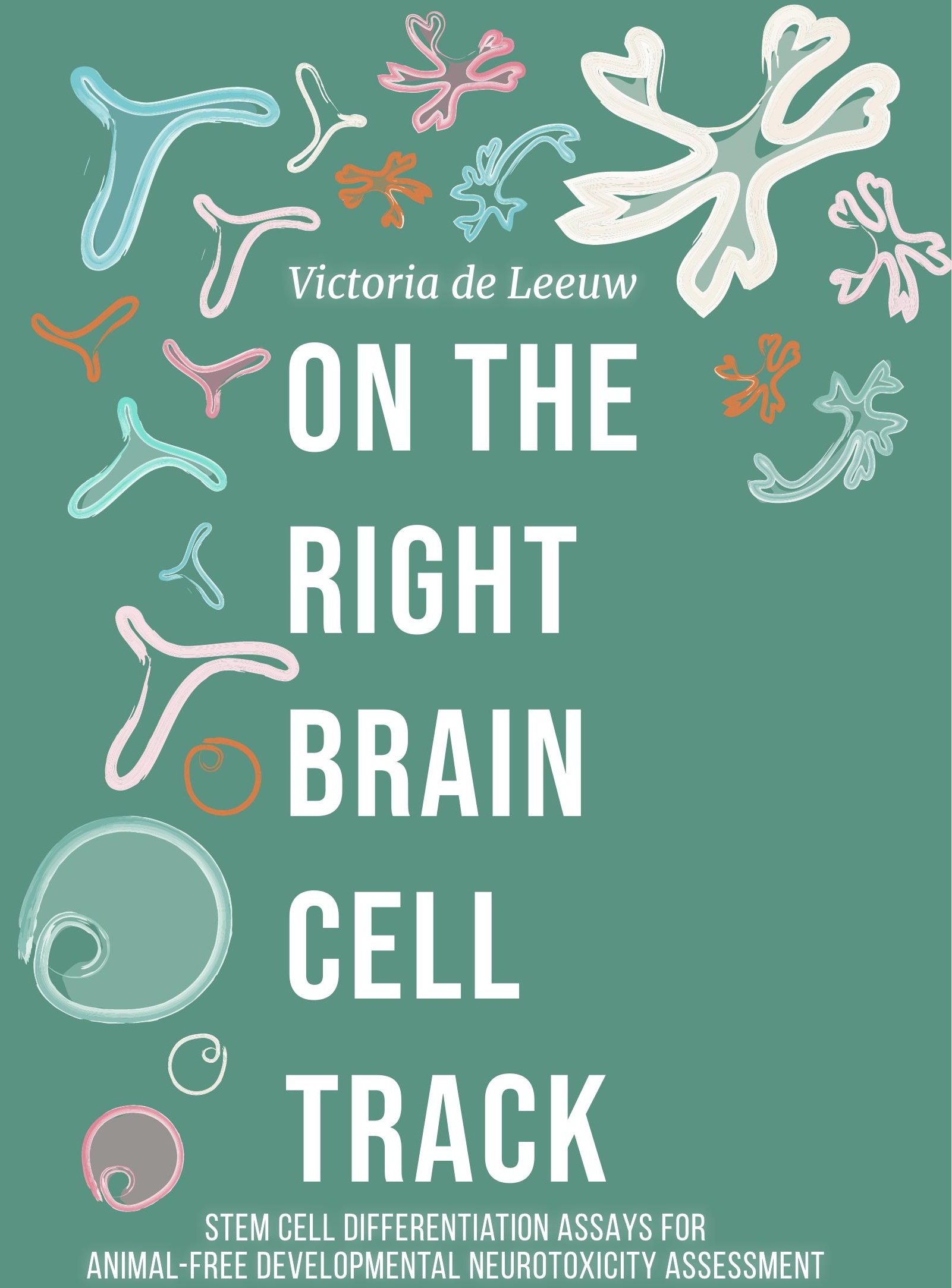





\section{ON THE RIGHT BRAIN CELL TRACK}

STEM CELL DIFFERENTIATION ASSAYS FOR ANIMAL-FREE DEVELOPMENTAL

NEUROTOXICITY ASSESSMENT

Victoria de Leeuw 
On the right brain cell track - Stem cell differentiation assays for animal-free developmental neurotoxicity assessment

(c) Victoria de Leeuw, 2021

ISBN/EAN: 978-94-6332-757-2

DOI: $10.33540 / 234$

Cover by Elsemieke de Boer

Printed by GVO Drukkers \& Vormgevers, NL

All rights reserved. No part of this thesis may be reproduced in any form or by any means, electronic or mechanical, including photocopying, recording or any information storage and retrieval without prior permission from the holder of the copyright. 


\title{
ON THE RIGHT BRAIN CELL TRACK
}

\author{
STEM CELL DIFFERENTIATION ASSAYS FOR ANIMAL-FREE DEVELOPMENTAL \\ NEUROTOXICITY ASSESSMENT
}

\section{OP HET GOEDE SPOOR NAAR HERSENCELLEN}

STAMCELDIFFERENTIATIE IN PROEFDIERVRIJE TESTEN VOOR ONTWIKKELINGSNEUROTOXICITEIT

(met een samenvatting in het Nederlands)

\section{Proefschrift}

ter verkrijging van de graad van doctor aan de Universiteit Utrecht op gezag van de rector magnificus, prof. dr. H.R.B.M. Kummeling, ingevolge het besluit van het college voor promo-

ties in het openbaar te verdedigen op dinsdag 11 mei 2021 des ochtends te 10.15 uur

door

Victoria Cathérine de Leeuw

geboren op 22 mei 1993 te Haarlem 


\section{Promotor:}

Prof. dr. A.H. Piersma

\section{Co-promotor:}

Dr. E.V.S. Hessel

Dit proefschrift werd mede mogelijk gemaakt door financiële steun van Stichting Proefdiervrij en het ministerie van Landbouw, Natuur en Voedselkwaliteit. 
'When I use a word,' Humpty Dumpty said in a rather scornful tone, 'it means just what I choose it to mean - neither more or less.'

'The question is,' said Alice, 'whether you can make the words mean different things.'

'The question is,' said Humpty Dumpty, 'which is to be the master - that's all.'

LEWIS CARROLL, Through the Looking-Glass 

CONTENTS

Abbreviations 9

Chapter 1

General introduction

Chapter 2 35

Exploring the biological domain of the neural embryonic stem cell test (ESTn): morphogenetic regulators, Hox genes and cell types, and their usefulness as biomarkers for embryotoxicity screening

Chapter 3

Culture conditions affect chemical-induced developmental toxicity in vitro: the case of folic acid, methionine and methotrexate in the neural embryonic stem cell test

Chapter 4

Oxygen tension influences embryonic stem cells in culture and has lineage specific effects on neural and cardiac differentiation

Chapter 5 103

Look-alikes may not act alike: Gene expression regulation and cell-type-specific responses of three valproic acid analogues in the neural embryonic stem cell test (ESTn)

Chapter 6

Differential effects of fluoxetine and venlafaxine in the neural embryonic stem cell test (ESTn) revealed by a cell lineage map

Chapter 7

An efficient neuron-astrocyte differentiation protocol from human embryonic stem cellderived neural progenitors to assess chemical-induced developmental neurotoxicity

Chapter 8

Neuronal differentiation pathways and compound-induced developmental neurotoxicity in the human neural progenitor cell test (hNPT) revealed by RNA-seq

Chapter 9

Going back and forth: episomal vector reprogramming of peripheral blood mononuclear cells to induced pluripotent stem cells and subsequent differentiation into cardiomyocytes and neuron-astrocyte co-cultures

Chapter10. 235

Summary, general discussion and concluding remarks

Appendix

Nederlandse samenvatting

List of publications

Dankwoord/acknowledgements

Curriculum Vitae 

$1 \mathrm{C}$

3R

ACR

AOP

ATRA

BMD

BMR

CDNA

CPF

CNS

DAPI

DMSO

DNA

DNT

EB

EHA

EMPA

FA

FC

FLX

hESC

hNPT

hiPSC

$\mathrm{IC}_{\mathrm{xx}}$

$I D_{x x}$

GO

$\mathrm{MeHg}$

MESC

MESTc

MESTn

MET

mRNA

MTX

MWMEA

NGS

NPC

NTD

PBMC

RNA

RNA-seq

qPCR

VNX

VPA

One-carbon metabolism

Replacement, Reduction, Refinement

Acrylamide

Adverse outcome pathway

All-trans retinoic acid

Benchmark dose

Benchmark response

Complementary DNA

Chlorpyrifos

Central nervous system

4',6-diamidino-2-phenylindole

Dimethyl sulfoxide

Deoxyribonucleic acid

Developmental neurotoxicity

Embryoid body

2-ethylhexanoic acid

2-ethyl-4-methylpentanoic acid

Folic acid

Fold change

Fluoxetine

Human embryonic stem cells

Human neural progenitor test

Human induced pluripotent stem cells

Inhibitory concentration of viability $x \times \%$

Inhibitory concentration of differentiation $x \mathrm{x} \%$

Gene ontology

Methyl mercury

Murine/mouse embryonic stem cells

Murine/mouse cardiac embryonic stem cell test

Murine/mouse neural embryonic stem cell test

Methionine

Messenger ribonucleic acid

Methotrexate

Multi-well micro-electrode array

Next generation sequencing

Neural progenitor cells

Neural tube defects

Peripheral blood mononuclear cells

Ribonucleic acid

RNA-sequencing

Quantitative polymerase chain reaction

Venlafaxine

Valproic acid 



\section{CHAPTER 1}

GENERAL INTRODUCTION 



\section{Animal testing and the transition towards animal-free testing}

\section{A brief history on animal testing}

The use of animals to understand the basic biology and physiology of humans and animals goes back to Ancient Greece [1]. During the Renaissance, animal use increased with the rise of scientific exploration and medical sciences in particular, and so did the resistance against animal testing [2]. By the end of the $19^{\text {th }}$ century the first laws that would protect animals against cruelty (e.g. the 1876 Cruelty to Animals Act and the 1898 Abolition of Vivisection in the United Kingdom) came into place. A few decades later, from the start of the $20^{\text {th }}$ century, the use of animal experiments became a legal obligation for companies for quality control of vaccines (e.g. the United States of America (US) Biologics Control Act from 1902). After a number of incidents involving drugs and chemicals in the 1950s', most notably the thalidomide tragedy and leakage of mercury into the Minamata bay [3,4], the number of animal experiments for regulatory purposes increased dramatically at the start of the 1960s'. In 1959, the scientists William Russell and Rex Burch defined three principles for humane experimental practices: Refinement, Reduction and Replacement, or the 3Rs [5]. In short, applying the 3Rs to an experiment would encompass decreasing the severity of harm to an animal, decreasing the number of animals being used and replacing the animal by non-living animals, insentient material or non-mammalian organisms while maintaining the quality of an experiment.

The application of the 3R principles did not gain much popularity until the end of the 1970s' when some countries included the principles in legislation [6]. For example, only in 1977 the first Dutch law on animal testing was installed, which dictated that the harm caused to the animal should be in proportion to the usefulness of the experiment (Wet op de Dierproeven, 1977 [7]). Alternatives to animal testing also had to be considered, which may have led to a moderate decrease in animal use, but the fear for the risks involving the use of alternatives hampered their implementation [8]. The introduction of genetically engineered animals in the $80 s^{\prime}$ and 90s', predominantly mice, led to a rise of their use in fundamental research [9]. Meanwhile, activist groups started to organise and protest, mainly in a non-violent manner, against the use of laboratory animals to the advantage of humans $[10,11]$. Next to the societal pressure, there were also scientific concerns about the validity of animal testing [12], which led to more research into alternative methods and the generation of a roadmap by the US National Research Council [13] that would spur the transition towards animal-free research. The use of great apes was banned in 2010 in the European Union (EU) and from 2013 on, full bans on animal testing for cosmetics were installed in the EU and other countries around the world [14, 15]. The Dutch government announced in 2016 that it had the ambition to become one of the international front runners in animal-free testing methods and the US Environmental Protection Agency (EPA) declared that it will phase out all animal testing by $2035[16,17]$. These and discoveries and initiatives from academia, industry and governments are all promising signs that the transition towards animal-free testing is accelerating.

Four areas of animal use can be defined: fundamental research, translational research, educational purposes, and tests required by law (safety testing and efficacy testing (pre-clinical trials)). The National committee on animal testing (NCad) that advised the Dutch government 
identified safety testing as the area where most reduction of animal testing could be achieved first [18]. At the same time, while alternatives to animal testing are widely used in research and development applications, the acceptance in the regulatory arena of safety testing is deemed challenging [19-21].

\section{Current regulatory testing frameworks for reproductive \& developmental toxicity and developmental neurotoxicity}

The safety of compounds is assessed according to a number of guidelines that are predominantly relying on animal testing. In short, a safe dose is derived by a no observed adverse effect level (NOAEL) from a range of doses that are given to animals, which is then divided by safety factors to determine a safe level for humans. Developmental and reproductive toxicity (DART) testing takes up the most animals according to calculations done for the Registration, Evaluation, Authorisation and Restriction (REACH) programme, with an average of 4000-4500 animals per compound for all tests required by law $[22,23]$. DART studies assess the potential of a compound to affect male or female fertility along the whole reproduction cycle and the development of the embryo and foetus during pregnancy [24]. The testing regime is dependent on the application, tonnage of the compound and certain triggers in one of the obligatory studies. Industrial chemicals can then be assessed by the Organisation for Economic Co-operation and Development (OECD) guidelines OECD 421 (Reproduction/Developmental Toxicity Screening) in combination with OECD 422 (Combined Repeated Dose Toxicity Study with OECD 421), OECD 414 (Prenatal Developmental Toxicity Study) and OECD 443 (Extended One-Generation Reproductive Toxicity Study) [25-27]. Agrochemicals are assessed by OPPTS 870.3700 (Prenatal Developmental Toxicity Study) and OPPTS 870.3800 (Reproduction and Fertility Effects), and pharmaceuticals are tested according to the ICH S5 (R3) [28-30].

Developmental Neurotoxicity (DNT) is defined as adverse effects caused by a compound during the various phases of brain development, which ranges between early embryonic stages to weaning [31, 32], although brain development actually continues into adolescence in mammals [33]. For industrial chemicals and agrochemicals DNT is assessed in OPPTS 870.6300 (Developmental Neurotoxicity Study), the OECD 426 (Developmental Neurotoxicity Study) and in the DNT cohort of OECD 443, but is only performed when there is a trigger in one of the other tests mentioned above [27, 31]. For pharmaceuticals there is only one neurobehavioural assessment performed in the first two weeks after birth [30]. All guidelines have a similar design and mainly rely on apical endpoints, such as morphological malformations, physiological alterations and behavioural disturbances [23, 34]. By 2009, only a hundred compounds were tested for DNT, while many more are suspected to affect the developing brain $[35,36]$.

Both DART and DNT guideline testing have produced many valuable insights into the (neuro)developmental toxicity of compounds and underlying mechanisms. However, the disadvantages of this testing regime have become more apparent over the last years. When REACH was rolled out, it was soon realised that testing of all the compounds in the programme requires a large amount of animals, hence money and time, which challenges the feasibility of the traditional approach [22]. Other fields of research and development made it clear that the sensitivity of the endpoints may not be sufficient, mechanistic understanding is limited and the 
human relevance of the findings is questionable. This is for example apparent in the high attrition rates of pharmaceuticals that enter clinical trials where neurological side effects are one of the major reasons to stop the development of a drug $[37,38]$.

A reconsideration of traditional regulatory testing towards a more mechanism-based approach has led to a number of initiatives that can reduce or replace animals [39-42]. Integrated Approaches to Testing and Assessment (IATA) are flexible, structured strategies that allow different types of data to be weighted and integrated to answer questions about the hazard, safety or risk of a compound within a specific regulatory decision context [43]. These include methods like read-across, (quantitative) structure-activity relationships ((Q)SAR), integrated or sequential testing strategies (ITS or STS, respectively), or weight-of-evidence approaches (WoE), which can be done with different kinds of tests (in silico, in chemico, in vitro, in vivo). Adverse Outcome Pathways (AOP) are mechanism-based conceptual frameworks that identify key events from the molecular point where a compound interacts up to the level of an organism or population $[44,45]$. An AOP can also function as the basis of a IATA that can result in a series of standard (animal-free) tests to assess the effect of a compound [46-50]. Several proofs-ofconcept for AOPs on developmental toxicity (e.g. AOP 22, 43) and developmental neurotoxicity (e.g. AOP 13,42, 48, 54) have been built, but these only cover a small fraction of the known processes of neurodevelopment [51-53].

\section{Towards animal-free testing strategies}

This paradigm shift in regulatory testing provided opportunities for the application of animalfree methods. The EU Reference Laboratory for alternatives to animal testing (EURL ECVAM) was founded in 1992 to actively support the development, validation and acceptance of alternatives to animal testing. The use of animal-free methods is encouraged by REACH legislation $[54,55]$ and Health institutes such as the Medicines and Healthcare products Regulatory Agency and Food and Drug Administration have prioritised the need for alternative methods in the pre-clinical phase to predict drug safety for pregnant women as they are typically not enrolled in clinical trials [56]. A number of in vitro methods are accepted for regulatory use to assess relatively simple endpoints, such as eye irritation and skin sensitisation, which have been used actively since their introduction in the REACH annexes in 2016 [55, 57]. More complicated endpoints relating to (neuro)development are still in need of proper animal-free innovations.

Scientists have been working for decades already on the development of animal-free methods in collaboration with industry and governments. The main approach that is being taken relies on (human) cell-based in vitro models and non-mammalian organisms in combination with computer models that should together result in a prediction for humans. Initial validation of animal-free methods was performed by comparing one alternative model against animal data, sometimes together with a prediction model as has been done for e.g. the validation of the mouse cardiac embryonic stem cell test (MESTc) [58]. It was soon realised that this approach was not going to be fruitful, because a single in vitro test could never replace a whole animal. In addition, the reference material, i.e. animals, were never validated against human as such and do not always represent human physiology, therefore potentially missing human-relevant endpoints [59]. Large-scale projects were set up to test thousands of compounds in hundreds 
of simple in vitro cell culture reporter assays, of which the prime examples are ToxCast and Tox21, mainly aimed at finding mechanisms of toxicity, prioritising compounds of concern and developing predictive tools to assess human toxicity [60-62]. Over the course of the past ten years, in vitro models have become more sophisticated, combining multiple (human) cell types that grow in 3D in order to more faithfully replicate human-relevant processes. Also guidelines were being developed to ensure good laboratory practices for in vitro tests and analysis of complex data that should aid regulatory acceptance [63-66].

Embryonic development is a complex processes, which requires a combination of tests with a higher degree of complexity than the relatively simple ToxCast assays. Over the years, a range of alternative (but not fully animal-free) tests became available for developmental toxicity assessment [67], of which three of them were validated by ECVAM: the limb bud test, the whole embryo culture and the mESTc $[58,68,69]$. These and others were combined in a test strategy (ReProTect) that was able to predict the adverse effects on reproduction of ten compounds [70]. Another promising model is the zebrafish embryotoxicity test, which has the advantage of being a fast-growing, transparent whole organism that allows for easy scoring of morphological features [71]. While these models have been predominantly used for screening purposes, their application for mechanism-driven toxicology is widely investigated, which could provide biological input for prediction models [72-76].

The development of the human brain is equally complex as development and very speciesspecific with regard to temporal and regional differences $[33,77]$. A series of workshops was organised by the Joint Research Centre (JRC) and Center for Alternatives to Animal Testing (CAAT) from 2005 on to facilitate the advancements of animal-free methods for DNT assessment, mainly relying on a combination of test systems integrated in testing strategies (i.e. TestSmart and ISNET) [78-81]. The focus was initially on pathways and processes that were highly conserved across species. More recently, attention shifted to later points in neural development, potentially due to the rise of human stem cell-based models and the growing interest to study components of more complex biological processes such as learning and memory, which are especially challenging to assess in animals. Over the past fifteen years, lists of critical processes for normal brain development were formulated that could be assessed as endpoint for DNT, amongst others commitment and proliferation, apoptosis, migration, neural and glial differentiation, neurite outgrowth, myelination, synaptogenesis and network formation $[79,82$, 83], based on neural development in vivo [84, 85]. These processes could be assessed using a range of animal-free approaches that could aid in more targeted animal testing or even predict compound effects without any animal testing $[52,80,81,86]$. There is a multitude of available in vitro systems (reviewed in Hessel et al. [85]; Schmidt et al., [87]; Fritsche et al., [82]) that have been assessed using endpoint-specific or known DNT compounds $[88,89]$ to determine their applicability domain. A framework has been developed to assess the 'readiness level' of in vitro tests for regulatory use [48] and a proof of concept to assess DNT in multiple of these systems has been published under the National Toxicology Program (DNT-DIVER; [90]). Current efforts to develop an OECD guideline for DNT are focussing on the selection of reference compounds, selection of in vitro tests, data generation with these compounds and tests, and proofs-ofconcept to accelerate the use and acceptance of the proposed battery of in vitro tests for regulatory DNT assessment $[52,81]$. 


\section{Stem cells for in vitro developmental neurotoxicity testing}

The first notion of stem cells in scientific literature dates back to the late $19^{\text {th }}$ century by Ernst Haeckel, who used the word "Stammzelle" both in an evolutionary meaning as single-cell predecessor of all multicellular organisms and in an embryological meaning as the fertilised egg that gives rise to a whole organism [91]. Since then, the term has been used both in the context of the origins of the hematopoietic system and the germline [92]. In its current definition, stem cells are cells that have the ability to both self-renew and develop in any specialised cell through the process of differentiation. They have proven to be of great value to study fundamental questions in developmental biology, as well as for medical applications. Since the 90s', stem cells have been used in various fields of toxicology, specifically for studying embryotoxicity since 1991 and neurotoxicity since 2003 [93-95]. The use of stem cells have gained popularity in DNT research especially in the last ten years [96], potentially due to improved control over differentiation of the cells into neural progenitor cells (NPCs), neurons and glial cells.

Mouse and human cells are the most used sources for stem cell derivation. While both mouse and human embryonic stem cells ( $\mathrm{mESC}$ and hESC, respectively) are obtained from the blastocyst stage, the state of pluripotency of mESC may be more 'naïve' than hESC [97]. Maintenance and differentiation of the mESC and hESC is also performed in different kinds of medium with different factors to repress and induce (neural) differentiation [98]. This may not be surprising as rodent and human neural development become progressively different over time; the time for development, the specific events at each point in development and the general structure, cellular composition and function of the brain [33, 99-102]. Still, mESC are valuable study objects, because most compound data is historically derived from mouse or at least rodent experiments, their differentiation is better understood and early differentiation is well conserved across species $[103,104]$. Although more complicated, human-based neural differentiation systems are quickly being improved by a wealth of differentiation protocols becoming available and have the obvious advantage in that they represent the ultimate target species: the human.

\section{Murine embryonic stem cells}

The first successful derivation of mESC from the inner cell mass of mouse blastocysts was performed in 1981 by two independent groups $[105,106]$. Soon after the first isolation, researchers realised it was most beneficial for mESC to grow them in an embryoid body (EB) structure consisting of a few hundred cells resembling anterior prestreak embryo that could differentiate into the three germ layers: ectoderm, mesoderm and endoderm [107]. This EB structure formed the basis for mESTc, first described by Spielmann et al. in 1997 to assess embryotoxicity in vitro. This 10-day protocol consisted of ES-D3 embryonic stem cells that spontaneously differentiated into beating cardiomyocytes representing the embryo, in which differentiation inhibition by compounds was studied, together with adult $3 \top 3$ fibroblast viability testing representing the mother. The test was combined with a prediction model and validated by ECVAM as an official alternative to animal testing, which was widely used as screening tool for developmental toxicity in the pharmaceutical sector $[58,108]$. Limits of mESTc as a stand- 
alone test were acknowledged, and one of the suggested improvements was to develop other differentiation routes along the other germ layers to improve its application.

Okabe et al. [109] were the first to differentiate mESC into neurons and it was already known since 1983 that all-trans retinoic acid (ATRA) could induce neural differentiation [110]. Since then several neural differentiation protocols were developed (e.g. [111-115]), which are mainly based on serum deprivation, addition of ATRA, addition of growth factors or a combination thereof [116]. The model used in this thesis is the mouse embryonic neural stem cell test (mESTn), which was based on protocols developed by Okabe et al. and Bibel et al. [109, 112, 117]. The starting point for the test is the same as the mESTc to allow for comparison between cardiac and neural differentiation. Like the mESTc, mESTn involves growing ES-D3 stem cells in an EB, which is then differentiated into the neural lineage by the addition of ATRA. Two days later, the serum is decreased and omitted, and a range of growth factors is added to simulate neural growth from the EB out into a corona.

\section{Human stem cells}

Human embryonic stem cells were derived for the first time in 1998, eighteen years after the first mESC isolation [118]. This elicited much ethical debate as this involved the destruction of human embryos in the blastocyst stage (left-overs from in vitro fertilisation procedures) and the incorrect assumption that it is possible to generate embryos from just these cells [119]. Taking these ethical considerations into account, researchers have shown that the use of hESC have provided valuable insights into basic developmental processes that are unique to human and can be just as predictive in compound screens as animals [98, 120,121]. This added value can justify their use, only by laboratories that have licence to perform restricted experiments with hESC. In the last ten years, the number of culturing and differentiation protocols for these cells greatly expanded and also found its way to the toxicology field. The developments in this field follow at a rapid pace, however historically researchers are more familiar working with rodent cells rather than with human cells, which may be one of the reasons for reproducibility issues [122-124]. While for e.g. regenerative medicine purposes the aim is to differentiate stem cells into a specific and pure population, basic research and toxicology may also benefit from differentiation protocols that generate mixed cell populations to study the emergence and interaction between these cells. Although commercial (neural) differentiation protocols and some neural progenitor cell lines are becoming more common to use, many researchers, also in the toxicology field, are developing their own custom protocols. Almost all protocols work with a two-step procedure that allows for selection of cells during differentiation and can vary in length from several weeks to months. Differences can be mainly found in culturing in 2D or 3D and the kind of cell types that researchers want to achieve. Labs have managed to differentiate stem cells into a mixture of neurons and astrocytes (e.g. [123, 125-129]), with oligodendrocytes ([130-132]) and microglia that had to be cultured separately and incorporated in relatively simple systems $[133,134]$ or developed innately in complex cerebral organoids [135]. The mostly used hESC cell source is the female $\mathrm{H9}$ (NIH code WA09) cell line, which is also used in this thesis.

In 2007, a whole new avenue of research was opened when Shinya Yamanaka proved for the first time that human somatic cells could be reprogrammed back to their pluripotent state, for 
which he won the Nobel Prize together with John Gurdon [136]. Induced pluripotent stem cells (iPSC) can be generated by taking e.g. skin or blood cells from an individual and transfect these cells with pluripotency transcription factors (initially OCT4, SOX2, CMYCand KLF4[137]). As for $\mathrm{hESC}$, these cells can be then differentiated into any cell type, with the advantage that no human embryonic material is needed to obtain these cells and the cells can be led back to a specific individual, allowing for personal assessment. iPSCs have also already been widely used in DNT research [138-142]. There is some debate about to what extent these cells are programmed back into a truly naive state as part of the epigenome stays on the cells' genome even after reprogramming, but improved protocols are under development [143].

\section{Endpoints for in vitro developmental neurotoxicity}

In order to assess toxicity in an in vitro system, endpoints need to be defined that can indicate toxic responses and that are sensitive as well as robust. The series of DNT workshops resulted in a list of processes that need to be assessed in a DNT framework: neural progenitor proliferation, apoptosis and migration, neural crest cell migration, neuron differentiation, oligodendrocyte differentiation and maturation, neurite outgrowth, synaptogenesis and network formation [52]. Additional endpoints may encompass neural tube formation and closure, axon and dendritogenesis, axon guidance, synaptic pruning, synaptic plasticity, astrocyte differentiation and maturation [85], and microglia innervation and maturation. These endpoints can be measured and compared to cell viability to assess the specificity of the measured endpoint. A single or multiple endpoints can be measured in an in vitro system, depending on what the system is able to mimic, and it is highly unlikely that these processes can all be assessed in one model. Therefore, it is important to assess which endpoints are represented, sufficiently sensitive and robust in each in vitro test, and to what extent a selection of endpoints in a range of tests cover the whole spectrum of cell differentiation and function.

\section{Readouts for in vitro developmental neurotoxicity}

Endpoints can be measured in a number of ways, assessing in vitro systems on the level of genes, gene expression, protein expression, metabolites, morphology and/or function. Toxicology is moving towards a mechanism-based approach, which necessitates readouts that support this. That means that besides apical readouts such as morphology, viability and functionality [87], underlying mechanisms that lead to proper development of the nervous system should be studied.

Toxicogenomics is the field of research where omics technologies (e.g. genome profiling, transcriptomics, proteomics, metabolomics) are applied to study the underlying mechanism of how compound exposure might cause adverse effects on human health and the environment [144]. Transcriptomics, the study of gene expression of the whole genome, is currently the most commonly used omics tool in toxicology based on the assumption that gene expression of cells is changed when exposed to a toxicant $[145,146]$. Because of its comprehensive and unbiased approach it can aid in the characterisation of in vitro models and can explore new biomarkers and gene signatures in these models when they are exposed to compounds [147, 148]. The technology has become more popular in the past decades due to a decrease in price per sample 
and major improvements in sequencing and data analysis tools [149]. There is a rapid increase in the use of RNA sequencing (RNA-seq), a Next Generation Sequencing (NGS) technology based on massive parallel sequencing of the transcriptome [150, 151]. Compared to microarrays, the previous dominant transcriptomics platform for the past twenty years [152], RNA-seq has comparable performance on endpoint prediction with the advantage for detecting lowabundance genes $[153,154]$. Another advantage is that for RNA-seq no prior knowledge of the genome is needed, which is important for the analysis of unknown genes and transcript isoforms [150]. Regardless the platform, transcriptomics approaches have proven to be of great use in studies to reveal mechanisms of toxicity and make predictions for sensitive biomarkers that can indicate toxic effects of compounds for human risk assessment [145, 146, 149]. Especially in combination with in vitro systems, concentration and time dependent effects of compounds can be studied in a relatively high-throughput manner and can subsequently be linked to other readouts such as morphology and functionality [155-160]. Based on NGS data, qPCR markers can be selected to further study of individual genes as a high-throughput and less expensive technology for sensitive detection of gene expression changes in response to compounds.

Transcriptomics provide a wealth of data with at least more than 20.000 protein-coding genes and another 15.000 non-coding genes and splice variants, with new genes being discovered regularly [151]. The analysis of transcriptome data is challenging and guidelines for standardisation of omics data are only just being developed [161]. Still, a standard first step is to analyse which individual genes are differentially regulated using a statistical measure, for example a pvalue or false discovery rate value that can optionally be combined with a fold change value of the regulated gene to select for the most regulated genes. A second step may be to analyse in which processes the differentially expressed genes are involved. This can be done for individual genes through databases such as the National Center for Biotechnology Information (NCBI), GeneCards, Gene Ontology (GO), the Comparative Toxicogenomics Database (CTB) for compounds reference and the Monarch Initiative, MGI and MalaCards for disease reference [162168]. Groups of genes can also be analysed to study their interrelationships. For example, STRING can visualise relationships between proteins and STITCH can do this for proteins and compounds [169]. Platforms such as DAVID GOrilla calculate enrichment of biological pathways, molecular processes, cellular localisation and GeneAnalytics additionally calculates cell type, tissue and disease enrichment [170-172]. KEGG and WikiPathways can map gene or protein expression profile on molecular networks $[173,174]$. Other platforms specialise in prediction of cell types that are present in a cell culture compared to in vivo such as Lifemap Discovery, CoNTexT, TISSUES and TissueEnrich [171, 175-177]. A limitation in all these platforms is that they are based on lists of differentially expressed genes and do not use the level of gene expression in their analysis. Gene Set Enrichment Analysis (GSEA) and GO-Quant take into account the whole gene expression profile to determine whether a priori defined gene sets are enriched $[178,179]$. Due to the rise of single cell sequencing (scRNA-seq), it may become possible to predict cell types present in transcriptomics data of a whole cell culture, which has already been shown for blood samples. For more complex cultures this is still under development [180].

While gene expression, and especially whole transcriptome approaches, is a good first lead to discover mechanisms, these need to be confirmed on the level of protein expression. Proteins 
can be measured in multiple manners that are quantitative or semi-quantitative in nature. Examples of quantitative readouts are Western blots and proteomics, enzyme-linked immunosorbent assays and flow cytometry. A disadvantage of these techniques, however, is that localisation information is lost and detection of subtle effects or low-abundance proteins may pose a challenge. This can be problematic when studying e.g. synaptic markers in neurons. When using immunocytochemistry the information about localisation of proteins in cells can be retained and even co-localisation can be measured when using a microscope with sufficient resolution [138]. It is also possible to measure proportions of different cell types using selective markers as a proxy for differentiation, and other endpoints such as migration, proliferation and cell morphology [87]. Quantification is possible but challenging, especially in 3D in vitrosystems and dense cell cultures or in tissue. Generation of sufficient samples is needed to measure effects of compounds, which in turn requires powerful software that is able to analyse the large amount of images. There are promising developments in the integration of Artificial Intelligence into current imaging software that may greatly enhance the data quality of image-based technologies. Commonly free platforms to analyse image data are ImageJ and CellProfiler [181, 182]. For large compound screens, high content imaging machines are pivotal [87].

\section{Objective and outline of this thesis}

\section{Objective of this thesis}

The aim of this thesis is to contribute to the advances in animal-free assessment of compound-induced DNT by applying and improving the use of mESTn and a hESC-based neural differentiation test using a combinational approach of RNA-seq and immunocytochemistry linked with morphological or functional readouts. The mESTn as employed here is an assay that was previously developed in our lab [112], while the human neural progenitor test (hNPT) was set up within the course of this project. The use of the mESTn is mostly for the assessment of early neural differentiation processes and the application of the hNPT is mainly to assess later time points in neural development where species differences may play a more important role [102]. The outcomes of this thesis contribute to the following objectives:

- Development of a novel test based on neural differentiation of hESC-derived NPCs. This test can complement mESTn data informing on processes of later neural development such as synaptogenesis;

- Exploration of the biological domains of mESTn and hNPT. This will inform about the use of these tests in a larger framework of in vitro tests;

- Gaining mechanistic knowledge on compound-induced DNT using these in vitro models based on transcriptomics data;

- Investigation of the influence of basic culture conditions on neural differentiation in vitro. 


\section{Outline of this thesis}

A schematic overview of the chapters in this thesis is outlined in Figure 1. This thesis consists of two parts. The subject of the first part is the mESTn. In chapter 2 the biological domain of the mESTn was explored based on previously generated gene expression data of neural differentiation (day $0,3,4,5,6$ and 7 ) and a new set of gene expression data including a later time point in mESTn (day $0,7,13)$. Three dimensions of neural development were assessed through marker gene expression of morphogenetic regulators, Hox genes and cell types. The data was compared to in vivo datasets to pinpoint what mESTn mimics in terms of developmental stage and location along the developing neural tube. The effects of $24 \mathrm{~h}$ compound exposure on this specific gene set was also investigated using previously generated data of ten compounds to reveal compound signatures along these three dimensions of neural differentiation.

Having knowledge about an in vitro culture's properties is important as basic culture conditions can influence differentiation of stem cells and alter the sensitivity of the in vitro system. Chapter 3 studied the effect of two nutrients, folic acid and methionine, on neural differentiation of mESTn. These nutrients are normally present in culture medium and are important for normal neural tube closure. mESTn was also challenged with the teratogen methotrexate under suboptimal folic acid or methionine concentrations to study whether the sensitivity of mESTn was changed. In chapter 4 the effect of oxygen tension in cell incubators on stem cells, mESTn and mESTc was examined. Gene and protein expression of cell type markers for stem cells, neural cells and cardiac cells were assessed to study whether the differentiation paths of these three cell cultures were affected when oxygen is lowered to $5 \%$ instead of the commonly used $20 \%$.

Gene expression experiments in mESTn have revealed compound-specific signatures across a diverse array of tested compounds $[157,183,184]$ and it has been shown that mESTc is able to discriminate compounds within one compound class [185]. Chapter 5 explored whether mESTn was able to discriminate compounds that are structural analogues of each other. The teratogens valproic acid and 2-ethylhexanoic acid, and non-teratogenic 2-ethyl-4-methylpentanoic acid were assessed by morphological scoring, gene expression and protein expression in mESTn on day 4, 7, 10 and 13. In chapter 6 the effects of two antidepressants with a slightly different mechanism were studied: the selective serotonin receptor inhibitor fluoxetine and the serotonin noradrenaline receptor inhibitor venlafaxine. Using RNA-seq on day 7 and 13 the time-dependent effects of these two compounds was described.

The second part of this thesis focusses on a novel human stem cell neural differentiation protocol. Chapter 7 describes the characteristics of this neural differentiation protocol based on gene expression, protein expression and functional measurements on spontaneous electrical activity. To assess the usefulness of this novel test to study DNT effects of compounds, five compounds were tested as described in chapter 8 . Human neural progenitor cells were differentiated to a neuron-astrocyte co-culture, and exposed for ten days to compounds that are known or suspected to cause DNT: acrylamide, chlorpyrifos, fluoxetine, methyl mercury or valproic acid. Whole transcriptome analysis was performed using RNA-seq to examine the biological domain of this test and whether the biological processes present in this test were sensitive to compound exposure.

In the near future, ESC may be replaced by iPSC in these types of in vitro test systems. Chapter 9 presents a successful replication of a reprogramming method of human blood cells to iPSCs. 
These cells could be differentiated to neurons and astrocytes using the protocol originally developed for the hESC, as well as to cardiomyocytes.

Chapter 10 summarises the findings of all chapters and provides a general discussion on the implementation of the mouse and human neural differentiation tests in a testing strategy to assess DNT, as well as use of differentiation as an endpoint for DNT.

Readouts

Chapter 2

Chapter 3
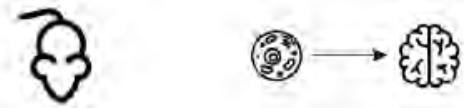

(5) Dav 4,13
S. $24,240 \mathrm{~h}$
FA, MET, MTX

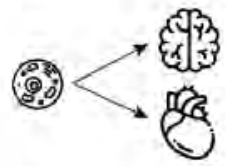

(C) Day 7, 10,13

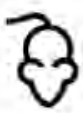

हैa

\&) $5 \% \mathrm{O}_{2}, 20 \% \mathrm{O}_{3}$

Chapter 5
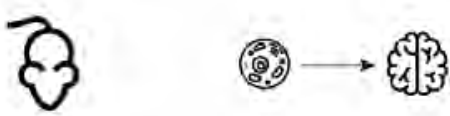

(C) Dav $4,7,10,13$

\{1 24,96, 168, 240 K Gene expression (PCR) Protein expression

Chapter 6
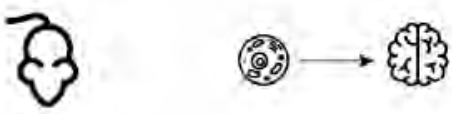

(C) Day 7.13

4. $24,240 \mathrm{~h}$

Chapter 7

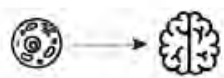

(5) Day 0-28

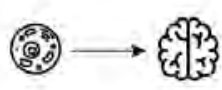

(L) Day 10
\&. $240 \%$
ACR, CPF

$A C R, C P F, F L X, M C H g, V P A$

Morphology

Gene expression (RNA-sea

Protein expression

Chapter 9
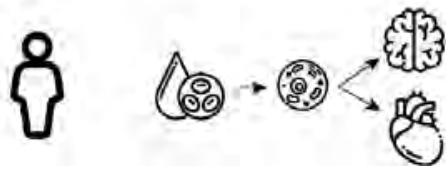

(L) Day 0-78

Gene expression (PC.R

Protein expression

Figure 1: Schematic overview of the experiments described in this thesis. 


\section{References}

[1] N.A. Rupke, Vivisection in historical perspective, Croon-Helm, London and New York, 1987.

[2] N. Henrique Franco, Animal experiments in biomedical research: A historical perspective, Animals. 3 (2013) 238-273. https://doi.org/10.3390/ani3010238.

[3] W. Lenz, A short history of thalidomide embryopathy, Teratology. 38 (1988) 203-215. https://doi.org/10.1002/tera.1420380303.

[4] M. Harada, Minamata disease: Methylmercury poisoning in Japan caused by environmental pollution, Crit. Rev. Toxicol. 25 (1995) 1-24. https://doi.org/10.3109/10408449509089885.

[5] W.M.S. Russell, R.L. Burch, C.W. Hume, The principles of humane experimental technique, Methuen London, 1959.

[6] M.L. Stephens, N.S. Mak, History of the 3Rs in Toxicity Testing: From Russell and Burch to 21st Century Toxicology, in: David G. Allen and Michael D. Waters (Ed.), Reducing, Refin. Replac. Use Anim. Toxic. Test., The Royal Society of Chemistry, London, 2014: pp. 1-29. https://doi.org/10.1039/9781849737920-00001.

[7] Wet op de dierproeven, 1977. https://wetten.overheid.nl/BWBR0003081/2014-12-18.

[8] M.J.W.A. Schiffelers, B.J. Blaauboer, J.M.F. Van Vlissingen, J. Kuil, R. Remie, J.W.G.M. Thuring, M.A. Vaal, C.F.M. Hendriksen, Factors stimulating or obstructing the implementation of the 3Rs in the regulatory process, ALTEX. 24 (2007) 271-278. https://doi.org/10.14573/altex.2007.4.271.

[9] D.J. Kevles, Of mice \& money: The story of the world's first animal patent, Daedalus. 131 (2002) 78-88.

[10] A.N. Rowan, Of mice, models, and men: a critical evaluation of animal research, (1984).

[11] L. Munro, Strategies, Action Repertoires and DIY Activism in the Animal Rights Movement, Soc. Mov. Stud. 4 (2005) 75-94. https://doi.org/10.1080/14742830500051994.

[12] H. Olson, G. Betton, D. Robinson, K. Thomas, A. Monro, G. Kolaja, P. Lilly, J. Sanders, G. Sipes, W. Bracken, M. Dorato, K. Van Deun, P. Smith, B. Berger, A. Heller, Concordance of the toxicity of pharmaceuticals in humans and in animals, Regul. Toxicol. Pharmacol. 32 (2000) 56-67. https://doi.org/10.1006/rtph.2000.1399.

[13] National Research Council, NRC, Toxicity testing in the 21 st century: a vision and a strategy, National Academies Press, 2007.

[14] Directive 2010/63/EU of the European Parliament and of the Council of 22 September 2010 on the protection of animals used for scientific purposes, European Parliament and European Council, Brussels, 2010.

[15] Commission Regulation (EU) No 658/2013 of 10 July 2013 amending Annexes II and III to Regulation (EC) No 1223/2009 of the European Parliament and of the Council on cosmetic products, European Parliament and European Council, Brussels, 2013.

[16] NCad, Advies NCad over hoe Nederland voortrekker proefdiervrij onderzoek kan worden, (2016). https://www.ncadierproevenbeleid.nl/actueel/nieuws/16/12/15/staatssecretaris-ontvangt-ncad-advies.

[17] EPA, Administrator Wheeler Signs Memo to Reduce Animal Testing, Awards \$4.25 Million to Advance Research on Alternative Methods to Animal Testing, (2019). https://www.epa.gov/newsreleases/administrator-wheeler-signs-memo-reduce-animal-testing-awards425-million-advance.

[18] NCad, Transitie naar proefdiervrij onderzoek over mogelijkheden voor het uitfaseren van dierproeven en het stimuleren van proefdiervrije innovatie. Advies van het Nationaal Comité advies dierproevenbeleid, 2016. https://www.ncadierproevenbeleid.nl/documenten/rapport/2016/12/15/ncad-advies-transitie-naarproefdiervrij-onderzoek

[19] M.J.W.A. Schiffelers, Animal testing, 3R models and regulatory acceptance: Technology transition in a riskaverse context, Utrecht University, 2016.

[20] M. Kooijman, Why animal studies are still being used in drug development, Universiteit Utrecht, 2013.

[21] T. Hartung, G. Daston, Are In Vitro Tests Suitable for Regulatory Use?, Toxicol. Sci. 111 (2009) $233-237$. https://doi.org/10.1093/toxsci/kfp149.

[22] C. Rovida, T. Hartung, Re-evaluation of animal numbers and costs for in vivo tests to accomplish REACH legislation requirements for chemicals - a report by the transatlantic think tank for toxicology (t(4))., ALTEX. 26 (2009) 187-208

[23] M. Beekhuijzen, The era of 3Rs implementation in developmental and reproductive toxicity (DART) testing Current overview and future perspectives, Reprod. Toxicol. 72 (2017) 86-96. https://doi.org/10.1016/j.reprotox.2017.05.006.

[24] C.D. Klaassen, M.O. Amdur, Casarett and Doull's toxicology: the basic science of poisons, McGraw-Hill New York, 2013.

[25] OECD, Test Guideline 421, OECD Guideline for Reproduction/Developmental Toxicity Screening Test, (2016). https://doi.org/10.1787/9789264264380-en.

[26] OECD, Test Guideline 414, OECD Guideline for Prenatal Developmental Toxicity Study, (2018). https://doi.org/10.1787/9789264070820-en.

[27] OECD, Test Guideline 443, OECD Guideline for Testing of Chemicals, Extended One-generation Study, (2018). https://www.oecd-ilibrary.org/environment/test-no-443-extended-one-generation-reproductive-toxicitystudy_9789264185371-en. 
[28] EPA, OPPTS 870.3700 Prenatal Developmental Toxicity Study, (1998).

$\begin{array}{llllll}\text { http://www.regulations.gov/\#!documentDetail;D=EPA-HQ-OPPT-2009-0156-0017. } & \\ \text { [29] EPA, OPPTS } 870.3800 \quad \text { Reproduction and Fertility } & \text { Effects, (1998) }\end{array}$ http://www.regulations.gov/\#!documentDetail;D=EPA-HQ-OPPT-2009-0156-0018.

[30] $\mathrm{ICH}$ Expert Working Group, Detection of Reproductive and Developmental Toxicity for Human Pharmaceuticals S5 (R3), (2020). https://www.ich.org/page/safety-guidelines\#5-2.

[31] OECD, Test Guideline 426, OECD Guideline for Testing of Chemicals. Developmental Neurotoxicity Study, (2007). https://doi.org/10.1787/9789264067394-en.

[32] EPA, Guidelines for Neurotoxicity Risk Assessment, (1998) Federal register 63, 26926-26954.

[33] D. Rice, S. Barone, Critical periods of vulnerability for the developing nervous system: Evidence from humans and animal models, Environ. Health Perspect. 108 (2000) 511-533. https://doi.org/10.2307/3454543.

[34] R. Tsuji, K.M. Crofton, Developmental neurotoxicity guideline study: Issues with methodology, evaluation and regulation, Congenit. Anom. (Kyoto). 52 (2012) 122-128. https://doi.org/10.1111/j.1741-4520.2012.00374.x.

[35] S.L. Makris, K. Raffaele, S. Allen, W.J. Bowers, U. Hass, E. Alleva, G. Calamandrei, L. Sheets, P. Amcoff, N Delrue, K.M. Crofton, A retrospective performance assessment of the developmental neurotoxicity study in support of OECD test guideline 426., Environ. Health Perspect. 117 (2009) 17-25. https://doi.org/10.1289/ehp.11447.

[36] P. Grandjean, P.J. Landrigan, Neurobehavioural effects of developmental toxicity, Lancet Neurol. 13 (2014) 330-338. https://doi.org/10.1016/S1474-4422(13)70278-3.

[37] R.J. Weaver, J.-P. Valentin, Today's Challenges to De-Risk and Predict Drug Safety in Human "Mind-theGap," Toxicol. Sci. 167 (2019) 307-321. https://doi.org/10.1093/toxsci/kfy270.

[38] S. Authier, J. Arezzo, M.S. Delatte, M.J. Kallman, C. Markgraf, D. Paquette, M.K. Pugsley, S. Ratcliffe, W.S. Redfern, J. Stevens, J.P. Valentin, H.M. Vargas, M.J. Curtis, Safety pharmacology investigations on the nervous system: An industry survey, J. Pharmacol. Toxicol. Methods. 81 (2016) 37-46. https://doi.org/10.1016/j.vascn.2016.06.001.

[39] K.M. Crofton, W.R. Mundy, T.J. Shafer, Developmental neurotoxicity testing: A path forward, Congenit. Anom. (Kyoto). 52 (2012) 140-146. https://doi.org/10.1111/j.1741-4520.2012.00377.x.

[40] A.H. Piersma, Alternative methods for developmental toxicity testing, Basic Clin. Pharmacol. Toxicol. 98 (2006) 427-431. https://doi.org/10.1111/j.1742-7843.2006.pto_373.x.

[41] A. Terron, S.H. Bennekou, Towards a regulatory use of alternative developmental neurotoxicity testing (DNT), Toxicol. Appl. Pharmacol. 354 (2018) 19-23. https://doi.org/10.1016/j.taap.2018.02.002.

[42] C. Rovida, F. Longo, R.R. Rabbit, How are reproductive toxicity and developmental toxicity addressed in REACH dossiers?, ALTEX. 28 (2011) 273-294. https://doi.org/10.14573/altex.2011.4.273.

[43] OECD, Report of a workshop on integrated approaches to testing and assessment (IATA), Paris, 2008. http://www.oecd.org/officialdocuments/publicdisplaydocumentpdf/?cote=env/jm/mono(2008)10\&doclang uage $=$ en .

[44] G.T. Ankley, R.S. Bennett, R.J. Erickson, D.J. Hoff, M.W. Hornung, R.D. Johnson, D.R. Mount, J.W. Nichols, C.L. Russom, P.K. Schmieder, J.A. Serrrano, J.E. Tietge, D.L. Villeneuve, Adverse outcome pathways: A conceptual framework to support ecotoxicology research and risk assessment, Environ. Toxicol. Chem. 29 (2010) 730741. https://doi.org/10.1002/etc.34.

[45] OECD, Users' Handbook supplement to the Guidance Document for developing and assessing Adverse Outcome Pathways, Paris, 2018. https://doi.org/10.1787/5jlv1m9d1g32-en.

[46] OECD, GUIDANCE DOCUMENT FOR THE USE OF ADVERSE OUTCOME PATHWAYS IN DEVELOPING INTEGRATED APPROACHES TO TESTING AND ASSESSMENT (IATA), 2016.

[47] K.E. Tollefsen, S. Scholz, M.T. Cronin, S.W. Edwards, J. de Knecht, K. Crofton, N. Garcia-Reyero, T. Hartung, A. Worth, G. Patlewicz, Applying Adverse Outcome Pathways (AOPs) to support Integrated Approaches to Testing and Assessment (IATA), Regul. Toxicol. Pharmacol. 70 (2014) 629-640. https://doi.org/10.1016/j.yrtph.2014.09.009.

[48] A. Bal-Price, H.T. Hogberg, K.M. Crofton, M. Daneshian, R.E. Fitzgerald, E. Fritsche, T. Heinonen, S.H. Bennekou, S. Klima, A.H. Piersma, M. Sachana, T.J. Shafer, A. Terron, F. Monnet-Tschudi, B. Viviani, T. Waldmann, R.H.S. Westerink, M.F. Wilks, H. Witters, M.-G. Zurich, M. Leist, Workshop report recommendation on test readiness criteria for new approach methods in toxicology: exemplified for developmental neurotoxicity 1, ALTEX. 35 (2018) 306-352. https://doi.org/10.14573/altex.1712081.

[49] M. Sachana, E. Leinala, Approaching chemical safety assessment through application of integrated approaches to testing and assessment: Combining mechanistic information derived from adverse outcome pathways and alternative methods, Appl. Vitr. Toxicol. 3 (2017) 227-233. https://doi.org/10.1089/aivt.2017.0013.

[50] Y. Sakuratani, M. Horie, E. Leinala, Integrated Approaches to Testing and Assessment: OECD Activities on the Development and Use of Adverse Outcome Pathways and Case Studies, Basic Clin. Pharmacol. Toxicol. 123 Suppl (2018) 20-28. https://doi.org/10.1111/bcpt.12955.

[51] A. Bal-Price, M.E.E. Meek, Adverse outcome pathways: Application to enhance mechanistic understanding of neurotoxicity, Pharmacol. Ther. 179 (2017) 84-95. https://doi.org/10.1016/j.pharmthera.2017.05.006. 
[52] M. Sachana, A. Bal-Price, K.M. Crofton, S.H. Bennekou, T.J. Shafer, M. Behl, A. Terron, International regulatory and scientific effort for improved developmental neurotoxicity testing, Toxicol. Sci. 167 (2019) 45-57. https://doi.org/10.1093/toxsci/kfy211.

[53] D. Knapen, L. Vergauwen, D.L. Villeneuve, G.T. Ankley, The potential of AOP networks for reproductive and developmental toxicity assay development, Reprod. Toxicol. $56 \quad$ (2015) 52-55. https://doi.org/10.1016/j.reprotox.2015.04.003.

[54] K. Van der Jagt, S.J. Munn, J. TORSLOV, J. DE BRUIJN, Alternative Approaches Can Reduce the Use of Test Animals under REACH, 2004. https://ec.europa.eu/jrc/en/publication/eur-scientific-and-technicalresearch-reports/alternative-approaches-can-reduce-use-test-animals-under-reach.

[55] European Chemicals Agency, The use of alternatives to testing on animals for the REACH Regulation, Helsinki, 2020. https://doi.org/10.2823/509114.

[56] J.M. Clements, R.G. Hawkes, D. Jones, A. Adjei, T. Chambers, L. Simon, H. Stemplewski, N. Berry, S. Price, M. Pirmohamed, A.H. Piersma, G. Waxenecker, P. Barrow, M.E.W. Beekhuijzen, A. Fowkes, H. Prior, F. Sewell, Predicting the safety of medicines in pregnancy: A workshop report, in: Reprod. Toxicol., Elsevier Inc., 2020: pp. 199-210. https://doi.org/10.1016/j.reprotox.2020.02.011

[57] P. Bos, Towards an animal-free human health assessment: starting from the current regulatory needs, ALTEX. 37 (2020). https://doi.org/10.14573/altex.1912041.

[58] E. Genschow, H. Spielmann, G. Scholz, I. Pohl, A. Seiler, N. Clemann, S. Bremer, K. Becker, Validation of the embryonic stem cell test in the international ECVAM validation study on three in vitro embryotoxicity tests, in: ATLA Altern. to Lab. Anim., 2004: pp. 209-244.

[59] T. Burgdorf, A.H. Piersma, R. Landsiedel, R. Clewell, N. Kleinstreuer, M. Oelgeschläger, B. Desprez, A. Kienhuis, P. Bos, R. de Vries, L. de Wit, T. Seidle, J. Scheel, G. Schönfelder, J. van Benthem, A.M. Vinggaard, C. Eskes, J. Ezendam, Workshop on the validation and regulatory acceptance of innovative 3R approaches in regulatory toxicology - Evolution versus revolution, Toxicol. Vitr. $59 \quad$ (2019) 1-11. https://doi.org/10.1016/j.tiv.2019.03.039.

[60] D.J. Dix, K.A. Houck, M.T. Martin, A.M. Richard, R.W. Setzer, R.J. Kavlock, The toxcast program for prioritizing toxicity testing of environmental chemicals, Toxicol. Sci. 95 (2007) 5-12. https://doi.org/10.1093/toxsci/kfl103.

[61] S.J. Shukla, R. Huang, C.P. Austin, M. Xia, The future of toxicity testing: A focus on in vitro methods using a quantitative high-throughput screening platform, Drug Discov. Today. 15 (2010) 997-1007. https://doi.org/10.1016/j.drudis.2010.07.007.

[62] S. Bhattacharya, Q. Zhang, P.L. Carmichael, K. Boekelheide, M.E. Andersen, Toxicity Testing in the $21 \mathrm{st}$ Century: Defining New Risk Assessment Approaches Based on Perturbation of Intracellular Toxicity Pathways, PLoS One. 6 (2011) e20887. https://doi.org/10.1371/journal.pone.0020887.

[63] S. Coecke, M. Balls, G. Bowe, J. Davis, G. Gstraunthaler, T. Hartung, R. Hay, O.W. Merten, A. Price, L. Schechtman, G. Stacey, W. Stokes, Guidance on good cell culture practice: A Report of the Second ECVAM Task Force on good cell culture practice, ATLA Altern. to Lab. Anim. 33 (2005) 261-287.

[64] D. Pamies, A. Bal-Price, A. Simeonov, D. Tagle, D. Allen, D. Gerhold, D. Yin, F. Pistollato, T. Inutsuka, K. Sullivan, G. Stacey, H. Salem, M. Leist, M. Daneshian, M.C. Vemuri, R. Mcfarland, S. Coecke, S.C. Fitzpatrick, U. Lakshmipathy, A. Mack, W.B. Wang, D. Yamazaki, Y. Sekino, Y. Kanda, L. Smirnova, T. Hartung, Good cell culture practice for stem cells \& stem-cell-derived models, ALTEX. 34 (2017) 95-132. https://doi.org/10.14573/altex.1607121.

[65] D. Pamies, A. Bal-Price, C. Chesné, S. Coecke, A. Dinnyes, C. Eskes, R. Grillari, G. Gstraunthaler, T. Hartung, P. Jennings, M. Leist, U. Martin, R. Passier, J.C. Schwamborn, G.N. Stacey, H. Ellinger-Ziegelbauer, M. Daneshian, Advanced Good Cell Culture Practice for human primary, stem cell-derived and organoid models as well as microphysiological systems, ALTEX. 35 (2018) 353-378. https://doi.org/10.14573/altex. 1710081.

[66] H.M. Kauffmann, H. Kamp, R. Fuchs, B.N. Chorley, L. Deferme, T. Ebbels, J. Hackermüller, S. Perdichizzi, A. Poole, U.G. Sauer, K.E. Tollefsen, T. Tralau, C. Yauk, B. van Ravenzwaay, Framework for the quality assurance of 'omics technologies considering GLP requirements, Regul. Toxicol. Pharmacol. 91 (2017) S27-S35. https://doi.org/10.1016/j.yrtph.2017.10.007.

[67] A.L. Luz, E.J. Tokar, Pluripotent stem cells in developmental toxicity testing: A review of methodological advances, Toxicol. Sci. 165 (2018) 31-39. https://doi.org/10.1093/toxsci/kfy174.

[68] H. Spielmann, E. Genschow, N.A. Brown, A.H. Piersma, A. Verhoef, M.Q.I. Spanjersberg, H. Huuskonen, F. Paillard, A. Seiler, Validation of the rat limb bud micromass test in the international ECVAM validation study on three in vitro embryotoxicity tests, Altern. to Lab. Anim. 32 (2004) 245-274.

[69] A.H. Piersma, E. Genschow, A. Verhoef, M.Q.I. Spanjersberg, N.A. Brown, M. Brady, A. Burns, N. Clemann, A Seiler, H. Spielmann, Validation of the postimplantation rat whole-embryo culture test in the international ECVAM validation study on three in vitro embryotoxicity tests, Altern. to Lab. Anim. 32 (2004) 275-307.

[70] B. Schenk, M. Weimer, S. Bremer, B. van der Burg, R. Cortvrindt, A. Freyberger, G. Lazzari, C. Pellizzer, A Piersma, W.R. Schäfer, A. Seiler, H. Witters, M. Schwarz, The ReProTect Feasibility Study, a novel comprehensive in vitro approach to detect reproductive toxicants, Reprod. Toxicol. 30 (2010) 200-218. https://doi.org/10.1016/j.reprotox.2010.05.012. 
[71] S.A.B. Hermsen, E.J. van den Brandhof, L.T.M. van der Ven, A.H. Piersma, Relative embryotoxicity of two classes of chemicals in a modified zebrafish embryotoxicity test and comparison with their in vivo potencies, Toxicol. Vitr. 25 (2011) 745-753. https://doi.org/10.1016/j.tiv.2011.01.005.

[72] M. Dimopoulou, A. Verhoef, C.A. Gomes, C.W. van Dongen, I.M.C.M. Rietjens, A.H. Piersma, B. van Ravenzwaay, A comparison of the embryonic stem cell test and whole embryo culture assay combined with the BeWo placental passage model for predicting the embryotoxicity of azoles, Toxicol. Lett. 286 (2018) 1021. https://doi.org/10.1016/j.toxlet.2018.01.009.

[73] D.A.M. van Dartel, J.L.A. Pennings, J.F. Robinson, J.C.S. Kleinjans, A.H. Piersma, Discriminating classes of developmental toxicants using gene expression profiling in the embryonic stem cell test, Toxicol. Lett. 201 (2011) 143-151. https://doi.org/10.1016/J.TOXLET.2010.12.019.

[74] S.A.B. Hermsen, T.E. Pronk, E.J. van den Brandhof, L.T.M. van der Ven, A.H. Piersma, Transcriptomic analysis in the developing zebrafish embryo after compound exposure: Individual gene expression and pathway regulation, Toxicol. Appl. Pharmacol. 272 (2013) 161-171. https://doi.org/10.1016/j.taap.2013.05.037.

[75] Y.C.M. Staal, J.L.A. Pennings, E.V.S. Hessel, A.H. Piersma, Advanced Toxicological Risk Assessment by Implementation of Ontologies Operationalized in Computational Models, Appl. Vitr. Toxicol. 3 (2017) aivt.2017.0019. https://doi.org/10.1089/aivt.2017.0019.

[76] N. Kleinstreuer, D. Dix, M. Rountree, N. Baker, N. Sipes, D. Reif, R. Spencer, T. Knudsen, A Computational Model Predicting Disruption of Blood Vessel Development, PLoS Comput. Biol. 9 (2013) e1002996. https://doi.org/10.1371/journal.pcbi.1002996.

[77] A.K. Bal-Price, H.T. Hogberg, L. Buzanska, S. Coecke, Relevance of in vitro neurotoxicity testing for regulatory requirements: Challenges to be considered, Neurotoxicol. Teratol. 32 (2010) 36-41. https://doi.org/10.1016/j.ntt.2008.12.003.

[78] P. Lein, E. Silbergeld, P. Locke, A.M. Goldberg, In vitro and other alternative approaches to developmental neurotoxicity testing (DNT), in: Environ. Toxicol. Pharmacol., Elsevier, 2005: pp. 735-744. https://doi.org/10.1016/j.etap.2004.12.035.

[79] S. Coecke, A.M. Goldberg, S. Allen, L. Buzanska, G. Calamandrei, K. Crofton, L. Hareng, T. Hartung, H. Knaut, P. Honegger, M. Jacobs, P. Lein, A. Li, W. Mundy, D. Owen, S. Schneider, E. Silbergeld, T. Reum, T. Trnovec, F. Monnet-Tschudi, A. Bal-Price, Workgroup report: Incorporating In Vitro Alternative Methods for Developmental Neurotoxicity into International Hazard and Risk Assessment Strategies, Environ. Health Perspect. 115 (2007) 924-931. https://doi.org/10.1289/ehp.9427.

[80] A. Bal-Price, K.M. Crofton, M. Leist, S. Allen, M. Arand, T. Buetler, N. Delrue, R.E. FitzGerald, T. Hartung, T. Heinonen, H. Hogberg, S.H. Bennekou, W. Lichtensteiger, D. Oggier, M. Paparella, M. Axelstad, A. Piersma, E. Rached, B. Schilter, G. Schmuck, L. Stoppini, E. Tongiorgi, M. Tiramani, F. Monnet-Tschudi, M.F. Wilks, T. Ylikomi, E. Fritsche, International STakeholder NETwork (ISTNET): creating a developmental neurotoxicity (DNT) testing road map for regulatory purposes, Arch. Toxicol. 89 (2015) 269-287. https://doi.org/10.1007/s00204-015-1464-2.

[81] E. Fritsche, K.M. Crofton, A.F. Hernandez, S.H. Bennekou, M. Leist, A. Bal-Price, E. Reaves, M.F. Wilks, A Terron, R. Solecki, M. Sachana, A. Gourmelon, OECD/EFSA workshop on developmental neurotoxicity (DNT): The use of non-animal test methods for regulatory purposes, in: ALTEX, 2017: pp. 311-315. https://doi.org/10.14573/altex.1701171

[82] E. Fritsche, H. Alm, J. Baumann, L. Geerts, H. Håkansson, S. Masjosthusmann, H. Witters, Literature review on in vitro and alternative Developmental Neurotoxicity (DNT) testing methods, EFSA Support. Publ. 12 (2015) 778E. https://doi.org/10.2903/sp.efsa.2015.en-778.

[83] A. Bal-Price, F. Pistollato, M. Sachana, S.K. Bopp, S. Munn, A. Worth, Strategies to improve the regulatory assessment of developmental neurotoxicity (DNT) using in vitro methods, Toxicol. Appl. Pharmacol. 354 (2018) 7-18. https://doi.org/10.1016/j.taap.2018.02.008.

[84] W.M. Cowan, T.M. Jessell, S.L. Zipursky, Molecular and Cellular Approaches to Neural Development, Oxford University Press, New York, 1998. https://doi.org/10.1093/acprof:oso/9780195111668.001.0001.

[85] E.V.S. Hessel, Y.C.M. Staal, A.H. Piersma, Design and validation of an ontology-driven animal-free testing strategy for developmental neurotoxicity testing, Toxicol. Appl. Pharmacol. 1 (2018) 136-152. https://doi.org/10.1016/j.taap.2018.03.013

[86] K.M. Crofton, W.R. Mundy, P.J. Lein, A. Bal-Price, S. Coecke, A.E.M. Seiler, H. Knaut, L. Buzanska, A. Goldberg Developmental neurotoxicity testing: recommendations for developing alternative methods for the screening and prioritization of chemicals., ALTEX. 28 (2011) 9-15. https://doi.org/10.14573/altex.2011.1.009.

[87] B.Z. Schmidt, M. Lehmann, S. Gutbier, E. Nembo, S. Noel, L. Smirnova, A. Forsby, J. Hescheler, H.X. Avci, T. Hartung, M. Leist, J. Kobolák, A. Dinnyés, In vitro acute and developmental neurotoxicity screening: an overview of cellular platforms and high-throughput technical possibilities, Arch. Toxicol. 91 (2017) 1-33. https://doi.org/10.1007/s00204-016-1805-9.

[88] W.R. Mundy, S. Padilla, J.M. Breier, K.M. Crofton, M.E. Gilbert, D.W. Herr, K.F. Jensen, N.M. Radio, K.C. Raffaele, K. Schumacher, T.J. Shafer, J. Cowden, Expanding the test set: Chemicals with potential to disrupt mammalian brain development, Neurotoxicol. Teratol. $52 \quad$ (2015) 25-35 https://doi.org/10.1016/j.ntt.2015.10.001.

[89] M. Aschner, S. Ceccatelli, M. Daneshian, E. Fritsche, N. Hasiwa, T. Hartung, H.T. Hogberg, M. Leist, A. Li, W.R. Mundy, S. Padilla, A.H. Piersma, A. Bal-Price, A. Seiler, R.H. Westerink, B. Zimmer, P.J. Lein, Reference 
compounds for alternative test methods to indicate developmental neurotoxicity (DNT) potential of chemicals: Example lists \& criteria for their selection \& use, in: ALTEX, 2017: pp. 49-74. https://doi.org/10.14573/altex.1604201.

[90] M. Behl, K. Ryan, J.H. Hsieh, F. Parham, A.J. Shapiro, B.J. Collins, N.S. Sipes, L.S. Birnbaum, J.R. Bucher, P.M.D. Foster, N.J. Walker, R.S. Paules, R.R. Tice, Screening for developmental neurotoxicity at the national toxicology program: The future is here, Toxicol. Sci. 167 (2019) 258-268. https://doi.org/10.1093/toxsci/kfy278.

[91] E.H.P.A. Haeckel, Natürliche Schöpfungsgeschichte. Gemeinverständliche wissenschaftliche Vorträge über die Entwickelungslehre im Allgemeinen und diejenige von Darwin, Goethe und Lamarck und Besonderen. Von Dr. Ernst Haeckel., 1868. https://doi.org/10.5962/bhl.title.15259.

[92] M. Ramalho-Santos, H. Willenbring, On the Origin of the Term "Stem Cell," Cell Stem Cell. 1 (2007) 35-38. https://doi.org/10.1016/j.stem.2007.05.013.

[93] Y. Qu, S. Vadivelu, L. Choi, S. Liu, A. Lu, B. Lewis, R. Girgis, C.S. Lee, B.J. Snider, D.I. Gottlieb, J.W. McDonald, Neurons derived from embryonic stem (ES) cells resemble normal neurons in their vulnerability to excitotoxic death, Exp. Neurol. 184 (2003) 326-336. https://doi.org/10.1016/j.expneurol.2003.07.001.

[94] M. Barenys, E. Fritsche, A historical perspective on the use of stem/progenitor cell-based in vitro methods for neurodevelopmental toxicity testing, Toxicol. Sci. 165 (2018) 10-13. https://doi.org/10.1093/toxsci/kfy170.

[95] G. Laschinski, R. Vogel, H. Spielmann, Cytotoxicity test using blastocyst-derived euploid embryonal stem cells: A new approach to in vitro teratogenesis screening, Reprod. Toxicol. 5 (1991) 57-64 https://doi.org/10.1016/0890-6238(91)90111-R.

[96] E. Fritsche, M. Barenys, J. Klose, S. Masjosthusmann, L. Nimtz, M. Schmuck, S. Wuttke, J. Tigges, Current availability of stem cell-based in vitro methods for Developmental Neurotoxicity (DNT) testing, Toxicol. Sci. 165 (2018) 21-30. https://doi.org/10.1093/toxsci/kfy178.

[97] J. Nichols, A. Smith, The origin and identity of embryonic stem cells, Development. 138 (2011) 3-8. https://doi.org/10.1242/dev.050831.

[98] J. Kim, B.K. Koo, J.A. Knoblich, Human organoids: model systems for human biology and medicine, Nat. Rev. Mol. Cell Biol. (2020). https://doi.org/10.1038/s41580-020-0259-3.

[99] B.D. Semple, K. Blomgren, K. Gimlin, D.M. Ferriero, L.J. Noble-Haeusslein, Brain development in rodents and humans: Identifying benchmarks of maturation and vulnerability to injury across species, Prog. Neurobiol. 106-107 (2013) 1-16. https://doi.org/https://doi.org/10.1016/j.pneurobio.2013.04.001.

[100] M. Florio, W.B. Huttner, Neural progenitors, neurogenesis and the evolution of the neocortex, Development. 141 (2014) 2182. https://doi.org/10.1242/dev.090571.

[101] N.A. Oberheim, X. Wang, S. Goldman, M. Nedergaard, Astrocytic complexity distinguishes the human brain, Trends Neurosci. 29 (2006) 547-553. https://doi.org/https://doi.org/10.1016/j.tins.2006.08.004

[102] S. Masjosthusmann, D. Becker, B. Petzuch, C. Siebert, R. Deenen, M. Barenys, K. Dach, J. Tigges, U. Hübenthal, E. Fritsche, C. Siebert, R. Deenen, M. Barenys, J. Baumann, K. Dach, J. Tigges, U. Hübenthal, K. Köhrer, E. Fritsche, A transcriptome comparison of time-matched developing human, mouse and rat neural progenitor cells reveals human uniqueness, Toxicol. Appl. Pharmacol. 354 (2018) 40-55 https://doi.org/10.1016/j.taap.2018.05.009.

[103] P. Kügler, B. Zimmer, T. Waldmann, B. Baudis, S. Ilmjärv, J. Hescheler, P. Gaughwin, P. Brundin, W. Mundy, A.K. Bal-Price, A. Schrattenholz, K.-H. Krause, C. von Thriel, M.S. Rao, S. Kadereit, M. Leist, Markers of murine embryonic and neural stem cells, neurons and astrocytes : reference points for developmental neurotoxicity testing, Altern. to Anim. Exp. ALTEX. 27 (2010) 16-42. https://doi.org/10.14573/altex.2010.1.16.

[104] N. Irie, S. Kuratani, Comparative transcriptome analysis reveals vertebrate phylotypic period during organogenesis, Nat. Commun. 2 (2011). https://doi.org/10.1038/ncomms1248.

[105] M.J. Evans, M.H. Kaufman, Establishment in culture of pluripotential cells from mouse embryos, Nature. 292 (1981) 154-156. https://doi.org/https://doi.org/10.1038/292154a0.

[106] G.R. Martin, Isolation of a pluripotent cell line from early mouse embryos cultured in medium conditioned by teratocarcinoma stem cells, Proc. Natl. Acad. Sci. U. S. A. 78 (1981) 7634-7638. https://doi.org/10.1073/pnas.78.12.7634.

[107] T.C. Doetschman, H. Eistetter, M. Katz, The in vitro development of blastocyst-derived embryonic stem cell lines: Formation of visceral yolk sac, blood islands and myocardium, J. Embryol. Exp. Morphol. 87 (1985) $27-$ 45. http://dev.biologists.org/content/87/1/27.abstract.

[108] P. Marx-Stoelting, E. Adriaens, H.-J. Ahr, S. Bremer, B. Garthoff, H.-P. Gelbke, A. Piersma, C. Pellizzer, U. Reuter, V. Rogiers, B. Schenk, S. Schwengberg, A. Seiler, H. Spielmann, M. Steemans, D.B. Stedman, P. Vanparys, J.A. Vericat, M. Verwei, F. van der Water, M. Weimer, M. Schwarz, A review of the implementation of the embryonic stem cell test (EST). The report and recommendations of an ECVAM/ReProTect Workshop., Altern. Lab. Anim. 37 (2009) 313-328. https://doi.org/10.1177/026119290903700314.

[109] S. Okabe, K. Forsberg-Nilsson, A.C. Spiro, M. Segal, R.D.G. McKay, Development of neuronal precursor cells and functional postmitotic neurons from embryonic stem cells in vitro, Mech. Dev. 59 (1996) 89-102. https://doi.org/10.1016/0925-4773(96)00572-2. 
[110] E.M. Jones-Villeneuve, M.A. Rudnicki, J.F. Harris, M.W. McBurney, Retinoic acid-induced neural differentiation of embryonal carcinoma cells., Mol. Cell. Biol. 3 (1983) 2271-2279. https://doi.org/10.1128/mcb.3.12.2271.

[111] T.C. Stummann, L. Hareng, S. Bremer, Embryotoxicity hazard assessment of methylmercury and chromium using embryonic stem cells, Toxicology. 242 (2007) 130-143. https://doi.org/10.1016/j.tox.2007.09.022

[112] P.T. Theunissen, S.H.W. Schulpen, D.A.M. van Dartel, S.A.B. Hermsen, F.J. van Schooten, A.H. Piersma, An abbreviated protocol for multilineage neural differentiation of murine embryonic stem cells and its perturbation by methyl mercury, Reprod. Toxicol. $29 \quad$ (2010) 383-392. https://doi.org/10.1016/j.reprotox.2010.04.003.

[113] B. Zimmer, P. Kuegler, B. Baudis, A. Genewsky, V. Tanavde, W. Koh, B. Tan, T. Waldmann, S. Kadereit, M. Leist Coordinated waves of gene expression during neuronal differentiation of embryonic stem cells as basis for novel approaches to developmental neurotoxicity testing, Cell Death Differ. 18 (2010) 383-395. https://doi.org/10.1038/cdd.2010.109.

[114] A. Visan, K. Hayess, D. Sittner, E.E. Pohl, C. Riebeling, B. Slawik, K. Gulich, M. Oelgeschläger, A. Luch, A.E.M. Seiler, Neural differentiation of mouse embryonic stem cells as a tool to assess developmental neurotoxicity in vitro, Neurotoxicology. 33 (2012) 1135-1146. https://doi.org/10.1016/j.neuro.2012.06.006.

[115] J. Bian, J. Zheng, S. Li, L. Luo, F. Ding, Sequential differentiation of embryonic stem cells into neural epitheliallike stem cells and oligodendrocyte progenitor cells, PLoS One. 11 (2016). https://doi.org/10.1371/journal.pone.0155227.

[116] C. Cai, L. Grabel, Directing the differentiation of embryonic stem cells to neural stem cells, Dev. Dyn. 236 (2007) 3255-3266. https://doi.org/10.1002/dvdy.21306.

[117] M. Bibel, J. Richter, K. Schrenk, K.L. Tucker, V. Staiger, M. Korte, M. Goetz, Y.-A. Barde, Differentiation of mouse embryonic stem cells into a defined neuronal lineage, Nat. Neurosci. 7 (2004) 1003 http://dx.doi.org/10.1038/nn1301.

[118] J.A. Thomson, J. Itskovitz-Eldor, S.S. Shapiro, M.A. Waknitz, J.J. Swiergiel, V.S. Marshall, J.M. Jones, Embryonic stem cell lines derived from human blastocysts, Science. 282 (1998) 1145-1147. https://doi.org/10.1126/science.282.5391.1145.

[119] M. Leist, S. Bremer, P. Brundin, J. Hescheler, A. Kirkeby, K.H. Krause, P. Pörzgen, M. Pucéat, M. Schmidt, A. Schrattenholz, N.B. Zak, H. Hentze, The biological and ethical basis of the use of human embryonic stem cells for in vitro test systems or cell therapy, ALTEX. 25 (2008) 163-190 https://doi.org/10.14573/altex.2008.3.163.

[120] Y. Li, R. Wang, N. Qiao, G. Peng, K. Zhang, K. Tang, J.D.J. Han, N. Jing, Transcriptome analysis reveals determinant stages controlling human embryonic stem cell commitment to neuronal cells, J. Biol. Chem. 292 (2017) 19590-19604. https://doi.org/10.1074/jbc.M117.796383.

[121] T.J. Zurlinden, K.S. Saili, N. Rush, P. Kothiya, R.S. Judson, K.A. Houck, E.S. Hunter, N.C. Baker, J.A. Palmer R.S. Thomas, T.B. Knudsen, Profiling the ToxCast Library with a Pluripotent Human (H9) Stem Cell LineBased Biomarker Assay for Developmental Toxicity, Toxicol. Sci. 174 (2020) 189-209. https://doi.org/10.1093/toxsci/kfaa014.

[122] I. Kelava, M.A. Lancaster, Dishing out mini-brains: Current progress and future prospects in brain organoid research, Dev. Biol. 420 (2016) 199-209. https://doi.org/10.1016/j.ydbio.2016.06.037.

[123] A.M. Pasca, S.A. Sloan, L.E. Clarke, Y. Tian, C.D. Makinson, N. Huber, C.H. Kim, J.Y. Park, N.A. O'Rourke, K.D. Nguyen, S.J. Smith, J.R. Huguenard, D.H. Geschwind, B.A. Barres, S.P. Pasca, Functional cortical neurons and astrocytes from human pluripotent stem cells in 3D culture, Nat. Methods. 12 (2015) 671-678. https://doi.org/10.1038/nmeth.3415.

[124] S.-J. Yoon, L.S. Elahi, A.M. Pașca, R.M. Marton, A. Gordon, O. Revah, Y. Miura, E.M. Walczak, G.M. Holdgate, H.C. Fan, J.R. Huguenard, D.H. Geschwind, S.P. Pașca, Reliability of human cortical organoid generation, Nat. Methods. 16 (2019) 75-78. https://doi.org/10.1038/s41592-018-0255-0.

[125] F. Pistollato, D. Canovas-Jorda, D. Zagoura, A. Price, Protocol for the differentiation of human induced pluripotent stem cells into mixed cultures of neurons and glia for neurotoxicity testing, J. Vis. Exp. 2017 (2017) e55702. https://doi.org/10.3791/55702.

[126] B.E. Reubinoff, M.F. Pera, C.Y. Fong, A. Trounson, A. Bongso, Embryonic stem cell lines from human blastocysts: somatic differentiation in vitro, Nat. Biotechnol. 18 (2000) 399-404. https://doi.org/10.1038/74447.

[127] M.K. Carpenter, M.S. Inokuma, J. Denham, T. Mujtaba, C.P. Chiu, M.S. Rao, Enrichment of neurons and neural precursors from human embryonic stem cells, Exp. Neurol. 172 (2001) 383-397. https://doi.org/10.1006/exnr.2001.7832.

[128] A. Chandrasekaran, H.X. Avci, M. Leist, J. Kobolák, A. Dinnyés, Astrocyte differentiation of human pluripotent stem cells: New tools for neurological disorder research, Front. Cell. Neurosci. 10 (2016). https://doi.org/10.3389/fncel.2016.00215.

[129] R.S. Lappalainen, M. Salomäki, L. Ylä-Outinen, T.J. Heikkilä, J.A.K. Hyttinen, H. Pihlajamäki, R. Suuronen, H. Skottman, S. Narkilahti, Similarly derived and cultured hESC lines show variation in their developmental potential towards neuronal cells in long-term culture., Regen. Med. 5 (2010) 749-762. https://doi.org/10.2217/rme.10.58. 
[130] D. Pamies, P. Barreras, K. Block, G. Makri, A. Kumar, D. Wiersma, L. Smirnova, C. Zhang, J. Bressler, K.M. Christian, G. Harris, G.L. Ming, C.J. Berlinicke, K. Kyro, H. Song, C.A. Pardo, T. Hartung, H.T. Hogberg, A human brain microphysiological system derived from induced pluripotent stem cells to study neurological diseases and toxicity, ALTEX. 34 (2017) 362-376. https://doi.org/10.14573/altex.1609122.

[131] R. Taléns-Visconti, I. Sanchez-Vera, J. Kostic, M.A. Perez-Arago, S. Erceg, M. Stojkovic, C. Guerri, Neural differentiation from human embryonic stem cells as a tool to study early brain development and the neuroteratogenic effects of ethanol, Stem Cells Dev. $20 \quad$ (2011) 327-339. https://doi.org/10.1089/scd.2010.0037.

[132] J. Sandström, E. Eggermann, I. Charvet, A. Roux, N. Toni, C. Greggio, A. Broyer, F. Monnet-Tschudi, L. Stoppini, Development and characterization of a human embryonic stem cell-derived 3D neural tissue model for neurotoxicity testing, Toxicol. Vitr. 38 (2017) 124-135. https://doi.org/10.1016/j.tiv.2016.10.001.

[133] M.P. Schwartz, Z. Hou, N.E. Propson, J. Zhang, C.J. Engstrom, V.S. Costa, P. Jiang, B.K. Nguyen, J.M. Bolin, W. Daly, Y. Wang, R. Stewart, C.D. Page, W.L. Murphy, J.A. Thomson, Human pluripotent stem cell-derived neural constructs for predicting neural toxicity, Proc. Natl. Acad. Sci. U. S. A. 112 (2015) 12516-12521. https://doi.org/10.1073/pnas.1516645112.

[134] C.M. Abreu, L. Gama, S. Krasemann, M. Chesnut, S. Odwin-Dacosta, H.T. Hogberg, T. Hartung, D. Pamies, Microglia Increase Inflammatory Responses in iPSC-Derived Human BrainSpheres, Front. Microbiol. 9 (2018) 2766. https://doi.org/10.3389/fmicb.2018.02766.

[135] P.R. Ormel, R. Vieira de Sá, E.J. van Bodegraven, H. Karst, O. Harschnitz, M.A.M. Sneeboer, L.E. Johansen, R.E. van Dijk, N. Scheefhals, A. Berdenis van Berlekom, E. Ribes Martínez, S. Kling, H.D. MacGillavry, L.H. van den Berg, R.S. Kahn, E.M. Hol, L.D. de Witte, R.J. Pasterkamp, Microglia innately develop within cerebral organoids, Nat. Commun. 9 (2018) 4167. https://doi.org/10.1038/s41467-018-06684-2.

[136] The Nobel Prize in Physiology or Medicine - 2012 Press Release, Nobel Media AB 2020. (2012). https://www.nobelprize.org/prizes/medicine/2012/press-release/.

[137] K. Takahashi, K. Tanabe, M. Ohnuki, M. Narita, T. Ichisaka, K. Tomoda, S. Yamanaka, Induction of Pluripotent Stem Cells from Adult Human Fibroblasts by Defined Factors, Cell. 131 (2007) 861-872. https://doi.org/10.1016/j.cell.2007.11.019.

[138] F. Pistollato, E.M. De Gyves, D. Carpi, S.K. Bopp, C. Nunes, A. Worth, A. Bal-Price, Assessment of developmental neurotoxicity induced by chemical mixtures using an adverse outcome pathway concept, Environ. Heal. A Glob. Access Sci. Source. 19 (2020) 23. https://doi.org/10.1186/s12940-020-00578-X.

[139] R. Lieberman, E.S. Levine, H.R. Kranzler, C. Abreu, J. Covault, Pilot study of iPS-derived neural cells to examine biologic effects of alcohol on human neurons in vitro, Alcohol. Clin. Exp. Res. 36 (2012) 1678-1687. https://doi.org/10.1111/j.1530-0277.2012.01792.x.

[140] M. Hofrichter, L. Nimtz, J. Tigges, Y. Kabiri, F. Schröter, B. Royer-Pokora, B. Hildebrandt, M. Schmuck, A. Epanchintsev, S. Theiss, J. Adjaye, J.M. Egly, J. Krutmann, E. Fritsche, Comparative performance analysis of human iPSC-derived and primary neural progenitor cells (NPC) grown as neurospheres in vitro, Stem Cell Res. 25 (2017) 72-82. https://doi.org/10.1016/j.scr.2017.10.013.

[141] J. Kobolak, A. Teglasi, T. Bellak, Z. Janstova, K. Molnar, M. Zana, I. Bock, L. Laszlo, A. Dinnyes, Human Induced Pluripotent Stem Cell-Derived 3D-Neurospheres are Suitable for Neurotoxicity Screening, Cells. 9 (2020) 1122. https://doi.org/10.3390/cells9051122.

[142] X. Zhong, G. Harris, L. Smirnova, V. Zufferey, R. de C. da S. e Sá, F. Baldino Russo, P.C. Baleeiro Beltrao Braga, M. Chesnut, M.-G. Zurich, H.T. Hogberg, T. Hartung, D. Pamies, Antidepressant Paroxetine Exerts Developmental Neurotoxicity in an iPSC-Derived 3D Human Brain Model, Front. Cell. Neurosci. 14 (2020). https://doi.org/10.3389/fncel.2020.00025.

[143] V. Perrera, G. Martello, How Does Reprogramming to Pluripotency Affect Genomic Imprinting?, Front. Cell Dev. Biol. 7 (2019) 76. https://doi.org/10.3389/fcell.2019.00076.

[144] E.F. Nuwaysir, M. Bittner, J. Trent, J.C. Barrett, C.A. Afshari, Microarrays and toxicology: The advent of toxicogenomics, Mol. Carcinog. 24 (1999) 153-159. https://doi.org/10.1002/(SICI)10982744(199903)24:3<153::AID-MC1>3.0.CO;2-P.

[145] J.F. Robinson, A.H. Piersma, Toxicogenomic approaches in developmental toxicology testing, in: P.C. Barrow (Ed.), Methods Mol. Biol., Humana Press, Totowa, NJ, 2013: pp. 451-473. https://doi.org/10.1007/978-162703-131-8-31

[146] V.S. Wilson, N. Keshava, S. Hester, D. Segal, W. Chiu, C.M. Thompson, S.Y. Euling, Utilizing toxicogenomic data to understand chemical mechanism of action in risk assessment, Toxicol. Appl. Pharmacol. 271 (2013) 299-308. https://doi.org/10.1016/j.taap.2011.01.017.

[147] C.A. Afshari, H.K. Hamadeh, P.R. Bushel, The Evolution of Bioinformatics in Toxicology: Advancing Toxicogenomics, Toxicol. Sci. 120 (2010) S225-S237. https://doi.org/10.1093/toxsci/kfq373.

[148] B.A. Merrick, R.S. Paules, R.R. Tice, Intersection of toxicogenomics and high throughput screening in the Tox21 program: An NIEHS perspective, Int. J. Biotechnol. 14 (2015) 7-27. https://doi.org/10.1504/IJBT.2015.074797.

[149] Z. Liu, R. Huang, R. Roberts, W. Tong, Toxicogenomics: A 2020 Vision, Trends Pharmacol. Sci. 40 (2019) 92103. https://doi.org/10.1016/j.tips.2018.12.001.

[150] R. Hrdlickova, M. Toloue, B. Tian, RNA-Seq methods for transcriptome analysis, Wiley Interdiscip. Rev. RNA. 8 (2017). https://doi.org/10.1002/wrna.1364. 
[151] B.A. Merrick, Next-generation sequencing data for use in risk assessment, Curr. Opin. Toxicol. 18 (2019) $18-$ 26. https://doi.org/10.1016/j.cotox.2019.02.010.

[152] D.J. Duggan, M. Bittner, Y. Chen, P. Meitzer, J.M. Trent, Expression profiling using cdna microarrays, Nat. Genet. 21 (1999) 14. https://doi.org/10.1038/4434.

[153] C. Wang, B. Gong, P.R. Bushel, J. Thierry-Mieg, D. Thierry-Mieg, J. Xu, H. Fang, H. Hong, J. Shen, Z. Su, J. Meehan, X. Li, L. Yang, H. Li, P.P. Łabaj, D.P. Kreil, D. Megherbi, S. Gaj, F. Caiment, J. Van Delft, J. Kleinjans, A. Scherer, V. Devanarayan, J. Wang, Y. Yang, H.R. Qian, L.J. Lancashire, M. Bessarabova, Y. Nikolsky, C. Furlanello, M. Chierici, D. Albanese, G. Jurman, S. Riccadonna, M. Filosi, R. Visintainer, K.K. Zhang, J. Li, J.H. Hsieh, D.L. Svoboda, J.C. Fuscoe, Y. Deng, L. Shi, R.S. Paules, S.S. Auerbach, W. Tong, The concordance between RNA-seq and microarray data depends on chemical treatment and transcript abundance, Nat. Biotechnol. 32 (2014) 926-932. https://doi.org/10.1038/nbt.3001.

[154] W. Zhang, Y. Yu, F. Hertwig, J. Thierry-Mieg, W. Zhang, D. Thierry-Mieg, J. Wang, C. Furlanello, V. Devanarayan, J. Cheng, Y. Deng, B. Hero, H. Hong, M. Jia, L. Li, S.M. Lin, Y. Nikolsky, A. Oberthuer, T. Qing, Z. Su, R. Volland, C. Wang, M.D. Wang, J. Ai, D. Albanese, S. Asgharzadeh, S. Avigad, W. Bao, M. Bessarabova, M.H. Brilliant, B. Brors, M. Chierici, T.M. Chu, J. Zhang, R.G. Grundy, M.M. He, S. Hebbring, H.L. Kaufman, S. Lababidi, L.J. Lancashire, Y. Li, X.X. Lu, H. Luo, X. Ma, B. Ning, R. Noguera, M. Peifer, J.H. Phan, F. Roels, C. Rosswog, S. Shao, J. Shen, J. Theissen, G.P. Tonini, J. Vandesompele, P.Y. Wu, W. Xiao, J. Xu, W. Xu, J. Xuan, Y. Yang, Z. Ye, Z. Dong, K.K. Zhang, Y. Yin, C. Zhao, Y. Zheng, R.D. Wolfinger, T. Shi, L.H. Malkas, F. Berthold, J. Wang, W. Tong, L. Shi, Z. Peng, M. Fischer, Comparison of RNA-seq and microarray-based models for clinical endpoint prediction, Genome Biol. 16 (2015) 133. https://doi.org/10.1186/s13059-015-0694-1.

[155] S.H.W. Schulpen, J.L.A. Pennings, E.C.M. Tonk, A.H. Piersma, A statistical approach towards the derivation of predictive gene sets for potency ranking of chemicals in the mouse embryonic stem cell test, Toxicol. Lett. 225 (2014) 342-349. https://doi.org/10.1016/j.toxlet.2014.01.017.

[156] J.L.A. Pennings, P.T. Theunissen, A.H. Piersma, An optimized gene set for transcriptomics based neurodevelopmental toxicity prediction in the neural embryonic stem cell test, Toxicology. 300 (2012) 158167. https://doi.org/10.1016/j.tox.2012.06.016.

[157] P.T. Theunissen, J.F. Robinson, J.L.A. Pennings, E. De jong, S.M.H. Claessen, J.C.S. Kleinjans, A.H. Piersma, Transcriptomic concentration-response evaluation of valproic acid, cyproconazole, and hexaconazole in the neural Embryonic Stem Cell Test (ESTn), Toxicol. Sci. 125 (2012) 430-438. https://doi.org/10.1093/toxsci/kfr293.

[158] D.A.M. van Dartel, J.L.A. Pennings, P.J.M. Hendriksen, F.J. van Schooten, A.H. Piersma, Early gene expression changes during embryonic stem cell differentiation into cardiomyocytes and their modulation by monobuty phthalate, Reprod. Toxicol. 27 (2009) 93-102. https://doi.org/10.1016/j.reprotox.2008.12.009.

[159] T. Waldmann, M. Grinberg, A. König, E. Rempel, S. Schildknecht, M. Henry, A. K. Holzer, N. Dreser, V. Shinde, A. Sachinidis, J. Rahnenführer, J.G. Hengstler, M. Leist, Stem cell transcriptome responses and corresponding biomarkers that indicate the transition from adaptive responses to cytotoxicity, Chem. Res. Toxicol. 30 (2017) 905-922. https://doi.org/10.1021/acs.chemrestox.6b00259.

[160] H. Chen, H. Seifikar, N. Larocque, Y. Kim, I. Khatib, C.J. Fernandez, N. Abello, J.F. Robinson, Using a MultiStage hESC Model to Characterize BDE-47 Toxicity during Neurogenesis, Toxicol. Sci. 171 (2019) 221-234. https://doi.org/10.1093/toxsci/kfz136.

[161] M. Verheijen, W. Tong, L. Shi, T.W. Gant, B. Seligman, F. Caiment, Towards the development of an omics data analysis framework, Regul. Toxicol. Pharmacol. $112 \quad$ (2020) 104621. https://doi.org/https://doi.org/10.1016/j.yrtph.2020.104621.

[162] R. Agarwala, T. Barrett, J. Beck, D.A. Benson, C. Bollin, E. Bolton, D. Bourexis, J.R. Brister, S.H. Bryant, K. Canese, C. Charowhas, K. Clark, M. Dicuccio, I. Dondoshansky, S. Federhen, M. Feolo, K. Funk, L.Y. Geer, V. Gorelenkov, M. Hoeppner, B. Holmes, M. Johnson, V. Khotomlianski, A. Kimchi, M. Kimelman, P. Kitts, W. Klimke, S. Krasnov, A. Kuznetsov, M.J. Landrum, D. Landsman, J.M. Lee, D.J. Lipman, Z. Lu, T.L. Madden, T. Madej, A. Marchler-Bauer, I. Karsch-Mizrachi, T. Murphy, R. Orris, J. Ostell, C. O'sullivan, A. Panchenko, L. Phan, D. Preuss, K.D. Pruitt, K. Rodarmer, W. Rubinstein, E. Sayers, V. Schneider, G.D. Schuler, S.T. Sherry, K. Sirotkin, K. Siyan, D. Slotta, A. Soboleva, V. Soussov, G. Starchenko, T.A. Tatusova, K. Todorov, B.W. Trawick, D. Vakatov, Y. Wang, M. Ward, W.J. Wilbur, E. Yaschenko, K. Zbicz, Database resources of the National Center for Biotechnology Information, Nucleic Acids Res. 44 (2016) D7-D19. https://doi.org/10.1093/nar/gkv1290.

[163] G. Stelzer, N. Rosen, I. Plaschkes, S. Zimmerman, M. Twik, S. Fishilevich, T. Iny Stein, R. Nudel, I. Lieder, Y. Mazor, S. Kaplan, D. Dahary, D. Warshawsky, Y. Guan-Golan, A. Kohn, N. Rappaport, M. Safran, D. Lancet, The GeneCards suite: From gene data mining to disease genome sequence analyses, Curr. Protoc. Bioinforma. 2016 (2016) 1.30.1-1.30.33. https://doi.org/10.1002/cpbi.5.

[164] A.P. Davis, C.J. Grondin, R.J. Johnson, D. Sciaky, R. McMorran, J. Wiegers, T.C. Wiegers, C.J. Mattingly, The Comparative Toxicogenomics Database: update 2019, Nucleic Acids Res. 47 (2019) D948-D954. https://doi.org/10.1093/nar/gky868.

[165] C.J. Mungall, J.A. McMurry, S. Kohler, J.P. Balhoff, C. Borromeo, M. Brush, S. Carbon, T. Conlin, N. Dunn, M. Engelstad, E. Foster, J.P. Gourdine, J.O.B. Jacobsen, D. Keith, B. Laraway, S.E. Lewis, J.N. Xuan, K. Shefchek, N. Vasilevsky, Z. Yuan, N. Washington, H. Hochheiser, T. Groza, D. Smedley, P.N. Robinson, M.A. Haendel, The Monarch Initiative: An integrative data and analytic platform connecting phenotypes to genotypes across species, Nucleic Acids Res. 45 (2017) D712-D722. https://doi.org/10.1093/nar/gkw1128. 
[166] N. Rappaport, M. Twik, I. Plaschkes, R. Nudel, T.I. Stein, J. Levitt, M. Gershoni, C.P. Morrey, M. Safran, D. Lancet, MalaCards: An amalgamated human disease compendium with diverse clinical and genetic annotation and structured search, Nucleic Acids Res. 45 (2017) D877-D887. https://doi.org/10.1093/nar/gkw1012.

[167] C.J. Bult, J.A. Blake, C.L. Smith, J.A. Kadin, J.E. Richardson, A. Anagnostopoulos, R. Asabor, R.M. Baldarelli, J.S. Beal, S.M. Bello, O. Blodgett, N.E. Butler, K.R. Christie, L.E. Corbani, J. Creelman, M.E. Dolan, H.J. Drabkin, S.L. Giannatto, P. Hale, D.P. Hill, M. Law, A. Mendoza, M. McAndrews, D. Miers, H. Motenko, L. Ni, H. Onda, M. Perry, J.M. Recla, B. Richards-Smith, D. Sitnikov, M. Tomczuk, G. Tonorio, L. Wilming, Y. Zhu, Mouse Genome Database (MGD) 2019, Nucleic Acids Res. 47 (2019) D801-D806. https://doi.org/10.1093/nar/gky1056.

[168] M. Ashburner, C.A. Ball, J.A. Blake, D. Botstein, H. Butler, J.M. Cherry, A.P. Davis, K. Dolinski, S.S. Dwight, J.T. Eppig, M.A. Harris, D.P. Hill, L. Issel-Tarver, A. Kasarskis, S. Lewis, J.C. Matese, J.E. Richardson, M. Ringwald, G.M. Rubin, G. Sherlock, Gene ontology: tool for the unification of biology. The Gene Ontology Consortium, Nat. Genet. 25 (2000) 25-29. https://doi.org/10.1038/75556.

[169] D. Szklarczyk, A.L. Gable, D. Lyon, A. Junge, S. Wyder, J. Huerta-Cepas, M. Simonovic, N.T. Doncheva, J.H. Morris, P. Bork, L.J. Jensen, C. Von Mering, STRING v1 1: Protein-protein association networks with increased coverage, supporting functional discovery in genome-wide experimental datasets, Nucleic Acids Res. 47 (2019) D607-D613. https://doi.org/10.1093/nar/gky1131.

[170] E. Eden, R. Navon, I. Steinfeld, D. Lipson, Z. Yakhini, GOrilla: A tool for discovery and visualization of enriched GO terms in ranked gene lists, BMC Bioinformatics. 10 (2009) 48. https://doi.org/10.1186/1471-2105-10-48.

[171] S. Ben-Ari Fuchs, I. Lieder, G. Stelzer, Y. Mazor, E. Buzhor, S. Kaplan, Y. Bogoch, I. Plaschkes, A. Shitrit, N. Rappaport, A. Kohn, R. Edgar, L. Shenhav, M. Safran, D. Lancet, Y. Guan-Golan, D. Warshawsky, R. Shtrichman, GeneAnalytics: An Integrative Gene Set Analysis Tool for Next Generation Sequencing, RNAseq and Microarray Data, Omi. A J. Integr. Biol. 20 (2016) 139-151. https://doi.org/10.1089/omi.2015.0168.

[172] D.W. Huang, B.T. Sherman, R.A. Lempicki, Systematic and integrative analysis of large gene lists using DAVID bioinformatics resources, Nat. Protoc. 4 (2009) 44-57. https://doi.org/10.1038/nprot.2008.211.

[173] M. Kutmon, M.P. van lersel, A. Bohler, T. Kelder, N. Nunes, A.R. Pico, C.T. Evelo, PathVisio 3: An Extendable Pathway Analysis Toolbox, PLoS Comput. Biol. 11 (2015) e1004085. https://doi.org/10.1371/journal.pcbi.1004085.

[174] M. Kanehisa, Y. Sato, M. Kawashima, M. Furumichi, M. Tanabe, KEGG as a reference resource for gene and protein annotation, Nucleic Acids Res. 44 (2016) D457-D462. https://doi.org/10.1093/nar/gkv1070.

[175] J.L. Stein, L. de la Torre-Ubieta, Y. Tian, N.N. Parikshak, I.A. Hernández, M.C. Marchetto, D.K. Baker, D. Lu, C.R. Hinman, J.K. Lowe, E.M. Wexler, A.R. Muotri, F.H. Gage, K.S. Kosik, D.H. Geschwind, A quantitative framework to evaluate modeling of cortical development by neural stem cells, Neuron. 83 (2014) 69-86. https://doi.org/10.1016/j.neuron.2014.05.035.

[176] O. Palasca, A. Santos, C. Stolte, J. Gorodkin, L.J. Jensen, TISSUES 2.0: An integrative web resource on mammalian tissue expression, Database. 2018 (2018) bay003. https://doi.org/10.1093/database/bay003.

[177] A. Jain, G. Tuteja, TissueEnrich: Tissue-specific gene enrichment analysis, Bioinformatics. 35 (2019) 19661967. https://doi.org/10.1093/bioinformatics/bty890.

[178] A. Subramanian, P. Tamayo, V.K. Mootha, S. Mukherjee, B.L. Ebert, M.A. Gillette, A. Paulovich, S.L. Pomeroy, T.R. Golub, E.S. Lander, J.P. Mesirov, Gene set enrichment analysis: A knowledge-based approach for interpreting genome-wide expression profiles, Proc. Natl. Acad. Sci. U. S. A. 102 (2005) 15545-15550. https://doi.org/10.1073/pnas.0506580102

[179] X. Yu, W.C. Griffith, K. Hanspers, J.F. Dillman, H. Ong, M.A. Vredevoogd, E.M. Faustman, A system-based approach to interpret dose- and time-dependent microarray data: Quantitative integration of gene ontology analysis for risk assessment, Toxicol. Sci. 92 (2006) 560-577. https://doi.org/10.1093/toxsci/kfj184.

[180] F. Avila Cobos, J. Vandesompele, P. Mestdagh, K. De Preter, Computational deconvolution of transcriptomics data from mixed cell populations, Bioinformatics. $34 \quad$ (2018) 1969-1979. https://doi.org/10.1093/bioinformatics/bty019.

[181] W.S. Rasband, ImageJ, U. S. Natl. Institutes Heal. Bethesda, Maryland, USA. (n.d.). https://imagej.nih.gov/ij/.

[182] C. McQuin, A. Goodman, V. Chernyshev, L. Kamentsky, B.A. Cimini, K.W. Karhohs, M. Doan, L. Ding, S.M. Rafelski, D. Thirstrup, W. Wiegraebe, S. Singh, T. Becker, J.C. Caicedo, A.E. Carpenter, CellProfiler 3.0: Nextgeneration image processing for biology, PLoS Biol. 16 (2018) e2005970https://doi.org/10.1371/journal.pbio.2005970.

[183] P.T. Theunissen, J.F. Robinson, J.L.A. Pennings, M.H. van Herwijnen, J.C.S. Kleinjans, A.H. Piersma Compound-specific effects of diverse neurodevelopmental toxicants on global gene expression in the neural embryonic stem cell test (ESTn), Toxicol. Appl. Pharmacol. 262 (2012) 330-340. https://doi.org/10.1016/j.taap.2012.05.011.

[184] P.T. Theunissen, J.L.A. Pennings, J.F. Robinson, S.M.H. Claessen, J.C.S. Kleinjans, A.H. Piersma, Timeresponse evaluation by transcriptomics of methylmercury effects on neural differentiation of murine embryonic stem cells, Toxicol. Sci. 122 (2011) 437-447. https://doi.org/10.1093/toxsci/kfr134.

[185] S.H.W. Schulpen, J.F. Robinson, J.L.A. Pennings, D.A.M. van Dartel, A.H. Piersma, Dose response analysis of monophthalates in the murine embryonic stem cell test assessed by cardiomyocyte differentiation and gene expression., Reprod. Toxicol. 35 (2013) 81-88. https://doi.org/10.1016/j.reprotox.2012.07.002. 
Image credits Figure 1: Kiranshastry (lightning), Freepick (human, mouse, brain, heart, cell, looking glass), Eucalyp (blood drop), bqlan (clock). 



\section{CHAPTER 2}

\section{EXPLORING THE BIOLOGICAL DOMAIN OF THE NEURAL EMBRYONIC STEM CELL TEST (ESTN): MORPHOGENETIC REGULATORS, HOX GENES AND CELL TYPES, AND THEIR USEFULNESS AS BIOMARKERS FOR EMBRYOTOXICITY SCREENING}

Victoria C. de Leeuw ${ }^{1,2}$, Ellen V.S. Hessel ${ }^{1}$, Aldert H. Piersma ${ }^{1,2}$

${ }^{1}$ Centre for Health Protection, National Institute for Public Health and the Environment, Bilthoven, the Netherlands

${ }^{2}$ Institute for Risk Assessment Sciences, Utrecht University, Utrecht, the Netherlands

Toxicology, 2021 Feb, 454: 152735

DOI: 10.1016/j.tox.2021.152735 



\begin{abstract}
Animal-free assessment of compound-induced developmental neurotoxicity will most likely be based on batteries of multiple in vitro tests. The optimal battery is built by combining tests with complementary biological domains that together ideally cover all relevant toxicity pathways. Thus, biological domain definition, i.e. which biological processes and cell types are represented, is an important assay characteristic for determining the place of assays in testing strategies. The murine neural embryonic stem cell test (ESTn) is employed to predict the developmental neurotoxicity of compounds. The aim of this study was to explore the biological domain of ESTn according to three groups of biomarker genes of early (neuro)development: morphogenetic regulators, Hox genes and cell type markers for the ectodermal and neural lineages. These biomarker groups were selected based on their crucial regulatory role in (neuro)development. Analysis of these genes in a series of previously generated whole transcriptome datasets of ESTn showed that at day 7 in culture cell differentiation resembled hindbrain/branchial/thoracic development between E6.5-E12.5 in vivo, with subsequent development into a mixed cell culture containing different neural subtypes, astrocytes and oligodendrocytes by day 13. In addition, the selected biomarkers showed common and distinct responses to compound exposure. Monitoring the biological domain of ESTn through gene expression patterns of morphogenetic regulators, Hox genes and cell type markers proved instrumental in providing mechanistic understanding of compound effects on neural differentiation in ESTn, and can aid in positioning of the test in a battery of complementary in vitro tests in integrated approaches to testing and assessment.
\end{abstract}




\section{Introduction}

The field of toxicology is increasingly focussing on the development of animal-free testing methods to reduce animal use and produce more mechanism-based toxicity data, with the aim of improving human risk assessment whilst phasing out animal studies. This requires a radical rethinking of toxicity testing and risk assessment towards testing strategies that integrate multiple complementary in vitro and in silico models. For successful implementation of an in vitro model it is essential to explore its biological domain, i.e. the biological processes that the assay represents and related biomarkers that are measured [1-5]. This is especially important in the field of developmental toxicity, which addresses effects on the moving target of the developing embryo-foetus with its time-dependent windows of sensitivity. Stem cell based models are popular in this area as they can mimic essential parts of embryonic development. Extensive characterisation of the biological domain covered by these models is crucial for the interpretation of test results and their extrapolation in the wider context of hazard assessment $[5,6]$.

This study aims to explore the biological domain of the murine neural embryonic stem cell test (ESTn) that mimics parts of embryonic neural differentiation $[7,8]$. This model has been used for the purpose of investigating the developmental neurotoxic (DNT) potential of compounds [8-12]. A number of teratogenic and/or DNT compounds have been tested in ESTn, each of them having specific phenotypic effects in vivo that were also reflected in inhibited differentiation in ESTn (Table 1). To gain mechanistic understanding of the assay, whole transcriptome data was used to monitor cell differentiation, considering that gene expression ultimately underlies cell morphology and function [13]. Without claiming to be exhaustive, we focussed in this study on exploring the biological domain of ESTn based on three groups of biomarker genes essential for early developmental cell type specification: morphogenetic regulators, Hox genes, and cell type markers (Fig. 1), which likely cover a major area of the biological domain of ESTn. These biomarker gene groups are regulated during gastrulation, neural tube patterning and neurulation and may therefore also be sensitive to compounds that affect these processes in vivo and in vitro.
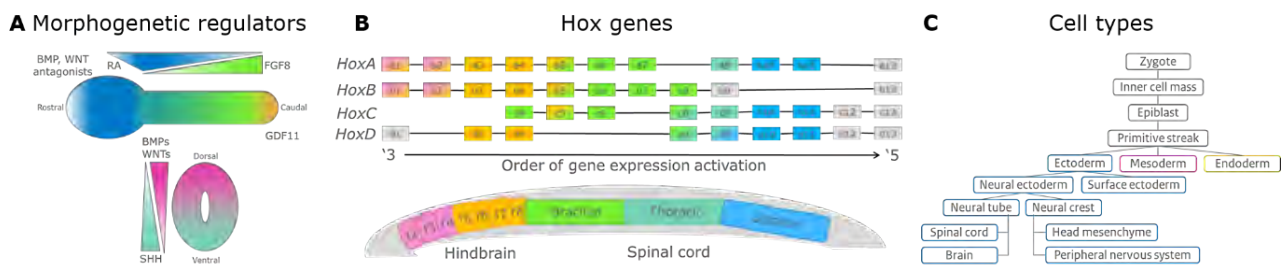

Figure 1. Schematic representation of exploring the biological domain of a stem cell-based in vitro system based on gene expression of three groups of genes: (A) morphogenetic regulator gradients that run along the embryo body axes, (B) Hox genes and (C) cell types of the ectodermal and neural lineages. (A) is adapted from Davis-Dusenbery et al., [27], Rogers \& Schier [28] and Lemke et al. [29], (B) is adapted from Pang \& Thompson [30] and Philippidou \& Dasen [37] and (C) is adapted from LifeMap Discovery. 
Table 7. In vivo developmental toxicity of selected compounds tested in ESTn.

\begin{tabular}{|c|c|c|c|c|c|}
\hline Compound & $\begin{array}{l}\text { Abbrevia- } \\
\text { tion }\end{array}$ & $\begin{array}{l}\text { Compound classifi- } \\
\text { cation }\end{array}$ & $\begin{array}{l}\text { In vivo developmental tox- } \\
\text { icity (species) }\end{array}$ & $\begin{array}{l}\text { Reference } \\
\text { in vivo find- } \\
\text { ings }\end{array}$ & $\begin{array}{l}\text { Refer- } \\
\text { ence } \\
\text { ESTn } \\
\text { findings }\end{array}$ \\
\hline Acetaldehyde & ACE & DNT & $\begin{array}{l}\text { Foetal alcohol syndrome } \\
\text { (human)? } \\
\text { Neural tube defects, haem- } \\
\text { orrhages, growth retarda- } \\
\text { tion (rat) }\end{array}$ & {$[14,15]$} & [11] \\
\hline Carbamazepine & $\mathrm{CBZ}$ & Teratogen/DNT & $\begin{array}{l}\text { Neural tube defects, cardi- } \\
\text { ovascular and urinary tract } \\
\text { anomalies, and cleft palate } \\
\text { (human) }\end{array}$ & [16] & [11] \\
\hline Cyproconazole & CYP & Teratogen/DNT & $\begin{array}{l}\text { Delayed ossification bones, } \\
\text { cleft palate, hydrocephalus, } \\
\text { hydronephrosis (rat) }\end{array}$ & [17] & [10] \\
\hline Flusilazole & FLU & Teratogen & $\begin{array}{l}\text { Cleft palate, vascular de- } \\
\text { fects, skeletal variations } \\
\text { and retarded development } \\
\text { (human) }\end{array}$ & [18] & [11] \\
\hline Hexaconazole & HEX & Teratogen & $\begin{array}{l}\text { Skeletal malformations } \\
\text { (rat) }\end{array}$ & [19] & [10] \\
\hline $\begin{array}{l}\text { Mono(2- } \\
\text { ethylhexyl) } \\
\text { phthalate }\end{array}$ & MEHP & Teratogen & $\begin{array}{l}\text { Cleft palate, skeletal abnor- } \\
\text { malities (mouse) }\end{array}$ & {$[20,21]$} & [11] \\
\hline Methyl mercury & $\mathrm{MeHg}$ & DNT & $\begin{array}{l}\text { Mental retardation, motor } \\
\text { deficits (human) }\end{array}$ & [22] & [9] \\
\hline Phenytoin & PHE & Teratogen/DNT & $\begin{array}{l}\text { Cleft palate, cardiovascular } \\
\text { defects, urogenital defects, } \\
\text { neurobehavioural defects } \\
\text { (human) }\end{array}$ & [23] & [11] \\
\hline Penicillin G & PENG & Non-teratogen & No effects & [24] & [11] \\
\hline Valproic acid & VPA & Teratogen/DNT & $\begin{array}{l}\text { Neural tube effects, heart } \\
\text { defects, neurobehavioural } \\
\text { defects (human) }\end{array}$ & {$[25,26]$} & [10] \\
\hline
\end{tabular}

Morphogenetic regulators are diffusible factors that define the basic head-trunk-tail layout of the embryo during early development (Fig. 1A) [32]. Gradients of morphogenetic regulators pattern the dorsoventral (DV) and rostrocaudal (RC) axis of the neural tube, giving rise to regionally defined cell types, and have an especially important role in neural commitment [31]. The dominant morphogenetic regulators along the $\mathrm{RC}$ axis are anterior all-trans retinoic acid (ATRA) and posterior fibroblast growth family (FGFs) signals that start around mouse embryonic day 7 (E7.0), later followed by growth differentiation factor 11 (GDF11) in the tail region (Fig. 1A). The bone morphogenetic protein family (BMPs) and sonic hedgehog (SHH) define the DV axis and neural subtype specification from E8.5 [33,34]. WNT3 (from E6.0) and WNT3A (from E7.2) are involved in DV axis specification and work together with ATRA and FGF signalling to specify motor neuron subtypes $[35,36]$. There are multiple other signalling molecules involved, which are listed in Table 2.

Hox genes are a subfamily of the homeobox genes and are responsible for the further determination of the body plan and specifically in the CNS for hindbrain patterning (Fig. 1B) [31]. Their expression is initiated by WNT3 in the posterior streak [35,37]. From there, expression moves anteriorly in a temporal collinear fashion, meaning that Hox genes are expressed along the rostrocaudal axis in the same sequence as they are encoded on the chromosomes, both in space 
Table 2. Signals participating in early development, adapted from LifeMap Discovery.

\begin{tabular}{ll}
\hline Tissue (embryonic day in mouse) & Morphogenetic regulators \\
\hline Inner cell mass (3.0-E5.0) & FGF4, NODAL \\
Epiblast (E5.0-E6.5) & BMP2, BMP4, BMP8B, FGFs, FGF8, NODAL, ATRA, TGF 3 1,WNT3 \\
Primitive streak (E7.0) & BMP4, NODAL, ATRA, TGF 17 \\
Neural tube (E7.0-E9.5) & ACTIVIN, BMP2, BMP4, BMP7, BMPs, CNTF, CT1, FGFs, FGF2, FGF8, LIF, \\
Somites (E8.0-E10.0) & FGF4, FHH, WNT3A \\
& \\
\hline
\end{tabular}

and time [38,39]. Further specification of Hox genes is regulated by Hox-Hox interactions [4042] and by the morphogenetic regulators [31]. For example, ATRA primarily induces Hox 1-5, FGF8 induces Hox6-9, and GDF11 induces Hox10-13 gene expression [37,43,44].

While the embryonic body plan further evolves, the three germ layers and subsequent tissues develop consisting of an increasing number of different cell types. Within the scope of this paper, given the focus on ectodermal and neural differentiation in ESTn, here we only discuss the ectodermal lineage (Fig. 1C). The ectodermal germ layer divides into neural and surface (or non-neural) ectoderm. The first develops into the neural tube and adjacent neural crest, the latter into the skin. The neural tube develops into the brain and the spinal cord in which a plethora of neural subtypes as well as astrocytes and oligodendrocytes are further specified by morphogenetic regulators and Hox genes $[31,45,46]$. The neural crest gives rise amongst others to the peripheral nervous system, craniofacial skeleton, smooth muscles, and melanocytes [28].

In combination these three groups of biomarker genes can be employed to explore the biological domain of ESTn. Morphogenetic regulator gene expression can reveal to what extent spatial patterning mechanisms are mimicked in ESTn. Hox gene expression can be indicative of the extent of coverage of rostro-caudal body axis specification and the regional identity of the (neural) cells. Cell type marker expression can provide further insight into which cell types are generated at which stage of differentiation. Thus, rather than performing a fishing expedition of detecting responsive genes in a whole genome analysis after compound exposure, we here start from exploring the biological domain of the assay, and attempt to interpret compound effects within this biological domain. For example, biomarker gene changes may indicate how a compound exerts its effects on neural differentiation (a DNT positive readout), while absence of biomarker responses in the assay may be explained by either the compound mode of action lying outside the biological domain of the assay (resulting in a false negative) or the compound is not a (neuro)developmental toxicant (a true negative). Regardless, complementary test systems are needed to further explore the compound's potential DNT properties. Biological domain information can assist in composing test batteries of these assays with complementary biological domains. Such test batteries are instrumental in innovative animal-free approaches towards human hazard and risk assessment. 


\section{Materials and methods}

\section{Datasets}

For this study existing datasets were used of gene expression in control and exposed cultures of ESTn, which is a neural differentiation test based on murine embryonic stem cells. Briefly, initiation of differentiation is performed according to the hanging drop method. Suspensions of stem cells are put up-side-down on the lid of a dish to form embryonic bodies (EB) over the course of three days. On day 3 , neural differentiation is induced by adding ATRA to the medium. The EBs are allowed to grow adherently between day 5 and 7 in different media compositions with decreasing concentrations of foetal bovine serum. On day 7 , the EBs are dissociated and plated again in neural medium until day 11 or 13. Compound testing is done by exposure from day 3-6 in the protocol, when neural differentiation is induced with ATRA. Morphological scoring is performed by assessing the fullness of the corona of neurites around the EB. When the corona is less than $75 \%$, the EB is considered as affected. Based on morphological scoring, gene expression experiments have been performed by exposing EBs to a range of concentrations of the compounds for $24 \mathrm{~h}$ between day 3 and 4 (Table 3 ). A detailed protocol can be found in Theunissen et al. [9].

Raw and normalised Affymetrix microarray data from Theunissen et al. are available at ArrayExpress (www.ebi.ac.uk/) and RNA-seq data from de Leeuw et al. is available at the Gene Expression Omnibus (GEO, https://www.ncbi.nlm.nih.gov/geo) (Table 3). Microarray data was processed as described in Theunissen et al. [9], RNA-seq data was processed as described in de Leeuw et al. [8]. Gene expression from ESTn was compared to in vivo mouse neural tube and mouse embryo data (Table 3). Mouse neural tube data was obtained from a study performed by Beccari et al. [47]. Raw data was downloaded from GEO and was processed as described in de Leeuw et al. [8]. Mouse embryo data was obtained from experiments performed by Irie et al. [48]. Processed microarray data was accessed through ArrayExpress. When multiple probe sets were available for one gene, the median was taken from all probe sets, except the low quality probe sets (ending at_x_at), which were not used.

\section{Biomarker selection}

A selection of biomarkers was made based on the three selected dimensions of (neuro)development as explained in the introduction. For morphogenetic regulators, the biomarker list was based on literature [32-36] and the list summarised by LifeMap Discovery (Table 1). Since retinoic acid is not encoded by a gene, biomarkers involved in its synthesis (Dhrs3, Rdh10, Aldh7a1, Aldh7a2, Aldh7a3) and metabolism (Cyp26a1, Cyp26b7, Cyp26c7) were selected. All Hox genes were taken into the analysis, because together they form a well-defined functionally related set of genes. For the cell types, biomarkers were previously selected in de Leeuw et al. [8] based on often used selective markers in literature (e.g. Beccari et al., 2018; Kügler et al., 2010; Spangler et al., 2018; Tao and Zhang, 2016). 
Table 3. Overview of models used for this study.

\begin{tabular}{|c|c|c|c|c|c|c|}
\hline Model & $\begin{array}{l}\text { Gene ex- } \\
\text { pression } \\
\text { analysis } \\
\text { type }\end{array}$ & $\begin{array}{l}\text { Time points } \\
\text { of gene ex- } \\
\text { pression } \\
\text { analysis }\end{array}$ & $\begin{array}{l}\text { Sample size per } \\
\text { condition }\end{array}$ & Compound data & Reference no. & $\begin{array}{l}\text { Publica- } \\
\text { tion }\end{array}$ \\
\hline \multicolumn{7}{|c|}{ Comparison with in vivo gene expression } \\
\hline \multirow[t]{2}{*}{ ESTn } & Microarray & $\begin{array}{l}\text { Day } 0,3,4,5 \text {, } \\
6,7\end{array}$ & 8 & NA & E-TABM-1108 & [9] \\
\hline & RNA-seq & Day $0,7,13$ & 7 & NA & GSE153836 & [8] \\
\hline $\begin{array}{l}\text { Mouse } \\
\text { neural } \\
\text { tube }\end{array}$ & RNA-seq & $\begin{array}{l}E 6.5,7.8,8.5, \\
9.5\end{array}$ & $2(8.5,9.5)-3$ & NA & GSE113885 & {$[47]$} \\
\hline $\begin{array}{l}\text { Mouse } \\
\text { em- } \\
\text { bryo }\end{array}$ & Microarray & $\begin{array}{l}\text { E7.5, 8.5, 9.5, } \\
10.5,12.5, \\
14.5,16.5 \\
18.5\end{array}$ & $\begin{array}{l}2(12.5,14.5 \\
16.5,18.5)-3\end{array}$ & NA & E-MTAB-368 & [48] \\
\hline \multicolumn{7}{|c|}{ Compound exposure } \\
\hline ESTn & Microarray & Day 4 & 8 & $\begin{array}{l}\text { Methyl mercury } \\
\text { Cyproconazole } \\
\text { Hexaconazole } \\
\text { Valproic acid } \\
\text { Acetaldehyde } \\
\text { Carbamazepine } \\
\text { Flusilazole } \\
\text { Mono(2-ethylhexyl) } \\
\text { phthalate } \\
\text { Phenytoin } \\
\text { Penicillin G }\end{array}$ & $\begin{array}{l}\text { E-TABM-1108 } \\
\text { E-TABM-1205 }\end{array}$ & $\begin{array}{l}9] \\
{[10]}\end{array}$ \\
\hline
\end{tabular}

\section{Data analysis, statistics and visualisation}

For this study, we used existing data sets that were obtained using different techniques, namely microarray and RNA-seq. These techniques are based on different types of measurement (fluorescence signal for microarray versus sequence read counts for RNA-seq) and accordingly represent different dynamic ranges. For statistical analysis, we therefore chose to take an absolute $p$-value cut-off of $p<0.001$ for all datasets. These analyses were performed as described in Theunissen et al. [9] and de Leeuw et al. [8]. In addition, to ensure that comparisons between data sets could reliably be made, we based our visualisation on time trends within each individual study. For ESTn control data, morphogenetic regulator gene expression of every time point in the Theunissen microarray dataset was presented relative to expression levels in the stem cell culture (day 0). Hox genes, also from the Theunissen dataset, were each compared to the median of all time points. Cell type marker expression of each gene of both the microarray and the RNAseq dataset was compared to the average expression of day 0 and 7 to allow for some extent of comparison between the two datasets. Datasets of Beccari et al. [47] and Irie et al. [48] were treated in the same manner for the morphogenetic regulators and Hox genes, and the cell type markers were expressed in the same manner as the Hox genes. For the comparison of Hox gene expression between the three datasets, log2-transformed processed data (microarray signal or vst-normalised counts) was taken to show the full dynamics of Hox gene expression of every dataset. For ESTn exposure data every gene from an exposed condition was compared to the time-matched control group from the same experiment (day 4). Visualisation was performed using Graphpad (version 8.4.1; www.graphpad.com), R (version 3.6.0; [52]), Excel and the cell lineage map [8], which was visualised with PathVisio (version 3.3.0; [53]). 


\section{Results}

\section{ESTn revealed morphogenetic regulator, Hox gene and cell type gene expression towards a neural fate}

ESTn showed morphogenetic regulator patterns that globally resembled expression in early development from the epiblast to the neural tube stage (Table 2, Fig 2A). During the first three days of embryoid body (EB) formation, rostrocaudal (RC) regulators like Fgf8, Wnt3 and some of the all-trans retinoic acid (ATRA)-machinery regulators (Cyp26a 7, Dhrs3 and Rdh10) were upregulated, and Fgf4 was downregulated. Dorsoventral (DV) regulators Bmp2 and Noda/were also upregulated. Bmp4 and Bmp8b, however, were downregulated. The upregulated genes were overall consistent with the epiblast stage (Table 2). Upon the addition of external ATRA a marked decrease of Fgf8 and Wnt3 in combination with an upregulation of RA regulating enzymes Cyp26a 1, Cyp26b7, Dhrs3 and Aldh1a2 was apparent, indicating that ATRA effectively inhibited expression of Fgf8 and Wnt3. Wnt3a, Wnt6 and Gdf7 7 showed an increase in expression, consistent with their later expression pattern in the neural tube (Table 2). Gene expression of DV regulators stayed relatively stable, except for a marked downregulation of Nodal, which is downregulated in the transition from epiblast to neural tube (Table 2). Removal of ATRA after 48h resulted in downregulation of ATRA-metabolising enzymes (e.g. Cyp26a7, Cyp26b7) and the other $\mathrm{RC}$ regulators remained at a steady expression level. DV regulators Shh and Notch 7 were upregulated, consistent with their role in neural tube formation and neural (crest) differentiation (Table 2). Morphogenetic regulator expression stayed relatively stable between seven and thirteen days of differentiation, except for upregulation of Cyp26b7 expression and downregulation of Cyp26a 1 and Wnt6 (Fig. S1A).

Hox genes were expressed in a colinear manner from Hox 1 to Hox9 paralogues from day 3 on, after the addition of ATRA (Fig. 2B). Hox 7 a and Hox 7 b were strongly upregulated by ATRA, after which additional Hox genes were activated. Even when ESTn was cultured for thirteen days, Hox genes beyond the Hox9 paralogues were barely regulated (Fig. S1B), demarcating a clear regional boundary of the biological domain of ESTn.

Markers for cell types of the germ layers and ectodermal lineage showed that ESTn progressed from stem cells to neural and glial cells over the course of differentiation (Fig. 2C). In the first seven days (represented by the first six blocks, Fig. 2C) stem cell markers were downregulated, germ layer markers were intermediately upregulated and neural progenitor, neural crest cell and early neural cell gene expression increased steadily over time, indicating an immature neural-neural crest culture. Longer differentiation (represented by the last three blocks, Fig. 2C) additionally resulted in upregulation of mature neuron, astrocyte, oligodendrocyte and neural subtype markers, indicative for a matured mixed neural-glial cell culture.

In short, gene expression in the first seven days of ESTn differentiation showed morphogenetic regulator patterning, mainly of those that act along the $\mathrm{RC}$ axis, along with colinear Hox expression and upregulation of early neural and neural crest cell type markers. Longer differentiation did not result in major changes in morphogenetic regulator or Hox gene expression, but did show upregulation of neural subtype and glial markers. Given these results, gene expression in ESTn may represent neural cell differentiation restricted to the hindbrain/branchial/thoracic region (Fig. 1B), characterised by a wide array of ectodermal and neural cell types. 

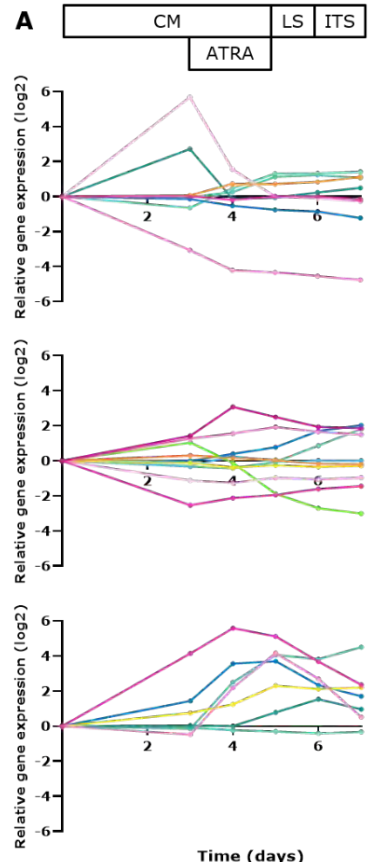

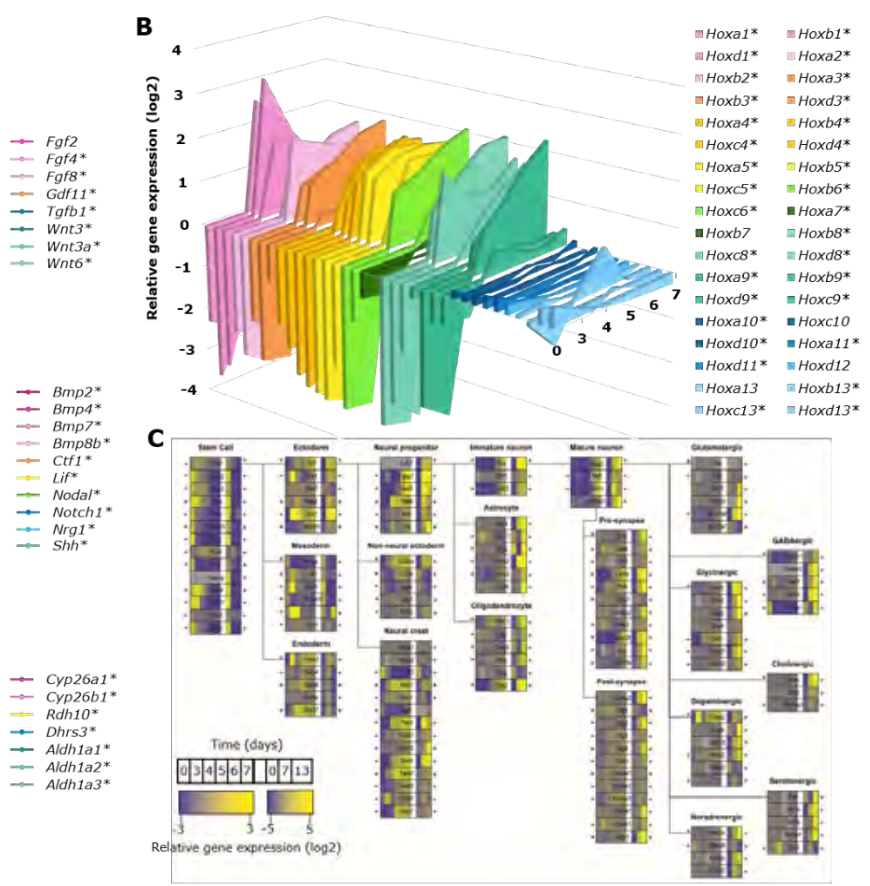

Figure 2. ESTn gene expression of morphogenetic regulators, Hox genes and cell type markers. (A) Microarray gene expression (log2) relative to stem cell culture of morphogenetic regulators listed in Table 2. For clarity, morphogenetic regulators were split in three graphs roughly representing $R C$ morphogenetic regulators, DV morphogenetic regulators and regulators of ATRA-homeostasis. Media used during differentiation are indicated above the graph and composition can be found in Theunissen et al. [9]. CM: complete medium, ATRA: all-trans retinoic acid, LS. Iow serum medium, ITS: insulin-transferrin-sodium selenite medium. (B) Microarray gene expression (log2) of all Hox genes relative to the average expression of each gene over time. (C) Cell lineage map of ectodermal and neural differentiation based on selective markers for a range of cell types. Microarray and RNA-seq gene expression (log2) is relative to the average expression on day 0 and 7 of each gene. * indicates statistically significant regulation over time $(p<0.007)$.

\section{ESTn gene expression corresponded to E6.5-E12.5 in vivo development of the hindbrain-thoracic region}

In order to further pinpoint the developmental progression of ESTn, a comparison was made with two existing in vivo datasets of neural tube development between E6.5 and E9.5 [47] and of whole embryo development between E7.5 and E18.5 [48]. As mentioned above, Hox gene expression in ESTn was induced from day 3, which resembled E6.5-E7.5 in vivo (Fig. 3A, B). Similar Hox gene expression dynamics in ESTn and both neural tube and whole embryo development could be observed with the exception of Hox10-Hox13 paralogues expression, which was absent in ESTn but clearly present in vivo (Fig 3C). Day 7 in ESTn corresponded to E10.5E12.5 in whole embryo development, indicated by a downregulation in the HoxB (Hoxb4, Hoxb5) and HoxC (Hoxc5) cluster in ESTn (Fig. 3A, C). 
A
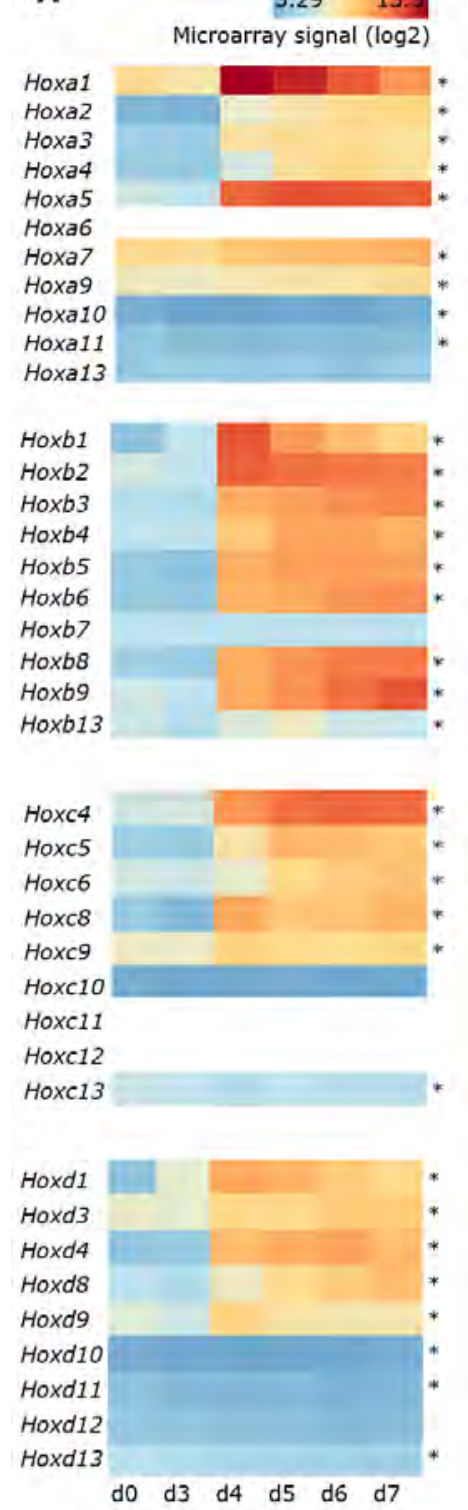

B

vst-normalised counts $(\log 2)$
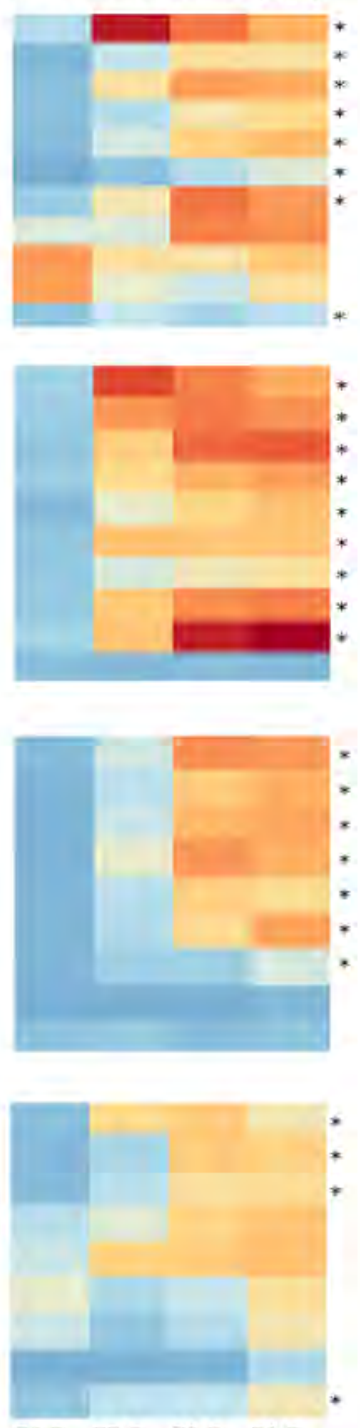

E6.5 E7.5 E8.5 E9.5
C

$1.77 \quad 11.9$

Microarray signal $(\log 2)$
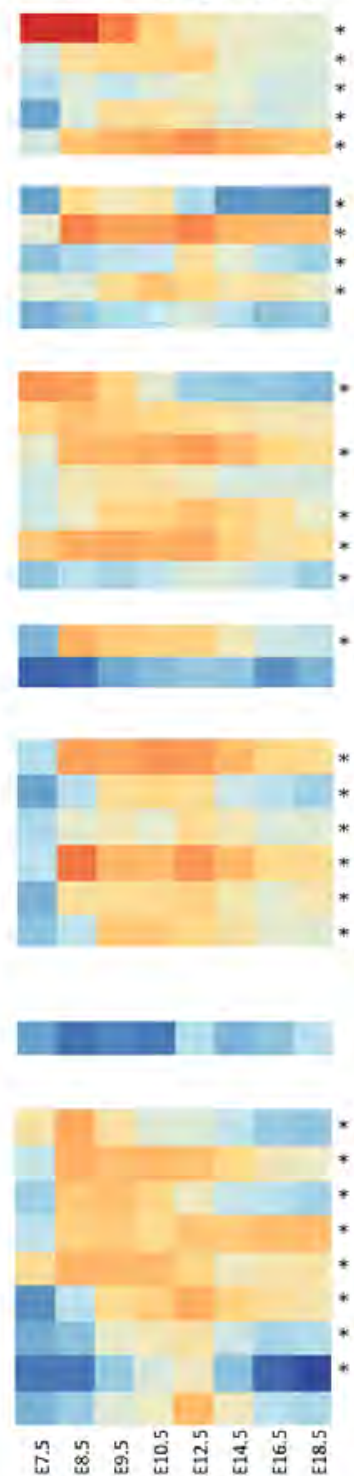

Figure 3. Hox gene expression in ESTn, mouse neural tube and mouse whole embryo derived from datasets of (A) Theunissen et al. [9], (B) Beccari et al. [47] and (C) Irie et al. [48], respectively. Time scale: d0 7 = days of differentiation, E6.5-78.5 = days post conception. Hox genes that were not present on the microarray were left white. * indicates statistically significant regulation over time $(p<0.001)$.

Morphogenetic regulator expression in ESTn did not correspond well with the in vivo datasets. Compared to in vivo neural tube development, only Gdf71, Nodal, Cyp26b1 and Aldh1a2 showed similar trends in ESTn (Fig. 2A; Fig. 4A). There was even less correspondence to whole 
embryo development, whereby virtually all genes were not regulated or regulated in opposite direction relative to ESTn (Fig. 2A; Fig. 4B). This is reminiscent of the absence of normal spatial morphogenesis and related differences in resolution in ESTn, as compared to in vivo embryogenesis. Cell type expression, on the other hand, did show interesting parallels between the models. Neural tube gene expression patterns showed a downregulation of stem cell markers and upregulation of neural progenitors and neural crest cell markers, similar to ESTn at day 56 (Fig. 2C; Fig. S2). The gene expression patterns of whole embryo development showed similar trends with day 13 in ESTn; not all markers were regulated to the same extent as in ESTn, but when gene expression was regulated it showed similar expression patterns (Fig 2C; Fig. S3).

A
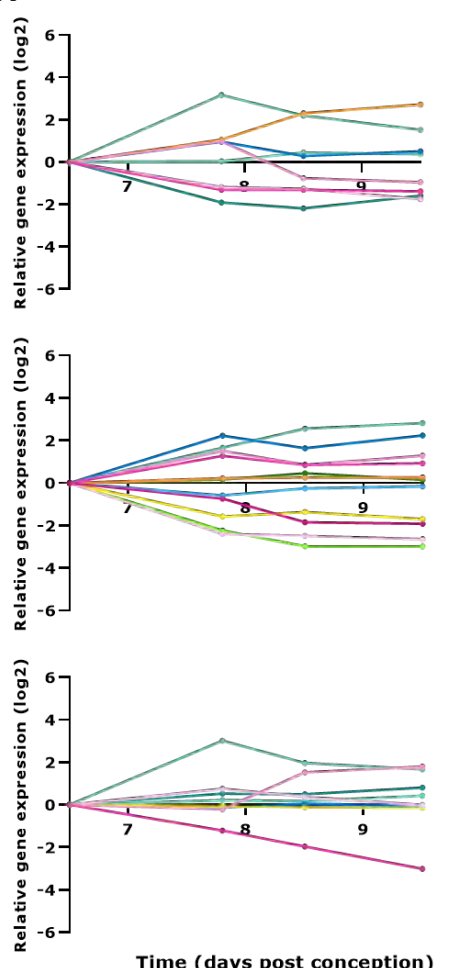

B
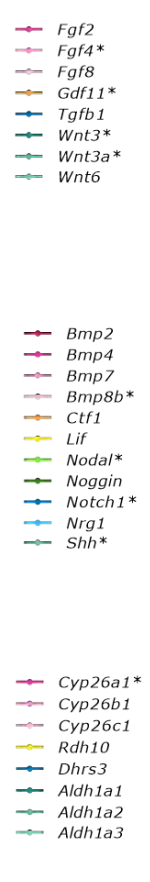

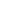

Figure 4. Mouse neural tube and mouse whole embryo gene expression of morphogenetic regulators. (A) Gene expression (log2) of morphogenetic regulators listed in Table 2 from (A) mouse neural tube relative to E6.5 [47] and (B) mouse whole embryo relative to E7.5 [48]. * indicates statistically significant regulation over time $(p<0.001)$.

\section{Diverse compounds induced common and distinct changes in ESTn gene expression}

We studied the responses of the above gene sets after exposure to a range of teratogenic and/or neurodevelopmental compounds, based on a whole transcriptome analysis data set measured after $24 \mathrm{~h}$ exposure from day 3-4 of differentiation in ESTn [9-11]. 
Figure 5 shows gene expression changes caused by ten different compounds in ESTn relative to a day-matched control for each of the three explored biomarker gene groups. Gene expression responses were observed at concentrations that did not affect morphology, illustrating relatively high sensitivity of gene expression readout in ESTn as compared to morphology.

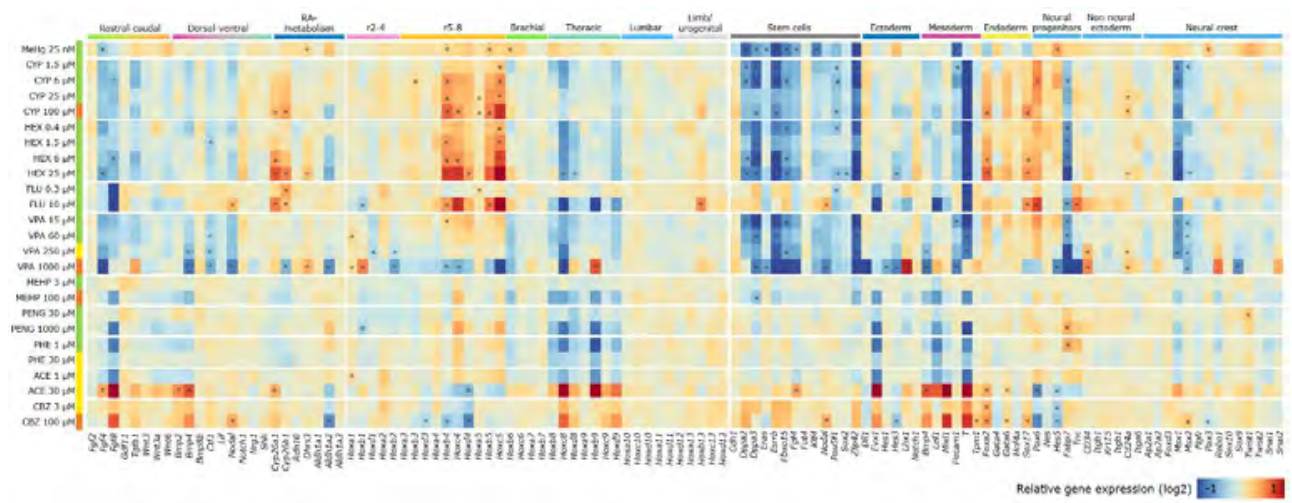

Figure 5. Gene expression regulation (log2) relative to a day-matched control group of morphogenetic regulators, Hox genes and cell type markers caused by a range of compounds: methyl mercury (MeHg), cyproconazole (CYP), hexaconazole (HEX), flusilazole (FLU), valproic acid (VPA), flusilazole (FLU), mono(2-ethylhexyl) phthalate (MEHP), phenytoin (PHE) and penicillin G (PENG), acetaldehyde (ACE), carbamazepine (CBZ). Colours of horizontal bars correspond to Fig. 1. Colours of vertical bars indicate neural outgrowth inhibition in ESTn. Green: no effect; yellow: inhibition in less than 50\% of the EB; orange: inhibition in more than 50\% of the EBs. * indicates statistically significant regulation over time $(p<0.001)$.

Another interesting general trend is that there seemed to be an association between a compound-induced downregulation of Fgf8and Bmp4on the one hand and an upregulation of Hox4 and Hox5 paralogues and downregulation of Hox8 and Hox9 paralogues on the other hand (CYP, HEX, FLU, VPA, MEHP, PENG, PHE, see Fig. 5 for compound code legend). The opposite was observed too, particularly in CBZ and even with two concentrations of ACE, further illustrating the inverse relation between the expression changes of these genes. Similar trends were found only to a very limited extent in changes in cell type markers; ectodermal marker Evx 7 , mesodermal marker Tand neural crest cell marker MsX7 were the only cell type markers that consistently changed with the regulation in RC and Hox genes. MeHg stood out in its expression profile as it caused no clear regulation of morphogenetic regulators or Hox genes in the presence of a specific downregulation of stem cell markers and an upregulation of ectodermal lineages.

Aside from this general trend, there were some groups of compounds that could be distinguished based on their biomarker gene regulation. The azoles CYP and HEX and to some extent VPA showed a similar expression pattern with a downregulation of stem cell, mesoderm and neural crest cell markers, and an upregulation of endodermal markers (Fig. 5). Additionally, CYP and HEX upregulated some of the ATRA metabolism genes (Cyp26a 7 and Cyp26b7 up, and Aldh 1a2trend down). The highest concentration of VPA caused a deviation of the gene expression pattern, regulating a large number of additional genes. FLU, which also belongs to the azole class, induced Hox gene expression only at a high concentration, along with changes in cell type markers that only partly overlapped with CYP and HEX: stem cell markers were regulated in a mixed fashion, while the mesoderm and endoderm markers were regulated in a similar 
manner. Specifically neural progenitor marker Fabp7 was downregulated by these four compounds.

MEHP, PENG, PHE and low concentration of ACE predominantly downregulated Hox8 and Hox9 paralogues. There was no clear effect on specific cell types, only a trend towards downregulation of a small number of ectoderm and mesoderm markers (EVX T, Lefty 7, T).

CBZ and a high concentration of ACE showed an inverse expression pattern compared to the azoles and VPA with regard to morphogenetic regulators, Hox genes, stem cell and mesoderm markers. The remaining cell type markers were not necessarily regulated in an opposite manner and showed trends towards mixed regulation of endoderm and neural crest cell markers, and an upregulation of non-neural ectoderm.

\section{Discussion}

Within the context of animal-free hazard assessment of chemical and pharmaceutical compounds, detailed knowledge of the biological domain of an in vitro test is needed to facilitate the interpretation of test results as well as to determine its optimal positioning in a testing strategy. For example, false negatives may be observed in case of compounds affecting processes not represented within the biological domain of the test. In such cases, in fact the individual test performed well, but this can only be judged based on knowledge of its biological domain. On the level of integrating multiple tests, knowledge of the biological domain of a test is crucial to enable integration of different tests with complementary domains in a testing strategy, and to ensure coverage of all biological mechanisms of the whole human-relevant physiology that needs to be challenged for integral hazard assessment. Comprehensive assessment of the biological domain of a test system can be done in detail using molecular approaches such as a transcriptomics approach, exploring the underlying regulation of morphological observations. Especially in the light of developmental toxicity, with a test based on cell differentiation being a moving target itself, it is important to define the span of the biological domain by mapping the behaviour of regulators essential during development.

Using three groups of biomarker genes representing important regulators of neural differentiation, we were able to monitor dynamic gene expression changes in ESTn over the course of cell differentiation. While non-exhaustive, these groups of genes enabled comparison of ESTn with gene expression of in vivo (neural) development as well as in other in vitro DNT assays. Specifically, ESTn gene expression showed regulation of most of the key morphogenetic regulators as listed in Table 2, and resembled gene expression changes in other in vitro EB-shaped [54] and elongated gastruloid systems [47,55], predominantly among the RC morphogenetic regulators (e.g. Fg8 and Wnt3). In fact, in 2D cultures and in a microfluidic system designed to mimic spinal cord patterning, FGF8 and WNT3 were added externally $[56,57]$. Although morphogenetic regulators showed clear regulation patterns in ESTn, its comparison with the in vivo situation is logically limited, given that spatial neural tube morphogenesis is not mimicked in ESTn $[47,48]$.

The wave of Hox gene expression induced by ATRA was similar to that observed in embryonic carcinoma cells [58], in mouse embryonic stem cell (ESC) gastruloids [47] and in human ESC 
and induced pluripotent stem cell (iPSC) monolayers [56], which all showed Hox gene expression until Hox9 paralogues. Only with the addition of external GDF11 it was possible to induce more caudal patterning in human ESC and iPSCs [56], suggesting that additional external inducers are needed for more caudal neural tube identity. Gene expression between Hox2 and Hox9 remained high up until day 13 of differentiation, indicating continuous broad neural tube patterning and specification of cells of the hindbrain/branchial/thoracic region, similar to other in vitro systems $[59,60]$.

In contrast to most neural cell differentiation protocols mentioned above, mainly aimed at creating motor neurons, ESTn differentiated in a diverse array of neural subtypes, as evidenced by upregulation of a considerable number of cell type markers across all major neurotransmitter systems and of the synaptic machinery. At the same time, the lack of gene expression regulation of more mature markers suggests that neural differentiation in ESTn was limited, and gene expression changes of markers for cell types in the brain that derive from other germ layers like microglia and pericytes were not observed, suggesting that these cell types were not present in ESTn (data not shown). Evidently, the array of more than a hundred neural and non-neural subtypes, and the regional diversity of the developing in vivo brain cannot be represented in a relatively simple model as ESTn $[61,62]$. Thus, this array of biomarkers of morphogenesis and cellular differentiation gives insight into the extent as well as limitations of the biological domain of ESTn. It would be interesting to investigate continued differentiation in ESTn into the hindbrain/branchial/thoracic region or into a more caudal neural identity.

The purpose of ESTn is to detect developmental neurotoxicants and to gain mechanistic understanding of how compounds may disturb neural development. Therefore, effects of a range of compounds tested in ESTn on these biomarker genes were analysed. We revealed a wide range of gene expression regulation by compounds that showed both common and distinct effects within their compound class. For example, the three azoles CYP, HEX and FLU presented largely similar expression patterns for morphogenetic regulators and Hox genes, but FLU had clearly different effects on cell type biomarkers indicating an additional mode of action, which may be linked with its in vivo effect on hindbrain development that does not occur with CYP and HEX exposure [17,19,63]. All three anticonvulsants (VPA, CBZ and PHE) showed distinct gene expression signatures, which may be due to their different affinity for ion channels and neurotransmitter interference that are already important during neural tube development. $[64,65]$. Some compounds that belong to different compound classes presented a similar expression pattern, as was the case for MEHP, PHE and PENG $[20,21,24,66]$. Lastly, MeHg presented a pattern considerably different from all other compounds, specifically affecting cell type biomarkers, with limited regulation of morphogens and Hox genes, in line with its effect on neuron differentiation and migration and less on neural tube development $[22,67]$. These gene regulation patterns shed light on compound-specific mechanisms of DNT within the biological domain of ESTn.

The selection of markers also revealed specific mechanisms matching observed phenotypic effects in vivo. For example, CYP, HEX and FLU caused retinoid-like abnormalities in rodents, such as cleft palate and skeletal malformations $[17,19,63]$. Whole transcriptome analysis in in vitro models like the zebrafish embryo test and rat whole embryo culture showed interference of these compounds with ATRA homeostasis $[68,69]$. The gene selection studied here indicated effects on this mechanism too, along with its consequences for genes regulating patterning 
and cell differentiation. There was some redundancy in the selected markers as indicated by very similar response patterns, especially in the stem cell markers of which some are indeed mechanistically coupled (e.g. Zfp42and Essrb; [70]). On the other hand, ESTn with this selection of biomarker genes obviously has its limitations in detecting compounds and their mechanisms of action (Table 1). For instance, based on whole transcriptome data, MEHP, PENG and PHE generated little response in ESTn [11], which indicates that they either act outside the biological domain of ESTn or are not toxic to development. Indeed, in vivo effects of MEHP occur at maternally toxic dosages only, PENG is not considered embryotoxic, and PHE may act through sodium and potassium channels that may not have arisen yet in ESTn. The list of biomarkers needs continuous optimisation based on new insights in developmental biology and toxicology, strengthening mechanistic assessments while maintaining an overview that is readily interpretable.

Concentration-dependent effects were apparent for all compounds, with increasing magnitudes of gene expression changes in the same direction, with a number of notable exceptions. ACE presented a flip over in its gene expression pattern, which may be due to the fact that ACE competed with ATRA in the same homeostasis pathway [71]. VPA showed dose-dependency in an inverse manner, if any, and at the highest concentration quite radically changed the gene expression signature. This may be explained by the different effects of VPA calcium signalling, FA-metabolism and methylation [72-75], which may be induced at different concentrations. PHE showed less gene expression changes at a higher concentration, which may be due to the fact that this concentration was both inhibiting neural differentiation and inducing cytotoxicity [11]. The supra-physiologically high concentrations of MEHP and PENG tested presented a similar pattern as $\mathrm{PHE}$, but were only inhibiting neural differentiation without cytotoxicity or were not toxic at all, respectively [11]. These observations at a single time point limit the detection of gene expression changes, which are time-dependent, and show different dynamics between genes. This has been observed before in ESTn with MeHg, VPA and two anti-depressant drugs, fluoxetine and venlafaxine, of which the latter affected oligodendrocyte gene expression, whereas this cell type is not present until after thirteen days of neural differentiation $[8,9,12]$. Moreover, it should be realised that not all changes in gene expression regulation do necessarily indicate adversity, which stresses the need for concentration-response assessment, careful interpretation of individual assay results and integration of results of multiple assays with in silico models for proper hazard identification [76].

The Hox gene paralogues between Hox 2 and Hox 10 were most sensitive to compound effects. Specifically, Hox4 and Hox5 paralogues (except for Hox5a) versus Hox8 and Hox9 paralogues were inversely regulated by compound exposures, most strongly by HEX and CYP, and the other way around by $\mathrm{ACE}$ and $\mathrm{CBZ}$, suggesting that these changes in expression were interrelated. Downregulation of Hox 8/9 paralogues (and hence upregulation of Hox4/5 paralogues) coincided with lower expression of Fgf8, Bmp4, MsX7, Evx 7 and $T$, which is consistent with their role and interconnectedness in rostrocaudal and limb pattering $[28,77,78]$. Hox genes that were not regulated by compounds were either barely regulated between day 3 and 4 of neural differentiation (Hox10 and higher) or highly regulated, i.e. Hoxa7, Hoxb7, Hoxb2 and Hoxa5. Overall, these effects on Hox family gene expression shows different sensitivities between different zones in the embryo illustrating the usefulness of this gene family as biomarkers of effect in ESTn. 
In conclusion, by design, ESTn aims at monitoring the effects of xenobiotics on diverse parts of embryonic neural cell differentiation. Added value is given by molecular analysis of developmental regulators exploring the developmental window mimicked by the model, which is important in the light of assessing compound-induced (neuro)developmental toxicity. Using this approach, we showed that ESTn represents parts of mouse early neural development between E6.5 and E12.5 with cells of a hindbrain/branchial/thoracic nature. These cells further differentiate into neural cells and subtypes, astrocytes and oligodendrocytes. The same biomarkers give insight into effects of compounds on early neural differentiation, showing correlates with a number of in vivo adverse outcomes of these compounds. Differentiation into other germ layers and organs, as well as further differentiation along the neural lineage are not covered by ESTn, which requires other (and more complex) in vitro models with complementary biological domains to more comprehensively mimic embryonic development and the detection of effects of toxic compounds. Improved knowledge about the biological domain of ESTn facilitates better interpretation of the effects of compounds. Together with testing more compounds in ESTn, it provides information crucial for determining the optimal positioning of ESTn in testing strategies.

\section{Acknowledgements}

This research is funded by the Dutch NGO Stichting Proefdiervrij, the Dutch Ministry of Agriculture, Nature and Food Quality and the Dutch Ministry of Health, Welfare and Sports. We would like to thank Yvonne Staal for a critical review of the manuscript. 


\section{References}

[1] T. Hartung, S. Bremer, S. Casati, S. Coecke, R. Corvi, S. Fortaner, L. Gribaldo, M. Halder, S. Hoffmann, A.J. Roi, P. Prieto, E. Sabbioni, L. Scott, A. Worth, V. Zuang, A modular approach to the ECVAM principles on test validity, ATLA Altern. to Lab. Anim. 32 (2004) 467-472.

[2] OECD, Guidance document on the validation and international acceptance of new or updated test methods for hazard assessment, Paris, 2005. https://doi.org/ENV/JM/MONO(2005)14.

[3] A. Bal-Price, K.M. Crofton, M. Leist, S. Allen, M. Arand, T. Buetler, N. Delrue, R.E. FitzGerald, T. Hartung, T. Heinonen, H. Hogberg, S.H. Bennekou, W. Lichtensteiger, D. Oggier, M. Paparella, M. Axelstad, A. Piersma, E. Rached, B. Schilter, G. Schmuck, L. Stoppini, E. Tongiorgi, M. Tiramani, F. Monnet-Tschudi, M.F. Wilks, T. Ylikomi, E. Fritsche, International STakeholder NETwork (ISTNET): creating a developmental neurotoxicity (DNT) testing road map for regulatory purposes, Arch. Toxicol. 89 (2015) 269-287. https://doi.org/10.1007/s00204-015-1464-2

[4] A.H. Piersma, J. Ezendam, M. Luijten, J.J.A. Muller, E. Rorije, L.T.M. Van Der Ven, J. Van Benthem, A critical appraisal of the process of regulatory implementation of novel in vivo and in vitro methods for chemical hazard and risk assessment, Crit. Rev. Toxicol. $44 \quad$ (2014) 876-894. https://doi.org/10.3109/10408444.2014.940445.

[5] E.V.S. Hessel, Y.C.M. Staal, A.H. Piersma, Design and validation of an ontology-driven animal-free testing strategy for developmental neurotoxicity testing, Toxicol. Appl. Pharmacol. 1 (2018) 136-152. https://doi.org/10.1016/j.taap.2018.03.013.

[6] E. Fritsche, M. Barenys, J. Klose, S. Masjosthusmann, L. Nimtz, M. Schmuck, S. Wuttke, J. Tigges, Development of the concept for stem cell-based developmental neurotoxicity evaluation., Toxicol. Sci. 165 (2018) 14-20. https://doi.org/10.1093/toxsci/kfy175

[7] P.T. Theunissen, S.H.W. Schulpen, D.A.M. van Dartel, S.A.B. Hermsen, F.J. van Schooten, A.H. Piersma, An abbreviated protocol for multilineage neural differentiation of murine embryonic stem cells and its perturbation by methyl mercury, Reprod. Toxicol. 29 (2010) 383-392. https://doi.org/10.1016/j.reprotox.2010.04.003.

[8] V.C. de Leeuw, E.V.S. Hessel, J.L.A. Pennings, H.M. Hodemaekers, P.F.K. Wackers, C.T.M. van Oostrom, A.H. Piersma, Differential effects of fluoxetine and venlafaxine in the neural embryonic stem cell test (ESTn) revealed by a cell lineage map, Neurotoxicology. 76 (2020) 1-9. https://doi.org/10.1016/j.neuro.2019.09.014.

[9] P.T. Theunissen, J.L.A. Pennings, J.F. Robinson, S.M.H. Claessen, J.C.S. Kleinjans, A.H. Piersma, Time-response evaluation by transcriptomics of methylmercury effects on neural differentiation of murine embryonic stem cells, Toxicol. Sci. 122 (2011) 437-447. https://doi.org/10.1093/toxsci/kfr134.

[10] P.T. Theunissen, J.F. Robinson, J.L.A. Pennings, E. De jong, S.M.H. Claessen, J.C.S. Kleinjans, A.H. Piersma, Transcriptomic concentration-response evaluation of valproic acid, cyproconazole, and hexaconazole in the neural Embryonic Stem Cell Test (ESTn), Toxicol. Sci. 125 (2012) 430-438. https://doi.org/10.1093/toxsci/kfr293.

[11] P.T. Theunissen, J.F. Robinson, J.L.A. Pennings, M.H. van Herwijnen, J.C.S. Kleinjans, A.H. Piersma, Compound-specific effects of diverse neurodevelopmental toxicants on global gene expression in the neural embryonic stem cell test (ESTn), Toxicol. Appl. Pharmacol. 262 (2012) 330-340. https://doi.org/10.1016/j.taap.2012.05.011.

[12] V.C. de Leeuw, E.V.S. Hessel, A.H. Piersma, Look-alikes may not act alike: Gene expression regulation and cell-type-specific responses of three valproic acid analogues in the neural embryonic stem cell test (ESTn), Toxicol. Lett. 303 (2019) 28-37. https://doi.org/10.1016/j.toxlet.2018.12.005.

[13] R. Yuste, M. Hawrylycz, N. Aalling, D. Arendt, R. Armananzas, G. Ascoli, C. Bielza, V. Bokharaie, T. Bergmann, I. Bystron, M. Capogna, Y. Chang, A. Clemens, C. de Kock, J. DeFelipe, S. Dos Santos, K. Dunville, D. Feldmeyer, R. Fiath, G. Fishell, A. Foggetti, X. Gao, P. Ghaderi, O. Gunturkun, V.J. Hall, M. Helmstaedter, S. HerculanoHouzel, M. Hilscher, H. Hirase, J. Hjerling-Leffler, R. Hodge, Z.J. Huang, R. Huda, Y. Juan, K. Khodosevich, O. Kiehn, H. Koch, E. Kuebler, M. Kuhnemund, P. Larranaga, B. Lelieveldt, E.L. Louth, J. Lui, H. Mansvelder, O. Marin, J. Martínez-Trujillo, H. Moradi, N. Goriounova, A. Mohapatra, M. Nedergaard, P. Němec, N. Ofer, U. Pfisterer, S. Pontes, W. Redmond, J. Rossier, J. Sanes, R. Scheuermann, E.S. Saiz, P. Somogyi, G. Tamás, A. Tolias, M. Tosches, M.T. Garcia, A. Aguilar-Valles, H. Munguba, C. Wozny, T. Wuttke, L. Yong, H. Zeng, E.S. Lein, A community-based transcriptomics classification and nomenclature of neocortical cell types, Nat. Neurosci. (2020) 1-13. https://doi.org/10.1038/s41593-020-0685-8.

[14] R.N. Sreenathan, R. Padmanabhan, S. Singh, Teratogenic effects of acetaldehyde in the rat, Drug Alcohol Depend. 9 (1982) 339-350. https://doi.org/10.1016/0376-8716(82)90072-2.

[15] F. Ehrhart, S. Roozen, J. Verbeek, G. Koek, G. Kok, H. van Kranen, C.T. Evelo, L.M.G. Curfs, Review and gap analysis: molecular pathways leading to fetal alcohol spectrum disorders, Mol. Psychiatry. 24 (2019) 10-17. https://doi.org/10.1038/s41380-018-0095-4.

[16] S. Matalon, S. Schechtman, G. Goldzweig, A. Ornoy, The teratogenic effect of carbamazepine: A meta-analysis of 1255 exposures, Reprod. Toxicol. 16 (2002) 9-17. https://doi.org/10.1016/S0890-6238(01)00199-X.

[17] K. Machera, Developmental toxicity of cyproconazole, an inhibitor of fungal ergosterol biosynthesis, in the rat, Bull. Environ. Contam. Toxicol. 54 (1995) 363-369. https://doi.org/10.1007/BF00195106.

[18] T. Vergieva, Triazoles teratogenicity in rat, Teratology. 42 (1990) 27A-28A. 
[19] M. Killick, G. Wickramaratne, P. Banham, M. Thomas, PP523: Teratogenicity Study in the Rat, ICl Agrochemicals, UK. (Unpublished), 1984.

[20] M. Ema, R. Kurosaka, H. Amano, Y. Ogawa, Developmental toxicity evaluation of mono-n-butyl phthalate in rats, Toxicol. Lett. 78 (1995) 101-106. https://doi.org/10.1016/0378-4274(94)03241-X.

[21] K. Shiota, S. Mima, Assessment of the teratogenicity of di(2-ethylhexyl)phthalate and mono(2ethylhexyl)phthalate in mice, Arch. Toxicol. 56 (1985) 263-266. https://doi.org/10.1007/BF00295165.

[22] J. Aaseth, D.R. Wallace, K. Vejrup, J. Alexander, Methylmercury and developmental neurotoxicity: A global concern, Curr. Opin. Toxicol. 19 (2020) 80-87. https://doi.org/10.1016/J.COTOX.2020.01.005.

[23] D. Scolnik, I. Nulman, J. Rovet, D. Gladstone, D. Czuchta, R. Weksberg, H.A. Gardner, R. Gladstone, P. Ashby, G. Koren, T. Einarson, Neurodevelopment of Children Exposed In Utero to Phenytoin and Carbamazepine Monotherapy, JAMA J. Am. Med. Assoc. $271 \quad$ (1994) 767-770. https://doi.org/10.1001/jama.1994.03510340057034.

[24] A.E. Czeizel, M. Rockenbauer, J. Olsen, H.T. Sørensen, Oral phenoxymethylpenicillin treatment during pregnancy. Results of a population-based Hungarian case-control study, Arch. Gynecol. Obstet. 263 (2000) 178181. https://doi.org/10.1007/s004040050277.

[25] D.S. Hill, B.J. Wlodarczyk, A.M. Palacios, R.H. Finnell, Teratogenic effects of antiepileptic drugs, Expert Rev. Neurother. 10 (2010) 943-959. https://doi.org/10.1586/ern.10.57.

[26] A.M. Tartaglione, S. Schiavi, G. Calamandrei, V. Trezza, Prenatal valproate in rodents as a tool to understand the neural underpinnings of social dysfunctions in autism spectrum disorder, Neuropharmacology. 159 (2019). https://doi.org/10.1016/j.neuropharm.2018.12.024.

[27] B.N. Davis-Dusenbery, L.A. Williams, J.R. Klim, K. Eggan, How to make spinal motor neurons, Development. 141 (2014) 491-501. https://doi.org/10.1242/dev.097410.

[28] K.W. Rogers, A.F. Schier, Morphogen Gradients: From Generation to Interpretation, Annu. Rev. Cell Dev. Biol. 27 (2011) 377-407. https://doi.org/10.1146/annurev-cellbio-092910-154148.

[29] K.A. Lemke, A. Aghayee, R.S. Ashton, Deriving, regenerating, and engineering CNS tissues using human pluripotent stem cells, Curr. Opin. Biotechnol. 47 (2017) 36-42. https://doi.org/10.1016/j.copbio.2017.05.010.

[30] D. Pang, D.N.P.P. Thompson, Embryology and bony malformations of the craniovertebral junction, Child's Nerv. Syst. 27 (2011) 523-564. https://doi.org/10.1007/s00381-010-1358-9.

[31] P. Philippidou, J.S. Dasen, Hox Genes: Choreographers in Neural Development, Architects of Circuit Organization, Neuron. 80 (2013) 12-34. https://doi.org/10.1016/j.neuron.2013.09.020.

[32] M. Mallo, Reassessing the Role of Hox Genes during Vertebrate Development and Evolution, Trends Genet. 34 (2018) 209-217. https://doi.org/10.1016/j.tig.2017.11.007.

[33] R. Shparberg, H. Glover, M.B. Morris, Modelling mammalian commitment to the neural lineage using embryos and embryonic stem cells, Front. Physiol. 10 (2019) 705. https://doi.org/10.3389/fphys.2019.00705.

[34] R. Del Corral Diez, I. Olivera-Martinez, A. Goriely, E. Gale, M. Maden, K. Storey, Opposing FGF and retinoid pathways control ventral neural pattern, neuronal differentiation, and segmentation during body axis extension, Neuron. 40 (2003) 65-79. https://doi.org/10.1016/S0896-6273(03)00565-8.

[35] R. Neijts, S. Amin, C. van Rooijen, S. Tan, M.P. Creyghton, W. de Laat, J. Deschamps, Polarized regulatory landscape and Wnt responsiveness underlie Hox activation in embryos, Genes Dev. 30 (2016) 1937-1942. https://doi.org/10.1101/gad.285767.116.

[36] U. Nordström, E. Maier, T.M. Jessell, T. Edlund, An early role for Wnt signaling in specifying neural patterns of $\mathrm{Cdx}$ and Hox gene expression and motor neuron subtype identity, PLoS Biol. 4 (2006) 1438-1452. https://doi.org/10.1371/journal.pbio.0040252.

[37] J. Deschamps, D. Duboule, Embryonic timing, axial stem cells, chromatin dynamics, and the Hox clock, Genes Dev. 31 (2017) 1406-1416. https://doi.org/10.1101/gad.303123.117.

[38] E.B. Lewis, A gene complex controlling segmentation in Drosophila, Nature. 276 (1978) 565-570. https://doi.org/10.1038/276565a0.

[39] J.C. Izpisúa-Belmonte, H. Falkenstein, P. Dollé, A. Renucci, D. Duboule, Murine genes related to the Drosophila $\mathrm{AbdB}$ homeotic genes are sequentially expressed during development of the posterior part of the body., EMBO J. 10 (1991) 2279-2289. https://doi.org/10.1002/j.1460-2075.1991.tb07764.x.

[40] J.S. Dasen, B.C. Tice, S. Brenner-Morton, T.M. Jessell, A Hox regulatory network establishes motor neuron pool identity and target-muscle connectivity, Cell. 123 (2005) 477-491. https://doi.org/10.1016/j.cell.2005.09.009.

[41] S. Tümpel, L.M. Wiedemann, R. Krumlauf, Chapter 8 Hox Genes and Segmentation of the Vertebrate Hindbrain, Curr. Top. Dev. Biol. 88 (2009) 103-137. https://doi.org/10.1016/S0070-2153(09)88004-6.

[42] H. Jung, J. Lacombe, E.O. Mazzoni, K.F. Liem, J. Grinstein, S. Mahony, D. Mukhopadhyay, D.K. Gifford, R.A. Young, K. V Anderson, H. Wichterle, J.S. Dasen, Global Control of Motor Neuron Topography Mediated by the Repressive Actions of a Single Hox Gene, Neuron. 67 (2010) 781-796. https://doi.org/10.1016/j.neuron.2010.08.008.

[43] J.P. Liu, E. Laufer, T.M. Jessell, Assigning the positional identity of spinal motor neurons: Rostrocaudal patterning of Hox-c expression by FGFs, Gdf11, and retinoids, Neuron. 32 (2001) 997-1012. https://doi.org/10.1016/S0896-6273(01)00544-X. 
[44] S. Bel-Vialar, N. Itasaki, R. Krumlauf, Initiating Hox gene expression: In the early chick neural tube differential sensitivity to FGF and RA signaling subdivides the HoxB genes in two distinct groups, Development. 129 (2002) 5103-5115. http://dev.biologists.org/content/129/22/5103.abstract.

[45] A. Miguez, S. Ducret, T. Di Meglio, C. Parras, H. Hmidan, C. Haton, S. Sekizar, A. Mannioui, M. Vidal, A. Kerever, O. Nyabi, J. Haigh, B. Zalc, F.M. Rijli, J.L. Thomas, Opposing roles for Hoxa2 and Hoxb2 in hindbrain oligodendrocyte patterning, J. Neurosci. 32 (2012) 17172-17185. https://doi.org/10.1523/JNEUROSCI.088512.2012

[46] D.H. Rowitch, A.R. Kriegstein, Developmental genetics of vertebrate glial-cell specification, Nature. 468 (2010) 214-222. https://doi.org/10.1038/nature09611.

[47] L. Beccari, N. Moris, M. Girgin, D.A. Turner, P. Baillie-Johnson, A.C. Cossy, M.P. Lutolf, D. Duboule, A.M. Arias, Multi-axial self-organization properties of mouse embryonic stem cells into gastruloids, Nature. 562 (2018) 272-276. https://doi.org/10.1038/s41586-018-0578-0.

[48] N. Irie, S. Kuratani, Comparative transcriptome analysis reveals vertebrate phylotypic period during organogenesis, Nat. Commun. 2 (2011). https://doi.org/10.1038/ncomms1248.

[49] P. Kügler, B. Zimmer, T. Waldmann, B. Baudis, S. Ilmjärv, J. Hescheler, P. Gaughwin, P. Brundin, W. Mundy, A.K. Bal-Price, A. Schrattenholz, K.-H. Krause, C. von Thriel, M.S. Rao, S. Kadereit, M. Leist, Markers of murine embryonic and neural stem cells, neurons and astrocytes : reference points for developmental neurotoxicity testing, Altern. to Anim. Exp. ALTEX. 27 (2010) 16-42. https://doi.org/10.14573/altex.2010.1.16.

[50] A. Spangler, E.Y. Su, A.M. Craft, P. Cahan, A single cell transcriptional portrait of embryoid body differentiation and comparison to progenitors of the developing embryo, Stem Cell Res. 31 (2018) 201-215 https://doi.org/10.1016/j.scr.2018.07.022.

[51] Y. Tao, S.C. Zhang, Neural Subtype Specification from Human Pluripotent Stem Cells, Cell Stem Cell. 19 (2016) 573-586. https://doi.org/10.1016/j.stem.2016.10.015.

[52] R Core Team, R: A language and environment for statistical computing, (2020). https://www.r-project.org/.

[53] M. Kutmon, M.P. van lersel, A. Bohler, T. Kelder, N. Nunes, A.R. Pico, C.T. Evelo, PathVisio 3: An Extendable Pathway Analysis Toolbox, PLoS Comput. Biol. 11 (2015) e1004085. https://doi.org/10.1371/journal.pcbi. 1004085.

[54] X.-J. Li, X. Zhang, M.A. Johnson, Z.-B. Wang, T. Lavaute, S.-C. Zhang, Coordination of sonic hedgehog and Wnt signaling determines ventral and dorsal telencephalic neuron types from human embryonic stem cells, Development. 136 (2009) 4055-4063. https://doi.org/10.1242/dev.036624.

[55] E.L.L. Warkus, Y. Marikawa, Fluoxetine Inhibits Canonical Wnt Signaling to Impair Embryoid Body Morphogenesis: Potential Teratogenic Mechanisms of a Commonly Used Antidepressant, Toxicol. Sci. 165 (2018) 372-388. https://doi.org/10.1093/toxsci/kfy143.

[56] E.S. Lippmann, C. E.williams, D.A. Ruhl, M.C. Estevez-Silva, E.R. Chapman, J.J. Coon, R.S. Ashton, Deterministic HOX patterning in human pluripotent stem cell-derived neuroectoderm, Stem Cell Reports. 4 (2015) 632-644. https://doi.org/10.1016/j.stemcr.2015.02.018.

[57] P. Rifes, M. Isaksson, G.S. Rathore, P. Aldrin-Kirk, O.K. Møller, G. Barzaghi, J. Lee, K.L. Egerod, D.M. Rausch, M. Parmar, T.H. Pers, T. Laurell, A. Kirkeby, Modeling neural tube development by differentiation of human embryonic stem cells in a microfluidic WNT gradient, Nat. Biotechnol. (2020). https://doi.org/10.1038/s41587-020-0525-0.

[58] A. Simeone, D. Acampora, V. Nigro, A. Faiella, M. D'Esposito, A. Stornaiuolo, F. Mavilio, E. Boncinelli, Differential regulation by retinoic acid of the homeobox genes of the four HOX loci in human embryonal carcinoma cells, Mech. Dev. 33 (1991) 215-227. https://doi.org/10.1016/0925-4773(91)90029-6.

[59] R. Patani, A.J. Hollins, T.M. Wishart, C.A. Puddifoot, S. Álvarez, A.R. De Lera, D.J.A. Wyllie, D.A.S. Compston, R.A. Pedersen, T.H. Gillingwater, G.E. Hardingham, N.D. Allen, S. Chandran, Retinoid-independent motor neurogenesis from human embryonic stem cells reveals a medial columnar ground state, Nat. Commun. 2 (2011) 1-10. https://doi.org/10.1038/ncomms1216.

[60] M. Peljto, J.S. Dasen, E.O. Mazzoni, T.M. Jessell, H. Wichterle, Functional diversity of ESC-derived motor neuron subtypes revealed through intraspinal transplantation, Cell Stem Cell. 7 (2010) 355-366. https://doi.org/10.1016/j.stem.2010.07.013.

[61] J. Delile, T. Rayon, M. Melchionda, A. Edwards, J. Briscoe, A. Sagner, Single cell transcriptomics reveals spatial and temporal dynamics of gene expression in the developing mouse spinal cord, Development. 146 (2019). https://doi.org/10.1242/dev.173807.

[62] A.B. Rosenberg, C.M. Roco, R.A. Muscat, A. Kuchina, P. Sample, Z. Yao, L.T. Graybuck, D.J. Peeler, S. Mukherjee, W. Chen, S.H. Pun, D.L. Sellers, B. Tasic, G. Seelig, Single-cell profiling of the developing mouse brain and spinal cord with split-pool barcoding, Science (80-. ). 360 (2018) 176-182. https://doi.org/10.1126/science.aam8999.

[63] E. Menegola, M.L. Broccia, F. Di Renzo, V. Massa, E. Giavini, Study on the common teratogenic pathway elicited by the fungicides triazole-derivatives, Toxicol. In Vitro. 19 (2005) 737-748. https://doi.org/10.1016/j.tiv.2005.04.005.

[64] S. Hernández-Díaz, M. Levin, Alteration of bioelectrically-controlled processes in the embryo: a teratogenic mechanism for anticonvulsants, Reprod. Toxicol. 47 (2014) 111-114. https://doi.org/10.1016/j.reprotox.2014.04.008. 
[65] R. Goyal, K.A. Spencer, L.N. Borodinsky, From Neural Tube Formation Through the Differentiation of Spinal Cord Neurons: Ion Channels in Action During Neural Development, Front. Mol. Neurosci. 13 (2020). https://doi.org/10.3389/fnmol.2020.00062.

[66] S. Hernández-Díaz, M.M. Werler, A.M. Walker, A.A. Mitchell, Neural Tube Defects in Relation to Use of Folic Acid Antagonists during Pregnancy, Am. J. Epidemiol. $153 \quad$ (2001) 961-968. http://dx.doi.org/10.1093/aje/153.10.961.

[67] G.W. Hwang, K. Ryoke, T. Takahashi, A. Naganuma, Silencing of the gene for homeobox protein HOXB13 by siRNA confers resistance to methylmercury on HEK293 cells, J. Toxicol. Sci. 35 (2010) 941-944. https://doi.org/10.2131/jts.35.941.

[68] S.A.B. Hermsen, T.E. Pronk, E.-J. van den Brandhof, L.T.M. van der Ven, A.H. Piersma, Triazole-induced gene expression changes in the zebrafish embryo., Reprod. Toxicol. 34 (2012) 216-224. https://doi.org/10.1016/j.reprotox.2012.05.093.

[69] J.F. Robinson, E.C.M. Tonk, A. Verhoef, A.H. Piersma, Triazole induced concentration-related gene signatures in rat whole embryo culture, Reprod. Toxicol. 34 (2012) 275-283. https://doi.org/10.1016/j.reprotox.2012.05.088.

[70] D.L.C. van den Berg, W. Zhang, A. Yates, E. Engelen, K. Takacs, K. Bezstarosti, J. Demmers, I. Chambers, R.A Poot, Estrogen-Related Receptor Beta Interacts with Oct4 To Positively Regulate Nanog Gene Expression, Mol. Cell. Biol. 28 (2008) 5986-5995. https://doi.org/10.1128/mcb.00301-08.

[71] Y. Shabtai, L. Bendelac, H. Jubran, J. Hirschberg, A. Fainsod, Acetaldehyde inhibits retinoic acid biosynthesis to mediate alcohol teratogenicity, Sci. Rep. 8 (2018) 347. https://doi.org/10.1038/s41598-017-18719-7.

[72] E.B. Sequerra, R. Goyal, P.A. Castro, J.B. Levin, L.N. Borodinsky, NMDA receptor signaling is important for neural tube formation and for preventing antiepileptic drug-induced neural tube defects, J. Neurosci. 38 (2018) 4762-4773. https://doi.org/10.1523/JNEUROSCI.2634-17.2018.

[73] M. Göttlicher, S. Minucci, P. Zhu, O.H. Krämer, A. Schimpf, S. Giavara, J.P. Sleeman, F. Lo Coco, C. Nervi, P.G Pelicci, T. Heinzel, Valproic acid defines a novel class of HDAC inhibitors inducing differentiation of transformed cells, EMBO J. 20 (2001) 6969-6978. https://doi.org/10.1093/emboj/20.24.6969.

[74] C.J. Phiel, F. Zhang, E.Y. Huang, M.G. Guenther, M.A. Lazar, P.S. Klein, Histone Deacetylase Is a Direct Target of Valproic Acid, a Potent Anticonvulsant, Mood Stabilizer, and Teratogen, J. Biol. Chem. 276 (2001) 3673436741. https://doi.org/10.1074/jbc.M101287200.

[75] M. Roy, D. Leclerc, Q. Wu, S. Gupta, W.D. Kruger, R. Rozen, Valproic acid increases expression of methylenetetrahydrofolate reductase (MTHFR) and induces lower teratogenicity in MTHFR deficiency, J. Cell. Biochem. 105 (2008) 467-476. https://doi.org/10.1002/jcb.21847.

[76] A.H. Piersma, J. van Benthem, J. Ezendam, A.S. Kienhuis, Validation redefined, Toxicol. Vitr. 46 (2017) $163-$ 165. https://doi.org/10.1016/j.tiv.2017.10.013.

[77] X. Sun, E.N. Meyers, M. Lewandoski, G.R. Martin, Targeted disruption of Fgf8 causes failure of cell migration in the gastrulating mouse embryo, Genes Dev. 13 (1999) 1834-1846. https://doi.org/10.1101/gad.13.14.1834.

[78] M. Bei, R. Maas, FGFs and BMP4 induce both Msx1-independent and Msx1-dependent signaling pathways in early tooth development, Development. 125 (1998) 4325-4333. http://dev.biologists.org/content/125/21/4325.abstract. 


\section{Supplementary material}
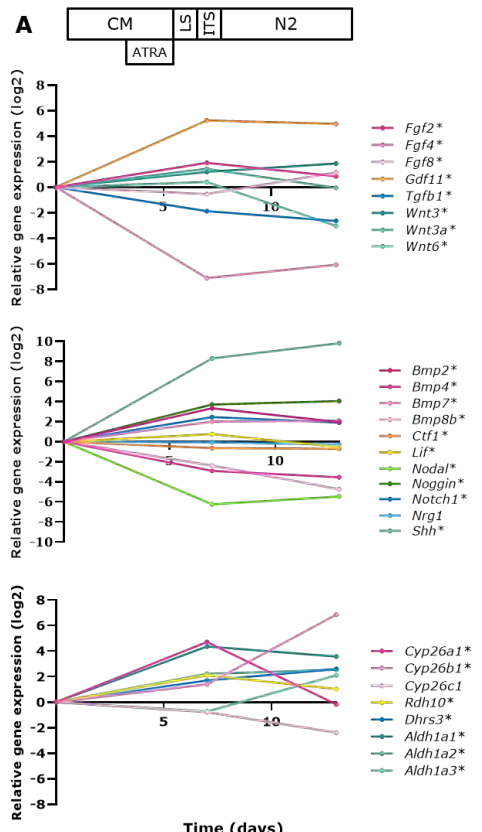

B
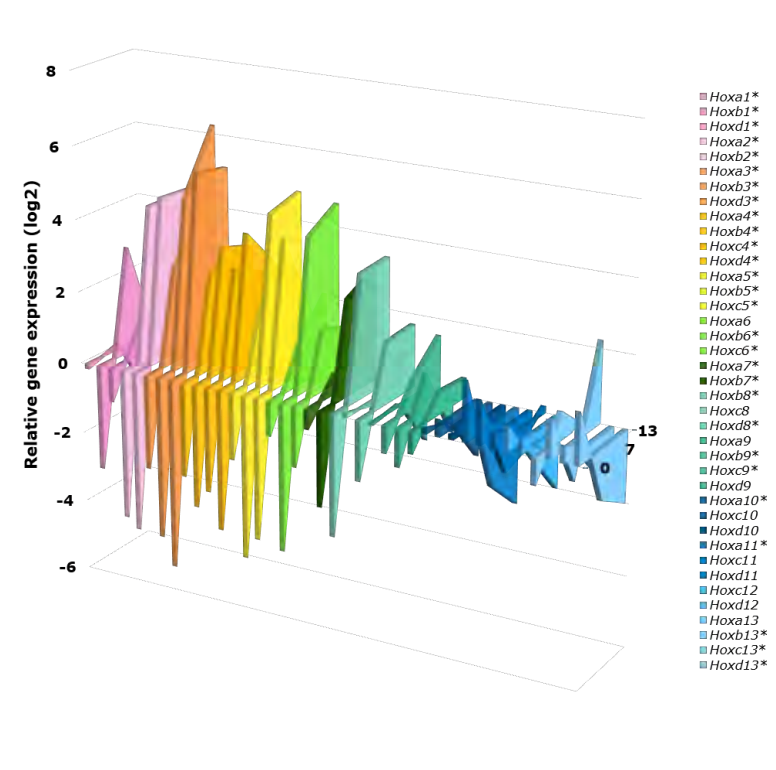

- Cyp26a1*
- Cyp26b1* $=$ Cyp26b1* - Rdh $10^{*}$

$\div$ Aldhta1*

- Aldh1a2*

Time (days)

Supplementary figure ST. ESTn gene expression of morphogenetic regulators, Hox genes and cell type expression at day 0, 7 and 13. (A) Gene expression (log2) relative to stem cell culture of morphogenetic regulators listed in Table 1. For clarity, morphogenetic regulators were split in three graphs approximately representing RC morphogenetic regulators, DV morphogenetic regulators and regulators of $R A$-homeostasis. Media used during differentiation are mentioned above the graph and composition can be found in Theunissen et al. (2017). CM: complete medium, RA. retinoic acid, LS: Iow serum medium, ITS: insulin-transferrin-sodium selenite medium, N2: N2 medium. (B) Gene expression (log2) of all Hox genes relative to the average expression of each gene over time. * indicates statistically significant regulation over time $(p<0.001)$. 


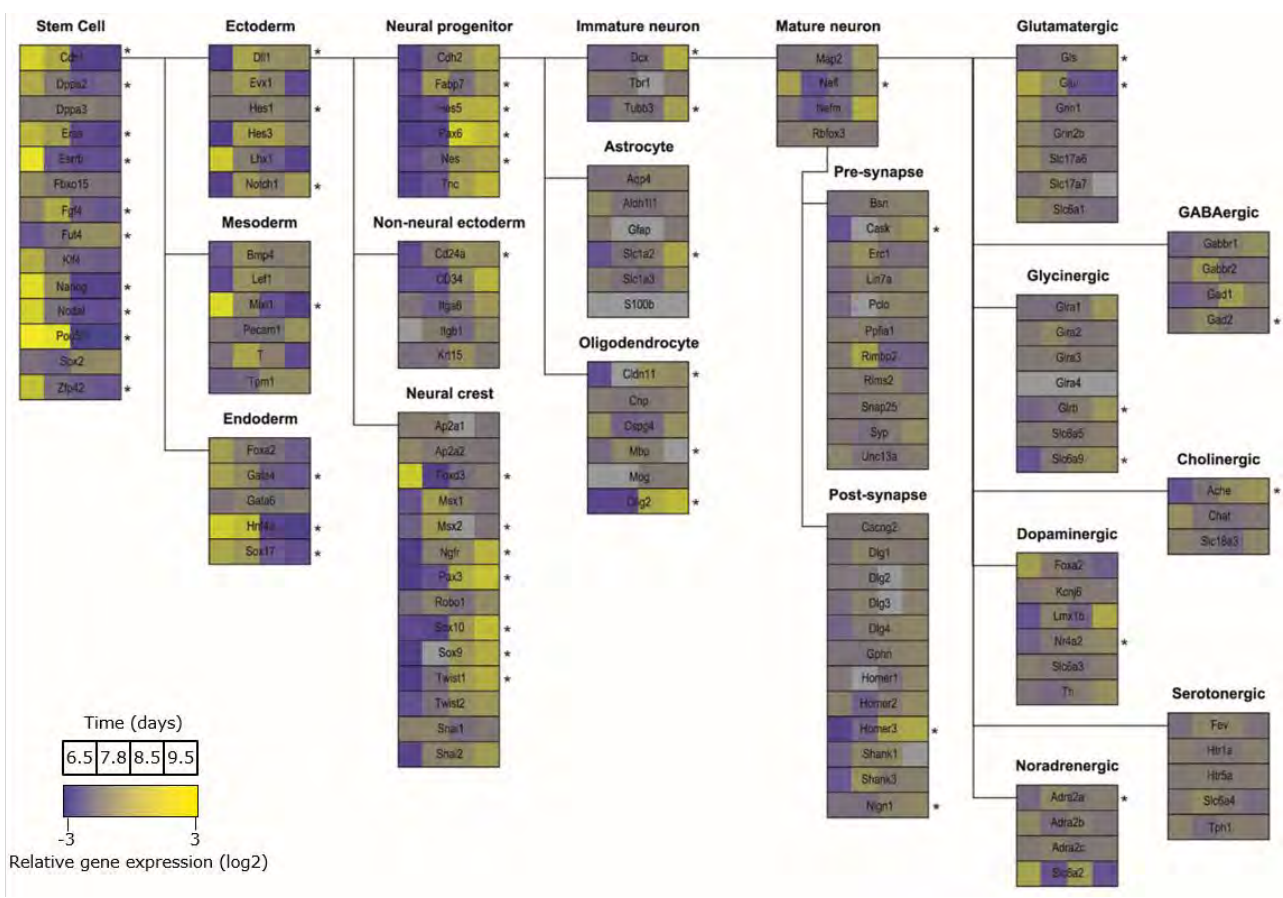

Supplementary figure S2. mouse neural tube gene expression of cell type gene expression between E6.5 and E9.5 [47]. * indicates statistically significant regulation over time $(p<0.001)$. 


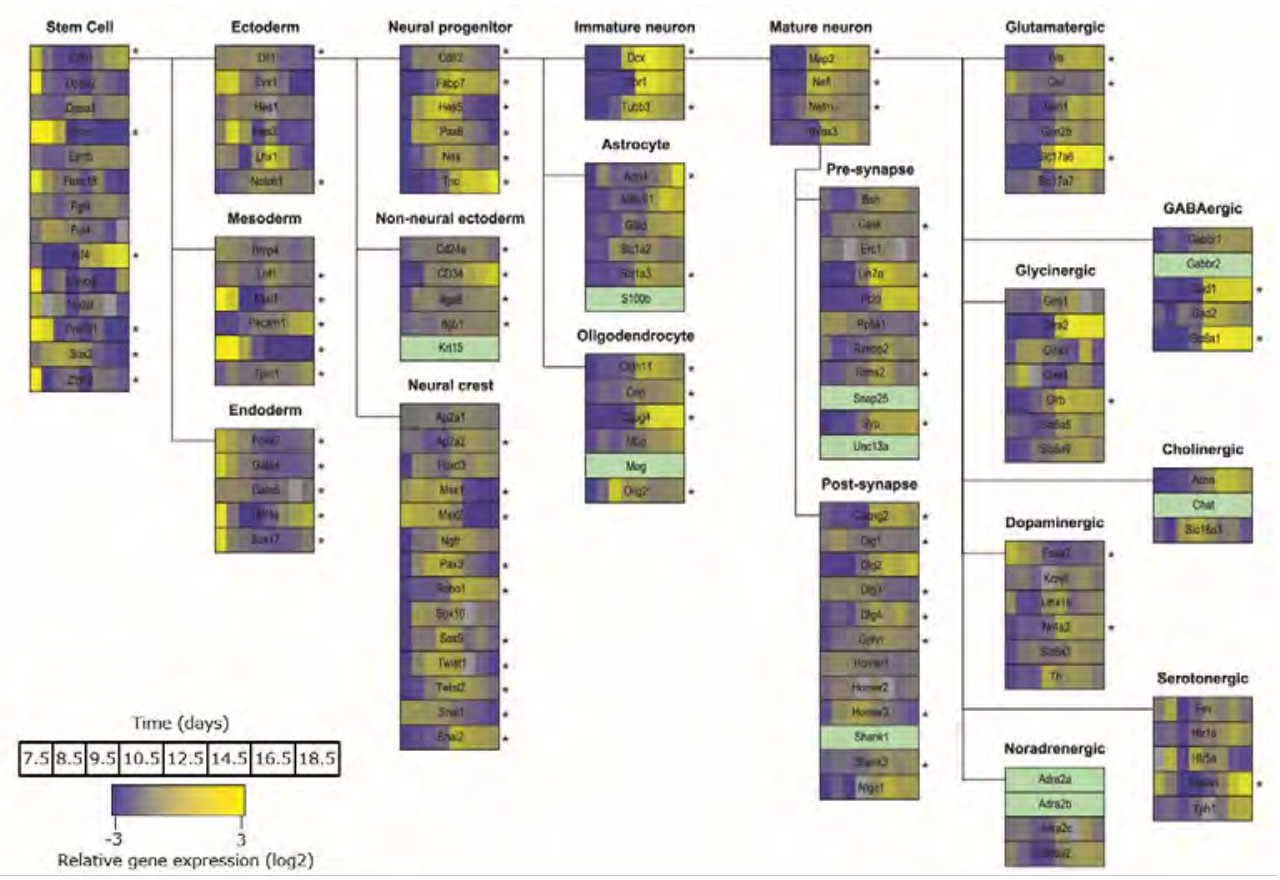

Supplementary figure S3. mouse whole embryo gene expression of cell type gene expression between E7.5 and E78.5 [48] * *indicates statistically significant regulation over time $(p<0.001)$. 




\section{CHAPTER 3}

\section{CULTURE CONDITIONS AFFECT CHEMICAL-INDUCED DEVELOPMENTAL TOXICITY IN VITRO: THE CASE OF FOLIC ACID, METHIONINE AND METHOTREXATE IN THE NEURAL EMBRYONIC STEM CELL TEST}

Victoria C. de Leeuw ${ }^{1,2}$, Marieke van Nieuwland ${ }^{1,3}$, Bas G. H. Bokkers'4, Aldert H. Piersma $^{1,2}$

${ }^{1}$ Centre for Health Protection, National Institute for Public Health and the Environment, Bilthoven, the Netherlands

${ }^{2}$ Institute for Risk Assessment Sciences, Utrecht University, Utrecht, the Netherlands

${ }^{3}$ Radboudumc, Medical Faculty, Nijmegen, the Netherlands

${ }^{4}$ Centre for Safety of Substances and Products, National Institute for Public Health and the Environment (RIVM), Bilthoven, the Netherlands

Alternatives to Laboratory Animals, 2020 Oct, 48(4): 173-183

DOI: $10.1177 / 0261192920961963$ 



\begin{abstract}
In vitro tests are increasingly applied in chemical hazard assessment. Basic culture conditions may affect the outcome of in vitro tests and should be optimised to reduce false predictions. The neural embryonic stem cell test (ESTn) can predict early neurodevelopmental effects of chemicals, as it mimics the differentiation of stem cells toward the neuroectodermal lineage. Normal early neural differentiation depends crucially on folic acid (FA) and methionine (MET), both elements of the one-carbon (1C) cycle. The aim of this study was to assess the concentration-dependent influence of FA and MET on neural differentiation in the ESTn, and its consequences for assay sensitivity to methotrexate (MTX), a compound that interferes with the $1 C$ cycle. Neural differentiation was inhibited below $0.007 \mathrm{mM}$ and above $0.22 \mathrm{mM} \mathrm{FA}$, while both stem cell viability $(<0.097 \mathrm{mM},>1.52 \mathrm{mM})$ and neural differentiation $(<0.181 \mathrm{mM},>1.35 \mathrm{mM})$ were affected when changing MET concentrations. A 10-day exposure to 13 nM MTX inhibited neural differentiation, especially in FA- and MET-deficient conditions. However, a 24-hour exposure to $39 \mathrm{nM}$ MTX decreased neural cell and neural crest cell differentiation markers only when the concentration of FA in the medium was three times the standard concentration, which was expected to have a protective effect against MTX. These results show the importance of nutrient concentrations, exposure scenarios and timing of read-outs for cell differentiation and compound sensitivity in the ESTn. Caution should be taken when interpreting results from a single in vitro test, especially when extrapolating to effects on complex morphogenetic processes, like neural tube development.
\end{abstract}




\section{Introduction}

The use of laboratory animals in toxicology is becoming increasingly problematic due to ethical concerns and the fact that they may not always represent human physiology [1,2]. In vitromodels provide powerful tools to study the effects of chemicals. Yet, culture conditions in vitro can be vastly different from the in vivo situation. To maintain viable cell cultures, the medium is often supplemented with nutrients at higher than physiological concentrations, which can result in a different physiological environment and lead to false positive or negative results [3]. Therefore, in vitro tests need to be fine-tuned to optimise assay performance in order to produce relevant findings, which are crucial for informing hazard assessment.

The neural embryonic stem cell test (ESTn) is an in vitro model that recapitulates parts of the early neural differentiation process, from stem cells to a mixed neural culture $[4,5]$. ESTn has been shown to be able to predict the developmental neurotoxic potential of chemicals that cause neural tube defects (NTDs) [6-8]. About one in a thousand children are born with some form of NTD $[9,10]$, which illustrates the importance of these malformations in humans.

Normal neural tube development is critically dependent on folic acid (FA) and methionine (MET) to feed the one-carbon (1C) cycle [11]. Through the initiation of methylation reactions, $1 \mathrm{C}$ metabolism is involved in nucleic acid synthesis, cell proliferation, DNA repair and epigenetic regulation [12,13]. Folate is an important element as $1 \mathrm{C}$ donor in the rate-limiting conversion of homocysteine to MET [14]. FA, the oxidised synthetic form of folate, needs to be reduced by dihydrofolate reductase (DHFR) to dihydrofolate and subsequently to tetrahydrofolate (THF), to enter the folate cycle (Figure 1A) [15]. THF receives a carbon group through conversion by methylenetetrahydrofolate-reductase activity into 5-methyl-tetrahydrofolate, which is then able to donate this carbon group to the methionine cycle through the enzymatic action of 5methyltetrahydrofolate-homocysteine methyltransferase (MTR) [16]. MET acts as the substrate for the enzyme that synthesises S-adenosyl-methionine (SAM), which subsequently transfers methyl groups to DNA via DNA methyltransferase (DNMT) enzymes [16].

Epidemiological and experimental studies have shown that a shortage of FA or MET during gestation results in a higher rate of NTDs in human and rodents $[17,18]$, which can be prevented with FA supplements [19-22]. Experiments on mouse embryos have also shown that oversupplementation of MET resulted in a higher rate of NTDs [23,24], which suggests the existence of an optimal balance in $1 \mathrm{C}$ metabolism that needs to be maintained. In vitro experiments have corroborated these findings, showing that FA in the culture medium at a low concentration has an inhibiting effect on the differentiation of (neural) stem cells $[16,25]$ and that FA (over-)supplementation for a limited time induces neurogenesis and decreases astroglial differentiation $[26,27]$. Both MET deficiency and over-supplementation, on the other hand, have an adverse impact on the viability and differentiation potential of stem cells [23,28]. Certain chemicals, such as methotrexate (MTX), can also interfere with the $1 \mathrm{C}$ cycle, leading to an increased rate of NTDs in rodents [29,30]. MTX is known to competitively inhibit the DHFR enzyme, which converts FA into THF, thereby disrupting carbon group supply for 1C metabolism [31].

The aim of this study was to investigate the effects of different FA and MET medium concentrations on ESTn differentiation and the sensitivity of the assay to the effects of MTX. Firstly, we assessed the effects of FA and MET deprivation and over-supplementation, to investigate 
the extent to which early neural differentiation in ESTn would be affected. Secondly, we assessed changes in the sensitivity of ESTn in the presence of low concentrations of FA or MET, by using MTX as a standard test compound. Given the in vitro experimental data and the existing human and rodent in vivo knowledge, it was hypothesised that MTX would have more severe effects on neural differentiation at reduced concentrations of FA or MET.

\section{Material and methods}

\section{Cell culture procedures}

Murine embryonic ES-D3 stem cells (mESCs; ATCC, Manassas, VA, USA) were maintained as described previously [32]. Neural differentiation of mESCs has been described previously by Theunissen et al. [33] except that we cultured ESTn for two additional days. In line with this stem cell culture and differentiation method, Dulbecco's Modified Eagle's Medium (DMEM; Gibco, Waltham, MA, USA) was used from day 0 to day 5, and DMEM/F12 (Gibco) was used from day 6 to 13 .

The DMEM and DMEM/F1 2 were customised for use in the deprivation experiments, to contain neither folic acid nor methionine. Folic acid (FA; CAS No. 59-30-3; Sigma-Aldrich, Saint Louis, MO, USA) and L-methionine (MET; CAS No. 63-68-3; Sigma-Aldrich) deprivation/supplementation and exposure to chemicals was carried out from day 3 (onset of neural differentiation) until day 13.

A range of different concentrations of $F A(0,0.0001,0.001,0.01,0.03,0.09,0.3$ and $0.9 \mathrm{mM})$ or $\operatorname{MET}(0,0.003,0.03,0.3,0.6,2,6$ and $20 \mathrm{mM}$ ) diluted in PBS (Gibco) was added to the customised DMEM and DMEM/F12 devoid of FA and MET (for the deprivation experiments) or standard DMEM and DMEM/F12 (for the supplementation experiments). The other compound, i.e. either FA or MET, was added at the concentration found in standard DMEM and DMEM/F12 (0.009 $\mathrm{mM}$ and $0.201 \mathrm{mM}$, respectively). Methotrexate (MTX; CAS No. 59-05-2; $3 \mathrm{nM}-3 \mu \mathrm{M}$ with $1 \frac{1}{2} \log$ increments; Sigma-Aldrich) was freshly prepared for each exposure in dimethyl sulphoxide (DMSO; CAS No. 67-68-5; Sigma-Aldrich) and added to the medium at a final concentration of $0.25 \%$ v/v DMSO. On day 13 of the protocol, scoring was performed by assessing neurite outgrowth on at least 20 embryoid bodies (EBs) in three dishes: an EB was considered affected when less than $75 \%$ of the neurite corona was intact [33], which was determined with bright field microscopy (Olympus IX51; Olympus Corporation, Shinjuku, Tokyo, Japan). The cell viability of mESCs was determined as described previously [33]. Briefly, confluent mESCs were seeded in a 96-well plate (Greiner Bio-One, Kremsmünster, Austria) and incubated for two hours, after which they were exposed to FA, MET or MTX and appropriate controls, namely: $0.25 \% \mathrm{v} / \mathrm{v}$ DMSO (solvent control), $0.1 \mu \mathrm{g} / \mathrm{ml} 5$-fluoruracil (positive control) and $500 \mu \mathrm{g} / \mathrm{ml}$ penicillin $\mathrm{G}$ (negative control; all from Sigma-Aldrich). A full medium change was performed on day 3 , and on day 5 the cells were incubated for two hours with the CellTiter-Blue reagent (Promega, Leiden, the Netherlands). Cell viability was measured on a Spectramax ${ }^{\circledR}$ M2 spectrofluorometer (Molecular Devices, Wokingham, Berkshire, UK). The experiments were performed at least three times with six technical replicates each. 
Immunocytochemistry and RNA isolation were performed as described previously [8]. The primary and secondary antibodies used for the immunocytochemistry are listed in Table 1. Imaging was performed on a Leica DMi8 inverted microscope (Leica Microsystems, Wetzlar, Germany) with a $10 \times$ and $40 \times$ objective. The primers used for the quantitative real-time PCR (qPCR), as supplied by Applied Biosystems (Foster City, CA, USA), are listed in Table 2.

Table 7. Primary and secondary antibodies used for immunocytochemistry

\begin{tabular}{|c|c|c|c|c|c|}
\hline Antibody & Marker for & Dilution & $\begin{array}{l}\text { Product } \\
\text { number }\end{array}$ & Company & $\begin{array}{l}\text { Incubation } \\
\text { protocol }\end{array}$ \\
\hline Rat anti E-cadherin (ECAD) & $\begin{array}{l}\text { Adhesion molecule pre- } \\
\text { sent before neural tube } \\
\text { closure }\end{array}$ & $1: 1000$ & $13-1900$ & Invitrogen & BSA \\
\hline Paired box protein (PAX6) & $\begin{array}{l}\text { Neural progenitor/ecto- } \\
\text { derm }\end{array}$ & 1:1000 & 901301 & $\begin{array}{l}\text { Bio-con- } \\
\text { nect }\end{array}$ & BSA/NGS \\
\hline $\begin{array}{l}\text { Mouse anti Microtubule-asso- } \\
\text { ciated protein } 2 \text { (MAP2) }\end{array}$ & Neuron-dendrite specific & $1: 2000$ & 801801 & Biolegend & BSA \\
\hline $\begin{array}{l}\text { Guinea pig anti-Vesicular glu- } \\
\text { tamate transporter } 2 \text { (VGLUT2) }\end{array}$ & $\begin{array}{l}\text { Synaptic vesicle excita- } \\
\text { tory neuron }\end{array}$ & $1: 2000$ & AB2551-I & Millipore & BSA \\
\hline $\begin{array}{l}\text { Rat anti Glial fibrillary acidic } \\
\text { protein (GFAP) }\end{array}$ & Early astrocyte & $1: 800$ & $13-0300$ & Invitrogen & BSA/NGS \\
\hline $\begin{array}{l}\text { Mouse anti Twist-related pro- } \\
\text { tein } 2 \text { (TWIST) }\end{array}$ & $\begin{array}{l}\text { Epithelial-Mesenchymal } \\
\text { transition }\end{array}$ & $1: 500$ & ab50887 & Abcam & NGS \\
\hline Goat anti rabbit Alexa 488 & & $1: 1000$ & A11034 & Invitrogen & BSA/NGS \\
\hline Goat anti guinea pig Alexa 488 & & $1: 1000$ & A11073 & Invitrogen & BSA/NGS \\
\hline Goat anti rat Alexa 555 & & $1: 500$ & A21434 & Invitrogen & BSA/NGS \\
\hline Goat anti mouse Alexa 647 & & $1: 500$ & 21236 & Invitrogen & BSA/NGS \\
\hline
\end{tabular}

Table 2. Primers used for gene expression quantification by qPCR (Applied Biosystems)

\begin{tabular}{lll}
\hline Gene & Marker for & Assay ID \\
\hline Fucosyltransferase 4 (Fut4) & Stem cell & Mm00487448_s1 \\
POU domain, class 5, transcription factor 1 & Stem cell & Mm03053917_g1 \\
(Pou5f7) & Adhesion molecule present before & Mm01247357_m1 \\
Cadherin 1 (Cdh7) & neural tube closure & Mm00450205_m1 \\
Nestin (Nes) & Neural progenitor & Mm00727586_s1 \\
Tubulin, beta 3 class III (Tubb3) & Neuron & Mm01253033_m1 \\
Flial fibrillary acidic protein (Gfap) & Early astrocyte & Mm00442992_m1 \\
Msh homeobox 2 (MsX2) & Early neural crest & Mm00441531_m1 \\
Snail family zinc finger 2 (Snai2) & Epithelial-Mesenchymal Transition & Mm00515662_m1 \\
Dihydrofolate reductase (Dhfi) & Reduction of DHF to THF & Mm01340053_m1 \\
5-methyltetrahydrofolate-homocysteine me- & Remethylation of homocysteine & \\
thyltransferase (Mtr) & & Mm01151063_m1 \\
DNA methyltransferase 1 (Dnmt7) & DNA methylation & Mm03024075_m1 \\
Hypoxanthine phosphoribosyltransferase 1 & Housekeeping gene & \\
(Hprt7) & & Mm01197698_m1 \\
Glucuronidase beta (Gusb) & Housekeeping gene & \\
\hline
\end{tabular}

\section{Data analysis and visualisation}

Dose-response curves of morphological scoring and cell viability were created with PROAST software version 67.0 [34] in R (R Core Team,[35] version 3.6.0), by using various models for regular toxicity curves or a single model $\left(y=a\left\{\left[c 1-(\mathrm{c} 1-1)\left(-(\mathrm{x} / \mathrm{b} 1)^{\wedge} \mathrm{d} 1\right)\right]\right.\right.$ * $\left.\left.\left[\mathrm{c} 2-(\mathrm{c} 2-1)\left(-(\mathrm{x} / \mathrm{b} 2)^{\wedge} \mathrm{d} 2\right)\right]\right\}\right)$ to find an optimum in the toxicity curves, if applicable. For the derivation of the concentrations at which a certain percentage of EBs was affected, compared to the 
effects at the (non-zero) standard medium concentration, a custom script was created (see Supplementary material). A custom code was needed because the current PROAST software only allows calculation of changes in response or effect compared to dose or concentration zero. Concentrations with a 95\% confidence interval were derived from the resulting curves. Each average value represents three independent experiments with three technical replicates for differentiation toxicity and six replicates for cytotoxicity, except for the over-supplementation data, which was performed once with three technical replicates.

Viability was expressed as a percentage relative to the control culture, differentiation toxicity was expressed as the fraction of EBs that had a neurite corona that was greater than $75 \%$ full. Primer efficiency was validated against several housekeeping genes by using a reference pool of samples from all experimental conditions. Hypoxanthine phosphoribosyltransferase 7 (Hprt7) and Glucuronidase beta (Gusb) presented the most comparable efficiency to the selected primers. Relative gene expression differences were calculated by using the $2^{-\Delta \Delta C t}$ method [36], which were all normalised against the average expression of Hprt7 and Gusb. For visualisation, GraphPad Prism (version 8.2.1) and Adobe Illustrator were used. For each gene, one-way ANOVA and post-hoc Sidak's multiple comparisons test were performed, to adjust for multiple testing.

\section{Results}

\section{Optimal FA and MET concentrations are crucial for cell viability and differentiation in ESTn}

Cell viability and differentiation were assessed in $\mathrm{mESCs}$, following exposure to a range of concentrations of FA or MET (Figure 1B). FA only moderately decreased stem cell viability, with cytotoxic effects (i.e. less than $95 \%$ viability) evident only at concentrations greater than 0.46 $\mathrm{mM}(\mathrm{Cl}=0.13-0.65)$. This concentration is about $50 \times$ the concentration that is normally present in the culture medium. Differentiation was affected at both lower and higher concentrations of $\mathrm{FA}\left(\mathrm{ID}_{5}<0.0070 \mathrm{mM}, \mathrm{Cl}=0.0033-0.0085\right.$ and $\mathrm{ID}_{5}>0.22 \mathrm{mM}, \mathrm{Cl} 0.11-0.27$, respectively). However, complete omission of FA from the medium still resulted in half of the EBs differentiating successfully.

On the other hand, MET concentration changes were cytotoxic to the stem cells both at lower and higher concentrations $\left(\mathrm{IC}_{5}<0.097 \mathrm{mM}\right.$, no $\mathrm{Cl}$ defined and $\mathrm{IC}_{5}>1.52 \mathrm{mM}, \mathrm{Cl}=0.30-5.32$, respectively), and differentiation was affected at similar concentrations $\left(I_{5}<0.181 \mathrm{mM}, \mathrm{Cl}=\right.$ $0.178-0.184$ and $\mathrm{ID}_{5}>1.35 \mathrm{mM}$, no $\mathrm{Cl}$ defined, respectively), suggesting that the apparent difference observed in terms of cell differentiation may have been caused by a decrease in cell viability. Immunostaining corroborated these findings (Figure 1C and 1D): for low concentrations of FA, MAP2 expression indicated that neurites around the EBs were partly affected. However, markers for other cell types (PAX6 for neural progenitors, GFAP for astrocytes and neural progenitors, and TWIST for neural crest cells transitioning from epithelial to mesenchymal (EMT) or migratory fate) did not seem to be decreased, even in the absence of FA. Supplementation with FA to $3 \times$ the standard medium concentration did not cause any effects on the studied cell types. In the case of MET, lower concentrations concurred with a decrease or complete absence of neurites and an increase in the undifferentiated neuroepithelial marker E-cadherin 
(ECAD). A proportionate decrease in PAX6, GFAP and TWIST expression was observed, together with a smaller EB size.

A

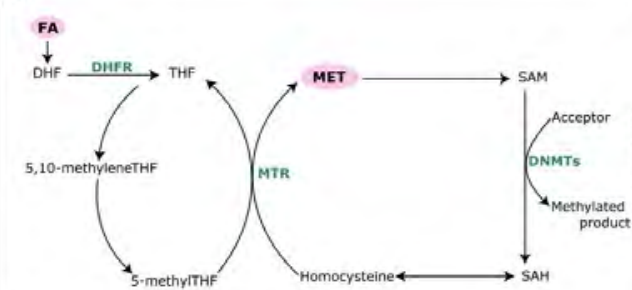

C

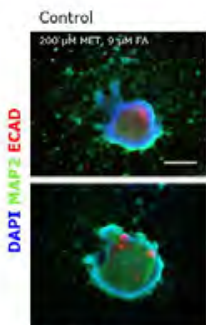

FA $30 \mu \mathrm{M}$

D

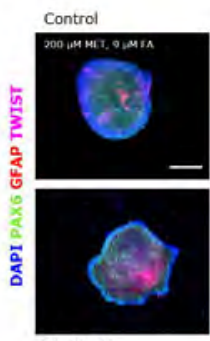

$\mathrm{FA} 30 \mu \mathrm{M}$
MET $300 \mu \mathrm{M}$
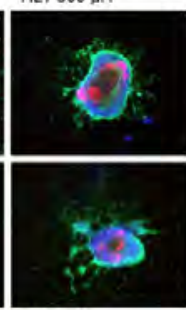

FA $10 \mu \mathrm{M}$

MET $300 \mu \mathrm{M}$

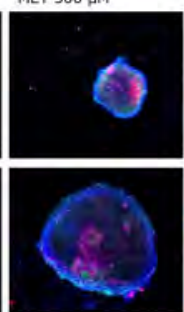

FA $10 \mu \mathrm{M}$
MET $30 \mu \mathrm{M}$

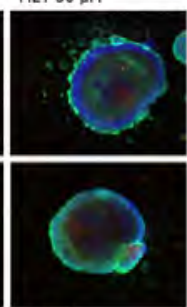

FA $1 \mu \mathrm{M}$

MET $30 \mu \mathrm{M}$
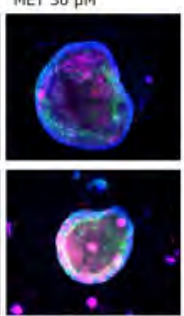

FA $1 \mu M$
B

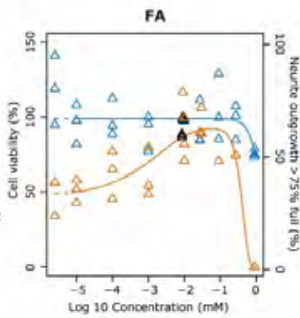

MET $0.3 \mu \mathrm{M}$

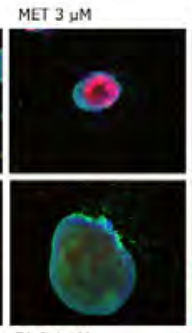

FA $0.1 \mu \mathrm{M}$

MET $3 \mu \mathrm{M}$

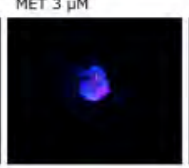

MET $0.3 \mu \mathrm{M}$

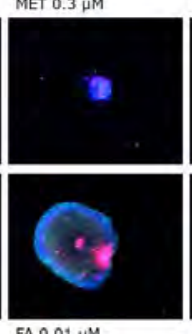

FA $0.01 \mu \mathrm{M}$

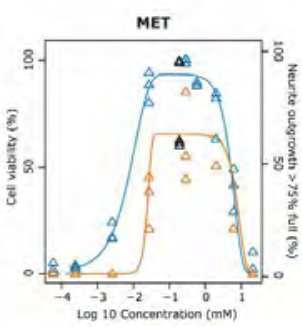

no MET

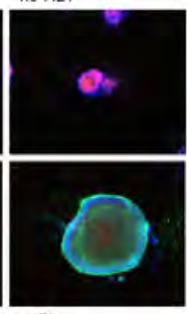

no FA

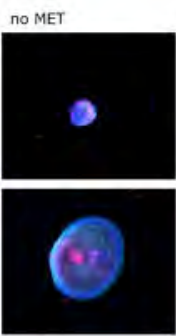

no FA

Figure 1. The effects of FA and MET on cell viability and the extent of neural differentiation in the ESTn. A) A simplified scheme of the $1 C$ cycle and the involvement of FA and MET (shown in pink), intermediate molecules (shown in black) and enzymes (shown in green). Adapted from James et al.[76]. B) The graphs show cell viability (in blue) in mESC and the extent of differentiation assessed by the fullness of the corona (in orange) in the ESTn, at a range of concentrations of FA or MET. The black triangles indicate standard medium concentrations. ( $C$ and $D$ ) The images show protein expression in different cell types at a range of concentrations of FA or MET: ECAD (undifferentiated neuroepithelial cells); MAP2 (neurons); PAX6 (neural progenitors); GFAP (astrocytes); and TWIST (neural crest cells transitioning from epithelial to mesenchymal fate). The nuclei were stained with DAPI (4',6-diamidine-2'-phenylindole dihydrochloride). $F A=$ folic acid; $M E T=$ methionine; $M T X=$ methotrexate DHF = dihydrofolate; $D H F R=$ dihydrofolate reductase; THF = tetrahydrofolate; $M T R=5$-methyltetrahydrofolate-homocysteine methyltransferase; $S A M=S$ adenosyl methionine; DNMTS = DNA methyltransferases; $S A H=S$-adenosyl homocysteine. Scale bar $=500 \mu m$.

\section{MTX affected neural differentiation differently under control versus}

\section{low FA or low MET conditions}

MTX is known to interfere with $1 \mathrm{C}$ metabolism and to cause NTD in vivo. To determine whether ESTn performed with low FA or low MET concentrations could successfully mimic an NTDprone situation in vitro, we tested sensitivity to MTX. To this end, we lowered the concentrations 
of FA or MET in the medium to $5.25 \mu \mathrm{M}$ and $163 \mu \mathrm{M}$, respectively (hereafter called 'low FA' or 'Iow MET' conditions), concentrations at which $90 \%$ of the EBs differentiated successfully relative to normal medium concentrations (Figure 2A). MTX treatment was applied for 10 days, at the ID50 concentration of $39 \mathrm{nM}$ and at one-third of the ID 50 concentration (i.e. $13 \mathrm{nM}$ ) (see Figure 2B). MTX exposure decreased the extent of differentiation and viability at similar concentrations. Interestingly, stem cell viability did not decrease further than $40 \%$ relative to the control, while differentiation was fully inhibited at these concentrations.

Immunostaining for a range of cell types in ESTn revealed no obvious changes in cell types under low FA or low MET conditions; all cell type markers, as mentioned above, and the excitatory neuron marker VGLUT2 were present (Figures 2C, 2D and 2E). Exposure to 39 nM MTX led to an increase in ECAD expression under all conditions, suggesting an inhibition of differentiation (Figure 2D). In the case of low MET, even $13 \mathrm{nM} \mathrm{MTX} \mathrm{resulted} \mathrm{in} \mathrm{an} \mathrm{increase} \mathrm{in} \mathrm{ECAD}{ }^{+}$cells in the EB and in the corona (Figures 2D and 2E). No other cell types seemed to be specifically affected by MTX exposure.

To quantitatively assess the changes observed with the immunostaining, qPCR was used to detect changes in gene expression of a range of cell type markers and enzymes involved in 1C metabolism. Since 39 nM MTX treatment resulted in overt cytotoxicity, only gene expression after exposure to 13 nM MTX was studied (Figure 2F). Interestingly, Fut4 and Cdh 1 expression did not change under any of the tested conditions, despite a clear increase in ECAD protein expression upon MTX exposure.

Neural differentiation was not statistically significantly affected - however, certain trends could be observed, namely a tendency toward decreased expression of neural progenitor marker Nes and/or neural marker Tubb3 following MTX treatment under standard FA/MET conditions (i.e. 'control') and under low FA conditions, but not under low MET conditions. A tendency toward decreased expression was also evident in the case of low MET alone, without MTX treatment.

The same was true for Gfap expression, which was clearly affected by MTX exposure under standard FA/MET conditions and under low FA conditions, but not under low MET conditions. Early neural crest marker Msx2 expression was unchanged under any of the conditions tested, while the expression of another EMT marker, Snai2, specifically increased after exposure to MTX under low MET conditions. Interestingly, the only 1C metabolism enzyme that was affected by MTX treatment under low FA conditions was Dnmt7.

In summary, gene or protein expression analysis showed that MTX exposure for 10 days:

- downregulated Gfap under standard FA/MET and low FA conditions (suggesting inhibition of astroglial differentiation);

- downregulated Tubb3 and the 1C enzyme Dnmt1 under low FA conditions (suggesting inhibition of neural differentiation); and

- increased ECAD expression and Snai2 expression under low MET conditions (suggesting inhibited neural crest cell differentiation). 
These data suggest that MTX exposure led to a wider array of effects as well as unique effects under low FA and low MET conditions than that occurring in standard medium.

A

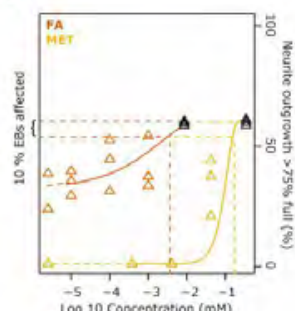

Log 10 Concentration $(\mathrm{mM})$
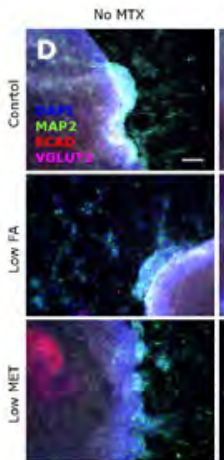

B

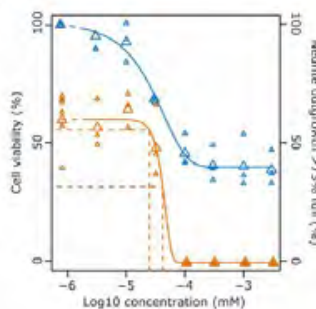

$D_{50}$ MTX

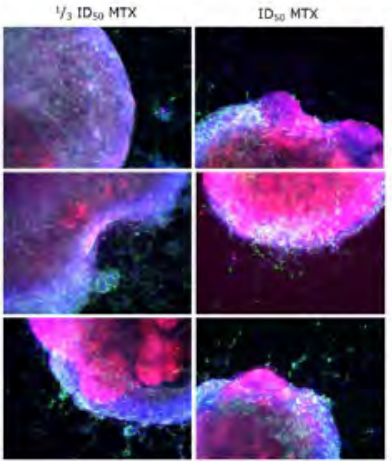

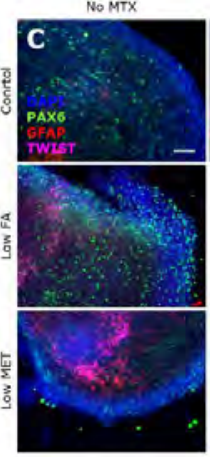

No MTX
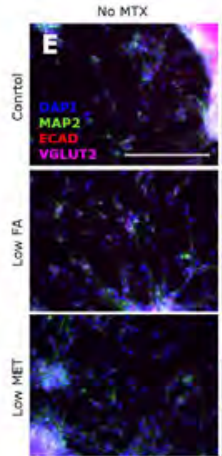

$1 / 3$ ID $M T X$

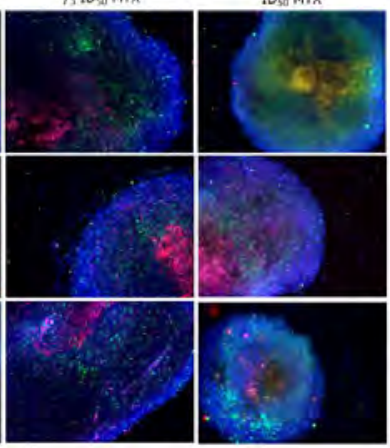

$1 / 3$ ID $D_{50} M T X$
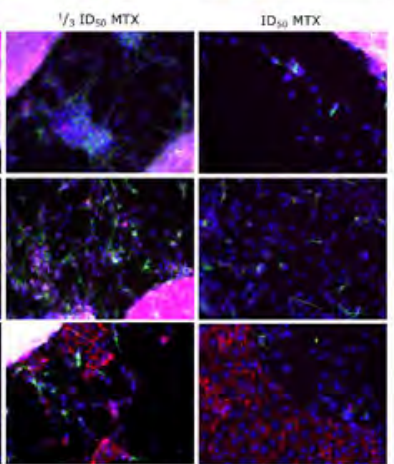

$\mathbf{F}$
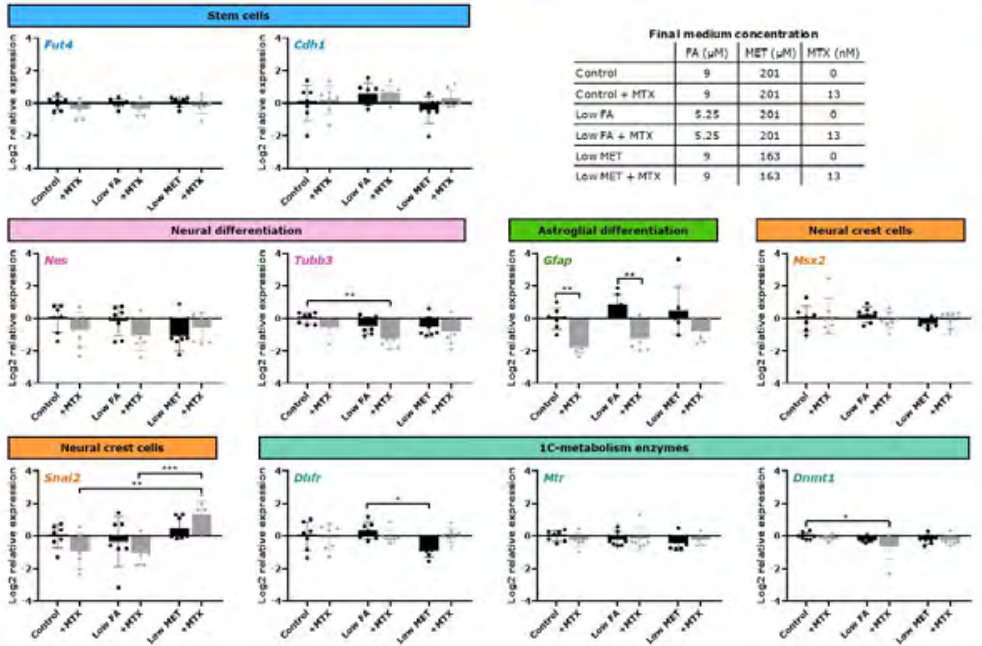

Figure 2. The effects of a 10-day exposure to MTX under low FA or low MET concentrations. A) The graph shows a dose-response curve for FA (in orange) and MET (in yellow). The concentrations at which 10\% of the EBs were affected by low FA or MET levels are indicated. Black triangles indicate standard medium concentrations. B) The graph shows cell viability (in blue) and the extent of differentiation (in orange), which was assessed by the fullness of the ESTn corona, after exposure to MTX; the $I D_{50}$ and $1 / 3 I_{50}$ concentrations are indicated as dotted lines. C-E) 
Immunostainings showing cell type marker expression under low FA or low MET conditions, with or without exposure to MTX at $1 / 3$ of $I D_{50}$ and at ID 50 concentrations. The cell markers used were: VGLUT2 (synaptic vesicle); ECAD (undifferentiated neuroepithelial cells); MAP2 (neurons); PAX6 (neural progenitors); GFAP (astrocytes); and TWIST (neural crest cells transitioning from epithelial to mesenchymal fate). The nuclei were stained with DAPI (4;,6-diamidine-2'-phenylindole dihydrochloride). FA = folic acid; MET = methionine; MTX = methotrexate. F) Gene expression changes (log2) relative to the control culture. Markers for a range of cell types were assessed: Fut4 and Cdh 1 (stem cells); Nes (neural progenitors); Tubb3 (neurons); Msx2 and Snai2 (neural crest cells); Gfap (astrocytes); and Dhfr, Mtr and Dnmt7 (1C metabolism enzymes). Scale bar $=100 \mu \mathrm{m}$. Significance levels: $* p<0.05, * * p<0.01, * * * p<$ 0.007 .

\section{Shorter exposure under more extreme conditions did not affect gene expression profiles in ESTn cell types}

It has been shown before that ESTn gene expression profiles are most pronounced after 24 hours of exposure $[33,37,38]$. ESTn was therefore carried out under more extreme conditions, in which FA or MET were lowered to the ID ${ }_{50}$ concentrations - i.e. $0 \mu \mathrm{M}$ FA and $30 \mu \mathrm{M}$ MET. These extreme conditions aimed to create a more sensitive model for the 10-day exposure. Also, to study whether an increased FA concentration would have a protective effect, we tested $3 \times$ the normal FA medium concentration $(30 \mu \mathrm{M})$. Under these three conditions, ESTn was exposed for 24 hours to 39 nM MTX (ID50).

Only when a high concentration of FA $(30 \mu \mathrm{M})$ was present in the culture medium, did MTX statistically significantly downregulate the expression of Nes, Tubb3 and Msx2, these genes seemed to be upregulated by FA relative to the normal FA concentration control (although the change was not statistically significant). No other statistically significant changes in the analysed gene expression was observed under the other conditions tested (Figure 3). This suggests that the sensitivity of ESTn to MTX exposure is dependent on the FA concentration present in the culture medium.

\section{Discussion}

In vitro assays are now widely applied in the study of chemical toxicity. However, the results of such assays are not always easy to interpret. Basic culture conditions can often influence assay outcome, and thus may affect the extrapolation of in vitro results to the broader context of adverse health effects in vivo. For example, nutrient concentrations are often higher in culture medium than in vivo, as in the case of FA and MET. Normal blood concentrations of FA are 20$120 \mathrm{nM}$ [39] and MET concentrations range from 3-30 $\mu \mathrm{M}$ [40]. In cranial embryonic tissue, the concentration of FA can be as low as $50 \mathrm{pmol} / \mathrm{g}$ [41], which is several orders of magnitude lower than the concentrations in standard DMEM media (0.009 mM FA and 0.201 mM MET). However, this is in agreement with findings from other studies, which have shown that such high in vitro concentrations of FA and MET are actually needed to ensure a viable and healthy cell culture $[25,28]$. The current study specifically showed that the concentrations of FA and MET in standard DMEM media were at the lower end of the optimal range for neural differentiation in ESTn (0.007-0.22 mM for FA and 0.181-1.35 mM for MET).

Previous in vitro studies have shown that FA deficiency in vitro affects the neural differentiation of (neural) stem cells [25,26] and (over-)supplementation for a limited time decreases astroglial differentiation $[26,27]$. In line with these findings, we found that a reduction in FA caused a trend 

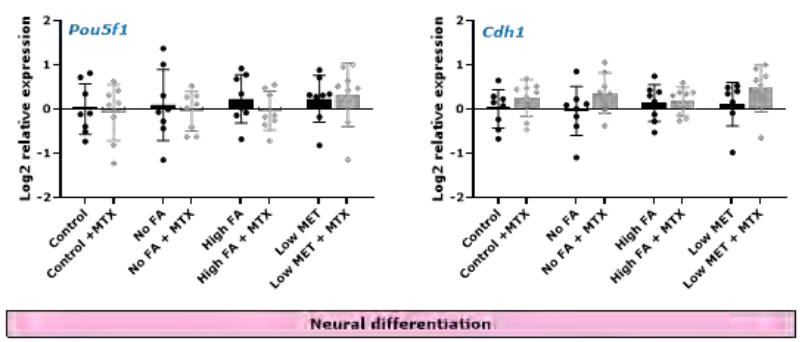

\begin{tabular}{l|c|c|c}
\multicolumn{4}{c}{ Final medium concen tration } \\
\hline Control & FA ( $\mu$ M) & MET $(\mu \mathrm{M})$ & MTX (nM) \\
\hline Control + MTX & 9 & 201 & 0 \\
\hline No FA & 0 & 201 & 39 \\
\hline No FA + MTX & 0 & 201 & 0 \\
\hline High FA & 30 & 201 & 39 \\
\hline High FA + MTX & 30 & 201 & 39 \\
\hline Low MET & 9 & 30 & 0 \\
\hline Low MET + MTX & 9 & 30 & 39
\end{tabular}

Neural differentiation
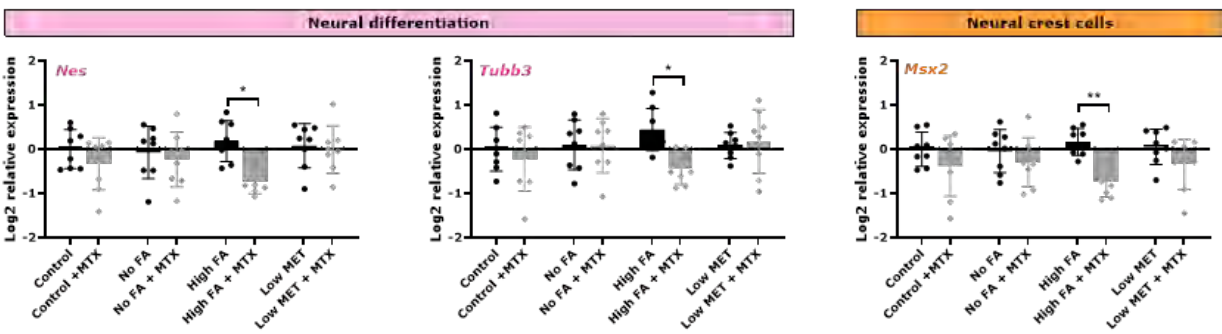

1C-metabolism enxymes
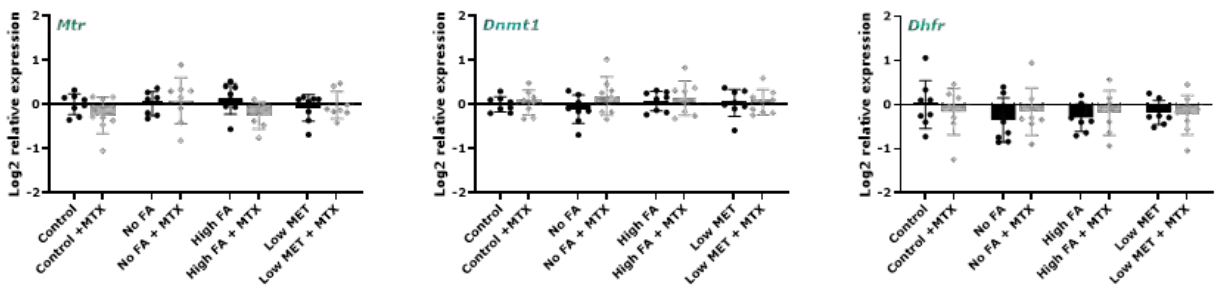

Figure 3. Relative gene expression (log2) changes of cell type markers and $1 C$ enzymes in different culture media, after exposure to MTX. The relative gene expression (log2) changes of cell type markers and $1 C$ metabolism enzymes are shown with and without MTX exposure, in the control medium (i.e. standard FA and MET concentrations), as well as in the absence of FA, at high FA concentration, and at low MET concentration. Markers for a range of cell types were assessed: Pou5f7 and Cdh1 (stem cells); Nes (neural progenitors); Tubb3 (neurons); Msx2 (neural crest cells); and Dhfr, Mtr and Dnmt7 (1C metabolism enzymes). Significance levels: $* p<0.05, * * p<0.01$.

toward increased Gfap expression. Both MET deficiency and over-supplementation in vitro affects the viability as well as differentiation of stem cells $[23,28]$. Similarly, our study showed that in the presence of low concentrations of MET, differentiation was inhibited, EB size was reduced and ECAD expression was increased, which indicates impaired stem cell differentiation and viability. It was apparent that stem cells and ESTn were more sensitive to changes in the concentration of MET than to changes in FA concentration. This could be explained by their respective roles in $1 \mathrm{C}$ metabolism: while FA plays a supportive role, i.e. increasing homocysteine re-methylation via the FA cycle, MET participates in the central MET cycle, which cannot be enhanced by increasing FA levels $[42,43]$.

In addition to FA and MET being two of the many constituents of standard culture medium, they are also present in fetal bovine serum (FBS), which is added to the culture medium at a $20 \% \mathrm{~V} / \mathrm{V}$ dilution during the first five days of ESTn differentiation protocol. However, this FBS-derived contribution of FA and MET to the final concentrations of each component in the culture medium is limited due to the level of each in the FBS being 500x and 25x lower, respectively, than 
the concentrations that are present in the standard medium $[44,45]$. As early effects were specifically found after FA supplementation, the contribution of FBS-derived FA to the results is also believed to be negligible.

In addition to effects on cell viability and differentiation, culture conditions may also affect assay sensitivity to compound exposure, possibly affecting toxicity prediction. Here we showed that lowering FA or MET concentrations for 10 days affected the response to MTX exposure. The MTX-related downregulation of Gfap, both under standard and low FA conditions, is in line with previous observations of astrocytes being the most sensitive cell population in the central nervous system to MTX toxicity [46-48]. Downregulation of Tubb3 and the $1 \mathrm{C}$ enzyme Dnmt7 at low FA concentrations, and increased ECAD expression and Snai2 expression at low MET concentrations, suggests that ESTn may, under these conditions, mimic an NTD-prone situation. The lack of Cdh 7 upregulation in the presence of increased ECAD expression after 10 days of exposure to MTX, could be due to the fact that, at that particular time point, Cdh 7 expression might have returned to normal levels, while the MTX exposure had longer-lasting effects on the upregulation of ECAD expression.

The inhibition of neural differentiation has been shown in previous in vitro studies $[25,49]$. Some parallels can be drawn with human studies of MTX exposure, as foetal MTX syndrome revealed a higher number of microcephaly cases than expected, and regulation of neural crest cell differentiation could result in potential neural crest-related malformations (such as the typical facial dysmorphic features). However, this remains speculative [50]. Short-term exposure to MTX resulted in the downregulation of the expression of Nes, Tubb3 and Msx2, specifically in the presence of increased FA in the medium, suggesting inhibition of neural and neural crest differentiation. This was surprising, as FA supplementation was expected to lower the sensitivity of the cells to MTX. In addition, it has been shown that FA could rescue the effects of MTX in (neural) stem cell models $[25,51,52]$. An explanation for our observations might be that the addition of FA enhances the neural differentiation potential of ESTn [26,27], but also renders the cells more prone to insults by a chemical that affects $1 \mathrm{C}$ metabolism and/or neural tube closure. More compounds should be tested, in order to substantiate this proposal.

Together, these results show that the composition of the culture medium, the duration of the exposure and the timing of the read-out, are all crucial parameters to carefully monitor and control in in vitro tests. Simple in vitro assays to determine isolated biological phenomena (e.g. receptor activation) produce results that can be interpreted relatively readily (e.g. by potency comparison with positive and negative control compounds) [53]. More complex assays (such as ESTn), with a host of biological phenomena all contributing to the outcome, necessitate a more detailed molecular analysis of, for example, gene and protein expression, in order to understand and interpret the experimental results [54,55]. Nevertheless, ESTn remains just a single in vitro test, and extrapolating its findings to a complex morphogenetic process, such as neural tube development, requires integration at higher levels of complexity. Emerging computational approaches may provide solutions for this requirement, as recent examples have shown [56-58]. It remains important to realise that in vitro assays mimic the in vivo situation only to a certain extent. As such, they should not be used in isolation, and their results should be interpreted in a broader context for proper hazard assessment. 


\section{Acknowledgements}

We would like to thank Jeroen Pennings for a critical review of the manuscript.

\section{Conflict of interest statement}

The authors declare that they have no conflict of interest that could have appeared to influence the content of this paper.

\section{Funding}

This research is funded by the Dutch NGO Stichting Proefdiervrij, the Dutch Ministry of Agriculture, Nature and Food Quality and the Dutch Ministry of Health, Welfare and Sports. 


\section{References}

[1] A. Bal-Price, S. Coecke, L. Costa, K.M. Crofton, E. Fritsche, A. Goldberg, P. Grandjean, P.J. Lein, A. Li, R. Lucchini, W.R. Mundy, S. Padilla, A.M. Persico, A.E.M. Seiler, J. Kreysa, Advancing the science of developmental neurotoxicity (DNT): testing for better safety evaluation, ALTEX. 29 (2012) 202-215. https://doi.org/10.14573/altex.2012.2.202.

[2] H.R. Ferdowsian, N. Beck, Ethical and scientific considerations regarding animal testing and research., PLoS One. 6 (2011) e24059. https://doi.org/10.1371/journal.pone.0024059.

[3] T. Hartung, Food for thought ... on cell culture, ALTEX. $24 \quad$ (2007) 143-147. https://doi.org/10.14573/altex.2007.3.143.

[4] P.T. Theunissen, S.H.W. Schulpen, D.A.M. van Dartel, S.A.B. Hermsen, F.J. van Schooten, A.H. Piersma, An abbreviated protocol for multilineage neural differentiation of murine embryonic stem cells and its perturbation by methyl mercury, Reprod. Toxicol. $29 \quad$ (2010) 383-392. https://doi.org/10.1016/j.reprotox.2010.04.003.

[5] V.C. de Leeuw, E.V.S. Hessel, J.L.A. Pennings, H.M. Hodemaekers, P.F.K. Wackers, C.T.M. van Oostrom, A.H Piersma, Differential effects of fluoxetine and venlafaxine in the neural embryonic stem cell test (ESTn) revealed by a cell lineage map, Neurotoxicology. 76 (2020) 1-9. https://doi.org/10.1016/j.neuro.2019.09.014.

[6] P.T. Theunissen, J.F. Robinson, J.L.A. Pennings, E. De jong, S.M.H. Claessen, J.C.S. Kleinjans, A.H. Piersma Transcriptomic concentration-response evaluation of valproic acid, cyproconazole, and hexaconazole in the neural Embryonic Stem Cell Test (ESTn), Toxicol. Sci. 125 (2012) 430-438. https://doi.org/10.1093/toxsci/kfr293.

[7] P.T. Theunissen, J.F. Robinson, J.L.A. Pennings, M.H. van Herwijnen, J.C.S. Kleinjans, A.H. Piersma, Compound-specific effects of diverse neurodevelopmental toxicants on global gene expression in the neural embryonic stem cell test (ESTn), Toxicol. Appl. Pharmacol. 262 (2012) 330-340. https://doi.org/10.1016/j.taap.2012.05.011.

[8] V.C. de Leeuw, E.V.S. Hessel, A.H. Piersma, Look-alikes may not act alike: Gene expression regulation and cell-type-specific responses of three valproic acid analogues in the neural embryonic stem cell test (ESTn), Toxicol. Lett. 303 (2019) 28-37. https://doi.org/10.1016/j.toxlet.2018.12.005.

[9] L.E. Mitchell, Epidemiology of neural tube defects, in: Am. J. Med. Genet. - Semin. Med. Genet., Wiley Subscription Services, Inc., A Wiley Company, 2005: pp. 88-94. https://doi.org/10.1002/ajmg.c.30057.

[10] H. Blencowe, V. Kancherla, S. Moorthie, M.W. Darlison, B. Modell, Estimates of global and regional prevalence of neural tube defects for 2015: A systematic analysis, Ann. N. Y. Acad. Sci. (2018). https://doi.org/10.1111/nyas.13548.

[11] G.S. Ducker, J.D. Rabinowitz, One-Carbon Metabolism in Health and Disease, Cell Metab. 25 (2017) $27-42$. https://doi.org/10.1016/j.cmet.2016.08.009.

[12] K.S. Au, T.O. Findley, H. Northrup, Finding the genetic mechanisms of folate deficiency and neural tube defects-Leaving no stone unturned, Am. J. Med. Genet. Part A. 173 (2017) 3042-3057. https://doi.org/10.1002/ajmg.a.38478.

[13] S.J. Mentch, J.W. Locasale, One-carbon metabolism and epigenetics: Understanding the specificity, Ann. N Y. Acad. Sci. 1363 (2016) 91-98. https://doi.org/10.1111/nyas.12956.

[14] L.B. Bailey, P.J. Stover, H. McNulty, M.F. Fenech, J.F. Gregory, J.L. Mills, C.M. Pfeiffer, Z. Fazili, M. Zhang, P.M. Ueland, A.M. Molloy, M.A. Caudill, B. Shane, R.J. Berry, R.L. Bailey, D.B. Hausman, R. Raghavan, D.J. Raiten, Biomarkers of Nutrition for Development-Folate Review, J. Nutr. 145 (2015) 1636S-1680S. https://doi.org/10.3945/jn.114.206599.

[15] A.J.A. Wright, J.R. Dainty, P.M. Finglas, Folic acid metabolism in human subjects revisited: Potential implications for proposed mandatory folic acid fortification in the UK, Br. J. Nutr. 98 (2007) 667-675. https://doi.org/10.1017/S0007114507777140.

[16] P. James, S. Sajjadi, A.S. Tomar, A. Saffari, C.H.D. Fall, A.M. Prentice, S. Shrestha, P. Issarapu, D.K. Yadav, L. Kaur, K. Lillycrop, M. Silver, G.R. Chandak, Candidate genes linking maternal nutrient exposure to offspring health via DNA methylation: a review of existing evidence in humans with specific focus on one-carbon metabolism, Int. J. Epidemiol. 47 (2018) 1910-1937. https://doi.org/10.1093/ije/dyy153.

[17] A.E. Beaudin, P.J. Stover, Insights into metabolic mechanisms underlying folate-responsive neural tube defects: A minireview, Birth Defects Res. Part A - Clin. Mol. Teratol. 85 (2009) 274-284. https://doi.org/10.1002/bdra.20553.

[18] J. Safi, L. Joyeux, G.E. Chalouhi, Periconceptional folate deficiency and implications in neural tube defects, J. Pregnancy. 2012 (2012) 295083. https://doi.org/10.1155/2012/295083.

[19] MRC, Prevention of neural tube defects: Results of the Medical Research Council Vitamin Study, Lancet. 338 (1991) 131-137. https://doi.org/10.1016/0140-6736(91)90133-A.

[20] A.E. Czeizel, I. Dudás, Prevention of the First Occurrence of Neural-Tube Defects by Periconceptional Vitamin Supplementation, N. Engl. J. Med. 327 (1992) 1832-1835. https://doi.org/10.1056/NEJM199212243272602.

[21] H.D. Shoob, R.G. Sargent, S.J. Thompson, R.G. Best, J.W. Drane, A. Tocharoen, Dietary Methionine Is Involved in the Etiology of Neural Tube Defect-Affected Pregnancies in Humans, J. Nutr. 131 (2001) 2653-2658. https://doi.org/10.1093/jn/131.10.2653. 
[22] R.W. Smithells, S. Sheppard, C.T. Schorah, M.J. Seller, N.C. Nevin, R. Harris, A.P. Read, D.W. Fielding, S. Walker, Vitamin supplementation and neural tube defects, Lancet. 318 (1981) 1425. https://doi.org/10.1016/S01406736(81)92841-5.

[23] L.P.E. Dunlevy, K.A. Burren, L.S. Chitty, A.J. Copp, N.D.E. Greene, Excess methionine suppresses the methylation cycle and inhibits neural tube closure in mouse embryos, FEBS Lett. 580 (2006) 2803-2807. https://doi.org/10.1016/j.febslet.2006.04.020.

[24] W.D. Rees, F.A. Wilson, C.A. Maloney, Sulfur Amino Acid Metabolism in Pregnancy: The Impact of Methionine in the Maternal Diet, J. Nutr. 136 (2006) 1701S-1705S. https://doi.org/10.1093/jn/136.6.1701s.

[25] Y. Chen, Z. Wang, Y. Xie, X. Guo, X. Tang, S. Wang, S. Yang, K. Chen, Y. Niu, W. Ji, Folic acid deficiency inhibits neural rosette formation and neuronal differentiation from rhesus monkey embryonic stem cells, J. Neurosci. Res. (2012). https://doi.org/10.1002/jnr.23030.

[26] S. Luo, X. Zhang, M. Yu, H. Yan, H. Liu, J. Wilson, G. Huang, Folic Acid Acts Through DNA Methyltransferases to Induce the Differentiation of Neural Stem Cells into Neurons, Cell Biochem. Biophys. 66 (2013) 559-566. https://doi.org/10.1007/s12013-012-9503-6.

[27] D. yong Jia, H. juan Liu, F. wu Wang, S. ming Liu, E.A. Ling, K. Liu, A. jun Hao, Folic acid supplementation affects apoptosis and differentiation of embryonic neural stem cells exposed to high glucose, Neurosci. Lett. 440 (2008) 27-31. https://doi.org/10.1016/j.neulet.2008.05.053.

[28] N. Shiraki, Y. Shiraki, T. Tsuyama, F. Obata, M. Miura, G. Nagae, H. Aburatani, K. Kume, F. Endo, S. Kume Methionine metabolism regulates maintenance and differentiation of human pluripotent stem cells, Cell Metab. 19 (2014) 780-794. https://doi.org/10.1016/j.cmet.2014.03.017.

[29] M.B. Johnson, P.P. Wang, K.D. Atabay, E.A. Murphy, R.N. Doan, J.L. Hecht, C.A. Walsh, Single-cell analysis reveals transcriptional heterogeneity of neural progenitors in human cortex, Nat. Neurosci. 18 (2015) $637-$ 646. https://doi.org/10.1038/nn.3980.

[30] X. Wang, J. Wang, T. Guan, Q. Xiang, M. Wang, Z. Guan, G. Li, Z. Zhu, Q. Xie, T. Zhang, B. Niu, Role of methotrexate exposure in apoptosis and proliferation during early neurulation, J. Appl. Toxicol. 34 (2014) 862-869. https://doi.org/10.1002/jat.2901.

[31] J. Zhao, T. Guan, J. Wang, Q. Xiang, M. Wang, X. Wang, Z. Guan, Q. Xie, B. Niu, T. Zhang, Influence of the antifolate drug Methotrexate on the development of murine neural tube defects and genomic instability, J. Appl. Toxicol. 33 (2013) 915-923. https://doi.org/10.1002/jat.2769.

[32] H. Spielmann, I. Pohl, B. Döring, M. Liebsch, F. Moldenhauer, The Embryonic Stem cell Test, an in vitro embryotoxicity test using two permanent mouse cell lines: 3T3 fibroblasts and embryonic stem cells, Vitr. Mol. Toxicol. J. Basic Appl. Res. 10 (1997) 119-127. https://doi.org/10.1007/978-3-7091-7500-2_69.

[33] P.T. Theunissen, J.L.A. Pennings, J.F. Robinson, S.M.H. Claessen, J.C.S. Kleinjans, A.H. Piersma, Timeresponse evaluation by transcriptomics of methylmercury effects on neural differentiation of murine embryonic stem cells, Toxicol. Sci. 122 (2011) 437-447. https://doi.org/10.1093/toxsci/kfr134.

[34] W. Slob, Dose-response modeling of continuous endpoints, Toxicol. Sci. 66 (2002) $298-312$. https://doi.org/10.1093/toxsci/66.2.298.

[35] R Core Team, R: A language and environment for statistical computing, (2019). https://www.r-project.org/.

[36] Applied Biosystems, User Bulletin \#2 ABI PRISM 7700 Sequence Detection System, (2001) 1-36. http://tools.thermofisher.com/content/sfs/manuals/cms_040980.pdf.

[37] D.A.M. van Dartel, J.L.A. Pennings, F.J. van Schooten, A.H. Piersma, Transcriptomics-based identification of developmental toxicants through their interference with cardiomyocyte differentiation of embryonic stem cells, Toxicol. Appl. Pharmacol. 243 (2010) 420-428. https://doi.org/10.1016/j.taap.2009.12.021.

[38] D.A.M. van Dartel, J.L.A. Pennings, P.J.M. Hendriksen, F.J. van Schooten, A.H. Piersma, Early gene expression changes during embryonic stem cell differentiation into cardiomyocytes and their modulation by monobutyl phthalate, Reprod. Toxicol. 27 (2009) 93-102. https://doi.org/10.1016/j.reprotox.2008.12.009.

[39] C.M. Pfeiffer, M.R. Sternberg, Z. Fazili, D.A. Lacher, M. Zhang, C.L. Johnson, H.C. Hamner, R.L. Bailey, J.I. Rader, S. Yamini, R.J. Berry, E.A. Yetley, Folate status and concentrations of serum folate forms in the US population: National Health and Nutrition Examination Survey 2011 -2, Br. J. Nutr. 113 (2015) 1965-1977. https://doi.org/DOI: 10.1017/S0007114515001142.

[40] S.J. Mentch, M. Mehrmohamadi, L. Huang, X. Liu, D. Gupta, D. Mattocks, P. Gómez Padilla, G. Ables, M.M. Bamman, A.E. Thalacker-Mercer, S.N. Nichenametla, J.W. Locasale, Histone Methylation Dynamics and Gene Regulation Occur through the Sensing of One-Carbon Metabolism, Cell Metab. 22 (2015) 861-873. https://doi.org/https://doi.org/10.1016/j.cmet.2015.08.024.

[41] E. Kur, N. Mecklenburg, R.M. Cabrera, T.E. Willnow, A. Hammes, LRP2 mediates folate uptake in the developing neural tube, J. Cell Sci. 127 (2014) 2261. https://doi.org/10.1242/jcs.140145

[42] F. Stam, Y.M. Smulders, C. van Guldener, C. Jakobs, C.D.A. Stehouwer, K. de Meer, Folic acid treatment increases homocysteine remethylation and methionine transmethylation in healthy subjects, Clin. Sci. 108 (2005) 449-456. https://doi.org/10.1042/CS20040295.

[43] C.N.D. Coelho, J.A. Weber, N.W. Klein, W.G. Daniels, T.A. Hoagland, Whole rat embryos require methionine for neural tube closure when cultured on cow serum, J. Nutr. 119 (1989) 1716-1725. https://doi.org/10.1093/jn/119.11.1716. 
[44] E. Anckaert, S. Romero, T. Adriaenssens, J. Smitz, Effects of Low Methyl Donor Levels in Culture Medium During Mouse Follicle Culture on Oocyte Imprinting Establishment1, Biol. Reprod. 83 (2010) 377-386. https://doi.org/10.1095/biolreprod.109.082164.

[45] T. Lindl, Zell- und Gewebekultur, 2nd edition, Spektrum Akademischer, Heidelberg, Germany, 2002.

[46] Y. Shao, B. Tan, J. Shi, Q. Zhou, Methotrexate induces astrocyte apoptosis by disrupting folate metabolism in the mouse juvenile central nervous system, Toxicol. Lett. 301 (2019) 146-156. https://doi.org/10.1016/j.toxlet.2018.11.016.

[47] J.B. Gregorios, D. Soucy, Effects of methotrexate on astrocytes in primary culture: light and electron microscopic studies, Brain Res. 516 (1990) 20-30. https://doi.org/10.1016/0006-8993(90)90892-F.

[48] J.H. Bruce-Gregoros, D.M. Soucy, M.G. Chen, M.D. Norenberg, Effect of methotrexate on glial fibrillary acidic protein content of astrocytes in primary culture, J. Neuropathol. Exp. Neurol. 50 (1991) 118-125. https://doi.org/10.1097/00005072-199103000-00003

[49] V. Sahakyan, E. Pozzo, R. Duelen, J. Deprest, M. Sampaolesi, Methotrexate and Valproic Acid Affect Early Neurogenesis of Human Amniotic Fluid Stem Cells from Myelomeningocele, Stem Cells Int. 2017 (2017) 6101609. https://doi.org/10.1155/2017/6101609.

[50] S.C. Hyoun, S.G. Običan, A.R. Scialli, Teratogen update: Methotrexate, Birth Defects Res. Part A - Clin. Mol. Teratol. 94 (2012) 187-207. https://doi.org/10.1002/bdra.23003.

[51] V. Sahakyan, R. Duelen, W.L. Tam, S.J. Roberts, H. Grosemans, P. Berckmans, G. Ceccarelli, G. Pelizzo, V. Broccoli, J. Deprest, F.P. Luyten, C.M. Verfaillie, M. Sampaolesi, Folic Acid Exposure Rescues Spina Bifida Aperta Phenotypes in Human Induced Pluripotent Stem Cell Model, Sci. Rep. 8 (2018) 2942 https://doi.org/10.1038/s41598-018-21103-8.

[52] F.R. Melo, R.B. Bressan, B. Costa-Silva, A.G. Trentin, Effects of Folic Acid and Homocysteine on the Morphogenesis of Mouse Cephalic Neural Crest Cells In Vitro, Cell. Mol. Neurobiol. 37 (2017) 371-376. https://doi.org/10.1007/s10571-016-0383-y.

[53] J. Legler, C.E. Van Den Brink, A. Brouwer, A.J. Murk, P.T. Van Der Saag, A.D. Vethaak, B. Van Der Burg, Development of a stably transfected estrogen receptor-mediated luciferase reporter gene assay in the human T47D breast cancer cell line, Toxicol. Sci. 48 (1999) 55-66. https://doi.org/10.1093/toxsci/48.1.55.

[54] P. Marx-Stoelting, E. Adriaens, H.-J. Ahr, S. Bremer, B. Garthoff, H.-P. Gelbke, A. Piersma, C. Pellizzer, U. Reuter, V. Rogiers, B. Schenk, S. Schwengberg, A. Seiler, H. Spielmann, M. Steemans, D.B. Stedman, P. Vanparys, J.A. Vericat, M. Verwei, F. van der Water, M. Weimer, M. Schwarz, A review of the implementation of the embryonic stem cell test (EST). The report and recommendations of an ECVAM/ReProTect Workshop., Altern. Lab. Anim. 37 (2009) 313-328. https://doi.org/10.1177/026119290903700314.

[55] P.T. Theunissen, A.H. Piersma, Innovative approaches in the embryonic stem cell test (EST), Front. Biosci. 17 (2012) 1965-1975. https://doi.org/10.2741/4032.

[56] N. Kleinstreuer, D. Dix, M. Rountree, N. Baker, N. Sipes, D. Reif, R. Spencer, T. Knudsen, A Computational Model Predicting Disruption of Blood Vessel Development, PLoS Comput. Biol. 9 (2013) e1002996. https://doi.org/10.1371/journal.pcbi.1002996.

[57] M.C.K. Leung, M.S. Hutson, A.W. Seifert, R.M. Spencer, T.B. Knudsen, Computational modeling and simulation of genital tubercle development, Reprod. Toxicol. $64 \quad$ (2016) 151-161. https://doi.org/10.1016/j.reprotox.2016.05.005.

[58] M.S. Hutson, M.C.K. Leung, N.C. Baker, R.M. Spencer, T.B. Knudsen, Computational Model of Secondary Palate Fusion and Disruption, Chem. Res. Toxicol. $30 \quad$ (2017) 965-979. https://doi.org/10.1021/acs.chemrestox.6b00350. 



\section{CHAPTER 4}

\section{OXYGEN TENSION INFLUENCES EMBRYONIC STEM CELLS IN CULTURE AND HAS LINEAGE SPECIFIC EFFECTS ON NEURAL AND CARDIAC DIFFERENTIATION}

Regina H. Mennen, Victoria C. de Leeuw, Aldert H. Piersma

Centre for Health Protection, National Institute for Public Health and the Environment, Bilthoven, the Netherlands

Institute for Risk Assessment Sciences, Utrecht University, Utrecht, the Netherlands

Differentiation, 2020 July, 115: 1-10

DOI: 10.1016/j.diff.2020.07.001 



\section{Abstract}

The importance of oxygen tension in in vitro cultures and its effect on embryonic stem cell (ESC) differentiation has been widely acknowledged. Research has mainly focussed on ESC maintenance or on one line of differentiation and only few studies have examined the potential relation between oxygen tension during ESC maintenance and differentiation. In this study we investigated the influence of atmospheric (20\%) versus physiologic (5\%) oxygen tension in ESC cultures and their differentiation within the cardiac and neural embryonic stem cell tests (ESTC, ESTn). Oxygen tension was set at $5 \%$ or $20 \%$ and cells were kept in these conditions from starting up cell culture until use for differentiation. Under these oxygen tensions, ESC culture showed no differences in proliferation and gene and protein expression levels. Differentiation was either performed in the same or in the alternative oxygen tension compared to ESC culture creating four different experimental conditions. Cardiac differentiation in $5 \%$ instead of $20 \%$ oxygen resulted in reduced development of spontaneously beating cardiomyocytes and lower expression of cardiac markers Nkx2.5, Myh6 and MF20 (myosin), regardless whether ESC had been cultured in $5 \%$ or $20 \%$ oxygen tension. As compared to the control (20\% oxygen during stem cell maintenance and differentiation), neural differentiation in 5\% oxygen with ESC cultured in $20 \%$ oxygen led to more cardiac and neural crest cell differentiation. The opposite experimental condition of neural differentiation in 20\% oxygen with ESC cultured in 5\% oxygen resulted in more glial differentiation. ESC that were maintained and differentiated in $5 \%$ oxygen showed an increase in neural crest and oligodendrocytes as compared to $20 \%$ oxygen during stem cell maintenance and differentiation. This study showed major effects on ESC differentiation in ESTc and ESTn of oxygen tension, which is an important variable to consider when designing and developing a stem cell-based in vitro system. 


\section{Introduction}

The importance of oxygen tension on cell behaviour cannot be underestimated, as has been officially acknowledged in 2019 by awarding the Nobel Prize in Physiology or Medicine to William Kaelin Jr, Sir Peter Ratcliffe and Gregg Semenza for their important work in this field [13]. This also holds true for embryonic development in which oxygen levels range between around $2.4 \%$ between week 7 and 11 and $8 \%$ after week 11 [4,5], which is considerably lower than atmospheric pressure. These oxygen levels vary since $\mathrm{O}_{2}$ gradients play a crucial and dynamic role in directing differentiation into specific organs $[6,7]$. The importance of oxygen tension is also widely acknowledged in therapeutic applications in which cells are cultured in vitro to be placed back in vivo. For example, oocytes that are grown for in vitro fertilisation survive better in $5 \%$ than $20 \%$ oxygen tension [8]. For regenerative medicine purposes, purer, healthier and better differentiated cells are obtained by culturing under low oxygen tension $[9,10]$.

Also in the field of cell culturing for basic research there is an increasing appreciation that oxygen tension, amongst other basic culture conditions, can have a substantial effect on the outcome of experiments [11]. In the case of stem cell differentiation, there is a link between the oxygen sensing system and the activation of specific differentiation pathways [12-14]. In vitro cell cultures are typically kept at $5 \% \mathrm{CO}_{2}$ and $18.5 \%$ oxygen [15], but a wealth of literature has shown that maintaining stem cells under lower oxygen tension is beneficial for keeping cells in an undifferentiated state $[9,14,16,17]$ and increases survival and expansion $[14,18]$. The oxygen level can influence the differentiation track of stem cells, when stimulating them into one of the three germ lines and their derivatives. For example, differentiation to endoderm and subsequently lung cells may benefit from short $1 \%$ oxygen treatment [19] and hepatic cells from $5 \%$ oxygen [20]. Differentiation of mouse ESC to mesodermal cells and subsequently spontaneous beating cardiomyocytes, conversely, is inhibited by low oxygen tension [21-24]. Interestingly, short treatment with lower oxygen levels may actually increase cardiomyocyte differentiation $[25,26]$, in combination with other mechanistic agitation or addition of extracellular matrix proteins $[27,28]$. Lower oxygen tension in ectodermal and subsequently neural differentiation increases the differentiation of neural precursors [29] and starting from these precursors, lower oxygen tension leads to enhanced multi-lineage competence [18,30-32].

Most studies examined a single differentiation path for one cell type or tissue. Additionally, much research has focused on either the influence on stem cell maintenance or differentiation, while the state of the stem cells may affect the differentiation potential and direction [33,34]. In this study, the oxygen tension and its effects on the differentiation tracks of murine ESC used in the cardiac and neural embryonic stem cell test (ESTc and ESTn respectively) were investigated. ESTC and ESTn are typically used in developmental toxicology to study the effects of chemicals on early differentiation towards the cardiac or neural lineage [35]. Previous studies have shown the presence of cardiac and neural crest cells in ESTc [36] and neural, neural crest cells and glial cells in ESTn [37,38], which may be modulated when differentiated under different oxygen tensions. Therefore, the aim of this study was to investigate the influence of physiological levels of oxygen (i.e. 5\%) on ESC and their subsequent differentiation into the cardiac or neural lineage in terms of their differentiation potential and cell type expression. 


\section{Material and methods}

\section{Maintenance}

Murine ESC (ES-D3, ATCC, Manassas, VA, USA) were maintained on polystyrene $35 \mathrm{~mm}$ plates (Corning, New York, NY, USA) according to the protocol described by Spielmann et al. [39]. For the experiment, cells were kept under either physiological $\left(5 \% \mathrm{O}_{2}\right)$ or atmospheric $\left(20 \% \mathrm{O}_{2}\right)$ oxygen levels. Cells were passaged every two to three days. The culture medium (CM) consisted of Dulbecco's modified Eagle's medium (DMEM; Gibco, Waltham, MA, USA) supplemented with 20\% foetal bovine serum (FBS; Greiner Bio-One, Kremsmünster, Austria), 200 mM L-glutamine (Gibco), 1\% nonessential amino acids (Gibco), 1\% $5000 \mathrm{lU} / \mathrm{ml}$ Penicillin/5000 $\mu \mathrm{g} / \mathrm{ml}$ Streptomycin (Gibco), and 0.1 mM $\beta$-mercaptoethanol (Sigma-Aldrich, Zwijndrecht, The Netherlands). CM was supplemented with 1000 units/ml murine leukemia inhibitory factor (mLIF; Millipore, Burlington, MA, USA) to maintain pluripotency of the cells. These cells were used for all subsequent experiments between passages 7 and 18 .

\section{Cardiac Differentiation}

Cardiac differentiation of the ES-D3 cells was performed according to a protocol previously described $[39,40]$. Embryoid Bodies (EBs) were formed in hanging drops from a cell suspension of $15 \times 10^{4} \mathrm{cell} / \mathrm{s} / \mathrm{ml}$ in $\mathrm{CM}$ without $\mathrm{mLIF}$ that was put on ice and further diluted to a suspension of $3.75 \times 10^{4}$ cells $/ \mathrm{ml}$. Hanging drops were made by placing $5620 \mu \mathrm{l}$ droplets of the cell suspension to the inside of the lid of a 100/20 mm CELLSTARß cell culture dish (Greiner Bio-One). The culture dish contained $5 \mathrm{ml}$ of ice-cold phosphate buffered saline (PBS; $\mathrm{Ca}^{2+}, \mathrm{Mg}^{2+}$ free; Gibco). The hanging drops were incubated for 3 days at $37^{\circ} \mathrm{C}, 5 \% \mathrm{CO}_{2}$ at one of the four oxygen conditions. At differentiation day 3, EBs were transferred in $5 \mathrm{ml} \mathrm{CM}$ to a $60 \mathrm{~mm}$ bacterial petri dish (Greiner Bio-One). After two days of incubation at differentiation day 5, EBs were transferred to a 24-wells plate (TPP, Trasadingen, Switzerland) containing one EB per well in $1 \mathrm{ml}$ CM. Each plate contained 24 replicates per condition and two plates per condition were tested. After five days of incubation, at differentiation day 10, the EBs were scored for presence or absence of beating cardiomyocytes. The fractions of beating EBs were calculated per 24-wells plate.

\section{Neural Differentiation of embryonic stem cells}

Neural differentiation was performed as described in Theunissen et al. [41]. Differentiation days 0 to 3 were the same as described for the cardiac differentiation of ESC, with the exception of adding $0.5 \mu \mathrm{M}$ retinoic acid to $\mathrm{CM}$ on day 3 to induce neural differentiation. On differentiation day 5, EBs were transferred to $35 \mathrm{~mm}$ laminin-coated dishes (Sigma-Aldrich) in low serum medium (LS) supplemented with $2.5 \mu \mathrm{g} / \mathrm{ml}$ fibronectin. LS contained $10 \%$ FBS instead of $20 \%$ as in CM. On day 6, medium was exchanged for insulin-transferrin-selenite (ITS) medium supplemented with $2.5 \mu \mathrm{g} / \mathrm{ml}$ fibronectin. ITS was comprised of DMEM/Ham's nutrient mixture F12 medium (DMEM/F12; Gibco), 0.2 g/ml bovine insulin (Sigma-Aldrich), 1\% $5000 \mathrm{lU} / \mathrm{ml}$ Penicillin/5000 $\mathrm{mg} / \mathrm{ml}$ Streptomycin (Gibco), $200 \mathrm{mM} \mathrm{L-glutamine} \mathrm{(Gibco),} 30 \mathrm{nM}$ sodium selenite (Sigma-Aldrich), and $50 \mu \mathrm{g} / \mathrm{ml}$ apo-transferrin (Sigma-Aldrich). On day 7, EBs were dissociated 
and placed on dishes coated with poly-L-ornithine- (Sigma-Aldrich) and laminin containing N2 medium. This medium was comprised of DMEM/F12 medium (Gibco) supplemented with 0.2 $\mu \mathrm{g} / \mathrm{ml}$ bovine insulin (Sigma-Aldrich), 1\% $5000 \mathrm{lU} / \mathrm{ml}$ Penicillin/5000 $\mathrm{mg} / \mathrm{ml}$ Streptomycin (Gibco), $30 \mathrm{nM}$ sodium selenite (Sigma-Aldrich), $20 \mathrm{nM}$ progesterone (Sigma-Aldrich), $100 \mu \mathrm{M}$ putrescine (Sigma-Aldrich), and $50 \mu \mathrm{g} / \mathrm{ml}$ apo-transferrin (Sigma-Aldrich). Later on day 7 , medium was replaced by $\mathrm{N} 2$ medium supplemented with $10 \mathrm{ng} / \mathrm{ml}$ basic fibroblast growth factor (Miltenyi Biotech, Bergisch Gladbach, Germany). EBs received one more medium refreshment on day 10 before the end of the test at day 13 .

\section{Oxygen tension conditions}

Cells were all maintained in a humidified atmosphere at $37^{\circ} \mathrm{C}$ and $5 \% \mathrm{CO}_{2}$. Oxygen tension was set at $5 \%$ or $20 \%$ and cells were kept in these conditions from starting up the culture until use for differentiation. Differentiation was either performed in the same or in the alternative oxygen tension as outlined in Table 1, creating four different experimental conditions.

Table 7. experimental set-up

\begin{tabular}{lll}
\hline Stem cell culture oxygen levels & Differentiation oxygen levels & Resulting experimental conditions \\
\hline $20 \%$ & $20 \%$ & $20-20 \%$ \\
$20 \%$ & $5 \%$ & $20-5 \%$ \\
$5 \%$ & $20 \%$ & $5-20 \%$ \\
$5 \%$ & $5 \%$ & $5-5 \%$ \\
\hline
\end{tabular}

\section{RNA isolation and quantitative real-time PCR}

Following the cell differentiation protocol, sample collection was done for all four oxygen conditions for the ESC cultures, and for cardiac and neural differentiation protocols at the end-point of differentiation. Eight samples per condition were fixed in QIAzol (Qiagen, Hilden, Germany) and kept at $-80^{\circ} \mathrm{C}$ until further use. The QIAshredder (Qiagen) was used to homogenise samples and the RNeasy mini kit (Qiagen) and protocol were used to perform the RNA isolation. Concentration of RNA was determined with the NanoDrop ${ }^{\text {TM }} 1000$ spectrophotometer (Nanodrop Technologies, Wilmington, DE, USA) and purity was defined using the 2100 BioAnalyzer (Aligent Technologies, Amstelveen, the Netherlands). RNA samples were subsequently synthesised into cDNA using the cDNA archive kit, which contains random hexamer primers (Applied Biosystems, Foster City, CA, USA). Gene quantification was performed on a 7500 Fast Real-Time PCR system (Applied Biosystems) with the following thermal cycling conditions: $95^{\circ} \mathrm{C}$ for $20 \mathrm{~s}$, followed by 40 cycles of $95^{\circ} \mathrm{C}$ for $3 \mathrm{~s}$ and $60^{\circ} \mathrm{C}$ for $30 \mathrm{~s}$. Table 2 lists the primers (Applied Biosystems) used in all experiments.

\section{Immunocytochemistry}

Samples were rinsed with pre-warmed PBS and fixed for 30 minutes with $4 \%$ formaldehyde (Electron Microscopy Sciences, Hatfield, PA, USA). The fixed cells were stored at $4^{\circ} \mathrm{C}$ up to one week until starting the staining protocol. Samples were rinsed three times for 5 minutes with 
Table 2. primers used for qPCR procedure

\begin{tabular}{|c|c|c|c|}
\hline Gene name & $\begin{array}{l}\text { Abbrevia- } \\
\text { tion }\end{array}$ & Marker for & $\begin{array}{l}\text { Assay ID/primer } \\
\text { sequence }\end{array}$ \\
\hline POU domain, class 5, transcription factor 1 & Pou5f1 & Stem cell & Mm03053917_g1 \\
\hline Cadherin 1 & Cdh1 & $\begin{array}{l}\text { Adhesion molecule present before } \\
\text { neural tube closure }\end{array}$ & Mm01247357_m1 \\
\hline Bone morphogenetic protein 4 & Bmp4 & Mesoderm & Mm00432087_m1 \\
\hline \multirow[t]{2}{*}{ Nestin } & Nes & Ectoderm / Neural progenitor & Mm00450205_m1 \\
\hline & Gata4 & Endoderm & Mm00484689_m1 \\
\hline Msh homeobox 2 & Msx2 & Early neural crest marker & Mm00442992_m1 \\
\hline Snail family zinc finger 2 & Snai2 & Epithelial-Mesenchymal Transition & Mm00441531_m1 \\
\hline NK2 transcription factor related, locus 5 & $N k \times 2.5$ & Early cardiomyocyte & Mm01309813_s1 \\
\hline $\begin{array}{l}\text { myosin, heavy polypeptide } 6 \text {, cardiac muscle, } \\
\text { alpha }\end{array}$ & Myh6 & Cardiomyocyte & Mm00440359_m1 \\
\hline Tubulin, beta 3 class III & Tubb3 & Neuron & Mm00727586_s1 \\
\hline Glial fibrillary acidic protein & Gfap & Early astrocyte & Mm01253033_m1 \\
\hline Myelin basic protein & $M b p$ & Oligodendrocyte & Mm01266402_m1 \\
\hline Glucuronidase beta & Gusb & Housekeeping gene & Mm01197698_m1 \\
\hline Hypoxanthine phosphoribosyltransferase 1 & Hprt1 & Housekeeping gene & Mm03024075_m1 \\
\hline RNA Polymerase II Subunit A & Polr2a & Housekeeping gene & Mm00839502_m1 \\
\hline
\end{tabular}

PBS before and after storage and in between each step of the process. The cells were permeabilised using $0.2 \%$ Triton X-100 in PBS (0.5\% for TWIST; T9284, Sigma-Aldrich) for 5 minutes. Then, samples were blocked with blocking buffer for 1 hour (1\% bovine serum albumin (BSA, Sigma-Aldrich), 0.5\% Tween-20 (Sigma-Aldrich) in PBS (TWIST staining: 5\% BSA in PBS)). Rinsed cells were incubated with the primary antibodies in dilution buffer $(0.5 \%$ BSA, $0.5 \%$ Tween-20 in PBS; TWIST staining: 5\% normal goat serum (NGS, G9023, Sigma-Aldrich), 0.5\% Tween-20 in PBS), which are listed in Table 3, overnight at $4^{\circ} \mathrm{C}$. After incubation, samples were incubated with secondary antibodies (Table 2) for 1 hour in dilution buffer. Nuclei were stained with $1 \mu \mathrm{g} / \mathrm{ml}$ DAPI (Sigma-Aldrich), which was put on the samples for 10 minutes. Cells were rinsed once with PBS for 10 minutes and then covered with SlowFade ${ }^{\circledR}$ Diamond Antifade Mountant (Thermo Fisher) and a cover glass. Imaging of the samples was performed on a Leica DMi8 microscope system (Wetzlar, Germany) using a 10x objective and further processed in Fiji/ImageJ (version 1.51n; [42]).

\section{Data visualisation and statistics}

Relative gene expression differences were calculated using the 2- $\Delta \Delta \mathrm{Ct}$ method [43], which were all normalised against an average of the housekeeping genes Hypoxanthine phosphoribosyltransferase 7 (Hprt7), Glucuronidase beta (Gusb), and RNA Polymerase // Subunit A (Polr2a). Statistical analysis was performed using a one-way ANOVA test and post-hoc Sidak's multiple comparisons test using GraphPad Prism 8.1.2 (www.graphpad.com). The cell map was constructed in GraphPad Prism and the heatmap was made with R software [44]. For the heatmaps, each condition was plotted against the average of all conditions of a specific culture (stem cells, ESTc or ESTn). 
Table 3. antibodies used for immunocytochemistry

\begin{tabular}{|c|c|c|c|c|c|}
\hline Antibody & $\begin{array}{l}\text { Abbrevi- } \\
\text { ation }\end{array}$ & Marker for & $\begin{array}{l}\text { Product } \\
\text { number }\end{array}$ & Company & Dilution \\
\hline $\begin{array}{l}\text { Mouse POU domain, class 5, tran- } \\
\text { scription factor } 1\end{array}$ & OCT4 & Stem cell & sc-5279 & Santa Cruz & $1: 500$ \\
\hline $\begin{array}{l}\text { Mouse anti Stage Specific Embry- } \\
\text { onic Antigen-1 }\end{array}$ & SSEA1 & Stem cell & bs-1702R & Millipore & $1: 250$ \\
\hline Rat anti E-cadherin & ECAD & $\begin{array}{l}\text { Adhesion molecule present } \\
\text { before neural tube closure }\end{array}$ & 13-1900 & Invitrogen & $1: 1000$ \\
\hline Rabbit anti Paired homeobox 6 & PAX6 & Neural progenitor & 901301 & Biolegend & $1: 1000$ \\
\hline Mouse anti Nestin & NES & Neural progenitor & N5413 & Sigma-Aldrich & $1: 200$ \\
\hline $\begin{array}{l}\text { Mouse anti Activating Enhancer- } \\
\text { Binding Protein 2-Alpha }\end{array}$ & $\mathrm{AP} 2 \alpha$ & Neural crest cell & sc-12726 & Santa Cruz & $1: 400$ \\
\hline $\begin{array}{l}\text { Mouse anti Twist Family BHLH Tran- } \\
\text { scription Factor } 2\end{array}$ & TWIST & $\begin{array}{l}\text { Epithelial to mesenchymal } \\
\text { transition }\end{array}$ & ab50887 & Abcam & $1: 400$ \\
\hline Mouse anti Myosin Heavy Chain & MF20 & Cardiomyocyte & MAB4470 & Sigma-Aldrich & $1: 100$ \\
\hline Rabbit anti $\beta$-Tubulin III & TUBB3 & Neuron & $\mathrm{T} 2200$ & Sigma-Aldrich & 1:1000 \\
\hline Rat anti Glial fibrillary acidic protein & GFAP & Early astrocyte & $13-0300$ & Invitrogen & $1: 800$ \\
\hline \multicolumn{6}{|l|}{ Secondary antibodies } \\
\hline Goat anti rabbit Alexa 488 & & & A11034 & Invitrogen & $1: 1000$ \\
\hline Goat anti rabbit Alexa 555 & & & A21429 & Invitrogen & 1:1000 \\
\hline Goat anti mouse Alexa 555 & & & A21424 & Invitrogen & $1: 1000$ \\
\hline Goat anti rat Alexa 555 & & & A21434 & Invitrogen & $1: 500$ \\
\hline Goat anti mouse Alexa 647 & & & A21236 & Invitrogen & $1: 500$ \\
\hline
\end{tabular}

\section{Results}

\section{Oxygen tension had no effect on ESC viability, density and pluripotency}

ESC cultures were tested for effects on cell growth under 20\% and $5 \%$ oxygen tension and no differences in the levels of cell viability (Fig. 1A) or cell density (Fig. 1B) were found. The pluripotency markers SSEA-1, ECAD, and OCT4 showed clear protein expression in both groups without obvious differences (Fig. 1C). The early neural differentiation markers NES and PAX6 were present in a small number of cells in both groups (Fig. 1C). These results indicated that oxygen tension affected neither cell growth nor the level of pluripotency.

\section{Oxygen tension had generally no effect on gene expression level during ESC culture}

Various genes related to pluripotency or to one of the primordial germ layers were analysed for their expression levels (Fig. 2A). Gene expression alterations were summarised in a heatmap (Fig. 2B), which showed small differences with trends towards relatively higher expression of stem cell markers (Pou5f7, Cdh7) under 5\% oxygen tension. Markers for early differentiation stages (Nes, Gata4, Msx2, Snai2, Nkx2.5) showed a tendency towards lower expression levels in the $5 \%$ oxygen group. Later markers for differentiation (Myh6, Tubb3, Mbp) tended to be up- 
regulated in the $5 \%$ oxygen group. However, these limited tendencies were not significantly different between the two groups (Fig. 2C), except for a statistically significant difference in Nkx2.5 expression levels.
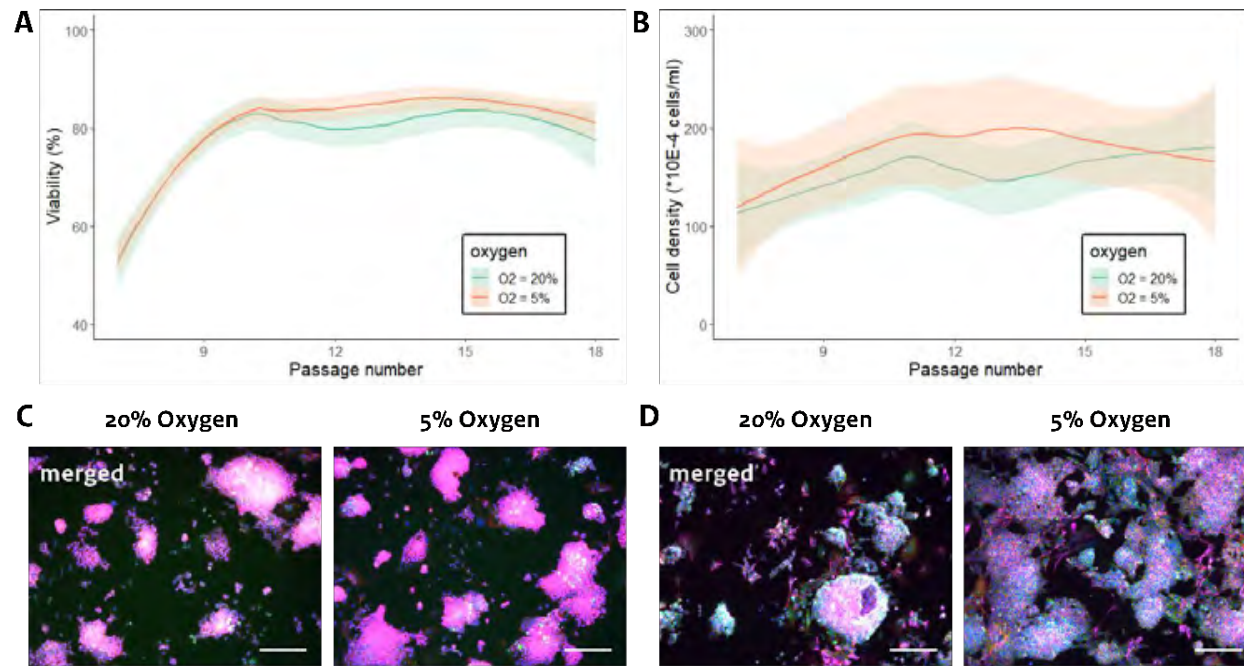

D $\quad 20 \%$ Oxygen
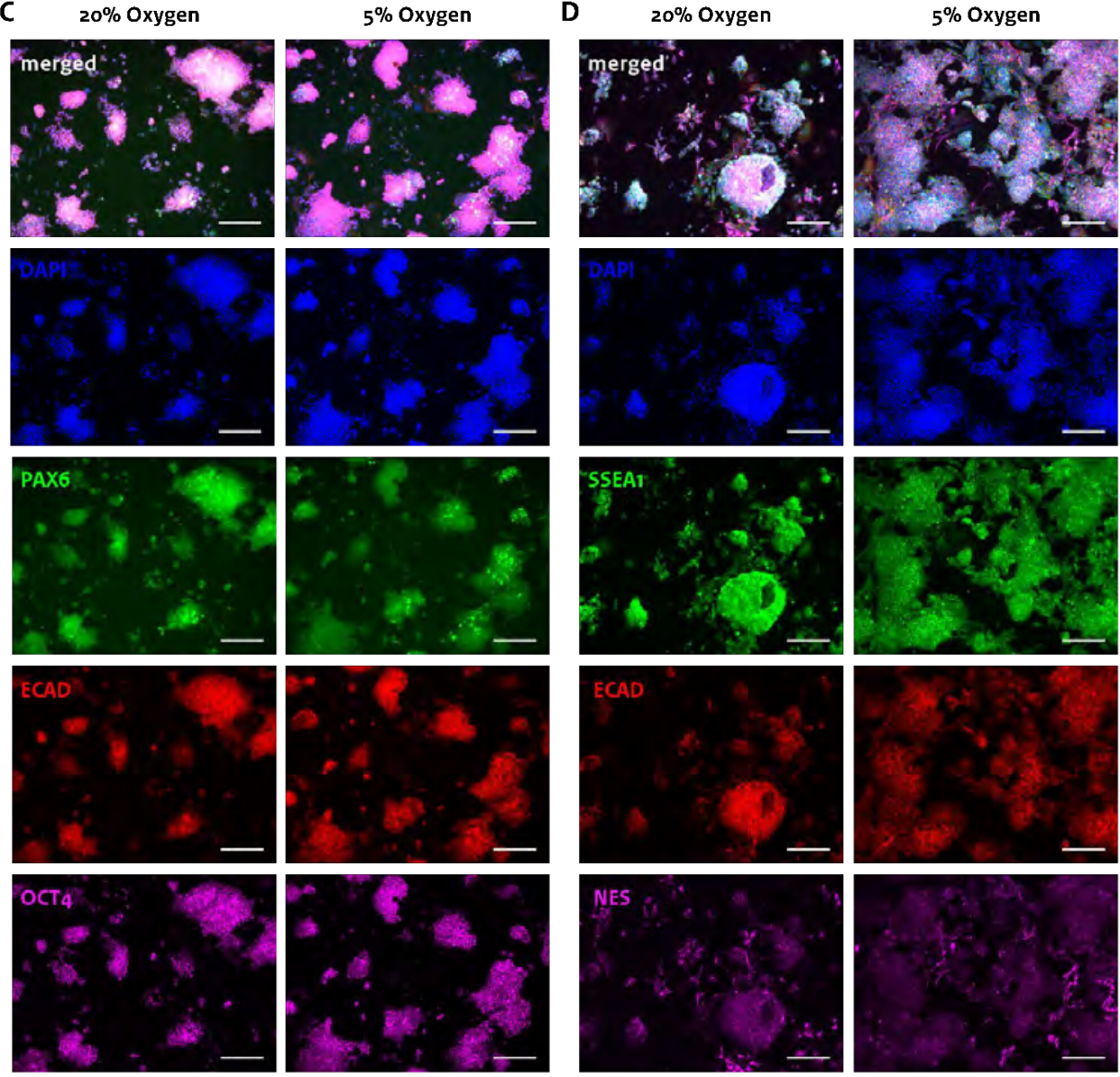

Figure 1. Characteristics of ESC grown under 5 or $20 \%$ oxygen tension. (A) Viability (as percentage of total number of cells) and (B) density (x $70^{4} \mathrm{cell} / \mathrm{s} / \mathrm{ml}$ ) of viable ESC from passage 7 to 78 . (C) Expression of stem cell markers ECAD and OCT4, and differentiation marker PAX6. (D) Expression of stem cell markers SSEA 1 and ECAD and differentiation marker NES. Scale bar: $200 \mu \mathrm{m}$. 
A

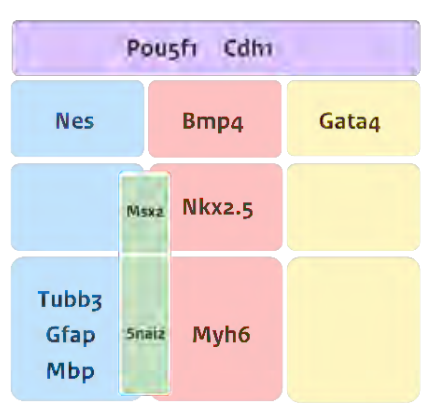

C
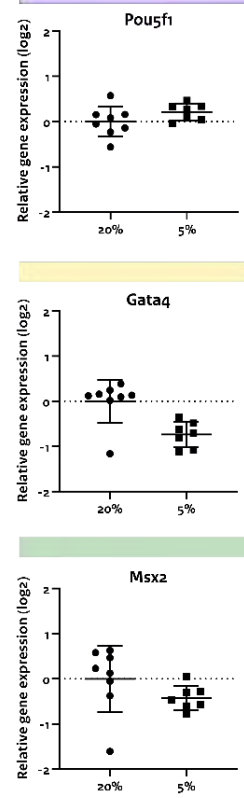
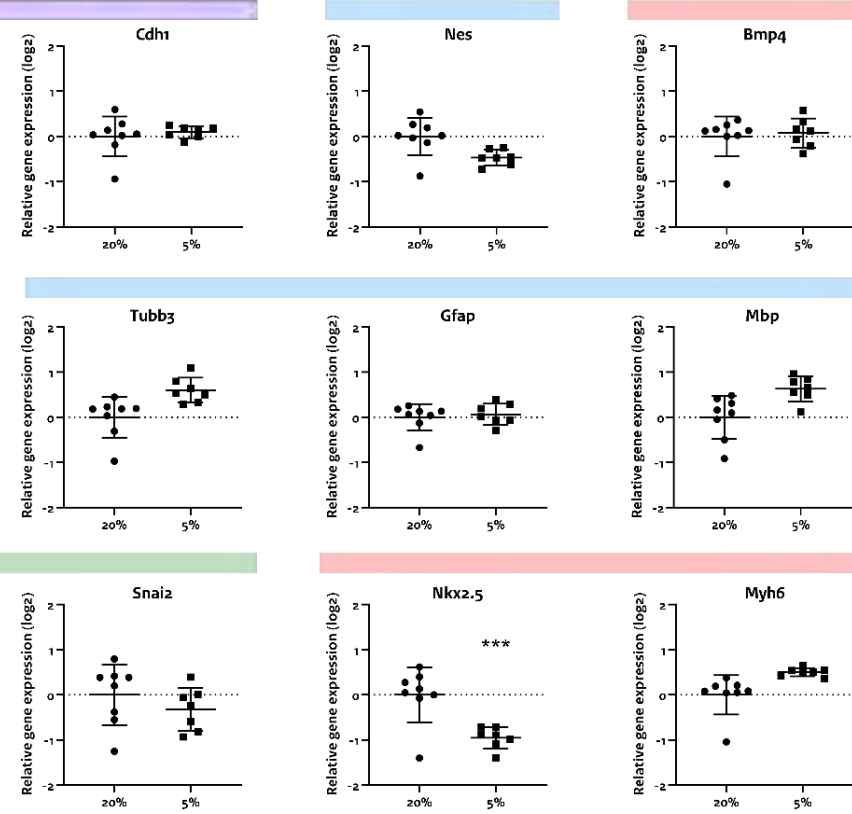

Figure 2. Gene expression alterations in ESC grown under 5 or $20 \%$ oxygen tension. (A) Overview of tested cell type markers in time related to pluripotency (purple), ectoderm (blue), mesoderm (red), endoderm (yellow) and neural crest (green). (B) Heatmap of relative gene expression (log2) of cell type markers in ESC after culturing in 20\% or 5\% oxygen tension. (C) Relative gene expression (log2) per cell type marker. Significance levels: *** p<0.001.

\section{Oxygen tension affected morphology and cell differentiation in ESTC and ESTn}

Next, the differentiation behaviour of stem cells into the cardiac and neural lineage was investigated. To this end, ESC grown under $5 \%$ and $20 \%$ oxygen tensions were differentiated in the same or in the other oxygen level, which resulted in four conditions as described in Table 1. 
The development of beating cardiomyocytes was severely impaired when differentiated under $5 \%$ as compared to $20 \%$ oxygen (Fig. 3). Also ESTc morphology was clearly affected when differentiated under 5\% oxygen, resulting in necrosis in the 5-5\% condition and evident balloonlike structures in 20-5\% (Fig. 4A), both accompanied by a change in colour of the medium to yellow (data not shown). Immunostainings showed neural crest cell marker AP2a expression under all oxygen conditions (Fig. 4B). The myosin marker MF20 was clearly expressed when ESTc was differentiated under $20 \%$ oxygen tension at day 7 (data not shown) and 10 (Fig. 4C), but not when the oxygen tension was $5 \%$.

ESTn also showed a particular morphological change per condition. Compared to the control (20-20\%), ESC that were grown under $20 \%$ and differentiated under $5 \%$ oxygen showed an increase in cells migrating out of EB, while an opposite oxygen regimen (5-20\%) resulted in less migration (Fig. 4D). The 5-5\% and $20-20 \%$ conditions showed comparable morphology. Staining of ESTn at day 7 revealed that the cells migrating out of the EB especially under $5 \%$ oxygen during differentiation were strongly positive for neural progenitor marker NES (Fig. 4E). Neural marker TUBB3 was present in all conditions (Fig. 4E), as well as AP2a (data not shown). By day 13, cell type markers for neural progenitors (PAX6), late neural crest cells (TWIST) and astrocytes (GFAP, data not shown) were present in all conditions (Fig. 4F).

In short, while oxygen tension did not seem to have effects of gene- or protein expression of cell type markers in ESC, differentiating these into cardiac or neural cells influenced morphology as well as the expression of certain cell types. For ESTc, regardless of the oxygen tension in the stem cell culture, 5\% oxygen tension in the differentiation phase did not support the development of cardiac function and cardiac cells. ESTn morphology was mostly affected by a change from one oxygen level to the other, without obvious effects on cell type loss or gain, except for more NES ${ }^{+}$staining in the $20-5 \%$ condition.

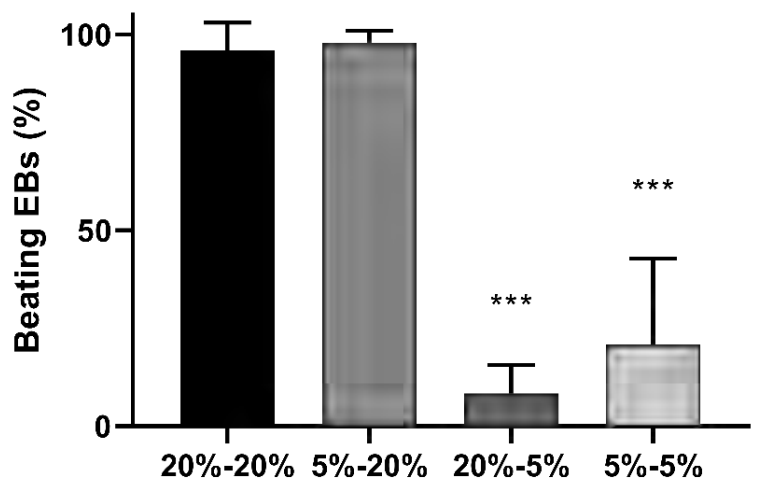

Figure 3. Differentiation of beating cardiomyocytes at different oxygen tensions. Groups were compared to the 20$20 \%$ contro/ group using a one-way ANOVA with Sidak's multiple comparisons test $* * * p<0.001$. 


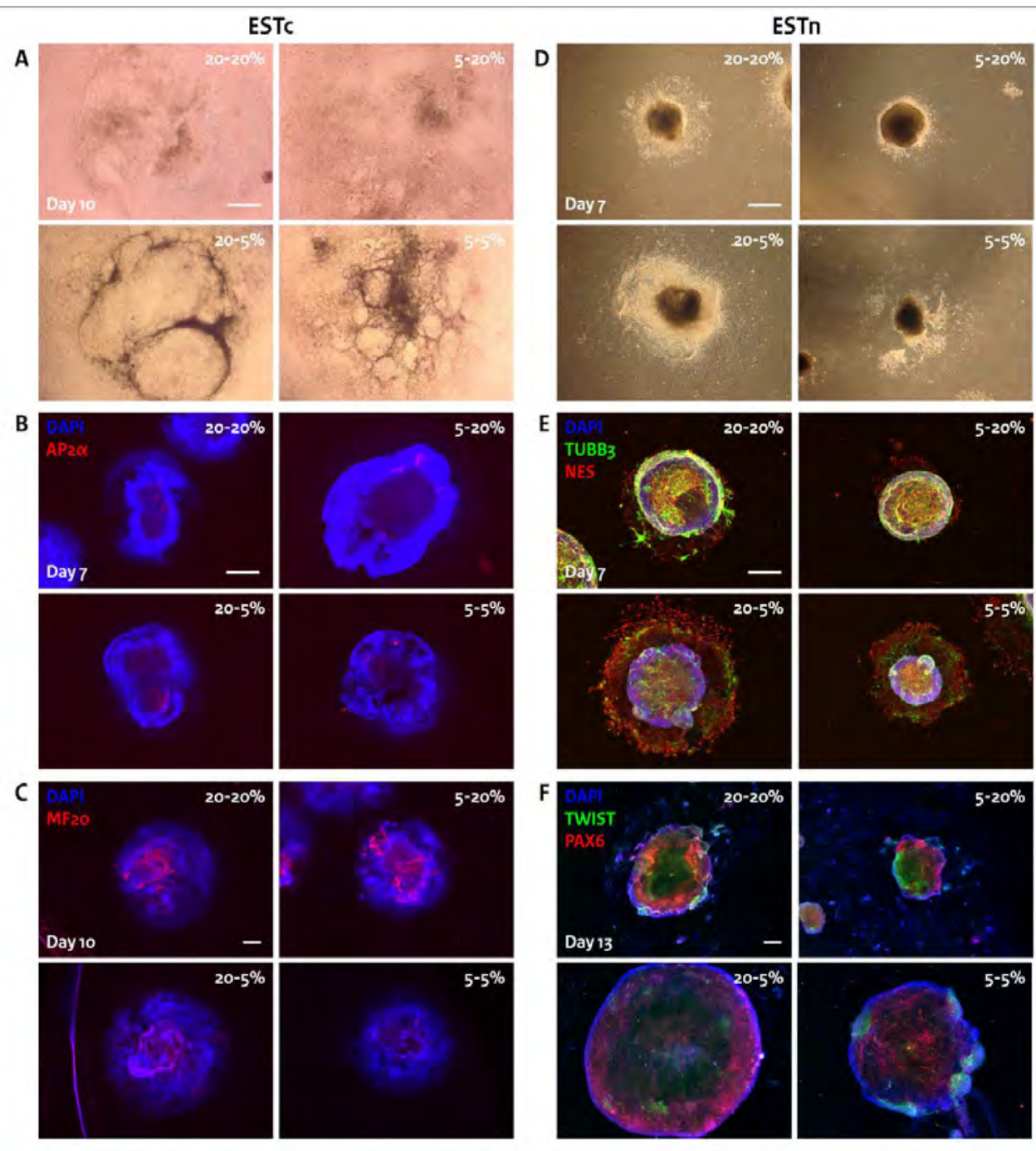

Figure 4. Morphology and cell type changes in ESTC and ESTn under different oxygen tension conditions. (A) Brightfield images of ESTC day 10. (B,C) Immunocytochemistry on ESTC showed expression of (B) early neural crest cell marker AP2a at day 7 and (C) cardiac marker MF20 at day 10. (D) Bright-field images of ESTn day 7. (B,C) Immunocytochemistry on ESTn showed expression of (E) neural marker TUBB3 and neural progenitor marker NES at day 7, and (C) neural progenitor marker PAX6, astrocyte marker GFAP and late neural crest cell marker TWIST at day 73. Scale bar: $500 \mu \mathrm{m}$.

\section{Oxygen tension altered cell type gene expression in distinct ways in ESTc and ESTn}

To quantitatively assess the changes in cell differentiation induced by differences in oxygen tension, qPCR was performed on ESTc and ESTn for each of the conditions with the same cell type markers as outlined in Fig. 2A. 
Hierarchical clustering of the four oxygen conditions in ESTc based on their gene expression profiles revealed that, consistent with above results, oxygen tension in the differentiation phase was the dominant determinant for gene expression changes (Fig. 5A). Most clear was the decreased appearance of the cardiac marker Myh6 upon differentiation under 5\% as compared to $20 \%$ oxygen. Moreover, $5 \%$ rather than $20 \%$ oxygen tension in the differentiation phase caused higher expression of endoderm marker Gata4 and mesoderm marker Bmp4, and lower expression of stem cell marker Oct4, ectoderm marker Nes and cardiac differentiation marker Nkx2.5 expression (Fig. 5C). Neural crest markers (Msx2, Snai2) and glial markers (Gfap, Mbp) were not affected. Interestingly, Tubb3 expression was less expressed in all conditions relative to $20-20 \%$ oxygen. The lower expression of cardiac markers in combination with the increased expression of endoderm marker Gata4 and mesoderm marker Bmp4 suggest that ESTc was pushed off its cardiac differentiation track under $5 \%$ versus $20 \%$ oxygen tension.

Hierarchical clustering of gene expression in ESTn showed that the $20-5 \%$ condition deviated most from the $20-20 \%$ condition, showing higher expression of non-neural markers and lower expression of neural differentiation related markers (Fig. 5B). As with ESTc, oxygen tension during the differentiation phase determined most of the gene expression differences (Fig. 5C). Expression of Cdh7, Bmp4, Gata4 and Snai2 were higher, and Tubb3 and Gfap expression were lower in 5\% oxygen tension relative to ESTn differentiation under 20\% oxygen tension. Switching stem cells from 20\% to 5\% oxygen additionally enhanced Msx2and Myh6 expression, which together suggested higher expression of non-ectodermal (Cdh7, Bmp4, Gata4), cardiac (Myh6) and neural crest differentiation (Msx2, Snai2) and lower expression of neural (Tubb3) and astroglial differentiation (Gfap) compared to the 20-20\% control group. Nes and Mbp expression were not affected. The 5-5\% group did show higher expression of Nes and Mbp and lower expression of $N k \times 2.5$, but no change in Msx2 and Myh6 expression relative to the $20-20 \%$ group, indicating a more complex phenotype compared to the 20-5\% condition. Expression patterns indicated higher expression of non-ectodermal differentiation (Cdh7, Bmp4, Gata4) in the 20$5 \%$ versus the $20-20 \%$ group, but additionally a lower expression of early cardiac differentiation and upregulation of early neural differentiation. Neural ( Tubb3) and astroglial (Gfap) differentiation were less expressed in the presence of higher expression of oligodendrocyte (Mbp) and neural crest cell (Snai2) differentiation. ESC that were grown in 5\% and differentiated in $20 \%$ oxygen resembled the $20-20 \%$ group most, although with some notable differences. Compared to the $20-20 \%$ condition, the $5-20 \%$ condition showed higher expression of glial (Gfapand Mbp) and early cardiac differentiation (Nkx2.5), together with less late cardiac (Myh6) and neural crest cell (Msx2, Snai2) expression.

In short, oxygen tension in the differentiation phases of ESTc as well as ESTn seemed to be most important for determining differences in cell differentiation. Cardiac and stem cell marker expression in ESTC was lower under $5 \%$ versus $20 \%$ oxygen tension and endoderm marker expression was higher, regardless of whether stem cells were grown under $5 \%$ or $20 \%$ oxygen. Other cell types were not influenced by the different oxygen tension regimens, except for neural differentiation (Tubb3). In ESTn a different distribution of cell types seemed to be generated, depending on both the ESC culture and differentiation oxygen tensions. A switch from 20 to $5 \%$ oxygen seemed to lead ESTn off the neural differentiation track to more cardiac and neural crest cell differentiation. Conversely, changing from 5 to $20 \%$ oxygen resulted in more glial differentiation and less neural crest cell differentiation. The 5-5\% group presented a more mixed 
phenotype, but within the ectodermal lineage there was more neural crest and oligodendrocytes and less astroglial and neural differentiation.

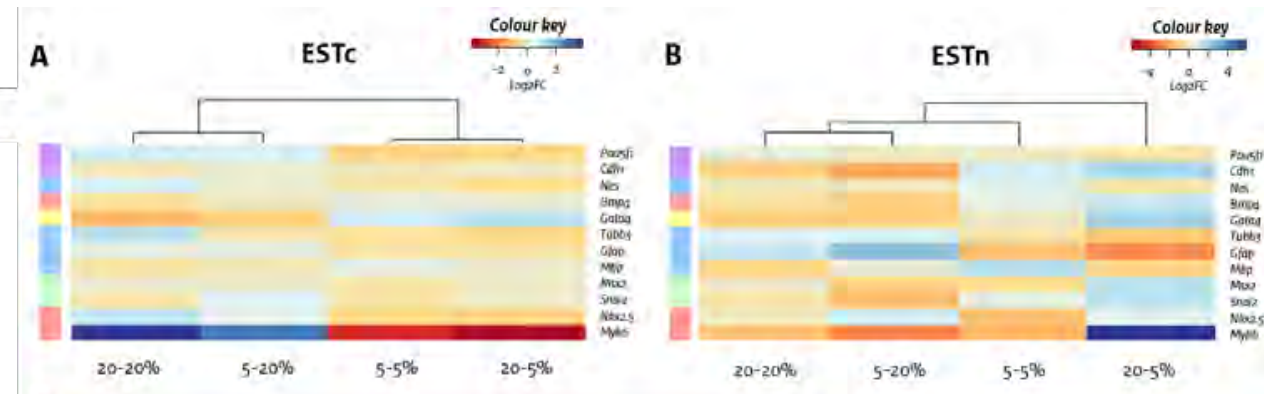

C
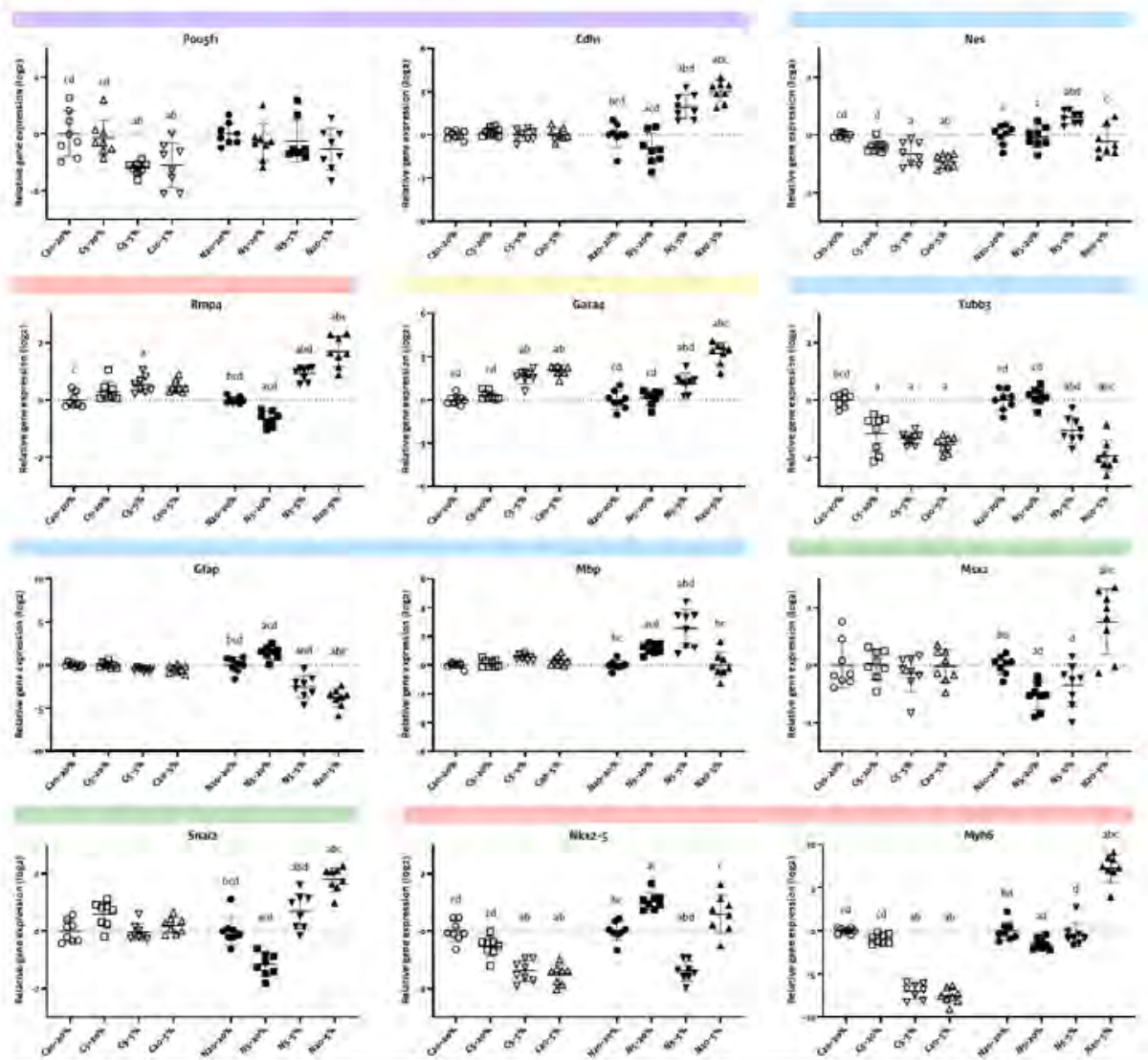

Figure 5. Gene expression of cell type markers in ESTC and ESTn under 5\% and 20\% oxygen tensions. (A,B) Heatmap summarising gene expression changes in (A) ESTC (day 10) and (B) ESTn (day 13), relative to the average expression per gene, per model. (C) Same data as shown in (A) and (B), plotted per gene, relative to the control condition (2020\%), per model. Significant difference from a condition is indicated as: a (different from 20-20\%), b (5-20\%), c (5$5 \%), d(20-5 \%)$. Significance levels are summarised in supplementary data 7. 


\section{Discussion}

This study revealed the importance of oxygen tension within the ESTc and ESTn lineage differentiation. There were generally no significant differences between oxygen tensions when studying effects on ESC maintenance cultures alone. Differentiation into cardiomyocytes profited from $20 \%$ oxygen tension irrespective of the oxygen tension during ESC culture. An oxygen tension of $5 \%$ seemed to stimulate differentiation into endodermal differentiation rather than mesoderm-derived cardiomyocytes. Neural differentiation depended both on oxygen tension during stem cell maintenance and during differentiation, which resulted in different distributions of cell types. Relative to continuously culturing in $20 \%$ oxygen, the $20-5 \%$ oxygen condition seemed to push cells off the neural differentiation track, the $5-20 \%$ condition stimulated the cells more towards glial differentiation, and 5-5\% showed a more mixed phenotype.

Although there were generally no statistically significant differences in cell density, viability and cell type markers between the oxygen tensions during ESC maintenance, cell density tended to be higher under 5\% oxygen tension (Fig. 1B). Increased cell density has been reported before under low oxygen tensions with ESC of different origin $[16,18]$. However, studies that used murine ESC reported decreased cell density under $2 \%$ oxygen tension compared to $20 \%[33,45]$. This inconsistency may indicate that $2 \%$ oxygen tension is potentially too low for optimal ESC culture. This study showed trends of increased expression in stem cell markers, decreased expression in early differentiation markers, and increased expression in late differentiation markers (Fig. 2B). Although these trends were not statistically significant, the tendencies were in line with results showing that low oxygen tension resulted in inhibition of differentiation $[9,14,16,17]$.

Differentiation into the cardiac lineage was lower under 5\% versus $20 \%$ oxygen tension as shown by affected morphology including stimulation of necrosis (Fig. 4A), reduced beating cardiomyocytes (Fig. 3), and decreased gene expression of the early and late cardiomyocyte markers Nkx2.5 and Myh6 (Fig. 5C). Also 5\% oxygen tension resulted in a colour change of the medium to yellow indicating nutrient deprivation related to enhanced cell proliferation at the expense of differentiation into beating cardiomyocytes. However, cell death and reduced development of beating cardiomyocytes were previously reported in both mESCs and murine induced pluripotent stem cells (iPSCs), which were differentiated to cardiomyocytes at $2 \%$ oxygen or $5 \%$ oxygen tension, respectively [22,23]. Interestingly, iPSCs derived from mouse dermal fibroblasts could not be differentiated into beating cardiomyocytes at $2 \%$ oxygen levels, while showing an upregulation of cardiac markers like Myh6 [26]. This contradiction was also seen in bone marrow derived mesenchymal stem cells from rats in which $0.5 \%$ oxygen tension did not result in functional cardiomyocyte differentiation, while cardiomyocyte gene and protein markers were upregulated [46]. Human ESCs showed more beating cardiomyocytes, a higher cardiac yield and a higher beating frequency when differentiated in 5\% oxygen levels compared to $21 \%$ oxygen levels [27]. These contradictory results could be explained by e.g. methodological differences, species differences or nutrient depletion. For example, Wang et al. [26] performed only part of the differentiation in $2 \%$ oxygen and Choi et al. [46] measured gene expression already after 12 hours. This illustrates again the impact of the employed experimental procedure [9]. The decrease of the cardiomyocyte markers Nkx2.5 and Myh6 and concurring upregulation of endoderm marker Gata4 suggests a stimulation of the endodermal lineage rather than the mesoderm-related cardiomyocyte route. One explanation may be that cardiomyocyte 
functioning needs sufficient oxygen for contraction and, in case of low oxygen, this severely impairs their development resulting in a differentiation in an alternative direction.

Differentiation into the neural lineage was, in contrast to cardiac differentiation, dependent of the oxygen tension during ESC culture and resulted in different morphologies for the different conditions. Compared to the control (20-20\%), ESC that were grown in 20\% and differentiated in $5 \%$ oxygen showed an increase in cells migrating out of $E B$, while an opposite oxygen regimen (5-20\%) resulted in less migration (Fig. 4D). This enlarged corona suggests an increase in proliferation, which is in line with previous findings showing increased proliferation of neural precursors in hypoxic conditions [47].

The changes in oxygen tension from ESC culture to differentiation not only affected morphology but also gene and protein expression levels, and indicated deviations from the differentiation tracks in all conditions compared to the $20-20 \%$ control condition. Rather than almost complete absence of a cell type as seen in ESTc it seemed that in ESTn the ratios between cell types were changed by different oxygen tensions. The oxygen tension level has an active role during the differentiation process [18]. Differentiation in 5\% oxygen tension resulted in less neural (Tubb3) differentiation, which is consistent with previous research [16]. Another study has shown that $2 \%$ oxygen tension may enhance neural differentiation and that changing oxygen tension between 0 and $10 \%$ can result in different proportions of cell types $[29,48]$. The change of 20 to $5 \%$ oxygen tension in our study resulted in an upregulated expression of mesoderm and endoderm lineage markers instead of ectoderm lineage markers. Additionally, neural crest markers were upregulated during this condition, in line with previous research $[18,49]$. Chen et al. [18] showed that a high oxygen tension of $20 \%$ led to a loss in cell density and a loss in astrocytes and oligodendrocytes compared to a low oxygen tension (2-5\%) and Xie et al. [34] showed that $2 \%$ oxygen tension enhanced glial differentiation compared to $20 \%$ oxygen tension. This is partly consistent with results in our study only for oligodendrocyte (Mbp) but not astrocyte (Gfap) expression. Again, this may be due to methodological differences and more research is needed to further delineate the effects of oxygen tension with regard to conditions like timing, duration and cell source (e.g. ESCs versus neural progenitor cells)[9].

As mentioned before, oxygen tension and switching between high and low oxygen levels seems to have an active role in lineage commitment, which indicates a potential underlying mechanism. One of the potential mechanisms is through Hypoxia-Inducible Factor (HIF), which is activated upon a low oxygen tension and regulates differentiation [12,13,34,50-52]. A low oxygen tension can also regulate differentiation epigenetically in terms of myosin expression by inhibiting the oxygen sensitive KDM6A, which is a H3K27 histone demethylase [53]. These possible underlying mechanisms for oxygen dependent differentiation into specific lineages in the EST, should be investigated in future research.

In summary, this study exemplified the importance of oxygen tension for both maintenance and differentiation of murine ESCs into the neural and cardiac lineage. To our knowledge, this is the first study that assessed in parallel the effect of oxygen tension on two differentiation pathways from the same stem cell source. By separating the stem cell maintenance phase and the differentiation phase, we could distinguish specifically between the effects on either phase, and the relation between the two. ESTc and ESTn were affected in a different manner, which stresses that controlling oxygen tension during stem cell culture as well as during differentiation can greatly influence the differentiation path and can offer a valuable tool in optimising the 
desired in vitro system. Controlling oxygen tension can thus offer a valuable tool in optimizing ESC maintenance and differentiation, towards more realistic cell models for the purpose of for example personalised medicine, disease modelling, basic research and toxicology.

\section{Acknowledgements}

Victoria de Leeuw was funded by the Dutch NGO Stichting Proefdiervrij and the Dutch Ministry of Agriculture, Nature and Food Quality. Gina Mennen was supported by a CIFRE PhD grant, which was co-supervised by Nina Hallmark, Marc Pallardy, Remi Bars, and Helen Tinwell. Aldert Piersma was funded by the Dutch Ministry of Health, Welfare and Sports. We would like to thank Anne Kienhuis for a critical review of the manuscript. 


\section{References}

[1] M. Ivan, K. Kondo, H. Yang, W. Kim, J. Valiando, M. Ohh, A. Salic, J.M. Asara, W.S. Lane, J. Kaelin, HIFa targeted for VHL-mediated destruction by proline hydroxylation: Implications for 02 sensing, Science (80-. ). 292 (2001) 464-468. https://doi.org/10.1126/science.1059817.

[2] P.H. Maxwell, M.S. Wlesener, G.W. Chang, S.C. Clifford, E.C. Vaux, M.E. Cockman, C.C. Wykoff, C.W. Pugh, E.R. Maher, P.J. Ratcliffe, The tumour suppressor protein VHL targets hypoxia-inducible factors for oxygendependent proteolysis, Nature. 399 (1999) 271-275. https://doi.org/10.1038/20459.

[3] G.L. Wang, B.H. Jiang, E.A. Rue, G.L. Semenza, Hypoxia-inducible factor 1 is a basic-helix-loop-helix-PAS heterodimer regulated by cellular $\mathrm{O} 2$ tension, Proc. Natl. Acad. Sci. U. S. A. 92 (1995) 5510-5514. https://doi.org/10.1073/pnas.92.12.5510.

[4] E. Jauniaux, A. Watson, O. Ozturk, D. Quick, G. Burton, In-vivo measurement of intrauterine gases and acidbase values early in human pregnancy, Hum. Reprod. 14 (1999) 2901-2904. https://doi.org/10.1093/humrep/14.11.2901.

[5] F. Rodesh, P. Simon, C. Donner, E. Jauniaux, Oxygen Measurements in Endometrial and Trophoblastic Tissues During Early Pregnancy, Obstet. Gynecol. 80 (1992) 235-238.

[6] D.M. Panchision, The role of oxygen in regulating neural stem cells in development and disease, J. Cell. Physiol. 220 (2009) 562-568. https://doi.org/10.1002/jcp.21812.

[7] S. Burr, A. Caldwell, M. Chong, M. Beretta, S. Metcalf, M. Hancock, M. Arno, S. Balu, V.L. Kropf, R.K. Mistry, A.M. Shah, G.E. Mann, A.C. Brewer, Oxygen gradients can determine epigenetic asymmetry and cellular differentiation viadifferential regulation of Tet activity in embryonic stem cells, Nucleic Acids Res. 46 (2018) 1210-1226. https://doi.org/10.1093/nar/gkx1197.

[8] E. Kasterstein, D. Strassburger, D. Komarovsky, O. Bern, A. Komsky, A. Raziel, S. Friedler, R. Ron-El, The effect of two distinct levels of oxygen concentration on embryo development in a sibling oocyte study, J. Assist. Reprod. Genet. 30 (2013) 1073-1079. https://doi.org/10.1007/s10815-013-0032-z.

[9] C. Mas-Bargues, J. Sanz-Ros, A. Román-Domínguez, M. Inglés, L. Gimeno-Mallench, M. El Alami, J. ViñaAlmunia, J. Gambini, J. Viña, C. Borrás, Relevance of oxygen concentration in stem cell culture for regenerative medicine, Int. J. Mol. Sci. 20 (2019). https://doi.org/10.3390/ijms20051195.

[10] S.R.L. Stacpoole, B. Bilican, D.J. Webber, A. Luzhynskaya, X.L. He, A. Compston, R. Karadottir, R.J.M. Franklin, S. Chandran, Derivation of neural precursor cells from human ES cells at $3 \% 02$ is efficient, enhances survival and presents no barrier to regional specification and functional differentiation, Cell Death Differ. 18 (2011) 1016-1023. https://doi.org/10.1038/cdd.2010.171.

[11] T. Ast, V.K. Mootha, Oxygen and mammalian cell culture: are we repeating the experiment of Dr. Ox?, Nat. Metab. 1 (2019) 858-860. https://doi.org/10.1038/s42255-019-0105-0.

[12] A. Mohyeldin, T. Garzón-Muvdi, A. Quiñones-Hinojosa, Oxygen in Stem Cell Biology: A Critical Component of the Stem Cell Niche, Cell Stem Cell. 7 (2010) 150-161. https://doi.org/10.1016/J.STEM.2010.07.007.

[13] Y. Zhao, M. Matsuo-Takasaki, I. Tsuboi, K. Kimura, G.T. a. Salazar, T. Yamashita, O. Ohneda, Dual functions of hypoxia-inducible factor 1 alpha for the commitment of mouse embryonic stem cells toward a neural lineage, Stem Cells Dev. 23 (2014) 2143-2155. https://doi.org/10.1089/scd.2013.0278.

[14] C.E. Forristal, K.L. Wright, N.A. Hanley, R.O.C. Oreffo, F.D. Houghton, Hypoxia inducible factors regulate pluripotency and proliferation in human embryonic stem cells cultured at reduced oxygen tensions, Reproduction. 139 (2010) 85-97. https://doi.org/10.1530/REP-09-0300.

[15] T.P. Keeley, G.E. Mann, Defining Physiological Normoxia for Improved Translation of Cell Physiology to Animal Models and Humans, Physiol Rev. 99 (2019) 161-234. https://doi.org/10.1152/physrev.00041.2017.-The.

[16] M. V. Gustafsson, X. Zheng, T. Pereira, K. Gradin, S. Jin, J. Lundkvist, J.L. Ruas, L. Poellinger, U. Lendahl, M. Bondesson, Hypoxia requires Notch signaling to maintain the undifferentiated cell state, Dev. Cell. 9 (2005) 617-628. https://doi.org/10.1016/j.devcel.2005.09.010.

[17] T. Ezashi, P. Das, R.M. Roberts, Low $\mathrm{O} 2$ tensions and the prevention of differentiation of hES cells, Proc. Natl. Acad. Sci. U. S. A. 102 (2005) 4783-4788. https://doi.org/10.1073/pnas.0501283102.

[18] H.-L. Chen, F. Pistollato, D.J. Hoeppner, H.-T. Ni, R.D.G. McKay, D.M. Panchision, Oxygen Tension Regulates Survival and Fate of Mouse Central Nervous System Precursors at Multiple Levels, Stem Cells. 25 (2007) 2291-2301. https://doi.org/10.1634/stemcells.2006-0609.

[19] P. Pimton, S. Lecht, C.T. Stabler, G. Johannes, E.S. Schulman, P.I. Lelkes, Hypoxia enhances differentiation of mouse embryonic stem cells into definitive endoderm and distal lung cells, Stem Cells Dev. 24 (2015) 663676. https://doi.org/10.1089/scd.2014.0343

[20] T. Katsuda, T. Teratani, M.M. Chowdhury, T. Ochiya, Y. Sakai, Hypoxia efficiently induces differentiation of mouse embryonic stem cells into endodermal and hepatic progenitor cells, Biochem. Eng. J. 74 (2013) 95101. https://doi.org/10.1016/j.bej.2013.02.012.

[21] T.L. Medley, M. Furtado, N.T. Lam, R. Idrizi, D. Williams, P.J. Verma, M. Costa, D.M. Kaye, Effect of Oxygen on Cardiac Differentiation in Mouse iPS Cells: Role of Hypoxia Inducible Factor-1 and Wnt/Beta-Catenin Signaling, PLoS One. 8 (2013) e80280. https://doi.org/10.1371/journal.pone.0080280. 
[22] M.A. Ramírez, E. Pericuesta, M. Yáñez-Mó, A. Palasz, A. Gutiérrez-Adán, Effect of long-term culture of mouse embryonic stem cells under low oxygen concentration as well as on glycosaminoglycan hyaluronan on cell proliferation and differentiation, Cell Prolif. 44 (2011) 75-85. https://doi.org/10.1111/j.13652184.2010.00732.x.

[23] A. Brodarac, T. Saric, B. Oberwallner, S. Mahmoodzadeh, K. Neef, J. Albrecht, K. Burkert, M. Oliverio, F. Nguemo, Y.H. Choi, W.F. Neiss, I. Morano, J. Hescheler, C. Stamm, Susceptibility of murine induced pluripotent stem cell-derived cardiomyocytes to hypoxia and nutrient deprivation, Stem Cell Res. Ther. 6 (2015) 83. https://doi.org/10.1186/s13287-015-0057-6.

[24] C.Y. Huang, S.Y. Chen, R.H. Fu, Y.C. Huang, S.Y. Chen, W.C. Shyu, S.Z. Lin, S.P. Liu, Differentiation of embryonic stem cells into cardiomyocytes used to investigate the cardioprotective effect of salvianolic acid B through BNIP3 involved pathway, Cell Transplant. 24 (2015) 561-571. https://doi.org/10.3727/096368915X686995.

[25] C. Bianco, C. Cotten, E. Lonardo, L. Strizzi, C. Baraty, M. Mancino, M. Gonzales, K. Watanabe, T. Nagaoka, C. Berry, A.E. Arai, G. Minchiotti, D.S. Salomon, Cripto-1 is required for hypoxia to induce cardiac differentiation of mouse embryonic stem cells, Am. J. Pathol. $175 \quad$ (2009) 2146-2158. https://doi.org/10.2353/ajpath.2009.090218.

[26] Y. Wang, S. Shi, H. Liu, L. Meng, Hypoxia enhances direct reprogramming of mouse fibroblasts to cardiomyocyte-like cells, Cell. Reprogram. 18 (2016) 1-7. https://doi.org/10.1089/cell.2015.0051.

[27] R.E. Horton, D.T. Auguste, Synergistic effects of hypoxia and extracellular matrix cues in cardiomyogenesis, Biomaterials. 33 (2012) 6313-6319. https://doi.org/10.1016/j.biomaterials.2012.05.063.

[28] C. Correia, M. Serra, N. Espinha, M. Sousa, C. Brito, K. Burkert, Y. Zheng, J. Hescheler, M.J.T. Carrondo, T. Šarić, P.M. Alves, Combining Hypoxia and Bioreactor Hydrodynamics Boosts Induced Pluripotent Stem Cell Differentiation Towards Cardiomyocytes, Stem Cell Rev. Reports. 10 (2014) 786-801. https://doi.org/10.1007/s12015-014-9533-0.

[29] P. Mondragon-Teran, G.J. Lye, F.S. Veraitch, Lowering oxygen tension enhances the differentiation of mouse embryonic stem cells into neuronal cells, Biotechnol. Prog. 25 (2009) 1480-1488. https://doi.org/10.1002/btpr.248.

[30] F. Pistollato, H.L. Chen, P.H. Schwartz, G. Basso, D.M. Panchision, Oxygen tension controls the expansion of human CNS precursors and the generation of astrocytes and oligodendrocytes, Mol. Cell. Neurosci. 35 (2007) 424-435. https://doi.org/10.1016/j.mcn.2007.04.003.

[31] A. Storch, G. Paul, M. Csete, B.O. Boehm, P.M. Carvey, A. Kupsch, J. Schwarz, Long-term proliferation and dopaminergic differentiation of human mesencephalic neural precursor cells, Exp. Neurol. 170 (2001) $317-$ 325. https://doi.org/10.1006/exnr.2001.7706.

[32] D. Lukmanto, V.C. Khanh, S. Shirota, T. Kato, M.M. Takasaki, O. Ohneda, Dynamic Changes of Mouse Embryonic Stem Cell-Derived Neural Stem Cells under in Vitro Prolonged Culture and Hypoxic Conditions, Stem Cells Dev. 28 (2019) 1434-1450. https://doi.org/10.1089/scd.2019.0101.

[33] K. Fynes, R. Tostoes, L. Ruban, B. Weil, C. Mason, F.S. Veraitch, The Differential Effects of $2 \%$ Oxygen Preconditioning on the Subsequent Differentiation of Mouse and Human Pluripotent Stem Cells, Stem Cells Dev. 23 (2014) 1910-1922. https://doi.org/10.1089/scd.2013.0504.

[34] Y. Xie, J. Zhang, Y. Lin, X. Gaeta, X. Meng, D.R.R. Wisidagama, J. Cinkornpumin, C.M. Koehler, C.S. Malone, M.A. Teitell, W.E. Lowry, Defining the role of oxygen tension in human neural progenitor fate, Stem Cell Reports. 3 (2014) 743-757. https://doi.org/10.1016/j.stemcr.2014.09.021.

[35] P.T. Theunissen, J.L.A. Pennings, D.A.M. van Dartel, J.F. Robinson, J.C.S. Kleinjans, A.H. Piersma Complementary detection of embryotoxic properties of substances in the neural and cardiac embryonic stem cell tests, Toxicol. Sci. 132 (2013) 118-130. https://doi.org/10.1093/toxsci/kfs333.

[36] R.H.G. Mennen, J.L.A.J. Pennings, A.H.A. Piersma, Neural crest related gene transcript regulation by valproic acid analogues in the cardiac embryonic stem cell test, Reprod. Toxicol. 90 (2019) 44-52. https://doi.org/10.1016/j.reprotox.2019.08.013.

[37] V.C. de Leeuw, E.V.S. Hessel, A.H. Piersma, Look-alikes may not act alike: Gene expression regulation and cell-type-specific responses of three valproic acid analogues in the neural embryonic stem cell test (ESTn), Toxicol. Lett. 303 (2019) 28-37. https://doi.org/10.1016/j.toxlet.2018.12.005.

[38] P.T. Theunissen, S.H.W. Schulpen, D.A.M. van Dartel, S.A.B. Hermsen, F.J. van Schooten, A.H. Piersma, An abbreviated protocol for multilineage neural differentiation of murine embryonic stem cells and its perturbation by methyl mercury, Reprod. Toxicol. $29 \quad$ (2010) 383-392. https://doi.org/10.1016/j.reprotox.2010.04.003.

[39] H. Spielmann, I. Pohl, B. Döring, M. Liebsch, F. Moldenhauer, The Embryonic Stem cell Test, an in vitro embryotoxicity test using two permanent mouse cell lines: 3T3 fibroblasts and embryonic stem cells, Vitr. Mol. Toxicol. J. Basic Appl. Res. 10 (1997) 119-127. https://doi.org/10.1007/978-3-7091-7500-2_69.

[40] E. Genschow, H. Spielmann, G. Scholz, I. Pohl, A. Seiler, N. Clemann, S. Bremer, K. Becker, Validation of the embryonic stem cell test in the international ECVAM validation study on three in vitro embryotoxicity tests, in: ATLA Altern. to Lab. Anim., 2004: pp. 209-244.

[41] P.T. Theunissen, J.L.A. Pennings, J.F. Robinson, S.M.H. Claessen, J.C.S. Kleinjans, A.H. Piersma, Timeresponse evaluation by transcriptomics of methylmercury effects on neural differentiation of murine embryonic stem cells, Toxicol. Sci. 122 (2011) 437-447. https://doi.org/10.1093/toxsci/kfr134 
[42] J. Schindelin, I. Arganda-Carreras, E. Frise, V. Kaynig, M. Longair, T. Pietzsch, S. Preibisch, C. Rueden, S. Saalfeld, B. Schmid, J.Y. Tinevez, D.J. White, V. Hartenstein, K. Eliceiri, P. Tomancak, A. Cardona, Fiji: An opensource platform for biological-image analysis, Nat. Methods. 9 (2012) 676-682. https://doi.org/10.1038/nmeth.2019.

[43] Applied Biosystems, User Bulletin \#2 ABI PRISM 7700 Sequence Detection System, (2001) 1-36 http://tools.thermofisher.com/content/sfs/manuals/cms_040980.pdf.

[44] R Core Team, R: A language and environment for statistical computing, (2019). https://www.r-project.org/.

[45] T.G. Fernandes, M.M. Diogo, A. Fernandes-Platzgummer, C.L. da Silva, J.M.S. Cabral, Different stages of pluripotency determine distinct patterns of proliferation, metabolism, and lineage commitment of embryonic stem cells under hypoxia, Stem Cell Res. 5 (2010) 76-89. https://doi.org/10.1016/j.scr.2010.04.003.

[46] J.W. Choi, K.E. Kim, C.Y. Lee, J. Lee, H.H. Seo, K.H. Lim, E. Choi, S. Lim, S. Lee, S.W. Kim, K.C. Hwang, Alterations in Cardiomyocyte Differentiation-Related Proteins in Rat Mesenchymal Stem Cells Exposed to Hypoxia, Cell. Physiol. Biochem. 39 (2016) 1595-1607. https://doi.org/10.1159/000447861.

[47] L. Studer, M. Csete, S.H. Lee, N. Kabbani, J. Walikonis, B. Wold, R. McKay, Enhanced proliferation, survival, and dopaminergic differentiation of CNS precursors in lowered oxygen, J. Neurosci. 20 (2000) 7377-7383. https://doi.org/10.1523/JNEUROSCI.20-19-07377.2000.

[48] P. Mondragon-Teran, J.Z. Baboo, C. Mason, G.J. Lye, F.S. Veraitch, The full spectrum of physiological oxygen tensions and step-changes in oxygen tension affects the neural differentiation of mouse embryonic stem cells, Biotechnol. Prog. 27 (2011) 1700-1708. https://doi.org/10.1002/btpr.675.

[49] S.J. Morrison, M. Csete, A.K. Groves, W. Melega, B. Wold, D.J. Anderson, Culture in Reduced Levels of Oxygen Promotes Clonogenic Sympathoadrenal Differentiation by Isolated Neural Crest Stem Cells, J. Neurosci. 20 (2000) 7370. https://doi.org/10.1523/JNEUROSCI.20-19-07370.2000.

[50] B. Ateghang, M. Wartenberg, M. Gassmann, H. Sauer, Regulation of cardiotrophin-1 expression in mouse embryonic stem cells by HIF-1a and intracellular reactive oxygen species, J. Cell Sci. 119 (2006) 1043-1052. https://doi.org/10.1242/jcs.02798.

[51] J. Kudová, J. Procházková, O. Vašiček, T. Perečko, M. Sedláčková, M. Pešl, J. Pacherník, L. Kubala, HIF-1alpha deficiency attenuates the cardiomyogenesis of mouse embryonic stem cells, PLoS One. 11 (2016) e0158358. https://doi.org/10.1371/journal.pone.0158358.

[52] M.C. Simon, B. Keith, The role of oxygen availability in embryonic development and stem cell function, Nat. Rev. Mol. Cell Biol. 9 (2008) 285-296. https://doi.org/10.1038/nrm2354.

[53] A.A. Chakraborty, T. Laukka, M. Myllykoski, A.E. Ringel, M.A. Booker, M.Y. Tolstorukov, Y.J. Meng, S.R. Meier, R.B. Jennings, A.L. Creech, Z.T. Herbert, S.K. McBrayer, B.A. Olenchock, J.D. Jaffe, M.C. Haigis, R. Beroukhim, S. Signoretti, P. Koivunen, W.G. Kaelin, Histone demethylase KDM6A directly senses oxygen to control chromatin and cell fate, Science (80-. ). 363 (2019) 1217. https://doi.org/10.1126/science.aaw1026. 
Supplementary data

\begin{tabular}{|c|c|c|c|c|c|}
\hline Gene & Sidak's multiple comparisons test & Mean Diff. & $95.00 \% \mathrm{Cl}$ of diff. & Summary & Adjusted P Value \\
\hline \multirow[t]{4}{*}{ Pou5f7 } & C20-20\% vs. C20-5\% & 1.103 & 0.2179 to 1.988 & $\star \star$ & 0.0052 \\
\hline & C20-20\% vs. C5-5\% & 1.195 & 0.3105 to 2.080 & ** & 0.0018 \\
\hline & C20-5\% vs. C5-20\% & -0.9523 & -1.837 to -0.06746 & * & 0.0258 \\
\hline & C5-20\% vs. C5- $5 \%$ & 1.045 & 0.1601 to 1.930 & $\star \star$ & 0.0098 \\
\hline \multirow[t]{6}{*}{ Cdh7 } & N20-20\% vs. N20-5\% & -2.999 & -3.929 to -2.069 & 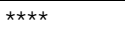 & $<0.0001$ \\
\hline & N20-20\% vs. N5-20\% & 0.9775 & 0.04735 to 1.908 & * & 0.0323 \\
\hline & N20-20\% vs. N5-5\% & -1.969 & -2.900 to -1.039 & 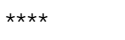 & $<0.0001$ \\
\hline & N20-5\% vs. N5-5\% & 1.03 & 0.09964 to 1.960 & * & 0.0196 \\
\hline & N20-5\% vs. N5-20\% & 3.977 & 3.046 to 4.907 & $\star \star \star \star *$ & $<0.0001$ \\
\hline & N5-20\% vs. N5-5\% & -2.947 & -3.877 to -2.017 & $\star * * *$ & $<0.0001$ \\
\hline \multirow[t]{6}{*}{ Nes } & C20-20\% vs. C20-5\% & 0.9119 & 0.4321 to 1.392 & 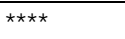 & $<0.0001$ \\
\hline & C20-20\% vs. C5-5\% & 0.659 & 0.1792 to 1.139 & $\star \star$ & 0.0015 \\
\hline & C20-5\% vs. C5-20\% & -0.5017 & -0.9815 to -0.02190 & * & 0.0338 \\
\hline & N20-20\% vs. N5-5\% & -0.5975 & -1.077 to -0.1177 & $\star \star$ & 0.0053 \\
\hline & N20-5\% vs. N5-5\% & -0.8276 & -1.307 to -0.3478 & $\star \star \star \star \star ~$ & $<0.0001$ \\
\hline & N5-20\% vs. N5-5\% & -0.6726 & -1.152 to -0.1928 & $\star \star$ & 0.0011 \\
\hline \multirow[t]{7}{*}{ Bmp4 } & C20-20\% vs. C5-5\% & -0.5386 & -1.014 to -0.06340 & * & 0.0154 \\
\hline & N20-20\% vs. N20-5\% & -1.679 & -2.154 to -1.203 & 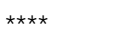 & $<0.0001$ \\
\hline & N20-20\% vs. N5-20\% & 0.6683 & 0.1931 to 1.143 & $\star \star$ & 0.001 \\
\hline & N20-20\% vs. N5-5\% & -0.9058 & -1.381 to -0.4306 & $\star \star \star \star *$ & $<0.0001$ \\
\hline & N20-5\% vs. N5-5\% & 0.7729 & 0.2977 to 1.248 & 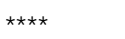 & $<0.0001$ \\
\hline & N20-5\% vs. N5-20\% & 2.347 & 1.872 to 2.822 & $\star \star \star \star *$ & $<0.0001$ \\
\hline & N5-20\% vs. N5-5\% & -1.574 & -2.049 to -1.099 & 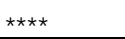 & $<0.0001$ \\
\hline \multirow[t]{9}{*}{ Gata4 } & C20-20\% vs. C20-5\% & -2.051 & -2.803 to -1.298 & 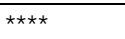 & $<0.0001$ \\
\hline & C20-20\% vs. C5-5\% & -1.625 & -2.378 to -0.8729 & 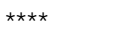 & $<0.0001$ \\
\hline & C20-5\% vs. C5-20\% & 1.735 & 0.9823 to 2.487 & 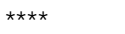 & $<0.0001$ \\
\hline & C5-20\% vs. C5-5\% & -1.309 & -2.062 to -0.5568 & $\star \star \star \star \star ~$ & $<0.0001$ \\
\hline & N20-20\% vs. N20-5\% & -3.26 & -4.013 to -2.508 & 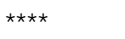 & $<0.0001$ \\
\hline & N20-20\% vs. N5-5\% & -1.165 & -1.917 to -0.4123 & $\star \star \star$ & 0.0002 \\
\hline & N20-5\% vs. N5-5\% & 2.095 & 1.343 to 2.848 & $\star * \star \star *$ & $<0.0001$ \\
\hline & N20-5\% vs. N5-20\% & 3.097 & 2.344 to 3.850 & 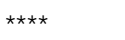 & $<0.0001$ \\
\hline & N5-20\% vs. N5-5\% & -1.002 & -1.754 to -0.2491 & $\star \star$ & 0.0023 \\
\hline \multirow[t]{8}{*}{ Tubb3 } & C20-20\% vs. C20-5\% & 1.55 & 0.9577 to 2.143 & 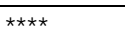 & $<0.0001$ \\
\hline & C20-20\% vs. C5-20\% & 1.174 & 0.5817 to 1.767 & 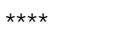 & $<0.0001$ \\
\hline & C20-20\% vs. C5-5\% & 1.341 & 0.7483 to 1.933 & $\star \star \star \star *$ & $<0.0001$ \\
\hline & N20-20\% vs. N20-5\% & 1.941 & 1.349 to 2.534 & 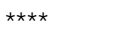 & $<0.0001$ \\
\hline & N20-20\% vs. N5-5\% & 1.049 & 0.4560 to 1.641 & 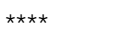 & $<0.0001$ \\
\hline & N20-5\% vs. N5-5\% & -0.8926 & -1.485 to -0.3001 & 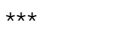 & 0.0004 \\
\hline & N20-5\% vs. N5-20\% & -2.065 & -2.658 to -1.473 & $\star \star \star \star *$ & $<0.0001$ \\
\hline & N5-20\% vs. N5-5\% & 1.173 & 0.5800 to 1.765 & 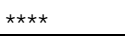 & $<0.0001$ \\
\hline \multirow[t]{6}{*}{ Gfap } & N20-20\% vs. N20-5\% & 3.819 & 2.802 to 4.836 & 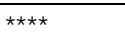 & $<0.0001$ \\
\hline & N20-20\% vs. N5-20\% & -1.434 & -2.451 to -0.4167 & 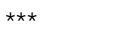 & 0.001 \\
\hline & N20-20\% vs. N5-5\% & 2.546 & 1.529 to 3.563 & 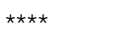 & $<0.0001$ \\
\hline & N20-5\% vs. N5-5\% & -1.273 & -2.291 to -0.2561 & $\star \star$ & 0.005 \\
\hline & N20-5\% vs. N5-20\% & -5.253 & -6.270 to -4.236 & 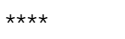 & $<0.0001$ \\
\hline & N5-20\% vs. N5-5\% & 3.98 & 2.962 to 4.997 & $\star \star \star * \star$ & $<0.0001$ \\
\hline \multirow[t]{5}{*}{$M b p$} & N20-20\% vs. N5-20\% & -1.136 & -1.988 to -0.2841 & $\star \star *$ & 0.0022 \\
\hline & N20-20\% vs. N5-5\% & -2.543 & -3.395 to -1.691 & 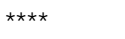 & $<0.0001$ \\
\hline & N20-5\% vs. N5-5\% & -2.526 & -3.378 to -1.674 & 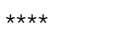 & $<0.0001$ \\
\hline & N20-5\% vs. N5-20\% & -1.12 & -1.972 to -0.2677 & ** & 0.0027 \\
\hline & N5-20\% vs. N5-5\% & -1.407 & -2.259 to -0.5547 & 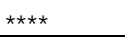 & $<0.0001$ \\
\hline \multirow[t]{4}{*}{ Ms $\times 2$} & N20-20\% vs. N20-5\% & -1.505 & -2.503 to -0.5068 & 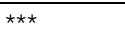 & 0.0004 \\
\hline & N20-20\% vs. N5-20\% & 1.078 & 0.08000 to 2.077 & * & 0.0249 \\
\hline & N20-5\% vs. N5-5\% & 2.2 & 1.202 to 3.199 & 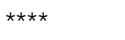 & $<0.0001$ \\
\hline & N20-5\% vs. N5-20\% & 2.583 & 1.585 to 3.582 & 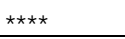 & $<0.0001$ \\
\hline \multirow[t]{5}{*}{ Snai2 } & N20-20\% vs. N20-5\% & -1.792 & -2.480 to -1.103 & 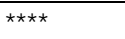 & $<0.0001$ \\
\hline & N20-20\% vs. N5-20\% & 1.164 & 0.4755 to 1.853 & 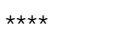 & $<0.0001$ \\
\hline & N20-20\% vs. N5-5\% & -0.6924 & -1.381 to -0.003579 & * & 0.0479 \\
\hline & N20-5\% vs. N5-5\% & 1.099 & 0.4104 to 1.788 & $\star \star \star$ & 0.0001 \\
\hline & N20-5\% vs. N5-20\% & 2.956 & 2.267 to 3.645 & 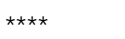 & $<0.0001$ \\
\hline
\end{tabular}




\begin{tabular}{|c|c|c|c|c|c|}
\hline Gene & Sidak's multiple comparisons test & Mean Diff. & $95.00 \% \mathrm{Cl}$ of diff. & Summary & Adjusted P Value \\
\hline & N5-20\% vs. N5-5\% & -1.857 & -2.545 to -1.168 & 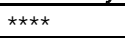 & $<0.0001$ \\
\hline \multirow[t]{8}{*}{$N k \times 2.5$} & C20-20\% vs. C20-5\% & 1.518 & 0.9033 to 2.132 & 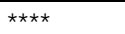 & $<0.0001$ \\
\hline & C20-20\% vs. C5-5\% & 1.388 & 0.7739 to 2.002 & 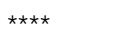 & $<0.0001$ \\
\hline & C20-5\% vs. C5- $20 \%$ & -0.9815 & -1.596 to -0.3672 & $\star \star \star \star$ & 0.0001 \\
\hline & C5- $20 \%$ vs. C5- $5 \%$ & 0.8521 & 0.2378 to 1.466 & $\star \star$ & 0.0013 \\
\hline & N20-20\% vs. N5-20\% & -1.039 & -1.654 to -0.4252 & $\star * \star *$ & $<0.0001$ \\
\hline & N20-20\% vs. N5-5\% & 1.39 & 0.7753 to 2.004 & 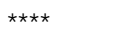 & $<0.0001$ \\
\hline & N20-5\% vs. N5-5\% & 1.976 & 1.362 to 2.590 & $* \star \star *$ & $<0.0001$ \\
\hline & N5-20\% vs. N5-5\% & 2.429 & 1.815 to 3.043 & $\star * \star * *$ & $<0.0001$ \\
\hline \multirow[t]{8}{*}{ Myh6 } & C20-20\% vs. C20-5\% & 7.54 & 6.189 to 8.891 & 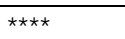 & $<0.0001$ \\
\hline & C20-20\% vs. C5-5\% & 6.954 & 5.603 to 8.305 & 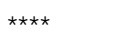 & $<0.0001$ \\
\hline & C20-5\% vs. C5-20\% & -6.615 & -7.966 to -5.264 & $\star \star \star \star *$ & $<0.0001$ \\
\hline & C5- $20 \%$ vs. C5-5\% & 6.029 & 4.678 to 7.379 & 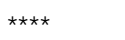 & $<0.0001$ \\
\hline & N20-20\% vs. N20-5\% & -7.295 & -8.646 to -5.944 & $\star \star \star \star *$ & $<0.0001$ \\
\hline & N20-20\% vs. N5-20\% & 1.461 & 0.1105 to 2.812 & * & 0.0246 \\
\hline & N20-5\% vs. N5-5\% & 7.716 & 6.366 to 9.067 & $* \star \star *$ & $<0.0001$ \\
\hline & N20-5\% vs. N5-20\% & 8.757 & 7.406 to 10.11 & 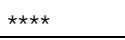 & $<0.0001$ \\
\hline
\end{tabular}






\section{CHAPTER 5}

\section{LOOK-ALIKES MAY NOT ACT ALIKE: GENE EXPRESSION REGULATION AND CELL- TYPE-SPECIFIC RESPONSES OF THREE VALPROIC ACID ANALOGUES IN THE NEURAL EMBRYONIC STEM CELL TEST [ESTN]}

Victoria C. de Leeuw ${ }^{1,2}$, Ellen V.S. Hessel ${ }^{1}$, Aldert H. Piersma ${ }^{1,2}$

${ }^{1}$ Centre for Health Protection, National Institute for Public Health and the Environment, Bilthoven, the Netherlands

${ }^{2}$ Institute for Risk Assessment Sciences, Utrecht University, Utrecht, the Netherlands

Toxicology Letters, 2019 Dec, 303: 28-37

DOI: 10.1016/j.toxlet.2018.12.005 



\section{Abstract}

In vitro assays to assess developmental neurotoxicity of chemicals are highly desirable. The murine neural embryonic stem cell test (ESTn) can mimic parts of early differentiation of embryonic brain and may therefore be useful for this purpose. The aim of this study was to investigate whether this test is able to rank the toxic potencies of three valproic acid analogues and to study their mode of action by investigating their individual effects on four cell types: stem cells, neurons, astrocytes and neural crest cells. Using immunocytochemical read-outs and qPCR for cell type-specific genes, the effects of valproic acid (VPA), 2-ethylhexanoic acid (EHA) and 2-ethyl-4-methylpentanoic (EMPA) were assessed. VPA and EHA but not EMPA downregulated cell type-specific differentiation makers and upregulated stem cell related markers (Fut4, $C d h 7$ ) at different time points during differentiation. Expression of Gfap, a marker for astrocytes, was dramatically downregulated by VPA and EHA, but not by EMPA. This finding was verified using immunostainings. Based on the number and extent of genes regulated by the three compounds, relative potencies were determined as VPA > EHA > EMPA, which is consistent with in vivo developmental toxicity potency ranking of these compounds. Thus, ESTn using a combination of morphology, gene and protein expression readouts, may provide a medium-throughput system for monitoring the effects of compounds on differentiation of cell types in early brain development. 


\section{Introduction}

Large numbers of laboratory animals are required for the safety assessment of chemicals [1] The field of developmental and reproductive toxicology alone requires millions of animals for testing chemicals under European Union legislation (REACH) $[1,2]$. Although the need for developmental neurotoxicity testing of chemicals is widely advocated, it is currently not obligatory by default to test for (developmental) neurotoxicity $[3,4]$. There have been scientific and societal concerns regarding testing for developmental neurotoxicity in animals $[5,6]$. Moreover, the human relevance of the animal data in this area is under debate, thereby potentially missing the harmful effects of compounds on the CNS. An integrated strategy of in vitro and in silico nonanimal methods to assess developmental neurotoxicity tests is therefore highly needed, both from an ethical point of view and given the need for better risk assessment approaches $[7,8]$. Since a single in vitro test cannot replace the intact animal, integrated testing strategies consisting of multiple complementary tests are needed in order to fully replace lab animals $[4,9-$ 11]. One of the tests that can serve in a strategy to assess developmental neurotoxicity is the neural embryonic stem cell test (ESTn)[12], a variant of the ECVAM-validated cardiac embryonic stem cell test (ESTC)[13]. Whereas the ESTc was developed as a tool to assess the potential teratogenic effects in general, the ESTn focusses on the prediction of neurodevelopmental effects of chemicals using their perturbation of early stem cell differentiation towards the neuroectodermal lineage and neural and related brain cell types. The ESTn has shown its potential by distinguishing a range of rodent developmental neurotoxic and non-neurotoxic compounds based on whole genome expression profiles [14-20]. The aim of the current study was to investigate the applicability of the ESTn with regard to whether this test is sufficiently sensitive to discriminate the neurodevelopmental toxic potency of compounds that are of the same class and molecular weight. Three structural analogues, valproic acid (VPA), 2-ethylhexanoic acid (EHA) and 2-ethyl-4-methylpentanoic acid (EMPA), were chosen based on studies done by Nau and co-workers [21-25]. VPA is an anticonvulsant drug and a well-known teratogenic compound that increases the risk of neural tube defects, cardiovascular- and musculoskeletal anomalies, which are seen both in humans [26-28] and rodents [24,29]. EHA is amongst others used as e.g. paint-dryer, food additive and plasticiser. It is also regarded as a neurodevelopmental toxicant, although rodent in vivo and in vitro studies showed that it is less potent than VPA at equimolar concentrations [24,30,31]. In a number of comparative studies it was shown that a third analogue, EMPA, does have anticonvulsant effects in mice but is not teratogenic $[21,23]$. We studied the effects of these three compounds on neural differentiation of the ESTn using gene expression, protein expression and morphological readouts. Using this combination of approaches, the relative potencies in rodents of VPA, EHA and EMPA could be discriminated based on gene expression and morphology. The ESTn may therefore be a suitable screening test to study the relative developmental neurotoxic potential of chemical analogues. Furthermore, the characterisation of the test and the leads it provides to mechanistic understanding of the effect of VPA analogues further outline the applicability domain of the ESTn. 


\section{Material and methods}

\section{Culture media}

Complete medium (CM) was composed of Dulbecco's modified Eagle's medium (DMEM; Gibco, Waltham, MA, USA) supplemented with 20\% fetal bovine serum (FBS; Greiner Bio-One, Kremsmünster, Austria), 200 mM L-glutamine (Gibco), 1\% nonessential amino acids (Gibco), 1\% penicillin/streptomycin (Gibco), and $0.1 \mathrm{mM} \beta$-mercaptoethanol (Sigma-Aldrich, Zwijndrecht, The Netherlands). Low-serum (LS) medium contained the same ingredients, apart from a lower concentration of $10 \%$ FBS. Insulin-transferrin-selenite (ITS) medium was comprised of DMEM/Ham's nutrient mixture F12 medium (DMEM/F12; Gibco), $0.2 \mu \mathrm{g} / \mathrm{mL}$ bovine insulin (Sigma-Aldrich), 1\% penicillin/ streptomycin (Gibco), 2 mM L-glutamine (Gibco), 30 nM sodium selenite (Sigma-Aldrich), and $50 \mu \mathrm{g} / \mathrm{mL}$ apo-transferrin (Sigma-Aldrich). N2 medium contained DMEM/F12 medium (Gibco) supplemented with $0.2 \mu \mathrm{g} / \mathrm{mL}$ bovine insulin (Sigma-Aldrich), $1 \%$ penicillin/streptomycin (Gibco), $20 \mathrm{nM}$ progesterone (Sigma-Aldrich), $30 \mathrm{nM}$ sodium selenite (Sigma-Aldrich) $100 \mu \mathrm{M}$ putrescine (Sigma-Aldrich), and $50 \mu \mathrm{g} / \mathrm{mL}$ apotransferrin (Sigma-Aldrich).

\section{Embryonic stem cells and neural differentiation}

Murine embryonic ES-D3 stem cells (ATCC, Manassas, VA, USA) were grown in a monolayer in $\mathrm{CM}$ with murine leukemia-inhibiting factor ( $\mathrm{mLIF}$; Millipore, Burlington, MA, USA) on polystyrene $35 \mathrm{~mm}$ plates (Corning, New York, NY, USA) and maintained in a humidified atmosphere at 37 ${ }^{\circ} \mathrm{C}$ and $5 \%$ CO2. Cells were routinely sub-cultured every 2-3 days from passage 10 to 22 [18]. Neural differentiation was induced as described before [18] and shown in Fig. 1. In brief, cells were suspended in CM at a concentration of $3.75 \times 10^{4}$ cells $/ \mathrm{mL}$ and put on ice. Drops of $20 \mu \mathrm{l}$ suspension were placed on the inner side of a $100 \mathrm{~mm}$ petri dish lid after which the lid was turned back around on the dish (Greiner BioOne) filled with PBS, resulting in hanging drops each containing 750 cells. After three days, embryonic bodies (EBs) had formed and were transferred to a bacterial $60 \mathrm{~mm}$ petri dish (Greiner Bio-One) containing CM with $0.5 \mu \mathrm{M}$ retinoic acid (Sigma-Aldrich). On the fifth day, EBs were replaced on laminin-(Sigma-Aldrich) coated dishes for two days in LS, supplemented with $2.5 \mu \mathrm{g} / \mathrm{mL}$ fibronectin (Gibco). After one day, the medium was replaced by ITS medium with fibronectin. On day 7, EBS were dissociated and transferred to poly-L-ornithine (Sigma-Aldrich)-laminin coated dishes in N2 medium supplemented with $10 \mathrm{ng} / \mathrm{mL}$ basic fibroblast growth factor (Miltenyi Biotech, Bergisch Gladbach, Germany), which was refreshed after three days.

\section{Treatment and morphological scoring}

Cells were exposed from day 3 until day 13 to a range of non-cytotoxic concentrations between 0.001 and $1 \mathrm{mM}$ of either valproic acid sodium salt (VPA; CAS\# 1069-66-5, Sigma-Aldrich), 2ethylhexanoic acid (EHA; CAS\# 149-57-5, Sigma-Aldrich), 2-ethyl-4-methylpentanoic acid (EMPA; CAS\# 108-81-6, Enamine) in dimethyl sulfoxide (DMSO; final concentration 0.25\%; Sigma-Aldrich) or to DMSO only. With every medium change, freshly prepared compound was added to the medium (Fig. 1). On day 13, EBs were evaluated for the extent of neurite outgrowth 


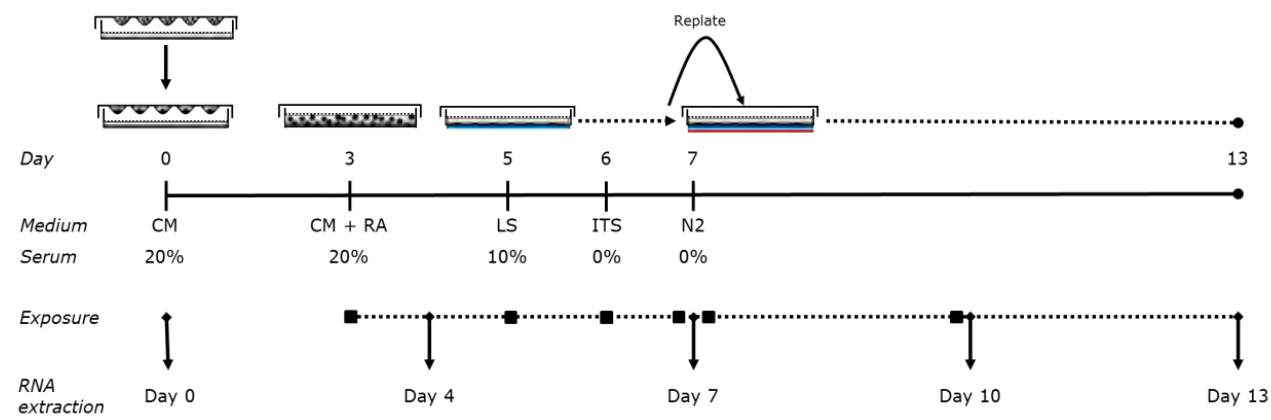

Figure 1. Graphical overview of the ESTh protocol. Cells are exposed from day 3 to 13. Each square indicates a refreshment of the exposure medium. On day 7 the medium is replaced a second time in the afternoon to remove loose cells after dissociation in the morning. Samples for RNA extraction were taken at indicated time points. Blue line under the dish on day 5 and 7 represents laminin coating, red line on day 7 is poly-L-ornithine coating. CM = complete medium, RA = Retinoic acid, LS = low serum medium, ITS = insulin-transferrin-selenite medium, N2 = N2medium. Figure adapted from Theunissen et al., [12].

according to Theunissen et al. [12]. The coronas were scored under a regular bright field microscope (Olympus IX51), irrespective of the length of the neurites. The cut-off value to determine whether a compound affected an EB was when less than $75 \%$ of the surrounding corona of neurites was intact. Three dishes per condition containing approximately 30 EBs were scored using an IX51 inverted microscope (Olympus).

\section{Cell viability assay}

Undifferentiated ES-D3 cells were cultured in a 96-well plate (Greiner Bio-One) at a density of $1 \times 10^{4}$ cells $/ \mathrm{mL}$ (500 cells) in CM supplemented with mLIF. Cells were allowed to adhere for two hours after which they were exposed to $0.001-1 \mathrm{mM}$ of one of the compounds. After three days of exposure, old medium was replaced with freshly prepared exposure medium and cultured for another two days. On day 5, cell viability was determined using a CellTiter-Blue ${ }^{\circledR}$ kit (Promega, Leiden, the Netherlands) and measured on a Spectramax ${ }^{\circledR}$ M2 spectrofluorometer (Molecular Devices, Berkshire, United Kingdom) at $544 \mathrm{~nm}$ and $590 \mathrm{~nm}$. Six technical replicates were performed in three independent experiments. Controls used were 0.25\% DMSO (SigmaAldrich) as solvent control, $0.1 \mathrm{ug} / \mathrm{mL}$ 5-Fluorouracil (Sigma-Aldrich) as postitive control and 0.5 $\mathrm{mg} / \mathrm{mL}$ Penicillin G (Sigma-Aldrich) as negative control in each experiment.

\section{RNA isolation and quantitative real-time}

PCR Samples (eight replicates) were isolated in $700 \mu \mathrm{L}$ QIAzol (Qiagen, Hilden, Germany) at five time points that each mark a critical time point in the culture protocol: day 0 , whereby the stem cells are undifferentiated; day 4, one day after the addition of RA to initiate neural differentiation; day 7 , the last day before the EBs are dissociated; day 10 and day 13 , during which the cells grow and mature after dissociation (Fig. 1). Samples were stored at $-80{ }^{\circ} \mathrm{C}$ until further processing. Before purification, samples were thawed in a $37^{\circ} \mathrm{C}$ water bath and homogenized with the QIAshredder (Qiagen) for higher RNA yields. Whole RNA extraction was performed using 
the RNeasy microarray tissue kit (Qiagen) following the manufacture's protocol. Concentration of RNA was determined with the NanoDrop ${ }^{\mathrm{TM}} 1000$ spectrophotometer (Nanodrop Technologies, Wilmington, DE, USA) and purity was defined using the 2100 BioAnalyzer (Aligent Technologies, Amstelveen, the Netherlands). The seven samples with the highest RNA yields and best quality were used for qPCR. Synthesis of CDNA was done using the CDNA archive kit containing random hexamer primers (Applied Biosystems, Foster City, CA, USA). Gene quantification was performed on a 7500 Fast Real-Time PCR system (Applied Biosystems) applying the following thermal cycling conditions: $95^{\circ} \mathrm{C}$ for $20 \mathrm{~s}$, followed by 40 cycles of $95^{\circ} \mathrm{C}$ for $3 \mathrm{~s}$ and $60{ }^{\circ} \mathrm{C}$ for $30 \mathrm{~s}$. Primers were bought from Applied Biosystems and are listed in Table 1. The $2^{-\Delta \Delta C t}$ method [32] was applied to quantify the relative differences between expression of genes, which were all normalized against an average of the housekeeping genes Hypoxanthine phosphoribosyltransferase 1 (Hprt7) and Glucuronidase beta (Gusb).

Table 1 Primers used for gene expression with corresponding marker function and assay ID. All primers, including custom-made primers, were bought from Applied Biosystems.

\begin{tabular}{|c|c|c|c|}
\hline Gene name & $\begin{array}{l}\text { Abbrevia- } \\
\text { tion }\end{array}$ & Marker for & Assay ID/primer sequence \\
\hline Fucosyltransferase 4 & Fut4 & Stem cell & Mm00487448_s1 \\
\hline Cadherin 1 & $C d h 1$ & $\begin{array}{l}\text { Adhesion molecule present before } \\
\text { neural tube closure }\end{array}$ & Mm01247357_m1 \\
\hline Nestin & Nes & Neural progenitor & Mm00450205_m1 \\
\hline Tubulin, beta 3 class III & Tubb3 & Neuron & Mm00727586_s1 \\
\hline Glial fibrillary acidic protein & Gfap & Early astrocyte & Mm01253033_m1 \\
\hline Msh homeobox 2 & Msx2 & Early neural crest marker & Mm00442992_m1 \\
\hline Snail family zinc finger 2 & Snai2 & Epithelial-Mesenchymal Transition & Mm00441531_m1 \\
\hline $\begin{array}{l}\text { Aldehyde dehydrogenase family } 1 \text {, } \\
\text { subfamily A2 }\end{array}$ & Aldh1a2 & Synthesising enzyme for retinoic acid & Mm00501306_m1 \\
\hline $\begin{array}{l}\text { Cytochrome P450, family } 26 \text {, sub- } \\
\text { family a, polypeptide } 1\end{array}$ & Cyp26a1 & Metabolising enzyme for retinoic acid & Mm00514486_m1 \\
\hline Glucuronidase beta & Gusb & Housekeeping gene & Mm01197698_m1 \\
\hline \multirow[t]{4}{*}{$\begin{array}{l}\text { Hypoxanthine phosphoribosyltrans- } \\
\text { ferase } 1\end{array}$} & Hprt1 & Housekeeping gene & $\begin{array}{l}\text { Forward primer: } \\
\text { GCCGAGGATTTGGAAAAAG }\end{array}$ \\
\hline & & & TGTTTA Reverse primer: \\
\hline & & & TTCATGACATCTCGAGCAAG \\
\hline & & & TCTTT \\
\hline
\end{tabular}

\section{Immunocytochemistry}

At day 0, 3, 4, 5, 7 and 13 EBs were fixated with 4\% prewarmed paraformaldehyde (Electron Microscopy Sciences, Hatfield, PA, USA) in PBS (Gibco) for 10-30 min and permeabilised with 0.2\% Triton X-100 (Sigma-Aldrich) in PBS (Gibco) for 5 min at room temperature (RT). Depending on the antibody used (see also Table 2), samples were either incubated in bovine albumin serum (BSA; Sigma-Aldrich) or a mix of BSA and normal goat serum (NGS; Sigma-Aldrich). The BSA treated samples were blocked with 1\% BSA (Sigma-Aldrich)/0.5\% Tween-20 (Sigma-Aldrich) in PBS (Gibco) for $1 \mathrm{~h}$ at $37^{\circ} \mathrm{C}$ and incubated with antibodies in 0.5\% BSA/0.5\% Tween20 in PBS (Gibco). BSA/NGS samples were blocked with 5\% BSA (Sigma-Aldrich) for 30 min at RT and incubated with 5\% NGS (Sigma-Aldrich)/0.5\% Tween-20 (SigmaAldrich) in PBS (Gibco). Primary antibodies were applied overnight at $4{ }^{\circ} \mathrm{C}$ and secondary antibodies were incubated for $1 \mathrm{~h}$ at $37^{\circ} \mathrm{C}$. In between all steps, cells were washed two times 5 min with PBS (Gibco). Nuclei 
were counter-stained with DAPI (Sigma-Aldrich). Primary and appropriate secondary antibodies are summarised in Table 2. Samples were imaged on an Olympus BX51 light microscope (Shinjuku, Japan) with 10x, 20x and 40x magnifications. Fig. 3E and I (right) were respectively imaged on a Nikon Confocal A1R system (Tokyo, Japan) with 10x magnification and a Rescan Confocal Microscope (Confocal.nl, Amsterdam, the Netherlands) with 100x magnification.

Table 2 Primary and secondary antibodies used for immunocytochemistry experiments with marker function, dilution and incubation protocol.

\begin{tabular}{|c|c|c|c|c|c|c|}
\hline Antibody & $\begin{array}{l}\text { Abbrevi- } \\
\text { ation }\end{array}$ & Marker for & $\begin{array}{l}\text { Product } \\
\text { number }\end{array}$ & Company & Dilution & $\begin{array}{l}\text { Incubation } \\
\text { protocol }\end{array}$ \\
\hline $\begin{array}{l}\text { Rabbit anti CD15/Fut4/Stage } \\
\text { Specific Embryonic Antigen-1 }\end{array}$ & Ssea-1 & Stem cell & bs-1702R & Bioss & $1: 200$ & BSA \\
\hline Rat anti E-cadherin & E-cad & $\begin{array}{l}\text { Adhesion molecule } \\
\text { present before neural } \\
\text { tube closure }\end{array}$ & $13-1900$ & Invitrogen & $1: 1000$ & BSA \\
\hline Mouse anti Nestin & Nes & Neural progenitor & MAB353 & Millipore & $1: 200$ & BSA \\
\hline Rabbit anti $\beta$-Tubulin III & Tubb3 & Neuron & T2200 & $\begin{array}{l}\text { Sigma-Al- } \\
\text { drich }\end{array}$ & 1:1000 & $\begin{array}{l}\text { BSA } \\
\text { BSA/NGS }\end{array}$ \\
\hline $\begin{array}{l}\text { Mouse anti Microtubule-asso- } \\
\text { ciated protein } 2\end{array}$ & Map2 & $\begin{array}{l}\text { Neuron, dendrite-spe- } \\
\text { cific }\end{array}$ & 801801 & Biolegend & $1: 2000$ & BSA \\
\hline Guinea pig anti Tau & Tau & Neuron, axon specific & 314004 & $\begin{array}{l}\text { Synaptic } \\
\text { Systems }\end{array}$ & $1: 1000$ & BSA \\
\hline $\begin{array}{l}\text { Rat anti Glial fibrillary acidic } \\
\text { protein }\end{array}$ & Gfap & Early astrocyte & $13-0300$ & Invitrogen & $1: 400$ & BSA \\
\hline Mouse anti O4 & $\mathrm{O} 4$ & Oligodendrocyte & 07139 & $\begin{array}{l}\text { Sigma-Al- } \\
\text { drich }\end{array}$ & $1: 400$ & BSA \\
\hline $\begin{array}{l}\text { Guinea pig anti-Vesicular glu- } \\
\text { tamate transporter } 2\end{array}$ & Vglut2 & $\begin{array}{l}\text { Synaptic vesicle excit- } \\
\text { atory neuron }\end{array}$ & AB2251-I & Millipore & $1: 2000$ & BSA \\
\hline $\begin{array}{l}\text { Rabbit anti Homeobox protein } \\
\text { Msx2 }\end{array}$ & Msx2 & Early neural crest cell & $\begin{array}{l}\text { HPA00056 } \\
52\end{array}$ & $\begin{array}{l}\text { Sigma-Al- } \\
\text { drich }\end{array}$ & $1: 100$ & BSA \\
\hline $\begin{array}{l}\text { Mouse anti Adaptor protein } \\
\text { complex AP-2 subunit alpha- } 2\end{array}$ & Ap2 $2 \alpha$ & Early neural crest cell & sc- 12726 & Santa Cruz & $1: 200$ & BSA \\
\hline $\begin{array}{l}\text { Mouse anti Zinc finger protein } \\
\text { Snai2 }\end{array}$ & Slug & $\begin{array}{l}\text { Epithelial-Mesenchy- } \\
\text { mal Transition }\end{array}$ & sc-166476 & Santa Cruz & $1: 200$ & BSA/NGS \\
\hline $\begin{array}{l}\text { Mouse anti Twist-related pro- } \\
\text { tein } 2\end{array}$ & Twist2 & $\begin{array}{l}\text { Epithelial-Mesenchy- } \\
\text { mal Transition }\end{array}$ & ab50887 & Abcam & $1: 400$ & BSA/NGS \\
\hline Goat anti rabbit FITC & & & F0205 & Dako & $1: 200$ & \\
\hline Goat anti guinea pig Alexa & & & A11073 & Invitrogen & $1: 1000$ & \\
\hline \multicolumn{7}{|l|}{488} \\
\hline Goat anti rabbit TRITC & & & T6778 & $\begin{array}{l}\text { Sigma-Al- } \\
\text { drich }\end{array}$ & $1: 500$ & \\
\hline Goat anti mouse Alexa 555 & & & A21424 & Invitrogen & $1: 1000$ & \\
\hline Goat anti rat TRITC & & & $\begin{array}{l}112-025- \\
167\end{array}$ & $\begin{array}{l}\text { Jackson } \\
\text { Immuno } \\
\text { Research }\end{array}$ & $1: 200$ & \\
\hline Goat anti mouse Alexa 647 & & & 21236 & Invitrogen & $1: 500$ & \\
\hline
\end{tabular}

\section{Statistics}

Dose-response curves were constructed from the morphological scoring data using PROAST software version 65.5, exponential model [33]. The $\mathrm{IC}_{50}$ and $\mathrm{ID}_{50}$ were derived from this curve with $95 \%$ confidence interval, at which $50 \%$ on the EBs had corona's $<75 \%$ relative to the control. Gene expression differences were statistically analysed using a one-way ANOVA test and post-hoc Tukey-test. VPA/ EHA and EMPA were compared to their own controls as these were performed in separate experiments. Significance levels were corrected for multiple testing. 


\section{Results}

\section{Characterization of ESTn differentiation based on gene- and protein expression patterns}

In unexposed differentiation cultures, the gene expression markers for stem cells, Fut4 and $C d h 7$, declined over time, while Nes expression increased steadily from day 0 to 10 and neuronal marker Tubb3from day 4 onwards (Fig. 2A). The marker for astrocytes, Gfap, which was initially barely expressed, came up as late as day 13. Msx2, an early neural crest marker, had a defined peak expression on day 7. Meanwhile, Snai2, which is a transition marker for these early neural crest cells, was increasingly expressed over time (Fig. 2B). The expression of the RAmetabolising Cyp26a7 gene peaked at day 4, probably due to the addition of RA to the culture medium. Cyp26a7 expression fell back after RA was washed out and declined steadily from day 7 till day 13. RA-synthesising gene Aldh1a2 rose progressively during the differentiation protocol (Fig. 2C).

To link the expression patterns of the above genes to protein expression, a series of immunostainings was performed. A time line from day 0 (the stem cell culture), 3, 5 and 7 shows the expression of Ssea-1 (encoded by Fut4), E-cadherin (encoded by Cdh7), and Nestin, which qualitatively matches the gene expression pattern (Fig. 3A-D). Tubb3 ${ }^{+}$cells increasingly appeared from day 5 , which ultimately resulted in a network of neurites extending from the EB. Gfap was only expressed from day 13, which is in concordance with its gene expression (Fig. 3E). Whilst Ssea-1 and Nestin were present in the culture up to day 13 (data not shown), Ecadherin was almost fully absent at this time point (Fig. 3F). Early neural crest cells, depicted by Msx2, were present widely throughout EBs at day 4. From day 7 on the signal steadily decreased, which is not entirely in line with the gene expression profile that peaked on day 7 (Fig. 3G). The signal of Slug, which is a marker for epithelial-to-mesenchymal transition (EMT), on the other hand became increasingly stronger in individual cells through later time points, congruent with its gene expression. Whether the number of Slug ${ }^{+}$cells increased relative to the total amount of cells in the culture could not be determined based on the images (Fig. $3 \mathrm{H})$. A number of additional markers were tested to further characterise the culture. Map2, which is a mature neuron marker, and Vglut2, a marker for synaptic vesicles, were expressed as early as day 7 , indicating that the neurons mature over time (Fig. 3I-J). However, at day 13 neurons did not have distinct axons $\left(\mathrm{Tau}^{+}\right)$and dendrites $\left(\mathrm{Map}^{+}\right)$, since the markers co-locate with each other (data not shown. $\mathrm{O4}^{+}$cells, indicating oligodendrocytes, were very rarely found in the ESTn (Fig. 3K). Even when culturing for as long as 19 days, 04 expression was generally not detected (see also [12]). Another marker for EMT, Twist2, followed a similar protein expression pattern as Slug (Fig. 3L). While Slug ${ }^{+}$cells were mostly located in the corona of the EB, Twist $2^{+}$cells resided mainly in the EB itself. AP-2a, which is a neural crest inducer and specifier similar to Msx2, was also expressed in this manner (Fig. 3G), being more abundant in number than EMT neural crest cells. In conclusion, in the ESTn stem cells differentiated into neurons, astrocytes and neural crest cells within 13 days of culture. 

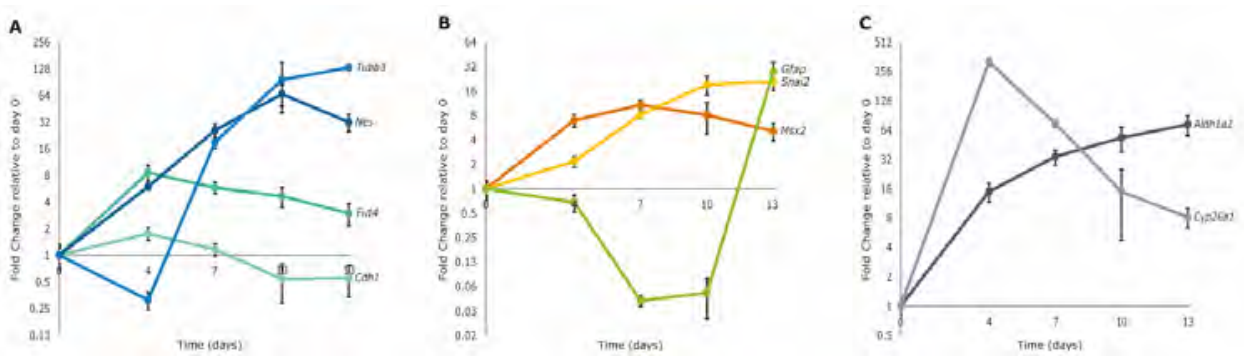

Figure 2. Relative gene expression changes at day 0, 4, 7, 10 and 13 of the ESTn differentiation protocol. Markers include (A) stem cells (Fut4, Cdh7), neuronal progenitor and neurons (Nes, Tubb3), (B) neural crest cells (Msx2, Snai2), astrocytes (Gfap) and (C) retinoic acid homeostasis (Aldh7a, Cyp26a7). All gene expression levels are expressed relative to the undifferentiated stem cell culture. Error bars: Standard deviation of $n=7$ samples per time point in a single experiment.

\section{Valproic acid analogues act in a dose-dependent manner on corona morphology}

EBs were exposed to VPA, EHA and EMPA (Fig. 4A). None of the three compounds was cytotoxic to undifferentiated stem cells up to the highest concentration tested (1 mM) (Fig. 4B). Congruent with literature, VPA $\left(\mathrm{ID}_{50}=0.087 \mathrm{mM}, \mathrm{Cl} 0.053-0.13 \mathrm{mM}\right)$ was significantly more toxic to the differentiating cells in the ESTn than EHA $\left(I_{50}=0.28 \mathrm{mM}, \mathrm{Cl} 0.17-0.46 \mathrm{mM}\right)$, as determined by the integrity of the corona surrounding the EB (see also Fig. 3E). EMPA was ineffective at the highest concentration tested (1 mM) as it did not affect differentiation (Fig. 4C). Since only VPA and EHA exert toxic effects on the morphological level in ESTn, these two compounds were more extensively studied using qPCR in order to elucidate how they affect different cell types.

\section{VPA and EHA affect different cell types at different stages of differentiation}

Fig. 5 shows changes in gene expression of the nine markers relative to their control at four different time points after exposure to $100 \mu \mathrm{M}$ of VPA or EHA. The most notable changes were apparent on the $7^{\text {th }}$ and $13^{\text {th }}$ day of the differentiation protocol. VPA and EHA upregulated the expression of pre-neural tube marker Cdh7 $(p<0.003)$ and neural progenitor Nes $(p<0.01)$ while only VPA suppressed neural crest cell EMT marker Snai2 $(p=0.0046)$ and RAsynthesising Aldh7a2 ( $p=0.00064)$. These effects were already visible as trends on day 4 , one day after the onset of exposure, except for the increase in Nes. The expression of neural marker Tubb3 ( $p=0.00008)$ and early neural crest marker Msx2 ( $p=0.0053)$ was decreased by VPA at day 13 in addition to the continuing suppression of Snai2 ( $p=0.0071)$ and $A / d h 1 a 2(p=0.0001)$. EHA at this time point caught up with VPA with regard to the decline in Snai2 $(p=0.0011)$ and Aldh7a2 ( $p=0.0026$ ) expression, supressing EMT and RA-synthesis as VPA did on day 7 . The decrease in neural crest cell markers Msx2 and Snai2 was not obvious in the immunostainings 

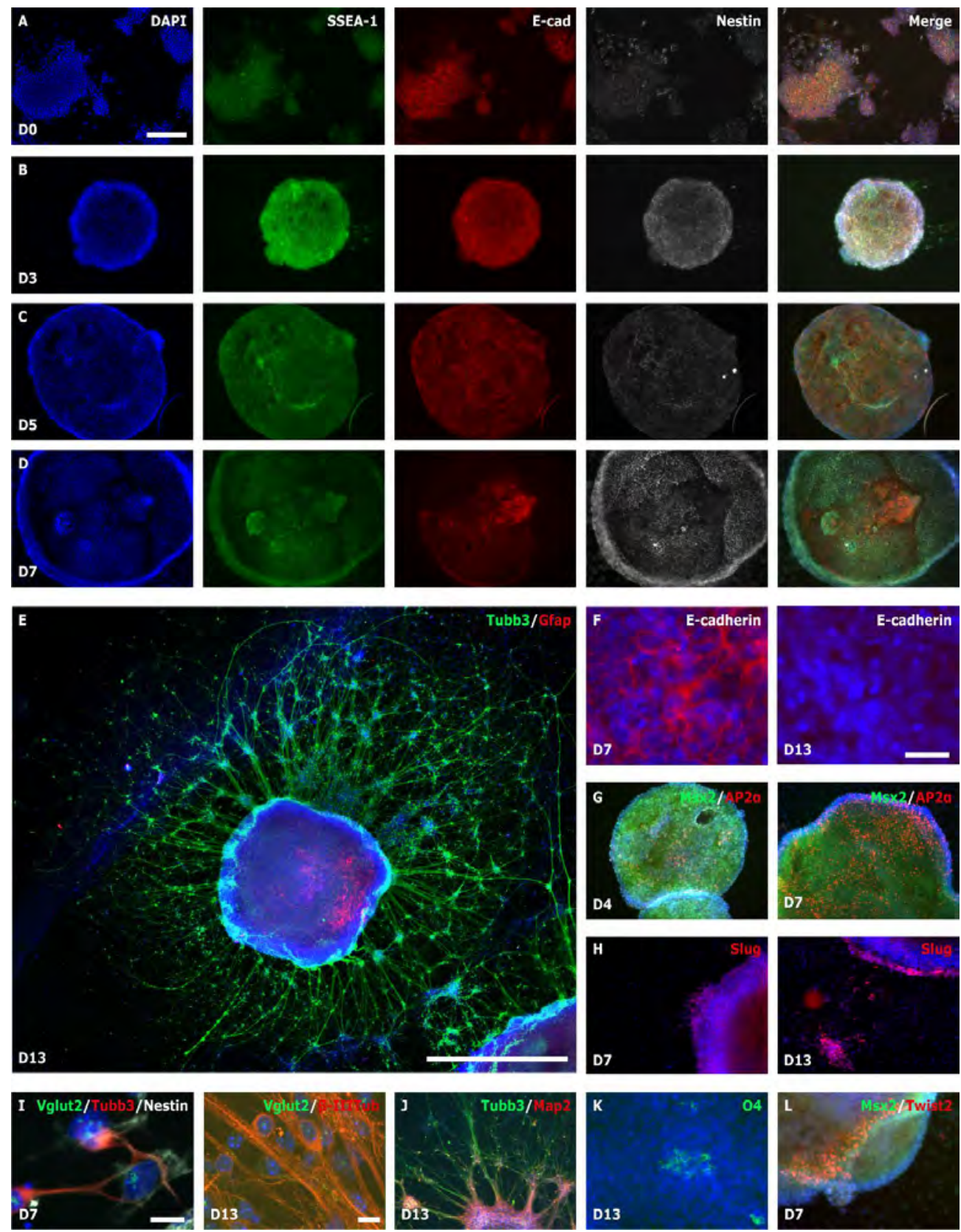

Figure 3. Representative images of cell types present in the ESTn at various stages of differentiation. (A-D) Timeline of Ssea-7, E-cadherin and Nestin expression in (A) undifferentiated stem cells, (B) day 3, (C) day 5 and (D) day 7 of the differentiation protocol. (E) After 13 days of differentiation, Tubb3 $3^{+}$cells (green) have formed a wide network around the EB. Gfap stays mainly in the EB itself. (F) E-cadherin expression after 7 and 13 days of differentiation. (G, $H, L)$ Markers for early neural crest cells (Msx2, AP2a) and cells in EMT (Slug, Twist2) at different time points. (I) $\checkmark$ glut2 is present as early as 7 days into differentiation and migrates from the nucleus into neural protrusions as seen on day 73. (J) Tubb3 is uniquely present in cells while Map2 is only present closer to the cell soma. (K) Oligodendrocytes are rarely found and only in the EB, not in the corona. Nuclei (blue) were stained with DAPI. Bottom left indicates the day of the differentiation protocol. Scale: $A-D, G, H, J, L: 200 \mu \mathrm{m}$. E: $7 \mathrm{~mm}, F, K: 50 \mu \mathrm{m}, 1: 20 \mu \mathrm{m}$. 
(data not shown). Interestingly, EHA but not VPA significantly downregulated the expression of RA-metabolising Cyp26a7 ( $p=0.0079)$. What is most striking is the dramatic decline in Gfap expression caused by both compounds ( $<<0.0000001)$. This has been verified with immunostainings, which showed almost no $\mathrm{Gfap}^{+}$cells compared to the control condition (data not shown). Taken together, different cell types were affected at different time points.

A

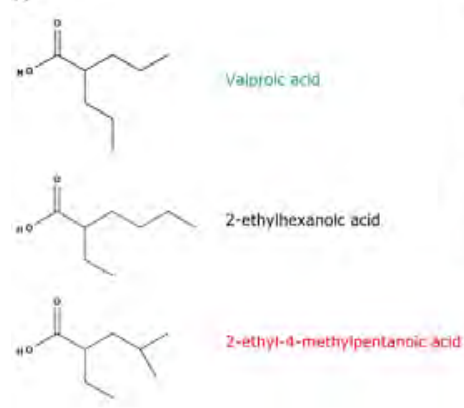

B

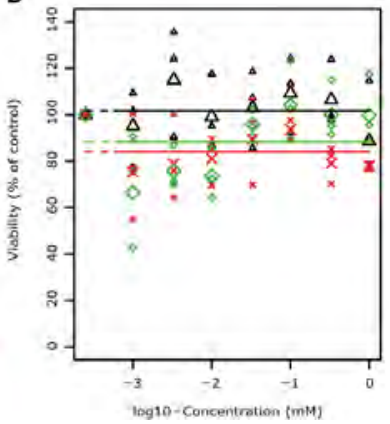

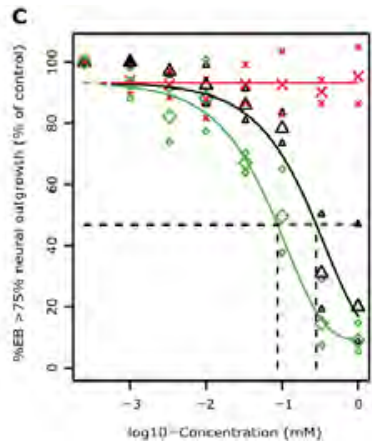

Figure 4. (A) Molecular structures of VPA, EHA and EMPA. (B) No cytotoxicity is measured in undifferentiated stem cells between 0.001 and $1 \mathrm{mM}$ exposure. Data was obtained from three independent experiments. (C) Concentration dependent effects were found in differentiating ESTh based on two independent experiments. Colours of compound names correspond to line colours in the graphs. Small symbols represent averages within individual experiments, large symbols represent the average of the experiments. Dose response curves were fit by PROAST software with exponential method, type m5-b.

\section{EMPA does not affect differentiation of cell types monitored}

Since the $7^{\text {th }}$ and the $13^{\text {th }}$ day of the differentiation protocol are most informative with regard to the effects of compounds on different cell types, the effects of EMPA were also tested on these days. After 7 days of differentiation, EMPA had no effect on any of the gene markers (Fig. 6 A). On day 13 Fut4 ( $p=0.022)$ was slightly decreased whereas VPA and EHA showed a tendency to upregulation of this gene (Fig. 5A and B). Other markers of stem cells, neurons and astrocytes were not affected. Interestingly, EMPA tended to suppress neural crest- and RA homeostasis markers, of which only MsX2 $(p=0.046)$ expression was significantly decreased.

\section{Potency differences between VPA, EHA and EMPA VPA and EHA act similarly, but possibly with different potencies.}

Compared to EHA, VPA regulated more genes. Additionally, VPA affected gene expression to a greater extent and earlier in the differentiation process (e.g. for Snai2 and Aldh1a2 at day 7 and Msx2 and Tubb3 at day 13). This is however not true for all genes as is exemplified with Cyp26a7 expression, for which EHA is a more potent inhibitor. EMPA started to regulate genes only later in the differentiation protocol and the effects were either small or showed substantial variability. From the gene expression data we can conclude that potency of the three compounds in the ESTn can be ranked as VPA > EHA > EMPA, which is in line with the morphological scoring of the compounds. 

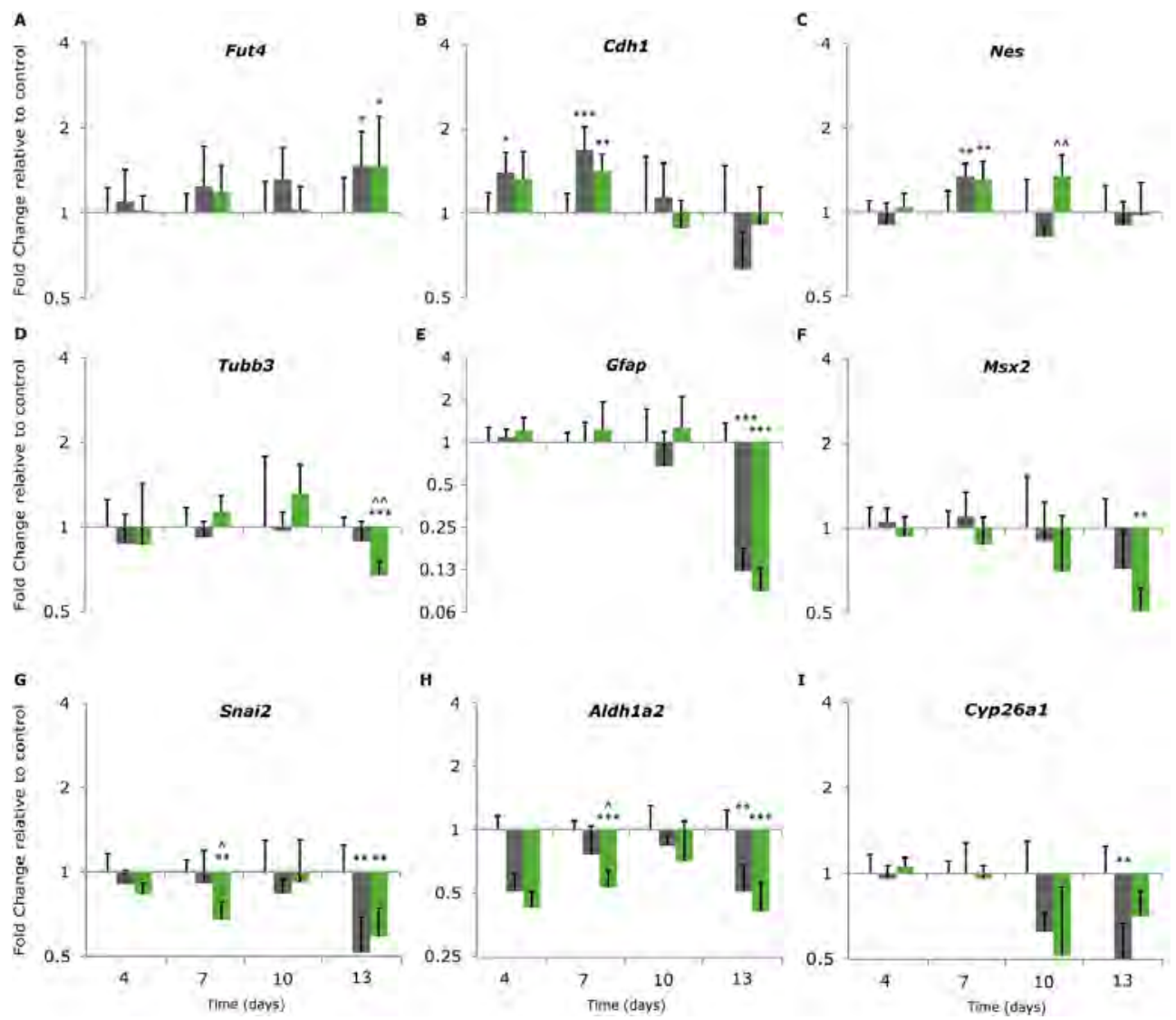

Figure 5. Relative gene expression changes between compounds and their time-matched control (control, EHA in grey, VPA in green). The vertical axis indicates fold change and the horizontal axis shows days of the differentiation protocol. *: compound different from control, 1: VPA different from EHA, *<0.05,**<0.01,***<0.001. Effect was considered significant when $p<0.01$. Error bars: Standard deviation; $n=7$ per condition in a single experiment.
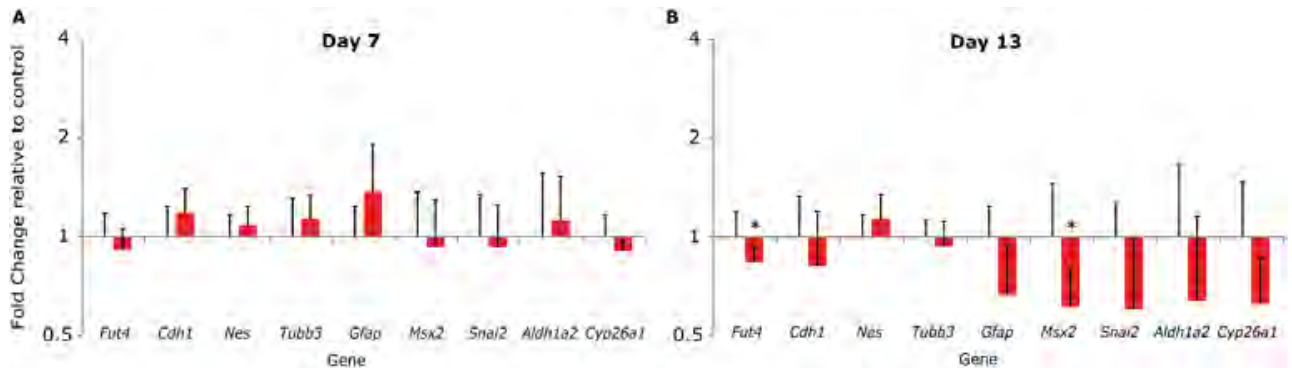

Figure. 6. Relative difference in gene expression between compounds and their time-matched control for (A) day 7 and $(B)$ day 13 (control, EMPA in red). The vertical axis indicates fold change for each of the genes on the horizontal axis. Significance $p<0.05$; error bars: Standard deviation; $n=7$ per condition in a single experiment. 


\section{Discussion}

In this study, we have explored the ability of the ESTn to distinguish chemical analogues based on effects on neural cell differentiation. Building on whole genome data from days 0 to 7 of the protocol [18], we have extended gene expression analysis until day 13 , specifically focusing on different cell types that are formed in the ESTn. The presence of these cell types was verified using immunostainings. Three VPA analogues could be discriminated from each other in terms of their effects on cell differentiation using a combination of morphological, gene expression and protein expression endpoints. With these three approaches we could not only define the relative potency of the compounds but also provide mechanistic insight into why these compounds may or may not be harmful for early differentiation in the brain. In short, VPA and EHA adversely affected normal differentiation while EMPA had no adverse effect on the neuronal differentiation of the ESTn up to $1 \mathrm{mM}$.

The ESTn expressed cell markers of at least four of the major cell types that can be found in the developing brain: stem cells, neurons, astrocytes and neural crest cells. Oligodendrocytes were not (yet) present, which may relate to their later formation in morphogenesis [34] and/or due to culture conditions [35]. The presence of microglia has not been tested, but it is unlikely that this cell type is present due to either or both of above-mentioned reasons. Evidence provided by immunostainings shows that neurons mature up to the point of creating Vglut2 ${ }^{+}$vesicles for synaptic transmission. This suggests that the ESTn mimics parts of early neurodevelopment from stem cells to neurons that could be capable of communicating with each other later in development. Amongst other genes, Snai2 transcriptionally suppresses $\mathrm{C} d h \mathbf{h}$ expression [36], which was also visible during differentiation of the ESTn. Both at a genetic and protein level, the increasing expression of Snai2/Slug concurred with a steady decrease of Cdh7/Ecadherin expression. The dynamics of RA metabolism were also apparent. Cyp26a 7 expression was upregulated dramatically on the $4^{\text {th }}$ differentiation day by the addition of RA, which is consistent with other experimental findings in various in vitro and in vivo models [18,37-39]. At the same time, $A / d h 7 a 2$ is supposed to be downregulated by RA in vivo [40], by which it can regulate its own homeostasis. Interestingly, in our cell culture, Aldh7a2 expression rises steadily over time, even in the presence of a high concentration of RA. This may be due to the absence of homeostasis in this in vitro system, as opposed to intact animals.

Taken the results together, VPA and EHA affect neural differentiation. These effects were observed in aggregate cultures at concentrations that did not affect undifferentiated cells in monolayer culture. Given that monolayer culture is more susceptible to cytotoxicity than aggregate culture [41-43], we therefore consider these compounds to cause specific effects on the differentiation process. This is consistent with research performed in other stem cell lines [4447]. In line with the order of occurrence of the different cell types, VPA and EHA initially mainly upregulated a pre-neural tube marker ( $C d h 7)$ and later on in the protocol primarily upregulated a stem cell marker (Fut4). Consistent with this, at first a marker for neural progenitors (Nes) is upregulated, while a marker for neurons (Tubb3) is downregulated later in differentiation. Neural crest cell expression, however, is affected by VPA in an opposite fashion, first affecting the EMT marker Snai2 and later the early neural crest cell markers. EHA may act similarly, but this cannot be stated based on the current data set. This effect suggests that the primary target of VPA, and potentially EHA, is aimed at the inhibition of EMT differentiation of early neural crest 
cells and secondarily at the early neural crest cells themselves. The concurrence of Snai2 inhibition and Cdh 7 upregulation are in line with the effect of Snai2 on Cdh1 as mentioned above.

In the ESTn, VPA and EHA caused a severe downregulation of Gfap expression on both the gene- and protein level. Both in vitro and in vivo studies have also found regulation of Gfap by VPA, however both up and downregulation of the protein have been reported [48-51]. This may be caused by species differences, use of different exposure methods or culture methods. An elegant study by Kazlauskas et al. [52] showed that the effects of VPA on Gfap expression may be time- and brain region dependent in vivo and does have behavioural consequences in the exposed pups. Regardless, VPA and EHA, but not EMPA, regulate Gfap expression and this might underlie the mechanisms of neurodevelopmental toxicity of these compounds.

While EMPA is not a teratogen $[23,38,53]$ and does not have significant effects on any of the genetic markers, it does tend to decrease neural crest cell markers, without affecting other cell types. Additionally, RA related gene expression also tends to be decreased by EMPA, similar effects as were found with VPA and EHA. This seems to be in line with research done in another stem cell model whereby EMPA acted in a similar way on Aldh1a2 and Cyp26a1 expression, but without being cytotoxic to the cells [38]. There may be a very small difference between the extent of gene expression changes that could explain why EMPA is not embryotoxic and VPA is. Another explanation may be that VPA acts through more mechanisms, such as rearrangement of the cytoskeleton, which was only seen in VPA treated cells and not in EMPA treated cells [38].

In relation to these compounds it has been proven again that a combination of several readouts enhances the interpretation of experimental findings. For example, the absence of $\mathrm{Gfap}^{+}$cells was obvious from the immunostainings, which provides a functional lead as to the potential toxicity mechanism of VPA and EHA. On the contrary, neural crest markers were not obviously affected on the protein level, exemplified by the lack of decline seen in immunostainings, while gene expression was affected. In this case, gene expression serves as the canary in the coal mine pointing to mechanisms that are not (yet) visible at a protein level. An interesting line of research would be to use of flow cytometry in addition to the immunostainings to determine more precisely the proportions of different cell types and the effects of compounds on these proportions $[19,44]$.

Day 7 and 13 in ESTn appear to be the most sensitive days to assess the toxicity of the VPA analogues on cell types. Both are relevant days since different cell types are present. Day 4 and 10 turned out to be less suitable days to measure gene expression. This is probably due to technical reasons; on the third day of the protocol, RA is added to the EBs, which in itself already has major effects on gene expression that may cloud more subtle effects of compound exposure. On the seventh day of the differentiation protocol, EBs are dissociated and replated, which is a relatively harsh but necessary procedure. This could explain why on day 10 gene expression still varies substantially within conditions and again makes it challenging to find effects caused by compounds at this stage within the differentiation protocol.

The added value of using the ESTn next to the ESTc is that with developmental mechanisms in the formation of the neural tube and early brain development it provides another differentiation route for testing adverse effects of chemicals. ESTc has proven to be useful for predicting teratogenicity of these compounds in general, but the ESTn turns out to be more sensitive for these compounds: VPA 251 vs $87.2 \mu \mathrm{M}$ (ESTc vs ESTn), EHA 794 vs $283 \mu \mathrm{M}$ and EMPA not 
toxic below $2.5 \mathrm{mM}$ vs not toxic below $1 \mathrm{mM}[30,54,55]$. Moreover, the effects on the neural and glial lineage (e.g. the effects on neural progenitors and astrocytes) can only be assessed in the ESTn.

Interspecies extrapolation is an important aspect in the light of in vitro to in vivo extrapolation $[7,56]$. As to the human-rodent comparison, the major differences lie in the higher integration level of pattern formation and in the complexity of the neuronal networks. The regulation of basic differentiation of individual cell types from embryonic stem and progenitor cells is thought to be highly conserved in vertebrates [57,58], and this is what is mimicked in the embryonic stem cell test [12]. Moreover, within species, different cell lines may require different culture conditions for optimal cell differentiation [59]. Therefore, although interspecies extrapolation is certainly relevant and important for mouse ESTn, its biological domain can be considered a useful corollary of the human situation.

While the cell types studied cover a considerable proportion of the cells present in the ESTn cell culture, it may be useful to use additional markers of cell types in the mesodermal and endodermal lineage, as well as the (non-)neural ectodermal lineage. It has been suggested based on whole genome analysis that, VPA upregulates the non-ectodermal lineage in differentiating human embryonic stem cells $[47,60,61]$. A promising line of research would be to test other neurodevelopmental toxicants with this addition of extra cell markers to investigate whether the model is able to pick up the toxic potential of these compounds [62-64]. A strategic selection of compounds with different modes of action at different time points in neural development can further characterise the applicability domain of the ESTn.

\section{Transparency document}

The Transparency document associated with this article can be found in the online version.

\section{Acknowledgements}

This research is funded by the Dutch NGO Stichting Proefdiervrij, the Dutch Ministry of Agriculture, Nature and Food Quality and the Dutch Ministry of Health, Welfare and Sports. We would like to thank Conny van Oostrom and Hennie Hodemakers for their contribution to the laboratory work, and Harm Heusinkveld for a critical review of the manuscript. 


\section{References}

[1] C. Rovida, T. Hartung, Re-evaluation of animal numbers and costs for in vivo tests to accomplish REACH legislation requirements for chemicals - a report by the transatlantic think tank for toxicology (t(4))., ALTEX. 26 (2009) 187-208.

[2] A.R. Scialli, A.J. Guikema, REACH and reproductive and developmental toxicology: still questions., Syst. Biol. Reprod. Med. 58 (2012) 63-69. https://doi.org/10.3109/19396368.2011.648301.

[3] A. Bal-Price, S. Coecke, L. Costa, K.M. Crofton, E. Fritsche, A. Goldberg, P. Grandjean, P.J. Lein, A. Li, R. Lucchini, W.R. Mundy, S. Padilla, A.M. Persico, A.E.M. Seiler, J. Kreysa, Advancing the science of developmental neurotoxicity (DNT): testing for better safety evaluation, ALTEX. 29 (2012) 202-215 https://doi.org/10.14573/altex.2012.2.202.

[4] A. Bal-Price, K.M. Crofton, M. Leist, S. Allen, M. Arand, T. Buetler, N. Delrue, R.E. FitzGerald, T. Hartung, T. Heinonen, H. Hogberg, S.H. Bennekou, W. Lichtensteiger, D. Oggier, M. Paparella, M. Axelstad, A. Piersma, E. Rached, B. Schilter, G. Schmuck, L. Stoppini, E. Tongiorgi, M. Tiramani, F. Monnet-Tschudi, M.F. Wilks, T. Ylikomi, E. Fritsche, International STakeholder NETwork (ISTNET): creating a developmental neurotoxicity (DNT) testing road map for regulatory purposes, Arch. Toxicol. 89 (2015) 269-287. https://doi.org/10.1007/s00204-015-1464-2.

[5] K.M. Crofton, W.R. Mundy, T.J. Shafer, Developmental neurotoxicity testing: A path forward, Congenit. Anom. (Kyoto). 52 (2012) 140-146. https://doi.org/10.1111/j.1741-4520.2012.00377.x.

[6] C. Tohyama, Developmental neurotoxicity test guidelines: problems and perspectives, J. Toxicol. Sci. 41 (2016) SP69-SP79. https://doi.org/10.2131/jts.41.SP69.

[7] A. Bal-Price, H.T. Hogberg, K.M. Crofton, M. Daneshian, R.E. Fitzgerald, E. Fritsche, T. Heinonen, S.H. Bennekou, S. Klima, A.H. Piersma, M. Sachana, T.J. Shafer, A. Terron, F. Monnet-Tschudi, B. Viviani, T. Waldmann, R.H.S. Westerink, M.F. Wilks, H. Witters, M.-G. Zurich, M. Leist, Workshop report recommendation on test readiness criteria for new approach methods in toxicology: exemplified for developmental neurotoxicity 1, ALTEX. 35 (2018) 306-352. https://doi.org/10.14573/altex.1712081.

[8] E. Fritsche, P. Grandjean, K.M. Crofton, M. Aschner, A. Goldberg, T. Heinonen, E.V.S. Hessel, H.T. Hogberg, S.H. Bennekou, P.J. Lein, M. Leist, W.R. Mundy, M. Paparella, A.H. Piersma, M. Sachana, G. Schmuck, R. Solecki, A. Terron, F. Monnet-Tschudi, M.F. Wilks, H. Witters, M.G. Zurich, A. Bal-Price, Consensus statement on the need for innovation, transition and implementation of developmental neurotoxicity (DNT) testing for regulatory purposes, Toxicol. Appl. Pharmacol. 354 (2018) 3-6. https://doi.org/10.1016/j.taap.2018.02.004.

[9] N. Baker, A. Boobis, L. Burgoon, E. Carney, R. Currie, E. Fritsche, T. Knudsen, M. Laffont, A.H. Piersma, A. Poole, S. Schneider, G. Daston, Building a developmental toxicity ontology, Birth Defects Res. 110 (2018) 502-518. https://doi.org/10.1002/bdr2.1189.

[10] E.V.S. Hessel, Y.C.M. Staal, A.H. Piersma, Design and validation of an ontology-driven animal-free testing strategy for developmental neurotoxicity testing, Toxicol. Appl. Pharmacol. 1 (2018) 136-152. https://doi.org/10.1016/j.taap.2018.03.013

[11] A.H. Piersma, T. Burgdorf, K. Louekari, B. Desprez, R. Taalman, R. Landsiedel, J. Barroso, V. Rogiers, C. Eskes, M. Oelgeschläger, M. Whelan, A. Braeuning, A.M. Vinggaard, A. Kienhuis, J. van Benthem, J. Ezendam, Workshop on acceleration of the validation and regulatory acceptance of alternative methods and implementation of testing strategies, in: Toxicol. Vitr., 2018: pp. 62-74. https://doi.org/10.1016/j.tiv.2018.02.018.

[12] P.T. Theunissen, S.H.W. Schulpen, D.A.M. van Dartel, S.A.B. Hermsen, F.J. van Schooten, A.H. Piersma, An abbreviated protocol for multilineage neural differentiation of murine embryonic stem cells and its perturbation by methyl mercury, Reprod. Toxicol. $29 \quad$ (2010) 383-392. https://doi.org/10.1016/j.reprotox.2010.04.003.

[13] E. Genschow, H. Spielmann, G. Scholz, I. Pohl, A. Seiler, N. Clemann, S. Bremer, K. Becker, Validation of the embryonic stem cell test in the international ECVAM validation study on three in vitro embryotoxicity tests, in: ATLA Altern. to Lab. Anim., 2004: pp. 209-244.

[14] D. Baek, T. Kim, H. Lim, J. Kang, S. Seong, S. Choi, S. Lim, S. Park, B. Nam, E. Kim, M. Kim, Park KL, Embryotoxicity assessment of developmental neurotoxicants using a neuronal endpoint in the embryonic stem cell test, J. Appl. Toxicol. 32 (2011) 617-626. https://doi.org/10.1002/jat.1747.

[15] P.T. Theunissen, J.L.A. Pennings, D.A.M. van Dartel, J.F. Robinson, J.C.S. Kleinjans, A.H. Piersma, Complementary detection of embryotoxic properties of substances in the neural and cardiac embryonic stem cell tests, Toxicol. Sci. 132 (2013) 118-130. https://doi.org/10.1093/toxsci/kfs333.

[16] P.T. Theunissen, J.F. Robinson, J.L.A. Pennings, E. De jong, S.M.H. Claessen, J.C.S. Kleinjans, A.H. Piersma, Transcriptomic concentration-response evaluation of valproic acid, cyproconazole, and hexaconazole in the neural Embryonic Stem Cell Test (ESTn), Toxicol. Sci. 125 (2012) 430-438. https://doi.org/10.1093/toxsci/kfr293.

[17] P.T. Theunissen, J.F. Robinson, J.L.A. Pennings, M.H. van Herwijnen, J.C.S. Kleinjans, A.H. Piersma Compound-specific effects of diverse neurodevelopmental toxicants on global gene expression in the neural embryonic stem cell test (ESTn), Toxicol. Appl. Pharmacol. 262 (2012) 330-340. https://doi.org/10.1016/j.taap.2012.05.011. 
[18] P.T. Theunissen, J.L.A. Pennings, J.F. Robinson, S.M.H. Claessen, J.C.S. Kleinjans, A.H. Piersma, Timeresponse evaluation by transcriptomics of methylmercury effects on neural differentiation of murine embryonic stem cells, Toxicol. Sci. 122 (2011) 437-447. https://doi.org/10.1093/toxsci/kfr134.

[19] A. Visan, K. Hayess, D. Sittner, E.E. Pohl, C. Riebeling, B. Slawik, K. Gulich, M. Oelgeschläger, A. Luch, A.E.M. Seiler, Neural differentiation of mouse embryonic stem cells as a tool to assess developmental neurotoxicity in vitro, Neurotoxicology. 33 (2012) 1135-1146. https://doi.org/10.1016/j.neuro.2012.06.006.

[20] B. Zimmer, P. Kuegler, B. Baudis, A. Genewsky, V. Tanavde, W. Koh, B. Tan, T. Waldmann, S. Kadereit, M. Leist, Coordinated waves of gene expression during neuronal differentiation of embryonic stem cells as basis for novel approaches to developmental neurotoxicity testing, Cell Death Differ. 18 (2010) 383-395. https://doi.org/10.1038/cdd.2010.109.

[21] U. Bojic, M.M.A. Elmazar, R.-S. Hauck, H. Nau, Further branching of valproate-related carboxylic acids reduces the teratogenic activity, but not the anticonvulsant effect, Chem. Res. Toxicol. 9 (1996) 866-870. https://doi.org/10.1021/tx950216s.

[22] C. Courage-Maguire, C.L. Bacon, H. Nau, C.M. Regan, Correlation of in vitro anti-proliferative potential with in vivo teratogenicity in a series of valproate analogues, Int. J. Dev. Neurosci. 15 (1997) 37-43. https://doi.org/10.1016/S0736-5748(96)00069-X.

[23] D. Eikel, A. Lampen, H. Nau, Teratogenic effects mediated by inhibition of histone deacetylases: Evidence from quantitative structure activity relationships of 20 valproic acid derivatives, Chem. Res. Toxicol. 19 (2006) 272-278. https://doi.org/10.1021/tx0502241.

[24] W. Löscher, H. Nau, Pharmacological evaluation of various metabolites and analogues of valproic acid Anticonvulsant and toxic potencies in mice, Neuropharmacology. 24 (1985) 427-435. https://doi.org/10.1016/0028-3908(85)90028-0.

[25] W.J. Scott, M.D. Collins, H. Nau, Pharmacokinetic determinants of embryotoxicity in rats associated with organic acids, in: Environ. Health Perspect., 1994: pp. 97-101.

[26] J. Jentink, M.A. Loane, H. Dolk, I. Barisic, E. Garne, J.K. Morris, L.T.W. de Jong-van den Berg, EUROCAT Antiepileptic Study Working Group, Valproic acid monotherapy in pregnancy and major congenital malformations., N. Engl. J. Med. 362 (2010) 2185-2193. https://doi.org/10.1056/NEJMoa0907328.

[27] E. Robert, P. Guibaud, Maternal valproic acid and congenital neural tube effects, Lancet. 2 (1982) 937. https://doi.org/10.1016/S0140-6736(82)90908-4.

[28] K. Wide, B. Winbladh, B. Källén, Major malformations in infants exposed to antiepileptic drugs in utero, with emphasis on carbamazepine and valproic acid: A nation-wide, population-based register study, Acta Paediatr. Int. J. Paediatr. 93 (2004) 174-176. https://doi.org/10.1080/08035250310021118.

[29] A. Hughes, N.D.E. Greene, A.J. Copp, G.L. Galea, Valproic acid disrupts the biomechanics of late spinal neural tube closure in mouse embryos, Mech. Dev. 149 (2018) 20-26. https://doi.org/10.1016/j.mod.2017.12.001.

[30] E.D. Kroese, S. Bosgra, H.E. Buist, G. Lewin, S.C. van der Linden, H. yen Man, A.H. Piersma, E. Rorije, S.H.W. Schulpen, M. Schwarz, F. Uibel, B.M.A. van Vugt-Lussenburg, A.P.M. Wolterbeek, B. van der Burg, Evaluation of an alternative in vitro test battery for detecting reproductive toxicants in a grouping context, Reprod. Toxicol. 55 (2015) 11-19. https://doi.org/10.1016/j.reprotox.2014.10.003.

[31] E.J. Ritter, W.J. Scott, J.L. Randall, J.M. Ritter, Teratogenicity of di(2-ethylhexyl) phthalate, 2-ethylhexanol, 2ethylhexanoic acid, and valproic acid, and potentiation by caffeine, Teratology. 35 (1987) 41-46. https://doi.org/10.1002/tera.1420350107.

[32] M.W. Pfaffl, A new mathematical model for relative quantification in real-time RT-PCR, Nucleic Acids Res. 29 (2001) e45. https://doi.org/10.1093/nar/29.9.e45.

[33] W. Slob, Dose-response modeling of continuous endpoints, Toxicol. Sci. 66 (2002) 298-312. https://doi.org/10.1093/toxsci/66.2.298.

[34] K. Reemst, S.C. Noctor, P.J. Lucassen, E.M. Hol, The indispensable roles of microglia and astrocytes during brain development, Front. Hum. Neurosci. 10 (2016) 566. https://doi.org/10.3389/fnhum.2016.00566.

[35] A. Bal-Price, F. Pistollato, M. Sachana, S.K. Bopp, S. Munn, A. Worth, Strategies to improve the regulatory assessment of developmental neurotoxicity (DNT) using in vitro methods, Toxicol. Appl. Pharmacol. In press (2018). https://doi.org/10.1016/j.taap.2018.02.008

[36] V. Bolós, H. Peinado, M.A. Perez-Moreno, M.F. Fraga, M. Esteller, A. Cano, The transcription factor Slug represses E-cadherin expression and induces epithelial to mesenchymal transitions: a comparison with Snail and E47 repressors, J. Cell Sci. 116 (2003) 499-511. https://doi.org/10.1242/jcs.188243.

[37] R.F. Gillespie, L.J. Gudas, Retinoid Regulated Association of Transcriptional Co-regulators and the Polycomb Group Protein SUZ12 with the Retinoic Acid Response Elements of Hoxa1, RARß2, and Cyp26A1 in F9 Embryonal Carcinoma Cells, J. Mol. Biol. 372 (2007) 298-316. https://doi.org/10.1016/j.jmb.2007.06.079.

[38] M. Jergil, M. Forsberg, H. Salter, K. Stockling, A.L. Gustafson, L. Dencker, M. Stigson, Short-time gene expression response to valproic acid and valproic acid analogs in mouse embryonic stem cells, Toxicol. Sci. 121 (2011) 328-342. https://doi.org/10.1093/toxsci/kfr070.

[39] R.J. White, T.F. Schilling, How degrading: Cyp26s in hindbrain development, Dev. Dyn. 237 (2008) 2775-2790 https://doi.org/10.1002/dvdy.21695.

[40] K. Niederreither, P. McCaffery, U.C. Dräger, P. Chambon, P. Dollé, Restricted expression and retinoic acidinduced downregulation of the retinaldehyde dehydrogenase type 2 (RALDH-2) gene during mouse 
development., Mech. Dev. 62 (1997) 67-78. https://doi.org/https://doi.org/10.1016/S0925-4773(96)006533 .

[41] K.F. Chambers, E.M.O. Mosaad, P.J. Russell, J.A. Clements, M.R. Doran, 3D cultures of prostate cancer cells cultured in a novel high-throughput culture platform are more resistant to chemotherapeutics compared to cells cultured in monolayer, PLoS One. 9 (2014). https://doi.org/10.1371/journal.pone.0111029.

[42] N.C. Cheng, S. Wang, T.H. Young, The influence of spheroid formation of human adipose-derived stem cells on chitosan films on stemness and differentiation capabilities, Biomaterials. 33 (2012) 1748-1758. https://doi.org/10.1016/j.biomaterials.2011.11.049.

[43] F.F. Sun, Y.H. Hu, L.P. Xiong, X.Y. Tu, J.H. Zhao, S.S. Chen, J. Song, X.Q. Ye, Enhanced expression of stem cell markers and drug resistance in sphere-forming non-small cell lung cancer cells, Int. J. Clin. Exp. Pathol. 8 (2015) 6287-6300. https://www.ncbi.nlm.nih.gov/pubmed/26261505.

[44] W.S. Cao, J.C. Livesey, R.F. Halliwell, An evaluation of a human stem cell line to identify risk of developmental neurotoxicity with antiepileptic drugs, Toxicol. Vitr. $29 \quad$ (2015) 592-599. https://doi.org/10.1016/J.TIV.2015.01.010.

[45] S.H.W. Schulpen, E. de Jong, L.J.J. de la Fonteyne, A. de Klerk, A.H. Piersma, Distinct gene expression responses of two anticonvulsant drugs in a novel human embryonic stem cell based neural differentiation assay protocol, Toxicol. Vitr. 29 (2015) 449-457. https://doi.org/10.1016/j.tiv.2014.12.001.

[46] V. Shinde, S. Perumal Srinivasan, M. Henry, T. Rotshteyn, J. Hescheler, J. Rahnenführer, M. Grinberg, J. Meisig, N. Blüthgen, T. Waldmann, M. Leist, J.G. Hengstler, A. Schinidis, Comparison of a teratogenic transcriptomebased predictive test based on human embryonic versus inducible pluripotent stem cells, Stem Cell Res. Ther. 7 (2016). https://doi.org/doi:10.1186/s13287-016-0449-2.

[47] T. Waldmann, M. Grinberg, A. König, E. Rempel, S. Schildknecht, M. Henry, A. K. Holzer, N. Dreser, V. Shinde, A. Sachinidis, J. Rahnenführer, J.G. Hengstler, M. Leist, Stem cell transcriptome responses and corresponding biomarkers that indicate the transition from adaptive responses to cytotoxicity, Chem. Res. Toxicol. 30 (2017) 905-922. https://doi.org/10.1021/acs.chemrestox.6b00259.

[48] V. Balasubramaniyan, E. Boddeke, R. Bakels, B. Küst, S. Kooistra, A. Veneman, S. Copray, Effects of histone deacetylation inhibition on neuronal differentiation of embryonic mouse neural stem cells, Neuroscience. 143 (2006) 939-951. https://doi.org/10.1016/j.neuroscience.2006.08.082.

[49] J. Brunn, V. Wiroth, M. Kowalski, U. Runge, M. Sabolek, Valproic acid in normal therapeutic concentration has no neuroprotective or differentiation influencing effects on long term expanded murine neural stem cells, Epilepsy Res. 108 (2014) 623-633. https://doi.org/10.1016/j.eplepsyres.2014.02.005.

[50] W. Chu, J. Yuan, L. Huang, X. Xiang, H. Zhu, F. Chen, Y. Chen, J. Lin, H. Feng, Valproic acid arrests proliferation but promotes neuronal differentiation of adult spinal NSPCs from SCI rats, Neurochem. Res. 40 (2015) 14721486. https://doi.org/10.1007/s11064-015-1618-x.

[51] H.J. Lee, C. Dreyfus, E. DiCicco-Bloom, Valproic acid stimulates proliferation of glial precursors during cortical gliogenesis in developing rat., Dev. Neurobiol. 76 (2016) 780-798. https://doi.org/10.1002/dneu.22359.

[52] N. Kazlauskas, M. Campolongo, L. Lucchina, C. Zappala, A.M. Depino, Postnatal behavioral and inflammatory alterations in female pups prenatally exposed to valproic acid, Psychoneuroendocrinology. 72 (2016) 11-21. https://doi.org/10.1016/j.psyneuen.2016.06.001.

[53] B.J. Eickholt, Effects of valproic acid derivatives on inositol trisphosphate depletion, teratogenicity, glycogen synthase kinase-3 inhibition, and viral replication: a screening approach for new bipolar disorder drugs derived from the valproic acid core structure, Mol. Pharmacol. 67 (2005) 1426-1433. https://doi.org/10.1124/mol.104.009308.

[54] E. de Jong, A.M.C.. M. Doedée, M.A. Reis-Fernandes, H. Nau, A.H. Piersma, Potency ranking of valproic acid analogues as to inhibition of cardiac differentiation of embryonic stem cells in comparison to their in vivo embryotoxicity., Reprod. Toxicol. 31 (2011) 375-382. https://doi.org/10.1016/j.reprotox.2010.11.012.

[55] C. Riebeling, R. Pirow, K. Becker, R. Buesen, D. Eikel, J. Kaltenhäuser, F. Meyer, H. Nau, B. Slawik, A. Visan, J. Volland, H. Spielmann, A. Luch, A. Seiler, The embryonic stem cell test as tool to assess structure-dependent teratogenicity: the case of valproic acid., Toxicol. Sci. 120 (2011) 360-370. https://doi.org/10.1093/toxsci/kfr001.

[56] L. Smirnova, H.T. Hogberg, M. Leist, T. Hartung, Food for thought...: Developmental neurotoxicity - Challenges in the 21st century and in vitro opportunities, ALTEX. 31 (2014) 129-156. https://doi.org/10.14573/altex.1403271.

[57] N. Irie, S. Kuratani, Comparative transcriptome analysis reveals vertebrate phylotypic period during organogenesis, Nat. Commun. 2 (2011). https://doi.org/10.1038/ncomms1248.

[58] N. Irie, S. Kuratani, The developmental hourglass model: a predictor of the basic body plan?, Development. 141 (2014) 4649-4655. https://doi.org/10.1242/dev.107318.

[59] M. Leist, A. Ringwald, R. Kolde, S. Bremer, C. van Thriel, K.-H. Krause, J. Rahnenführer, A. Sachinidis, J. Hescheler, J.G. Hengstler, Test systems of developmental toxicity: state-of-the art and future perspectives, Arch. Toxicol. 87 (2013) 2037-2042. https://doi.org/10.1007/s00204-013-1154-x.

[60] N. V. Balmer, S. Klima, E. Rempel, V.N. Ivanova, R. Kolde, M.K. Weng, K. Meganathan, M. Henry, A. Sachinidis, M.R. Berthold, J.G. Hengstler, J. Rahnenführer, T. Waldmann, M. Leist, From transient transcriptome responses to disturbed neurodevelopment: Role of histone acetylation and methylation as epigenetic switch 
between reversible and irreversible drug effects, Arch. Toxicol. 88 (2014) 1451-1468. https://doi.org/10.1007/s00204-014-1279-6.

[61] K. Meganathan, S. Jagtap, S.P. Srinivasan, V. Wagh, J. Hescheler, J. Hengstler, M. Leist, A. Sachinidis, Neuronal developmental gene and miRNA signatures induced by histone deacetylase inhibitors in human embryonic stem cells, Cell Death Dis. 6 (2015). https://doi.org/10.1038/cddis.2015.121.

[62] M. Aschner, S. Ceccatelli, M. Daneshian, E. Fritsche, N. Hasiwa, T. Hartung, H.T. Hogberg, M. Leist, A. Li, W. R. Mundy, S. Padilla, A.H. Piersma, A. Bal-Price, A. Seiler, R.H. Westerink, B. Zimmer, P.J. Lein, Reference compounds for alternative test methods to indicate developmental neurotoxicity (DNT) potential of chemicals: Example lists \& criteria for their selection \& use, in: ALTEX, 2017: pp. 49-74. https://doi.org/10.14573/altex.1604201.

[63] K.M. Crofton, W.R. Mundy, P.J. Lein, A. Bal-Price, S. Coecke, A.E.M. Seiler, H. Knaut, L. Buzanska, A. Goldberg, Developmental neurotoxicity testing: recommendations for developing alternative methods for the screening and prioritization of chemicals., ALTEX. 28 (2011) 9-15. https://doi.org/10.14573/altex.2011.1.009.

[64] W.R. Mundy, S. Padilla, J.M. Breier, K.M. Crofton, M.E. Gilbert, D.W. Herr, K.F. Jensen, N.M. Radio, K.C. Raffaele, K. Schumacher, T.J. Shafer, J. Cowden, Expanding the test set: Chemicals with potential to disrupt mammalian brain development, Neurotoxicol. Teratol. $52 \quad$ (2015) 25-35. https://doi.org/10.1016/j.ntt.2015.10.001. 




\section{CHAPTER 6}

\section{DIFFERENTIAL EFFECTS OF FLUOXETINE AND VENLAFAXINE IN THE NEURAL EMBRYONIC STEM CELL TEST (ESTN) REVEALED BY A CELL LINEAGE MAP}

Victoria C. de Leeuw ${ }^{1,2}$, Jeroen L.A. Pennings' ${ }^{1}$, Hennie M. Hodemaekers' ${ }^{1}$, Paul F.K. Wackers ${ }^{1}$, Conny T. M. van Oostrom ${ }^{1}$, Ellen V.S. Hessel ${ }^{1}$, Aldert H. Piersma ${ }^{1,2}$

${ }^{1}$ Centre for Health Protection, National Institute for Public Health and the Environment, Bilthoven, the Netherlands

${ }^{2}$ Institute for Risk Assessment Sciences, Utrecht University, Utrecht, the Netherlands

NeuroToxicology, 2020 Jan, 76:1-9

DOI: 10.1016/j.neuro.2019.09.014 



\section{Abstract}

There is a need for in vitro tests for the evaluation of chemicals and pharmaceuticals that may cause developmental neurotoxicity (DNT) in humans. The neural embryonic stem cell test (ESTn) is such an in vitrotest that mimics early neural differentiation. The aim of this study was to define the biological domain of ESTn based on the expression of selective markers for certain cell types, and to investigate the effects of two antidepressants, fluoxetine (FLX) and venlafaxine (VNX), on neural differentiation. A cell lineage map was made to track neural differentiation and the effects of FLX and VNX in ESTn. Whole transcriptome analysis revealed differentiation from an embryonic stem cell population to a mixed culture of neural progenitors, neurons and neural crest cells 7 days into differentiation. Maturing neurons, astrocytes and oligodendrocytes were present after 13 days. Exposure to FLX or VNX led to different expression patterns between compounds at both time points. On day 7 , both compounds upregulated most of the stem cell- and immature neuron markers, but had distinct effects on neural subtype markers. FLX downregulated glycinergic markers and upregulated cholinergic markers, while VNX had the opposite effect. On day 13, FLX and VNX affected their specific therapeutic targets, represented by mainly serotonergic markers by FLX- and dopaminergic and noradrenergic markers in VNX-exposed cultures, as well as oligodendrocyte and glycinergic neuron markers. This proof of concept study shows the added value of assessing DNT in ESTn through a cell lineage map and gives mechanistic insight in the potential neurodevelopmental effects of FLX and VNX. More compounds should be tested to further evaluate the use of the cell lineage map. 


\section{Introduction}

In the current regulatory frameworks for chemical safety, animal testing for the safety evaluation of chemicals regarding developmental and reproductive toxicity is mandatory and requires relatively large numbers of laboratory animals [1]. However, the use of laboratory animals is under ethical debate and animals represent human physiology only to a certain extent [2]. This is especially true for developmental neurotoxicity (DNT) due to the complex nature of the human brain [3]. There is increasing societal concern with regard to the effects of chemicals on human brain development whereas there are no reliable test systems to adequately investigate DNT [4]. In addition, (D)NT is currently not obligatory in regulatory testing. Therefore, there is a high need for a robust, set of non-animal in vitro and in silico tests that can be used to assess and provide mechanistic insight into the developmental neurotoxicity of chemicals [3,5-7].

One of the in vitro tests that can be used in this regard is the neural embryonic stem cell test (ESTn). This in vitro system replicates early neural differentiation of stem cells to neurons and neural-related cell types [8,9]. In our recent study, we have shown that ESTn is able to distinguish three valproic acid analogues [10], which are known to cause neural tube defects $[11,12]$. The analogues could be distinguished based on gene expression of a limited number of cell type markers.

In order to further test this approach, we measured a more extensive set of cell type markers in ESTn exposed to two types of anti-depressants: the selective serotonin receptor inhibitor (SSRI) fluoxetine (FLX, tradename Prozac) and the serotonin-norepinephrine reuptake inhibitor (SNRI) venlafaxine (VNX, tradename Effexor). Both drugs are classified as US pregnancy category $\mathrm{C}$, indicating possible human risks in pregnancy based on animal experiments, in the presence of major therapeutic benefits. The intended mechanism of FLX is to inhibit the serotonin receptor, but it also has weak affinity for dopamine and noradrenaline receptors [13]. VNX inhibits both the serotonin and noradrenaline receptor, and at high doses dopaminergic receptors [14]. In the developing embryo, these receptors are expressed throughout the body and are important for normal (neural) development [15-17]. FLX as well as VNX are able to cross the placental barrier $[18,19]$ and therefore may affect the embryo. Epidemiological evidence for the potential risks of these drugs is not conclusive, but mainly points towards cardiac malformations [20-22]. However, the absolute risks are often found to be small or findings do not reach statistical significance $[23,24]$. Whether the drugs may lead to neural tube defects and neurobehavioral effects such as autism and ADHD is also under debate [25-28]. Animal studies in rat pups have shown that both FLX and VNX exposure may lead to reduced numbers of neurons in the neocortex and may induce anxiety behaviour [29,30]. Limited in vitro evidence suggests that at least FLX may not only act via serotonin receptor inhibition. In a study using P19C5 cells, an in vitro test to assess axial elongation and patterning of the embryo, FLX but not VNX caused altered morphology of the embryoid body mediated by inhibition of the Wntpathway [31]. At the same time, VNX but not FLX caused decreased expression of synaptic genes and proteins in neuroblastoma cells exposed to levels of VNX that are found in ground water [32], while FLX has been shown to decrease neural network firing [33,34]. In conclusion, there are several lines of evidence that FLX and VNX may affect neural development at different stages, but mechanistic insight is largely lacking. 
The aim of the current study was twofold: firstly to define the biological domain of ESTn using whole transcriptome sequencing and zoom in on the presence of cell types throughout development. To this end, a cell lineage map was developed based on available literature. Secondly, the influence of FLX and VNX on biological processes and on cell types was assessed to study common and unique modes of action using the cell lineage map as read-out for developmental neurotoxicity in ESTn.

\section{Material and methods}

\section{Neural Differentiation of embryonic stem cells}

Murine embryonic stem cells (ES-D3, ATCC, Manassas, VA, USA) were maintained on polystyrene $35 \mathrm{~mm}$ plates (Corning, New York, NY, USA) in a humidified atmosphere at $37^{\circ} \mathrm{C}$ and $5 \%$ $\mathrm{CO}_{2}$, and passaged every two to three days. The culture medium, hereafter called complete medium (CM), consisted of Dulbecco's modified Eagle's medium (DMEM; Gibco, Waltham, MA, USA) supplemented with 20\% fetal bovine serum (FBS; Greiner Bio-One, Kremsmünster, Austria), 200 mM Lglutamine (Gibco), 1\% nonessential amino acids (Gibco), 1\% penicillin/ streptomycin (Gibco), and $0.1 \mathrm{mM} \beta$-mercaptoethanol (Sigma-Aldrich, Zwijndrecht, The Netherlands). $\mathrm{CM}$ was supplemented with murine leukemia-inhibiting factor (mLIF; Millipore, Burlington, MA, USA) to maintain pluripotency of the cells.

Neural differentiation was performed as described in Theunissen et al. [9]. A cell suspension in $\mathrm{CM}$ of $15 \times 10^{4}$ cells $/ \mathrm{mL}$ was made, which was further diluted to $3.75 \times 10^{4}$ cells $/ \mathrm{mL}$ and put on ice. The inner side of a $100 \mathrm{~mm}$ petri dish lid (Greiner Bio-One) was filled with suspension droplets of $20 \mu \mathrm{l}$ and placed back on the lower half of the dish that contained ice cold PBS. After three days, the embryonic bodies (EBs) that had formed were placed in a bacterial $60 \mathrm{~mm}$ petri dish (Greiner Bio-One) with $\mathrm{CM}$ and $0.5 \mu \mathrm{M}$ retinoic acid. Two days later, EBs were transferred on $35 \mathrm{~mm}$ dishes coated with laminin (Sigma-Aldrich) in low serum medium (LS) supplemented with $2.5 \mu \mathrm{g} / \mathrm{mL}$ fibronectin. LS contained the same ingredients as $\mathrm{CM}$, but the amount of FBS was lowered to $10 \%$. Medium was replaced the next day with insulin-transferrin-selenite (ITS) medium supplemented with $2.5 \mu \mathrm{g} / \mathrm{mL}$ fibronectin. ITS consisted of DMEM/Ham's nutrient mixture F12 medium (DMEM/F12; Gibco), $0.2 \mu \mathrm{g} / \mathrm{mL}$ bovine insulin (Sigma-Aldrich), 1\% penicillin/streptomycin (Gibco), 200 mM L-glutamine (Gibco), 30 nM sodium selenite (SigmaAldrich), and $50 \mu \mathrm{g} / \mathrm{mL}$ apotransferrin (Sigma-Aldrich). One day later, seven days into neural differentiation, EBs were dissociated and placed on poly-L-ornithine (Sigma-Aldrich)-laminin coated dishes in N2 medium. N2 medium was comprised of DMEM/F12 medium (Gibco) supplemented with $0.2 \mathrm{\mu g} / \mathrm{mL}$ bovine insulin (Sigma-Aldrich), 1\% penicillin/streptomycin (Gibco), $20 \mathrm{nM}$ progesterone (Sigma-Aldrich), $30 \mathrm{nM}$ sodium selenite (Sigma-Aldrich) $100 \mu \mathrm{M}$ putrescine (Sigma-Aldrich), and $50 \mu \mathrm{g} / \mathrm{mL}$ apotransferrin (Sigma-Aldrich). In the afternoon, medium was replaced by $\mathrm{N} 2$ medium supplemented with $10 \mathrm{ng} / \mathrm{mL}$ basic fibroblast growth factor (Miltenyi Biotech, Bergisch Gladbach, Germany). Medium was again refreshed on day 10 and EBs were cultured until day 13. 


\section{ESTn exposure to compounds and morphological scoring of coronas}

Stem cells were differentiated for three days to form an embryonic body (EB) before being exposed to a series of concentrations of fluoxetine hydrochloride (FLX, CAS \#56296-78-7, SigmaAldrich) or venlafaxine hydrochloride (VNX, CAS \#99300-78-4, Sigma-Aldrich). Concentrations used for FLX ranged from $3.3 \mathrm{nM}$ to $3.3 \mu \mathrm{M}$ and for VNX from $333 \mathrm{nM}$ to $333 \mu \mathrm{M}$ dissolved in medium. After 13 days of differentiation, EBs were scored based on the integrity of the corona of neurites surrounding an EB according to Theunissen et al. [8]. An EB was scored as affected when the corona was less than $75 \%$ intact. Approximately 30 EBs were scored in three dishes with an IX51 inverted microscope (Olympus). For transcriptomic analysis, EBs were exposed to either $2 \mu \mathrm{M}$ of FLX and $90 \mu \mathrm{M}$ of VNX for 4 or 10 days ( 7 and 13 days in differentiation respectively), based on the ID50 found with morphological scoring.

\section{Cell viability assay}

ES-D3 stem cells were seeded at a density of $1 \times 10^{4}$ cells $/ \mathrm{mL}$ in a 96 -well plate (Greiner BioOne) in CM supplemented with mLIF. After two hours, cells were exposed to either $33 \mathrm{nM}$ $33 \mu \mathrm{M} F L X$ or $1 \mu \mathrm{M}-1 \mathrm{mM}$ VNX. Medium was replaced after three days of exposure with freshly prepared exposure medium. On day 5 , cell viability was determined with a CellTiter-Blue ${ }^{\circledR}$ kit (Promega, Leiden, The Netherlands) and measured on a Spectramax ${ }^{\circledR}$ M2 spectrofluorometer (Molecular Devices, Berkshire, United Kingdom) at 544 nm and $590 \mathrm{~nm}$. Three independent experiments were performed with six technical replicates per experimental condition. In each of the experiments, a medium control, a positive control $(0.1 \mathrm{ug} / \mathrm{mL} 5$-fluorouracil (Sigma-Aldrich) ) and a negative control ( $0.5 \mathrm{mg} / \mathrm{mL}$ penicillin $\mathrm{G}$ (Sigma-Aldrich)) was included. The cytotoxic concentration was defined as the concentration in which the CellTiter-Blue signal was reduced by $20 \%$, which was calculated using PROAST software as described in Section 2.6.

\section{RNA isolation and RNAseq analysis}

Eight samples per condition were fixated in QIAzol (Qiagen, Hilden, Germany) and kept at -80 ${ }^{\circ} \mathrm{C}$ until further use. Samples were homogenised using the QIAshredder (Qiagen) and subsequently purified with the RNeasy microarray tissue kit (Qiagen) according to manufacturer's protocol. The Qubit (Qubit3, Invitrogen, Carlsbad, CA, USA) was used to determine the RNA concentration and the Bioanalyzer (Agilent) to determine the quality of the samples. Seven samples of each condition with the highest concentration RNA and purity score (RIN > 9.8) were further processed for Next Generation Sequencing according to the TruSeq Stranded mRNA protocol (Illumina, San Diego, CA, USA). Samples were enriched for mRNA using polyA-affinity purification converting into a multiplex library of 16 samples. Sequencing was performed using a NextSeq 500 sequencer (Illumina) and the NextSeq 500/550 High Output Kit version 2.5 (75 cycles). Bcl2fastq (Illumina, version 2.19.0.316) was used to base call and demultiplex raw bcl files into FASTQ files. Quality control reports (FastQC, version 0.11.5) were generated to identify possible anomalies with regard to library size, read length distribution, mean read quality distribution, mean quality for each position in the read, and base frequency for each position in the read. Reads were mapped to the mouse reference genome (GRCm38.p6, release 15) using 
STAR (version 2.6.0b) [35]. The number of mapped reads were counted for each gene and compiled into an expression matrix using featureCounts (version 1.6.1) [36]. Further analysis and visualisation of the data was done in $\mathrm{R}$ (version 3.5.1, [37]). As an additional QC step, principal component analysis was done on normalized data to identify potential outliers; no samples showed evidence of being outliers. Differential gene expression across time and treatment conditions was calculated using the DESeq2 package (version 1.22.2) [38].

\section{Enrichment analysis}

Differentially Expressed Genes (DEGs; adjusted p-value < 0.05) were analysed in GeneAnalytics [39] (http:// geneanalytics.genecards.org/). Abundant and housekeeping genes were kept in the dataset. For the analysis for differentiation over time, a cutoff value of fold change (FC) $>8$ was chosen in order to keep the number of genes for enrichment analysis reasonable (between 200 and 800 genes per cluster). For venlafaxine day 13, more than 1000 genes were differentially expressed, therefore only the top 1000 genes (based on the highest absolute fold change) were used in the enrichment analysis. In addition to GO-terms (biological processes and molecular function), we also used the Tissues\&Cells and Pathways tool provided by GeneAnalytics. The Tissues\&Cells tool relates expressed genes to anatomical compartments, organs and cell types and the Pathways tool gives insight into gene interactions in biological pathways.

\section{Data visualisation and statistics}

Gene expression data were visualized as a heatmap combined with hierarchical clustering (Euclidean distance and Ward.D linkage) in R. Sets of DEGs were compared using a Venn diagram, which was made using Venny (version 2.1.0, [40], http://bioinfogp.cnb.csic. es/tools/venny/index.html). A cell lineage map was built using the MAPPBuilder plugin (version 1.0.0) in Pathvisio (version 3.3.0, [41,42]). Morphological scores of the exposed EBs were used to construct a dose-response curve in PROAST software (version 65.5, exponential model [43]). $\mathrm{The}^{\mathrm{I}} \mathrm{C}_{20}$ (for cytotoxicity) and $\mathrm{ID}_{50}$ (for differentiation toxicity) with 95\% confidence interval were calculated and visualised by the software.

\section{Results}

\section{RNAseq of cell differentiation in ESTn}

At day 13 of differentiation, 20,363 genes were differentially expressed (adjusted $p$-value $<0.05$ ) as compared to undifferentiated ES cells. Of these genes, 3706 genes were up- or downregulated more than eightfold, in which six clusters were defined by hierarchical clustering based on time-dependent gene expression patterns (Euclidean distance, Ward's method, Fig. 1). Cluster $A$ represents genes that are highly expressed in stem cells (day 0 ) and downregulated during differentiation (day 7,13 ). GO-terms related to cluster A include stem cell maintenance processes, and mesodermal and cardiac differentiation. Cluster B represents a relatively small number of genes that are specifically downregulated on day 7 compared to day 0 and 13. GOterms mainly reveal processes that are expected to be upregulated later in differentiation, such 
as glial proliferation, ion transport and establishment of an electrochemical gradient. The pathways also mainly involve processes that are expected in a neural culture as opposed to a stem cell culture, such as serotonergic synapse, phenylalanine (serotonin precursor), and bloodbrain barrier and immune cell transmigration. In cluster $\mathrm{C}$, a pronounced downregulation between day 0 and 7 can be observed, followed by a slight upregulation on day 13 . This cluster contains a mix of stem cell related processes and immunological responses. Cluster D contains genes that peak on day 7 and decrease slightly towards day 13. This cluster is enriched for GOterms that indicate processes in early development, such as patterning (multicellular organism development, somitogenesis), skeletal- mesodermal- and neural differentiation, neural crest migration and epithelial-to-mesenchymal transition, which has been shown before in ESTn by immunocytochemistry [10]. It includes two important developmental pathways, Wnt- and Hedgehog signalling. Cluster $E$ gene expression steadily increases from day 0 to day 7 and 13 and is enriched for processes that are almost exclusively neural related. This cluster includes differentiation processes (neurons, oligodendrocytes), network formation (axongenesis) and maturation (synaptic transmission and maturation). In cluster $F$, gene expression increases most between day 7 and 13, and GO-term analysis reveals neural subtype specification (dopaminergic, noradrenergic), glial cell differentiation and neural transmission. Patterning GO-terms are also enriched, both dorso-ventral and anterio-posterior patterning, as well as important other patterning signals such as retinoic acid and notch signalling.

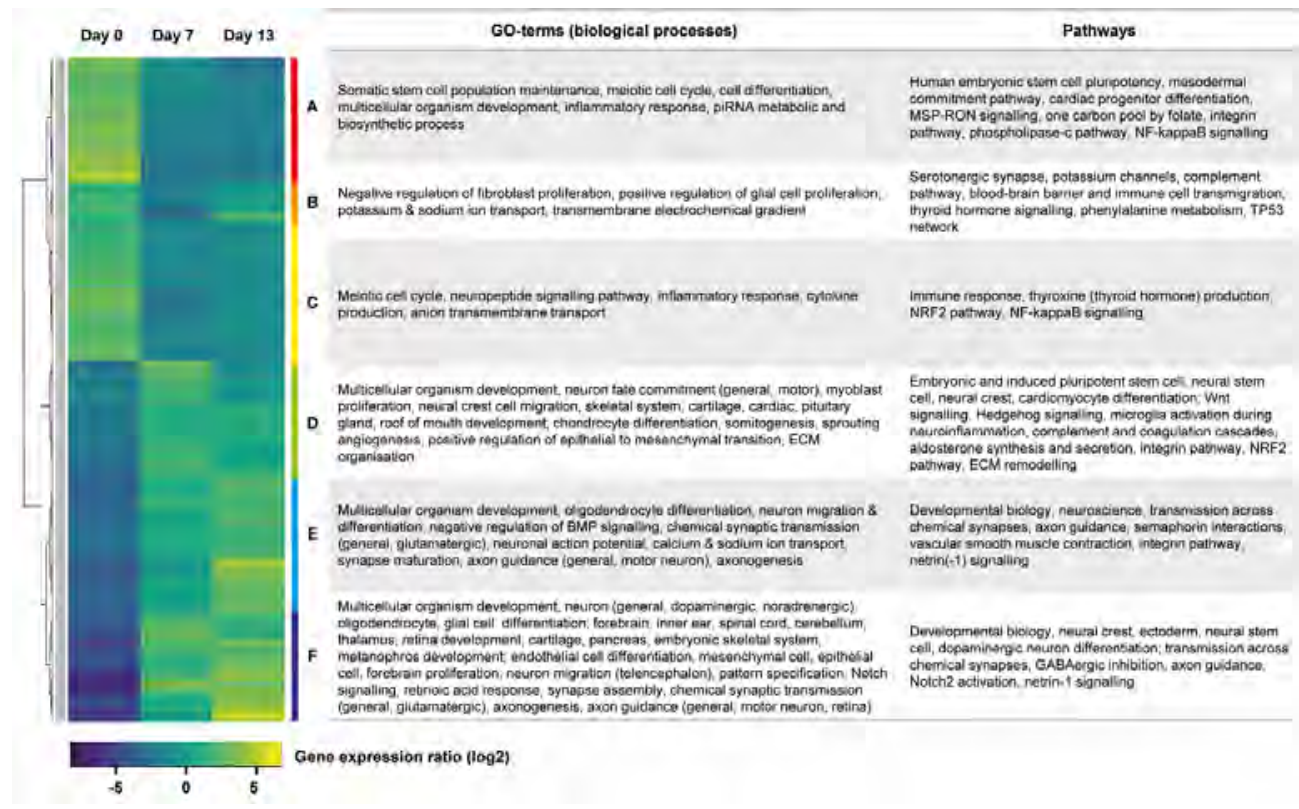

Figure 1. Differentially expressed genes over the course of ESTn differentiation with a fold change larger than eight and adjusted $p$-value $<0.05$. The heatmap can be divided in six clusters. Each row represents one gene. Number of genes: cluster A: 698, cluster B: 220, cluster C: 777 , cluster D: 644, cluster E: 749, cluster F: 627 . The table next to the heatmap lists a summary of the enriched GO-terms and pathways for each cluster, clustered per function. A full list of GO-terms and pathways can be found in supplementary table 7 and 2. 


\section{The ESTn differentiation representation in a cell lineage map}

In order to be able to monitor the complex cell differentiation patterns in ESTn, a cell lineage map was constructed, consisting of a set of cell types emerging during neural differentiation. A selection of cell type-specific markers was made based on literature (e.g. [44-47]) to distinguish these different cell types (Fig. 2).

In ESTn, all but two of these markers, Ngfrand G/ra4, were differentially expressed across time (adjusted p-value < 0.05). Out of 135 genes 58 were up- or downregulated more than eight times, as indicated by the green boxes in Fig. 2. The cell lineage map revealed that ESTn transitioned from stem cells on day 0 to mainly ectoderm and neural progenitors on day 7 , to immature neurons, astrocytes and mature neurons on day 13. Neural crest cell markers and oligodendrocyte markers were also upregulated, albeit to a lesser extent than the neural differentiation. Looking at the level of maturation in ESTn, most of the markers for the pre- and postsynapse were upregulated and some genes that are crucial in the assembly of the synaptic machinery (e.g. Dlg2 and Pclo) were upregulated more than eight times. Additionally, at least one marker of each neural subtype was strongly upregulated. There was, however, also a considerable number of markers that was downregulated or not regulated at all, particularly transporters for the neurotransmitters (S/C17a7, S/c18a3, S/c6a3) and neurotransmitter synthesis (Th, Tph T, G/ul). This indicates that ESTn showed a specific potential to differentiate into various neural subtypes.

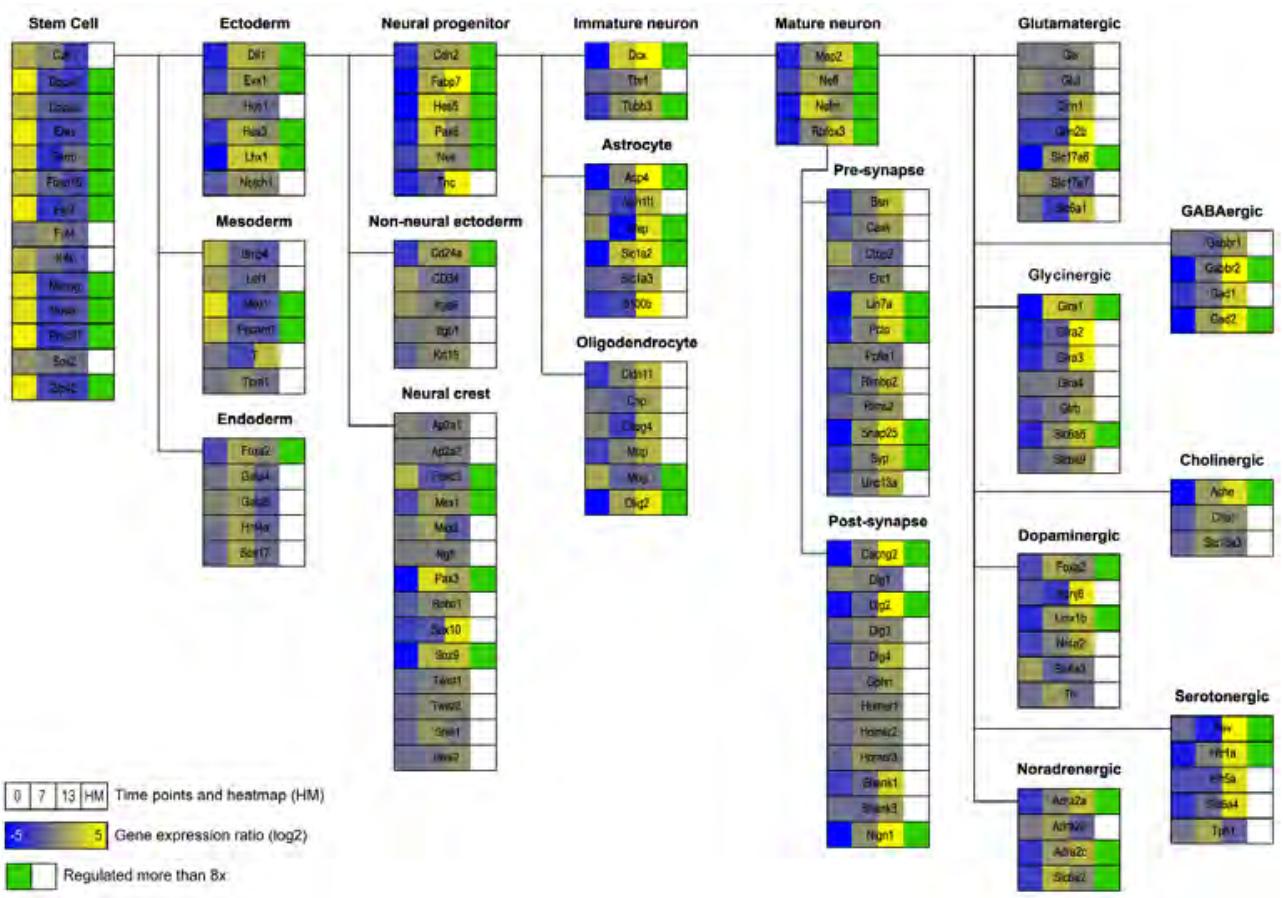

Figure 2. Cell lineage map for neural differentiation including cell type markers. Blue-yellow scaling indicates relative log2 gene expression ratio at day 0, 7 and 73 in ESTn. The green/white box indicates genes showing an at least 8 fold up-or downregulation with time and hence the presence/absence in the heatmap presented in Fig. 7. 


\section{Concentration-dependent effects of FLX and VNX in ESTn}

ESTn was exposed to a series of concentrations of FLX and VNX. The ID50 (with confidence interval $(\mathrm{CI}))$ of FLX and VNX based on morphological scoring of the coronas at day 13 were $1.8(1.2-2.4) \mu \mathrm{M}$ and $87.5(65-110) \mu \mathrm{M}$, respectively (Fig. 3). The $\mathrm{IC}_{20}$ of FLX and VNX were 6.712 (no $\mathrm{Cl}$ could be calculated) $\mu \mathrm{M}$ and $144.2(91-306) \mu \mathrm{M}$, respectively. VNX was about 48 times less potent than FLX, both with regard to cytotoxicity and differentiation toxicity. While there was a 3.5 times difference between ID50 and IC20 in the case of FLX, the confidence intervals of VNX cytotoxicity and differentiation toxicity partly overlapped, implying that the differentiation toxicity imposed on ESTn could at least partly have been caused by cytotoxicity. Based on these results, $2 \mu \mathrm{M}$ for FLX and $90 \mu \mathrm{M}$ for VNX were chosen for the RNAseq experiments.

A

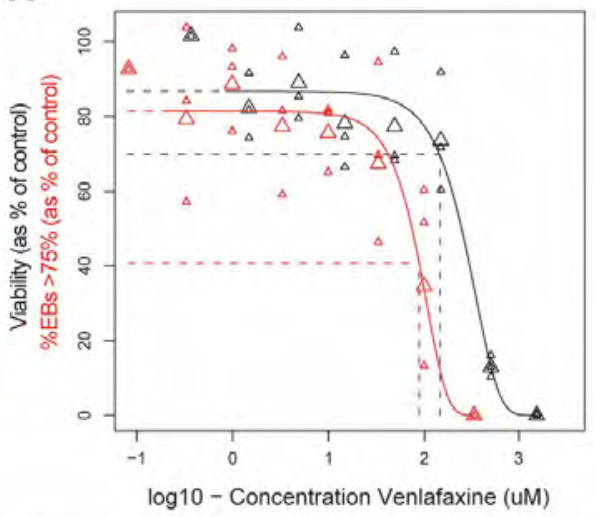

B

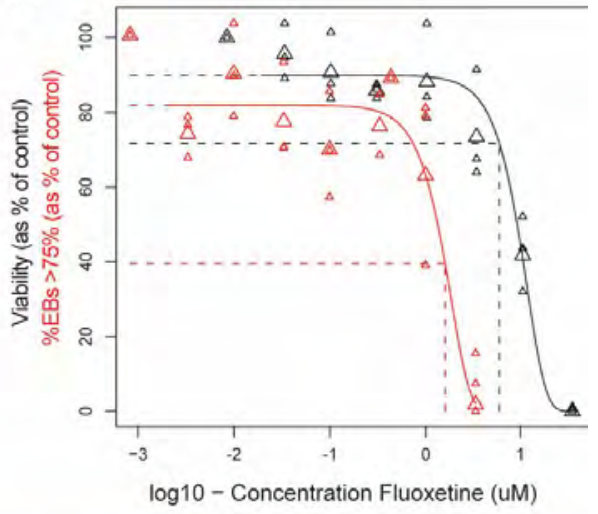

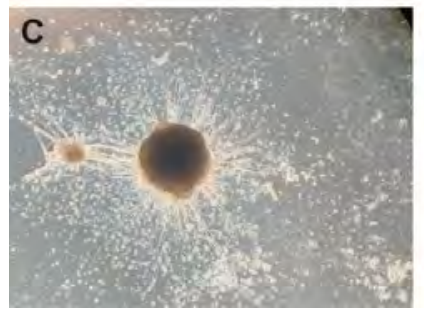
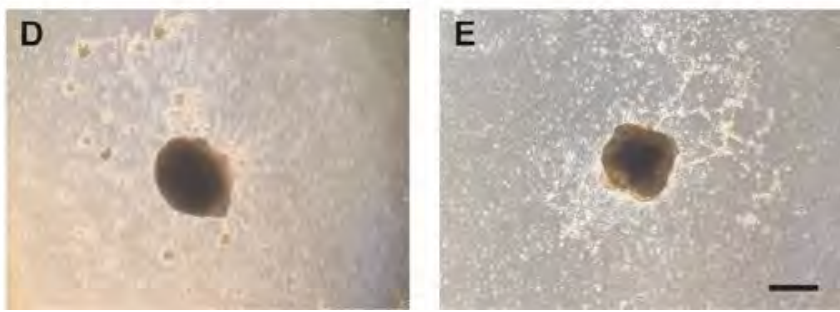

Figure 3. VNX (A) and FLX (B) concentration-response curves on viability (black symbols) of undifferentiated cells and differentiation (red symbols) as percentage of EBs that have a corona, which is more $75 \%$ complete. Large symbols represent mean of $n=3$ independent experiments, each of which are shown in small symbols. Dotted lines indicate $1 C_{20}$ (black) and ID 50 (red), respectively. (C)-(E)Representative images of ESTn coronas: (C) is $>75 \%,(D)$ and (E) are $<75 \%$ full. Scale bar: $500 \mu \mathrm{m}$.

\section{Comparative gene expression regulation in ESTn by FLX and VNX}

Gene expression in ESTn after exposure to $2 \mu \mathrm{M}$ of FLX or $90 \mu \mathrm{M}$ of VNX was compared to time-matched controls on day 7 and 13 of the assay (after 4 and 10 days of exposure respectively). VNX regulated a much larger number of genes than FLX (Fig. 4A). The overlap between compounds was larger at day 7 (80 of 115/803 genes) than at day 13 (172 of 413/3548 genes), 
indicating divergence of ESTn response to either compound with time. This was also reflected in the related GO-terms and GeneAnalytics pathways (Fig. 4B, C) with seven versus four common GO-terms and twelve versus no common pathways on day 7 versus 13 . Across time within the same compound, there was limited overlap in gene expression and no (FLX) or little (VNX) overlap in GO-terms and pathways.

VNX d7 was enriched for processes related to cell metabolism, growth, signalling, stress and responses to compounds. Migration and differentiation in all germ layers were positively regulated at the expense of proliferation and cell growth. Patterning-related processes (e.g. Wnt signalling) were also affected. In comparison to VNX, FLX exposure only enriched about half the number of GO-terms and pathways. Affected processes were mainly related to metabolism, immune response and differentiation of the mesodermal and ectodermal lineage. VNXexposed ESTn on day 13 was enriched in processes mostly related to upregulation of cell cycle processes and regulation. Additionally, a number of cell differentiation related processes were downregulated. Contrary to VNX, FLX enriched more differentiation and patterning processes. Pattering-, neuron-, oligodendrocyte- and astrocyte-processes were almost all upregulated, while synaptic transmission processes, such as glycinergic synaptic transmission, were downregulated. Pathway analysis additionally revealed regulation of neural crest cells, axon guidance and GABAergic transmission.
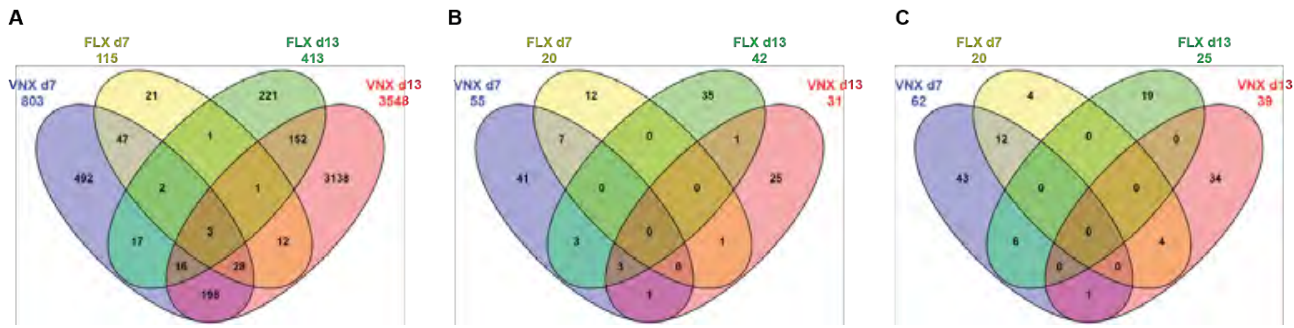

Figure. 4. Venn diagram of gene expression (A), GO-terms (B) and pathways (C), regulated in ESTn by FLX and VNX exposure (adjusted p-value <0.05). FLX: fluoxetine, VNX: venlafaxine, d7: day 7 of differentiation, d73: day 13 of differentiation. A full list of GO-terms and pathways can be found in supplementary tables 3 and 4.

\section{Brain tissue specificity of genes regulated by FLX and VNX}

Enrichment analysis in GeneAnalytics revealed that all anatomical compartments affected by any of the experimental conditions with 'high' or 'medium' score were parts of the brain (Table 1). Moreover, all four conditions affected genes that are expressed in the cerebral cortex and cerebellum. VNX regulated genes related to relatively less tissues compared to FLX, especially on day 13. On day $13 \mathrm{FLX}$ regulated genes represented parts present throughout developmental stages of the whole brain, mostly the cortex and cerebellum.

\section{Cell lineage effects of FLX and VNX}

Consistent with the number of affected genes, VNX affected cell types to a larger extent than FLX, both in terms of numbers and magnitude (Fig. 5). Of the genes represented in the cell 
Table 1. List of anatomical compartments that were most affected ('high' and 'medium' score as per Gene Analytics) in each of the experimental conditions. Numbers between brackets indicate the number of genes. VNX: venlafaxine, FLX: fluoxetine, $x$ : medium score, $x x$ : high score. List of all genes per anatomical compartment can be found in supplementary table 5.

\begin{tabular}{lllll}
\hline Anatomical compartment & $\begin{array}{l}\text { Vnx day 7 } \\
(803)\end{array}$ & $\begin{array}{l}\text { Flx day 7 } \\
(115)\end{array}$ & $\begin{array}{l}\text { Vnx day 13 } \\
(1000)\end{array}$ & $\begin{array}{l}\text { Flx day 13 } \\
(413)\end{array}$ \\
\hline Cerebral cortex (5055) & $\times(320)$ & $\times(51)$ & $\times(234)$ & $\times \times(175)$ \\
Cerebellum (3335) & $\times(196)$ & $\times(27)$ & $\times(175)$ & $\times \times(133)$ \\
Medulla oblongata (2179) & $\times(192)$ & $\times(27)$ & & $\times(131)$ \\
Thalamus (1666) & & $\times(21)$ & & $\times(106)$ \\
Striatum (1139) & & $\times(20)$ & & \\
Hypothalamus (1736) & & & $\times(104)$ \\
Hippocampus (2609) & & & $\times(105)$ \\
Telencephalon (1836) & & & $\times(85)$ \\
Pons (1033) & & & $\times(75)$ \\
Amygdala (1003) & & & $\times(74)$ \\
Metencephalic basal plate (1215) & & & $\times(76)$ \\
\hline
\end{tabular}

lineage map, on day 7 , fifteen genes were differentially expressed by VNX exposure versus one gene by FLX (adjusted p-value < 0.05). Both compounds at this time point tended to upregulate most of the stem cell- and immature neuron markers and to downregulate endoderm markers. Also serotonergic and dopaminergic markers were affected similarly by FLX and VNX, while only VNX-exposed ESTn presented an upregulation of glycinergic neurons and downregulation of cholinergic neurons.

On day 13, 52 genes in the cell lineage map were differentially expressed by VNX versus twelve genes by FLX. Similar expression changes could be observed among more cell types than on day 7 ; markers of more than half of the cell types were regulated in the same direction. Oligodendrocyte markers were upregulated and mature neuron- and synapse markers tended to be downregulated by both compounds. Some of the neural subtypes, glycinergic, GABAergic and dopaminergic markers, were also downregulated by both VNX and FLX. A pronounced difference could be observed in the serotonergic markers, which were upregulated by FLX and much less affected by VNX. Another difference was observed in the regulation of stem cell markers, which were upregulated by VNX and not much affected by FLX, consistent with the enriched GO-terms. In short, for both compounds and at both time points distinct expression patterns were revealed by the cell lineage map.

\section{Discussion}

In this study we mapped the biological domain of the ESTn, an in vitro test to assess early neural differentiation. Since the goal of ESTn is to assess effects of chemicals on cell differentiation, a cell lineage map of neural differentiation was developed based on literature. Whole transcriptome analysis in ESTn revealed differentiation from stem cells to maturing neurons and related neural cell types. Common and differential effects of FLX and VNX in ESTn at two time points could be distinguished with the cell lineage map. 
A

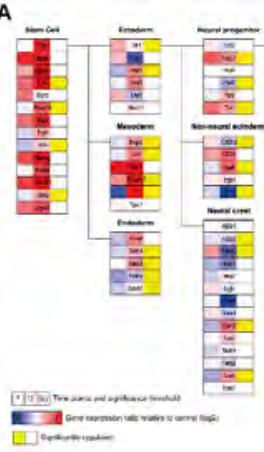

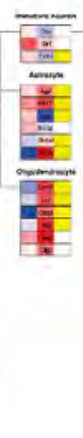
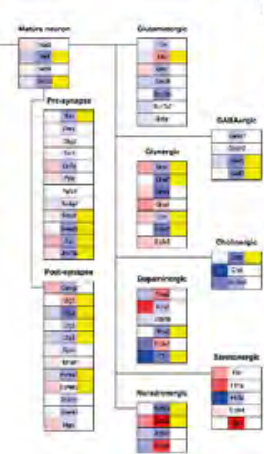

B

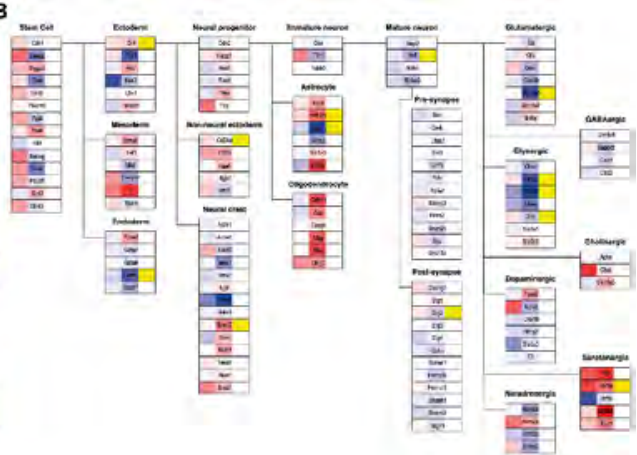

Figure 5. Cell lineage regulation in ESTn by VLX $(A)$ and $F L X(B)$. Blue-red scaling indicates gene expression relative to the control condition at 7 and 73 days of differentiation. The yellow/white box indicates that the gene is statistically significantly differentially expressed at either or both of the time points (adjusted $p$-value $<0.05$ ) relative to the time-matched control.

Studies have assessed DNT in vitro by investigating different readouts, such as transcriptomic changes [48-51], morphological features such as migration, proliferation and differentiation [52-54] or functional changes in spontaneous network activity $[33,55]$. This study took a novel approach by building a cell lineage map for neural differentiation. With this map it was possible to define the biological domain of ESTn and investigate the disturbance of the test system by chemicals in an easy manner. To our knowledge, this is the first study to focus in this detail on gene expression changes focused on cell types for the assessment of DNT.

The central hypothesis for which the cell lineage map was built was that a disturbance in the proportions of cell types indicates the potential of a chemical to alter neural differentiation. Others have used this idea already to determine alterations in e.g. neuron and astrocyte proportions using flow cytometry [56-58] or imaging [59]. However, these techniques are limited in their capacity compared to a transcriptomic approach. Using RNAseq it was possible to obtain gene expression of many markers for each cell type on the cell lineage map. This approach showed that the ESTn develops from stem cells to a mixed culture of maturing neurons, neural crest cells, astrocytes and oligodendrocytes, placing cell differentiation in this model approximately between gastrulation and E18 of murine development [60]. These results were in line with the enriched GO-terms and pathways that take all DEGs into consideration, suggesting that this cell lineage map covers proper markers to describe the biological domain of this test system.

It would be interesting to test classical DNT compounds in ESTn using the cell lineage map. For example, the acceleration of neural differentiation by methylmercury shown by Theunissen et al. [9] should also be visible in the cell lineage map. However, existing data on ESTn generated at an early stage of differentiation [51,61], is of limited use for applying the cell lineage map as most of the cell types in the map are not yet present at this stage.

The cell lineage map could also distinguish the effects of FLX and VNX at two time points in ESTn, showing that the effect of compounds can be different at different phases of differentiation. In vivo studies have shown that exposure to either compound could lead to less neurons in the frontal lobe (FLX, [30]) or a thinner neocortex (VNX, [62]). This is in line with our results. 
On day 7 , differentiation seemed to be distorted by an upregulation of stem cells by both compounds, an upregulation of non-neural ectoderm by FLX and altered mesoderm expression by VNX. On day 13 maturation and synaptic markers were downregulated by both compounds. These changes may lead to reduced neuron maturation, which might reflect disturbed neuron positioning in the cortex in vivo.

FLX is a SSRI and VNX is a SNRI, hence they differ slightly in therapeutic targets. This was reflected in the cell lineage map, with FLX having a pronounced effect on serotonergic markers already at day 7 and only to a much lesser extent on noradrenergic and dopaminergic markers. The magnitude of the effect of VNX exposure on the other hand was the reverse, which is overall in line with their therapeutic target selectivity. Apart from these differences, at day 13 of ESTn FLX and VNX showed largely the same effect.

It is known that FLX inhibits glycine receptors $[63,64]$, which might explain the downregulation of glycinergic cell markers by FLX. It seems that VNX has similar effects based on the gene expression data of day 13, but we found no supporting literature on this aspect.

One study by Jha et al. [65] has shown that white matter of neonates was affected when mothers had taken FLX during pregnancy. This is reminiscent of findings in the cell lineage map where both FLX and VNX upregulated virtually all oligodendrocyte markers on day 13. This is an example of the added value of this approach as this is typically a neurodevelopmental effect that may not be related to the primary therapeutic targets of FLX and VNX. However, oligodendrocyte regulation was not detected in VNX GO-terms. GO-term analysis alone may not detect such effects as they may be obscured by the large numbers of other processes being regulated.

In conclusion, the cell lineage map is an informative read-out to quickly assess the effects of compounds on cell type markers related to the complexity of neural cell differentiation in ESTn. It can be used complementary to traditional GO-terms and pathways in order to investigate mechanisms of action of chemicals. More compounds should be tested that are known to act on different stages of neural development to further evaluate the applicability of the cell lineage map for the use of DNT assessment. This test can contribute to mechanism-based, animalfree prediction of DNT, as an element in integrated testing strategies serving regulatory chemical safety assessment.

\section{Declaration of competing interest}

The authors declare that they have no known competing financial interests or personal relationships that could have appeared to influence the work reported in this paper.

\section{Acknowledgements}

This research is funded by the Dutch NGO Stichting Proefdiervrij, the Dutch Ministry of Agriculture, Nature and Food Quality and the Dutch Ministry of Health, Welfare and Sports. We would like to thank Yvonne Staal for a critical review of the manuscript. 


\section{References}

[1] A.R. Scialli, A.J. Guikema, REACH and reproductive and developmental toxicology: still questions., Syst. Biol. Reprod. Med. 58 (2012) 63-69. https://doi.org/10.3109/19396368.2011.648301.

[2] N. Baker, A. Boobis, L. Burgoon, E. Carney, R. Currie, E. Fritsche, T. Knudsen, M. Laffont, A.H. Piersma, A. Poole, S. Schneider, G. Daston, Building a developmental toxicity ontology, Birth Defects Res. 110 (2018) 502-518. https://doi.org/10.1002/bdr2.1189.

[3] E. Fritsche, P. Grandjean, K.M. Crofton, M. Aschner, A. Goldberg, T. Heinonen, E.V.S. Hessel, H.T. Hogberg, S.H. Bennekou, P.J. Lein, M. Leist, W.R. Mundy, M. Paparella, A.H. Piersma, M. Sachana, G. Schmuck, R. Solecki, A. Terron, F. Monnet-Tschudi, M.F. Wilks, H. Witters, M.G. Zurich, A. Bal-Price, Consensus statement on the need for innovation, transition and implementation of developmental neurotoxicity (DNT) testing for regulatory purposes, Toxicol. Appl. Pharmacol. 354 (2018) 3-6. https://doi.org/10.1016/j.taap.2018.02.004.

[4] A. Terron, S.H. Bennekou, Towards a regulatory use of alternative developmental neurotoxicity testing (DNT), Toxicol. Appl. Pharmacol. 354 (2018) 19-23. https://doi.org/10.1016/j.taap.2018.02.002.

[5] A. Bal-Price, K.M. Crofton, M. Leist, S. Allen, M. Arand, T. Buetler, N. Delrue, R.E. FitzGerald, T. Hartung, T. Heinonen, H. Hogberg, S.H. Bennekou, W. Lichtensteiger, D. Oggier, M. Paparella, M. Axelstad, A. Piersma, E. Rached, B. Schilter, G. Schmuck, L. Stoppini, E. Tongiorgi, M. Tiramani, F. Monnet-Tschudi, M.F. Wilks, T. Ylikomi, E. Fritsche, International STakeholder NETwork (ISTNET): creating a developmental neurotoxicity (DNT) testing road map for regulatory purposes, Arch. Toxicol. 89 (2015) 269-287. https://doi.org/10.1007/s00204-015-1464-2.

[6] E.V.S. Hessel, Y.C.M. Staal, A.H. Piersma, Design and validation of an ontology-driven animal-free testing strategy for developmental neurotoxicity testing, Toxicol. Appl. Pharmacol. 1 (2018) 136-152. https://doi.org/10.1016/j.taap.2018.03.013.

[7] A.H. Piersma, T. Burgdorf, K. Louekari, B. Desprez, R. Taalman, R. Landsiedel, J. Barroso, V. Rogiers, C. Eskes, M. Oelgeschläger, M. Whelan, A. Braeuning, A.M. Vinggaard, A. Kienhuis, J. van Benthem, J. Ezendam, Workshop on acceleration of the validation and regulatory acceptance of alternative methods and implementation of testing strategies, in: Toxicol. Vitr., 2018: pp. 62-74. https://doi.org/10.1016/j.tiv.2018.02.018.

[8] P.T. Theunissen, S.H.W. Schulpen, D.A.M. van Dartel, S.A.B. Hermsen, F.J. van Schooten, A.H. Piersma, An abbreviated protocol for multilineage neural differentiation of murine embryonic stem cells and its perturbation by methyl mercury, Reprod. Toxicol. $29 \quad$ (2010) 383-392. https://doi.org/10.1016/j.reprotox.2010.04.003.

[9] P.T. Theunissen, J.L.A. Pennings, J.F. Robinson, S.M.H. Claessen, J.C.S. Kleinjans, A.H. Piersma, Timeresponse evaluation by transcriptomics of methylmercury effects on neural differentiation of murine embryonic stem cells, Toxicol. Sci. 122 (2011) 437-447. https://doi.org/10.1093/toxsci/kfr134.

[10] V.C. de Leeuw, E.V.S. Hessel, A.H. Piersma, Look-alikes may not act alike: Gene expression regulation and cell-type-specific responses of three valproic acid analogues in the neural embryonic stem cell test (ESTn), Toxicol. Lett. 303 (2019) 28-37. https://doi.org/10.1016/j.toxlet.2018.12.005.

[11] J. Jentink, M.A. Loane, H. Dolk, I. Barisic, E. Garne, J.K. Morris, L.T.W. de Jong-van den Berg, EUROCAT Antiepileptic Study Working Group, Valproic acid monotherapy in pregnancy and major congenital malformations., N. Engl. J. Med. 362 (2010) 2185-2193. https://doi.org/10.1056/NEJMoa0907328.

[12] W. Löscher, H. Nau, Pharmacological evaluation of various metabolites and analogues of valproic acid. Anticonvulsant and toxic potencies in mice, Neuropharmacology. 24 (1985) 427-435. https://doi.org/10.1016/0028-3908(85)90028-0.

[13] R.W. Sommi, M.L. Crismon, C.L. Bowden, Fluoxetine: A Serotonin-specific, Second-generation Antidepressant, Pharmacother. J. Hum. Pharmacol. Drug Ther. 7 (1987) 1-14. https://doi.org/10.1002/j.1875-9114.1987.tb03496.x.

[14] E.A. Muth, J.T. Haskins, J.A. Moyer, G.E.M. Husbands, S.T. Nielsen, E.B. Sigg, Antidepressant biochemical profile of the novel bicyclic compound Wy-45,030, an ethyl cyclohexanol derivative, Biochem. Pharmacol. 35 (1986) 4493-4497. https://doi.org/10.1016/0006-2952(86)90769-0.

[15] S. Brummelte, E. Mc Glanaghy, A. Bonnin, T.F. Oberlander, Developmental changes in serotonin signaling: Implications for early brain function, behavior and adaptation., Neuroscience. 342 (2017) 212-231. https://doi.org/10.1016/j.neuroscience.2016.02.037.

[16] P. Gaspar, O. Cases, L. Maroteaux, The developmental role of serotonin: news from mouse molecular genetics, Nat. Rev. Neurosci. 4 (2003) 1002-1012. https://doi.org/10.1038/nrn1256.

[17] N. Narboux-Nême, L.M. Pavone, L. Avallone, X. Zhuang, P. Gaspar, Serotonin transporter transgenic (SERTcre) mouse line reveals developmental targets of serotonin specific reuptake inhibitors (SSRIs), Neuropharmacology. 55 (2008) 994-1005. https://doi.org/10.1016/j.neuropharm.2008.08.020.

[18] G. Ewing, Y. Tatarchuk, D. Appleby, N. Schwartz, D. Kim, Placental Transfer of Antidepressant Medications: Implications for Postnatal Adaptation Syndrome, Clin. Pharmacokinet. 54 (2015) 359-370. https://doi.org/10.1007/s40262-014-0233-3. 
[19] J. Rampono, K. Simmer, K.F. Ilett, L.P. Hackett, D.A. Doherty, R. Elliot, C.H. Kok, A. Coenen, T. Forman, Placental transfer of SSRI and SNRI antidepressants and effects on the neonate, Pharmacopsychiatry. 42 (2009) 95100. https://doi.org/10.1055/s-0028-1103296.

[20] S. Alwan, J.M. Friedman, C. Chambers, Safety of Selective Serotonin Reuptake Inhibitors in Pregnancy: A Review of Current Evidence, CNS Drugs. 30 (2016) 499-515. https://doi.org/10.1007/s40263-016-0338-3.

[21] K.F. Huybrechts, K. Palmsten, J. Avorn, L.S. Cohen, L.B. Holmes, J.M. Franklin, H. Mogun, R. Levin, M. Kowal, S. Setoguchi, S. Hernández-Díaz, Antidepressant Use in Pregnancy and the Risk for Cardiac Defects, Obstet. Gynecol. Surv. 69 (2014) 579-581. https://doi.org/10.1097/01.ogx.0000456348.32099.6d.

[22] I. Petersen, R. Gilbert, S. Evans, I. Nazareth, Selective serotonin reuptake inhibitors and risk for major $\begin{array}{lllll}\text { congenital } \quad \text { anomalies., } & \text { Obstet. } & \text { Gynecol. } & 119 & \text { (2012) }\end{array}$ https://doi.org/10.1097/AOG.0b013e318220edcc.

[23] S. Nikfar, R. Rahimi, N. Hendoiee, M. Abdollahi, Increasing the risk of spontaneous abortion and major malformations in newborns following use of serotonin reuptake inhibitors during pregnancy: A systematic review and updated meta-analysis, DARU, J. Pharm. Sci. 20 (2012) 75. https://doi.org/10.1186/2008-223120-75.

[24] L. Riggin, Z. Frankel, M. Moretti, A. Pupco, G. Koren, The Fetal Safety of Fluoxetine: A Systematic Review and Meta-Analysis, J. Obstet. Gynaecol. Canada. 35 (2013) 362-369. https://doi.org/10.1016/S17012163(15)30965-8.

[25] D.M. Campagne, Antidepressant use in pregnancy: are we closer to consensus?, Arch. Womens. Ment Health. 22 (2019) 189-197. https://doi.org/10.1007/s00737-018-0906-2.

[26] S.Y. Gao, Q.J. Wu, C. Sun, T.N. Zhang, Z.Q. Shen, C.X. Liu, T.T. Gong, X. Xu, C. Ji, D.H. Huang, Q. Chang, Y.H. Zhao, Selective serotonin reuptake inhibitor use during early pregnancy and congenital malformations: A systematic review and meta-analysis of cohort studies of more than 9 million births, BMC Med. 16 (2018) 205. https://doi.org/10.1186/s12916-018-1193-5.

[27] S. Jordan, J.. Morris, G.I.. Davies, D. Tucker, D.S.. Thayer, J.M.. Luteijn, M. Morgan, E. Garne, A.V.. Hansen, K. Klungsøyr, A. Engeland, H. Dolk, Selective serotonin reuptake inhibitor (SSRI) antidepressants in pregnancy and congenital anomalies: analysis of three national linked databases, PLoS One. 11 (2016) e0165122. https://doi.org/https://doi.org/10.1371/journal.pone.0165122.

[28] N. Rotem-Kohavi, T.F. Oberlander, Variations in Neurodevelopmental Outcomes in Children with Prenatal SSRI Antidepressant Exposure, Birth Defects Res. 109 (2017) 909-923. https://doi.org/10.1002/bdr2.1076.

[29] D.E. Conners, E.D. Rogers, K.L. Armbrust, J.W. Kwon, M.C. Black, Growth and development of tadpoles (Xenopus laevis) exposed to selective serotonin reuptake inhibitors, fluoxetine and sertraline, throughout metamorphosis, Environ. Toxicol. Chem. 28 (2009) 2671-2676. https://doi.org/10.1897/08-493.1.

[30] C.A.S. Swerts, A.M.D.D. Costa, A. Esteves, C.E.S. Borato, M.S.O. Swerts, Effects of fluoxetine and imipramine in rat fetuses treated during a critical gestational period: A macro and microscopic study, Rev. Bras. Psiquiatr. 32 (2010) 152-158. https://doi.org/10.1590/S1516-44462009005000015.

[31] E.L.L. Warkus, Y. Marikawa, Fluoxetine Inhibits Canonical Wnt Signaling to Impair Embryoid Body Morphogenesis: Potential Teratogenic Mechanisms of a Commonly Used Antidepressant, Toxicol. Sci. 165 (2018) 372-388. https://doi.org/10.1093/toxsci/kfy143.

[32] G. Kaushik, Y. Xia, J.C. Pfau, M.A. Thomas, Dysregulation of autism-associated synaptic proteins by psychoactive pharmaceuticals at environmental concentrations, Neurosci. Lett. 661 (2017) 143-148. https://doi.org/10.1016/J.NEULET.2017.09.058.

[33] C.L. Frank, J.P. Brown, K. Wallace, W.R. Mundy, T.J. Shafer, Developmental neurotoxicants disrupt activity in cortical networks on microelectrode arrays: Results of screening 86 compounds during neural network formation, Toxicol. Sci. 160 (2017) 121-135. https://doi.org/10.1093/toxsci/kfx169.

[34] C.M. Mack, B.J. Lin, J.D. Turner, A.F.M. Johnstone, L.D. Burgoon, T.J. Shafer, Burst and principal components analyses of MEA data for 16 chemicals describe at least three effects classes, Neurotoxicology. 40 (2014) 75-85. https://doi.org/10.1016/j.neuro.2013.11.008.

[35] A. Dobin, C.A. Davis, F. Schlesinger, J. Drenkow, C. Zaleski, S. Jha, P. Batut, M. Chaisson, T.R. Gingeras, STAR: Ultrafast universal RNA-seq aligner, Bioinformatics. $29 \quad$ (2013) 15-21. https://doi.org/10.1093/bioinformatics/bts635.

[36] Y. Liao, G.K. Smyth, W. Shi, FeatureCounts: An efficient general purpose program for assigning sequence reads to genomic features, Bioinformatics. $30 \quad$ (2014) 923-930. https://doi.org/10.1093/bioinformatics/btt656.

[37] R Core Team, R: A language and environment for statistical computing, (2019). https://www.r-project.org/.

[38] M.I. Love, W. Huber, S. Anders, Moderated estimation of fold change and dispersion for RNA-seq data with DESeq2, Genome Biol. 15 (2014) 550. https://doi.org/10.1186/s13059-014-0550-8.

[39] S. Ben-Ari Fuchs, I. Lieder, G. Stelzer, Y. Mazor, E. Buzhor, S. Kaplan, Y. Bogoch, I. Plaschkes, A. Shitrit, N. Rappaport, A. Kohn, R. Edgar, L. Shenhav, M. Safran, D. Lancet, Y. Guan-Golan, D. Warshawsky, R. Shtrichman, GeneAnalytics: An Integrative Gene Set Analysis Tool for Next Generation Sequencing, RNAseq and Microarray Data, Omi. A J. Integr. Biol. 20 (2016) 139-151. https://doi.org/10.1089/omi.2015.0168.

[40] J.C. Oliveros, VENNY. An interactive tool for comparing lists with Venn Diagrams., (2007) http://bioinfogp.cnnb.csic.es/tools/venny/index.ht. https://doi.org/10.1017/S0266267108002022. 
[41] M.P. van lersel, T. Kelder, A.R. Pico, K. Hanspers, S. Coort, B.R. Conklin, C. Evelo, Presenting and exploring biological pathways with PathVisio, BMC Bioinformatics. 9 (2008) 399. https://doi.org/10.1186/1471-21059-399.

[42] M. Kutmon, M.P. van lersel, A. Bohler, T. Kelder, N. Nunes, A.R. Pico, C.T. Evelo, PathVisio 3: An Extendable Pathway Analysis Toolbox, PLoS Comput. Biol. $11 \quad$ (2015) e1004085. https://doi.org/10.1371/journal.pcbi.1004085.

[43] W. Slob, Dose-response modeling of continuous endpoints, Toxicol. Sci. 66 (2002) $298-312$. https://doi.org/10.1093/toxsci/66.2.298.

[44] L. Beccari, N. Moris, M. Girgin, D.A. Turner, P. Baillie-Johnson, A.C. Cossy, M.P. Lutolf, D. Duboule, A.M. Arias, Multi-axial self-organization properties of mouse embryonic stem cells into gastruloids, Nature. 562 (2018) 272-276. https://doi.org/10.1038/s41586-018-0578-0.

[45] P. Kügler, B. Zimmer, T. Waldmann, B. Baudis, S. Ilmjärv, J. Hescheler, P. Gaughwin, P. Brundin, W. Mundy, A.K. Bal-Price, A. Schrattenholz, K.-H. Krause, C. von Thriel, M.S. Rao, S. Kadereit, M. Leist, Markers of murine embryonic and neural stem cells, neurons and astrocytes : reference points for developmental neurotoxicity testing, Altern. to Anim. Exp. ALTEX. 27 (2010) 16-42. https://doi.org/10.14573/altex.2010.1.16.

[46] A. Spangler, E.Y. Su, A.M. Craft, P. Cahan, A single cell transcriptional portrait of embryoid body differentiation and comparison to progenitors of the developing embryo, Stem Cell Res. 31 (2018) 201-215. https://doi.org/10.1016/j.scr.2018.07.022

[47] Y. Tao, S.C. Zhang, Neural Subtype Specification from Human Pluripotent Stem Cells, Cell Stem Cell. 19 (2016) 573-586. https://doi.org/10.1016/j.stem.2016.10.015.

[48] N. V. Balmer, S. Klima, E. Rempel, V.N. Ivanova, R. Kolde, M.K. Weng, K. Meganathan, M. Henry, A. Sachinidis, M.R. Berthold, J.G. Hengstler, J. Rahnenführer, T. Waldmann, M. Leist, From transient transcriptome responses to disturbed neurodevelopment: Role of histone acetylation and methylation as epigenetic switch between reversible and irreversible drug effects, Arch. Toxicol. 88 (2014) 1451-1468. https://doi.org/10.1007/s00204-014-1279-6.

[49] A.K. Krug, R. Kolde, J.A. Gaspar, E. Rempel, N. V. Balmer, K. Meganathan, K. Vojnits, M. Baquié, T. Waldmann, R. Ensenat-Waser, S. Jagtap, R.M. Evans, S. Julien, H. Peterson, D. Zagoura, S. Kadereit, D. Gerhard, I. Sotiriadou, M. Heke, K. Natarajan, M. Henry, J. Winkler, R. Marchan, L. Stoppini, S. Bosgra, J. Westerhout, M. Verwei, J. Vilo, A. Kortenkamp, J. Hescheler, L. Hothorn, S. Bremer, C. Van Thriel, K.H. Krause, J.G. Hengstler J. Rahnenführer, M. Leist, A. Sachinidis, Human embryonic stem cell-derived test systems for developmental neurotoxicity: A transcriptomics approach, Arch. Toxicol. $87 \quad$ (2013) 123-143. https://doi.org/10.1007/s00204-012-0967-3.

[50] S.H.W. Schulpen, E. de Jong, L.J.J. de la Fonteyne, A. de Klerk, A.H. Piersma, Distinct gene expression responses of two anticonvulsant drugs in a novel human embryonic stem cell based neural differentiation assay protocol, Toxicol. Vitr. 29 (2015) 449-457. https://doi.org/10.1016/j.tiv.2014.12.001.

[51] P.T. Theunissen, J.F. Robinson, J.L.A. Pennings, M.H. van Herwijnen, J.C.S. Kleinjans, A.H. Piersma Compound-specific effects of diverse neurodevelopmental toxicants on global gene expression in the neural embryonic stem cell test (ESTn), Toxicol. Appl. Pharmacol. 262 (2012) 330-340. https://doi.org/10.1016/j.taap.2012.05.011.

[52] J. Baumann, K. Gassmann, S. Masjosthusmann, D. DeBoer, F. Bendt, S. Giersiefer, E. Fritsche, Comparative human and rat neurospheres reveal species differences in chemical effects on neurodevelopmental key events, Arch. Toxicol. 90 (2016) 1415-1427. https://doi.org/10.1007/s00204-015-1568-8.

[53] J.A. Harrill, Human-Derived Neurons and Neural Progenitor Cells in High Content Imaging Applications, in: P.A. Johnston, O.J. Trask (Eds.), Methods Mol. Biol., Springer New York, New York, NY, 2018: pp. 305-338. https://doi.org/10.1007/978-1-4939-7357-6_18.

[54] B. Zimmer, G. Lee, N. V. Balmer, K. Meganathan, A. Sachinidis, L. Studer, M. Leist, Evaluation of developmental toxicants and signaling pathways in a functional test based on the migration of human neural crest cells, Environ. Health Perspect. 120 (2012) 1116-1122. https://doi.org/10.1289/ehp.1104489.

[55] H.T. Hogberg, T. Sobanski, A. Novellino, M. Whelan, D.G. Weiss, A.K. Bal-Price, Application of micro-electrode arrays (MEAs) as an emerging technology for developmental neurotoxicity: Evaluation of domoic acidinduced effects in primary cultures of rat cortical neurons, Neurotoxicology. 32 (2011) 158-168. https://doi.org/10.1016/j.neuro.2010.10.007.

[56] K. Hayess, C. Riebeling, R. Pirow, M. Steinfath, D. Sittner, B. Slawik, A. Luch, A.E.M. Seiler, The DNT-EST: A predictive embryonic stem cell-based assay for developmental neurotoxicity testing in vitro, Toxicology. 314 (2013) 135-147. https://doi.org/10.1016/j.tox.2013.09.012.

[57] M.A. Taylor, H.L. Kan, B.B. Gollapudi, M.S. Marty, An in vitro developmental neurotoxicity screening assay for retinoic acid-induced neuronal differentiation using the human NT2/D1 cell line, Neurotoxicology. 73 (2019) 258-264. https://doi.org/10.1016/J.NEURO.2019.04.005.

[58] A. Visan, K. Hayess, D. Sittner, E.E. Pohl, C. Riebeling, B. Slawik, K. Gulich, M. Oelgeschläger, A. Luch, A.E.M. Seiler, Neural differentiation of mouse embryonic stem cells as a tool to assess developmental neurotoxicity in vitro, Neurotoxicology. 33 (2012) 1135-1146. https://doi.org/10.1016/j.neuro.2012.06.006.

[59] L. Sandoval, A. Rosca, A. Oniga, A. Zambrano, J.J. Ramos, M.C. González, I. Liste, M. Motas, Effects of chlorpyrifos on cell death and cellular phenotypic specification of human neural stem cells, Sci. Total Environ. 683 (2019) 445-454. https://doi.org/10.1016/j.scitotenv.2019.05.270. 
[60] K. Reemst, S.C. Noctor, P.J. Lucassen, E.M. Hol, The indispensable roles of microglia and astrocytes during brain development, Front. Hum. Neurosci. 10 (2016) 566. https://doi.org/10.3389/fnhum.2016.00566.

[61] P.T. Theunissen, J.F. Robinson, J.L.A. Pennings, E. De jong, S.M.H. Claessen, J.C.S. Kleinjans, A.H. Piersma, Transcriptomic concentration-response evaluation of valproic acid, cyproconazole, and hexaconazole in the neural Embryonic Stem Cell Test (ESTn), Toxicol. Sci. 125 (2012) 430-438. https://doi.org/10.1093/toxsci/kfr293.

[62] M. Singh, K.P. Singh, S. Shukla, M. Dikshit, Assessment of in-utero venlafaxine induced, ROS-mediated apoptotic neurodegeneration in fetal neocortex and neurobehavioral sequelae in rat offspring, Int. J. Dev. Neurosci. 40 (2015) 60-69. https://doi.org/10.1016/J.IJDEVNEU.2014.10.007.

[63] H.-K. Chang, K.H. Kim, K.-W. Kang, Y.-J. Kang, T.-W. Kim, H.-K. Park, S.-E. Kim, C.-J. Kim, Antidepressants modulate glycine action in rat hippocampus, J. Exerc. Rehabil. 11 (2015) 311-319. https://doi.org/10.12965/jer.150263.

[64] Z.Y. Ye, Y.G. Lu, H. Sun, X.P. Cheng, T. Le Xu, J.N. Zhou, Fluoxetine inhibition of glycine receptor activity in rat hippocampal neurons, Brain Res. 1239 (2008) 77-84. https://doi.org/10.1016/j.brainres.2008.08.055.

[65] S.C. Jha, S. Meltzer-Brody, R.J. Steiner, E. Cornea, S. Woolson, M. Ahn, A.R. Verde, R.M. Hamer, H. Zhu, M. Styner, J.H. Gilmore, R.C. Knickmeyer, Antenatal depression, treatment with selective serotonin reuptake inhibitors, and neonatal brain structure: A propensity-matched cohort study, Psychiatry Res. - Neuroimaging. 253 (2016) 43-53. https://doi.org/10.1016/j.pscychresns.2016.05.004. 


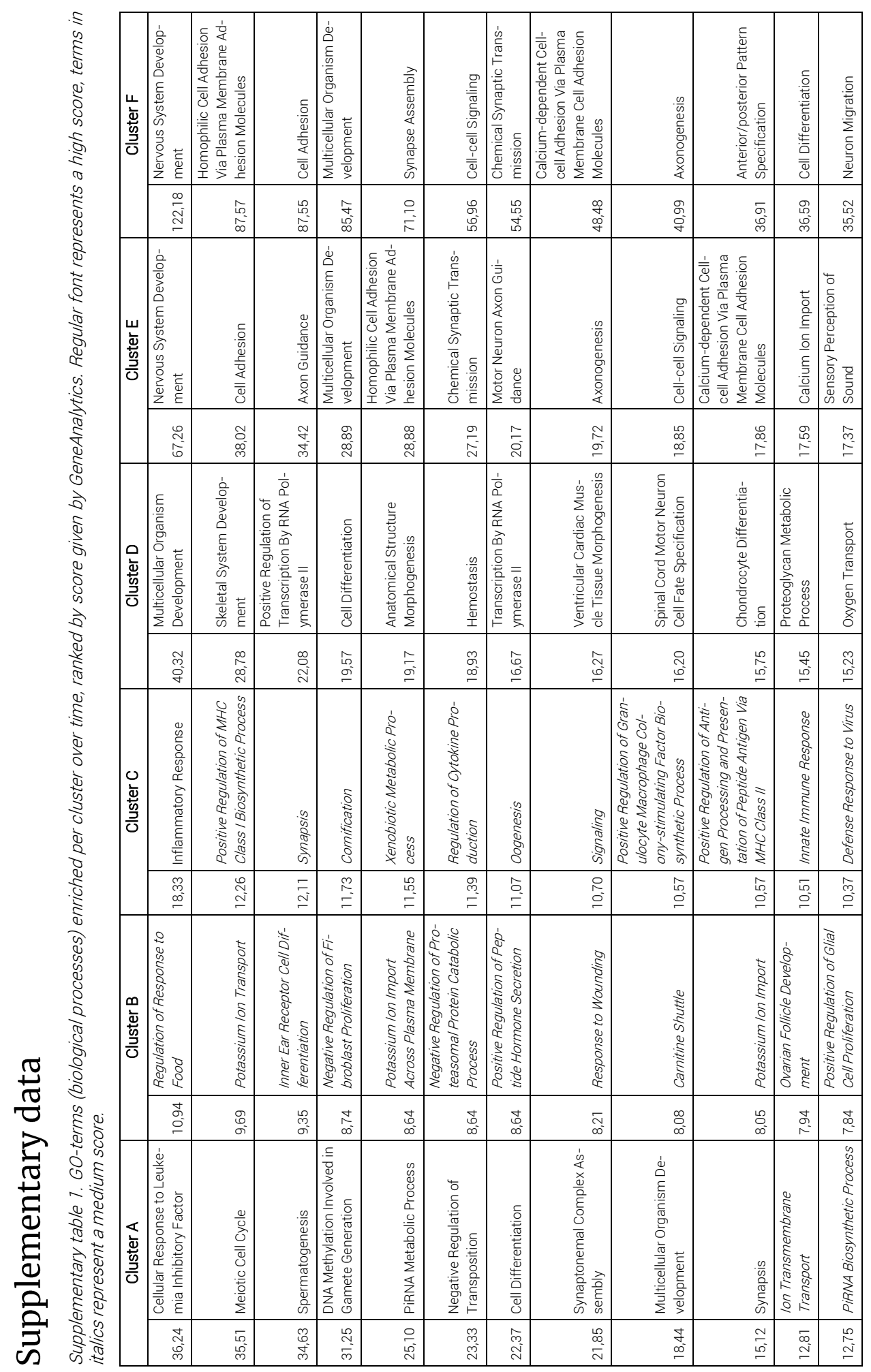




\begin{tabular}{|c|c|c|c|c|c|c|c|c|c|c|c|c|c|c|c|c|}
\hline 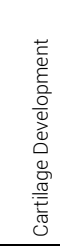 & 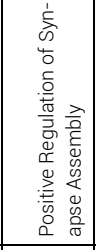 & 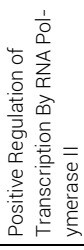 & 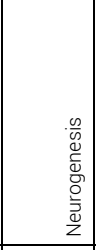 & 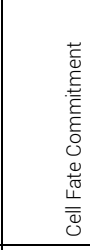 & 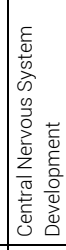 & 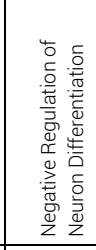 & 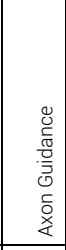 & 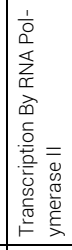 & 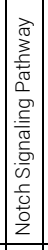 & 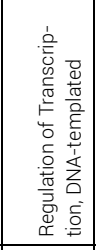 & 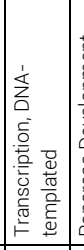 & 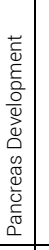 & 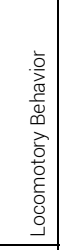 & 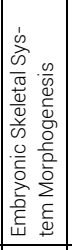 & 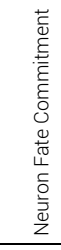 & 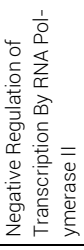 \\
\hline 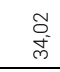 & $\begin{array}{l}\hat{\infty} \\
\tilde{p} \\
\end{array}$ & $\begin{array}{l}\stackrel{2}{\sim} \\
\text { d }\end{array}$ & $\frac{m}{\sigma^{\circ}}$ & \begin{tabular}{l} 
fo \\
\multirow{0}{*}{} \\
\multirow{2}{*}{}
\end{tabular} & 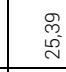 & 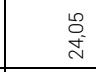 & $\underset{\sim}{N}$ & $\begin{array}{l}\overline{\text { J }} \\
\text {. }\end{array}$ & $\begin{array}{l}\text { O } \\
\text { ন্ } \\
\end{array}$ & 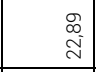 & 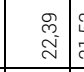 & $\begin{array}{l}\tilde{N} \\
\stackrel{N}{N} \\
\\
\end{array}$ & 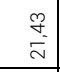 & 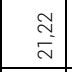 & 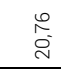 & $\begin{array}{l}\tilde{\Delta} \\
\stackrel{\sim}{~}\end{array}$ \\
\hline 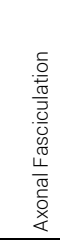 & 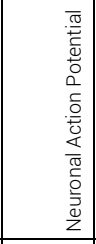 & 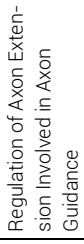 & 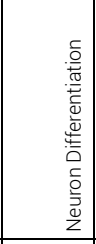 & 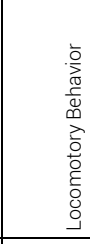 & 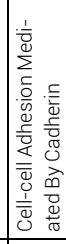 & 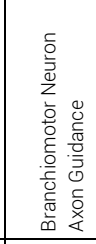 & 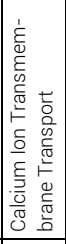 & 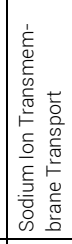 & 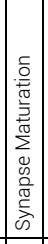 & 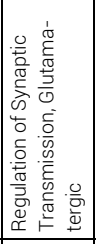 & 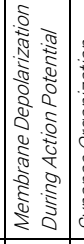 & 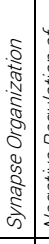 & 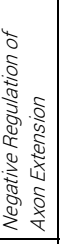 & 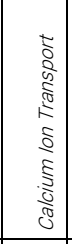 & 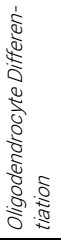 & 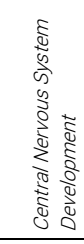 \\
\hline 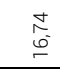 & $\begin{array}{l}\bar{\sigma} \\
\stackrel{\circ}{ } \\
\end{array}$ & 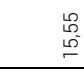 & $\begin{array}{l}\underset{\sim}{\sim} \\
\stackrel{5}{ } \\
\end{array}$ & 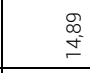 & $\begin{array}{l}\stackrel{\infty}{\leftarrow} \\
\leftarrow \\
\end{array}$ & $\begin{array}{l}\stackrel{̊}{\circ} \\
\underset{\leftarrow}{+} \\
\end{array}$ & $\begin{array}{l}\stackrel{g}{+} \\
\dot{\square} \\
\end{array}$ & $\begin{array}{l}\stackrel{\leftrightarrow}{2} \\
\stackrel{m}{-} \\
\end{array}$ & \begin{tabular}{|l|}
$\stackrel{\leftrightarrow}{ }$ \\
$\stackrel{\rho}{\circ}$ \\
\end{tabular} & $\begin{array}{l}\underset{\infty}{\infty} \\
\stackrel{\rho}{\rightleftharpoons} \\
\end{array}$ & 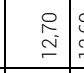 & : & $\begin{array}{l}\stackrel{\circ}{\sim} \\
\stackrel{\sim}{\sim} \\
\end{array}$ & $\underset{\stackrel{\leftrightarrow}{\leftrightarrow}}{\stackrel{\sim}{\sim}}$ & 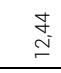 & $\stackrel{\bar{m}}{\stackrel{\bar{d}}{c}}$ \\
\hline 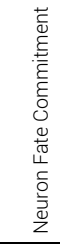 & 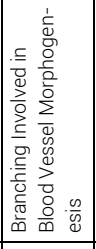 & 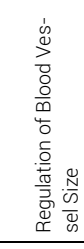 & 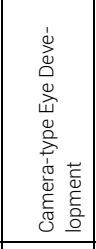 & 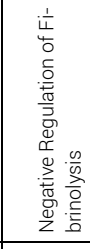 & 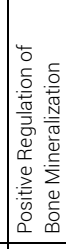 & 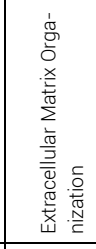 & 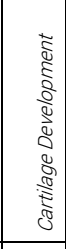 & 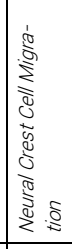 & 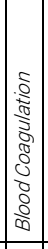 & 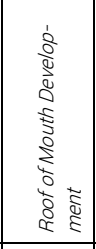 & 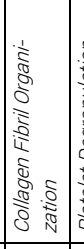 & & 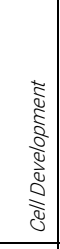 & 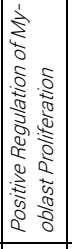 & 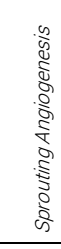 & 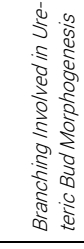 \\
\hline $\begin{array}{l}\infty \\
\stackrel{0}{b^{\circ}} \\
\stackrel{1}{\circ}\end{array}$ & $\begin{array}{l}\bar{\infty} \\
\dot{J} \\
\tau\end{array}$ & $\begin{array}{l}\text { f } \\
\dot{J}\end{array}$ & $\begin{array}{l}\stackrel{0}{o} \\
\stackrel{+}{ \pm}\end{array}$ & $\begin{array}{l}\bar{N} \\
\underset{J}{J}\end{array}$ & $\begin{array}{l}\infty \\
\infty \\
\infty \\
\end{array}$ & $\begin{array}{l}\infty \\
\stackrel{\infty}{\infty} \\
\stackrel{\Gamma}{\Gamma}\end{array}$ & 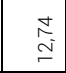 & 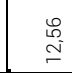 & 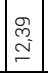 & $\underset{\underset{I}{\sim}}{\stackrel{\sim}{\sim}}$ & 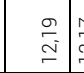 & 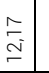 & 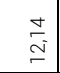 & $\begin{array}{l}\stackrel{\leftrightarrow}{\rightleftarrows} \\
\rightleftharpoons\end{array}$ & $\stackrel{\stackrel{\infty}{\rightleftarrows}}{=}$ & 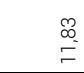 \\
\hline 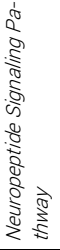 & 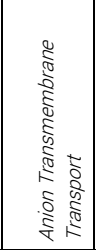 & 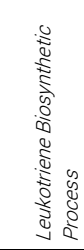 & 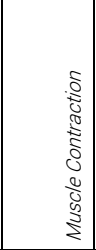 & 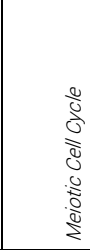 & 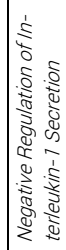 & 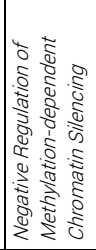 & 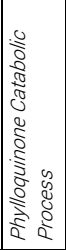 & & & & & & & & & \\
\hline $\begin{array}{l}\text { N } \\
\\
\end{array}$ & $\begin{array}{l}0 \\
\\
\end{array}$ & 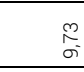 & $\stackrel{8}{\circ}$ & o. & $\begin{array}{l}\mathcal{J} \\
\sigma\end{array}$ & Fै & $\begin{array}{l}\mathcal{F} \\
\sigma\end{array}$ & & & & & & & & & \\
\hline 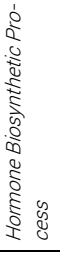 & $\begin{array}{l}5 \\
0 \\
0 \\
\frac{0}{2} \\
0 \\
0 \\
0 \\
0\end{array}$ & 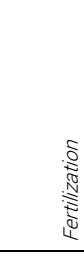 & 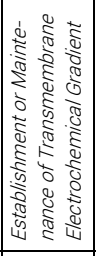 & 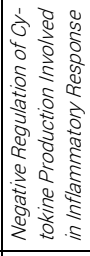 & 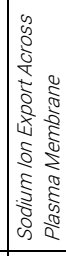 & 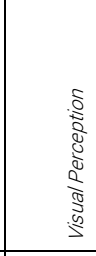 & 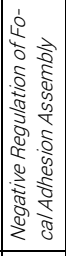 & & & & & & & & & \\
\hline 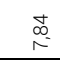 & $\stackrel{\substack{\infty \\
\sim}}{\stackrel{2}{*}}$ & 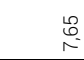 & $\stackrel{\substack{\sigma \\
\sim}}{.}$ & $\underset{\sim}{\stackrel{D}{N}}$ & $\underset{N}{\text { 黑 }}$ & $\stackrel{\infty}{\sim} \underset{\sim}{\sim}$ & 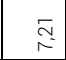 & & & & & & & & & \\
\hline 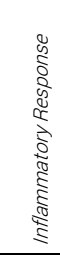 & 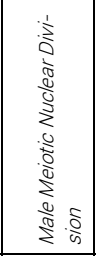 & 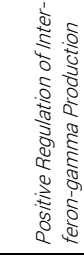 & 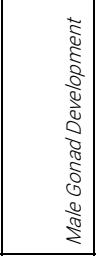 & 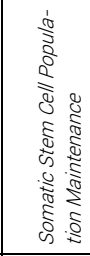 & 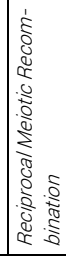 & 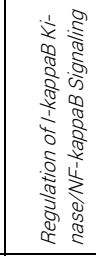 & 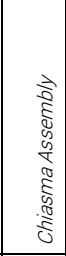 & & & & & & & & & \\
\hline$\underset{\mathbb{N}}{\mathbb{N}}$ & $\begin{array}{l}\underset{\sigma}{\sigma} \\
\check{\tau}\end{array}$ & $\stackrel{\substack{\infty\\
}}{=}$ & $\begin{array}{l}\stackrel{\Omega}{\sigma} \\
\stackrel{\sim}{\rightleftharpoons}\end{array}$ & $\stackrel{\text { 唱 }}{=}$ & 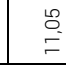 & $\begin{array}{l}\stackrel{\infty}{\infty} \\
\stackrel{\circ}{\subset} \\
\end{array}$ & $\begin{array}{l}\infty \\
\stackrel{0}{0} \\
\end{array}$ & & & & & & & & & \\
\hline
\end{tabular}




\begin{tabular}{|c|c|c|c|c|c|c|c|c|c|c|c|c|c|c|c|c|c|c|}
\hline 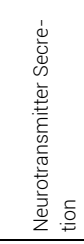 & 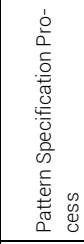 & 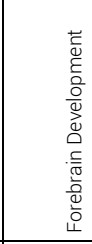 & 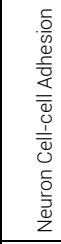 & 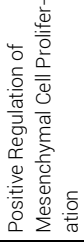 & 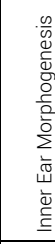 & 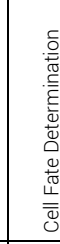 & & 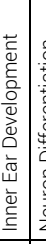 & 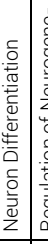 & 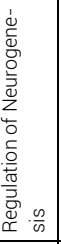 & 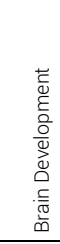 & 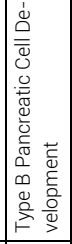 & 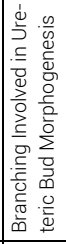 & 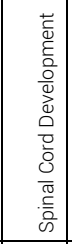 & 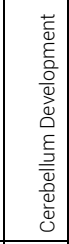 & 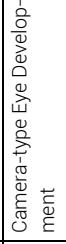 & 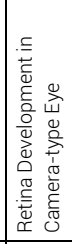 & 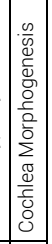 \\
\hline $\begin{array}{l}\text { ơ } \\
\text { d }\end{array}$ & $\begin{array}{l}\stackrel{2}{\circ} \\
\stackrel{\sigma}{\sigma}\end{array}$ & $\frac{\infty}{\sigma}$ & $\underset{\substack{0 \\
\infty}}{\infty}$ & $\stackrel{\substack{\infty \\
\sim}}{\sim}$ & $\stackrel{\stackrel{\infty}{\sim}}{\stackrel{\sim}{\sim}}$ & 兑 & & 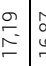 & $\begin{array}{l}\hat{\infty} \\
0 \\
\underline{0}\end{array}$ & 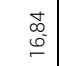 & 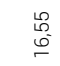 & $\begin{array}{l}0 \\
0 \\
0\end{array}$ & 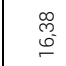 & $\begin{array}{l}\hat{\sigma} \\
\hat{\sigma} \\
\\
c\end{array}$ & 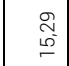 & 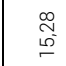 & & 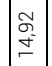 \\
\hline 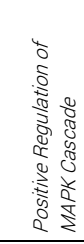 & 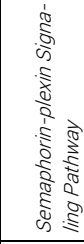 & 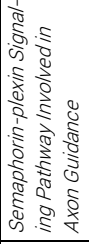 & 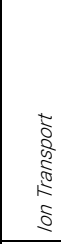 & 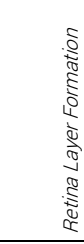 & 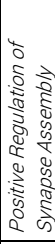 & 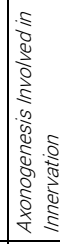 & 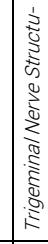 & 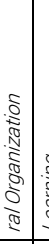 & 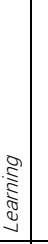 & 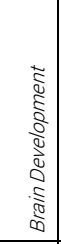 & 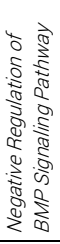 & 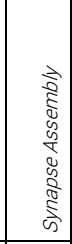 & 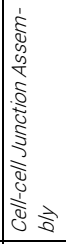 & 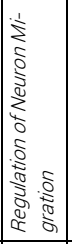 & 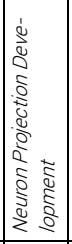 & 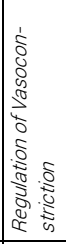 & & \\
\hline$\underset{\mathbb{N}}{\mathbb{N}}$ & 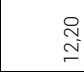 & $\stackrel{\mathbb{N}}{=}$ & $\underset{F}{\stackrel{N}{E}}$ & $\begin{array}{l}? \\
\stackrel{P}{E}\end{array}$ & 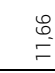 & 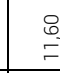 & & 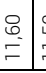 & & $\begin{array}{l}\stackrel{g}{f} \\
: \\
\end{array}$ & 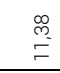 & $\stackrel{\tilde{m}}{=}$ & $\stackrel{\stackrel{m}{=}}{=}$ & $\begin{array}{l}\underset{\sim}{\sim} \\
F \\
\end{array}$ & $\begin{array}{l}\stackrel{\infty}{\sim} \\
\mp \\
\end{array}$ & $\stackrel{m}{=}$ & & \\
\hline 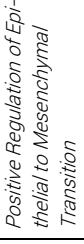 & 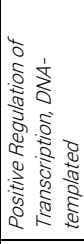 & 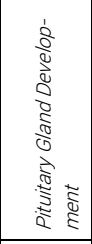 & 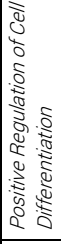 & 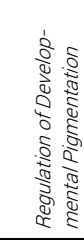 & $\begin{array}{l}0 \\
\frac{1}{2} \\
\frac{1}{2}\end{array}$ & 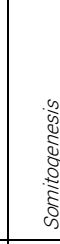 & & & & & & & & & & & & \\
\hline $\begin{array}{l}\stackrel{\leftrightarrow}{\rightleftarrows} \\
\stackrel{+}{二}\end{array}$ & $\stackrel{\tilde{L}}{\check{c}}$ & 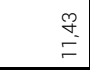 & 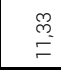 & 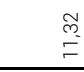 & $\mp$ & 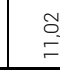 & & & & & & & & & & & & \\
\hline
\end{tabular}




\begin{tabular}{|c|c|c|c|c|c|c|c|c|c|c|c|c|c|c|c|c|c|c|}
\hline 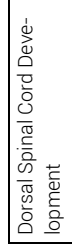 & 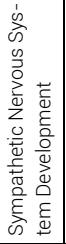 & 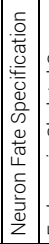 & 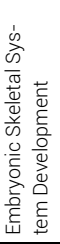 & 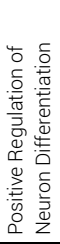 & 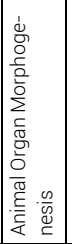 & 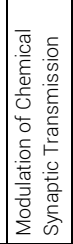 & 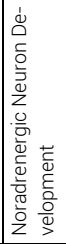 & 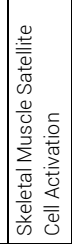 & 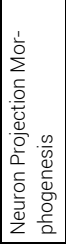 & 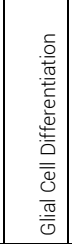 & 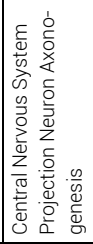 & 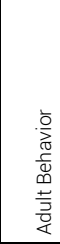 & 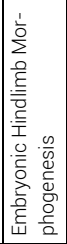 & 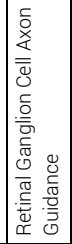 & 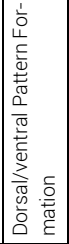 & 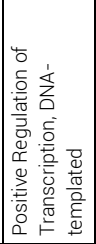 & 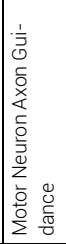 & 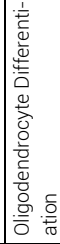 \\
\hline 尔 & \begin{tabular}{l}
$\stackrel{8}{8}$ \\
\multirow{2}{*}{}
\end{tabular} & 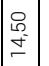 & 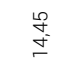 & $\underset{\substack{\tilde{丶} \\
\underset{\sim}{\sim}}}{ }$ & $\begin{array}{l}\stackrel{\stackrel{\sim}{*}}{\sim} \\
\end{array}$ & 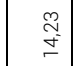 & $\frac{\infty}{\sigma^{\circ}}$ & $\frac{\infty}{\mp}$ & 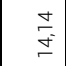 & 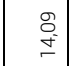 & -1 & 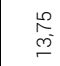 & - & $\stackrel{m}{-1}$ & $\stackrel{\stackrel{\infty}{\circ}}{\stackrel{\rho}{g}}$ & 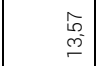 & - & \\
\hline & & & & & 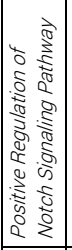 & 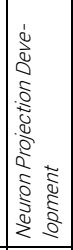 & 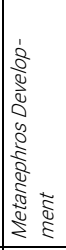 & 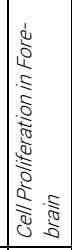 & 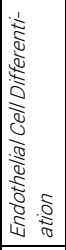 & 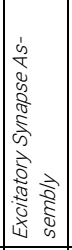 & 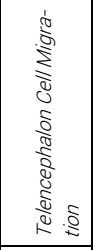 & 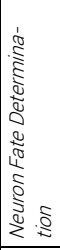 & 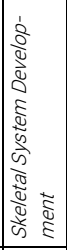 & 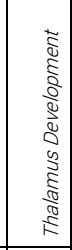 & 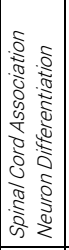 & 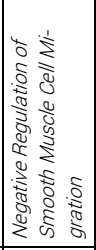 & 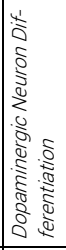 & 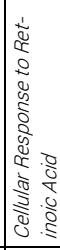 \\
\hline & & & & & 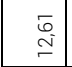 & 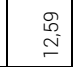 & $\stackrel{2}{\simeq}$ & $\simeq$ & $\stackrel{\sim}{\simeq}$ & 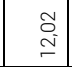 & & $\stackrel{2}{7}$ & & $=$ & & $F$ & & \\
\hline
\end{tabular}




\begin{tabular}{|c|c|c|c|c|c|c|}
\hline 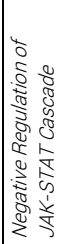 & 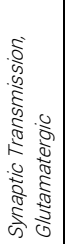 & 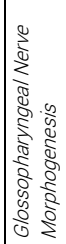 & 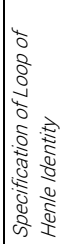 & 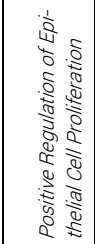 & 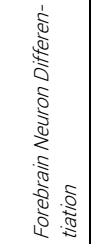 & 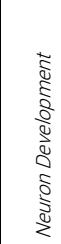 \\
\hline$\frac{\stackrel{\infty}{m}}{\stackrel{m}{\sigma}}$ & 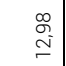 & : & 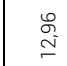 & $\begin{array}{l}\stackrel{0}{\sim} \\
\underset{\sim}{\sim}\end{array}$ & 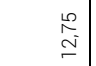 & $\underset{\sim}{\stackrel{\mathbb{N}}{\sim}}$ \\
\hline 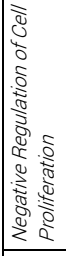 & 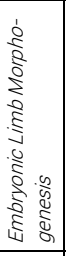 & 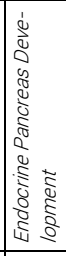 & 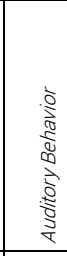 & 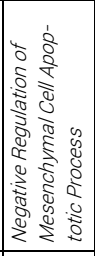 & 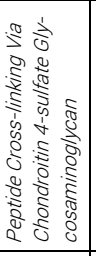 & 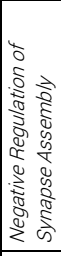 \\
\hline$\underset{F}{\stackrel{R}{E}}$ & 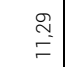 & 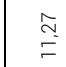 & 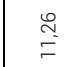 & $\begin{array}{l}\stackrel{0}{\stackrel{\sim}{二}} \\
F\end{array}$ & $\begin{array}{l}\stackrel{0}{\rightleftharpoons} \\
\rightleftharpoons\end{array}$ & 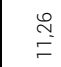 \\
\hline
\end{tabular}




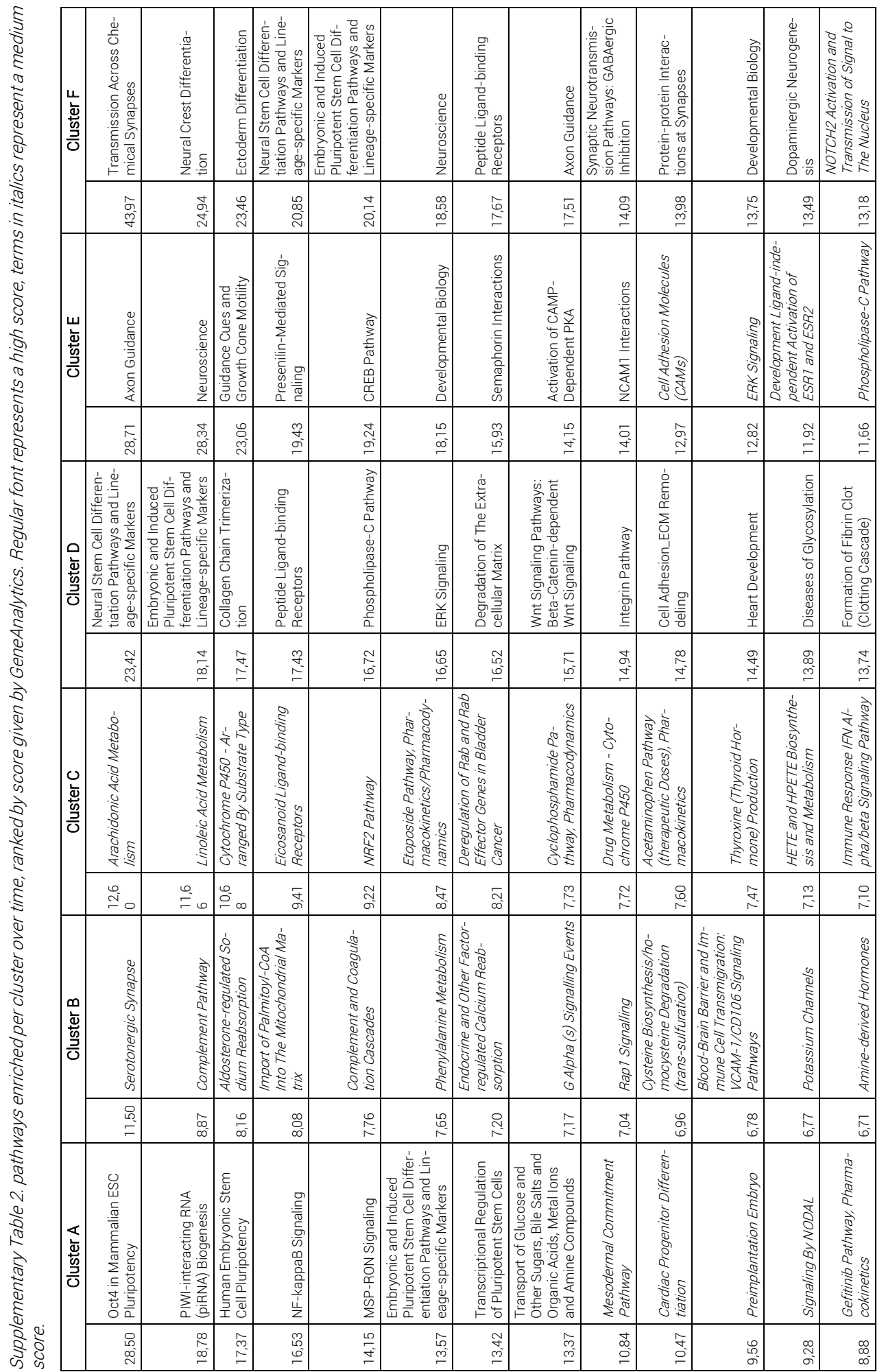




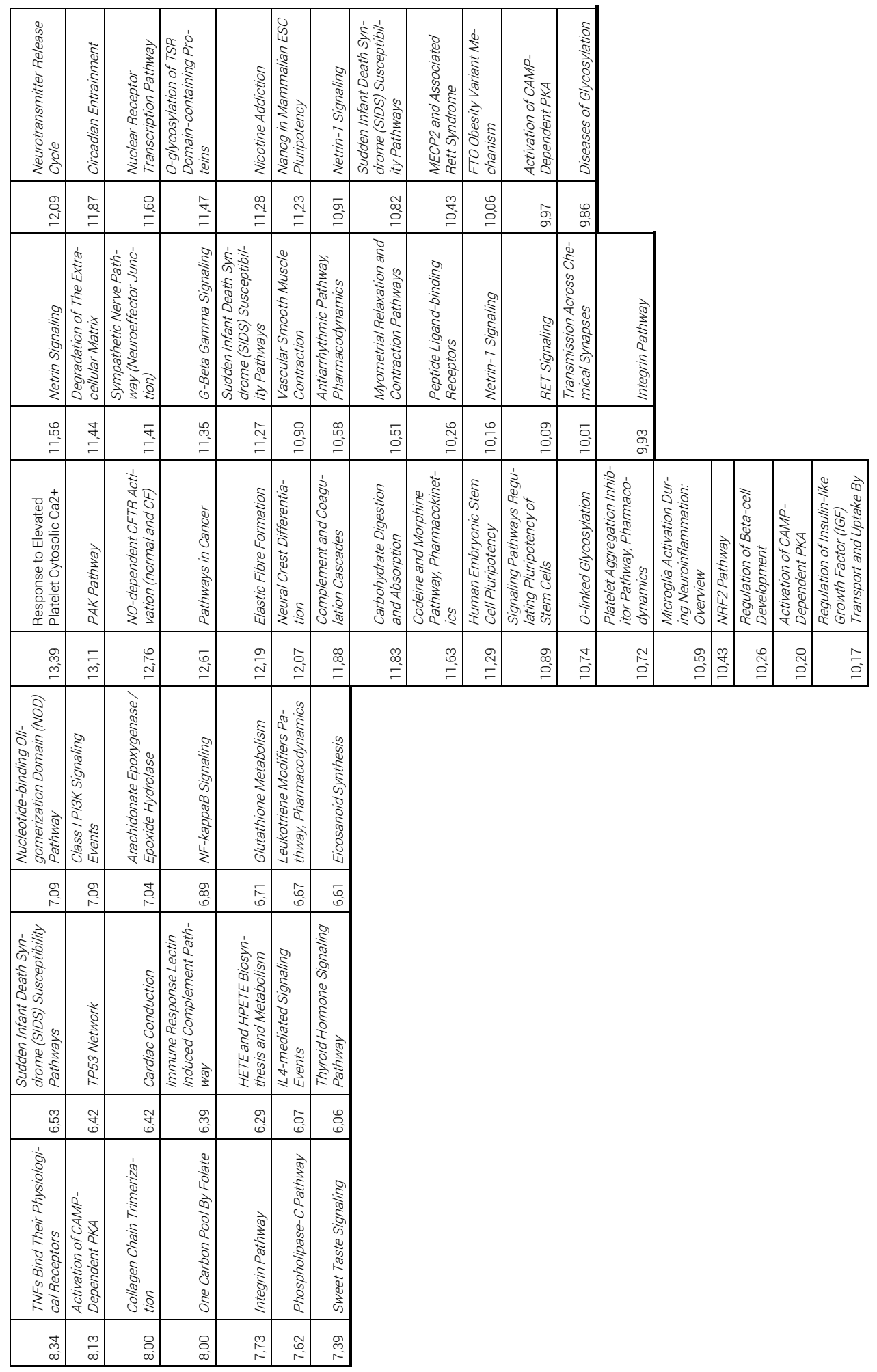




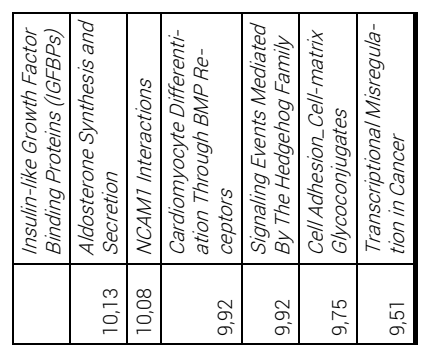




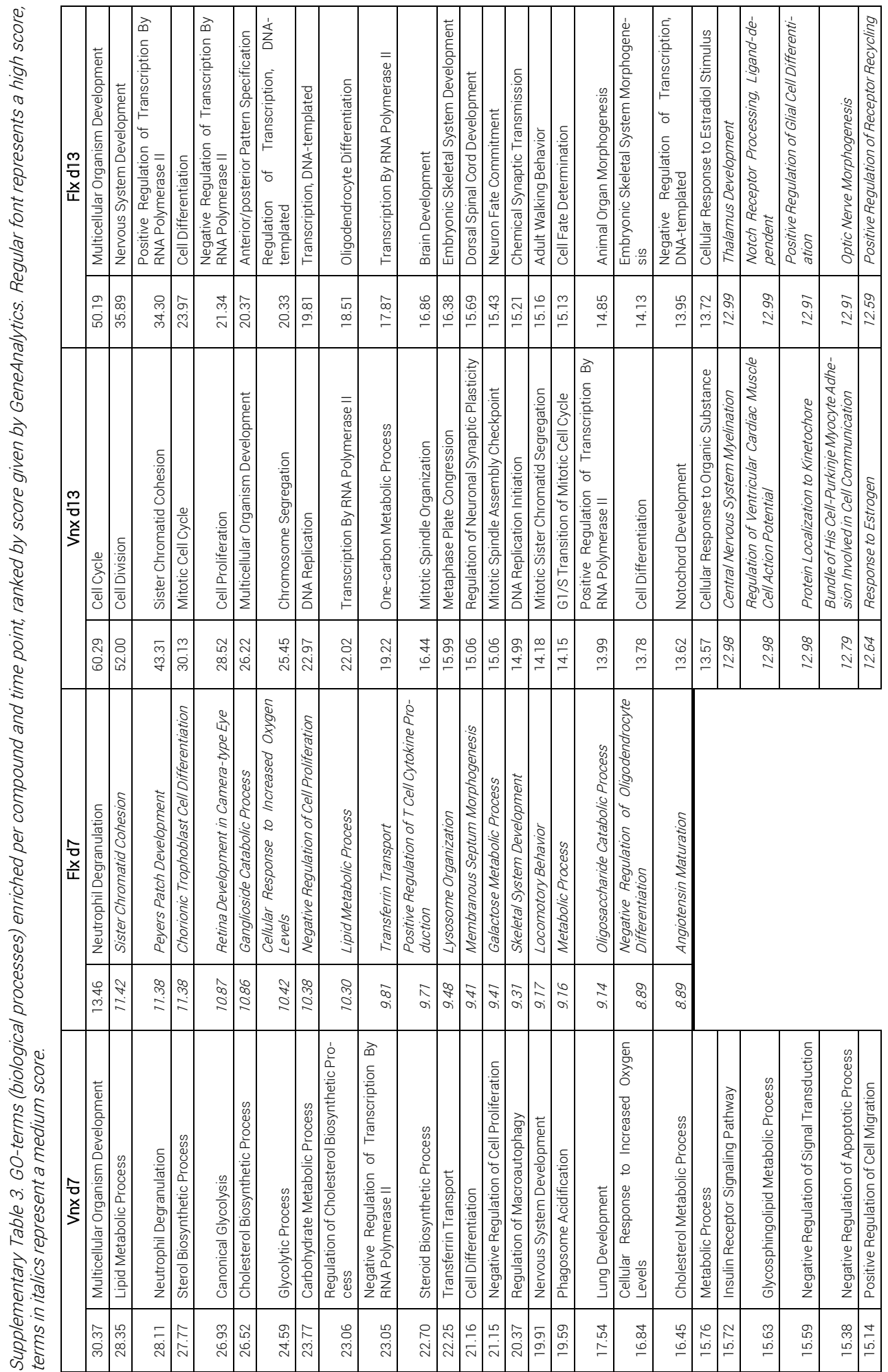



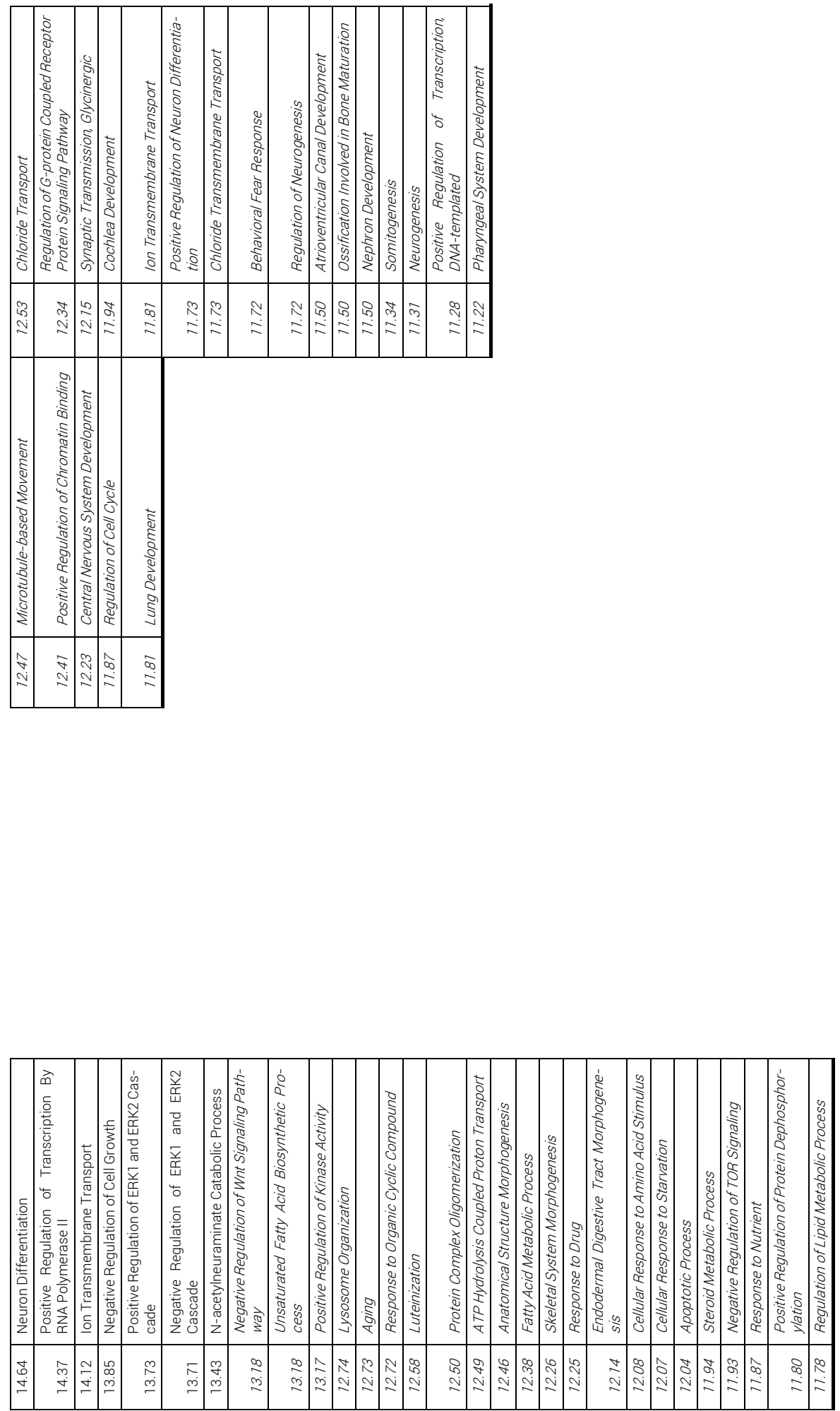


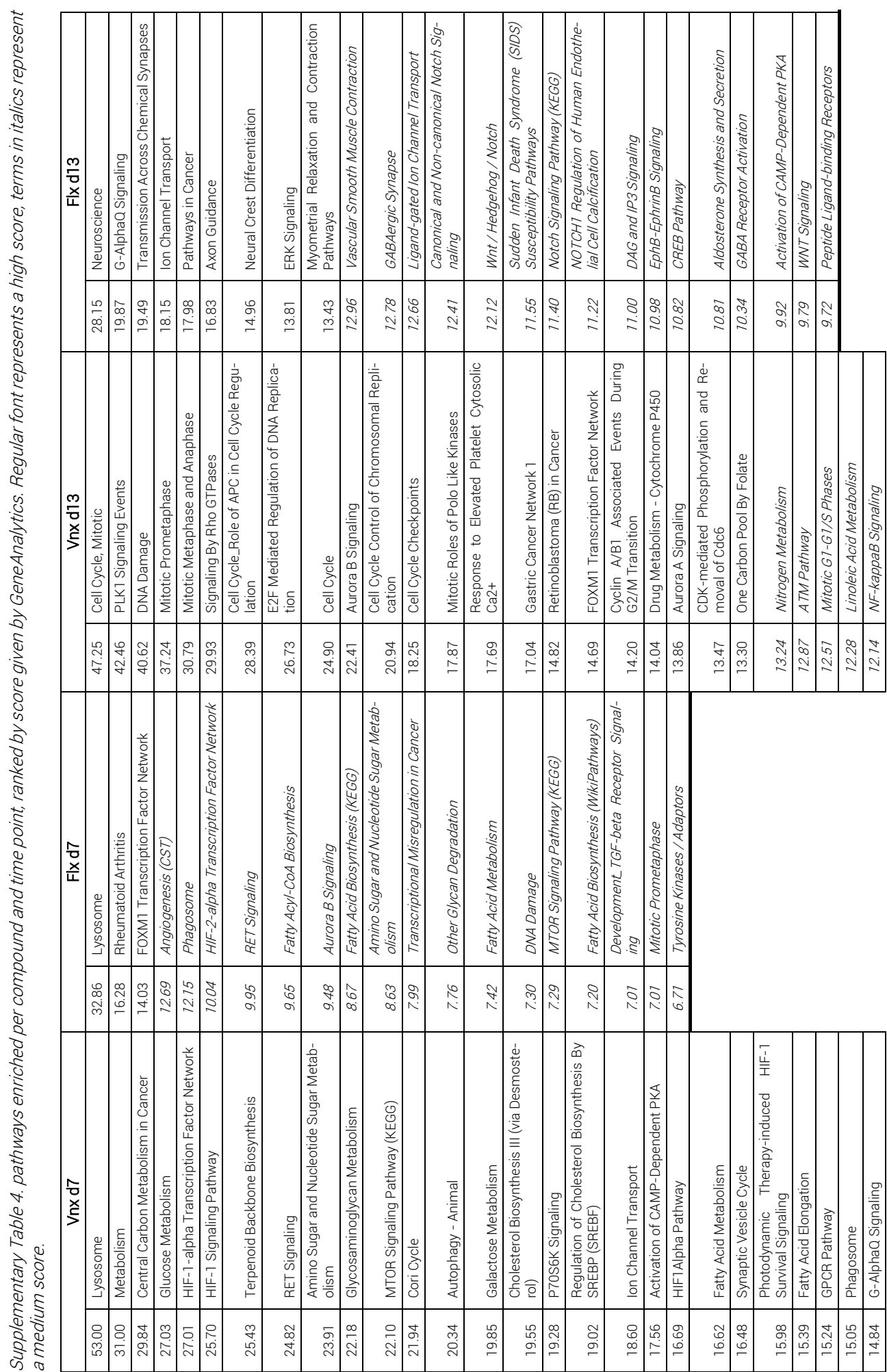



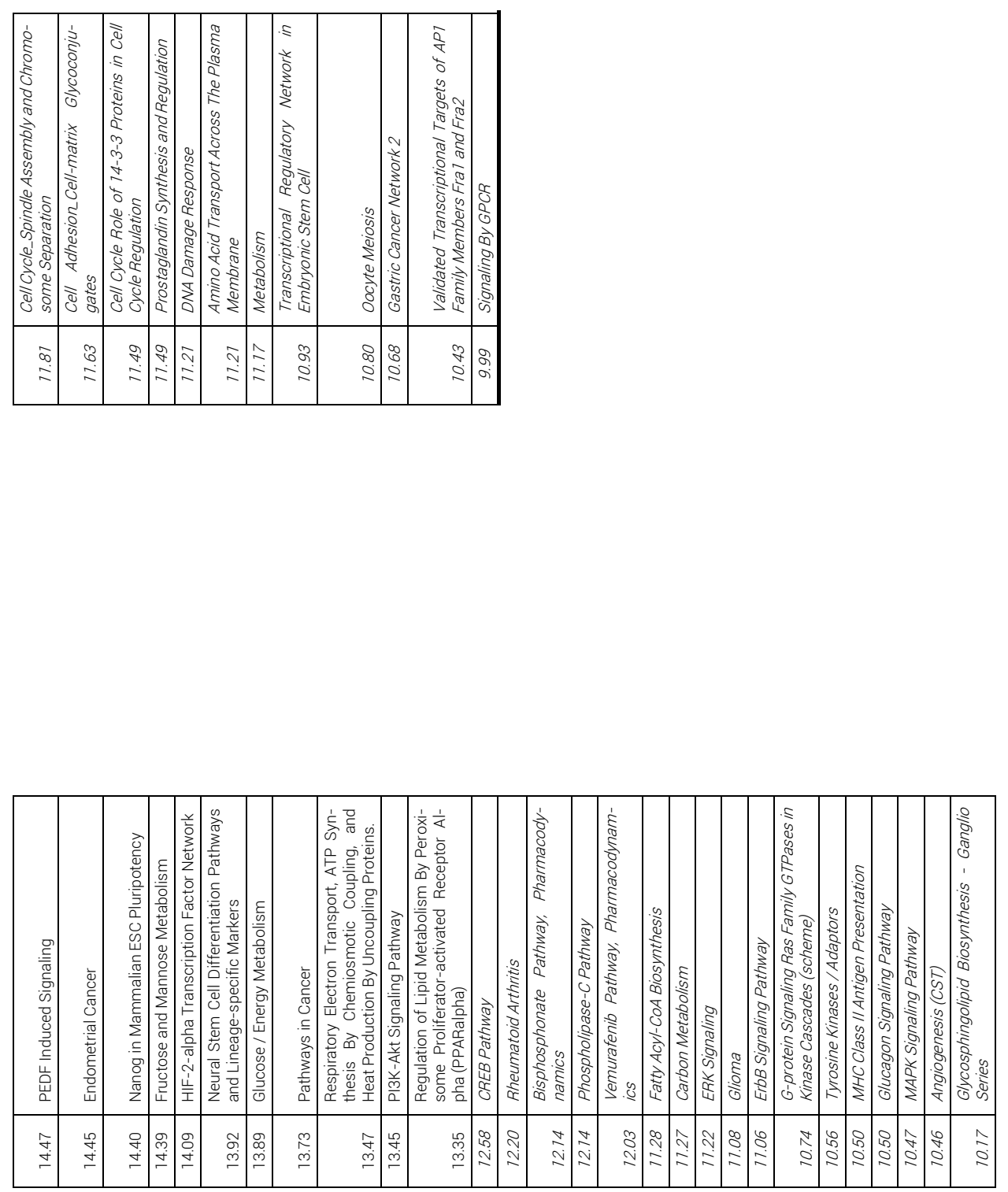


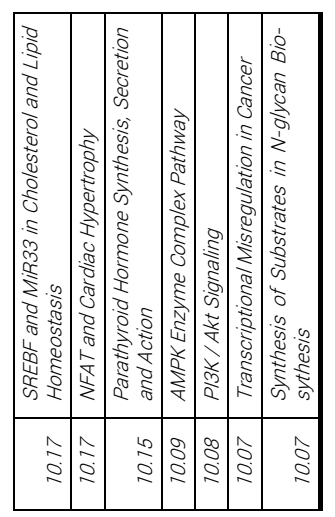




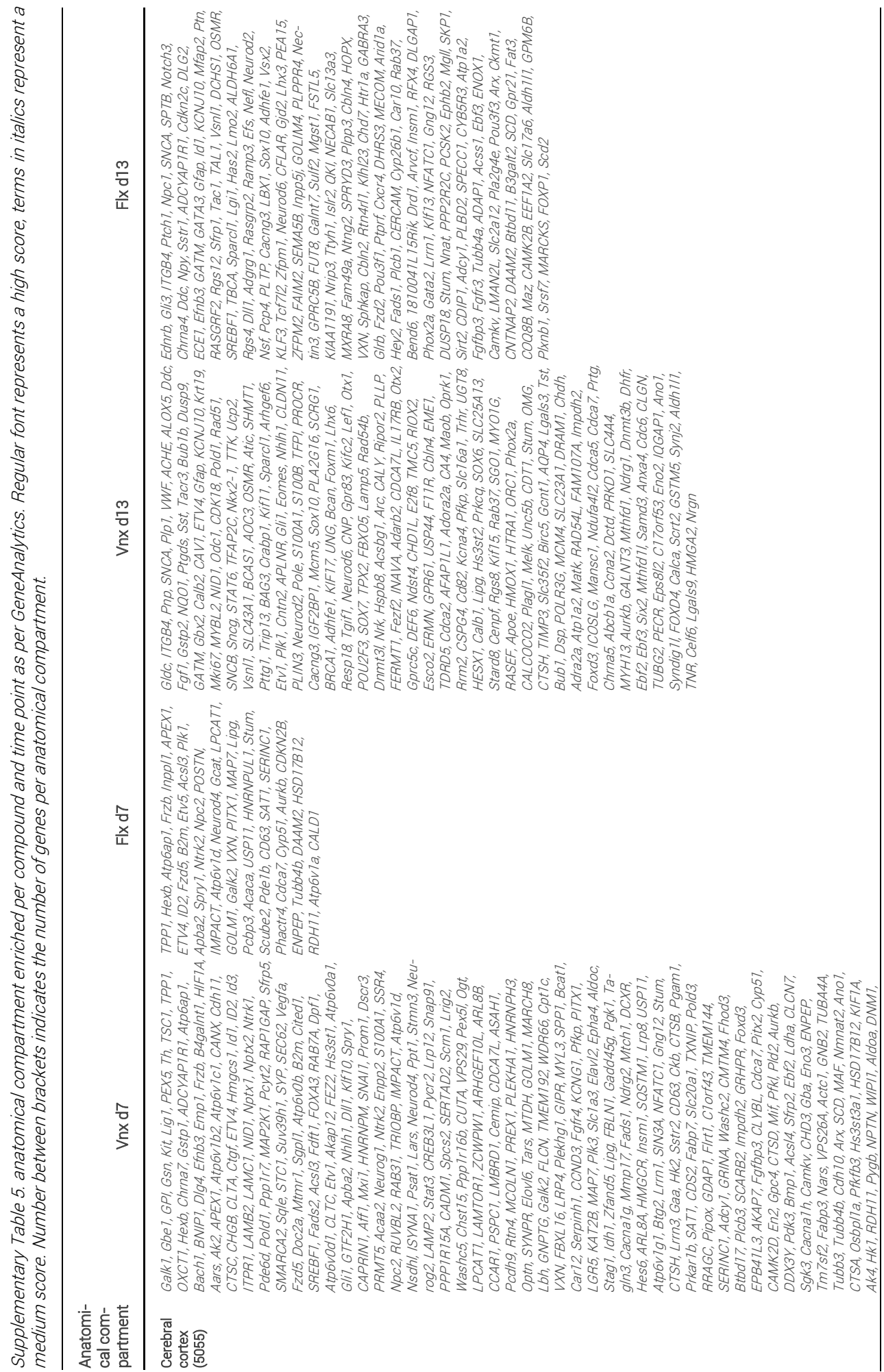




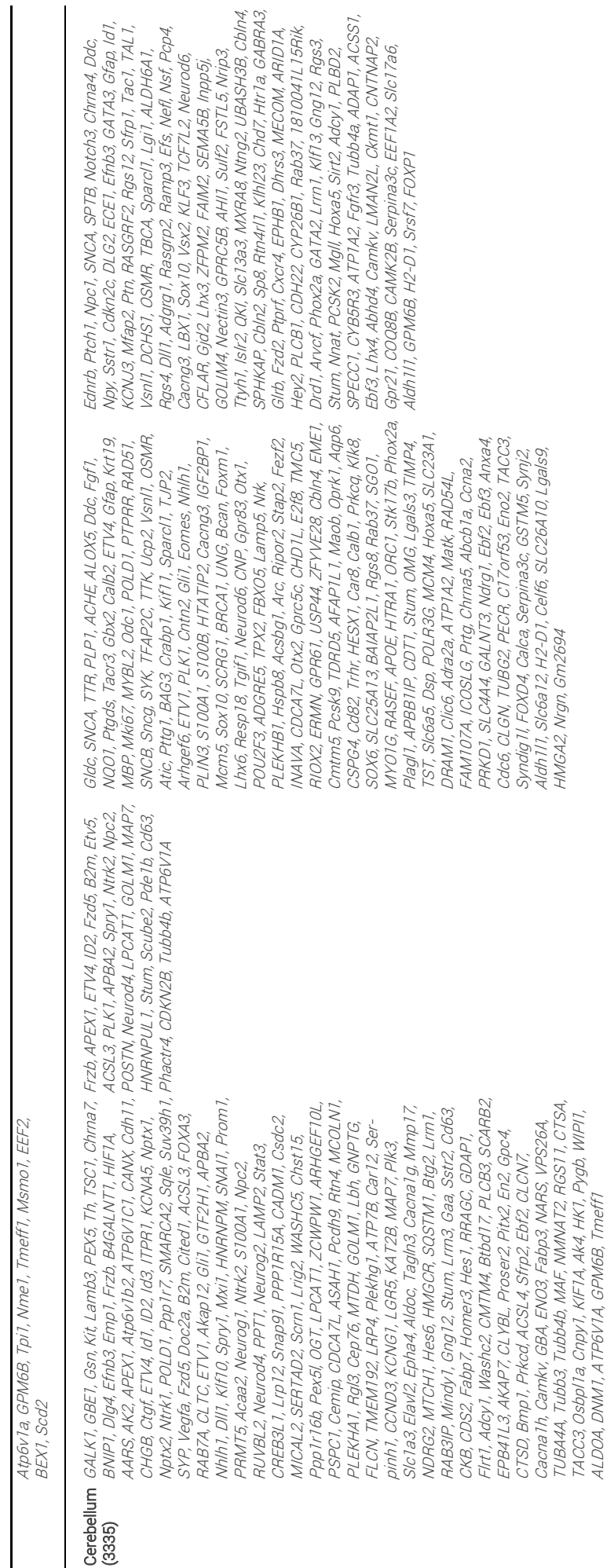

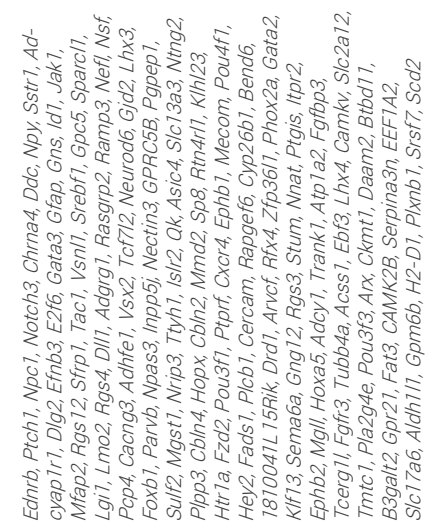

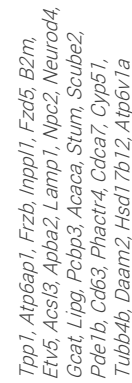

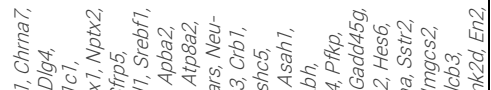

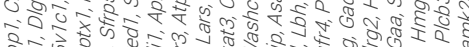

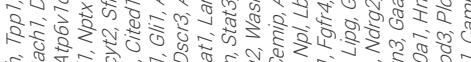

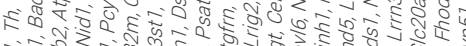

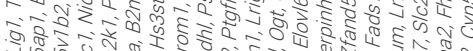

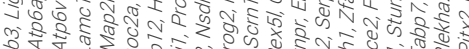

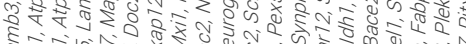

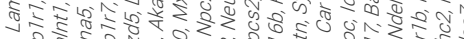
त्र

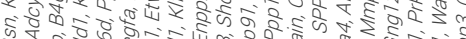
का व

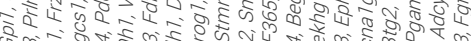

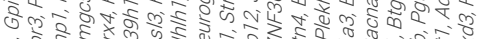

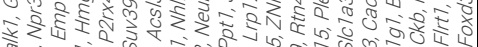

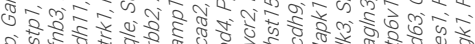

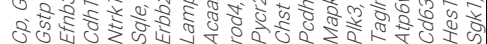
응 高影 


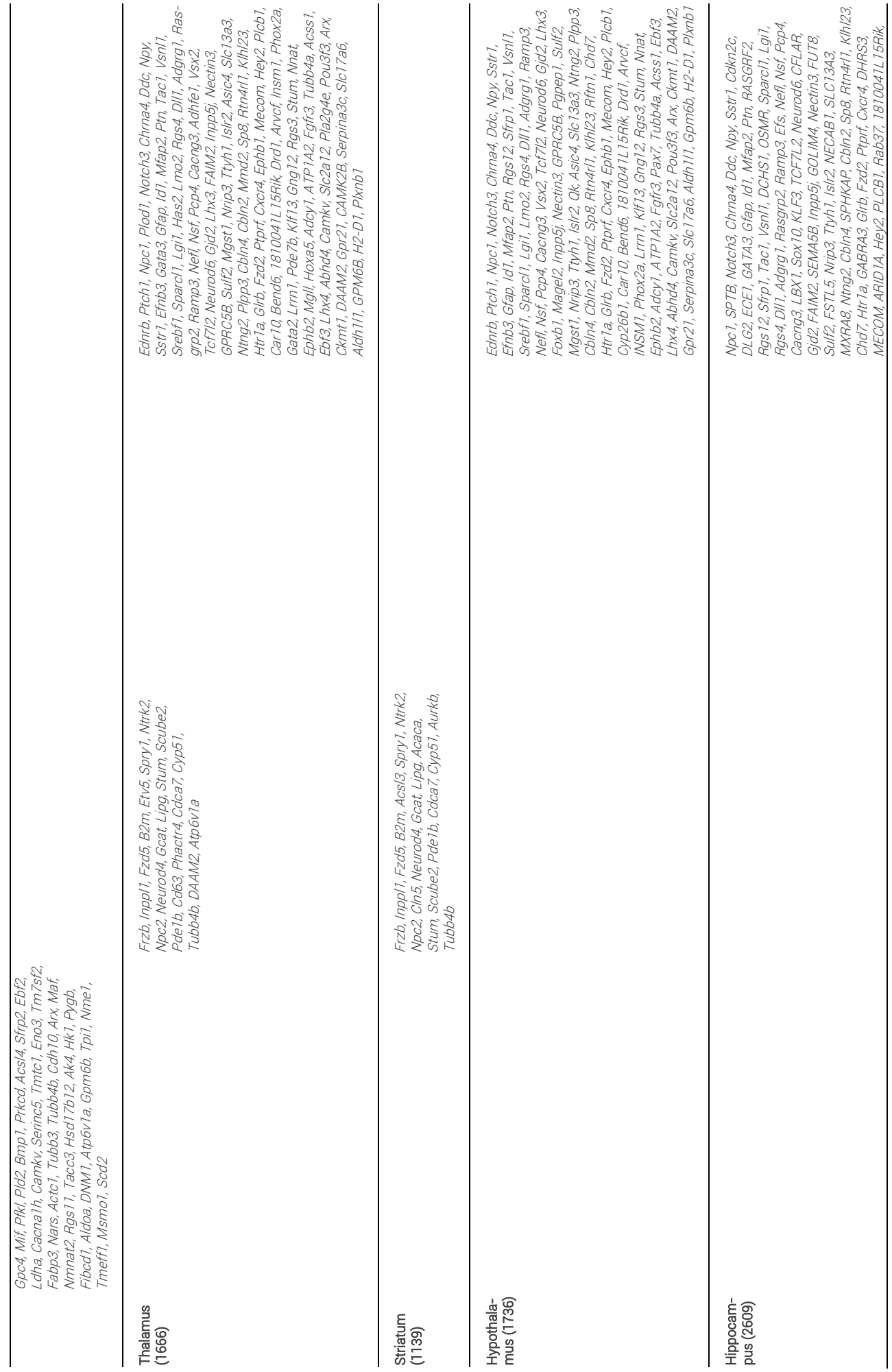



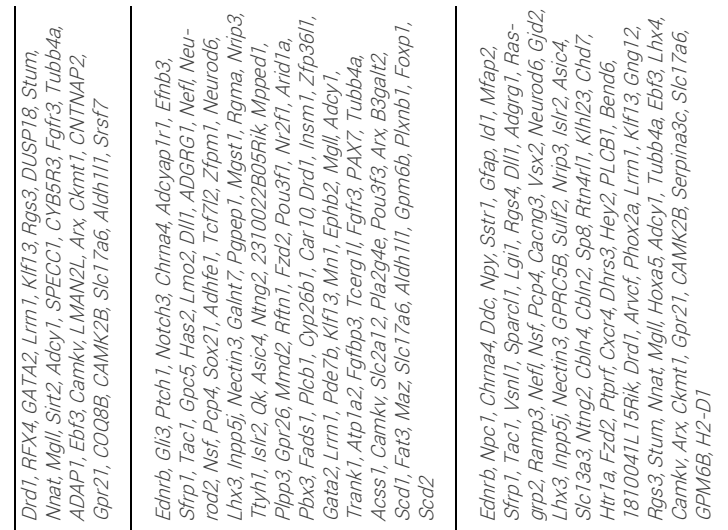

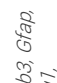

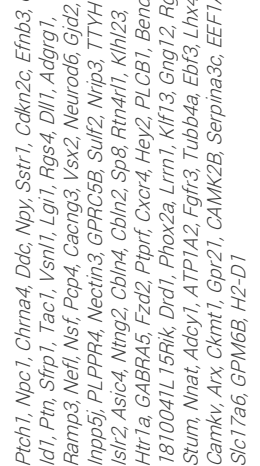

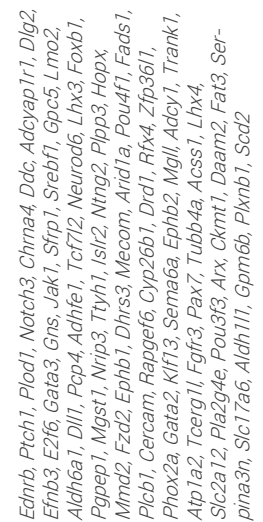





\section{CHAPTER 7}

\section{AN EFFICIENT NEURON-ASTROCYTE DIFFERENTIATION PROTOCOL FROM HUMAN EMBRYONIC STEM CELL-DERIVED NEURAL PROGENITORS TO ASSESS CHEMICAL- INDUCED DEVELOPMENTAL NEUROTOXICITY}

Victoria C. de Leeuw ${ }^{1,2}$, Conny T. M. van Oostrom ${ }^{1}$, Remco H.S. Westerink ${ }^{2}$, Aldert H. Piersma $^{1,2}$, Harm J. Heusinkveld ${ }^{1}$, Ellen V.S. Hessel ${ }^{1}$

${ }^{1}$ Centre for Health Protection, National Institute for Public Health and the Environment, Bilthoven, the Netherlands

${ }^{2}$ Institute for Risk Assessment Sciences, Utrecht University, Utrecht, the Netherlands

Reproductive Toxicology, 2020 Sep, 98:107-116

DOI: 10.1016/j.reprotox.2020.09.003 



\begin{abstract}
Human embryonic stem cell neuronal differentiation models provide promising in vitrotools for the prediction of developmental neurotoxicity of chemicals. Such models mimic essential elements of human relevant neuronal development, including the differentiation of a variety of brain cell types and their neuronal network formation as evidenced by specific gene and protein biomarkers. However, the reproducibility and lengthy culture duration of cell models present drawbacks and delay regulatory implementation. Here we present a relatively short and robust protocol to differentiate H9-derived neural progenitor cells (NPCs) into a neuron-astrocyte coculture. When frozen-stored NPCs were re-cultured and induced into neuron-astrocyte differentiation, they showed gene- and protein expression typical for these cells, and most notably they exhibited spontaneous electrical activity within three days of culture as measured by a multi-well micro-electrode array. Modulating the ratio of astrocytes and neurons through different growth factors including glial cell line-derived neurotrophic factor (GDNF), brain-derived neurotrophic factor (BDNF), and ciliary neurotrophic factor (CNTF) did not compromise the ability to develop spontaneous electrical activity. This robust neuronal differentiation model may serve as a functional component of a testing strategy for unravelling mechanisms of developmental neurotoxicity.
\end{abstract}




\section{Introduction}

Development of the central nervous system is extremely complex, involving many different processes at the molecular, cellular and tissue level. These processes include for example neurogenesis, migration, axon guidance, synaptogenesis, myelination, phenotypic specification of neurons, expression and maturation of receptors and ion channels, and brain segmentation [13]. Disruption of these processes can influence the development of motor deficiencies or behavioural conditions such as autism spectrum disorder, intellectual disability and attentiondeficit hyperactivity disorder [4].

The developing nervous system has unique and specific windows of vulnerability. The exact mechanisms and aetiologies of neurodevelopmental disorders are commonly unknown, but exposure to environmental chemicals may be contributing [5]. Regulatory developmental neurotoxicity (DNT) testing is done using animal based test guidelines (OECD TG-426, 443) [6,7]. However, given the complexity of the human brain, the predictivity of these animal tests for human health is limited. This notion has stimulated research into human relevant in vitro and in silico test methods for DNT. From the perspective of coverage of all relevant processes in the human brain development, one-in-one replacement of in vivo tests by relatively simple in vitro assays is not feasible. A testing strategy for DNT prediction covering all the essential processes in human brain development is needed based on a combination of human-relevant, robust and reproducible in vitro and in silico test. A multitude of alternative models have been developed over the years, providing insights into mechanisms of action of chemicals [8]. Most of these models, however, measure structural readouts such as proliferation, differentiation, migration and neurite outgrowth, but do not assess neuronal function readouts, which could provide evidence for DNT at a higher level of integration. Neuronal function readouts include for example network formation, inter- and intracellular signalling and electrical activity, for which proper synaptogenesis is essential $[9,10]$. Synaptogenesis is a critical process whereby neurons establish specialised contact sites, which facilitate neuronal communication [9]. The accumulation of presynaptic proteins (e.g., synapsin, synaptophysin) in close proximity to postsynaptic density proteins (e.g., PSD95) in the dendrites of neighbouring neurons are essential morphological features associated with synaptogenesis $[9,11,12]$.

Functional neuronal network development in vitro has proved challenging as spontaneous electrical activity was difficult to measure and/ or differentiation took several weeks [13-18]. These drawbacks represent important limitations for implementation in regulatory testing. Human embryonic stem cell differentiation protocols provide a continuous source of human neurons and astrocytes. These neuronal cultures can be used to analyse chemical disruption at different levels, from gene expression modulation to structural and morphological effects [19]. The addition of functional neuronal network characteristics, including synaptogenesis and electrical activity, in a robust cell culture model would provide added value for DNT assessment and mechanistic studies [20].

In this study a human stem cell based in vitro model is presented, which represents the differentiation of neural progenitors into a spontaneously firing neuron-astrocyte co-culture within three days of culture. The aim of this study was to examine the characteristics of this human stem cell neural network differentiation model and to define the biological domain of the model 
by measuring key elements of synaptogenesis and spontaneous electrical activity. This functional neuronal differentiation protocol may serve as an important component in a human relevant testing strategy for the animal-free assessment of DNT of chemicals and pharmaceuticals based on mechanistic knowledge of human biology and physiology of brain development.

\section{Material and methods}

All reagents were bought at Gibco (Waltham, MA, USA) unless mentioned otherwise.

\section{Neuronal differentiation of embryonic stem cells}

\section{hESC maintenance}

H9 human embryonic stem cells (WA09, passage 26, WiCell, Madison, WI, USA) were thawed and seeded at a density of $1 \times 10^{6}$ on Vitronectin (VTN-N; $5 \mathrm{ng} / \mathrm{mL}$ ) coated 6-well plates (Corning, Corning, NY, USA) in Essential 8 Flex medium according to Gibco's Essential 8 Flex protocol (Document MAN0013988 version 1.0, Gibco). Cells were kept in a humidified chamber $\left(37^{\circ} \mathrm{C}\right.$, $5 \% \mathrm{CO}_{2}, 20 \% \mathrm{O}_{2}$ ) and passaged at a split ratio of 1:2- 1:4 every 3-4 days when cells reached 80-90\% confluency. Instead of two washes with DPBS, cells were rinsed once with Versene solution and subsequently incubated with Versene solution for $7 \mathrm{~min}$ at room temperature (RT) to dissociate the cells. Stem cells with passage numbers 49-60 were used for differentiation experiments to ensure that continuous culturing in E8 medium for multiple passages resulted in a pure stem cell culture without too much contamination with other cells.

\section{Neural progenitors (NPCs) generation from hESCs}

Induction of differentiation was performed according to a neuronal induction protocol from Stemcell (Document \#28782, Stemcell Technologies, Vancouver, Canada), with the exception that from this moment all steps were performed in $3 \% \mathrm{O}_{2}$ to enhance neuronal differentiation $[21,22]$. The protocol comprised three steps: embryoid body (EB) generation, neural rosette formation and neural progenitor (NPC) expansion.

When confluent, stem cells were incubated with Gentle Cell Dissociation Reagent for 9 min, dissociated and replated at a density of $3 \times 10^{6}$ cells $/ \mathrm{mL}$ in a AggreWell ${ }^{\mathrm{m}} 800$ 24-well plate in STEMdiff ${ }^{\text {TM }}$ Neural Induction (NI) medium + SMADi supplemented with $10 \mu \mathrm{M}$ Y27632 (all from Stemcell). Half of the medium was replaced every day until day 5 . EBs were then transferred to Poly-L-Ornithine (PLO, $15 \mu \mathrm{g} / \mathrm{mL}$, Sigma) / laminin (10 $\mathrm{g} / \mathrm{mL}$, Sigma) coated a 6-well plate (Corning) in STEMdiff' Neural Induction Medium + SMADi (Stemcell) to form neural rosettes. Medium was fully changed on a daily basis for seven days. On day 12 of differentiation, neural rosettes were selected by incubating the cells for $1.5 \mathrm{~h}$ in Neural Rosette Selection Reagent (Stemcell) and replated on PLO/laminin dishes for another seven days. A second rosette selection round was performed on day 19 following the same procedure as on day 12 and rosettes were transferred to fresh PLO/ laminin 6-well plates (Corning) to grow until confluent ( one week), refreshing the whole medium every day. Around day 26, cells were rinsed once with DMEM/F12 medium and dissociated by incubating with StemPro ${ }^{\mathrm{TM}}$ Accutase $^{\mathrm{TM}}$ Cell Dissociation 
Reagent for 7 min and transferred at a density of $1.2-1.5 \times 10^{6}$ cells $/ \mathrm{mL}$ in STEMdiff ${ }^{\mathrm{TM}}$ Neural progenitor (NP) medium (Stemcell) on PLO/laminin coated 6-well plates (p1 NPCs). NPCs received daily complete medium changes and were passaged when they reached confluency ( one week) according to the NPC passaging protocol. NPCs were frozen at a density of 2- 8 $\times 10^{6}$ cells $/ \mathrm{mL}$ according to the Freezing protocol in STEMdiff ${ }^{\mathrm{TM}}$ Neural progenitor Freezing Medium (Stemcell) and stored in liquid nitrogen until use for neuron-astrocyte generation.

\section{Neuron-astrocyte generation cell culture}

Two media were used for neuron-astrocyte generation to determine the optimal medium composition. The medium from Pistollato et al. ([23]; hereafter called $\mathrm{P}$-) comprised neurobasal medium supplemented with $10 \mu \mathrm{l} / \mathrm{mL}$ N2 supplement, $20 \mu \mathrm{l} / \mathrm{mL}$ B-27 supplement, $10 \mu \mathrm{l} / \mathrm{mL}$ $5000 \mathrm{IU} / \mathrm{mL}$ Penicillin / 5000 $\mathrm{g} / \mathrm{mL}$ Streptomycin, $1 \mathrm{ng} / \mathrm{mL}$ glial cell line-derived neurotrophic factor (GDNF) and $2.5 \mathrm{ng} / \mathrm{mL}$ brain-derived neurotrophic factor (BDNF). The medium adopted from Gunhanlar et al. ([24]; hereafter called G-) consisted of neurobasal medium, $10 \mu \mathrm{l} / \mathrm{mL}$ N2 supplement, $20 \mu \mathrm{l} / \mathrm{mL}$ B-27-retinoic acid supplement, $10 \mu \mathrm{l} / \mathrm{mL} 5000 \mathrm{IU} / \mathrm{mL}$ Penicillin / 5000 $\mu \mathrm{g} / \mathrm{mL}$ Streptomycin, $10 \mu \mathrm{l} / \mathrm{mL}$ nonessential amino acids, $20 \mathrm{ng} / \mathrm{mL}$ GDNF, $20 \mathrm{ng} / \mathrm{mL}$ BDNF, 1 $\mu \mathrm{M}$ dibutyryl cyclic adenosine monophosphate (Sigma-Aldrich), $200 \mu \mathrm{M}$ ascorbic acid (SigmaAldrich) and $2 \mu \mathrm{g} / \mathrm{mL}$ laminin (Sigma-Aldrich). Ciliary neurotrophic factor (CNTF) was added to both media to a final concentration of $10 \mathrm{ng} / \mathrm{mL}$ to create a version of the media that promotes astroglial growth (P+ and $\mathrm{G}+$ ).

When NPCs were thawed from the freezer, cells were grown for six days before replating for neuron-astrocyte generation. NPCs were seeded $2.56 \times 10^{5}$ cells/cm2 on PLO/laminin-coated 48-well multi-well micro-electrode arrays (mwMEA, Axion Biosystems Inc., Atlanta, GA, USA) for MEA measurements, 8-well micro-slides (Ibidi, Gräfelfing, Germany) for immunocytochemistry or 12-well plates (Corning) for qPCR, depending on application. NPCs were cultured in the presence of NP medium for one day after which the medium was replaced by differentiation medium. Except for MEA-applications, cells were kept in low oxygen conditions $\left(3 \% \mathrm{O}_{2}\right)$. Medium replacements took place every 2-3 days and cultures were continued for up to four weeks.

\section{Immunocytochemistry}

Samples were rinsed with PBS and fixed for 30 min with $4 \%$ prewarmed paraformaldehyde (Electron Microscopy Sciences, Hatfield, PA, USA) in PBS. Cells were permeabilised for 5 min with $0.2 \%$ (Table 1, protocol A) or $0.5 \%$ (protocol B) Triton X-100 (Sigma-Aldrich) in PBS. Blocking was performed either in $1 \%$ bovine serum albumin (BSA; w/v; Sigma-Aldrich), 0.5\% Tween20 (Sigma-Aldrich) in PBS for $1 \mathrm{~h}$ at $37{ }^{\circ} \mathrm{C}$ (protocol A) or in 5\% BSA (Sigma-Aldrich) for $30 \mathrm{~min}$ at RT(protocol B), depending on the antibody used (Table 1). Primary antibodies were applied overnight at $4{ }^{\circ} \mathrm{C}$ in $0.5 \%$ BSA $/ 0.5 \%$ Tween-20 in PBS (protocol A) or 5\% normal goat serum ( $\mathrm{v} / \mathrm{v}$, Sigma-Aldrich)/0.5\% Tween-20 (Sigma-Aldrich) in PBS (protocol B). After washing away the primary antibodies, secondary antibodies were applied for $1 \mathrm{~h}$ in the same antibody incubation mixture. DAPI (Sigma-Aldrich) was used to stain nuclei of the cells. Imaging was performed 
on a Leica DMi8 microscope system (Leica, Wetzlar, Germany) using the appropriate Leica Software (LAS X). Images were further processed in ImageJ (version 1.51n; [25]).

Table 1. Primary and secondary antibodies.

\begin{tabular}{|c|c|c|c|c|c|c|}
\hline Antibody & $\begin{array}{l}\text { Abbre- } \\
\text { viation }\end{array}$ & Marker for & $\begin{array}{l}\text { Product } \\
\text { number }\end{array}$ & Company & Dilution & Protocol \\
\hline $\begin{array}{l}\text { Mouse anti Stage Specific Em- } \\
\text { bryonic Antigen-4 }\end{array}$ & SSEA4 & Stem cell & MAB4304 & Millipore & $1: 250$ & A \\
\hline Rat anti E-cadherin & ECAD & $\begin{array}{l}\text { Adhesion mole- } \\
\text { cule present be- } \\
\text { fore neuronal } \\
\text { tube closure }\end{array}$ & 13-1900 & Invitrogen & 1:1000 & $\mathrm{A} / \mathrm{B}$ \\
\hline Rabbit anti Paired homeobox 6 & PAX6 & $\begin{array}{l}\text { Neural progeni- } \\
\text { tor }\end{array}$ & 901301 & Biolegend & 1:1000 & $\mathrm{A} / \mathrm{B}$ \\
\hline $\begin{array}{l}\text { Mouse anti Zonula occludens- } \\
1\end{array}$ & ZO-1 & $\begin{array}{l}\text { Tight junction } \\
\text { protein typical in } \\
\text { neuronal induc- } \\
\text { tion }\end{array}$ & $33-9100$ & $\begin{array}{l}\text { Thermo } \\
\text { Fischer }\end{array}$ & 1:1000 & A \\
\hline Rabbit anti $\beta$-Tubulin III & TUBB3 & Neuron & T2200 & $\begin{array}{l}\text { Sigma-Al- } \\
\text { drich }\end{array}$ & 1:1000 & $\mathrm{A} / \mathrm{B}$ \\
\hline $\begin{array}{l}\text { Mouse anti Microtubule-asso- } \\
\text { ciated protein } 2\end{array}$ & MAP2 & $\begin{array}{l}\text { Neuron, den- } \\
\text { drite-specific }\end{array}$ & 801801 & Biolegend & $1: 2000$ & $\mathrm{~A} / \mathrm{B}$ \\
\hline Guinea pig anti Tau & TAU & $\begin{array}{l}\text { Neuron, axon } \\
\text { specific }\end{array}$ & 314004 & $\begin{array}{l}\text { Synaptic } \\
\text { Systems }\end{array}$ & 1:1000 & $\mathrm{A} / \mathrm{B}$ \\
\hline $\begin{array}{l}\text { Rat anti Glial fibrillary acidic } \\
\text { protein }\end{array}$ & GFAP & Early astrocyte & $13-0300$ & Invitrogen & 1:800 & $\mathrm{A} / \mathrm{B}$ \\
\hline $\begin{array}{l}\text { Guinea pig anti- Vesicular glu- } \\
\text { tamate transporter } 2\end{array}$ & $\begin{array}{l}\text { VGLUT } \\
2\end{array}$ & $\begin{array}{l}\text { Synaptic vesicle } \\
\text { excitatory neu- } \\
\text { ron }\end{array}$ & AB2251-I & Millipore & $1: 2000$ & A \\
\hline $\begin{array}{l}\text { Mouse anti vesicular GABA } \\
\text { transporter }\end{array}$ & VGAT & $\begin{array}{l}\text { Synaptic vesicle } \\
\text { inhibitory neuron }\end{array}$ & 131011 & $\begin{array}{l}\text { Synaptic } \\
\text { Systems }\end{array}$ & $1: 500$ & B \\
\hline $\begin{array}{l}\text { Mouse anti postsynaptic den- } \\
\text { sity } 95\end{array}$ & PSD95 & Post-synapse & MAB1598 & Merck & $1: 500$ & B \\
\hline Rabbit anti synaptoporin & SYNPR & Pre-synapse & 102002 & $\begin{array}{l}\text { Synaptic } \\
\text { Systems }\end{array}$ & 1:500 & A \\
\hline Goat anti rabbit Alexa 488 & & & A11034 & Invitrogen & 1:1000 & \\
\hline Goat anti guinea pig Alexa 488 & & & A11073 & Invitrogen & 1:1000 & \\
\hline Goat anti rabbit Alexa 555 & & & A21429 & Invitrogen & $1: 500$ & \\
\hline Goat anti mouse Alexa 555 & & & A21424 & Invitrogen & $1: 1000$ & \\
\hline Goat anti rat Alexa 555 & & & A21434 & Invitrogen & $1: 200$ & \\
\hline Goat anti mouse Alexa 647 & & & A21236 & Invitrogen & 1:500 & \\
\hline
\end{tabular}

\section{RNA isolation and $q P C R$}

Medium from samples ( $\mathrm{hESC} n=4$, EB/NPC $n=2$, Rosette $n=3, P-/ P+n=5, G-n=6, G+n=$ 7; all technical replicates from one continuous experiment) was aspirated, cells were fixed in QIAzol (Qiagen, Hilden, Germany) and stored at $-80{ }^{\circ} \mathrm{C}$ until further processing. Samples were ran through a QIAshredder (Qiagen) prior to RNA isolation to homogenise samples and whole RNA extraction was performed according to the manufacturer's protocol with the RNeasy ${ }^{\circledR}$ mini kit, including the DNase digestion step (Qiagen, version October 2019). Concentration of RNA was determined using the NanoDrop ${ }^{\text {TM }} 1000$ spectrophotometer (Nanodrop Technologies, 
Wilmington, DE, USA) and the 2100 Bioanalyzer (Agilent Technologies, Amstelveen, the Netherlands) to determine the quality of the samples. Synthesis of cDNA was performed using the cDNA archive kit consisting of random hexamer primers (Applied Biosystems, Foster City, CA, USA). Subsequent qPCR was done using a 7500 Fast Real-Time PCR system (Applied Biosystems; thermal cycling conditions: $95^{\circ} \mathrm{C}$ for $20 \mathrm{~s}, 40$ cycles of $95{ }^{\circ} \mathrm{C}$ for $3 \mathrm{~s}, 60^{\circ} \mathrm{C}$ for $30 \mathrm{~s}$ ). The primers used are summarised in Table 2 . Relative gene expression differences were calculated using the 2- $\triangle \triangle \mathrm{Ct}$-method [26], normalised against the housekeeping genes Hypoxanthine phosphoribosyltransferase 7 (HPRT7) and Glucuronidase beta (GUSB). Statistical analysis was performed in GraphPad Prism (version 8.2.1) using a one-way ANOVA test and post-hoc Sidak's multiple comparisons test.

Table 2. Primers used for gene expression with corresponding marker function and assay ID. All primers were bought from Applied Biosystems.

\begin{tabular}{llll}
\hline Gene name & Abbreviation & Marker for & Assay ID \\
\hline POU Class 5 Homeobox 1 & POU5F1 & Stem cell & Hs00999632_g1 \\
Neurogenin 1 & NEUROG1 & Neural ectoderm & Hs01029249_s1 \\
Nestin & NES & Neural progenitor & Hs00707120_s1 \\
Tubulin, beta 3 class III & TUBB3 & Neuron & Hs00801390_s1 \\
Microtubule-associated protein 2 & MAP2 & Mature neuron & Hs00258900_m1 \\
Synaptoporin & SYNPR & Pre-synapse & Hs01548398_m1 \\
Discs Large MAGUK Scaffold Protein 4 & DLG4 & Post-synapse & Hs01555373_m1 \\
Vesicular glutamate transporter & SLC77A6 & Excitatory neuron & Hs00220439_m1 \\
Vesicular inhibitory amino acid transporter & SLC32A7 & Inhibitory neuron & Hs00369773_m1 \\
Glial fibrillary acidic protein & GFAP & Early astrocyte & Hs00909233_m1 \\
Glucuronidase beta & GUSB & Housekeeping gene & Hs00939627_m1 \\
Hypoxanthine phosphoribosyltransferase 1 & HPRT1 & Housekeeping gene & Hs02800695_m1 \\
\hline
\end{tabular}

\section{MEA measurements during neuron-astrocyte generation}

To assess whether the combined expression of synaptic markers in the different neuron-astrocyte cultures resulted in functional connections, cultures were screened for the development of spontaneous electrical activity starting three days after the initiation of neuronal differentiation. Cultures were grown mwMEA plates as mentioned in Section "Neuron-astrocyte generation cell culture" with each well containing 16 individual embedded nanotextured gold microelectrodes, yielding a total of 768 channels (Axion Biosystems Inc., Atlanta, GA, USA). Recordings were made as previously described [27] every two to three days for 30 days. Briefly, a 48-wells mwMEA plate was placed into the Maestro 768-channel amplifier with integrated heating system, temperature controller (set at $37^{\circ} \mathrm{C}$ ) and data acquisition interface (Axion BioSystems Inc.). After a 5 min stabilisation period, a 30 min recording of spontaneous activity was started. All culture conditions were tested in at least two independent cultures from one NPC bank and reproduced in a NPC bank generated from another $\mathrm{H} 9$ aliquot. Data acquisition was performed using Axion's Integrated Studio (AxIS, version 1.7.8) and channels were sampled at $12.5 \mathrm{kHz}$. Signals were pre-amplified with a gain of $1200 \times(61 \mathrm{~dB})$ and band-pass filtered at $0.2-5 \mathrm{kHz}$. This raw data was re-recorded and spikes were detected using the AxIS spike detector (Adaptive threshold crossing, Ada BandFit version 2) with a post/pre spike duration of 3.6/2.4 ms and 
a spike threshold of $6 \times$ SD of the internal noise level (rms) of each individual electrode. Subsequent sorting and analysis of the re-recorded data was performed using custom-made Excel macros. Data on spontaneous electrical activity was presented as mean spike rate (MSR; average number of spikes per second per well) and weighted mean burst rate (MBR; average number of bursts per second per active well) obtained from two (Pistollato protocols) or three (Gunhanlar protocols) independent experiments with 10-12 wells per culture condition.

\section{Results}

\section{Differentiating Ho cells into neural progenitors and a neuron- astrocyte co-culture}

The neuronal differentiation protocol consisted of two components: A) NPC generation consisting of four stages (1: H9, 2: EB, 3: Rosettes, 4: NPCs) and B) Neuron-astrocyte generation (stage 5: Neuronsastrocytes), which are depicted in a time line with representative images in Fig. $1 \mathrm{~A}$ and $\mathrm{B}$.

\section{NPC generation and characterisation}

EBs were formed from $\mathrm{H} 9$ stem cells from day $\mathrm{O}$ to day 5 . The $\mathrm{H} 9$ stem cell culture consisted predominantly of stem cells as shown by stem cell marker SSEA-4 and pre-neural tube tight junction marker ECAD with a few cells that entered the differentiation process indicated by PAX6 ${ }^{+}$cells, a marker for neural progenitors (Fig. 1C; H9). This was confirmed by gene expression of stem cell marker POU5F1, which was relatively highly expressed in stem cell culture in comparison to the differentiation stages. Gene expression of early and late neuronal differentiation markers (NEUROG 1, NESTIN, TUBB3, MAP2, GFAP) was low in the stem cell culture compared to the other stages of differentiation (Fig. 1D). After EB formation, individual EBs grew out into neural rosettes over the course of one week (day 5-12). In order to obtain a more homogeneous NPC culture, neural rosettes were selected and replated to grow as rosettes for a second time (day 12-19). This step was repeated on day 19 and cells were grown as NPCs for one week (day 19-26) before further expansion to freeze down the cells or start neuron-astrocyte generation cultures. Neural rosettes were positively stained for PAX6 (Fig. 1C; Rosettes) and some cells also expressed neuronal marker TUBB3 (data not shown). Tight junction ZO-1 completely replaced ECAD and was specifically expressed on the apical side of the rosettes, analogous to expression of ZO-1 on the inside of the neural tube. Gene expression patterns corroborated the immunostainings, showing a large increase of early neurogenesis marker NEUROG 7, neural progenitor marker NESTINand neuronal markers TUBB3 and MAP2 (Fig. 1D). NPCs presented a mix of PAX6 ${ }^{+}$and $\mathrm{TUBB}^{+}$cells, whereby the PAX6 expression was markedly lower than in the rosette stage, indicating that the NPC culture already contained some differentiating neurons (Fig. 1C; NPCs). NEUROG 7 gene expression peaked th this point in time while NESTIN expression stabilised and TUBB3 and MAP2 expression steadily increased (Fig. 1D). 


\section{Neuron-astrocyte generation and characterisation}

Two protocols were chosen to initiate neuron-astrocyte generation in order to assess the optimal protocol for the generation of a functional neuronal network, from Pistollato et al. [23] (P-) and Gunhanlar et al. [24] (G-), as described in Section "Neuron-astrocyte generation cell culture". Two other conditions were created by adding CNTF to each of the media to stimulate the growth of astrocytes ( $P+$ and $G+)$.

In all four neuron-astrocyte generation protocols a clear increase in neuronal markers was seen, which is apparent from representative images for all protocols at day 14 and 28 (Fig. 1C). After fourteen days, a mixed neuron-astrocyte culture had developed, expressing some PAX6 ${ }^{+}$ cell populations, maturing neurons shown by $\mathrm{TAU}^{+}$axons and $\mathrm{MAP}^{+}$dendrites (Fig. 1C; $\mathrm{Neu}-$ rons day 14), and astrocytes (GFAP, data shown in Fig. 3). GFAP gene expression increased dramatically at this point, while TUBB3 and MAP2 expression steadily increased further and NEUROG 7 expression decreased, indicating that the cell culture was maturing at this point (Fig. 1D). Two weeks later, GFAP ${ }^{+}$astrocytes became more predominant and neurotransmitter transporters such as VGLUT2 were abundantly present (Fig. 1C; Neurons day 28).

\section{Neuron-astrocyte cultures expressed transporters and synaptic markers indicative for synaptogenesis}

The gene expression of pre-synaptic marker SYNPR, post-synaptic marker $D L G 4$, and vesicular transporters for excitatory glutamate SLC17A6 and inhibitory GABA SLC32A 7 were measured at each of the differentiation stages (Fig. 2A). Each of the markers presented a distinct expression pattern over time. SYNPR expression initially dropped upon differentiation and increased only in the neuron-astrocyte generation stage, while expression of SLC32A7 was already upregulated from the NPC stage. SLC17A6 gene expression was increased even earlier in the rosettes and DLG4 expression steadily increased from the earliest time points on. Immunocytochemistry of the neuron-astrocyte culture on day 14 confirmed the presence of all of the synaptic and transporter markers. VGAT (encoded by SCL32A7) was only present in some neurites (Fig. 2B), while SYNPR, PSD95 (encoded by DLG4) and VGLUT2 (encoded by SLC77A6) were abundantly present throughout the cell culture (Fig. 2C, D).

There were no obvious differences in protein expression between the four neuron-astrocyte generation protocols $\mathrm{P}-/ \mathrm{P}+/ \mathrm{G}-/ \mathrm{G}+$ (data not shown). Also with regard to overall trends in gene expression of synaptic- and transporter markers there were no major differences between the four protocols. No statistically significant differences were found between P- and G-, and between $\mathrm{P}+$ and $\mathrm{G}+$ protocols, indicating that all protocols resulted in a comparable distribution of these markers. The addition of CNTF to each of the protocols, however, resulted in lower gene expression of SYNPR, DLG4 and SLC77A6, and a trend in lower SLC32A7 expression compared to the cell cultures without CNTF (Fig. 2E). The presence of vesicular neurotransmitter transporters in the neuron-astrocyte generation suggests that another prerequisite for a functional network may have formed. 

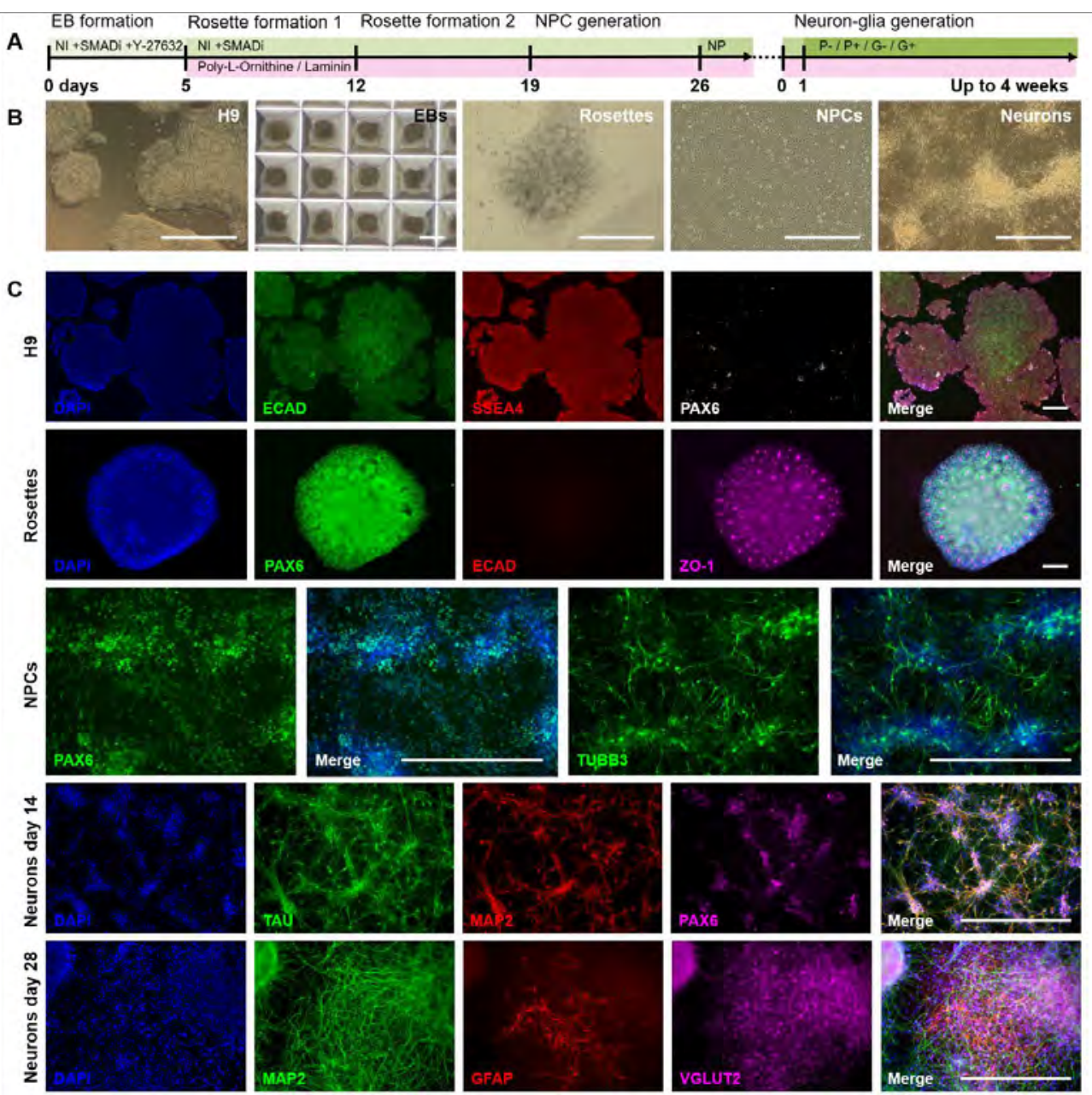

D

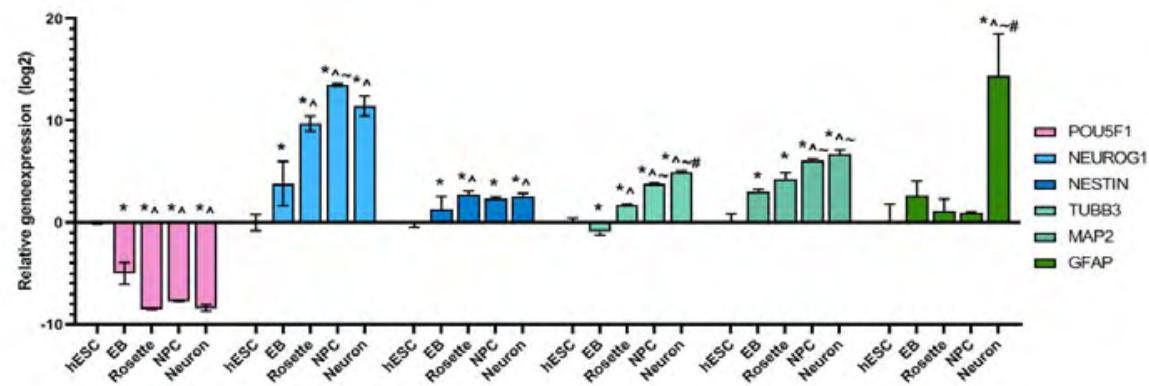

Figure 1. Differentiation protocol of hESC into neural progenitors and subsequently into a network of neurons and astrocytes. (A) Protocol of NPC generation and neuron-astrocyte generation as described in Materials \& Methods section. (B) Bright-field images showing the different stages of the differentiation process. (C) Characterisation of cell types present at different stages of differentiation with selected differentiation markers for stem cells (ECAD, SSEA-4), neural tube-like structures (ZO-7), NPCS (PAX6), immature neurons (TUBB3), axons (TAU), mature neurons/dendrites (MAP2), astrocytes (GFAP) and neurotransmitter vesicles (VGLUT2). (D) Relative gene expression changes throughout the NPC generation and differentiation shown by markers for stem cells (POU5F1), ectodermal differentiation (NEUROG T, NES), neurons (TUBB3, MAP2) and astrocytes (GFAP). Gene expression of all four differentiation protocols were combined in one bar ("Neuron"). Sample size: $h E S C n=4, E B / N P C n=2$, Rosette $n=3$, 


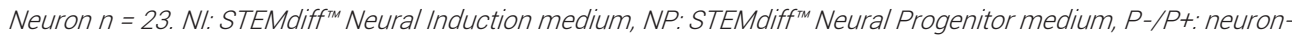
astrocyte generation medium adopted from Pistollato et al. [23] without (-) and with (+) addition of CNTF, G-/t. medium from Gunhanlar et al. [24] without (-) and with(+) CNTF. Scale bar: $500 \mu \mathrm{m}$. Error bars: standard deviation. Significant difference $(p<0.005)$ from *: H9 stem cells, 1 : EBS, : rosette, \#: NPC.
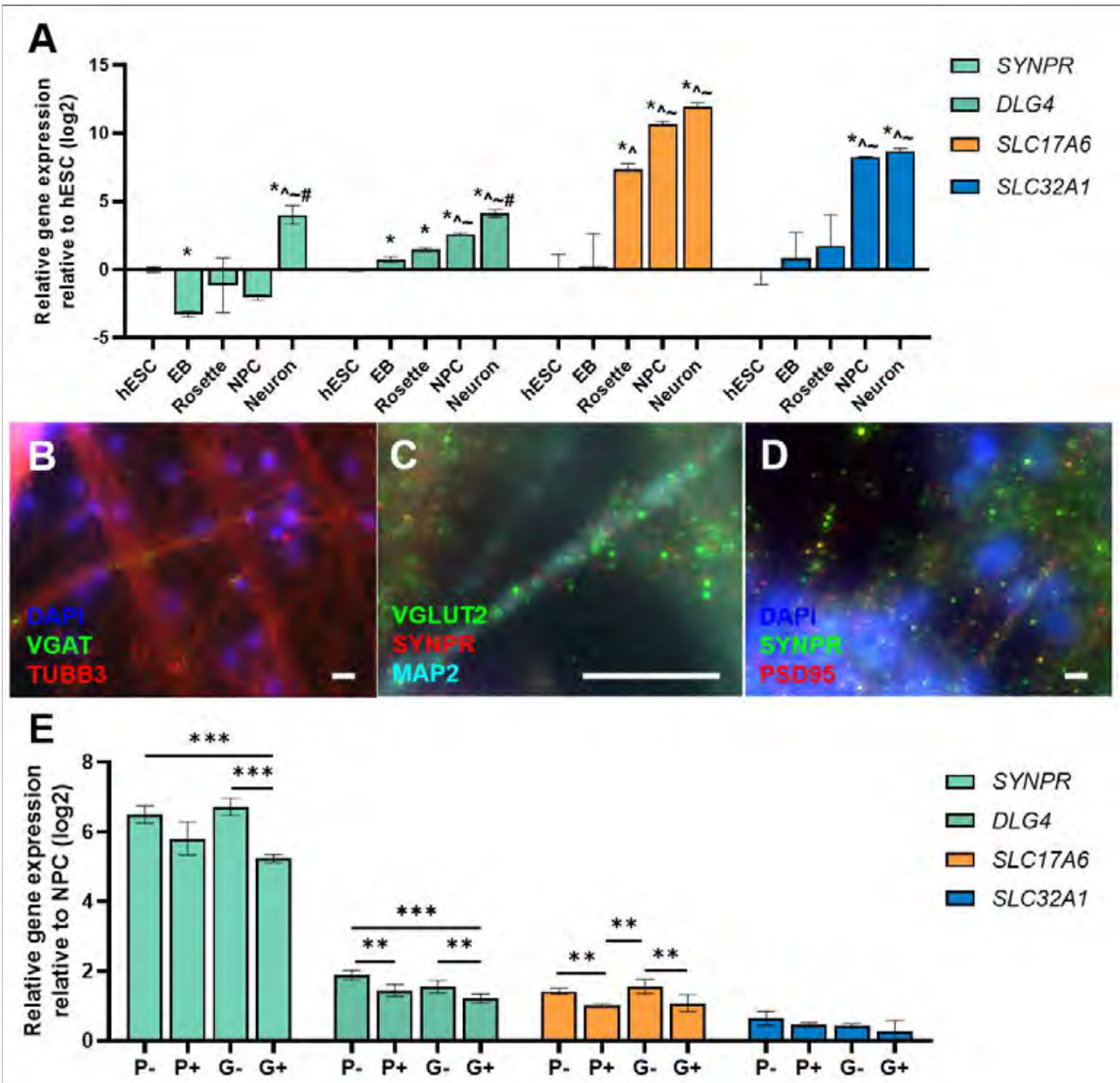

Figure 2. Gene- and protein expression of transporters and synaptic proteins at various stages of differentiation. (A) Relative gene expression of synaptic-and transporter markers at each differentiation stage relative to the hESC culture. DLG4 gene encodes the PSD95 protein, SLC77A6 encodes VLGUT2, SLC32A7 encodes VGAT and SYNPR encodes SYNPR. (B)-(D) Immunostainings showing vesicle marker (B) VGAT at day 28, (C) vesicle marker VGLUT2 and synaptic marker SYNPR at day 14 and (D) synaptic markers PSD95 and SYNPR at day 28. (E) Day 14 gene expression of the four neuronal differentiation protocols relative to the NPC culture. $P-, P+, G-, G+$ represent the four neuron-astrocyte generation protocols used. Sample size: $h E S C n=4, E B / N P C n=2$, Rosette $n=3$, Neuron $n=23$ $(P-/ P+n=5, G-n=6, G+n=7)$. Scale bar: $10 \mu \mathrm{m}$. Error bars: standard deviation. Significance: $* *: p<0.008 . * * *:<p<$ 0.0007

\section{Neuron-astrocyte generation protocols alter neuron-astrocyte ratio}

The ratio between neurons and astrocytes is an important factor influencing the functioning of a neuronal network. Fig. 3 presents the development of the neuron-astrocyte culture in terms 
of structural protein expression, gene expression relative to the NPC culture (at the stage just before differentiation) initiation, and spontaneous electrical activity in each of the four differentiation culture protocols.

P- cultures contained only a few $\mathrm{GFAP}^{+}$cells at day 14 , which grew slightly in number over the course of the consecutive two weeks (Fig. 3A, P-). When enriched with CNTF, P+ cultures presented a marked increase in cell number overall and in astrocytes in particular (Fig. 3A, P+). The $\mathrm{G}$ - protocol caused more cell growth in general and more astrocyte growth on day 28 as shown by more GFAP ${ }^{+}$cells compared to P- (Fig. 3A, G-). Supplementation with CNTF (G+) led to a sharp increase in cell numbers and in particular GFAP ${ }^{+}$astrocytes compared to P+ (Fig. 3A, G+).

Gene expression profiles largely followed the same pattern in all protocols: relative to NPCs, POUF51 and NEUROG 1 expression decreased, while TUBB3, MAP2 and GFAP expression increased at day 14 (Fig. 3B). Of note is the lower upregulation of TUBB3 in the G-protocols relative to $\mathrm{P}$-, and the higher upregulation of GFAP with the addition of CNTF. This may suggest that astrocyte differentiation was increased at the expense of neural differentiation. Despite the strong upregulation of GFAP, protein expression seemed to be delayed in P- and G- (Fig. 3A). $\mathrm{P}+$ and $\mathrm{G}+$ cultures did show GFAP protein expression at day 14, although $\mathrm{G}+$ cultures contained more astrocytes, which could not be seen in the gene expression.

Spontaneous electrical activity developed under all culture conditions (Fig. 3C). Spontaneous activity for the majority of the protocols could be observed from day 3 after starting of differentiation on as single spikes across wells, and single spikes developed into spike trains and bursting activity within the first week. Activity generally increased steadily over time, although no synchronised network firing has been observed under the tested culture conditions.

The neuron-astrocyte cultures expressed relatively low spontaneous electrical activity. In order to improve the activity, half instead of full medium refreshments were performed at the same time interval as the full medium refreshments. Additionally, for P+ and G+, CNTF was added only until day 8. Using this refreshment scheme, $\mathrm{P}$ - and $\mathrm{G}$ - cultures showed an increase in the number of GFAP ${ }^{+}$astrocytes at day 14 and 28, while in the P+ and G+ condition the opposite effect was observed (Suppl. Fig. 1). The MSR did not change with this refreshment regime, but the percentage of active wells increased to $90 \%$ in the $\mathrm{G}+$ protocol, which was not observed in other culture conditions (Fig. 3D). The MBR and percentage of active wells showing bursting activity did not change.

The above results demonstrate that all culture conditions showed different ratios of neurons and astrocytes, and presented spontaneous electrical activity over time. These results were successfully repeated once within and once across cell banks.

Figure 3 (next page). Gene- and protein expression, and spontaneously firing of four differentiation protocols. (A) Immunostaining images of each of the protocols $P-, P+, G-, G+$ on day 74 and day 28 of neurons (TUBB3, green) and astrocytes (GFAP, red). (B) Gene expression differences (log2) at day 14 relative to the NPC culture. (C) MWMEA measurements of mean spike rate (MSR) and weighted mean burst rate (MBR) in Hz per well of each of the protocols from day 3 until day 30 after full medium refreshments. Sample size $P-/ P+: N=2, G-/ G+: N=3$. (D) same as $C$, but after half medium refreshments and reduced CNTF exposure duration. Sample size $P-/ P+: N=2, G-/ G+: N=3$. Scale bar: $500 \mu \mathrm{m}$. Error bars: standard deviation. Significance: $* *: p<0.008$. $* * *: p<0.0001$ (For interpretation of the references to colour in this figure legend, the reader is referred to the web version of this article). 

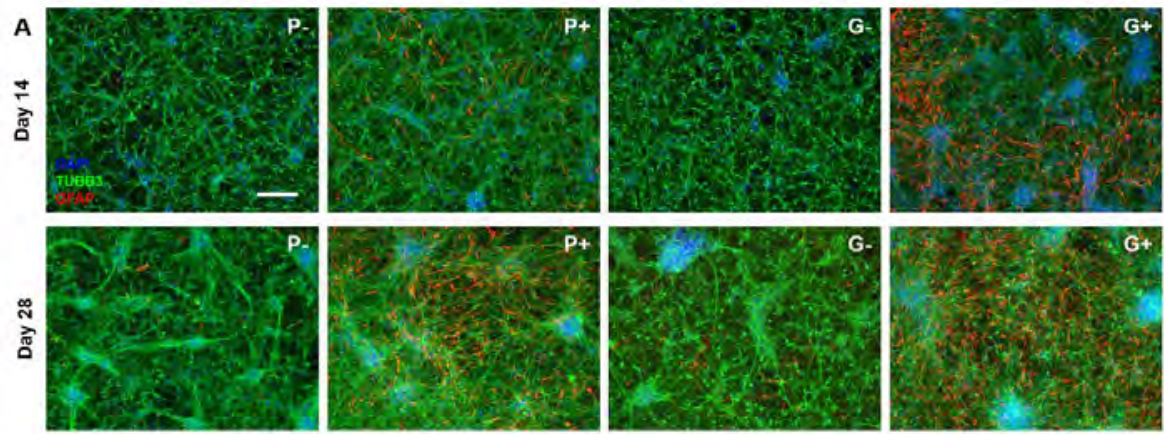

B

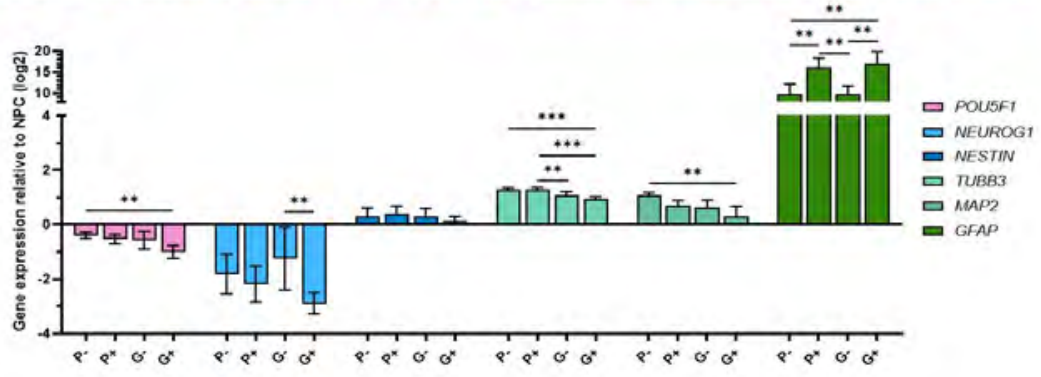

C
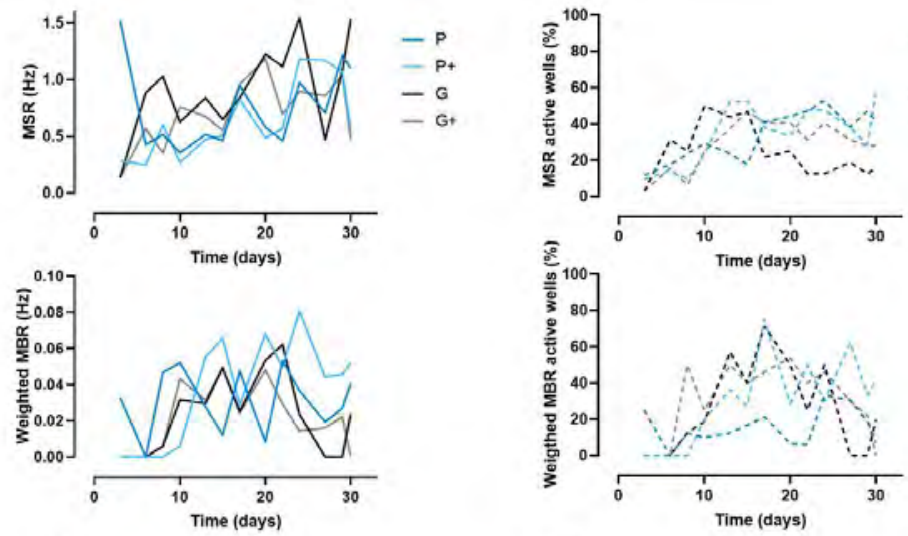

D
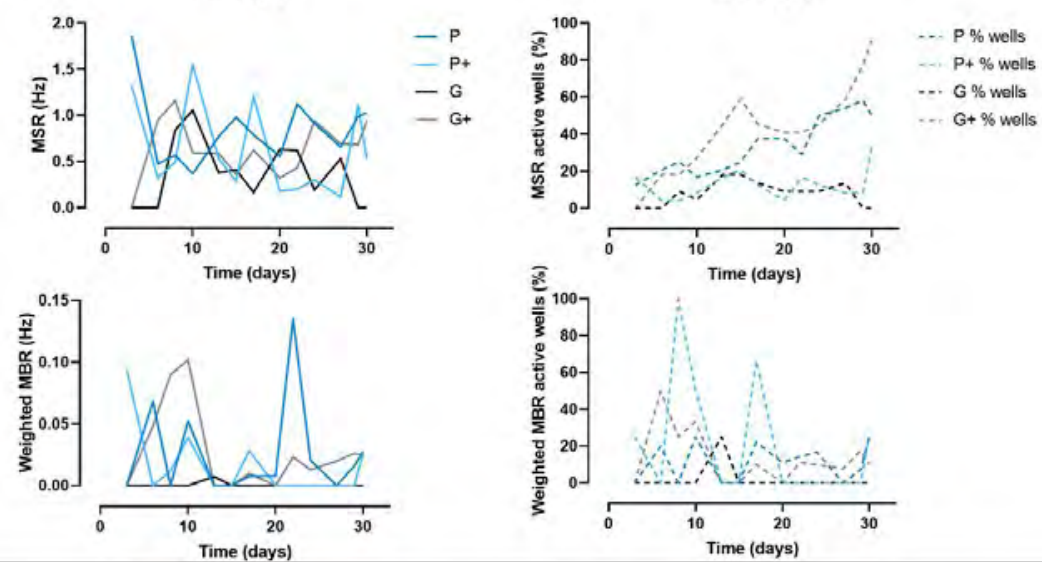


\section{Discussion}

In this study we presented an efficient protocol for the differentiation of NPCs into a spontaneously active network consisting of neurons and astrocytes. These NPCs were generated from hESCs in several consecutive steps (EBs; Rosettes and NPCs). Two NPC cell banks from two $\mathrm{H} 9$ aliquots have been generated and differentiation with these two different NPC banks based on protocols from other laboratories showed that the current protocol is robust and reproducible, which is important in the light of harmonisation of in vitro models for regulatory testing and implementation of DNT guidelines. Using qPCR and immunocytochemistry, the NPC generation and the neuron-astrocyte generation were characterized and showed a transition of hESCs and NPC through a number of phases that mimic key events in neuronal differentiation. In most protocols, within three days of neuron-astrocyte generation, cells were transformed into a mixture of excitatory neurons, inhibitory neurons and astrocytes that presented synaptic markers and showed spontaneous electrical activity over the course of multiple weeks, indicating a neural network, indicative of the development of a functional neuronal network. By testing four different protocols the neuron-astrocyte ratio could be modulated.

The observation of electrical activity in a differentiated neuronal culture indicates that a sufficient ratio of inhibitory and excitatory neurons is present and cells are functionally interacting in this model. This provides important added complexity as compared to the presence of cell differentiation markers per se. Many groups have shown the presence of prerequisites for a functional neuronal network, but failed to substantiate this with electrical activity as a functional readout [28-36]. Compared to other studies in which electrical activity was shown in hESC (H9 and other cell lines) and induced pluripotent stem cell (iPSC)-based differentiation protocols similar to our protocol, NPCs generated in this study developed spontaneous electrical activity considerably faster, typically within three days, versus one to five weeks in published studies [16,18,37-44]. In fact, only the study from Pistollato et al. [45] showed activity within one day in iPSC-derived neurons. Part of the current protocol was based on this Pistollato study, suggesting that this is a robust and reproducible protocol that works with different cell sources ( $\mathrm{H} 9$ and iPSCs). The reason why activity occurred quickly in this study with hESC may be traced back to the second rosette selection in the differentiation of hESC into NPCs, which may have led to a select population of NPCs and early differentiating neurons that accelerated subsequent differentiation.

The levels of electrical activity shown in the present study were comparable to hESC-based models that were grown in a neurosphere configuration $[16,37,43,46]$. Cell models based on iPSCs $[45,47]$ however showed $3-100$ times higher maximum spontaneous firing and bursting activity. Rather than a direct readout for compound testing, the spontaneous electrical activity measured in this model provides an important basic proof of neuronal network quality as a prerequisite control condition for studying effects on biomarkers of neuronal differentiation and synaptogenesis.

The ratio between neurons and astrocytes is important for neuron maturation and firing function [47-49]. Furthermore, astrocytes are important for both endogenous and exogenous toxicity, e.g. by metabolising xenobiotics, which may affect their toxicity [50-52]. Our G+ protocol with $50 \%$ medium replacement and limited supplementation of CNTF resulted in the highest percentage of spiking wells among all protocols and therefore seems most promising for its 
intended purpose, i.e. a quickly differentiating neuron-astrocyte co-culture for compound-induced DNT assessment. By adding CNTF to the medium only during the first eight days of neuron-astrocyte generation, astrocytes could develop without overgrowing the neurons in the culture. By only changing half of the medium for every refreshment, the cells retained some of the local environment without being depleted of nutrients. This combination led to a steadily growing and maturing network without overgrowth of astrocytes. These observations support the important role of the neuron-astrocyte ratio in determining the extent of neuron firing in these cultures.

A single in vitro system will not suffice to replace the intact individual, especially in the case of the developing brain [53]. Therefore it is important to define the biological domain of an in vitro model, so that complementary assays can be joined in a testing strategy with broad coverage of mechanisms of action $[2,3,54]$. Based on the results on gene, protein and functional level, the differentiation from NPC to a neuron-astrocyte culture encompassed (early) differentiation of neurons and astrocytes, synaptogenesis and network formation [1]. Other major cell types in the brain such as oligodendrocytes and microglia are not likely to be present in this culture, which is a common challenge in these co-culture systems [3]. This may require a separate protocol starting from stem cells or NPCs and focusing on the generation of oligodendrocytes and/or microglia cells. To extend the detail of knowledge on the biological domain, research should focus on further characterisation of the model in terms of neuronal subtypes such as dopaminergic, cholinergic and serotonergic systems.

Characterisation of the neuron-astrocyte generation model with immunostainings and qPCR identified key processes in brain development such as neurite outgrowth, neuronal differentiation and glia formation. Within three days spontaneous electrical activity was observed that was maintained for several weeks, which confirmed formation of functional synapses, dendrite formation, balanced function of neuronal excitatory and inhibitory subtypes (glutamatergic and GABAergic) and neuronal maturation. This indicates that (most) prerequisites for development of a functional neuronal network were present. Future experiments will focus on the assessment of these essential endpoints to further delineate the biological domain of the model. This protocol may be used to efficiently predict DNT of compounds in a human relevant in vitro model mimicking essential processes in brain development.

\section{Declaration of competing interest}

The authors report no declarations of interest.

\section{Acknowledgements}

This research is funded by the Dutch NGO Stichting Proefdiervrij and the Dutch Ministry of Agriculture, Nature and Food Quality and the Dutch Ministry of Health, Welfare and Sports. We would like to thank Fiona Wijnolts, Anke Tukker and the rest of the Neurotoxicology team at IRAS (University Utrecht) for recording the MEA plates. We would like to thank Anne Kienhuis for a critical review of the manuscript. 


\section{References}

[1] E.V.S. Hessel, Y.C.M. Staal, A.H. Piersma, Design and validation of an ontology-driven animal-free testing strategy for developmental neurotoxicity testing, Toxicol. Appl. Pharmacol. 1 (2018) 136-152. https://doi.org/10.1016/j.taap.2018.03.013.

[2] E. Fritsche, P. Grandjean, K.M. Crofton, M. Aschner, A. Goldberg, T. Heinonen, E.V.S. Hessel, H.T. Hogberg, S.H. Bennekou, P.J. Lein, M. Leist, W.R. Mundy, M. Paparella, A.H. Piersma, M. Sachana, G. Schmuck, R. Solecki, A. Terron, F. Monnet-Tschudi, M.F. Wilks, H. Witters, M.G. Zurich, A. Bal-Price, Consensus statement on the need for innovation, transition and implementation of developmental neurotoxicity (DNT) testing for regulatory purposes, Toxicol. Appl. Pharmacol. 354 (2018) 3-6. https://doi.org/10.1016/j.taap.2018.02.004.

[3] A. Bal-Price, F. Pistollato, M. Sachana, S.K. Bopp, S. Munn, A. Worth, Strategies to improve the regulatory assessment of developmental neurotoxicity (DNT) using in vitro methods, Toxicol. Appl. Pharmacol. 354 (2018) 7-18. https://doi.org/10.1016/j.taap.2018.02.008.

[4] A. Thapar, M. Cooper, Attention deficit hyperactivity disorder, Lancet. 387 (2016) 1240-1250. https://doi.org/10.1016/S0140-6736(15)00238-X.

[5] P. Grandjean, P.J. Landrigan, Neurobehavioural effects of developmental toxicity, Lancet Neurol. 13 (2014) 330-338. https://doi.org/10.1016/S1474-4422(13)70278-3.

[6] OECD, Test Guideline 426, OECD Guideline for Testing of Chemicals. Developmental Neurotoxicity Study, (2007). https://doi.org/10.1787/9789264067394-en.

[7] OECD, Test Guideline 443, OECD Guideline for Testing of Chemicals, Extended One-generation Study, (2018). https://www.oecd-ilibrary.org/environment/test-no-443-extended-one-generation-reproductive-toxicitystudy_9789264185371-en.

[8] A. Bal-Price, K.M. Crofton, M. Leist, S. Allen, M. Arand, T. Buetler, N. Delrue, R.E. FitzGerald, T. Hartung, T. Heinonen, H. Hogberg, S.H. Bennekou, W. Lichtensteiger, D. Oggier, M. Paparella, M. Axelstad, A. Piersma, E. Rached, B. Schilter, G. Schmuck, L. Stoppini, E. Tongiorgi, M. Tiramani, F. Monnet-Tschudi, M.F. Wilks, T. Ylikomi, E. Fritsche, International STakeholder NETwork (ISTNET): creating a developmental neurotoxicity (DNT) testing road map for regulatory purposes, Arch. Toxicol. 89 (2015) 269-287. https://doi.org/10.1007/s00204-015-1464-2.

[9] J.A. Harrill, B.L. Robinette, W.R. Mundy, Use of high content image analysis to detect chemical-induced changes in synaptogenesis in vitro, Toxicol. Vitr. $25 \quad$ (2011) 368-387. https://doi.org/10.1016/j.tiv.2010.10.011.

[10] E. Taoufik, G. Kouroupi, O. Zygogianni, R. Matsas, Synaptic dysfunction in neurodegenerative and neurodevelopmental diseases: an overview of induced pluripotent stem-cell-based disease models., Open Biol. 8 (2018) 180138. https://doi.org/10.1098/rsob.180138.

[11] N.E. Ziv, C.C. Garner, Cellular and molecular mechanisms of presynaptic assembly, Nat. Rev. Neurosci. 5 (2004) 385-399. https://doi.org/10.1038/nrn1370.

[12] C.L. Waites, A.M. Craig, C.C. Garner, Mechanisms of vertebrate synaptogenesis., Annu. Rev. Neurosci. 28 (2005) 251-274. https://doi.org/10.1146/annurev.neuro.27.070203.144336.

[13] E. Fritsche, M. Barenys, J. Klose, S. Masjosthusmann, L. Nimtz, M. Schmuck, S. Wuttke, J. Tigges, Development of the concept for stem cell-based developmental neurotoxicity evaluation., Toxicol. Sci. 165 (2018) 14-20. https://doi.org/10.1093/toxsci/kfy175.

[14] A.C. Feutz, C. De Geyter, Accuracy, discriminative properties and reliability of a human ESC-based in vitro toxicity assay to distinguish teratogens responsible for neural tube defects, Arch. Toxicol. 93 (2019) 23752384. https://doi.org/10.1007/s00204-019-02512-8.

[15] D. Pamies, A. Bal-Price, A. Simeonov, D. Tagle, D. Allen, D. Gerhold, D. Yin, F. Pistollato, T. Inutsuka, K. Sullivan, G. Stacey, H. Salem, M. Leist, M. Daneshian, M.C. Vemuri, R. Mcfarland, S. Coecke, S.C. Fitzpatrick, U. Lakshmipathy, A. Mack, W.B. Wang, D. Yamazaki, Y. Sekino, Y. Kanda, L. Smirnova, T. Hartung, Good cell culture practice for stem cells \& stem-cell-derived models, ALTEX. 34 (2017) 95-132. https://doi.org/10.14573/altex.1607121.

[16] M. Mayer, O. Arrizabalaga, F. Lieb, M. Ciba, S. Ritter, C. Thielemann, Electrophysiological investigation of human embryonic stem cell derived neurospheres using a novel spike detection algorithm, Biosens. Bioelectron. 100 (2018) 462-468. https://doi.org/10.1016/j.bios.2017.09.034.

[17] M. Barenys, K. Gassmann, C. Baksmeier, S. Heinz, I. Reverte, M. Schmuck, T. Temme, F. Bendt, T.C. Zschauer, T.D. Rockel, K. Unfried, W. Watjen, S.M. Sundaram, H. Heuer, M.T. Colomina, E. Fritsche, Epigallocatechin gallate (EGCG) inhibits adhesion and migration of neural progenitor cells in vitro, Arch Toxicol. 91 (2016) 827837. https://doi.org/10.1007/s00204-016-1709-8.

[18] T. Paavilainen, A. Pelkonen, M.E.-L. Mäkinen, M. Peltola, H. Huhtala, D. Fayuk, S. Narkilahti, Effect of prolonged differentiation on functional maturation of human pluripotent stem cell-derived neuronal cultures, Stem Cell Res. 27 (2018) 151-161. https://doi.org/10.1016/J.SCR.2018.01.018.

[19] B.Z. Schmidt, M. Lehmann, S. Gutbier, E. Nembo, S. Noel, L. Smirnova, A. Forsby, J. Hescheler, H.X. Avci, T. Hartung, M. Leist, J. Kobolák, A. Dinnyés, In vitro acute and developmental neurotoxicity screening: an overview of cellular platforms and high-throughput technical possibilities, Arch. Toxicol. 91 (2017) 1-33. https://doi.org/10.1007/s00204-016-1805-9. 
[20] M. Telias, D. Ben-Yosef, Modeling neurodevelopmental disorders using human pluripotent stem cells., Stem Cell Rev. Reports. 10 (2014) 494-511. https://doi.org/10.1007/s12015-014-9507-2.

[21] D.M. Panchision, The role of oxygen in regulating neural stem cells in development and disease, J. Cell. Physiol. 220 (2009) 562-568. https://doi.org/10.1002/jcp.21812.

[22] D. Lukmanto, V.C. Khanh, S. Shirota, T. Kato, M.M. Takasaki, O. Ohneda, Dynamic changes of mouse embryonic stem cell-derived neural stem cells under in vitro prolonged culture and hypoxic conditions, Stem Cells Dev. 28 (2019) 1434-1450. https://doi.org/10.1089/scd.2019.0101.

[23] F. Pistollato, D. Canovas-Jorda, D. Zagoura, A. Price, Protocol for the differentiation of human induced pluripotent stem cells into mixed cultures of neurons and glia for neurotoxicity testing, J. Vis. Exp. 2017 (2017) e55702. https://doi.org/10.3791/55702.

[24] N. Gunhanlar, G. Shpak, M. van der Kroeg, L.A. Gouty-Colomer, S.T. Munshi, B. Lendemeijer, M. Ghazvini, C Dupont, W.J.G. Hoogendijk, J. Gribnau, F.M.S. de Vrij, S.A. Kushner, A simplified protocol for differentiation of electrophysiologically mature neuronal networks from human induced pluripotent stem cells, Mol. Psychiatry. 23 (2018) 1336-1344. https://doi.org/10.1038/mp.2017.56.

[25] W.S. Rasband, ImageJ, U. S. Natl. Institutes Heal. Bethesda, Maryland, USA. (n.d.). https://imagej.nih.gov/ij/.

[26] Applied Biosystems, User Bulletin \#2 ABI PRISM 7700 Sequence Detection System, (2001) 1-36. http://tools.thermofisher.com/content/sfs/manuals/cms_040980.pdf.

[27] A.M. Tukker, M.W.G.D.M. De Groot, F.M.J. Wijnolts, E.J. Emma, L. Hondebrink, R.H.S. Westerink, Is the time right for in vitro neurotoxicity testing using human iPSC-derived neurons?, ALTEX. 33 (2016) 261-271. https://doi.org/10.14573/altex.1510091.

[28] S.C. Zhang, M. Wernig, I.D. Duncan, O. Brustle, J.A. Thomson, In vitro differentiation of transplantable neural precursors from human embryonic stem cells, Nat. Biotechnol. 19 (2001) 1129-1133. https://doi.org/10.1038/nbt1201-1129.

[29] B.E. Reubinoff, M.F. Pera, C.Y. Fong, A. Trounson, A. Bongso, Embryonic stem cell lines from human blastocysts: somatic differentiation in vitro, Nat. Biotechnol. 18 (2000) 399-404. https://doi.org/10.1038/74447.

[30] S. Colleoni, C. Galli, S.G. Giannelli, M.T. Armentero, F. Blandini, V. Broccoli, G. Lazzari, Long-term culture and differentiation of CNS precursors derived from anterior human neural rosettes following exposure to ventralizing factors, Exp. Cell Res. 316 (2010) 1148-1158. https://doi.org/10.1016/j.yexcr.2010.02.013.

[31] O. Sterthaus, A.C. Feutz, H. Zhang, F. Pletscher, E. Bruder, P. Miny, G. Lezzi, M. De Geyter, C. De Geyter, Gene expression profiles of similarly derived human embryonic stem cell lines correlate with their distinct propensity to exit stemness and their different differentiation behavior in culture, Cell. Reprogram. 16 (2014) 185-195. https://doi.org/10.1089/cell.2013.0089.

[32] L. Buzanska, J. Sypecka, S. Nerini-Molteni, A. Compagnoni, H.T. Hogberg, R. Del Torchio, K. Domanska-Janik J. Zimmer, S. Coecke, A human stem cell-based model for identifying adverse effects of organic and inorganic chemicals on the developing nervous system, Stem Cells. 27 (2009) 2591-2601. https://doi.org/10.1002/stem.179.

[33] R. Taléns-Visconti, I. Sanchez-Vera, J. Kostic, M.A. Perez-Arago, S. Erceg, M. Stojkovic, C. Guerri, Neural differentiation from human embryonic stem cells as a tool to study early brain development and the neuroteratogenic effects of ethanol, Stem Cells Dev. $20 \quad$ (2011) 327-339. https://doi.org/10.1089/scd.2010.0037.

[34] M.P. Schwartz, Z. Hou, N.E. Propson, J. Zhang, C.J. Engstrom, V.S. Costa, P. Jiang, B.K. Nguyen, J.M. Bolin, W. Daly, Y. Wang, R. Stewart, C.D. Page, W.L. Murphy, J.A. Thomson, Human pluripotent stem cell-derived neural constructs for predicting neural toxicity, Proc. Natl. Acad. Sci. U. S. A. 112 (2015) 12516-12521. https://doi.org/10.1073/pnas.1516645112.

[35] A.K. Krug, R. Kolde, J.A. Gaspar, E. Rempel, N. V. Balmer, K. Meganathan, K. Vojnits, M. Baquié, T. Waldmann, R. Ensenat-Waser, S. Jagtap, R.M. Evans, S. Julien, H. Peterson, D. Zagoura, S. Kadereit, D. Gerhard, I. Sotiriadou, M. Heke, K. Natarajan, M. Henry, J. Winkler, R. Marchan, L. Stoppini, S. Bosgra, J. Westerhout, M. Verwei, J. Vilo, A. Kortenkamp, J. Hescheler, L. Hothorn, S. Bremer, C. Van Thriel, K.H. Krause, J.G. Hengstler, J. Rahnenführer, M. Leist, A. Sachinidis, Human embryonic stem cell-derived test systems for developmental neurotoxicity: a transcriptomics approach, Arch. Toxicol. $87 \quad$ (2013) 123-143. https://doi.org/10.1007/s00204-012-0967-3.

[36] C.R. Muratore, P. Srikanth, D.G. Callahan, T.L. Young-Pearse, Comparison and optimization of hiPSC forebrain cortical differentiation protocols, PLOS One. 9 (2014) e105807. https://doi.org/10.1371/journal.pone.0105807.

[37] A. Hyysalo, M. Ristola, M.E.-L. Mäkinen, S. Häyrynen, M. Nykter, S. Narkilahti, Laminin a5 substrates promote survival, network formation and functional development of human pluripotent stem cell-derived neurons in vitro, Stem Cell Res. 24 (2017) 118-127. https://doi.org/https://doi.org/10.1016/j.scr.2017.09.002.

[38] J.-E. Kim, M.L. Sullivan, C.A. Sanchez, M. Hwang, M.A. Israel, K. Brennand, T.J. Deerinck, L.S.B. Goldstein, F.H Gage, M.H. Ellisman, A. Ghosh, Investigating synapse formation and function using human pluripotent stem cell-derived neurons, Proc. Natl. Acad. Sci. 108 (2011) 3005-3010 https://doi.org/10.1073/pnas.1007753108. 
[39] M.K. Carpenter, M.S. Inokuma, J. Denham, T. Mujtaba, C.P. Chiu, M.S. Rao, Enrichment of neurons and neural precursors from human embryonic stem cells, Exp. Neurol. 172 (2001) 383-397. https://doi.org/10.1006/exnr.2001.7832.

[40] S.K. Goparaju, K. Kohda, K. Ibata, A. Soma, Y. Nakatake, T. Akiyama, S. Wakabayashi, M. Matsushita, M. Sakota, H. Kimura, M. Yuzaki, S.B.H. Ko, M.S.H. Ko, Rapid differentiation of human pluripotent stem cells into functional neurons by mRNAs encoding transcription factors, Sci. Rep. 7 (2017) 42367. https://doi.org/10.1038/srep42367.

[41] A. Chandrasekaran, H.X. Avci, A. Ochalek, L.N. Rösingh, K. Molnár, L. László, T. Bellák, A. Téglási, K. Pesti, A. Mike, P. Phanthong, O. Bíró, V. Hall, N. Kitiyanant, K.H. Krause, J. Kobolák, A. Dinnyés, Comparison of 2D and 3D neural induction methods for the generation of neural progenitor cells from human induced pluripotent stem cells, Stem Cell Res. 25 (2017) 139-151. https://doi.org/10.1016/j.scr.2017.10.010.

[42] R. Lieberman, E.S. Levine, H.R. Kranzler, C. Abreu, J. Covault, Pilot study of iPS-derived neural cells to examine biologic effects of alcohol on human neurons in vitro, Alcohol. Clin. Exp. Res. 36 (2012) 1678-1687. https://doi.org/10.1111/j.1530-0277.2012.01792.x.

[43] J. Sandström, E. Eggermann, I. Charvet, A. Roux, N. Toni, C. Greggio, A. Broyer, F. Monnet-Tschudi, L. Stoppini, Development and characterization of a human embryonic stem cell-derived 3D neural tissue model for neurotoxicity testing, Toxicol. Vitr. 38 (2017) 124-135. https://doi.org/10.1016/j.tiv.2016.10.001.

[44] L. D'Aiuto, Y. Zhi, D. Kumar Das, M.R. Wilcox, J.W. Johnson, L. McClain, M.L. MacDonald, R. Di Maio, M.E. Schurdak, P. Piazza, L. Viggiano, R. Sweet, P.R. Kinchington, A.G. Bhattacharjee, R. Yolken, V.L. Nimgaonkar, Large-scale generation of human iPSC-derived neural stem cells/early neural progenitor cells and their $\begin{array}{lllll}\text { neuronal } & \text { differentiation, } & \text { Organogenesis. } & 10 & \text { (2014) }\end{array}$ https://doi.org/10.1080/15476278.2015.1011921.

[45] F. Pistollato, D. Canovas-Jorda, D. Zagoura, A. Bal-Price, Nrf2 pathway activation upon rotenone treatment in human iPSC- derived neural stem cells undergoing differentiation towards neurons and astrocytes, Neurochem. Int. 108 (2017) 457-471. https://doi.org/10.1016/j.neuint.2017.06.006.

[46] T.J. Heikkilä, L. Ylä-Outinen, J.M.A. Tanskanen, R.S. Lappalainen, H. Skottman, R. Suuronen, J.E. Mikkonen J.A.K. Hyttinen, S. Narkilahti, Human embryonic stem cell-derived neuronal cells form spontaneously active neuronal networks in vitro, Exp. Neurol. $218 \quad$ (2009) 109-116. https://doi.org/10.1016/j.expneurol.2009.04.011.

[47] A.M. Tukker, F.M.J. Wijnolts, A. de Groot, R.H.S. Westerink, Human iPSC-derived neuronal models for in vitro $\begin{array}{lllll}\text { neurotoxicity } & \text { assessment, } & \text { Neurotoxicology. } & 67 & \text { (2018) }\end{array}$ https://doi.org/10.1016/j.neuro.2018.06.007.

[48] L.E. Clarke, B.A. Barres, Emerging roles of astrocytes in neural circuit development., Nat. Rev. Neurosci. 14 (2013) 311-321. https://doi.org/10.1038/nrn3484.

[49] M. Amiri, N. Hosseinmardi, F. Bahrami, M. Janahmadi, Astrocyte- neuron interaction as a mechanism responsible for generation of neural synchrony: a study based on modeling and experiments, J. Comput. Neurosci. 34 (2013) 489-504. https://doi.org/10.1007/s10827-012-0432-6.

[50] T. Ishii, E. Kawakami, K. Endo, H. Misawa, K. Watabe, Myelinating cocultures of rodent stem cell line-derived neurons and immortalized Schwann cells, Neuropathology. $37 \quad$ (2017) 475-481. https://doi.org/10.1111/neup.12397.

[51] T. Takemoto, Y. Ishihara, A. Ishida, T. Yamazaki, Neuroprotection elicited by nerve growth factor and brainderived neurotrophic factor released from astrocytes in response to methylmercury, Environ. Toxicol. Pharmacol. 40 (2015) 199-205. https://doi.org/10.1016/j.etap.2015.06.010.

[52] P. Bajpai, M.C. Sangar, S. Singh, W. Tang, S. Bansal, G. Chowdhury, Q. Cheng, J.K. Fang, M. V. Martin, F.P. Guengerich, N.G. Avadhani, Metabolism of 1-methyl-4-phenyl-1,2,3/6-tetrahydropyridine by mitochondriontargeted cytochrome P450 2D6 implications in parkinson disease, J. Biol. Chem. 288 (2013) 4436-4451. https://doi.org/10.1074/jbc.M112.402123.

[53] T. Hartung, H. Hodgberg, M. Leist, D. Pamies, L. Smirnova, Advanced cell techniques to study developmental neurobiology and toxicology, in: Neural Cell Biol., CRC Press, Boca Raton, FL, USA, 2017: pp. 187-217. https://doi.org/10.1201/9781315370491.

[54] M. Sachana, A. Bal-Price, K.M. Crofton, S.H. Bennekou, T.J. Shafer, M. Behl, A. Terron, International regulatory and scientific effort for improved developmental neurotoxicity testing, Toxicol. Sci. 167 (2019) 45-57. https://doi.org/10.1093/toxsci/kfy211. 



\section{CHAPTER 8}

\section{NEURONAL DIFFERENTIATION PATHWAYS AND COMPOUND-INDUCED DEVELOPMENTAL NEUROTOXICITY IN THE HUMAN NEURAL PROGENITOR CELL TEST [HNPT] REVEALED BY RNA-SEQ}

Victoria C. de Leeuw ${ }^{1,2}$, Conny T. M. van Oostrom ${ }^{1}$, Paul F.K. Wackers' ${ }^{1}$, Jeroen L.A. Pennings ${ }^{1}$, Hennie M. Hodemaekers ${ }^{1}$, Aldert H. Piersma ${ }^{1,2}$, Ellen V.S. Hessel ${ }^{1}$

${ }^{1}$ Centre for Health Protection, National Institute for Public Health and the Environment, Bilthoven, the Netherlands

${ }^{2}$ Institute for Risk Assessment Sciences, Utrecht University, Utrecht, the Netherlands 



\section{Abstract}

There is an increased awareness that the use of animals for compound-induced developmental neurotoxicity (DNT) testing has limitations. Animal-free innovations, especially the ones based on human stem cell-based models are pivotal in studying DNT since they can mimic processes relevant to human brain development. Here we present the human neural progenitor test (hNPT), a 10-day protocol in which neural progenitors differentiate into a neuron-astrocyte coculture. The study aimed to characterise differentiation over time and to find neurodevelopmental processes sensitive to compound exposure using a transcriptomics approach. The 7844 genes regulated in unexposed control cultures ( $p \leq 0.001, \log 2 F C \geq 0.5$ ) showed Gene Ontology (GO-) term enrichment for neuronal differentiation, axon and dendritogenesis, neuron apoptosis, synaptogenesis, and synaptic transmission. Exposure to known DNT compounds (acrylamide, chlorpyrifos, fluoxetine, methyl mercury, or valproic acid) at concentrations resulting in 95\% cell viability each regulated unique combinations of GO-terms relating to neural progenitor proliferation, neuronal and glial differentiation, axon development, synaptogenesis, synaptic transmission, and apoptosis. Further investigation of the GO-terms 'neuron apoptotic process' and 'axon development' revealed common genes that were responsive across all tested compounds, and may be used as biomarkers for DNT. The GO-term 'synaptic signalling', on the contrary, whilst also responsive to all compounds tested, showed little overlap in gene expression regulation patterns between the conditions. This GO-term may articulate compound-specific effects that may be relevant for revealing differences in mechanism of toxicity. These results indicate that hNPT can be a suitable model to detect as well as to study molecular mechanisms of human DNT compounds. 


\section{Introduction}

The prevalence of neurologic diseases with a developmental origin, like autism spectrum disorder, bipolar disorder, attention deficit hyperactivity disorder, and schizophrenia seems to be rising [1-5]. The aetiology of these disorders is multifactorial, even for those with a strong genetic background $[6,7]$. It is suggested that compound exposures may play an important role in these disorders, as in recent decades a sharp upward trend has been noticed in for example autism cases that could not be fully explained by other environmental factors [4]. Information on the neurotoxic potential of many compounds is scarce, but epidemiological data and animal experiments suggest that there is indeed a link between compound exposure and adverse outcomes [8-10]. Strong causative links between compound exposures and specific human health outcomes, however, are lacking $[1,6]$.

While proven useful in the past, animal studies to test the safety of chemicals or pharmaceuticals may not always be sufficient in representing human brain development [11]. Neurodevelopment becomes increasingly complex and species-specific over the course of development [12-14], and failure to account for human-specific effects is reflected in the high attrition rates when drugs enter clinical trials $[15,16]$. Furthermore, animal-testing is low-throughput, costly, and ethically debatable $[11,17]$. A different, human-relevant, and mechanism-based approach is therefore highly needed.

Animal-free safety testing of compounds requires a rethinking of the current testing paradigm [18]. The intact organism may in principle be replaced by a series of in vitroassays that together represent the key processes in human neurodevelopment in combination with in silicomodels to integrate experimental outcomes and extrapolate them to human hazard assessment. Current initiatives focus on building frameworks in which these key neurodevelopmental processes are defined, for example in ontologies, adverse outcome pathways (AOPs), integrated approaches to testing and assessment (IATA) [19-22]. The use of human stem cell-based models in these frameworks is especially promising, because they naturally transition through various developmental stages upon differentiation [23]. However, due to the inherent reductionist nature of these and other in vitro assays, their technical applicability domain (i.e. which kind of compounds are feasible to test in cell-based systems) as well as their biological domain (i.e. which biological processes does the assay mimic) are limited and need to be defined $[10,19]$.

A first step to define this biological domain can be done using a transcriptomics approach. Whole transcriptome analysis allows for an unbiased assessment of the expression of genes that are involved in (neurodevelopmental) biological processes, thereby identifying which of these processes may be represented in a given model. These neurodevelopmental processes may include neural progenitor commitment, neuronal and glial cell differentiation and maturation, synaptogenesis, and network formation [19,20,24]. Moreover, transcriptomics can provide mechanistic insights into the mode of action of compounds and offer biomarkers for DNT in vitro.

This study builds on previous research in which we have shown successful differentiation of hESC-derived neural progenitors (NPCs) into a neuron-astrocyte co-culture that presented spontaneous electrical activity after three days in culture [25]. The current study aimed to develop an exposure protocol using this differentiation method that is suitable for DNT testing: 
the human neural progenitor test (hNPT). To this end, the biological domain of hNPT and potential endpoints to measure DNT in this system were explored over time and in response to five compounds with diverse mechanisms of action using a whole transcriptome approach with RNA-seq.

\section{Materials and methods}

\section{Neuron-astrocyte generation from embryonic stem cell-derived neural progenitors: the human neural progenitor test (hNPT)}

Neural progenitors (NPCs) were generated from human embryonic stem cells as described previously [25]. For each experiment, NPCs were thawed and maintained according to the neuronal induction protocol from Stemcell (Document \#28782, Stemcell Technologies, Vancouver, Canada). Briefly, cells were kept in a humidified chamber $\left(37{ }^{\circ} \mathrm{C}, 5 \% \mathrm{CO}_{2}, 3 \% \mathrm{O}_{2}\right)$ in STEMdiff ${ }^{\mathrm{TM}}$ Neural Progenitor (NP) medium (Stemcell) on Poly-L-Ornithine (PLO, $15 \mu \mathrm{g} / \mathrm{mL}$, Sigma-Aldrich, Saint Louis, MO, USA) - laminin (10 $\mu \mathrm{g} / \mathrm{mL}$, Sigma-Aldrich) coated 6-well plates (Corning, New York, NY, USA). Culture medium was refreshed daily for a week until the NPCs were confluent. For neuron-astrocyte generation, NPCs were dissociated and seeded at $2.56 \times 10^{5} \mathrm{cells} / \mathrm{cm}^{2}$ on PLO-laminin-coated 8-well micro-slides (Ibidi, Gräfelfing, Germany), 12/24/48-well plates (Corning) or 96-well plates (Greiner Bio-One, Kremsmünster, Austria), depending on the application. Cells were kept for one day in NP medium, after which they were switched to differentiation medium adapted from Gunhanlar et al. [26]. This medium consisted of neurobasal medium, $10 \mu \mathrm{l} / \mathrm{mL}$ N2 supplement, $20 \mu \mathrm{l} / \mathrm{mL}$ B-27-retinoic acid supplement, $10 \mu \mathrm{l} / \mathrm{mL} 5000 \mathrm{lU} / \mathrm{mL}$ Penicillin / $5000 \mu \mathrm{g} / \mathrm{mL}$ Streptomycin, $10 \mu \mathrm{l} / \mathrm{mL}$ nonessential amino acids, $20 \mathrm{ng} / \mathrm{mL}$ glial cell line-derived neurotrophic factor (GDNF) and $20 \mathrm{ng} / \mathrm{mL}$ brain-derived neurotrophic factor (BDNF; all from Gibco, Waltham, MA, USA), $1 \mu \mathrm{M}$ dibutyryl cyclic adenosine monophosphate (Sigma-Aldrich), $200 \mu \mathrm{M}$ ascorbic acid (Sigma-Aldrich) and $2 \mu \mathrm{g} / \mathrm{mL}$ laminin (Sigma-Aldrich). Ciliary neurotrophic factor (CNTF; Gibco) was added during the first week of neuron-astrocyte generation at a final concentration of $10 \mathrm{ng} / \mathrm{mL}$. Half of the medium was refreshed every two to three days.

\section{Compound exposure and analysis}

Compounds were freshly prepared for each exposure. Acrylamide (ACR, CAS\# 79-06-1) and valproic acid sodium (VPA, \#CAS 1069-66-5) were dissolved in medium, and chlorpyrifos (CPF, \#CAS 2921-88-2), fluoxetine hydrochloride (FLX, \#CAS 59333-67-4) and methyl mercury chloride (MeHg, \#CAS 115-09-3) were dissolved in dimethyl sulfoxide (DMSO, CAS\# 67-68-5). Final concentrations of DMSO in the medium was $0.25 \%(\mathrm{~V} / \mathrm{v})$.

\section{NPC viability}

Cytotoxicity of compounds to NPCs was measured in a 5-day protocol. Briefly, when NPCs reached confluency, cells were dissociated and seeded in a PLO-laminin coated 96-wells plate at a density of $3.2 \times 10^{4}$ cells/well in NP medium. Cells were allowed to adhere to the plate for 
$2 \mathrm{~h}$ before exposure to either of the five compounds. NP medium was used as solvent control for ACR and VPA, NP medium with DMSO was used as solvent control for CPF, FLX, and MeHg, $0.3 \mu \mathrm{g} / \mathrm{mL}$ 5-Fluorouracil (Sigma-Aldrich) was used as positive control, and $0.5 \mathrm{mg} / \mathrm{mL}$ Penicillin $\mathrm{G}$ (Sigma-Aldrich) as negative control. Three experiments with six technical replicates per condition were performed. Exposure medium was refreshed on day 3. On day 5, cell viability was determined using the CellTiter-Blue ${ }^{\circledR}$ kit (Promega, Leiden, the Netherlands). Cells were incubated for $2 \mathrm{~h}$ and measured in a Spectramax ${ }^{\circledR} \mathrm{M} 2$ spectrofluorometer (Molecular Devices, Berkshire, United Kingdom).

\section{hNPT viability}

hNPT was prepared as mentioned above in PLO-laminin coated 48-well plates. Cells were exposed for ten days from the moment they were switched to differentiation medium. At least three experiments with three technical replicates per condition were performed. To determine cell viability, cells were incubated for $1 \mathrm{~h}$ with Cell Proliferation Reagent WST-1 (Roche, Mannheim, Germany) instead of the CellTiter-Blue ${ }^{\circledR}$ kit to avoid auto-fluorescence during fluorescence imaging.

\section{hNPT neurite area}

Immunocytochemistry was performed as described before [25]. Briefly, after WST-1 measurements, hNPT was rinsed two times with warm PBS and fixed with $4 \%$ pre-warmed paraformaldehyde (Electron Microscopy Sciences, Hatfield, PA, USA) in PBS for 30 minutes. Cells were then permeabilised with $0.2 \%$ Triton X-100 (Sigma-Aldrich) for 5 min in PBS, washed two times 5 minutes with PBS, and blocked for $1 \mathrm{~h}$ in blocking solution (1\% bovine serum albumin (BSA; w/v; Sigma-Aldrich), 0.5\% Tween-20 (Sigma-Aldrich) in PBS). After washing, primary antibodies were applied overnight at $4{ }^{\circ} \mathrm{C}$ in 0.5\% BSA/0.5\% Tween-20 in PBS. Samples were washed and incubated with secondary antibodies for $1 \mathrm{~h}$ in the same antibody incubation mixture. Nuclei were stained using DAPI (20 ng/mL, Sigma-Aldrich). Imaging was performed on a Leica DMi8 microscope system (Leica, Wetzlar, Germany) using the appropriate Leica Software (LAS $X)$. Images were further processed in Fiji/ImageJ (version 1.51n) [27] and CellProfiler (version 3.1.9) [28]. To measure neurite area, a mask was produced from the DAPI and MAP2 channel (fixed manual cut-off per experiment), which was then inverted to calculate the neurite area, normalised for the DAPI area.

Dose-response curves of cell viability and neurite area were created using PROAST software (version 67.0) [29] in R (version 4.0.0) [30]. Effect concentrations with a 95\% confidence interval were derived from the resulting curves. 
Table 7. Primary and secondary antibodies

\begin{tabular}{|c|c|c|c|c|c|}
\hline Antibody & Abbreviation & Marker for & $\begin{array}{l}\text { Product } \\
\text { number }\end{array}$ & Company & Dilution \\
\hline $\begin{array}{l}\text { Rabbit anti-Paired homeo- } \\
\text { box } 6\end{array}$ & PAX6 & Neural progenitor & 901301 & Biolegend & $1: 1000$ \\
\hline Rabbit anti-Nestin & NES & Neural progenitor & N5413 & $\begin{array}{l}\text { Sigma-Al- } \\
\text { drich }\end{array}$ & $1: 500$ \\
\hline Rabbit anti- $\beta$-Tubulin III & TUBB3 & Neuron & T2200 & $\begin{array}{l}\text { Sigma-Al- } \\
\text { drich }\end{array}$ & $1: 1000$ \\
\hline $\begin{array}{l}\text { Mouse anti-Microtubule-as- } \\
\text { sociated protein } 2\end{array}$ & MAP2 & $\begin{array}{l}\text { Neuron, dendrite- } \\
\text { specific }\end{array}$ & 801801 & Biolegend & $1: 2000$ \\
\hline $\begin{array}{l}\text { Rat anti-Glial fibrillary acidic } \\
\text { protein }\end{array}$ & GFAP & Early astrocyte & $13-0300$ & Invitrogen & $1: 800$ \\
\hline $\begin{array}{l}\text { Mouse anti-Postsynaptic } \\
\text { density } 95\end{array}$ & PSD95 & Postsynapse & MAB1598 & Merck & $1: 500$ \\
\hline $\begin{array}{l}\text { Mouse anti-Vesicular GABA } \\
\text { transporter }\end{array}$ & VGAT & Inhibitory neuron & 131011 & $\begin{array}{l}\text { Synaptic } \\
\text { Systems }\end{array}$ & $1: 500$ \\
\hline Goat anti-Rabbit Alexa 488 & & & A11034 & Invitrogen & $1: 1000$ \\
\hline Goat anti-Mouse Alexa 555 & & & A21424 & Invitrogen & $1: 500$ \\
\hline Goat anti-Rat Alexa 555 & & & A21434 & Invitrogen & $1: 500$ \\
\hline Goat anti-Mouse Alexa 647 & & & A21236 & Invitrogen & $1: 500$ \\
\hline
\end{tabular}

\section{RNA isolation, $q P C R$ and RNA-seq}

\section{RNA isolation}

Eight samples per condition (all technical replicates from one experiment) were fixated in QIAzol (Qiagen, Hilden, Germany) and stored at $-80{ }^{\circ} \mathrm{C}$ until further processing. Whole RNA extraction was performed following the manufacturer's protocol using the RNeasy ${ }^{\circledR}$ mini kit (Qiagen) with a DNase digestion step (Qiagen). RNA concentration was determined using the Qubit3 (Invitrogen, Carlsbad, CA, USA) and RNA quality was analysed using the 2100 Bioanalyzer (Agilent Technologies, Amstelveen, the Netherlands).

\section{qPCR}

Synthesis of cDNA was performed using the high capacity cDNA reverse transcription kit containing random hexamer primers (Applied Biosystems, Foster City, CA, USA). Gene quantification was done on a 7500 Fast Real-Time PCR system (Applied Biosystems) with the following thermal cycling conditions: $95^{\circ} \mathrm{C}$ for $20 \mathrm{sec}, 40$ cycles of $95^{\circ} \mathrm{C}$ for $3 \mathrm{sec}, 60^{\circ} \mathrm{C}$ for $30 \mathrm{sec}$. Primers are summarised in Table 2 . Relative gene expression differences were calculated using the $2^{-\Delta \Delta \mathrm{Ct}}$-method [31], normalised against the housekeeping genes Hypoxanthine phosphoribosyltransferase 1 (HPRT7), and Glucuronidase beta (GUSB). Statistical analysis was performed using a one-way ANOVA test and post-hoc Sidak's multiple comparisons test using GraphPad Prism (version 8.1.2, www.graphpad.com). 
Table 2. Primers used for gene expression with corresponding marker function and assay ID. All primers were bought from Applied Biosystems.

\begin{tabular}{llll}
\hline Gene name & Abbreviation & Marker for & Assay ID \\
\hline Nestin & NES & Neural progenitor & Hs00707120_s1 \\
Tubulin, beta 3 class III & TUBB3 & Neuron & Hs00801390_s1 \\
Microtubule-associated protein 2 & MAP2 & Mature neuron & Hs00258900_m1 \\
Synaptoporin & SYNPR & Pre-synapse & Hs01548398_m1 \\
Discs Large MAGUK Scaffold Protein 4 & DLG4 & Post-synapse & Hs01555373_m1 \\
Vesicular glutamate transporter & SLC17A6 & Excitatory neuron & Hs00220439_m1 \\
Vesicular GABA transporter & SLC32A7 & Inhibitory neuron & Hs00369773_m1 \\
Glial fibrillary acidic protein & GFAP & Early astrocyte & Hs00909233_m1 \\
Glucuronidase beta & GUSB & Housekeeping gene & Hs00939627_m1 \\
Hypoxanthine phosphoribosyltransferase 1 & HPRT1 & Housekeeping gene & Hs02800695_m1 \\
\hline
\end{tabular}

\section{RNA-seq}

All methodological information is summarised in Supplementary Table 1. Samples were processed according to the TruSeq Stranded mRNA protocol (Illumina, San Diego, CA, USA). Enrichment of mRNA was done using polyA-affinity purification converting it into a multiplex library of 16 samples. Sequencing was performed on the NextSeq 500 sequencer (Illumina) using the NextSeq 500/550 High Output Kit version 2.5 (75 cycles). Raw bcl files were base called and demultiplexed into FASTQ files with Bcl2fastq (Illumina, version 2.20.0.422). Quality control reports (FastQC, version 0.11.8) were generated using MultiQC (version 1.0) [32] to identify potential anomalies regarding library size, read length distribution, mean read quality distribution, mean quality for each position in the read, and base frequency for each position in the read. This revealed a GC- and a fragment length bias between the multiplex runs. Expression of the transcripts was quantified against the human transcriptome (GRCh38, version 30, Ensembl 96) using Salmon (version 1.3.0) [33]. The estimated transcript abundances were imported into RStudio (version 1.3.959) [34] and summarised into genes using tximport (version 1.16.1) [35].

Principal component analysis was performed on normalised (ratios) data to identify potential outliers; one sample was left out for further analysis due to the high sequence duplication levels ( $\mathrm{MeHg} I \mathrm{I}_{20} / 100$ sample 8, 59.3\%). Differential gene expression between conditions was calculated using the DESeq2 package (version 1.30.0) [36], adjusting for batch and using the IfcShrink ashrfunction to extract final log2 fold changes (FC) [37]. Differentially expressed genes (DEGs) were obtained by filtering results for $p \leq 0.001$ and Log2FC $\geq 0.5$. Functional enrichment of genes in Gene Ontology (GO-) terms (Biological processes, GO FAT) was performed using DAVID (consulted on 8 November 2020, version 6.8) [38] against a background of genes with at least one count in the analysis (38078 genes for time, 41485 for compounds). GO-terms with false discovery rate (FDR) $\leq 0.05$ were considered to be enriched. Categorisation of GO-terms was performed based on their GO classification ( http://amigo.geneontology.org/amigo) for producing the pie charts summarising all GO-terms, and terms relating to neurons were further categorised based on expert judgement. Interactions between genes were obtained with STRING (consulted on 15 November 2020, version 11.0) [39]. 
Graphs were visualised using GraphPad Prism (version 8.1.2, www.graphpad.com), heatmaps (ward.D clustering) and PCA plots were built in RStudio (version 4.0.0) [30], the cell lineage map was made in Pathvisio (version 3.3.0) [40], Venn diagrams were produced using Venny (version 2.1.0) [41] and gene interactions from STRING (full network, medium confidence) were visualised in Cytoscape (version 3.7.4) [42], using Perfuse force-directed layout.

\section{Results}

\section{hNPT consisted of excitatory neurons, inhibitory neurons, and astrocytes after ten days of differentiation}

In a previous study, we have characterised a neuronal-astroglial differentiation protocol over the course of four weeks in which we found excitatory neurons, inhibitory neurons, and astrocytes after two weeks of culturing [25]. For the development of the human neural progenitor test (hNPT), we followed the culture in more detail in the first two weeks to find the moment at which these three cell types were present. Gene expression showed that all markers related to functional neurons and astrocytes were upregulated between day 4 and day 14 and most of them plateaued from that time point (Fig. 1A). Neural progenitor marker NES was the only downregulated gene, consistent with the differentiation occurring in hNPT.

Observations on gene expression were verified by immunocytochemistry between day 0 and 14 (Fig 1B-E). While TUBB3 and MAP2 only showed gene upregulation on day 7 and day 14, respectively, protein expression of these genes was already visible in the neural progenitors (NPC) (Fig. 1A-C). The same was true for protein expression of synaptic markers SYNPR and PSD95 (encoded by DLG4), and vesicle marker VGLUT2 (encoded by SLC77A6) (Fig. 1A, D, unpublished data). GFAP was upregulated from day 4, but protein expression emerged from day 7 (Fig. 1A, B). Vesicle marker VGAT (encoded by SLC32A7) had a similar delay in protein expression as GFAP, only being present from day 10 (Fig. 1A, E). Together, these results led to the establishment of hNPT as a 10-day differentiation protocol for exposure experiments (Fig. 1F).

\section{RNA-seq revealed neurodevelopmental processes and cell types present in $h N P T$}

To define which cell types and neurodevelopmental processes were regulated during differentiation, RNA-seq was performed on the NPCs and hNPT. In total, 7844 differentially expressed genes (DEGs) were regulated over time (3951 up, 3893 down). Analysis of selective markers for neuronal cell types using our previously described cell lineage map [43] showed an upregulation of glutamatergic, GABA-ergic, and glycinergic neuron markers, mixed regulation of NPC, neuronal, astroglial, and synaptic component markers, and downregulation of oligodendrocyte markers (Fig. 2A). Less and mixed regulation was observed among cholinergic, dopaminergic, and serotonergic markers.

Enrichment analysis of the upregulated and downregulated genes resulted in 285 and 605 regulated Gene Ontology (GO-) terms, respectively (Fig. 2B, C, Supplementary Table 3). 42\% of GO- 

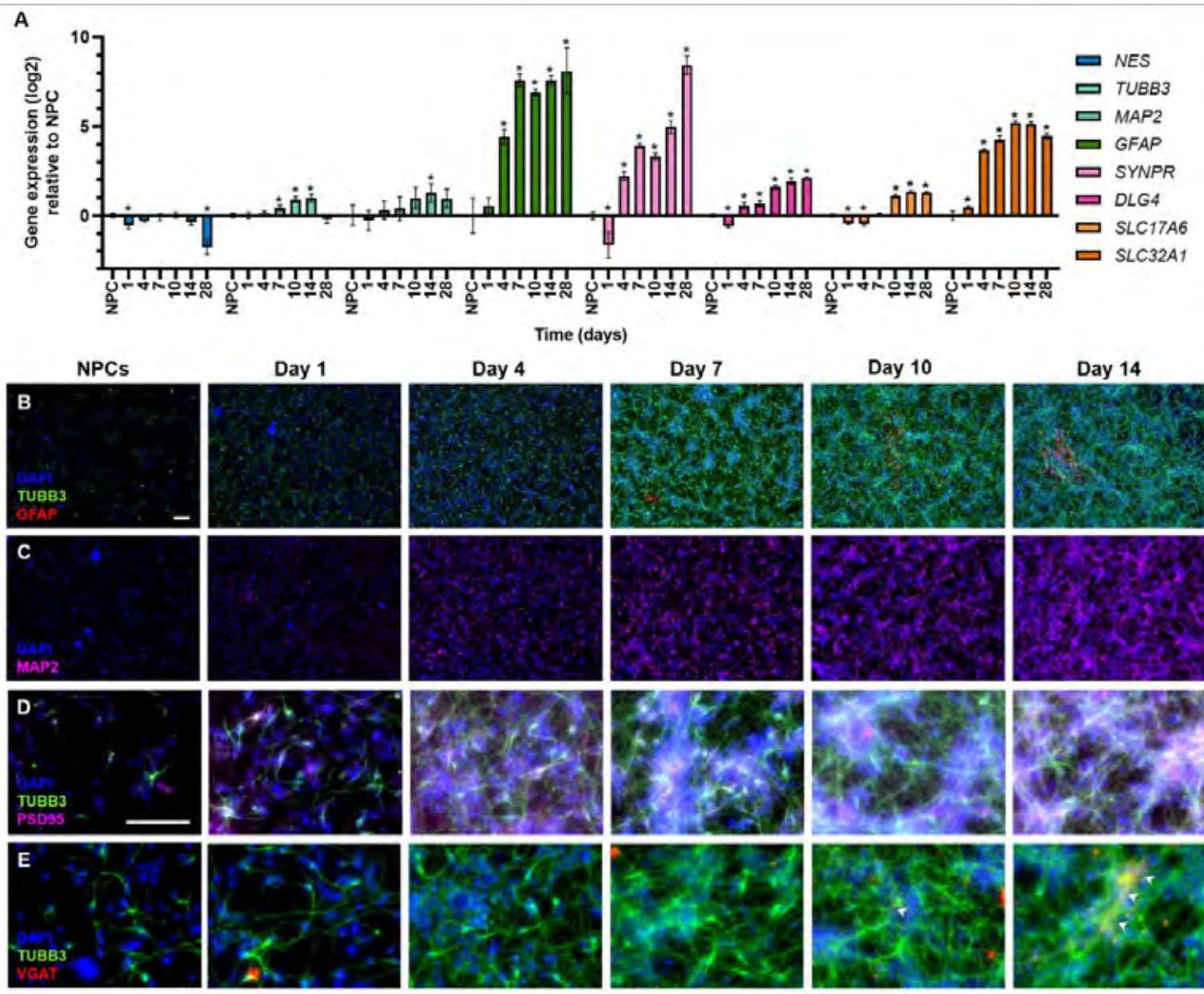

$\mathrm{F}$

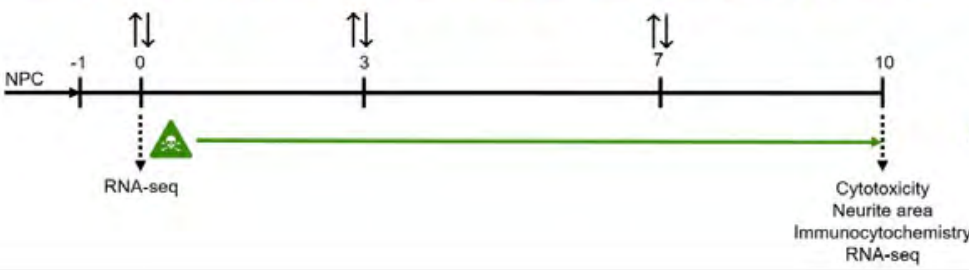

$\uparrow$ Medium refreshments $\uparrow$ (half on day 3,7 )

Acrylamide Chlorpyrifos Fluoxetine Methyl mercury Valproic acid

RNA-seq

Figure 1. Neuronal differentiation of hESC-derived NPCs and establishment of hNPT. (A) Gene expression relative to NPC culture of differentiation markers for cell types and cellular components at various time points in the differentiation: NPCS (NES), neurons (TUBB3, MAP2), astrocytes (GFAP), synapses (SYNPR, DLG4), excitatory (SLC17A6) and inhibitory (SLC32A1) neurotransmitter vesicles. (B-E) Protein expression over time of a selection of the same markers: neurons (TUBB3, MAP2), astrocytes (GFAP), synapses (PSD95 encoded by DLG4), and inhibitory (VGAT encoded by SLC32A 1) neurotransmitter vesicles. (F) Protocol of hNPT and endpoints assessed at given time points. Scale bar: $100 \mu \mathrm{m}$. Significance (adjusted p-value $\leq 0.05$ ) only relative to the NPC culture is indicated using an *. Full statistics can be found in Supplementary Table 2.

terms enriched by upregulated genes were of a neuronal nature, while only $0.7 \%$ of the GOterms enriched by downregulated genes were related to neuronal processes. These neuronal GO-terms were further categorised in a predefined list of important neurodevelopmental processes. We used a categorisation published by Wegner et al. [24] that was previously applied to a neuronal differentiation protocol and linked these to a more detailed list of important neurodevelopmental processes defined by Hessel et al. [19] (Table 3). Upregulated DEGs and related GO-terms clustered in neurogenesis (20 GO-terms, e.g. 'nervous system development', 
'neuron differentiation'), axonal and dendritic outgrowth, and synapse formation (24 GO-terms, e.g. 'dendrite development', 'axon development', 'axon guidance', 'synapse organization'), neurotransmission (49 GO-terms, e.g. 'glutamatergic synaptic transmission', 'GABA-ergic synaptic transmission', 'regulation of synaptic plasticity'), neuronal apoptosis (6 GO-terms, e.g. 'neuron apoptotic process') and regional specificity (10 GO-terms, e.g. 'forebrain development', 'hindbrain development', 'neuromuscular process'). Downregulated DEGs and GO-terms additionally regulated 'neural precursor cell proliferation'. There were no GO-terms related to glial differentiation and neuronal migration regulated in hNPT.

In summary, in hNPT, NPC differentiated in a mixed culture of excitatory neurons, inhibitory neurons, and astrocytes in which GO-terms for essential neurodevelopmental processes were regulated such as neuronal differentiation, axon guidance, synaptogenesis, and neurotransmission.

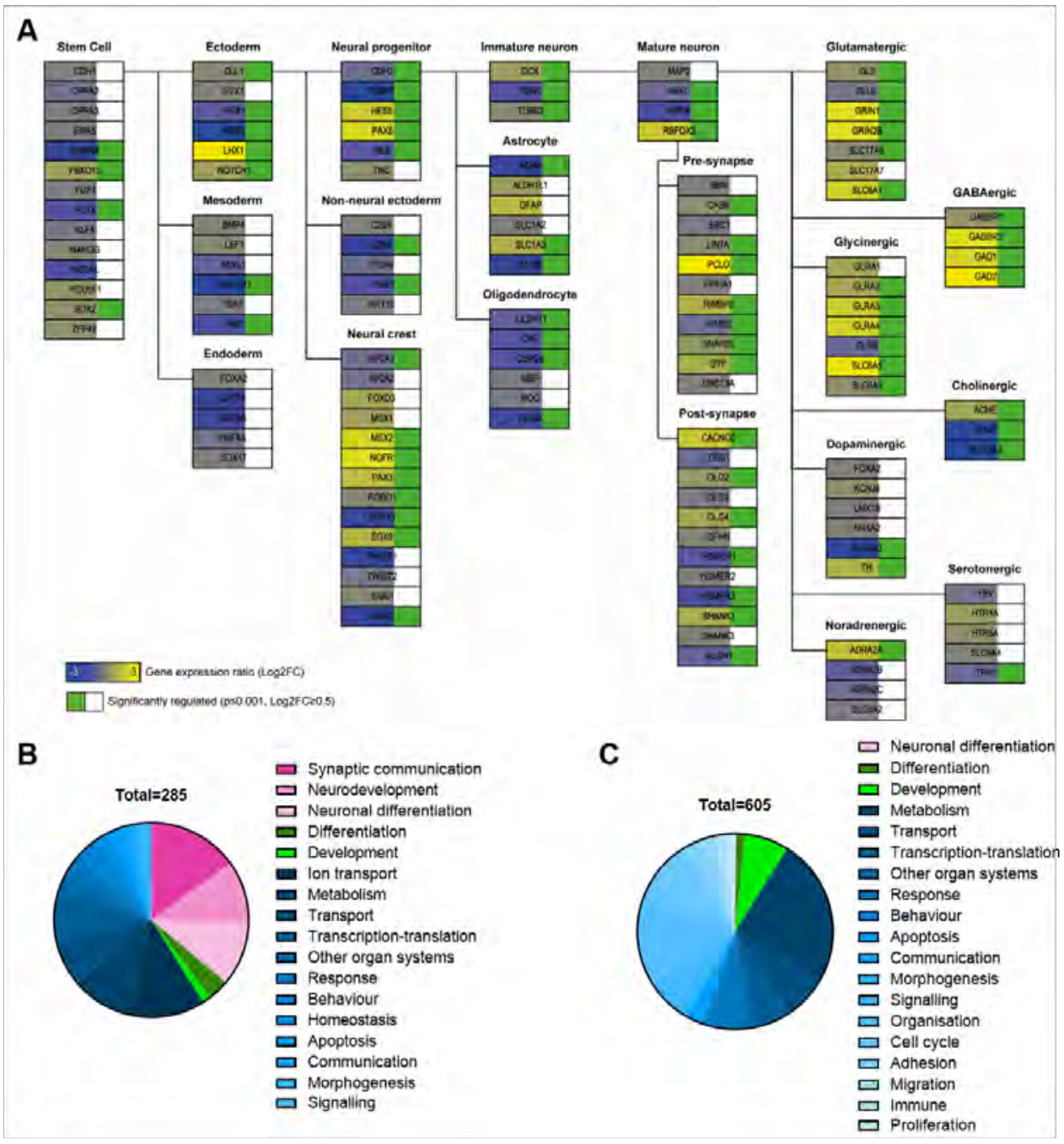


Figure 2 (previous page). Cell types present and GO-terms regulated in hNPT. (A) Cell lineage map [43] showing gene expression regulation (Log2 fold change (FC)) of selective markers for a range of cell types along the ectodermal and neuronal lineage in hNPT. Pie charts list GO-terms enriched by (B) upregulated and (C) downregulated genes summarised per category according to their GO classification (http://amigo.geneontology.org/amigo). Synaptic communication included terms from Neurotransmission in Table 3, Neurodevelopment included terms from Cell differentiation and development, and Neuronal differentiation included terms from Neurite outgrowth and synapse formation. All individual GO-terms with classification and statistics can be found in Supplementary Table 3.

Table 3. Number of neuronal-related GO-terms and numbers of regulated genes involved, grouped to neurodevelopmental processes as defined by Wegner et al. [24] and Hessel et al. [19]. All individual GO-terms with classification and statistics are listed in Supplementary Table 3.

\begin{tabular}{|c|c|c|c|c|c|}
\hline \multicolumn{6}{|c|}{ Neurodevelopmental processes } \\
\hline $\begin{array}{l}\text { Wegner et al. } \\
(2020)\end{array}$ & Hessel et al. (2018) & $\begin{array}{l}\text { GO-terms } \\
\text { upregulated } \\
\text { genes }(285)\end{array}$ & $\begin{array}{l}\text { No. of up- } \\
\text { regulated } \\
\text { genes } \\
\text { (3951) }\end{array}$ & $\begin{array}{l}\text { GO-terms } \\
\text { downregu- } \\
\text { lated genes } \\
(605)\end{array}$ & $\begin{array}{l}\text { No. of down- } \\
\text { regulated } \\
\text { genes (3893) }\end{array}$ \\
\hline \multirow{2}{*}{$\begin{array}{l}\text { Proliferation \& } \\
\text { stem cell mainte- } \\
\text { nance }\end{array}$} & \multicolumn{5}{|l|}{$\begin{array}{l}\text { Neural progenitor cell for- } \\
\text { mation }\end{array}$} \\
\hline & $\begin{array}{l}\text { Neural progenitor cell prolif- } \\
\text { eration }\end{array}$ & & & $2(0.33 \%)$ & $42(1.1 \%)$ \\
\hline \multirow{2}{*}{$\begin{array}{l}\text { Cell differentia- } \\
\text { tion and develop- } \\
\text { ment }\end{array}$} & Neurogenesis & $14(4.9 \%)$ & \multirow{2}{*}{\multicolumn{2}{|c|}{$427(10.8 \%) 1(0.17 \%)$}} & $166(4.2 \%)$ \\
\hline & $\begin{array}{l}\text { Neurons phenotypic specifi- } \\
\text { cation }\end{array}$ & $6(2.1 \%)$ & & & \\
\hline \multirow{2}{*}{$\begin{array}{l}\text { Gliogenesis and } \\
\text { myelination }\end{array}$} & \multicolumn{5}{|l|}{ Gliogenesis } \\
\hline & \multicolumn{5}{|l|}{ Myelination } \\
\hline Neural migration & \multicolumn{5}{|l|}{ Neuron migration } \\
\hline \multirow{5}{*}{$\begin{array}{l}\text { Neurite out- } \\
\text { growth and syn- } \\
\text { apse formation }\end{array}$} & Neurite outgrowth & $8(2.8 \%)$ & $196(5.0 \%)$ & & \\
\hline & $\begin{array}{l}\text { Dendritogenesis/dendrite } \\
\text { formation }\end{array}$ & $4(1.4 \%)$ & $51(1.3 \%)$ & & \\
\hline & Axon formation & $3(1.1 \%)$ & $114(2.9 \%)$ & & \\
\hline & $\begin{array}{l}\text { Axon guidance/axon path } \\
\text { finding }\end{array}$ & $3(1.1 \%)$ & $72(1.8 \%)$ & & \\
\hline & $\begin{array}{l}\text { Synaptogenesis/synapse } \\
\text { formation }\end{array}$ & $12(4.2 \%)$ & $127(3.2 \%)$ & & \\
\hline \multirow{3}{*}{$\begin{array}{l}\text { Neurotransmis- } \\
\text { sion }\end{array}$} & Synaptic connectivity & $39(13.7 \%)$ & $253(6.4 \%)$ & & \\
\hline & \multicolumn{5}{|l|}{ Synaptic pruning } \\
\hline & $\begin{array}{l}\text { Neural network function- } \\
\text { ing/synaptic plasticity }\end{array}$ & $4(1.4 \%)$ & $47(1.2 \%)$ & & \\
\hline \multicolumn{2}{|l|}{ Apoptosis } & $6(2.1 \%)$ & $117(3.0 \%)$ & & \\
\hline $\begin{array}{l}\text { Regional specific- } \\
\text { ity }\end{array}$ & Anatomical & $10(3.5 \%)$ & $142(3.6 \%)$ & $1(0.17 \%)$ & $16(0.4 \%)$ \\
\hline \multicolumn{6}{|c|}{ Percentages in brackets indicate which part of the GO-terms or genes of the total were regulated. } \\
\hline
\end{tabular}




\section{Exposure to five DNT compounds affected cell viability and neurite area at similar concentrations}

We next exposed hNPT to either of five known or suspected DNT compounds: acrylamide $(\mathrm{ACR})$, chlorpyrifos (CPF), fluoxetine (FLX), methyl mercury (MeHg), or valproic acid (VPA). Both cell viability and neurite area (Fig. S1A) were measured, and NPC cell viability was measured in a separate, shorter 5 -day exposure. No statistically different inhibitory concentrations (IC) were found between any of the methods, except for a slightly higher sensitivity of NPCs for MeHg exposure and a lack of NPC cytotoxic effects by VPA exposure (Fig. S1B). Due to the ease of the readout relative to 'neurite area', we chose hNPT cell viability measures to derive $\mathrm{IC}_{5}$ (slightly cytotoxic) and $\mathrm{IC}_{20} / 100$ (not cytotoxic) concentrations for RNA-seq experiments. Immunocytochemistry showed that using the concentrations listed in Table 4 resulted in similar morphology of all experimental conditions relative to the control condition, except for ACR $\mathrm{IC}_{5}$, which showed signs of cytotoxicity (Fig. S1C).

Table 4. $I C_{5}$ and $I C_{20} / 100$ values, and selected compound concentrations for RNA-seq experiments. All values are given in $\mu \mathrm{M}$.

\begin{tabular}{lllll}
\hline & $\begin{array}{l}\text { IC } \\
\text { (confidence interval) }\end{array}$ & $\begin{array}{l}\text { Chosen } \\
\text { concentration }\end{array}$ & $\begin{array}{l}I_{20} / 100 \\
\text { (confidence interval) }\end{array}$ & $\begin{array}{l}\text { Chosen } \\
\text { concentration }\end{array}$ \\
\hline ACR & $320(130-500)$ & 450 & $5.4(3.0-7.3)$ & 6.5 \\
CPF & $21(15-33)$ & 15 & $0.36(0.27-0.48)$ & 0.3 \\
FLX & $9.5(4.1-6.4)$ & 10 & $0.14(0.007-0.011)$ & 0.12 \\
MeHg & $0.11(0.040-0.14)$ & 0.1 & $0.0016(0.00083-0.0024)$ & 0.0015 \\
VPA & $180(57-530)$ & 250 & $5.3(3.3-8.0)$ & 6 \\
\hline
\end{tabular}

\section{Exposure to five DNT compounds caused global gene expression changes and regulated common and distinct GO-terms in hNPT}

RNA-seq analysis of exposed hNPT revealed that compounds regulated between 21 and 2764 DEGs (Fig. 3A). These large differences in DEG numbers were also reflected in a principal component analysis (PCA) and a heatmap based on the 3737 uniquely regulated DEGs (Fig. 3B, C). For example, $\mathrm{IC}_{5}$ of $\mathrm{ACR}$ and $\mathrm{VPA}$ showed distinct gene expression regulation patterns relative to each other and the other compounds, while CPF, FLX, and MeHg clustered together, showing more similar gene expression regulation patterns.

Enrichment of regulated genes revealed a distinct pattern of regulated GO-terms for each of the compounds. ACR and VPA IC $20 / 100$ did not enrich any GO-term. The other $I C_{20} / 100$ concentrations regulated mostly general cell processes and few differentiation $\mathrm{GO}$-terms, while $\mathrm{IC}_{5}$ concentrations elicited specific neuronal GO-terms as well (Fig. 4). In the case of CPF and FLX, the $\mathrm{IC}_{5}$ enriched additional $\mathrm{GO}$-terms relative to the $\mathrm{IC}_{20} / 100$, while in the case of $\mathrm{MeHg}$ the type rather than the amount of GO-terms changed to a neuronal nature after exposure to the $\mathrm{IC}_{5}$. 
Interestingly, while ACR IC 5 regulated most genes, these genes converged in the lowest number of GO-terms.

A

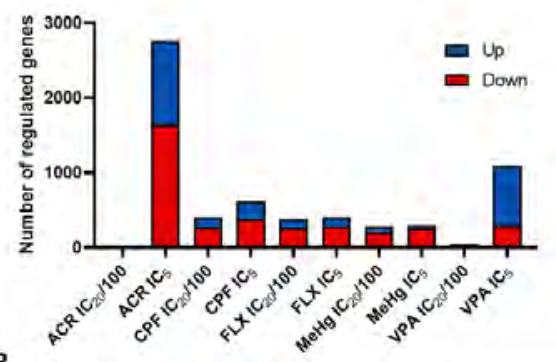

B

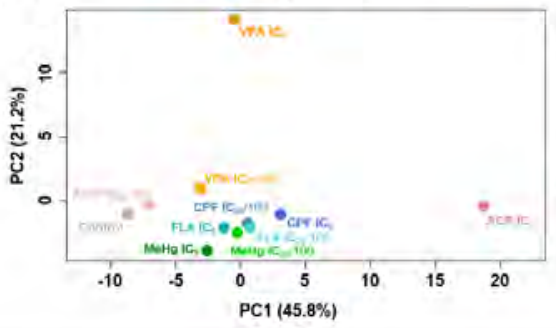

C

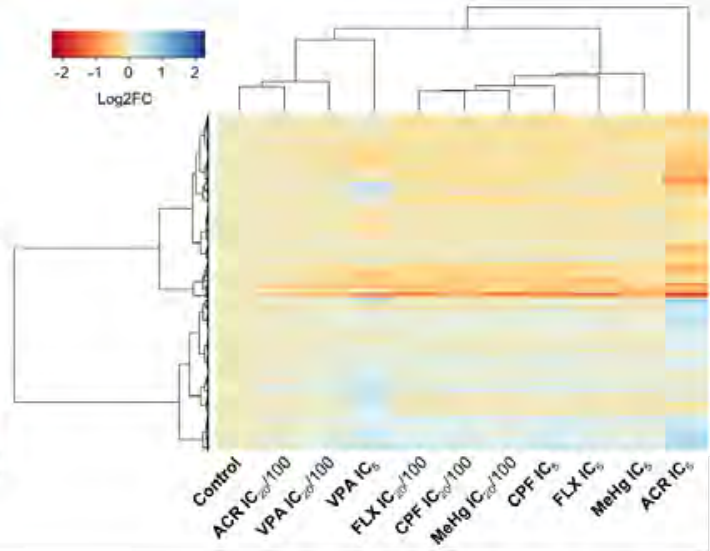

Figure 3. Global gene expression changes in hNPT in response to compound exposure. (A) Number of genes up and downregulated by each of the compounds and compound concentrations. (B) PCA plot of gene expression after exposure to compounds and the control condition based on 3737 genes that are differentially regulated in any of the IC5 exposure conditions. (C) Same data as in (B) presented in a heatmap. ACR: acrylamide, CPF: chlorpyrifos, FLX: fluoxetine, MeHg: methyl mercury, VPA: valproic acid. PC: principal component.
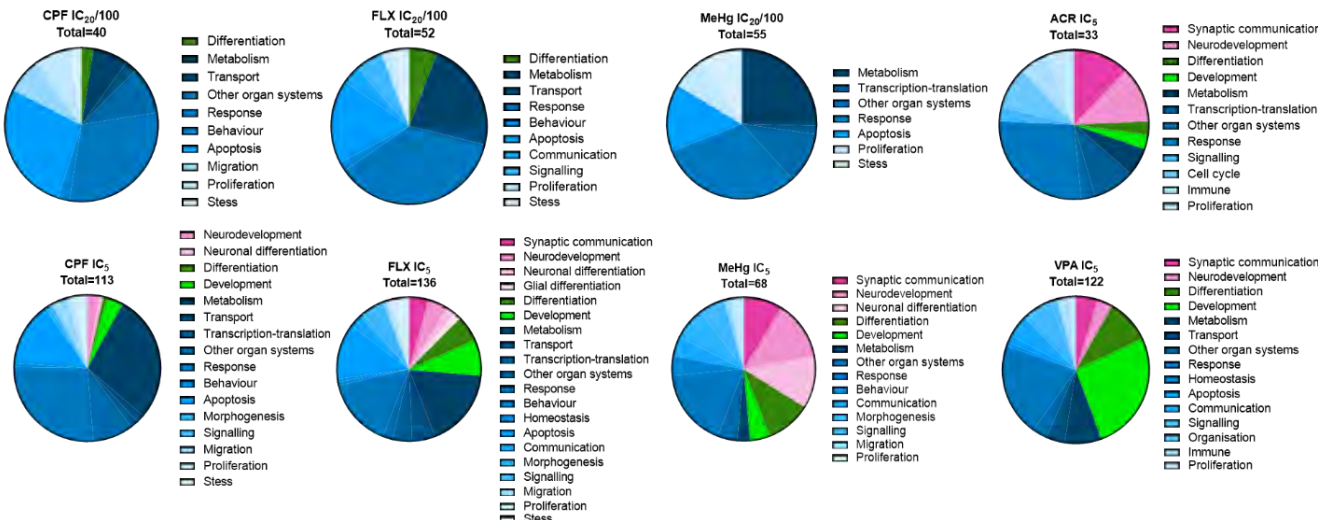

Figure 4. Summary of GO-terms regulated by each experimental condition. Pie chart list GO-terms summarised per category according to their GO classification (http://amigo.geneontology.org/amigo). Categories as in Fig. 2. All individual GO-terms with classification and statistics can be found in Supplementary Table 4. 
Categorisation of the neuronal terms in neurodevelopmental processes as done in Table 3 resulted in distinct but overlapping combinations of GO-terms regulated by each of the compounds. FLX IC ${ }_{20} / 100$ did not enrich any neuronal-specific GO-terms. At least one of the concentrations of each compound regulated GO-terms related to nervous system development, indicating that all compounds had the potential to cause DNT in hNPT. While glial differentiation

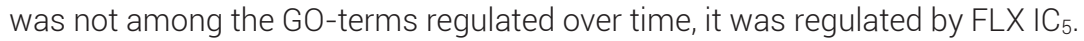

Table 5. Denomination of GO-terms relating to neurodevelopmental processes regulated by DNT compounds. All individual GO-terms with classification and statistics are listed in Supplementary Table 4.

\begin{tabular}{llllllll}
\hline & $\mathrm{ACR} \mathrm{IC}_{5}$ & $\begin{array}{l}\mathrm{CPF} \\
\mathrm{IC}_{20} / 100\end{array}$ & $\mathrm{CPF} \mathrm{IC}_{5}$ & $\mathrm{FLXIC} 5$ & $\begin{array}{l}\mathrm{MeHg} \\
\mathrm{IC}_{20} / 100\end{array}$ & $\mathrm{MeHg} \mathrm{IC}_{5}$ & $\mathrm{VPA} \mathrm{IC}_{5}$ \\
$\begin{array}{l}\text { Total no. of regu- } \\
\text { lated GO terms }\end{array}$ & 33 & 50 & 113 & 136 & 55 & 68 & 122 \\
$\begin{array}{l}\text { Total no. of genes } \\
\text { in regulated GO- } \\
\text { terms }\end{array}$ & 325 & 485 & 329 & 244 & 259 & 979 \\
\hline
\end{tabular}

\section{Proliferation \& stem cell mainte- nance \\ Gliogenesis and myelination \\ Neural migration \\ Neurite outgrowth and synapse for- mation}

Cell differentiation Nervous

and development system development $(4,298)$

Neurotransmission Synaptic signalling $(4,97)$

\section{Apoptosis}

Regional specificity
Neural pro-

genitor proliferation $(2,9)$

Nervous sys- Nervous system develop- tem development $(3,74)$ ment $(6,65)$

Glial cell differentiation $(2,11)$

Neuron pro- Neuron projection/axon jection/axon development development and guidance and guidance
$(1,24)$
$(3,19)$

Nervous Nervous syssystem de- tem developvelopment ment $(4,144)$ $(9,64)$

Neuron projection/axon development and guidance $(8,32)$

Synaptic signalling $(4,27)$ Glutamate receptor signalling $(1,8)$ Regulation of neurotransmitter levels $(2,18)$

Synaptic Synaptic sigsignalling nalling $(5,52)$ $(5,29) \quad$ Neurotrans-

Glutamate mitter receptor transport (1, signalling 23)

$(1,8) \quad$ Regulation of neurotransmitter levels $(1,23)$

GO-terms were summarised under the broadest denominator when they directly related to each other in Gene Ontology. Numbers in brackets indicate the total number of GO-terms per category and number of genes identified by DAVID, respectively. 


\section{Regulated neurodevelopmental processes revealed common biomarker genes and specificity of compounds}

Three of the enriched GO-terms related to specific neurodevelopmental processes were shared by at least three compounds: 'axon development' (G0:0061564, 443 genes), 'neuron apoptosis' (GO:0051402, 202 genes), and 'synaptic signalling' (GO:0099536, 587 genes, the other three synaptic terms contain the same genes) (Table 5). 'Axon development' and 'neuron apoptosis' had respectively eight and seven genes in common among the compounds that regulated these GO-terms (Fig. 5A, C). The regulation of these genes appeared highly similar across all compounds, except for ACR IC $20 / 100$ and VPA IC $20 / 100$ (Fig. 5B, D). Within the GO-term 'neuron apoptosis', MeHg IC 5 also presented a different gene expression regulation pattern relative to the other compounds. This was reflected in the GO-terms for general cell apoptosis, which were regulated in all experimental conditions, except for $\mathrm{MeHg} \mathrm{IC}_{5}$ (Fig. 4, 5D). UNC5B was regulated in both GO-terms (Fig. 5B, D).

A

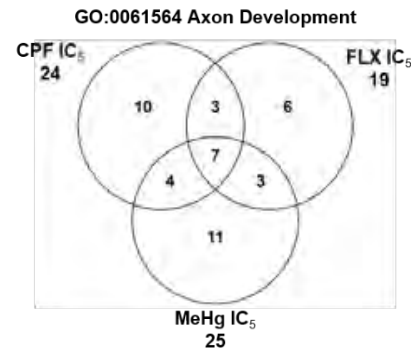

C

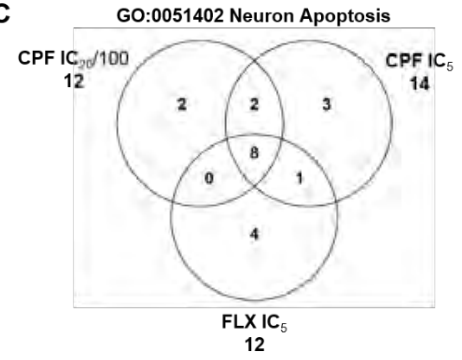

B

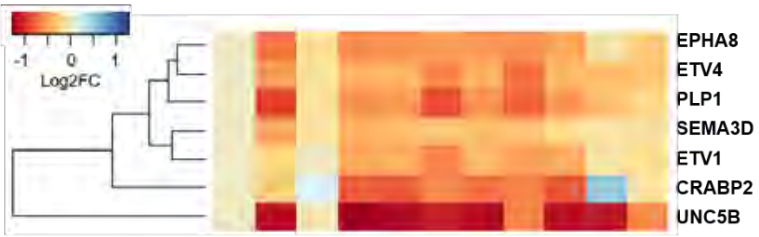

D

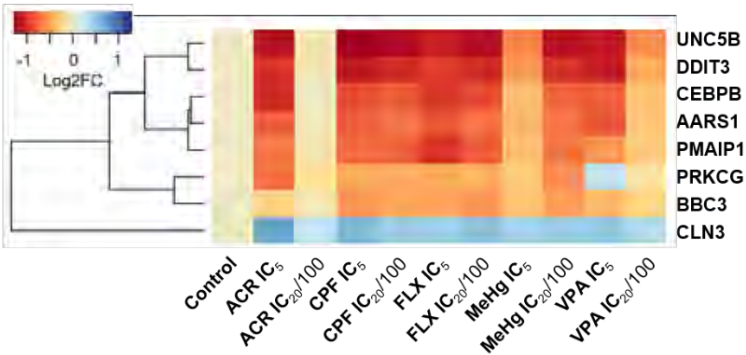

Figure 5. Comparison of common genes affected by different compound exposures. (A) Common genes among CPF $I_{5}, F L X \mid C_{5}$, and MeHg $I_{5}$ for the GO-term 'Axon development'. (B) Expression of the seven common genes (Log2FC) of (A) in all experimental conditions. (C) Common genes among CPF $/ C_{20} / 100, C P F / C_{5}$, and FLX $I C_{5}$ for the GO-term 'Neuron apoptotic process'. (D) Expression of the eight common genes (Log2FC) of (C) in all experimental conditions.

'Synaptic signalling', regulated in four experimental conditions, showed overlap between four test conditions of only two genes (Fig. 6A). Further investigation was performed on all regulated genes in this GO-term by analysing their interaction in STRING. This revealed a network of gene clusters that were specific for eight major neuron subtypes (Fig. 6B). Projecting gene expression regulation of the compounds that regulated this GO-term showed their diverse action on 
this gene set. ACR IC 5 regulated the majority of the genes, mostly downwards, across almost all neuron subtypes (Fig. 6C). VPA $\mathrm{IC}_{5}$, in contrast, mostly upregulated genes and specifically regulated the serotonergic and dopaminergic markers in the network. $\mathrm{MeHg} I \mathrm{C}_{5}$ showed a selective downregulation of genes, among which five of the nineteen glutamatergic markers. FLX $\mathrm{IC}_{5}$ showed a similar pattern, although the direction of regulation was more mixed. Analysis of $\mathrm{CPF} \mathrm{IC}_{5}$, which did not show regulation of this GO-term, altered gene expression of only 19 genes which did not focus on a specific neuron subtype.

Together, these results suggest that hNPT may be able to both detect DNT compounds by monitoring a limited number of genes, as well as to show the specificity of DNT compounds on one of the dominant and most complex processes in hNPT, which is synaptic signalling.

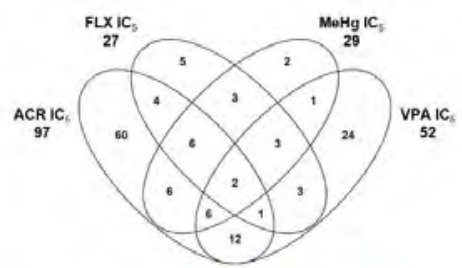

B

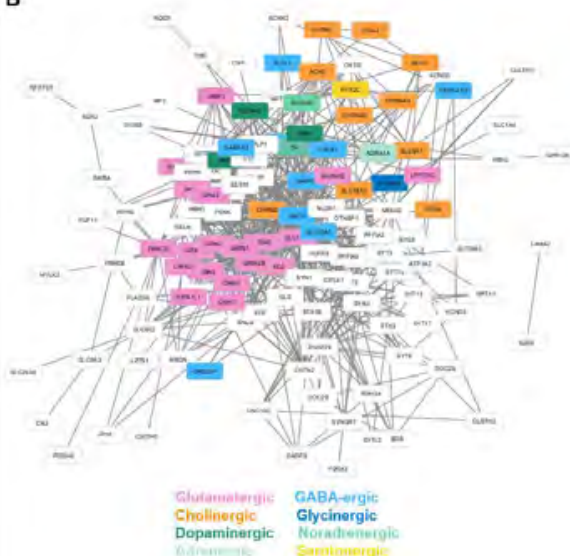

C FLXIC,
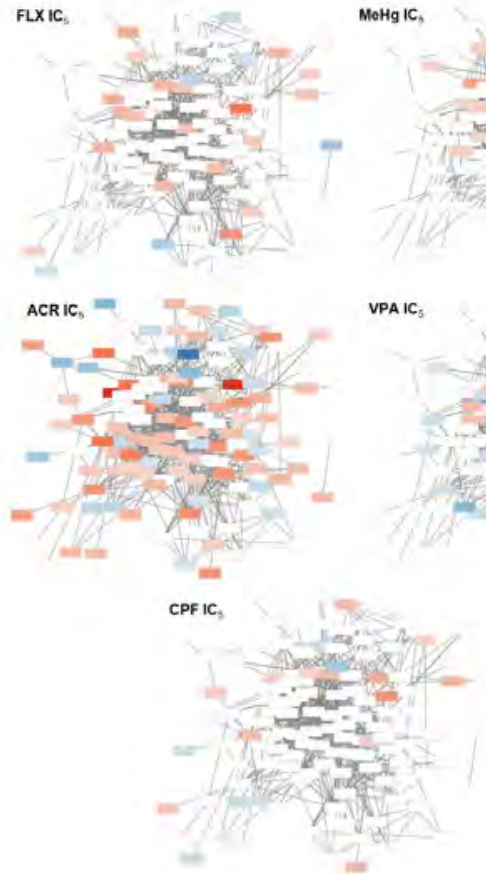

$\mathrm{MeHg}$ IC,

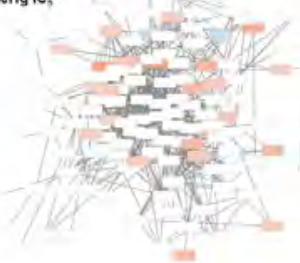

VPA IC,

Figure 6. Gene expression regulation patterns by compound exposures within the GO-term 'synaptic signalling'. (A) Venn diagram of four experimental conditions showing the overlap of genes in the GO-term. (B) Gene interaction network of 128 of the 138 genes in (A) that had a connection with each other in STRING, visualised in Cytoscape. Genes that were not connected are not shown in the image. Colours indicate neuron subtype specificity of genes. (C) Expression of genes in (A) projected on the network in (B), per compound, and CPF $1 C_{5}$ expression of 19 DEGS that were present among the 128 genes.

\section{Discussion}

The field of developmental neurotoxicity (DNT) needs fast, reliable in vitro models that truthfully resemble human neurodevelopmental processes. While there are already many cell models available representing earlier time windows in neurodevelopment, such as NPC proliferation, 
migration, and differentiation in various cell types (reviewed in $[23,44]$ ), models including markers for synaptogenesis and neurotransmission are currently sparse and still mainly based on rodent models [22]. hNPT is a 10-day protocol that has been shown to present functional electrical activity between neurons [25]. In the current study, we observed gene markers relevant for neuronal activity and showed that the expression of these genes was responsive to compound exposure. There are multiple promising human embryonic or induced pluripotent stem cell-based models that have recently been developed for the combined study of neurite outgrowth, synaptogenesis, and neurotransmission [24,45-51]. The advantage of hNPT over other currently available protocols is the short duration for these processes to occur. There is one protocol for 3D neurospheres that showed a similar development of key genes as hNPT [52]. While 3D cultures have the obvious advantage that they more reliably mimic the in vivo architecture, 2D cultures benefit from the ease of readout and by extension throughput possibilities. A potential reason why hNPT is developing fast may be due to the fact that the starting material of hNPT consists of both NPC and young neurons as shown by the immunostainings.

Transcriptomics represents a sensitive measure of molecular changes, by which effects may be detected at concentrations below those causing viability effects. In the present study, the concentration at which effects on neuronal development became apparent was just below those inducing serious cytotoxicity. This is in line with some studies in which molecular effects of compounds were apparent just below effects on cell viability were present $[53,54]$. Other studies, however, have shown robust transcriptomic effects already at concentrations considerably lower than those at which cytotoxicity occurred $[55,56]$. This may be due to the resilience of this specific cell culture the nature of the compounds, mainly early teratogens, that cause widespread differentiation changes as opposed to quite selective synaptic changes by most of these compounds.

RNA-seq analysis over time revealed regulation of expected processes such as neurite development (both dendrites and axons), synaptogenesis, neurotransmission, and apoptosis, a broad array of important neurodevelopmental processes as defined by many authors $[12,13,19,21,24,57]$. We did not observe gene expression changes related to neuron migration, which may suggest that the neurons rather grew within colonies of cells than that they migrated from these clusters. Glial differentiation-related GO-terms seemed to be regulated, but their responses fell above the FDR cut-off $(p=0.07)$ used in this study. This regulation may either have been statistically overwhelmed by other biological processes, or the process had not yet been initiated in full acceleration as may be suggested by the low numbers of astrocytes present in hNPT by day 10. This was also apparent in the compound exposure data, as only FLX elicited an effect on glial differentiation, while e.g. CPF had an increasing effect on the astrocyte-neuron ratio in two other human stem cell-based models $[58,59]$. Longer culturing may increase the strength of the astroglial differentiation GO-terms in hNPT.

Using the same framework as for neurodevelopmental processes over time, compounds showed a unique combination of affected GO-terms. Low compound concentrations affected either none (ACR, VPA) or mainly general cell function GO-terms (CPF, FLX, MeHg), while high compound concentrations elicited specific neuronal-related effects that could be related to existing literature. ACR is a peripheral neurotoxicant [60], which may explain the lack of effect in the low concentration of ACR on hNPT and other CNS models [61,62]. ACR IC , specifically affected genes relating to general neurogenesis and synaptic signalling, which is comparable to 
impaired synaptic function by ACR exposure in the CNS [63,64]. CPF only had a specific effect on a neurite outgrowth GO-term, an effect also found in other in vitro studies $[45,65,66]$. The DNT effects of FLX are still under debate [67], but this compound was previously shown to affect synaptic signalling in rodent in vitro and in vivo models [68-70], which was also the case in hNPT. MeHg is a classic neurotoxicant that affects neuron extension and glutamatergic neurotransmission $[61,71,72]$, in line with enriched GO-terms in hNPT. VPA is known for its widespread effects on differentiation, as was also apparent from the relatively large proportion of general development GO-terms affected, as well as neuronal-specific terms. These were mainly focussed around synaptic signalling in hNPT, which is in line with effects on the excitatory/inhibitory balance in rodents (reviewed in [73]). In short, hNPT mimicked some of the key effects of the tested DNT compounds in a dose dependent manner. This offers opportunities in hNPT to unravel physiological responses from adverse compound effects and to further explore the biological domain of the model.

Some of the expected effects of compounds were not detected in hNPT, which can mostly be traced back to the lack of the specific biological processes or cell types involved. For example, the effect of FLX on serotonergic markers, dopaminergic neuron differentiation, and suspected effects on oligodendrocytes [43,74-77] were not detected, probably due to the absence of these specific cell types. Similarly, CPF did not have expected effects on dopaminergic, serotonergic, and cholinergic neurotransmission $[78,79]$. MeHg is known to affect neuron migration in the developing cortex [80], but migration was not affected in hNPT, in line with its absence in this model. There were also a number of processes present in hNPT that were not disrupted by the tested compounds. For example, FLX decreases cortex thickness in rodents [81], which was not among the upregulated GO-terms in this study. Also, the effect of CPF on synapse formation found in similar in vitro models $[45,59]$ was not observed in hNPT.

Upon further investigation of a selection of common GO-terms among compounds, we found a set of common genes for axon development and neuron apoptosis, indicating conserved pathways. The genes involved in axon development encode a chemorepellant (SEMA3D), receptors for diverse chemoattractors or repellants (EPHA8, UNC5B), transcription factors and binding protein for motor axon outgrowth (CRABP2, ETV7, ETV4), a stabiliser of myelin ( $P L P 7)$ [82-84]. UNC5B is also involved in external apoptosis, as are DDIT3, CEBPB, BBC3, PMAIPT, $C L N 3$, and $P R K C G$ [85-87]. AARS7 is involved in tRNA synthesis [88]. These lists of genes may serve as a biomarker set for these specific processes or even as a general gene set for DNT detection. More compounds should be tested to confirm this. The genes involved in synaptic signalling, on the other hand, showed little overlap both in occurrence and direction of effect. This exemplifies the complexity of synaptic transmission as opposed to the other two processes [89] and may provide further mechanistic insight into how compounds may affect these processes.

Future efforts in hNPT may focus on characterisation of the model and benchmarking it against in vivo data [24] for which various tools are available $[90,91]$ to further define its biological domain. This is important in the light of studying the molecular basis of consequences of compound exposure on cognitive development, of which effects can be very time and region-dependent [10,92]. Furthermore, a quantitative readout on protein level, such as with flow cytometry, may enhance the interpretation of the consequences of transcriptomics findings from this 
study, and to investigate cell types specifically affected by compounds. Testing more compounds with diverse modes of action can also aid in mapping the boundaries and potential of hNPT to detect effects on various neurodevelopmental processes. Knowing its biological domain, hNPT may be a promising addition to the existing in vitro models to study compoundinduced DNT.

\section{Acknowledgements}

This research is funded by the Dutch NGO Stichting Proefdiervrij and the Dutch Ministry of Agriculture, Nature and Food Quality, and the Dutch Ministry of Health, Welfare and Sports. We would like to thank Harm Heusinkveld for a critical review of the manuscript.

\section{Supplementary material note}

Supplementary figure 1 and Supplementary Table 1 and 2 are presented in this thesis. Supplementary Table 3 and 4 are available as Excel documents upon request due to the size of the sheets. 


\section{References}

[1] P. Grandjean, P.J. Landrigan, Developmental neurotoxicity of industrial chemicals, Lancet. 368 (2006) 21672178. https://doi.org/10.1016/S0140-6736(06)69665-7.

[2] P. Grandjean, P.J. Landrigan, Neurobehavioural effects of developmental toxicity, Lancet Neurol. 13 (2014) 330-338. https://doi.org/10.1016/S1474-4422(13)70278-3.

[3] T. Schettler, Toxic threats to neurologic development of children., Environ. Health Perspect. 109 (2001) $813-$ 816. https://doi.org/10.1289/ehp.01109s6813.

[4] EPA, America's Children and the Environment, 2019.

[5] I. Hertz-Picciotto, L. Delwiche, The rise in autism and the role of age at diagnosis, Epidemiology. 20 (2009) 84-90. https://doi.org/10.1097/EDE.0b013e3181902d15.

[6] A. De Felice, L. Ricceri, A. Venerosi, F. Chiarotti, G. Calamandrei, Multifactorial origin of neurodevelopmental disorders: Approaches to understanding complex etiologies, Toxics. 3 (2015) 89-129. https://doi.org/10.3390/toxics3010089.

[7] J. Hallmayer, S. Cleveland, A. Torres, J. Phillips, B. Cohen, T. Torigoe, J. Miller, A. Fedele, J. Collins, K. Smith, L. Lotspeich, L.A. Croen, S. Ozonoff, C. Lajonchere, J.K. Grether, N. Risch, Genetic heritability and shared environmental factors among twin pairs with autism, Arch. Gen. Psychiatry. 68 (2011) 1095-1102. https://doi.org/10.1001/archgenpsychiatry.2011.76.

[8] A. Miodovnik, Prenatal Exposure to Industrial Chemicals and Pesticides and Effects on Neurodevelopment 2 , in: J.B.T.-E. of E.H. (Second E. Nriagu (Ed.), Encycl. Environ. Heal. (Second Ed., Elsevier, Oxford, 2019: pp. 342352. https://doi.org/https://doi.org/10.1016/B978-0-12-409548-9.11008-5.

[9] H.I. Zeliger, 20 - Autism: Effect of Maternal Exposure to Neurotoxic Chemicals, in: H.I.B.T.-H.T. of C.M. Zeliger (Ed.), Hum. Toxicol. Chem. Mix., William Andrew Publishing, Norwich, NY, 2008: pp. 335-349. https://doi.org/https://doi.org/10.1016/B978-081551589-0.50021-0.

[10] L.M. Carlson, F.A. Champagne, D.A. Cory-Slechta, L. Dishaw, E. Faustman, W. Mundy, D. Segal, C. Sobin, C. Starkey, M. Taylor, S.L. Makris, A. Kraft, Potential frameworks to support evaluation of mechanistic data for developmental neurotoxicity outcomes: A symposium report, Neurotoxicol. Teratol. 78 (2020) 106865. https://doi.org/10.1016/j.ntt.2020.106865.

[11] M. Paparella, S.H. Bennekou, A. Bal-Price, An analysis of the limitations and uncertainties of in vivo developmental neurotoxicity testing and assessment to identify the potential for alternative approaches, Reprod. Toxicol. 96 (2020) 327-336. https://doi.org/10.1016/j.reprotox.2020.08.002.

[12] D. Rice, S. Barone, Critical periods of vulnerability for the developing nervous system: Evidence from humans and animal models, Environ. Health Perspect. 108 (2000) 511-533. https://doi.org/10.2307/3454543.

[13] J.C. Silbereis, S. Pochareddy, Y. Zhu, M. Li, N. Sestan, The Cellular and Molecular Landscapes of the Developing Human Central Nervous System, Neuron. $89 \quad$ (2016) 248. https://doi.org/10.1016/j.neuron.2015.12.008.

[14] M. Cardoso-Moreira, J. Halbert, D. Valloton, B. Velten, C. Chen, Y. Shao, A. Liechti, K. Ascenção, C. Rummel, S. Ovchinnikova, P. V. Mazin, I. Xenarios, K. Harshman, M. Mort, D.N. Cooper, C. Sandi, M.J. Soares, P.G. Ferreira, S. Afonso, M. Carneiro, J.M.A. Turner, J.L. VandeBerg, A. Fallahshahroudi, P. Jensen, R. Behr, S. Lisgo, S. Lindsay, P. Khaitovich, W. Huber, J. Baker, S. Anders, Y.E. Zhang, H. Kaessmann, Gene expression across mammalian organ development, Nature. 571 (2019) 505-509. https://doi.org/10.1038/s41586-019-13385.

[15] R.J. Weaver, J.-P. Valentin, Today's Challenges to De-Risk and Predict Drug Safety in Human "Mind-theGap," Toxicol. Sci. 167 (2019) 307-321. https://doi.org/10.1093/toxsci/kfy270.

[16] S. Authier, J. Arezzo, M.S. Delatte, M.J. Kallman, C. Markgraf, D. Paquette, M.K. Pugsley, S. Ratcliffe, W.S. Redfern, J. Stevens, J.P. Valentin, H.M. Vargas, M.J. Curtis, Safety pharmacology investigations on the nervous system: An industry survey, J. Pharmacol. Toxicol. Methods. 81 (2016) 37-46. https://doi.org/10.1016/j.vascn.2016.06.001.

[17] L. Meigs, L. Smirnova, C. Rovida, M. Leist, T. Hartung, Animal testing and its alternatives - the most important omics is economics, ALTEX. 35 (2018) 275-305. https://doi.org/10.14573/altex.1807041.

[18] National Research Council, NRC, Toxicity testing in the 21 st century: a vision and a strategy, National Academies Press, 2007.

[19] E.V.S. Hessel, Y.C.M. Staal, A.H. Piersma, Design and validation of an ontology-driven animal-free testing strategy for developmental neurotoxicity testing, Toxicol. Appl. Pharmacol. 1 (2018) 136-152. https://doi.org/10.1016/j.taap.2018.03.013.

[20] E. Fritsche, K.M. Crofton, A.F. Hernandez, S.H. Bennekou, M. Leist, A. Bal-Price, E. Reaves, M.F. Wilks, A. Terron, R. Solecki, M. Sachana, A. Gourmelon, OECD/EFSA workshop on developmental neurotoxicity (DNT): The use of non-animal test methods for regulatory purposes, in: ALTEX, 2017: pp. 311-315. https://doi.org/10.14573/altex.1701171.

[21] A. Bal-Price, F. Pistollato, M. Sachana, S.K. Bopp, S. Munn, A. Worth, Strategies to improve the regulatory assessment of developmental neurotoxicity (DNT) using in vitro methods, Toxicol. Appl. Pharmacol. 354 (2018) 7-18. https://doi.org/10.1016/j.taap.2018.02.008. 
[22] M. Sachana, A. Bal-Price, K.M. Crofton, S.H. Bennekou, T.J. Shafer, M. Behl, A. Terron, International regulatory and scientific effort for improved developmental neurotoxicity testing, Toxicol. Sci. 167 (2019) 45-57. https://doi.org/10.1093/toxsci/kfy211.

[23] E. Fritsche, M. Barenys, J. Klose, S. Masjosthusmann, L. Nimtz, M. Schmuck, S. Wuttke, J. Tigges, Current availability of stem cell-based in vitro methods for Developmental Neurotoxicity (DNT) testing, Toxicol. Sci. 165 (2018) 21-30. https://doi.org/10.1093/toxsci/kfy178.

[24] S.H. Wegner, J.J. Park, T. Workman, S.A.B. Hermsen, J. Wallace, I.B. Stanaway, H.Y. Kim, W.C. Griffith, S. Hong, E.M. Faustman, Anchoring a dynamic in vitro model of human neuronal differentiation to key processes of early brain development in vivo, Reprod. Toxicol. $91 \quad$ (2020) 116-130. https://doi.org/10.1016/j.reprotox.2019.09.005.

[25] V.C. de Leeuw, C.T.M. van Oostrom, R.H.S. Westerink, A.H. Piersma, H.J. Heusinkveld, E.V.S. Hessel, An efficient neuron-astrocyte differentiation protocol from human embryonic stem cell-derived neural progenitors to assess chemical-induced developmental neurotoxicity, Reprod. Toxicol. (2020). https://doi.org/https://doi.org/10.1016/j.reprotox.2020.09.003.

[26] N. Gunhanlar, G. Shpak, M. van der Kroeg, L.A. Gouty-Colomer, S.T. Munshi, B. Lendemeijer, M. Ghazvini, C. Dupont, W.J.G. Hoogendijk, J. Gribnau, F.M.S. de Vrij, S.A. Kushner, A simplified protocol for differentiation of electrophysiologically mature neuronal networks from human induced pluripotent stem cells, Mol. Psychiatry. 23 (2018) 1336-1344. https://doi.org/10.1038/mp.2017.56.

[27] J. Schindelin, I. Arganda-Carreras, E. Frise, V. Kaynig, M. Longair, T. Pietzsch, S. Preibisch, C. Rueden, S. Saalfeld, B. Schmid, J.Y. Tinevez, D.J. White, V. Hartenstein, K. Eliceiri, P. Tomancak, A. Cardona, Fiji: An opensource platform for biological-image analysis, Nat. Methods. 9 (2012) 676-682. https://doi.org/10.1038/nmeth.2019.

[28] C. McQuin, A. Goodman, V. Chernyshev, L. Kamentsky, B.A. Cimini, K.W. Karhohs, M. Doan, L. Ding, S.M Rafelski, D. Thirstrup, W. Wiegraebe, S. Singh, T. Becker, J.C. Caicedo, A.E. Carpenter, CellProfiler 3.0: Nextgeneration image processing for biology, PLoS Biol. 16 (2018) e2005970https://doi.org/10.1371/journal.pbio.2005970.

[29] W. Slob, Dose-response modeling of continuous endpoints, Toxicol. Sci. 66 (2002) $298-312$. https://doi.org/10.1093/toxsci/66.2.298.

[30] R Core Team, R: A language and environment for statistical computing, (2020). https://www.r-project.org/.

[31] Applied Biosystems, User Bulletin \#2 ABI PRISM 7700 Sequence Detection System, (2001) 1-36. http://tools.thermofisher.com/content/sfs/manuals/cms_040980.pdf.

[32] P. Ewels, M. Magnusson, S. Lundin, M. Käller, MultiQC: Summarize analysis results for multiple tools and samples in a single report, Bioinformatics. 32 (2016) 3047-3048. https://doi.org/10.1093/bioinformatics/btw354.

[33] R. Patro, G. Duggal, M.I. Love, R.A. Irizarry, C. Kingsford, Salmon provides fast and bias-aware quantification of transcript expression, Nat. Methods. 14 (2017) 417-419. https://doi.org/10.1038/nmeth.4197.

[34] RStudio Team, RStudio: Integrated Development for R, (2020). http://www.rstudio.com/.

[35] C. Soneson, M.I. Love, M.D. Robinson, Differential analyses for RNA-seq: Transcript-level estimates improve gene-level inferences [version 2; referees: 2 approved], F1000Research. 4 (2016) 1521. https://doi.org/10.12688/F1000RESEARCH.7563.2.

[36] M.I. Love, W. Huber, S. Anders, Moderated estimation of fold change and dispersion for RNA-seq data with DESeq2, Genome Biol. 15 (2014) 550. https://doi.org/10.1186/s13059-014-0550-8.

[37] M. Stephens, False discovery rates: A new deal, Biostatistics. 18 (2017) 275-294 https://doi.org/10.1093/biostatistics/kxw041.

[38] D.W. Huang, B.T. Sherman, R.A. Lempicki, Systematic and integrative analysis of large gene lists using DAVID bioinformatics resources, Nat. Protoc. 4 (2009) 44-57. https://doi.org/10.1038/nprot.2008.211.

[39] D. Szklarczyk, A.L. Gable, D. Lyon, A. Junge, S. Wyder, J. Huerta-Cepas, M. Simonovic, N.T. Doncheva, J.H Morris, P. Bork, L.J. Jensen, C. Von Mering, STRING v1 1: Protein-protein association networks with increased coverage, supporting functional discovery in genome-wide experimental datasets, Nucleic Acids Res. 47 (2019) D607-D613. https://doi.org/10.1093/nar/gky1131.

[40] M. Kutmon, M.P. van lersel, A. Bohler, T. Kelder, N. Nunes, A.R. Pico, C.T. Evelo, PathVisio 3: An Extendable Pathway Analysis Toolbox, PLoS Comput. Biol. 11 (2015) e1004085. https://doi.org/10.1371/journal.pcbi.1004085.

[41] J.C. Oliveros, Venny. An interactive tool for comparing lists with Venn Diagrams., (2007) http://bioinfogp.cnnb.csic.es/tools/venny/index.ht. https://doi.org/10.1017/S0266267108002022.

[42] P. Shannon, A. Markiel, O. Ozier, N.S. Baliga, J.T. Wang, D. Ramage, N. Amin, B. Schwikowski, T. Ideker, Cytoscape: A software Environment for integrated models of biomolecular interaction networks, Genome Res. 13 (2003) 2498-2504. https://doi.org/10.1101/gr.1239303.

[43] V.C. de Leeuw, E.V.S. Hessel, J.L.A. Pennings, H.M. Hodemaekers, P.F.K. Wackers, C.T.M. van Oostrom, A.H. Piersma, Differential effects of fluoxetine and venlafaxine in the neural embryonic stem cell test (ESTn) revealed by a cell lineage map, Neurotoxicology. 76 (2020) 1-9. https://doi.org/10.1016/j.neuro.2019.09.014.

[44] A. Bal-Price, H.T. Hogberg, K.M. Crofton, M. Daneshian, R.E. Fitzgerald, E. Fritsche, T. Heinonen, S.H. Bennekou, S. Klima, A.H. Piersma, M. Sachana, T.J. Shafer, A. Terron, F. Monnet-Tschudi, B. Viviani, T. Waldmann, R.H.S. Westerink, M.F. Wilks, H. Witters, M.-G. Zurich, M. Leist, Workshop report recommendation 
on test readiness criteria for new approach methods in toxicology: exemplified for developmental neurotoxicity 1, ALTEX. 35 (2018) 306-352. https://doi.org/10.14573/altex.1712081.

[45] F. Pistollato, E.M. De Gyves, D. Carpi, S.K. Bopp, C. Nunes, A. Worth, A. Bal-Price, Assessment of developmental neurotoxicity induced by chemical mixtures using an adverse outcome pathway concept, Environ. Heal. A Glob. Access Sci. Source. 19 (2020) 23. https://doi.org/10.1186/s12940-020-00578-x.

[46] J. Kobolak, A. Teglasi, T. Bellak, Z. Janstova, K. Molnar, M. Zana, I. Bock, L. Laszlo, A. Dinnyes, Human Induced Pluripotent Stem Cell-Derived 3D-Neurospheres are Suitable for Neurotoxicity Screening, Cells. 9 (2020) 1122. https://doi.org/10.3390/cells9051122.

[47] L. Nimtz, J. Hartmann, J. Tigges, S. Masjosthusmann, M. Schmuck, E. Keßel, S. Theiss, K. Köhrer, P. Petzsch, J. Adjaye, C. Wigmann, D. Wieczorek, B. Hildebrandt, F. Bendt, U. Hübenthal, G. Brockerhoff, E. Fritsche, Characterization and application of electrically active neuronal networks established from human induced pluripotent stem cell-derived neural progenitor cells for neurotoxicity evaluation, Stem Cell Res. 45 (2020) e101761. https://doi.org/10.1016/j.scr.2020.101761.

[48] X. Zhong, G. Harris, L. Smirnova, V. Zufferey, R. de C. da S. e Sá, F. Baldino Russo, P.C. Baleeiro Beltrao Braga, M. Chesnut, M.-G. Zurich, H.T. Hogberg, T. Hartung, D. Pamies, Antidepressant Paroxetine Exerts Developmental Neurotoxicity in an iPSC-Derived 3D Human Brain Model, Front. Cell. Neurosci. 14 (2020). https://doi.org/10.3389/fncel.2020.00025.

[49] J. Baumann, K. Gassmann, S. Masjosthusmann, D. DeBoer, F. Bendt, S. Giersiefer, E. Fritsche, Comparative human and rat neurospheres reveal species differences in chemical effects on neurodevelopmental key events, Arch. Toxicol. 90 (2016) 1415-1427. https://doi.org/10.1007/s00204-015-1568-8.

[50] M. Barenys, K. Gassmann, C. Baksmeier, S. Heinz, I. Reverte, M. Schmuck, T. Temme, F. Bendt, T.C. Zschauer T.D. Rockel, K. Unfried, W. Watjen, S.M. Sundaram, H. Heuer, M.T. Colomina, E. Fritsche, Epigallocatechin gallate (EGCG) inhibits adhesion and migration of neural progenitor cells in vitro, Arch Toxicol. 91 (2016) 827837. https://doi.org/10.1007/s00204-016-1709-8.

[51] Q. Bu, Y. Huang, M. Li, Y. Dai, X. Fang, K. Chen, Q. Liu, A. Xue, K. Zhong, Y. Huang, H. Gao, X. Cen, Acrylamide exposure represses neuronal differentiation, induces cell apoptosis and promotes tau hyperphosphorylation in hESC-derived 3D cerebral organoids, Food Chem. Toxicol. 144 (2020) 111643. https://doi.org/10.1016/j.fct.2020.111643.

[52] J. Sandström, E. Eggermann, I. Charvet, A. Roux, N. Toni, C. Greggio, A. Broyer, F. Monnet-Tschudi, L. Stoppini, Development and characterization of a human embryonic stem cell-derived 3D neural tissue model for neurotoxicity testing, Toxicol. Vitr. 38 (2017) 124-135. https://doi.org/10.1016/j.tiv.2016.10.001.

[53] H. Chen, H. Seifikar, N. Larocque, Y. Kim, I. Khatib, C.J. Fernandez, N. Abello, J.F. Robinson, Using a MultiStage hESC Model to Characterize BDE-47 Toxicity during Neurogenesis, Toxicol. Sci. 171 (2019) 221-234. https://doi.org/10.1093/toxsci/kfz136.

[54] A.K. Krug, R. Kolde, J.A. Gaspar, E. Rempel, N. V. Balmer, K. Meganathan, K. Vojnits, M. Baquié, T. Waldmann, R. Ensenat-Waser, S. Jagtap, R.M. Evans, S. Julien, H. Peterson, D. Zagoura, S. Kadereit, D. Gerhard, I. Sotiriadou, M. Heke, K. Natarajan, M. Henry, J. Winkler, R. Marchan, L. Stoppini, S. Bosgra, J. Westerhout, M. Verwei, J. Vilo, A. Kortenkamp, J. Hescheler, L. Hothorn, S. Bremer, C. Van Thriel, K.H. Krause, J.G. Hengstler J. Rahnenführer, M. Leist, A. Sachinidis, Human embryonic stem cell-derived test systems for developmental neurotoxicity: a transcriptomics approach, Arch. Toxicol. $87 \quad$ (2013) 123-143. https://doi.org/10.1007/s00204-012-0967-3.

[55] T. Waldmann, E. Rempel, N. V. Balmer, A. König, R. Kolde, J.A. Gaspar, M. Henry, J. Hescheler, A. Sachinidis, J. Rahnenführer, J.G. Hengstler, M. Leist, Design principles of concentration-dependent transcriptome deviations in drug-exposed differentiating stem cells, Chem. Res. Toxicol. 27 (2014) 408-420. https://doi.org/10.1021/tx400402j.

[56] P.T. Theunissen, J.F. Robinson, J.L.A. Pennings, M.H. van Herwijnen, J.C.S. Kleinjans, A.H. Piersma Compound-specific effects of diverse neurodevelopmental toxicants on global gene expression in the neural embryonic stem cell test (ESTn), Toxicol. Appl. Pharmacol. 262 (2012) 330-340 https://doi.org/10.1016/j.taap.2012.05.011.

[57] M. Li, G. Santpere, Y.I. Kawasawa, O. V. Evgrafov, F.O. Gulden, S. Pochareddy, S.M. Sunkin, Z. Li, Y. Shin, Y. Zhu, A.M.M. Sousa, D.M. Werling, R.R. Kitchen, H.J. Kang, M. Pletikos, J. Choi, S. Muchnik, X. Xu, D. Wang, B. Lorente-Galdos, S. Liu, P. Giusti-Rodríguez, H. Won, C.A. De Leeuw, A.F. Pardiñas, M.A. Reimers, A.J. Willsey, A. Oldre, A. Szafer, A. Camarena, A. Cherskov, A.W. Charney, A. Abyzov, A. Kozlenkov, A. Safi, A.R. Jones, A. Ashley-Koch, A. Ebbert, A.J. Price, A. Sekijima, A. Kefi, A. Bernard, A. Amiri, A. Sboner, A. Clark, A.E. Jaffe, A.T.N Tebbenkamp, A.J. Sodt, A. Guillozet-Bongaarts, A.C. Nairn, A. Carey, A. Huttner, A. Chervenak, A. Szekely, A.W. Shieh, A. Harmanci, B.K. Lipska, B.C. Carlyle, B.W. Gregor, B.S. Kassim, B. Sheppard, C. Bichsel, C.G. Hahn, C.K. Lee, C. Chen, C.L. Kuan, C. Dang, C. Lau, C. Cuhaciyan, C. Armoskus, C.E. Mason, C. Liu, C.R. Slaughterbeck, C. Bennet, D. Pinto, D. Polioudakis, D. Franjic, D.J. Miller, D. Bertagnolli, D.A. Lewis, D. Feng, D. Sandman, D. Clarke, D. Williams, D. DelValle, D. Fitzgerald, E.H. Shen, E. Flatow, E. Zharovsky, E.E. Burke, E. Olson, E. Fulfs, E. Mattei, E. Hadjimichael, E. Deelman, F.C.P. Navarro, F. Wu, F. Lee, F. Cheng, F.S. Goes, F.M. Vaccarino, F. Liu, G.E. Hoffman, G. Gürsoy, G. Gee, G. Mehta, G. Coppola, G. Giase, G. Sedmak, G.D. Johnson, G.A. Wray, G.E. Crawford, G. Gu, H. van Bakel, H. Witt, H.J. Yoon, H. Pratt, H. Zhao, I.A. Glass, J. Huey, J. Arnold, J.P. Noonan, J. Bendl, J.M. Jochim, J. Goldy, J. Herstein, J.R. Wiseman, J.A. Miller, J. Mariani, J. Stoll, J. Moore, J. Szatkiewicz, J. Leng, J. Zhang, J. Parente, J. Rozowsky, J.F. Fullard, J.G. Hohmann, J. Morris, J.W. Phillips, 
J. Warrell, J.H. Shin, J.Y. An, J. Belmont, J. Nyhus, J. Pendergraft, J. Bryois, K. Roll, K.S. Grennan, K. Aiona, K.P. White, K.A. Aldinger, K.A. Smith, K. Girdhar, K. Brouner, L.M. Mangravite, L. Brown, L. Collado-Torres, L. Cheng, L. Gourley, L. Song, L.T. Ubieta, L. Habegger, L. Ng, M.E. Hauberg, M. Onorati, M.J. Webster, M. Kundakovic, M. Skarica, M.B. Johnson, M.M. Chen, M.E. Garrett, M. Sarreal, M. Reding, M. Gu, M.A. Peters, M. Fisher, M.J. Gandal, M. Purcaro, M. Smith, M. Brown, M. Shibata, M. Xu, M. Yang, M. Ray, N. V. Shapovalova, N. Francoeur, N. Sjoquist, N. Mastan, N. Kaur, N. Parikshak, N.F. Mosqueda, N.K. Ngo, N. Dee, N.A. Ivanov, O. Devillers, P. Roussos, P.D. Parker, P. Manser, P. Wohnoutka, P.J. Farnham, P. Zandi, P.S. Emani, R.A. Dalley, R. Mayani, R. Tao, R. Gittin, R.E. Straub, R.P. Lifton, R. Jacobov, R.E. Howard, R.B. Park, R. Dai, S. Abramowicz, S. Akbarian, S. Schreiner, S. Ma, S.E. Parry, S. Shapouri, S. Weissman, S. Caldejon, S. Mane, S.L. Ding, S. Scuderi, S. Dracheva, S. Butler, S.N. Lisgo, S.K. Rhie, S. Lindsay, S. Datta, T. Souaiaia, T. Roychowdhury, T. Gomez, T. Naluai-Cecchini, T. Beach, T. Goodman, T. Gao, T.A. Dolbeare, T. Fliss, T.E. Reddy, T. Chen, T. Brunetti, T.A. Lemon, T. Desta, T. Borrman, V. Haroutunian, V.N. Spitsyna, V. Swarup, X. Shi, Y. Jiang, Y. Xia, Y.H. Chen, Y. Wang, Y. Chae, Y. T. Yang, Y. Kim, Z.L. Riley, Z. Krsnik, Z. Deng, Z. Weng, Z. Lin, M. Hu, F. Jin, Y. Li, M.J. Owen, M.C. O'Donovan, J.T.R. Walters, D. Posthuma, P. Levitt, D.R. Weinberger, T.M. Hyde, J.E. Kleinman, D.H. Geschwind, M.J. Hawrylycz, M.W. State, S.J. Sanders, P.F. Sullivan, M.B. Gerstein, E.S. Lein, J.A. Knowles, N. Sestan, Integrative functional genomic analysis of human brain development and neuropsychiatric risks, Science (80-. ). 362 (2018). https://doi.org/10.1126/science.aat7615.

[58] E. Di Consiglio, F. Pistollato, E. Mendoza-De Gyves, A. Bal-Price, E. Testai, Integrating biokinetics and in vitro studies to evaluate developmental neurotoxicity induced by chlorpyrifos in human iPSC-derived neural stem cells undergoing differentiation towards neuronal and glial cells, Reprod. Toxicol. (2020). https://doi.org/10.1016/j.reprotox.2020.09.010.

[59] L. Sandoval, A. Rosca, A. Oniga, A. Zambrano, J.J. Ramos, M.C. González, I. Liste, M. Motas, Effects of chlorpyrifos on cell death and cellular phenotypic specification of human neural stem cells, Sci. Total Environ. 683 (2019) 445-454. https://doi.org/10.1016/j.scitotenv.2019.05.270.

[60] R.M. LoPachin, C.D. Balaban, J.F. Ross, Acrylamide axonopathy revisited, Toxicol. Appl. Pharmacol. 188 (2003) 135-153. https://doi.org/10.1016/S0041-008X(02)00072-8.

[61] K.R. Ryan, O. Sirenko, F. Parham, J.H. Hsieh, E.F. Cromwell, R.R. Tice, M. Behl, Neurite outgrowth in human induced pluripotent stem cell-derived neurons as a high-throughput screen for developmental neurotoxicity or neurotoxicity, Neurotoxicology. 53 (2016) 271-281. https://doi.org/10.1016/j.neuro.2016.02.003.

[62] L. Hoelting, S. Klima, C. Karreman, M. Grinberg, J. Meisig, M. Henry, T. Rotshteyn, J. Rahnenführer, N. Blüthgen, A. Sachinidis, T. Waldmann, M. Leist, Stem Cell-Derived Immature Human Dorsal Root Ganglia Neurons to Identify Peripheral Neurotoxicants, Stem Cells Transl. Med. 5 (2016) 476-487. https://doi.org/10.5966/sctm.2015-0108.

[63] D.S. Barber, S. Stevens, R.M. LoPachin, Proteomic analysis of rat striatal synaptosomes during acrylamide intoxication at a low dose rate, Toxicol. Sci. 100 (2007) 156-167. https://doi.org/10.1093/toxsci/kfm210.

[64] R.M. LoPachin, T. Gavin, Molecular mechanism of acrylamide neurotoxicity: Lessons learned from organic chemistry, Environ. Health Perspect. 120 (2012) 1650-1657. https://doi.org/10.1289/ehp.1205432.

[65] X. Wu, X.K. Yang, A. Majumder, R. Swetenburg, F.T. Goodfellow, M.G. Bartlett, S.L. Stice, Astrocytes Are Protective Against Chlorpyrifos Developmental Neurotoxicity in Human Pluripotent Stem Cell-Derived Astrocyte-Neuron Cocultures, Toxicol. Sci. 157 (2017) 410-420. https://doi.org/10.1093/toxsci/kfx056.

[66] D. Qiao, F.J. Seidler, T.A. Slotkin, Developmental neurotoxicity of chlorpyrifos modeled in vitro: Comparative effects of metabolites and other cholinesterase inhibitors on DNA synthesis in PC12 and C6 cells, Environ. Health Perspect. 109 (2001) 909-913. https://doi.org/10.1289/ehp.01109909.

[67] D.M. Campagne, Antidepressant use in pregnancy: are we closer to consensus?, Arch. Womens. Ment. Health. 22 (2019) 189-197. https://doi.org/10.1007/s00737-018-0906-2.

[68] C.L. Frank, J.P. Brown, K. Wallace, W.R. Mundy, T.J. Shafer, Developmental neurotoxicants disrupt activity in cortical networks on microelectrode arrays: Results of screening 86 compounds during neural network formation, Toxicol. Sci. 160 (2017) 121-135. https://doi.org/10.1093/toxsci/kfx169.

[69] C.M. Mack, B.J. Lin, J.D. Turner, A.F.M. Johnstone, L.D. Burgoon, T.J. Shafer, Burst and principal components analyses of MEA data for 16 chemicals describe at least three effects classes, Neurotoxicology. 40 (2014) 75-85. https://doi.org/10.1016/j.neuro.2013.11.008.

[70] H.-K. Chang, K.H. Kim, K.-W. Kang, Y.-J. Kang, T.-W. Kim, H.-K. Park, S.-E. Kim, C.-J. Kim, Antidepressants modulate glycine action in rat hippocampus, J. Exerc. Rehabil. 11 (2015) 311-319. https://doi.org/10.12965/jer.150263.

[71] M. Farina, J.B.T. Rocha, M. Aschner, Mechanisms of methylmercury-induced neurotoxicity: Evidence from experimental studies, in: Life Sci., Elsevier Inc., 2011: pp. 555-563. https://doi.org/10.1016/j.Ifs.2011.05.019.

[72] M. Fujimura, F. Usuki, Methylmercury causes neuronal cell death through the suppression of the TrkA pathway: In vitro and in vivo effects of TrkA pathway activators, Toxicol. Appl. Pharmacol. 282 (2015) 259266. https://doi.org/10.1016/j.taap.2014.12.008.

[73] A.M. Tartaglione, S. Schiavi, G. Calamandrei, V. Trezza, Prenatal valproate in rodents as a tool to understand the neural underpinnings of social dysfunctions in autism spectrum disorder, Neuropharmacology. 159 (2019). https://doi.org/10.1016/j.neuropharm.2018.12.024. 
[74] R.W. Sommi, M.L. Crismon, C.L. Bowden, Fluoxetine: A Serotonin-specific, Second-generation Antidepressant, Pharmacother. J. Hum. Pharmacol. Drug Ther. 7 (1987) 1-14. https://doi.org/10.1002/j.1875-9114.1987.tb03496.x.

[75] S.C. Jha, S. Meltzer-Brody, R.J. Steiner, E. Cornea, S. Woolson, M. Ahn, A.R. Verde, R.M. Hamer, H. Zhu, M. Styner, J.H. Gilmore, R.C. Knickmeyer, Antenatal depression, treatment with selective serotonin reuptake inhibitors, and neonatal brain structure: A propensity-matched cohort study, Psychiatry Res. - Neuroimaging. 253 (2016) 43-53. https://doi.org/10.1016/j.pscychresns.2016.05.004.

[76] Y. Kroeze, D. Peeters, F. Boulle, D.L.A. van den Hove, H. van Bokhoven, H. Zhou, J.R. Homberg, Long-term consequences of chronic fluoxetine exposure on the expression of myelination-related genes in the rat hippocampus (Translational Psychiatry, (2016), 5, e642, 10.1038/tp.2015.145), Transl. Psychiatry. 6 (2016) 642. https://doi.org/10.1038/tp.2016.60.

[77] D. Lupu, M.K. Varshney, D. Mucs, J. Inzunza, U. Norinder, F. Loghin, I. Nalvarte, J. Rüegg, Fluoxetine affects differentiation of midbrain dopaminergic neurons in vitro, Mol. Pharmacol. 94 (2018) 1220-1231. https://doi.org/10.1124/mol.118.112342.

[78] S.W. Todd, E.W. Lumsden, Y. Aracava, J. Mamczarz, E.X. Albuquerque, E.F.R. Pereira, Gestational exposures to organophosphorus insecticides: From acute poisoning to developmental neurotoxicity, Neuropharmacology. 180 (2020) 108271. https://doi.org/10.1016/j.neuropharm.2020.108271.

[79] T.A. Slotkin, J. Card, F.J. Seidler, Chlorpyrifos developmental neurotoxicity: Interaction with glucocorticoids in PC12 cells, Neurotoxicol. Teratol. 34 (2012) 505-512. https://doi.org/10.1016/j.ntt.2012.07.002.

[80] A. Antunes dos Santos, M. Appel Hort, M. Culbreth, C. López-Granero, M. Farina, J.B.T. Rocha, M. Aschner Methylmercury and brain development: A review of recent literature, J. Trace Elem. Med. Biol. 38 (2016) 99107. https://doi.org/10.1016/j.jtemb.2016.03.001.

[81] C.A.S. Swerts, A.M.D.D. Costa, A. Esteves, C.E.S. Borato, M.S.O. Swerts, Effects of fluoxetine and imipramine in rat fetuses treated during a critical gestational period: A macro and microscopic study, Rev. Bras. Psiquiatr. 32 (2010) 152-158. https://doi.org/10.1590/S1516-44462009005000015.

[82] H.J. Diehl, M. Schaich, R.M. Budzinski, W. Stoffel, Individual exons encode the integral membrane domains of human myelin proteolipid protein, Proc. Natl. Acad. Sci. U. S. A. 83 (1986) 9807-9811. https://doi.org/10.1073/pnas.83.24.9807.

[83] G.J. Bashaw, R. Klein, Signaling from axon guidance receptors., Cold Spring Harb. Perspect. Biol. 2 (2010) a001941. https://doi.org/10.1101/cshperspect.a001941.

[84] A.Y. Han, S. Gupta, B.G. Novitch, Molecular specification of facial branchial motor neurons in vertebrates, Dev. Biol. 436 (2018) 5-13. https://doi.org/10.1016/j.ydbio.2018.01.019.

[85] K. Thiébault, L. Mazelin, L. Pays, F. Llambi, M.O. Joly, J.Y. Scoazec, J.C. Saurin, G. Romeo, P. Mehlen, The netrin-1 receptors UNC5H are putative tumor suppressors controlling cell death commitment, Proc. Natl. Acad. Sci. U. S. A. 100 (2003) 4173-4178. https://doi.org/10.1073/pnas.0738063100.

[86] Y. Yang, L. Liu, I. Naik, Z. Braunstein, J. Zhong, B. Ren, Transcription factor C/EBP homologous protein in health and diseases, Front. Immunol. 8 (2017) 1612. https://doi.org/10.3389/fimmu.2017.01612.

[87] D.A.N.W. Persaud-Sawin, A. Vandongen, R.M.N. Boustany, Motifs within the CLN3 protein: Modulation of cell growth rates and apoptosis, Hum. Mol. Genet. $11 \quad$ (2002) 2129-2142. https://doi.org/10.1093/hmg/11.18.2129.

[88] K. Shiba, T. Ripmaster, N. Suzuki, R. Nichols, P. Plotz, T. Noda, P. Schimmel, Human Alanyl-tRNA Synthetase: Conservation in Evolution of Catalytic Core and Microhelix Recognition, Biochemistry. 34 (1995) 1034010349. https://doi.org/10.1021/bi00033a004.

[89] S.G.N. Grant, Synapse diversity and synaptome architecture in human genetic disorders, Hum. Mol. Genet. 28 (2019) R219-R225. https://doi.org/10.1093/hmg/ddz178.

[90] J.L. Stein, L. de la Torre-Ubieta, Y. Tian, N.N. Parikshak, I.A. Hernández, M.C. Marchetto, D.K. Baker, D. Lu, C.R. Hinman, J.K. Lowe, E.M. Wexler, A.R. Muotri, F.H. Gage, K.S. Kosik, D.H. Geschwind, A quantitative framework to evaluate modeling of cortical development by neural stem cells, Neuron. 83 (2014) 69-86. https://doi.org/10.1016/j.neuron.2014.05.035.

[91] J. van de Leemput, N.C. Boles, T.R. Kiehl, B. Corneo, P. Lederman, V. Menon, C. Lee, R.A. Martinez, B.P. Levi, C.L. Thompson, S. Yao, A. Kaykas, S. Temple, C.A. Fasano, CORTECON: A temporal transcriptome analysis of in vitro human cerebral cortex development from human embryonic stem cells, Neuron. 83 (2014) 51-68. https://doi.org/10.1016/j.neuron.2014.05.013.

[92] S. Prem, J.H. Millonig, E. DiCicco-Bloom, Dysregulation of Neurite Outgrowth and Cell Migration in Autism and Other Neurodevelopmental Disorders, Adv. Neurobiol. 25 (2020) 109-153. https://doi.org/10.1007/9783-030-45493-7_5. 


\section{Supplementary material}

A

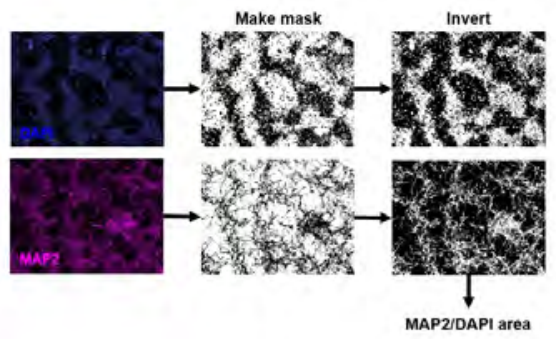

C

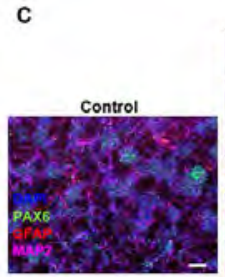

CPF
B
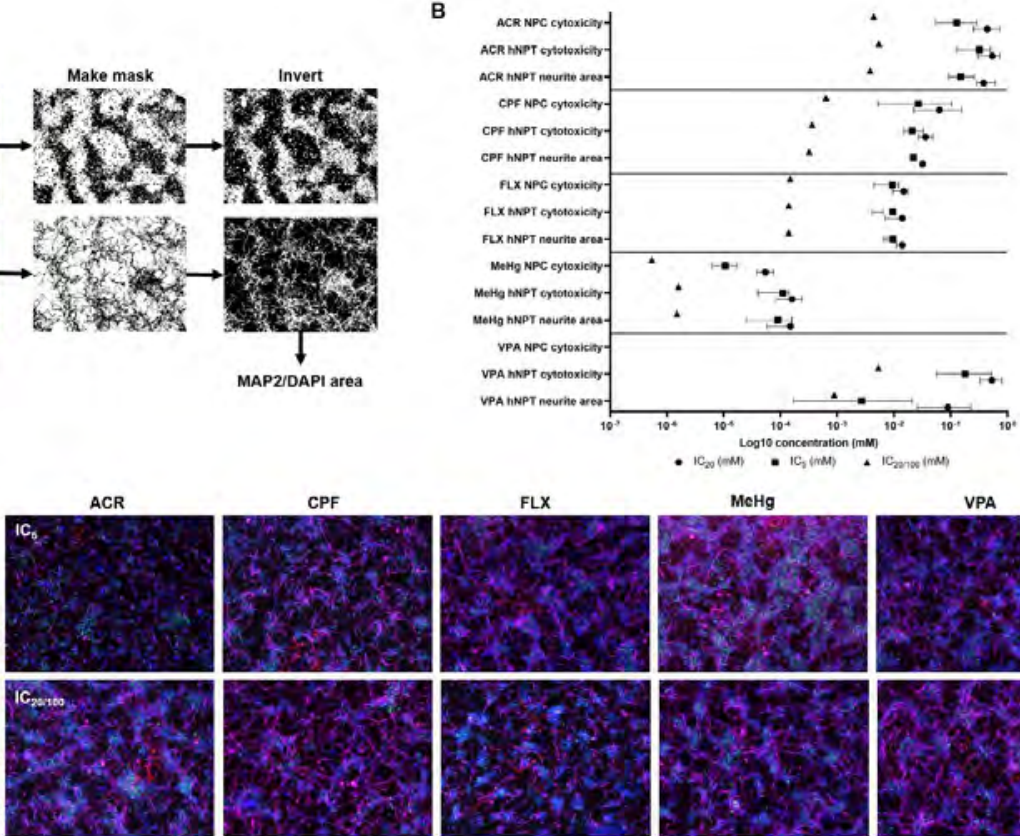

$\mathrm{MeHg}$

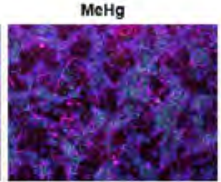

VPA
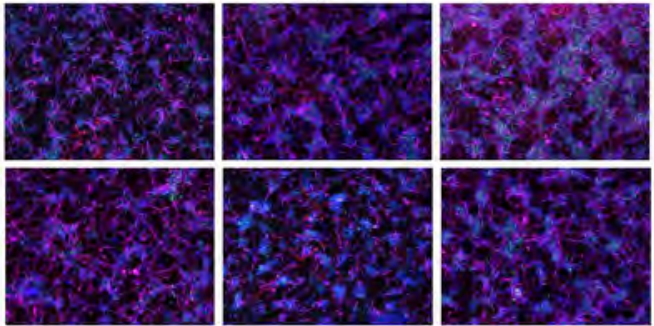
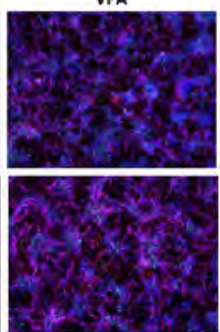

Supplementary Figure 1. Compound effects on NPCs and hNPT. (A) Graphical flow of CellProfiler image processing pipeline for calculating neurite area. (B) Summary of toxicity outcomes for all compounds. Error bars represent $95 \%$ confidence interval. (C) Protein expression of cell-type markers for NPCS (PAX6), neurons (MAP2), and astrocytes (GFAP) in experimental conditions used for RNA-seq. Scale bar: $100 \mu \mathrm{m}$. 
Supplementary Table 7. Methodological information for RNA-seq. All software uses standard settings, unless mentioned otherwise.

\begin{tabular}{|c|c|c|}
\hline \multirow[t]{8}{*}{ data generation } & sequencer & Illumina NextSeq 500 \\
\hline & control software & version 2.2.0.4 \\
\hline & service software & version 2.2.0.2 \\
\hline & FPGA firmware & version 3.16 \\
\hline & protocol & $\begin{array}{l}\text { TruSeq Stranded mRNA protocol (Illumina, San Diego, CA, } \\
\text { USA) }\end{array}$ \\
\hline & kit & High Output Kit version 2.5 \\
\hline & reading & single-end \\
\hline & number of cycles & $\# 75$ \\
\hline \multirow[t]{3}{*}{$\begin{array}{l}\text { data prepro- } \\
\text { cessing }\end{array}$} & $\begin{array}{l}\text { base calling software } \\
\text { (RTA) }\end{array}$ & version 2.4.11.0 \\
\hline & run copy service & version 1.0.14 \\
\hline & bcl2fastq2 & version: 2.20 .0 .422 \\
\hline \multirow[t]{3}{*}{ qc } & fastqc & version 0.11 .8 \\
\hline & multiqc & version 1.0 \\
\hline & $\mathrm{R}$ & version 4.0 .0 \\
\hline \multirow[t]{3}{*}{ quantification } & Salmon & version 1.3 .0 \\
\hline & & parameters: --validateMappings --gcBias --fldMean \\
\hline & & $\begin{array}{l}\text { reference: Human transcriptome (GRCh38), version 30, En- } \\
\text { sembl } 96\end{array}$ \\
\hline \multirow[t]{13}{*}{ analysis } & Rstudio & version 1.3 .959 \\
\hline & (R)tximport & version 1.16 .1 \\
\hline & & parameters: tx2gene \\
\hline & $(\mathrm{R}) \mathrm{DESeq} 2$ & version 1.30 .0 \\
\hline & & parameters: IfcShrink, ashr \\
\hline & & for compound comparisons: nbinomWaldTest maxit $=1000$ \\
\hline & (R)org.Hs.eg.db & version 3.11 .4 \\
\hline & (R)GenomicFeatures & version 1.40 .1 \\
\hline & (R)geneplotter & version 1.66 .0 \\
\hline & (R)limma & version 3.44 .3 \\
\hline & (R)rgl & version 0.100 .54 \\
\hline & DAVID & version 6.8, consulted on 8 November 2020 \\
\hline & STRING & version 11.0, consulted on 15 November 2020 \\
\hline \multirow[t]{7}{*}{ visualisation } & Rstudio & version 1.3 .959 \\
\hline & (R)RColorBrewer & version 1.1-2 \\
\hline & (R)gplots & version 3.1 .0 \\
\hline & (R)dnamr & version 1.1 \\
\hline & Pathvisio & version 3.3.0 \\
\hline & Venny & version 2.1.0 \\
\hline & Cytoscape & version 3.7.4 \\
\hline
\end{tabular}




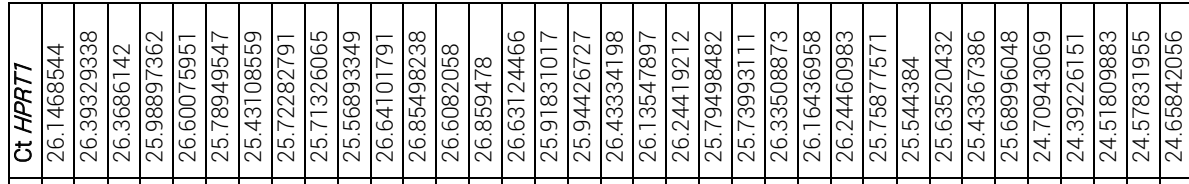

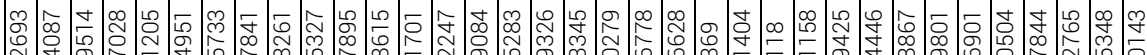

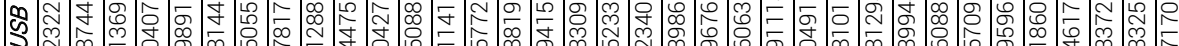

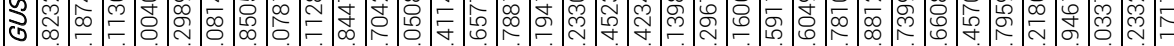

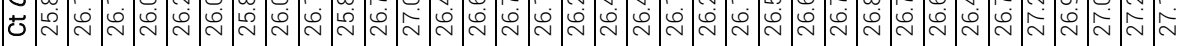

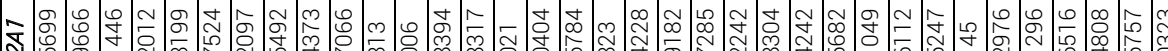

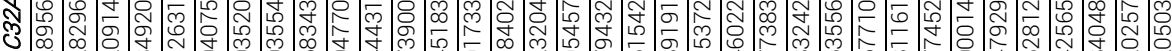

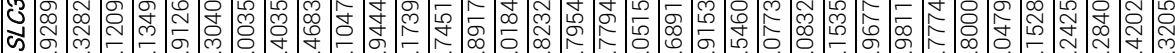

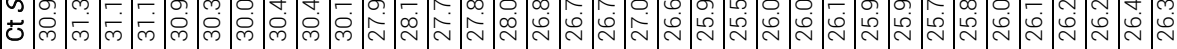

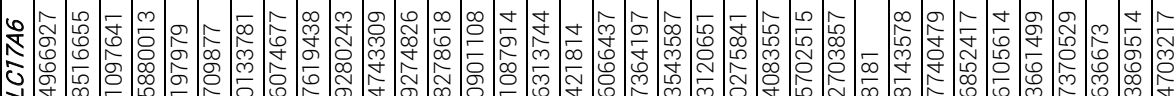
w

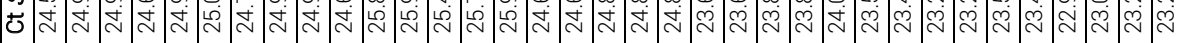

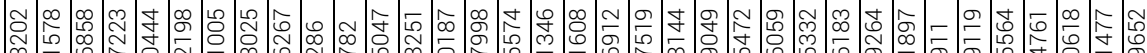

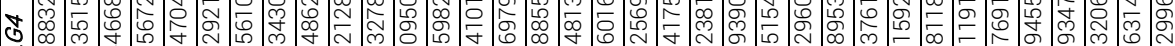
a

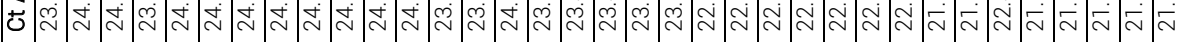

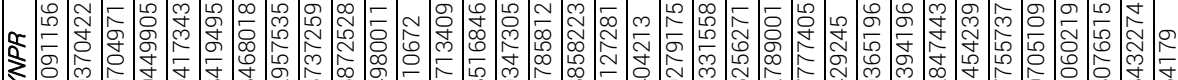

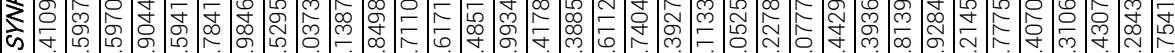

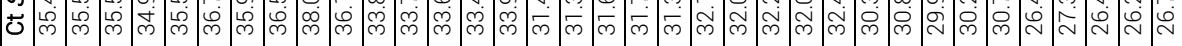

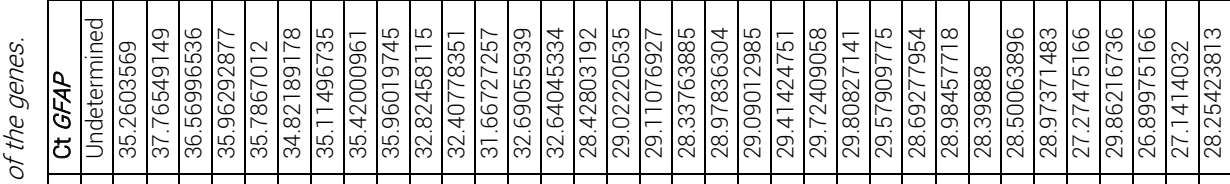

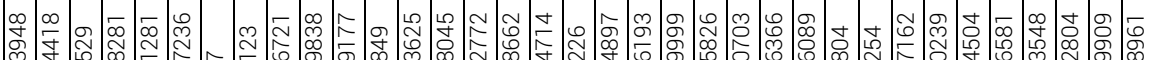

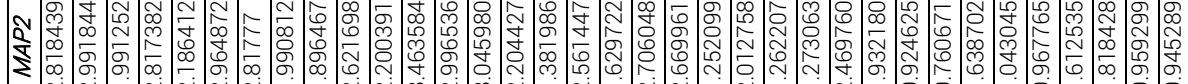

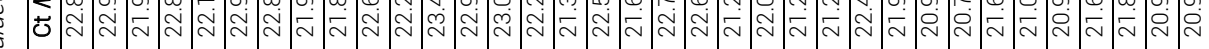
x

U

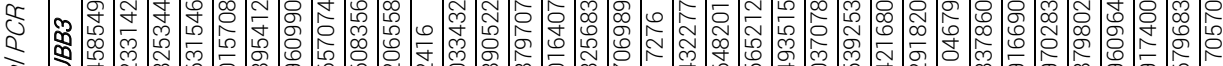

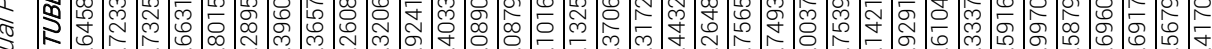

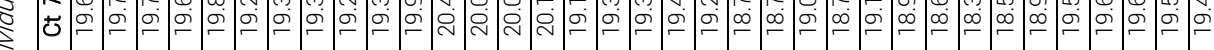

ङे

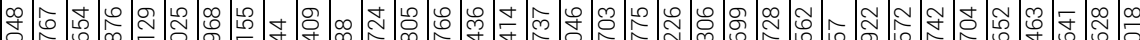

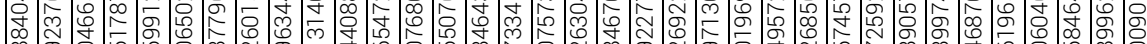

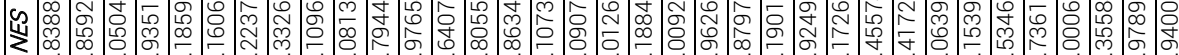

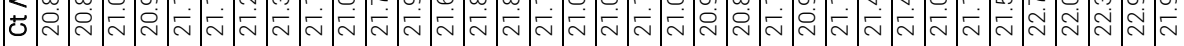

$\frac{0}{\infty}$

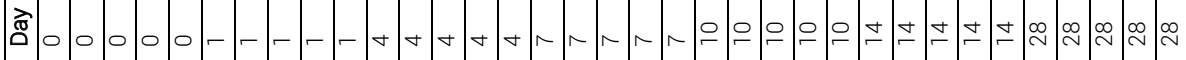

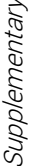

$\stackrel{\dot{9}}{9}$

$\frac{\mathrm{d}}{\stackrel{\circ}{े}}$

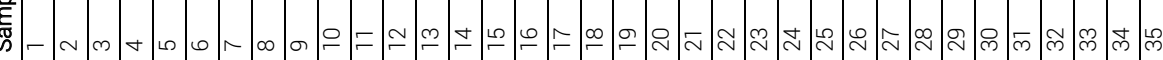




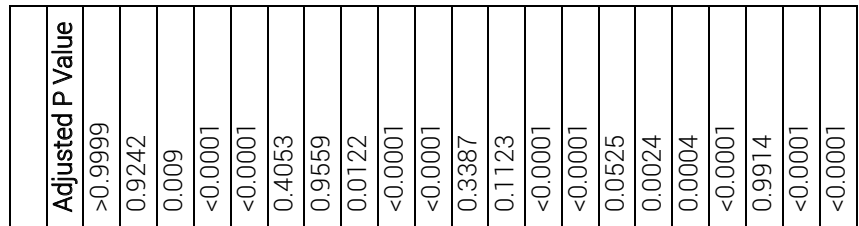

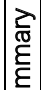

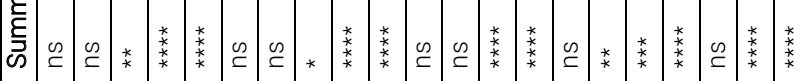

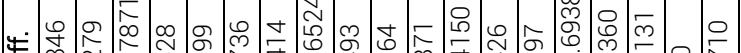
售等 ¿ u 0 今̊:

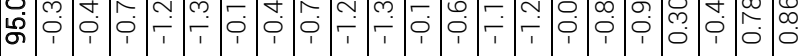

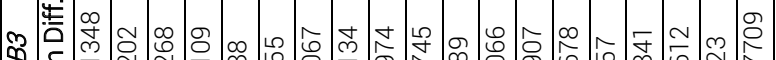

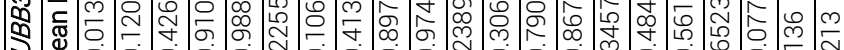

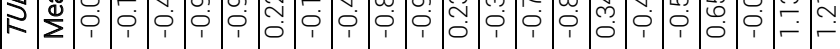

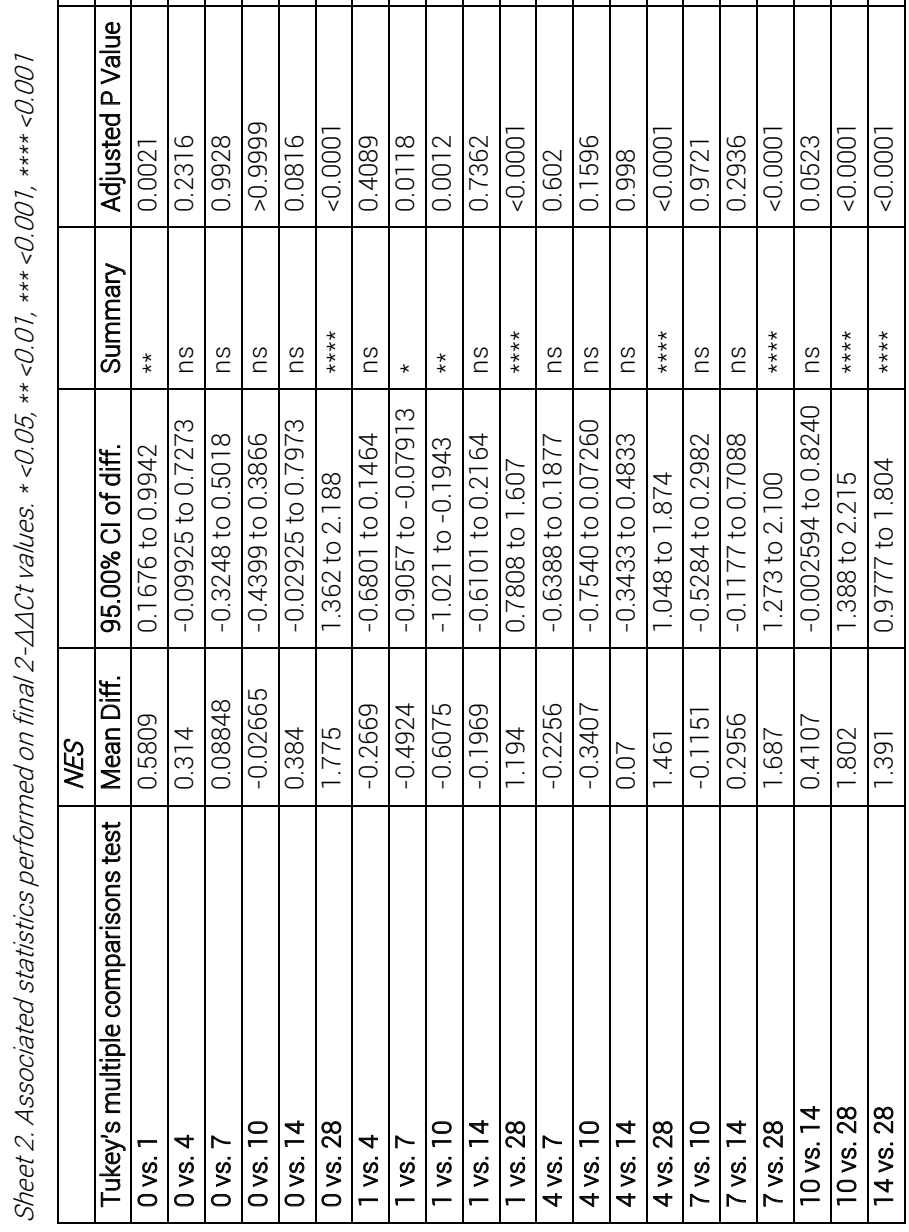

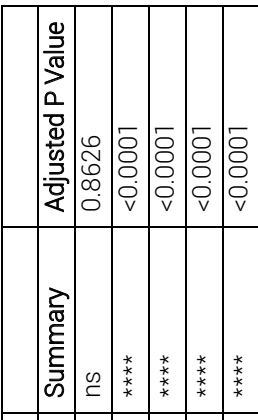

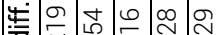

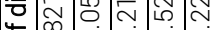

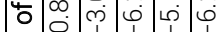

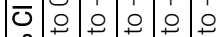

ஜ̊̊. டி

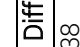

a $c$ m $\sim$

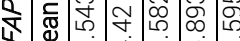

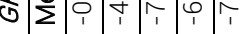

$\frac{\mathrm{g}}{\mathrm{m}}$

a

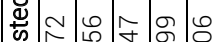

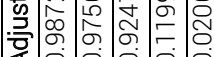

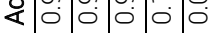

胥

ติ

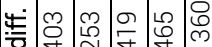

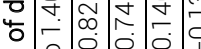

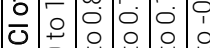

足

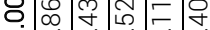

מूl

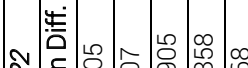

న

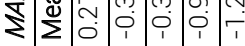

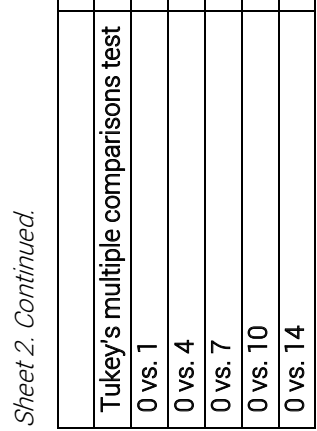




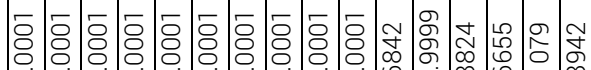

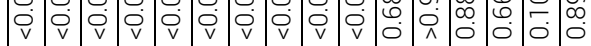

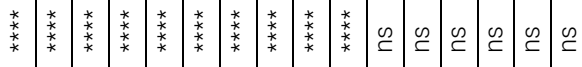
の

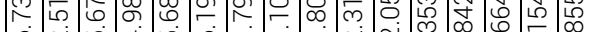
ம

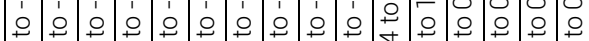

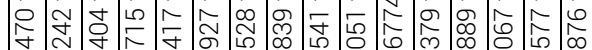

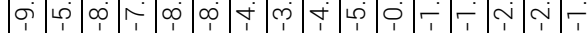

$\therefore$ م

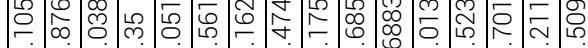

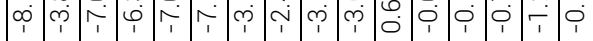

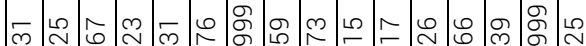

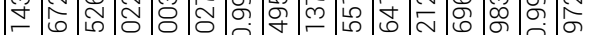

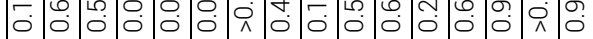

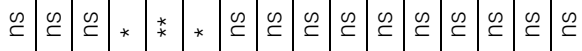

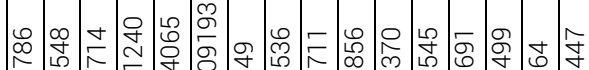

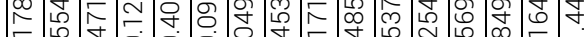

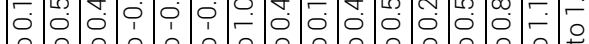

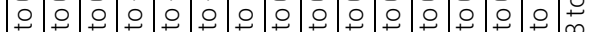
○

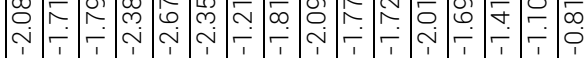

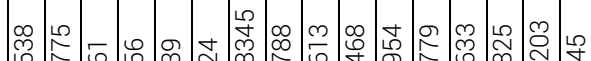

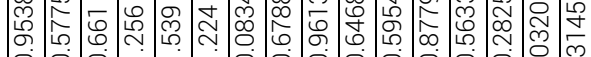

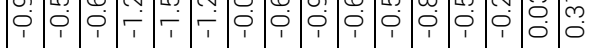

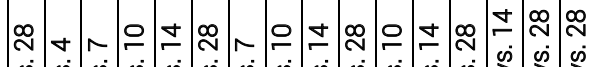

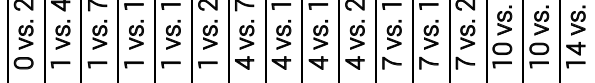

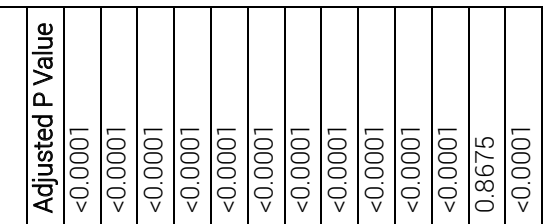

?

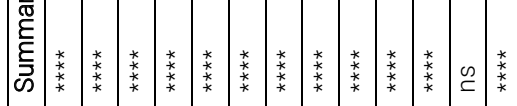

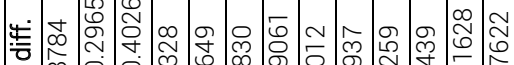

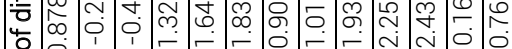

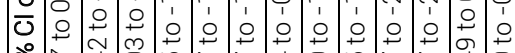

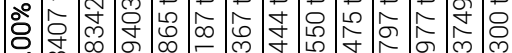

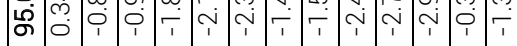

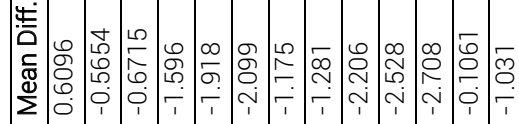

$\frac{\stackrel{0}{5}}{>}$

$>$

ষ্்

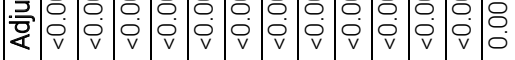

$\frac{7}{\overparen{\pi}}$

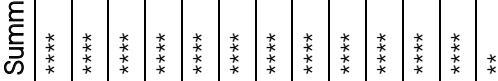

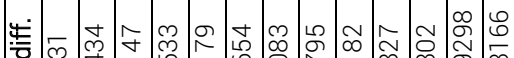

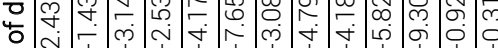

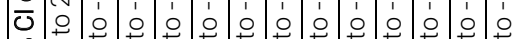
ठ̊̊. Lी

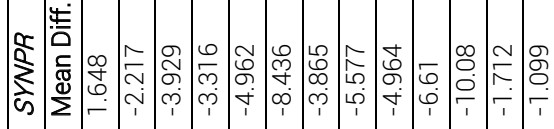

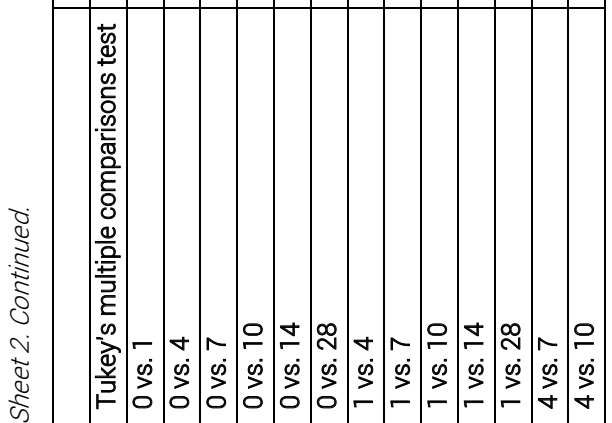




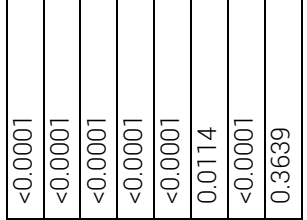

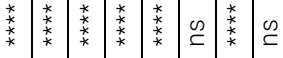

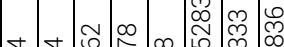

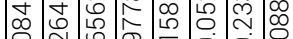

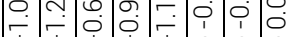

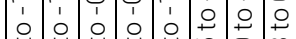
ㄴ. तิ $\left.\begin{array}{c}0 \\ 0\end{array}\right)$

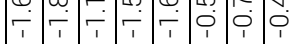

๓ூm

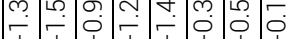

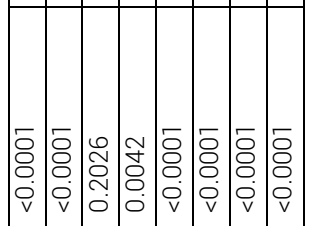

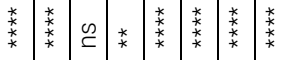

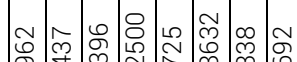

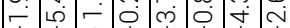

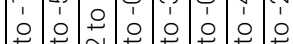
స กิ

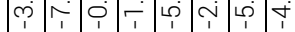

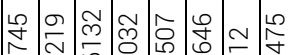

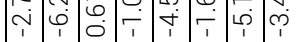

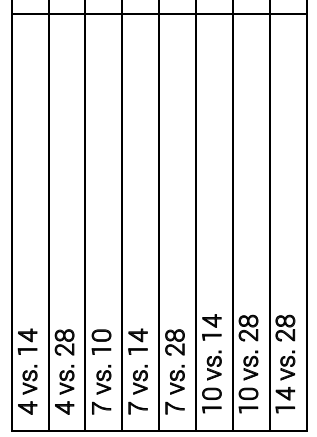

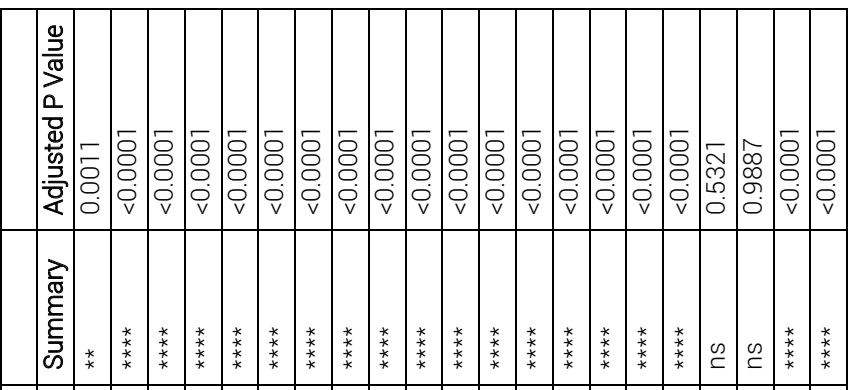

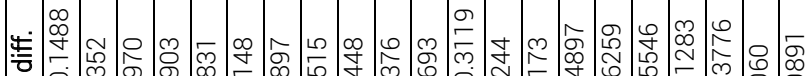

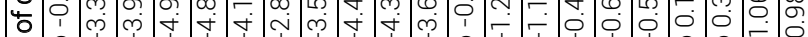

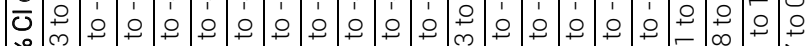

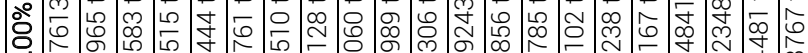

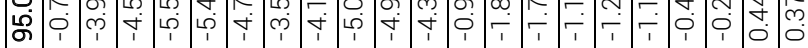

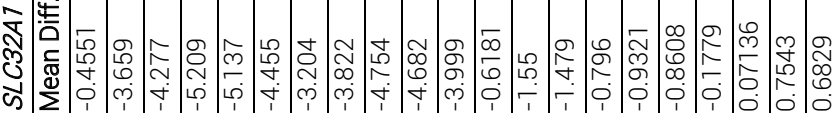

$\frac{\mathrm{g}}{\mathrm{T}}$

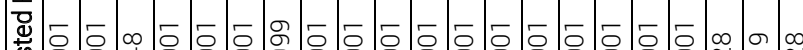
焉

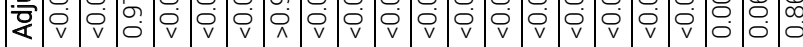

ฉ্

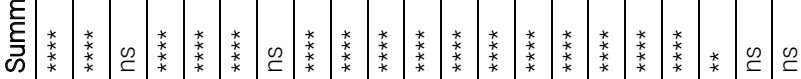

-

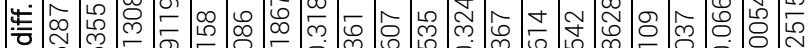

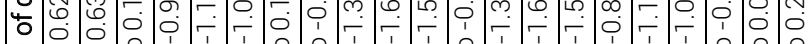

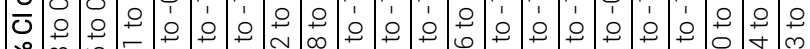

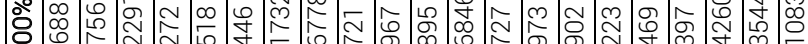

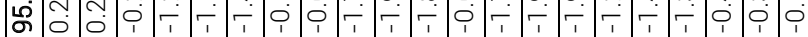

交焦

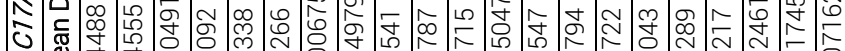

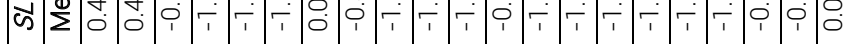

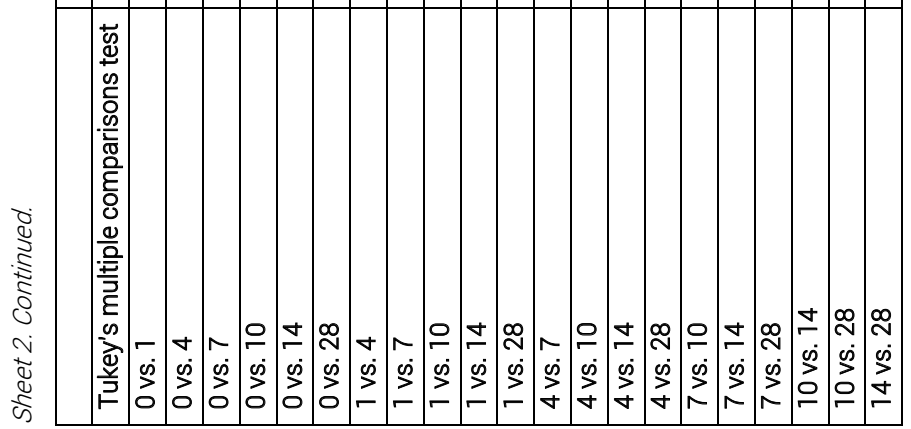





\section{CHAPTER 9}

GOING BACK AND FORTH: EPISOMAL VECTOR REPROGRAMMING OF PERIPHERAL BLOOD MONONUCLEAR CELLS TO INDUCED PLURIPOTENT STEM CELLS AND SUBSEQUUENT DIFFERENTIATION INTO CARDIOMYOCYTES AND NEURON-ASTROCYTE

CO-CULTURES

Victoria C. de Leeuw ${ }^{1,2}$, Conny T.M. van Oostrom ${ }^{1}$, Sandra Imholz' ${ }^{1}$, Aldert H. Piersma $^{1,2}$, Ellen V.S. Hessel ${ }^{1}$, Martijn E.T. Dollé ${ }^{1}$

${ }^{1}$ Centre for Health Protection, National Institute for Public Health and the Environment, Bilthoven, the Netherlands

${ }^{2}$ Institute for Risk Assessment Sciences, Utrecht University, Utrecht, the Netherlands

Cellular Reprogramming, 2020 Oct, 20(6): 300-310

DOI: $10.1089 /$ cell.2020.0040 



\begin{abstract}
Human induced pluripotent stem cells (iPSCs) can capture the diversity in the general human population as well as providing deeper insight in cellular mechanisms. This makes them suitable to study both fundamental and applied research subjects, such as disease modelling, gene-environment interactions, personalised medicine and chemical toxicity. In an independent laboratory, we were able to generate iPSCs originating from human peripheral blood mononuclear cells according to a modified version of a temporal episomal vector-based induction method. The iPSCs could subsequently be differentiated into two different lineages: mesoderm-derived cardiomyocytes and ectoderm-derived neuron-astrocyte co-cultures. It was shown that the neuron-astrocyte culture developed a mature phenotype within the course of five weeks and depending on the medium composition, network formation and neuron-astrocyte cell ratios could be modified. Whereas previously it has been described that iPSCs generated with this episomal vector based induction protocol could differentiate to mesenchymal stem cells, hepatocytes, cardiomyocytes and basic neuronal cultures, we now demonstrate differentiation into a culture containing both neurons and astrocytes.
\end{abstract}




\section{Introduction}

Since the demonstration by Yamanaka and colleagues $[1,2]$ that mouse and human fibroblasts could be induced into pluripotent stem cells, the application of this technique in human cells holds great promise for many applications for both clinical and research purposes. Generating induced pluripotent stem cells (iPSCs) from patients opens up possibilities for regenerative and personalised medicine, while making iPSCs from a range of people can provide insights into more fundamental questions around gene-environment interactions in cohorts, disease modelling, and screening tissue responses to chemicals, medicinal products, and implants.

While skin fibroblasts are a much-used source of cells, CD34+ peripheral blood mononuclear cells (PBMCs) as starting material are becoming more popular. Contrary to skin fibroblasts, PBMCs do not suffer from somatic mutations caused by UV [3], can be obtained in a noninvasive manner, are a suitable resource for large quantities of cells $[4,5]$, and are typically more readily available in established longitudinal cohort studies than skin fibroblasts.

There are numerous ways to reprogram PBMCs into iPSCs, of which the oriP/EBNA 7-based episomal vectors (EVs) $[6,7]$ to carry the Yamanaka factors appear to be the most suitable one. EVs facilitate an integration-free and transient transfection strategy, thereby avoiding disruptive mutations in the endogenous genome and allowing reversion to the same genetic content of the pre-transfected primary cell [7]. In addition, EVs are relatively cheap compared to other integration-free methods such as the Sendai virus [7]. The transfection needs to be performed only once, upon which the EVs are introduced by nucleofection, but will gradually be phased out upon cell division [8].

Su et al., $[9,10]$ have optimised the protocol to reprogram PBMCs into iPSCs by using four oriP/EBNA 7-based EV plasmids (pEVs) with a spleen focus-forming virus (SFFV) promotor carrying OCT4-SOX2, KLF4, MYC, and BCL-XL factors, and have also shown that the iPSCs obtained with this method were capable to differentiate into cardiomyocytes, hepatocytes, and mesenchymal stem cells [9].

In this study, we succeeded in reprogramming PBMCs into iPSCs by using this EV-based nucleofection method [10]. To demonstrate their pluripotent nature, these iPSCs could subsequently be differentiated into cells of different embryonic germ layers. We generated mesodermal cardiac cells, as has been shown before in literature, and as a novel addition differentiated into ectodermal neuron-astrocyte co-cultures based on our protocol that was developed for the differentiation of human embryonic stem cells (hESC; [11]). To our knowledge, this is the first study to show neuron-astrocyte differentiation using the reprogramming method of Su et al.

\section{Material and methods}

All ingredients were bought at Gibco (Waltham, MA) unless mentioned otherwise. 


\section{Isolation and reprogramming of PBMCs to iPSCs}

Buffy coat white blood cells were obtained from anonymous donors supplied by Sanquin blood bank (Amsterdam, The Netherlands) under a not-for-transfusion research agreement (NVT0243.02). Isolation and reprogramming of the PBMCs were performed as described previously by Su et al. $[9,10]$ with some adjustments. Briefly, buffy coat was mixed 1:1 with phosphate-buffered saline (PBS) after which Lymphoprep ${ }^{\text {TM }}$ (instead of Ficoll; Axis-shield, Dundee, UK) was pipetted on the bottom of the tube underneath the PB/PBS mix. The liquid layers were centrifuged for 30 minutes at $1000 \mathrm{~g}$ (instead of $400 \mathrm{~g}$ ) with slow acceleration and no brake. Of the resulting gradient, the PBMC layer was harvested, dissolved in PBS, and centrifuged for 8 minutes at $250 \mathrm{~g}$ (instead 10 minutes at $400 \mathrm{~g}$ ).

After removal of the supernatant, cells were dissolved in Red Blood Cell lysis buffer (containing 2.5 times less ethylenediaminetetraacetic acid) and centrifuged for 5 minutes at $400 \mathrm{~g}$. Cells were washed two times with PBS and resuspended in erythroid culture medium (ECM), counted, and optionally cryopreserved before mononuclear cell (MNC) culturing. PBMCs were cultured for 7 days at a density of $5 \times 10^{6} \mathrm{cells} / \mathrm{mL}$, changing the medium every $2-3$ days.

Cryopreservation was carried out by taking up MNCs in fetal calf serum at a density of 16-24 $\times \cdot 10^{6}$ cells $/ \mathrm{mL}$, aliquoting the cell suspension per $0.5 \mathrm{~mL}$, and putting them on ice. Approximately $0.5 \mathrm{~mL}$ ice-cold freezing medium ( $80 \%$ fetal calf serum $/ 20 \%$ dimethyl sulfoxide) was added dropwise to each aliquot and mixture was resuspended well before transferring the cells to freezing tubes for storage at $-135^{\circ} \mathrm{C}$.

One day before nucleofection, $2.6 \times 10^{5}$ cells $/ \mathrm{mL}$ mitomycin-inactivated murine embryonic fibroblast feeder cells (MEFs; instead of rat fibroblasts) were seeded on $0.1 \%$ gelatin (SigmaAldrich, Saint Louis, MO)-coated 6-well plates in Feeder Cell Culture Medium. On the day of nucleofection, medium was replaced with ECM. EVs were prepared in the following concentrations [12]: $2 \mu \mathrm{g}$ pEV SFFV-OCT4-E2A-SOX2 (pEV-OS); $1 \mu \mathrm{g}$ pEV SFFV-MYC (pEV-M); $1 \mu \mathrm{g}$ pEV SFFV- KLF4 (pEV-K); and $0.5 \mu \mathrm{g}$ pEV SFFV-BCL-XL (pEV-B) (ABMgood, Richmond, Canada). Around $2 \times 10^{6}$ PBMCs were nucleofected with indicated plasmids and cultured at a density of $1 \times 10^{5}$ to $1 \times 10^{6}$ cells in a humidified chamber $\left(37^{\circ} \mathrm{C}, 5 \% \mathrm{O}_{2}\right.$, and $5 \% \mathrm{CO}_{2}$; instead of a hypoxia chamber). After two days, ECM was replaced for iPSC generation medium and from day 6 , sodium butyrate was added to the medium. Refreshments took place every other day and new MEFs were added every five days.

Colonies were picked on day 21 and expanded in Essential 8 Flex medium according to Gibco's Essential 8 Flex protocol on feeder-free Vitronectin (VTN-N)-coated dishes (instead of in iPSC medium on rat fibroblasts as indicated in the original protocol) in a humidified chamber (passage $1,37^{\circ} \mathrm{C}, 5 \% \mathrm{O}_{2}$, and $5 \% \mathrm{CO}_{2}$ ). Medium changes were done every day and passaging was performed every three to four days. Cryopreservation was performed according to the PSC Cryopreservation kit from Gibco. For differentiation experiments, stem cells with passage 25-34 were used.

\section{Determination of plasmid copy numbers}

DNA extracts were made of PBMCs with EVs, without EVs, and with iPSCs from passage 1 and 5 to 13 as described previously [10]. Briefly, for quantification of the EV copy number, a standard 
curve was made by mixing $1 \mu \mathrm{g}$ DNA of PBMCs with $1.6 \mathrm{pg}$ pEV-OS, which was equivalent to 1 vector copy number per cell, and diluted four orders of magnitude. WHP Posttranscriptional Response Element (WPRE) and Epstein-Barr nuclear antigen (EBNA) were used to track residual DNA and were normalised against Beta-actin (ACTB; Table 1). Corresponding Ct-values from the samples were matched with the copy numbers of the standard curve for both genes.

Table 1. Overview Primers Used for Quantitative Polymerase Chain Reaction of Episomal Vector Plasmid

\begin{tabular}{ll}
\hline Gene name & Probe order no. (Applied Biosystems) or sequence \\
\hline WPRE & F: GGCTTTCATTTTCTCCTCCTTGTA \\
& R: CGGGCCACAACTCCTCATAA \\
EBNA & F: CAGCCCCTTCCACCATAGGT \\
R: TGCAGCTTTGACGATGGAGTA \\
HSO3023880_g 1
\end{tabular}

\section{Karyotyping}

A Giemsa staining was performed to karyotype the iPSC culture. Briefly, medium of confluent iPSCs was replaced with medium containing $20 \mu \mathrm{L} / \mathrm{mL}$ KaryoMAX Colcemid solution and incubated for 1.5 hours in the incubator. Cells were then dissociated using TripLE Select for 7 minutes and centrifuged for 5 minutes at $1000 \mathrm{rpm}$. Cells were carefully resuspended in $1 \mathrm{~mL}$ $0.075 \mathrm{M}$ prewarmed $\mathrm{KCl}, 2 \mathrm{~mL}$ extra $\mathrm{KCl}$ was added, and cells were incubated for 10 minutes in the incubator. Three drops of fixative (1:3 acetic acid: methanol) were added and suspension was centrifuged for 5 minutes at 1000 rpm. Cells were washed twice and resuspended in 2030 drops fixative.

The suspension was dropped onto cold, moist microscope slides and left to dry completely. Giemsa staining (SigmaAldrich) was applied onto the slides for 5 minutes, washed in deionised water and imaged on a Leica DMi8 microscope system (Leica, Wetzlar, Germany) using the appropriate Leica Software (LAS X).

\section{Cardiac differentiation of iPSCs}

Differentiation into the cardiac lineage was performed according to the PSC Cardiomyocyte Differentiation Kit protocol from Gibco. Briefly, single-cell iPSCs were seeded on Geltrex ${ }^{\mathrm{TM}}$ matrix-coated plates at a density of $20-40 \times 10^{4}$ cells $/ \mathrm{mL}$ in Essential 8 Flex medium. Medium was refreshed every day for four days, after which the medium was replaced by cardiomyocyte differentiation medium A. On day 6 of differentiation, the medium was replaced by cardiomyocyte differentiation medium B. Two days later, the medium was changed for cardiomyocyte maintenance medium. This medium was refreshed every other day until the end of the test on day 14 . 


\section{Neuronal differentiation of iPSCs}

For neuron-astrocyte differentiation, a protocol previously described in de Leeuw et al. [11] was used. The procedure consisted of four stages: embryoid body (EB) generation, rosette formation, neural progenitor cell (NPC) expansion, and neuron-astrocyte generation.

The first three steps were performed according to a Stemcell neuronal induction protocol (document no. 28782; Stemcell Technologies, Inc., Vancouver, Canada). Briefly, iPSCs were seeded in an AggreWell ${ }^{\mathrm{T}} 80024$-well plate at a density of $3 \times 10^{6} \mathrm{cell} / \mathrm{s} / \mathrm{mL}$ in STEMdiff Neural Induction Medium+SMADi (Stemcell) supplemented with Y-27632 ROCK inhibitor (Stemcell). Partial replacements of the medium were performed every day until day 5 , after which the EBs that had formed were washed off and transferred to Poly-L-Ornithine (PLO, $10 \mu \mathrm{g} / \mathrm{mL}$; Sigma-Aldrich)/laminin (10 $\mathrm{gg} / \mathrm{mL}$; SigmaAldrich)-coated dishes in STEMdiff Neuronal Induction Medium (NI)+SMADi (Stemcell) for rosette formation.

After a week with daily medium refreshments, the rosettes were dissociated with Neural rosette Selection Reagent (Stemcell) and transferred to new PLO/laminin dishes for another week, changing the medium every day. On day 19, rosettes were dissociated again and left to grow on new PLO/laminin dishes until confluent, refreshing the medium every day. After about a week, cells were dissociated with StemPro ${ }^{\text {TM }}$ Accutase Cell Dissociation Reagent and seeded at a density of 1.2-1.5 $\times 10^{6}$ cells $/ \mathrm{mL}$ in STEMdiff Neural progenitor medium (NP) (Stemcell) on PLO-/laminin-coated dishes. These NPCs (passage 1) were passaged every week and medium was refreshed on a daily basis. Cells were frozen after one to five passages in STEMdiff Neural progenitor Freezing Medium (Stemcell) according to the Stemcell protocol until use for differentiation.

Neuron-astrocyte generation was done using four different protocols to optimise culture conditions: medium described as by Pistollato et al. [13] without and with the addition of $10 \mathrm{ng} / \mathrm{mL}$ ciliary neurotrophic factor (CNTF) (hereafter called P- and P+, respectively), and as by Gunhanlar et al. [14] without and with CNTF (G- and G+). Medium from Pistollato et al. [13] was composed of neurobasal medium with 1\% N2 supplement, 2\% B-27 supplement, 1\% 5000 $\mathrm{IU} / \mathrm{mL}$ Penicillin $/ 5000 \mu \mathrm{g} / \mathrm{mL}$ Streptomycin, $1 \mathrm{ng} / \mathrm{mL}$ glial cell line-derived neurotrophic factor (GDNF), and $2.5 \mathrm{ng} / \mathrm{mL}$ brain-derived neurotrophic factor (BDNF). Medium from Gunhanlar et al. [14] comprised neurobasal medium, 1\% N2 supplement, 2\% B-27-retinoic acid supplement, $1 \% 5000 \mathrm{IU} / \mathrm{mL}$ Penicillin/5000 $\mathrm{kg} / \mathrm{mL}$ Streptomycin, $1 \%$ nonessential amino acids, $20 \mathrm{ng} / \mathrm{mL}$ GDNF, 20 ng/mL BDNF, 1 MM di-butyryl cyclic adenosine monophosphate (Sigma-Aldrich), 200 $\mu \mathrm{M}$ ascorbic acid (Sigma-Aldrich), and $2 \mu \mathrm{g} / \mathrm{mL}$ laminin (Sigma-Aldrich). NPCs were seeded $2.56 \times 10^{5}$ cells/cm2 on PLO/laminin-coated on 8- well plate (Ibidi, Gräfelfing, Germany). Medium replacements took place every two to three days.

\section{Immunocytochemistry}

iPSC and neuronal differentiation cultures were stained as previously described by de Leeuw et al. [15]. Cardiac differentiation cultures were stained using the Human Cardiomyocyte Immunocytochemistry Kit from Gibco. Primary and secondary antibodies used are listed in Table 2. Samples were imaged on a Leica DMi8 microscope system (Leica) using the appropriate Leica Software (LAS X). Image processing was performed in ImageJ (version 1.51n; [16]). 


\section{RNA isolation and quantitative polymerase chain reaction}

Medium was aspirated from the samples and cells (iPSCs/neurons day $14 n=4$, NPCs $n=3$, neurons day $7 / 21 / 28 n=5$ ) were directly fixed in QIAzol (Qiagen, Hilden, Germany). Samples were stored until further processing at $-80^{\circ} \mathrm{C}$. Whole RNA isolation was performed using the RNeasy ${ }^{\circledR}$ mini kit with a DNase digestion step according to the manufacturer's protocol (Qiagen, version October 2019). RNA concentration and quality were determined with the

Table 2. Primary and Secondary Antibodies

\begin{tabular}{|c|c|c|c|c|c|}
\hline Antibody & $\begin{array}{l}\text { Abbrevia- } \\
\text { tion }\end{array}$ & Marker for & $\begin{array}{l}\text { Product } \\
\text { number }\end{array}$ & Company & $\begin{array}{l}\text { Dilu- } \\
\text { tion }\end{array}$ \\
\hline $\begin{array}{l}\text { Mouse anti-Stage Specific } \\
\text { Embryonic Antigen-4 }\end{array}$ & SSEA4 & Stem cell & MAB4304 & Millipore & $1: 250$ \\
\hline Rat anti-E-cadherin & ECAD & $\begin{array}{l}\text { Adhesion molecule pre- } \\
\text { sent before neuronal } \\
\text { tube closure }\end{array}$ & 13-1900 & Invitrogen & $1: 1000$ \\
\hline $\begin{array}{l}\text { Rabbit anti Human homeo- } \\
\text { box protein NKX2-5 }\end{array}$ & NKX2-5 & $\begin{array}{l}\text { Myocardial differentia- } \\
\text { tion }\end{array}$ & A25974 & Thermo Fisher & $1: 1000$ \\
\hline $\begin{array}{l}\text { Mouse anti-Human car- } \\
\text { diac muscle Troponin T }\end{array}$ & TNNT2 & Cardiac cell & A25969 & Thermo Fisher & $1: 1000$ \\
\hline $\begin{array}{l}\text { Rabbit anti-Paired homeo- } \\
\text { box } 6\end{array}$ & PAX6 & Neural progenitor & 901301 & Biolegend & $1: 1000$ \\
\hline Rabbit anti-Nestin & NES & Neural progenitor & N5431 & Sigma Aldrich & $1: 200$ \\
\hline $\begin{array}{l}\text { Mouse anti-Zonula oc- } \\
\text { cludens-1 }\end{array}$ & ZO-1 & $\begin{array}{l}\text { Tight junction protein } \\
\text { typical in neuronal in- } \\
\text { duction }\end{array}$ & $33-9100$ & Thermo Fisher & $1: 1000$ \\
\hline Rabbit anti- $\beta$-Tubulin III & TUBB3 & Neuron & T2200 & Sigma-Aldrich & $1: 1000$ \\
\hline $\begin{array}{l}\text { Rabbit anti-Neuronal nu- } \\
\text { clei }\end{array}$ & NeuN & Mature neuron & ab177487 & Abcam & $1: 2000$ \\
\hline $\begin{array}{l}\text { Mouse anti-Microtubule- } \\
\text { associated protein } 2\end{array}$ & MAP2 & $\begin{array}{l}\text { Neuron, dendrite-spe- } \\
\text { cific }\end{array}$ & 801801 & Biolegend & $1: 2000$ \\
\hline Guinea pig anti-Tau & TAU & Neuron, axon specific & 314004 & $\begin{array}{l}\text { Synaptic Sys- } \\
\text { tems }\end{array}$ & $1: 1000$ \\
\hline $\begin{array}{l}\text { Rat anti-Glial fibrillary } \\
\text { acidic protein }\end{array}$ & GFAP & Early astrocyte & $13-0300$ & Invitrogen & $1: 800$ \\
\hline $\begin{array}{l}\text { Mouse anti-Postsynaptic } \\
\text { density } 95\end{array}$ & PSD95 & Post-synapse & MAB1598 & Merck & $1: 500$ \\
\hline Rabbit anti-Synaptoporin & SYNPR & Pre-synapse & 102002 & $\begin{array}{l}\text { Synaptic Sys- } \\
\text { tems }\end{array}$ & $1: 500$ \\
\hline Goat anti rabbit Alexa 488 & & & A11034 & Invitrogen & $1: 1000$ \\
\hline $\begin{array}{l}\text { Goat anti guinea pig Alexa } \\
488\end{array}$ & & & A11073 & Invitrogen & $1: 1000$ \\
\hline $\begin{array}{l}\text { Donkey anti Mouse Alexa } \\
488\end{array}$ & & & A25972 & Invitrogen & $1: 250$ \\
\hline Goat anti rabbit Alexa 555 & & & A21429 & Invitrogen & $1: 500$ \\
\hline Goat anti mouse Alexa 555 & & & A21424 & Invitrogen & $1: 1000$ \\
\hline Goat anti rat Alexa 555 & & & A21434 & Invitrogen & $1: 200$ \\
\hline $\begin{array}{l}\text { Donkey anti Rabbit Alexa } \\
555\end{array}$ & & & A25971 & Invitrogen & $1: 250$ \\
\hline Goat anti mouse Alexa 647 & & & A21236 & Invitrogen & $1: 500$ \\
\hline
\end{tabular}


NanoDrop ${ }^{\mathrm{TM}} 1000$ spectrophotometer (Nanodrop Technologies, Wilmington, DE) and the 2100 Bioanalyzer (Agilent Technologies, Amstelveen, The Netherlands), respectively. Synthesis of cDNA was performed with the high-capacity cDNA reverse transcription kit containing random hexamer primers (Applied Biosystems, Foster City, CA). After cDNA synthesis, quantitative polymerase chain reaction (qPCR) was performed on a 7500 Fast Real-Time PCR system (Applied Biosystems; thermal cycling conditions: $95^{\circ} \mathrm{C}$ for 20 seconds, 40 cycles of $95^{\circ} \mathrm{C}$ for 3 seconds, and $60{ }^{\circ} \mathrm{C}$ for 30 seconds). Primers are listed in Table 3 (all purchased from Applied Biosystems). Relative gene expression differences were calculated using the $2^{-\Delta \Delta \mathrm{Ct}}$-method [17] and normalised against the housekeeping genes Hypoxanthine phosphoribosyltransferase 1 (HPRT7), Glucuronidase beta (GUSB), and RNA Polymerase II Subunit A (POLR2A). Statistical analysis was performed in GraphPad Prism (version 8.4.1) using a one-way analysis of variance (ANOVA) test and post hoc Tukey's multiple comparisons test.

Table 3. Primers Used for Gene Expression with Corresponding Marker Function and Assay ID

\begin{tabular}{llll}
\hline Gene name & Abbreviation & Marker for & Assay ID \\
\hline POU Class 5 Homeobox 1 & POU5F1 & Stem cell & Hs00999632_g1 \\
Nanog homeobox & NANOG & Stem cell & Hs02387400_g1 \\
Neurogenin 1 & NEUROG7 & Neural ectoderm & Hs01029249_s1 \\
Nestin & NES & Neural progenitor & Hs00707120_s1 \\
Tubulin, beta 3 class III & TUBB3 & Neuron & Hs00801390_s1 \\
Microtubule-associated protein 2 & MAP2 & Mature neuron & Hs00258900_m1 \\
Synaptoporin & SYNPR & Pre-synapse & Hs00376149_m1 \\
Discs Large MAGUK Scaffold Protein 4 & DLG4 & Post-synapse & Hs01555373_m1 \\
Vesicular glutamate transporter & SLC77A6 & Excitatory neuron & Hs00220439_m1 \\
Vesicular inhibitory amino acid transporter & SLC32A7 & Inhibitory neuron & Hs00369773_m1 \\
Glial fibrillary acidic protein & GFAP & Early astrocyte & Hs00909233_m1 \\
Glucuronidase beta & GUSB & Housekeeping gene & Hs00939627_m1 \\
Hypoxanthine phosphoribosyltransferase 1 & HPRT1 & Housekeeping gene & Hs02800695_m1 \\
RNA Polymerase II Subunit A & POLR2A & Housekeeping gene & Hs00172187_m1 \\
\hline
\end{tabular}

\section{Results}

\section{Reprogramming of PBMCs to iPSCs using EVs}

Following the protocol of Su et al. $[9,10]$ we were able to generate iPSCs from adult PBMCs within 4 weeks (Fig. 1A). One major adjustment to the original protocol was the shortened culturing on a feeder layer by switching from MEFs to vitronectin coating for picking and expansion of iPSC colonies, which yielded better results than culturing on fibroblasts.

Two weeks after nucleofection, visible iPSC colonies started to form, which were picked and expanded in feeder-free dishes (Fig. 1B). Tight colonies formed and presented the typical morphology of iPSCs (Fig. 1B). Using primer sets for two common loci of the four nucleofected pEVs presented in Figure 1C, there were no detectable levels of residual pEVs present $(<0.01$ copies per cell after one passage and $<0.0001$ copies per cell after passaging the iPSCs five times) as determined by qPCR (Fig. 1D). 
Karyotyping of the iPSC clone revealed a normal human karyotype of which a representative image is shown in Figure 1E. Immunostaining of iPSCs showed abundant expression of pluripotency markers OCT4 and SSEA4, and tight junction marker ECAD (Fig. 1F). Neural progenitor marker PAX6 was absent and there were only a few NES ${ }^{+}$cells on the edges of the iPSC colonies.

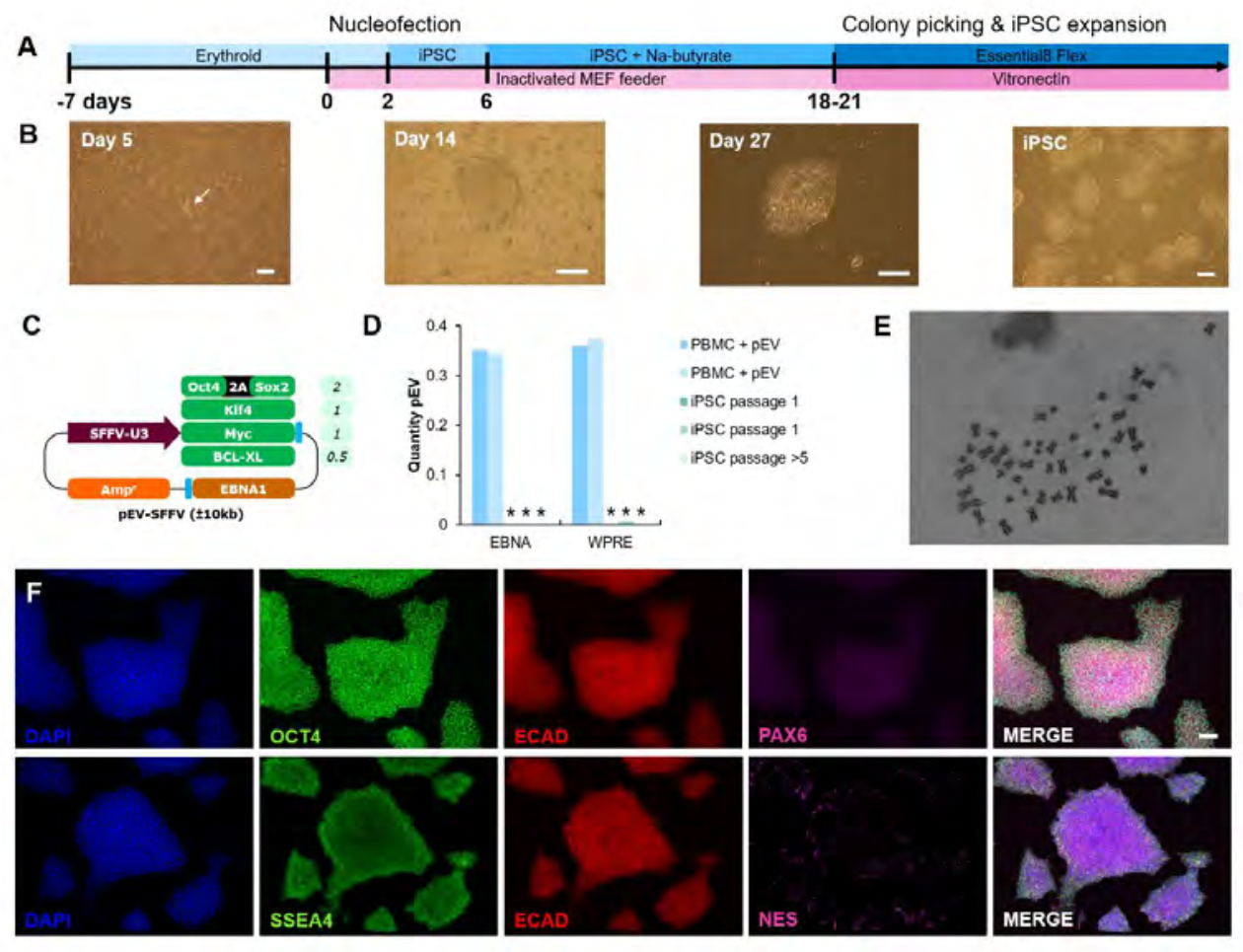

Figure 1. Reprogramming protocol of human PBMCs to iPSCS. (A) Time line of protocol depicting the media used in the upper bars and coatings used in the lower bars. (B) Bright-field images showing the transformation of cells during the reprogramming process. (C) Schematic view of the pEV and the ratio in which they were used for nucleofection. The blue elements indicate the two approximate qPCR amplification sites used for the results in panel $D$ (features are not to scale). (D) Amount of EV present in two PBMC+pEV samples, two iPSC samples in passage 7, and a representative example of iPSC samples in passage 5 or higher, based on two loci (EBNA and WPRE) of pEV by qPCR. *Measurements lower than 0.01 copies per cell. (E) Representative karyogram of iPSCS. (F) Immunostaining of iPSCS after five passages with stem cell markers OCT4 and SSEA4, neuronal differentiation markers NES and PAXG, and tight junction marker ECAD. Scale bar: $100 \mu \mathrm{m}$. EBNA, Epstein-Barr nuclear antigen; iPSC, induced pluripotent stem cell; MEF, mouse embryonic fibroblast; $P B M C$, peripheral blood mononuclear cell; pEV, episomal vector plasmid; qPCR, quantitative polymerase chain reaction; WPRE, WHP Posttranscriptional Response Element.

\section{Differentiation from iPSCs to beating cardiomyocytes}

To explore the potential of the generated iPSCs, cells were differentiated into cardiomyocytes, which has been shown feasible by Su et al. [9]. Starting from single iPSCs, cells were cultured on Geltrex and three optimised media were used to drive differentiation through cardiac pro- 
genitors toward beating cardiomyocytes (Fig. 2A, B). After 2 weeks, clusters of cells were positively stained for cardiomyocyte markers TNNT2 and NKX2.5 (Fig. 2C) and aligned beating cardiomyocytes were observed (Supplementary Videos S1-S3).

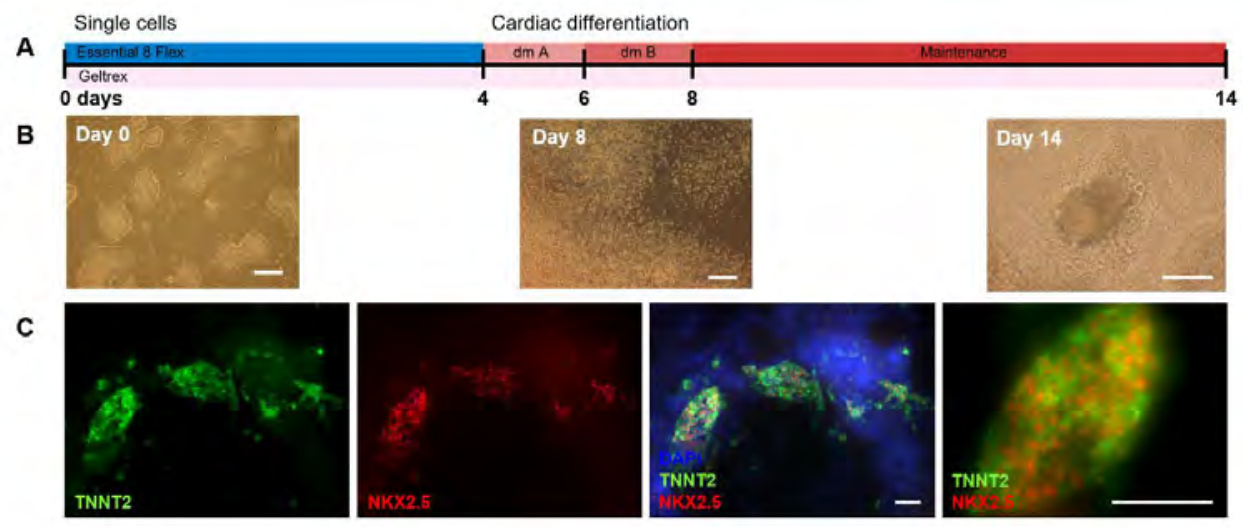

Figure 2. Differentiation of iPSCs to cardiomyocytes. (A) Time line of cardiac differentiation protocol adopted from Gibco. (B) Bright-field images of different stages in the cardiac differentiation protocol $(0,6$, and 74 days of differentiation). (C) Immunostaining on day 74 of cardiac differentiation showing clusters of cells positive for cardiac muscle marker TNNT2 and cardiac differentiation marker NKX2.5. Scale bar: $100 \mu \mathrm{m}$. The rightmost image is an enlarged detail of the combined signals of the two images on the left.

\section{Differentiation from iPSCs to a neuron-astrocyte co-culture}

Subsequently, we differentiated the same iPSC clone to a neuron-astrocyte culture using the protocol we developed for hESCs [11]. A schematic timeline of the procedure is depicted in Figure 3A. In the initial culture step of $\sim 26$ days, NPCs were generated with clear morphological phases such as EB formation and formation of rosettes and later single-cell NPCs (Fig. 3B), which are suitable for cryopreservation. NPCs were virtually all positively stained for neural progenitor marker NES, but negative for neural progenitor marker PAX6. Some cells already entered neuronal differentiation to some extent (TUBB3 and MAP2) and there were no pluripotency markers present (ECAD and SSEA4). Within the larger cell clusters, there was still a small amount of ZO-1 expression left, which is typical for the previous stage of neural rosette formation (Fig. 3C).

Next, in a second culture step of up to four weeks, NPCs were differentiated into a neuronastrocyte culture (Fig. 3B, D). Regardless of the neuron-astrocyte differentiation protocol used, differentiation of NPCs resulted in a mixed neuron-astrocyte culture, expressing markers for neurons (TUBB3), mature neurons (NeuN), axons (TAU), dendrites (MAP2), synaptic vesicles (SYNPR), and astrocytes (GFAP) on 14 days in vitro (DIV14). On DIV28, post-synaptic marker PSD95 was also abundantly present (Fig. 3D). Quantitative gene expression measurements at different time points along the differentiation path were in agreement with the immunostainings (Fig. 3E; see Supplementary Data S1 for statistical details). Stem cell marker expression of POU5F7 (which encodes OCT4) and NANOG strongly decreased, while expression of a range 


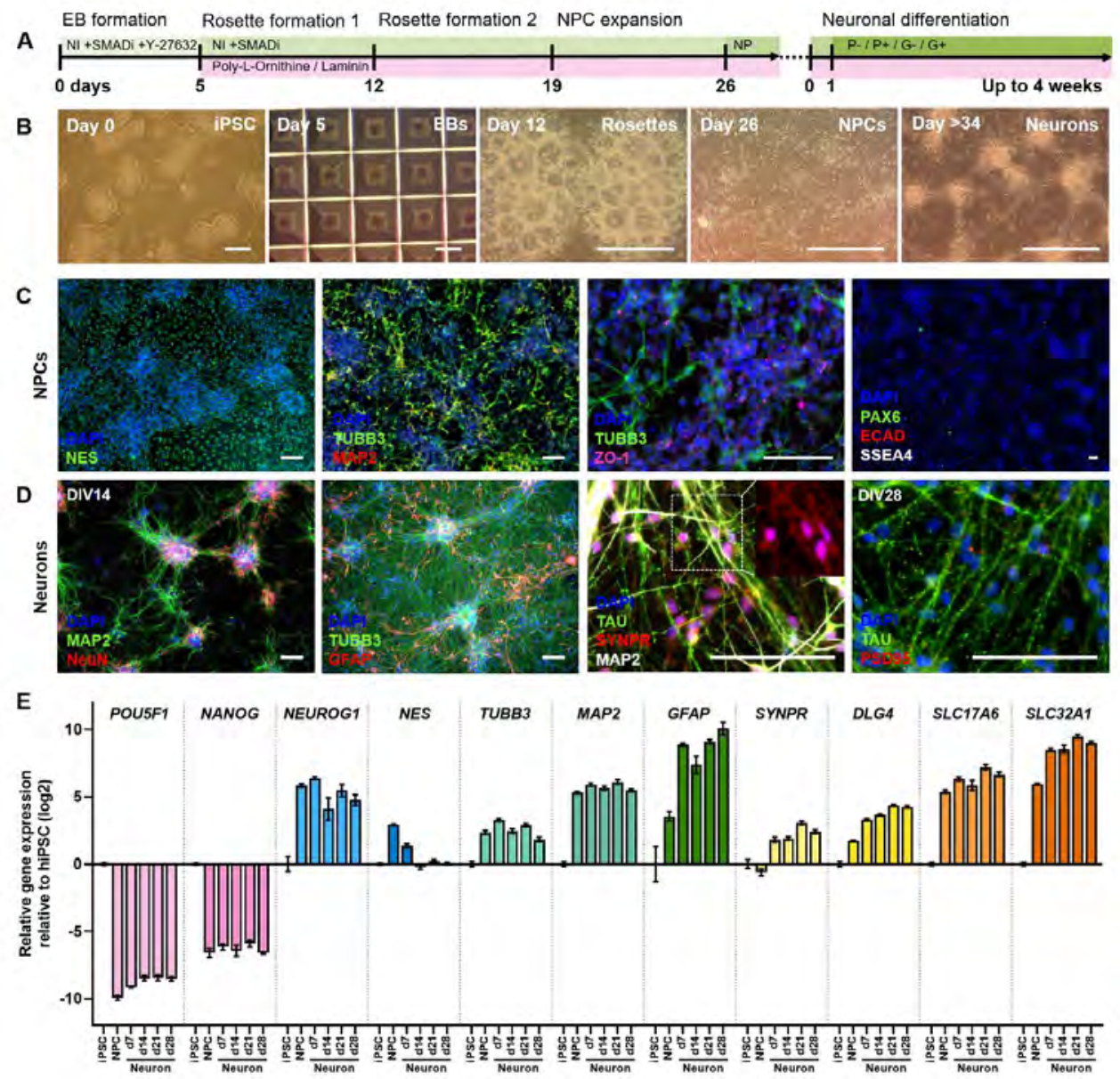

Figure 3. Differentiation protocol of iPSCs into a co-culture of neurons and astrocytes. (A) Protocol of neural differentiation as published in de Leeuw et al. [7 7]. (B) Bright-field images of the neuronal differentiation process. (C) Characterisation of cell types present in the NPC stage. NPCs were positive for neural progenitor marker NES, neuronal TUBB3, and MAP2, and to some extent for neural rosette marker ZO-1. Neural progenitor marker PAX6 and stem cell markers SSEA4 and ECAD were absent at this stage. (D) Characterisation of cell types present in the neuronal differentiation stage. Neurons expressed TUBB3, mature marker NeuN, and axonal TAU and dendritic MAP2 in specific regions of the cells. Astrocyte marker GFAP and markers for synaptic signaling SYNPR and PSD95 were also abundantly present on DIV14 and DIV28. Insert on the third image from the left shows SYNPR staining only for clarity. (E) Relative gene expression changes in iPSCS, NPCS, and the neuron-astrocyte co-culture of cell markers for stem cells (POU5F1 and NANOG), ectodermal differentiation (NEUROG 1 and NES), neurons (TUBB3 and MAP2), astrocytes (GFAP), synaptic markers (SYNPR and DLG4), and vesicle transporters (SLC17A6 and SLC32A 1). Sample size: iPSCs/neurons day $74 n=4, N P C s n=3$, neurons day $7 / 27 / 28 n=5$. For clarity reasons, the reader is referred to the supplementary data for mean differences and significance values between experimental groups. Scale bar. $100 \mu \mathrm{m}$. CNTF, ciliary neurotrophic factor; EB, embryoid body; G-/t, medium from Gunhanlar et al. [14] without (-) and with (+) CNTF; NI, STEMdiff' Neural Induction Medium; NP, STEMdiff Neural Progenitor Medium; $P-/ P+$, neural differentiation medium adopted from Pistollato et al. [13] without (-) and with (+) addition of CNTF; NPC, neural progenitor cell.

of early and late neuronal differentiation markers increased upon neuronal differentiation. Expression of NEUROG 7, a marker for early neuronal differentiation, and neuron markers TUBB3 
and MAP2 increased and plateaued from the NPC stage on. Neural progenitor marker NES expression peaked only in the NPCs and decreased upon further differentiation. Expression of astroglial marker GFAP, synaptic markers SYNPR and DLG4 (which encodes PSD95), and transporter markers SLC77A6 (which encodes VGLUT2) and SLC32A7 (which encodes VGAT) increased in the maturing neuron-astrocyte culture relative to the NPCs. In summary, both gene and protein expression of neuronal markers increased when neuronal differentiation was induced, which is indicative of a maturing neuronal network.

\section{Neuronal differentiation protocols altered neuron-astrocyte ratio}

To find the optimal neuron-astrocyte differentiation conditions, we tested four protocols as originally developed by Pistollato et al. [13] and Gunhanlar et al. [14] without (hereafter P- and $\mathrm{G}^{-}$, respectively) and with the addition of Ciliary neurotrophic factor (CNTF; $\mathrm{P}+, \mathrm{G}+$ ). The effect of half medium refreshments and shorter CNTF supplementation was also examined.

The most apparent difference between the four applied protocols was the difference between the protocol according to Pistollato et al. [13] and the protocol according to Gunhanlar et al. [14]. Regardless of the addition of CNTF, the latter protocol resulted in more cell growth in general and a higher number of astrocytes relative to neurons (Fig. 4A, B, compare top row [P] with bottom row [G]). The addition of CNTF to the medium also enhanced cell growth, but predominantly increased the astrocyte to neuron ratio (Fig. 4A, B, compare left [-CNTF] and right [+CNTF] images within panels). The Gunhanlar-protocol and CNTF supplementation also accelerated the maturity of the neurons, as exemplified by increased MAP2 expression by CNTF $(\mathrm{P}+/ \mathrm{G}+)$ and increased NeuN expression by Gunhanlar (G-; Fig. 5).

Leaving part of the cell culture medium during refreshments may benefit the cell culture as the local environment stays intact, while the nutrients do not get depleted. Also, since in the G+ condition the astrocytes overgrew the neurons, CNTF was added only at the start of the differentiation. The half refreshments changed the shape of the network in both P- and $\mathrm{G}-$, which presented smaller cell colonies (Fig. 4A, C, compare left images). The effect on astrocyte growth was diminished in the cultures with CNTF $(\mathrm{P}+/ \mathrm{G}+)$, while in $\mathrm{G}^{-}$, there were more astrocytes compared to full medium refreshments (Fig. 4B, D, left images).

Shorter supplementation with CNTF did not so much change the network morphology, but did decrease the amount of astrocytes (Fig. 4B, D, right images). Also, the effect of CNTF addition was less extreme than in the full refreshment conditions. In conclusion, it was possible to change the neuron astrocyte ratios by changing medium compositions.

\section{Discussion}

In this study, we have shown the ability to reprogram adult human PBMCs into iPSCs using EVs, which could be subsequently differentiated into cardiomyocytes and a neuron-astrocyte co-culture, highlighting the pluripotent nature of the iPSCs and adding ectodermal tissue differentiation to the repertoire of the iPSC method of the Zhang laboratory [9]. We could also change the network formation and the cell-type ratios between neurons and astrocytes in a similar way as shown with hESCs in our laboratory [11]. 

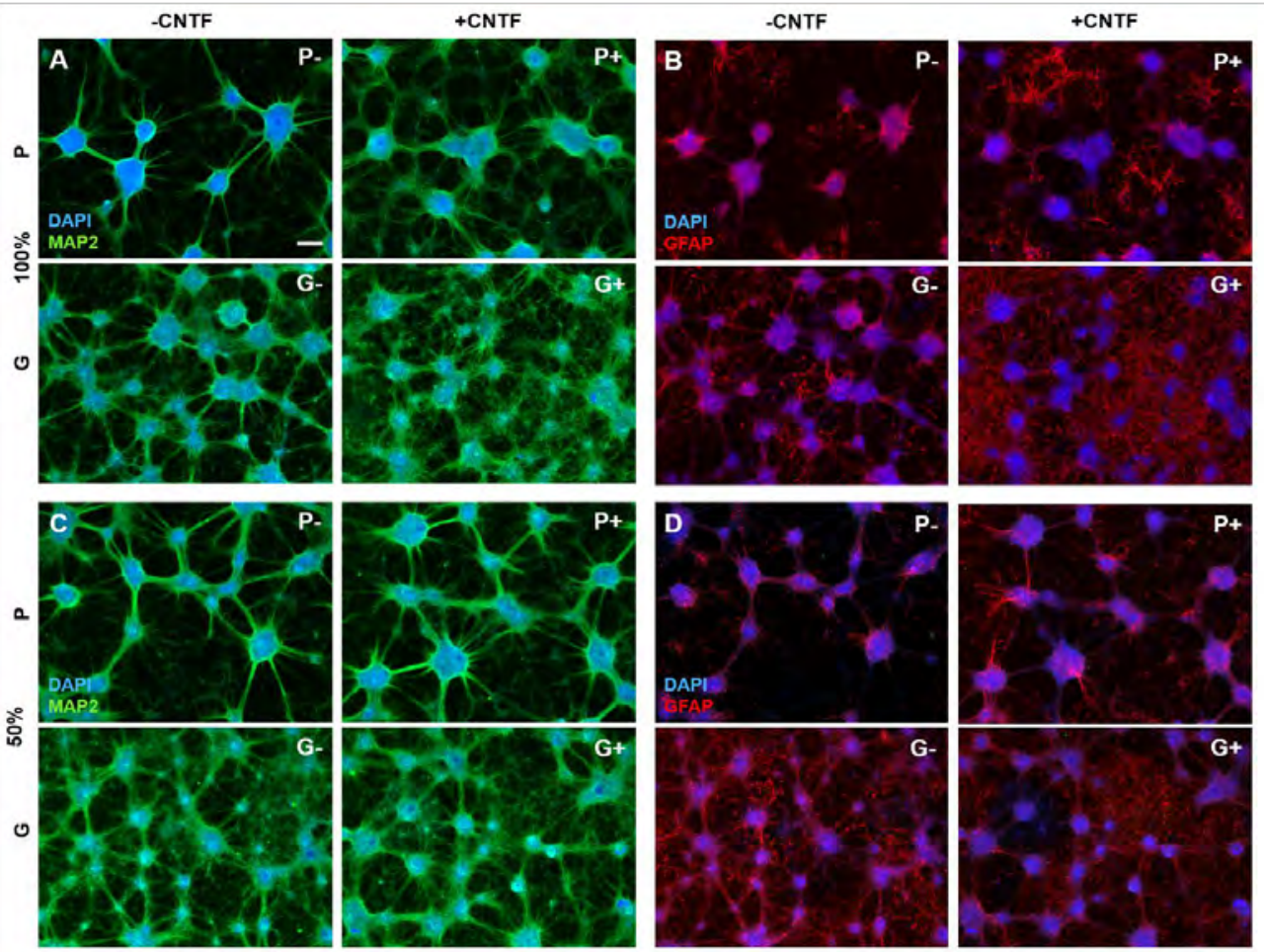

Figure 4. Comparison of four protocols $P$-, $P+, G$-, and $G+$ in terms of neuron-astrocyte ratio. (A) Immunostaining of MAP2 in neuron-astrocyte cultures on DIV28 that received different medium compositions. (B) Same cultures as in (A), but with astrocyte marker GFAP stained in red. (C/D) Same as (A/B), but cultures received half medium refreshments and $P+$ and $G+$ conditions only received CNTF during the first four medium changes. Scale bar: $100 \mu m$.

Su et al. $[9,10]$ have established a protocol with which they could obtain iPSC colonies with a relatively high efficiency, and which we have replicated in our laboratory. Improvements of the protocol are still being made in all phases of the reprogramming [18], which holds great promise to make this method more efficient and economically feasible. We modified the protocol by replacing fibroblasts by a xeno-free and feeder-free coating for the expansion of the iPSC colonies. In our hands, the prolonged usage of murine feeder layers according to the original protocol did not result in the isolation of viable iPSCs. The modification could be seen as an improvement as it simplifies the culture conditions and eliminates xenogeneic contamination of the iPSCs earlier on.

Recently, we have shown that hESCs could be differentiated to a spontaneously firing neuronal network within the course of five weeks [11]. Using the same protocol, iPSCs could be differentiated to a similar phenotype containing both neurons and astrocytes, although there were two notable differences. The iPSC-derived NPCs were NES ${ }^{+} /$PAX6 $^{-}$, while the hESC-derived NPCs were $\mathrm{NES}^{+} / \mathrm{PAX} 6^{+}$, which suggests that the cells differ in NPC subtype or developmental stage [19-22].

Also, the morphology of the neuron-astrocyte cultures was different: iPSC-derived neurons clustered faster and a larger amount of astrocytes were present in the G- protocol compared 

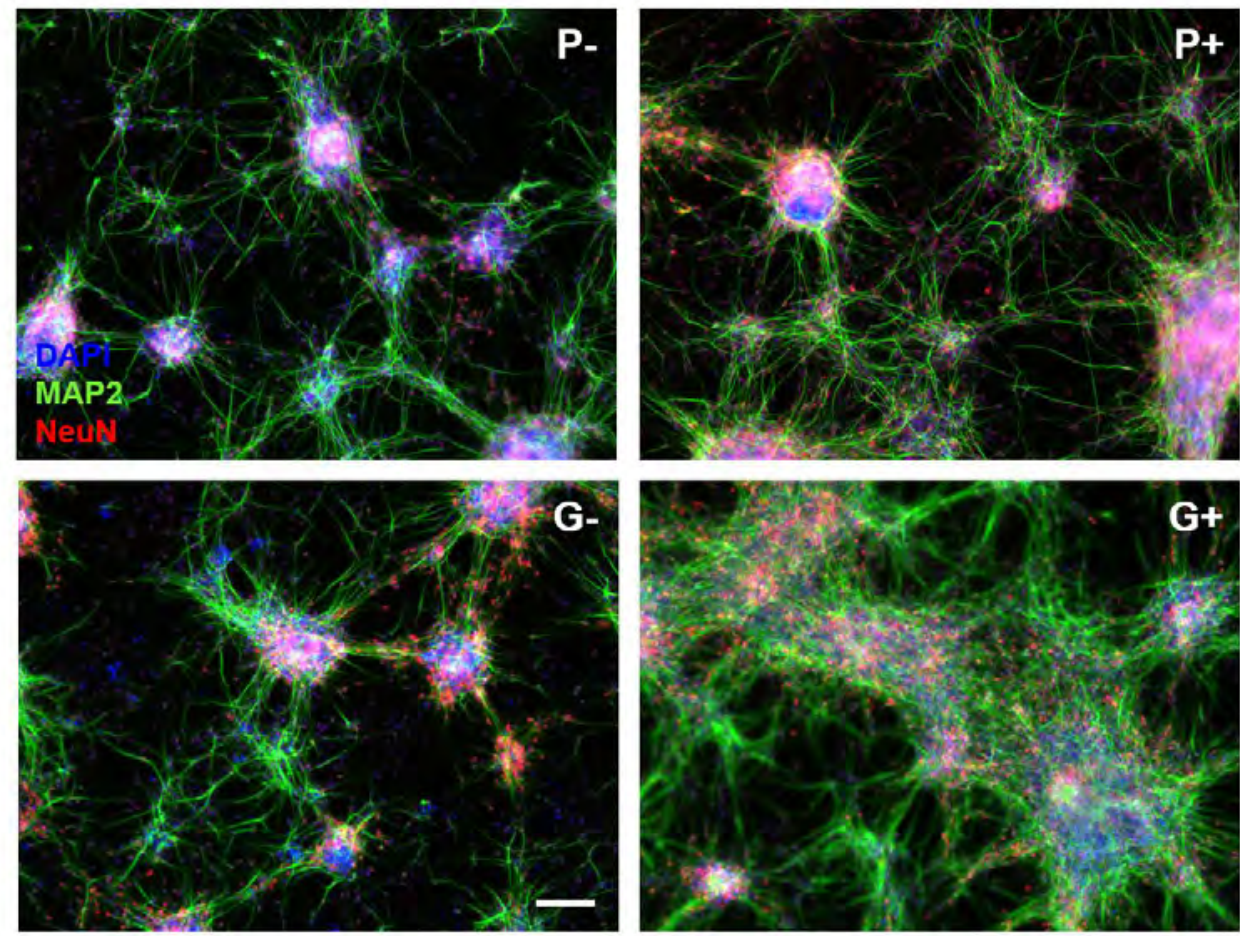

Figure 5. Expression of mature neuron markers MAP2 and NeuN on DIV14 in the four protocols. Scale bar: $100 \mu m$.

to the hESC-derived cultures. Gene expression patterns were highly similar between the two cultures [11]. These differences are in line with the similar, but not identical gene expression profiles of both cell lines as shown before [23]. The differentiation potential of both cell types is alike as shown by similar gene and protein expression of neuron, astroglial, and synaptic markers, which implies that iPSC-derived neuron-astrocyte culture matures in a similar manner as hESC-derived culture does. It will be interesting to test whether these iPSC-derived cultures can form functional networks such as we observed in hESC-derived neuronal cultures.

Tang et al. [24] have shown that it is possible to directly convert PBMCs into NPCs using episomal factors, skipping over the stem cell stage. This has advantages over indirect programming; the culturing time can be greatly reduced and one can obtain a homogeneous cell population [25]. However, iPSCs have higher proliferative potential, yielding higher cell numbers, and true self-replication, although mutations can still occur [26]. The slower differentiation and cell heterogeneity could also be an advantage when mimicking or studying processes in vitro, especially development.

Moreover, to our knowledge, this is the first time it has been shown that iPSCs generated from the Su-protocol could be differentiated into a neuron-astrocyte co-culture instead of only neurons [27-29]. However, perhaps the most compelling arguments for implementing a protocol based on the generation of stable and expandable iPSC cultures with cryopreservation options 
are the far more versatile application possibilities, as various cell and tissue types can be generated from such a resource.

Indeed, this method of reprogramming blood cells into stem cells and expanding these cells for differentiation to various organs of interest may provide a useful tool to study patient-specific disease modeling and drug screening. Research groups have already shown examples generating somatic cells from PBMC-derived iPSCs that replicate genetic diseases in all kind of organs, for example, the brain [30,31], blood [32], and heart [33]. There are also promising examples of drug and toxicity screening [34,35]. Another research direction with iPSCs is studying gene-environment interactions in groups of people who are exposed to certain chemicals $[36,37]$ or studying cohorts of whom a wealth of information is readily available to study complex processes such as "healthy" aging.

\section{Acknowledgements}

We would like to thank Nick Beijer for a critical review of the article.

\section{Author Disclosure Statement}

The authors declare they have no conflicting financial interests.

\section{Funding Information}

This research is funded by the National Institute of Health (NIH)/National Institute of Aging (NIA) (AG017242), the Dutch Ministry of Agriculture, Nature and Food Quality, the Dutch Ministry of Health, Welfare and Sports, and the Dutch NGO Stichting Proefdiervrij.

\section{Supplementary Material}

The reader is referred to the online version of the article to view Supplementary Video S1-3. 


\section{References}

[1] K. Takahashi, S. Yamanaka, Induction of Pluripotent Stem Cells from Mouse Embryonic and Adult Fibroblast Cultures by Defined Factors, Cell. 126 (2006) 663-676. https://doi.org/10.1016/j.cell.2006.07.024.

[2] K. Takahashi, K. Tanabe, M. Ohnuki, M. Narita, T. Ichisaka, K. Tomoda, S. Yamanaka, Induction of Pluripotent Stem Cells from Adult Human Fibroblasts by Defined Factors, Cell. 131 (2007) 861-872. https://doi.org/10.1016/j.cell.2007.11.019.

[3] A. Abyzov, J. Mariani, D. Palejev, Y. Zhang, M.S. Haney, L. Tomasini, A.F. Ferrandino, L.A. Rosenberg Belmaker A. Szekely, M. Wilson, A. Kocabas, N.E. Calixto, E.L. Grigorenko, A. Huttner, K. Chawarska, S. Weissman, A.E. Urban, M. Gerstein, F.M. Vaccarino, Somatic copy number mosaicism in human skin revealed by induced pluripotent stem cells, Nature. 492 (2012) 438-442. https://doi.org/10.1038/nature11629.

[4] Y.-H. Loh, S. Agarwal, I.-H. Park, A. Urbach, H. Huo, G.C. Heffner, K. Kim, J.D. Miller, K. Ng, G.Q. Daley, Generation of induced pluripotent stem cells from human blood., Blood. 113 (2009) 5476-5479. https://doi.org/10.1182/blood-2009-02-204800.

[5] J. Staerk, M.M. Dawlaty, Q. Gao, D. Maetzel, J. Hanna, C.A. Sommer, G. Mostoslavsky, R. Jaenisch, Reprogramming of human peripheral blood cells to induced pluripotent stem cells, Cell Stem Cell. 7 (2010) 20-24. https://doi.org/10.1016/j.stem.2010.06.002.

[6] J. Yu, K. Hu, K. Smuga Otto, S. Tian, R. Stewart, I.I. Slukvin, J.A. Thomson, Human induced pluripotent stem cells free of vector and transgene sequences, Science (80-. ). 324 (2009) 797-801. https://doi.org/10.1126/science.1172482.

[7] X.B. Zhang, Cellular Reprogramming of Human Peripheral Blood Cells, Genomics, Proteomics Bioinforma. 11 (2013) 264-274. https://doi.org/10.1016/j.gpb.2013.09.001.

[8] A. Nanbo, A. Sugden, B. Sugden, The coupling of synthesis and partitioning of EBV's plasmid replicon is revealed in live cells, EMBO J. 26 (2007) 4252-4262. https://doi.org/10.1038/sj.emboj.7601853.

[9] R.J. Su, D.J. Baylink, A. Neises, J.B. Kiroyan, X. Meng, K.J. Payne, B. Tschudy-Seney, Y. Duan, N. Appleby, M. Kearns-Jonker, D.S. Gridley, J. Wang, K.H.W. Lau, X.B. Zhang, Efficient Generation of Integration-Free iPS Cells from Human Adult Peripheral Blood Using BCL-XL Together with Yamanaka Factors, PLoS One. 8 (2013). https://doi.org/10.1371/journal.pone.0064496.

[10] R.J. Su, A. Neises, X.B. Zhang, Generation of iPS cells from human peripheral blood mononuclear cells using episomal vectors, in: K. Turksen, A. Nagy (Eds.), Methods Mol. Biol., Humana Press Inc., New York, NY, 2016: pp. 57-69. https://doi.org/10.1007/7651_2014_139.

[11] V.C. de Leeuw, C.T.M. van Oostrom, R.H.S. Westerink, A.H. Piersma, H.J. Heusinkveld, E.V.S. Hessel, An efficient neuron-astrocyte differentiation protocol from human embryonic stem cell-derived neural progenitors to assess chemical-induced developmental neurotoxicity, Reprod. Toxicol. (2020). https://doi.org/https://doi.org/10.1016/j.reprotox.2020.09.003.

[12] W. Wen, J.P. Zhang, J. Xu, R.J. Su, A. Neises, G.Z. Ji, W. Yuan, T. Cheng, X.B. Zhang, Enhanced generation of integration-free iPSCs from human adult peripheral blood mononuclear cells with an optimal combination of episomal vectors, Stem Cell Reports. 6 (2016) 873-884. https://doi.org/10.1016/j.stemcr.2016.04.005.

[13] F. Pistollato, D. Canovas-Jorda, D. Zagoura, A. Price, Protocol for the differentiation of human induced pluripotent stem cells into mixed cultures of neurons and glia for neurotoxicity testing, J. Vis. Exp. 2017 (2017) e55702. https://doi.org/10.3791/55702.

[14] N. Gunhanlar, G. Shpak, M. van der Kroeg, L.A. Gouty-Colomer, S.T. Munshi, B. Lendemeijer, M. Ghazvini, C. Dupont, W.J.G. Hoogendijk, J. Gribnau, F.M.S. de Vrij, S.A. Kushner, A simplified protocol for differentiation of electrophysiologically mature neuronal networks from human induced pluripotent stem cells, Mol. Psychiatry. 23 (2018) 1336-1344. https://doi.org/10.1038/mp.2017.56.

[15] V.C. de Leeuw, E.V.S. Hessel, A.H. Piersma, Look-alikes may not act alike: Gene expression regulation and cell-type-specific responses of three valproic acid analogues in the neural embryonic stem cell test (ESTn), Toxicol. Lett. 303 (2019) 28-37. https://doi.org/10.1016/j.toxlet.2018.12.005.

[16] W.S. Rasband, ImageJ, U. S. Natl. Institutes Heal. Bethesda, Maryland, USA. (n.d.). https://imagej.nih.gov/ij/.

[17] Applied Biosystems, User Bulletin \#2 ABI PRISM 7700 Sequence Detection System, (2001) 1-36. http://tools.thermofisher.com/content/sfs/manuals/cms_040980.pdf.

[18] H. Gu, X. Huang, J. Xu, L. Song, S. Liu, X.B. Zhang, W. Yuan, Y. Li, Optimizing the method for generation of integration-free induced pluripotent stem cells from human peripheral blood, Stem Cell Res. Ther. 9 (2018) 163. https://doi.org/10.1186/s13287-018-0908-z.

[19] A. Chandrasekaran, H.X. Avci, A. Ochalek, L.N. Rösingh, K. Molnár, L. László, T. Bellák, A. Téglási, K. Pesti, A. Mike, P. Phanthong, O. Bíró, V. Hall, N. Kitiyanant, K.H. Krause, J. Kobolák, A. Dinnyés, Comparison of 2D and 3D neural induction methods for the generation of neural progenitor cells from human induced pluripotent stem cells, Stem Cell Res. 25 (2017) 139-151. https://doi.org/10.1016/j.scr.2017.10.010.

[20] B.J. Molyneaux, P. Arlotta, J.R.L. Menezes, J.D. Macklis, Neuronal subtype specification in the cerebral cortex, Nat. Rev. Neurosci. 8 (2007) 427-437. https://doi.org/10.1038/nrn2151.

[21] R. Nat, M. Nilbratt, S. Narkilahti, B. Winblad, O. Hovatta, A. Nordberg, Neurogenic neuroepithelial and radial glial cells generated from six human embryonic stem cell lines in serum-free suspension and adherent cultures, Glia. 55 (2007) 385-399. https://doi.org/10.1002/glia.20463. 
[22] M. Zhang, J. Ngo, F. Pirozzi, Y.P. Sun, A. Wynshaw-Boris, Highly efficient methods to obtain homogeneous dorsal neural progenitor cells from human and mouse embryonic stem cells and induced pluripotent stem cells, Stem Cell Res. Ther. 9 (2018) 67. https://doi.org/10.1186/s13287-018-0812-6.

[23] H.E. Marei, A. Althani, S. Lashen, C. Cenciarelli, A. Hasan, Genetically unmatched human iPSC and ESC exhibit equivalent gene expression and neuronal differentiation potential, Sci. Rep. 7 (2017) 17504. https://doi.org/10.1038/s41598-017-17882-1.

[24] X. Tang, S. Wang, Y. Bai, J. Wu, L. Fu, M. Li, Q. Xu, Z.Q.D. Xu, Y. Alex Zhang, Z. Chen, Conversion of adult human peripheral blood mononuclear cells into induced neural stem cell by using episomal vectors, Stem Cell Res. 16 (2016) 236-242. https://doi.org/10.1016/j.scr.2016.01.016.

[25] J. Ladewig, P. Koch, O. Brüstle, Leveling Waddington: The emergence of direct programming and the loss of cell fate hierarchies, Nat. Rev. Mol. Cell Biol. 14 (2013) 225-236. https://doi.org/10.1038/nrm3543.

[26] K. Tanabe, D. Haag, M. Wernig, Direct somatic lineage conversion., Philos. Trans. R. Soc. Lond. B. Biol. Sci. 370 (2015) 20140368. https://doi.org/10.1098/rstb.2014.0368.

[27] Y. Wang, Q. Fen, H. Yu, H. Qiu, X. Ma, Y. Lei, J. Zhao, Establishment of TUSMi005-A, an induced pluripotent stem cell (iPSC) line from a 32-year old Chinese Han patient with Bipolar Disorder (BD), Stem Cell Res. 33 (2018) 65-68. https://doi.org/10.1016/j.scr.2018.10.014.

[28] X. Liu, J. Chen, W. Liu, X. Li, Q. Chen, T. Liu, S. Gao, M. Deng, The fused in sarcoma protein forms cytoplasmic aggregates in motor neurons derived from integration-free induced pluripotent stem cells generated from a patient with familial amyotrophic lateral sclerosis carrying the FUS-P525L mutation, Neurogenetics. 16 (2015) 223-231. https://doi.org/10.1007/s10048-015-0448-y

[29] G. Liu, X.M. Li, S. Tian, R.R. Lu, Y. Chen, H.Y. Xie, K.W. Yu, J.J. Zhang, J.F. Wu, Y.L. Zhu, Y. Wu, The effect of magnetic stimulation on differentiation of human induced pluripotent stem cells into neuron, J. Cell. Biochem. 121 (2020) 4130-4141. https://doi.org/10.1002/jcb.29647.

[30] M. Frega, K. Linda, J.M. Keller, G. Gümüş-Akay, B. Mossink, J.R. van Rhijn, M. Negwer, T. Klein Gunnewiek, K. Foreman, N. Kompier, C. Schoenmaker, W. van den Akker, I. van der Werf, A. Oudakker, H. Zhou, T. Kleefstra, D. Schubert, H. van Bokhoven, N. Nadif Kasri, Neuronal network dysfunction in a model for Kleefstra syndrome mediated by enhanced NMDAR signaling, Nat. Commun. $10 \quad$ (2019) 4928. https://doi.org/10.1038/s41467-019-12947-3.

[31] E.I. Ustyantseva, S.P. Medvedev, A.S. Vetchinova, S.N. Illarioshkin, S. V. Leonov, S.M. Zakian, Generation of an induced pluripotent stem cell line, ICGi014-A, by reprogramming peripheral blood mononuclear cells from a patient with homozygous D90A mutation in SOD1 causing Amyotrophic lateral sclerosis, Stem Cell Res. 42 (2020) 101675. https://doi.org/10.1016/j.scr.2019.101675.

[32] C. Lyu, J. Shen, R. Wang, H. Gu, J. Zhang, F. Xue, X. Liu, W. Liu, R. Fu, L. Zhang, H. Li, X. Zhang, T. Cheng, R. Yang, L. Zhang, Targeted genome engineering in human induced pluripotent stem cells from patients with hemophilia B using the CRISPR-Cas9 system, Stem Cell Res. Ther. 9 (2018) 92. https://doi.org/10.1186/s13287-018-0839-8

[33] K. Perepelina, P. Klauzen, A. Khudiakov, A. Zlotina, Y. Fomicheva, D. Rudenko, M. Gordeev, A. Sergushichev, A. Malashicheva, A. Kostareva, Generation of two iPSC lines (FAMRCi006-A and FAMRCi006-B) from patient with dilated cardiomyopathy and Emery-Dreifuss muscular dystrophy associated with genetic variant LMNAp.Arg527Pro., Stem Cell Res. 43 (2020) 101714. https://doi.org/10.1016/j.scr.2020.101714.

[34] Y.C. Chang, W.C. Chang, K.H. Hung, D.M. Yang, Y.H. Cheng, Y.W. Liao, L.C. Woung, C.Y. Tsai, C.C. Hsu, T.C. Lin, J.H. Liu, S.H. Chiou, C.H. Peng, S.J. Chen, The generation of induced pluripotent stem cells for macular degeneration as a drug screening platform: Identification of curcumin as a protective agent for retinal pigment epithelial cells against oxidative stress, Front. Aging Neurosci. 6 (2014) 191. https://www.frontiersin.org/article/10.3389/fnagi.2014.00191.

[35] M.S. Elitt, L. Barbar, P.J. Tesar, Drug screening for human genetic diseases using iPSC models, Hum. Mol. Genet. 27 (2018) R89-R98. https://doi.org/10.1093/hmg/ddy186.

[36] P. Joshi, C. Bodnya, I. Ilieva, M.D. Neely, M. Aschner, A.B. Bowman, Huntington's disease associated resistance to $\mathrm{Mn}$ neurotoxicity is neurodevelopmental stage and neuronal lineage dependent, Neurotoxicology. 75 (2019) 148-157. https://doi.org/10.1016/j.neuro.2019.09.007.

[37] L.M. Prince, M. Aschner, A.B. Bowman, Human-induced pluripotent stems cells as a model to dissect the selective neurotoxicity of methylmercury, Biochim. Biophys. Acta - Gen. Subj. 1863 (2019) 129300. https://doi.org/10.1016/j.bbagen.2019.02.002. 


\section{Supplementary data S1}

Mean differences and significance levels for gene expression differences between iPSCS, NPCs and neurons at different time points. Lower left half of each table lists adjusted p-values by Tukey's multiple comparison test. Bold numbers indicate a statistically significant difference. Upper right half lists fold change differences between two groups.

\begin{tabular}{|c|c|c|c|c|c|c|c|}
\hline \multirow[t]{2}{*}{ POU5F1 } & \multicolumn{7}{|c|}{ Mean difference } \\
\hline & & iPSC & NPC & Neuron d7 & Neuron d14 & Neuron d21 & Neuron d28 \\
\hline \multirow{6}{*}{ 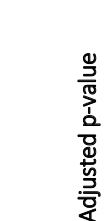 } & iPSC & & 9.935 & 9.135 & 8.49 & 8.473 & 8.545 \\
\hline & NPC & $<0.0001$ & & -0.7995 & -1.445 & -1.462 & -1.39 \\
\hline & Neuron d7 & $<0.0001$ & $<0.0001$ & & -0.6454 & -0.6622 & -0.5906 \\
\hline & Neuron d14 & $<0.0001$ & $<0.0001$ & 0.0001 & & -0.0168 & 0.05481 \\
\hline & Neuron d 21 & $<0.0001$ & $<0.0001$ & $<0.0001$ & $>0.9999$ & & 0.07161 \\
\hline & Neuron d28 & $<0.0001$ & $<0.0001$ & 0.0002 & 0.9954 & 0.9798 & \\
\hline
\end{tabular}

\begin{tabular}{|c|c|c|c|c|c|c|c|}
\hline \multirow[t]{2}{*}{ NANOG } & \multicolumn{7}{|c|}{ Mean difference } \\
\hline & & iPSC & NPC & Neuron d7 & Neuron d14 & Neuron d21 & Neuron d28 \\
\hline \multirow{6}{*}{ 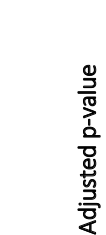 } & iPSC & & 6.604 & 6.169 & 6.445 & 5.916 & 6.619 \\
\hline & NPC & $<0.0001$ & & -0.4352 & -0.1583 & -0.6878 & 0.01527 \\
\hline & Neuron d7 & $<0.0001$ & 0.1831 & & 0.2769 & -0.2526 & 0.4505 \\
\hline & Neuron d14 & $<0.0001$ & 0.9527 & 0.5445 & & -0.5295 & 0.1736 \\
\hline & Neuron d 21 & $<0.0001$ & 0.0102 & 0.5782 & 0.0394 & & 0.7031 \\
\hline & Neuron d28 & $<0.0001$ & $>0.9999$ & 0.0751 & 0.8881 & 0.0021 & \\
\hline
\end{tabular}

\begin{tabular}{|c|c|c|c|c|c|c|c|}
\hline \multirow[t]{2}{*}{ NEUROG1 } & \multicolumn{7}{|c|}{ Mean difference } \\
\hline & & iPSC & NPC & Neuron d7 & Neuron d14 & Neuron d21 & Neuron d 28 \\
\hline \multirow{6}{*}{ 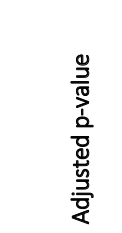 } & iPSC & & -5.836 & -6.389 & -4.085 & -5.47 & -4.758 \\
\hline & NPC & $<0.0001$ & & -0.5536 & 1.75 & 0.3657 & 1.077 \\
\hline & Neuron d7 & $<0.0001$ & 0.6172 & & 2.304 & 0.9193 & 1.631 \\
\hline & Neuron d14 & $<0.0001$ & 0.0014 & $<0.0001$ & & -1.385 & -0.6729 \\
\hline & Neuron d21 & $<0.0001$ & 0.8962 & 0.0618 & 0.0039 & & 0.7117 \\
\hline & Neuron d28 & $<0.0001$ & 0.0564 & 0.0004 & 0.3279 & 0.2199 & \\
\hline
\end{tabular}

\begin{tabular}{|c|c|c|c|c|c|c|c|}
\hline \multirow[t]{2}{*}{ NES } & \multicolumn{7}{|c|}{ Mean difference } \\
\hline & & iPSC & NPC & Neuron d7 & Neuron d14 & Neuron d21 & Neuron d 28 \\
\hline \multirow{6}{*}{ 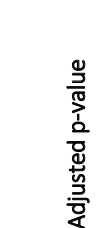 } & iPSC & & -2.928 & -1.371 & 0.2128 & -0.2206 & -0.04218 \\
\hline & NPC & $<0.0001$ & & 1.557 & 3.14 & 2.707 & 2.885 \\
\hline & Neuron d7 & $<0.0001$ & $<0.0001$ & & 1.584 & 1.15 & 1.329 \\
\hline & Neuron d14 & 0.1409 & $<0.0001$ & $<0.0001$ & & -0.4334 & -0.255 \\
\hline & Neuron d21 & 0.0895 & $<0.0001$ & $<0.0001$ & 0.0002 & & 0.1784 \\
\hline & Neuron d28 & 0.9934 & $<0.0001$ & $<0.0001$ & 0.0365 & 0.1879 & \\
\hline
\end{tabular}




\begin{tabular}{|c|c|c|c|c|c|c|c|}
\hline \multirow[t]{2}{*}{ TUBB3 } & \multicolumn{7}{|c|}{ Mean difference } \\
\hline & & iPSC & NPC & Neuron d7 & Neuron d14 & Neuron d21 & Neuron d28 \\
\hline \multirow{6}{*}{ 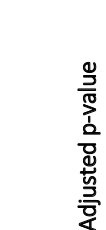 } & iPSC & & -2.354 & -3.267 & -2.447 & -2.886 & -1.823 \\
\hline & NPC & $<0.0001$ & & -0.9132 & -0.09287 & -0.5327 & 0.5306 \\
\hline & Neuron d7 & $<0.0001$ & $<0.0001$ & & 0.8203 & 0.3805 & 1.444 \\
\hline & Neuron d14 & $<0.0001$ & 0.9653 & $<0.0001$ & & -0.4399 & 0.6234 \\
\hline & Neuron d 21 & $<0.0001$ & 0.0014 & 0.0093 & 0.0042 & & 1.063 \\
\hline & Neuron d28 & $<0.0001$ & 0.0015 & $<0.0001$ & $<0.0001$ & $<0.0001$ & \\
\hline
\end{tabular}

\begin{tabular}{|c|c|c|c|c|c|c|c|}
\hline \multirow[t]{2}{*}{ MAP2 } & \multicolumn{7}{|c|}{ Mean difference } \\
\hline & & iPSC & NPC & Neuron d7 & Neuron d14 & Neuron d21 & Neuron d28 \\
\hline \multirow{6}{*}{ 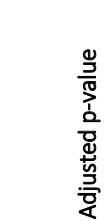 } & iPSC & & -5.306 & -5.911 & -5.643 & -6.111 & -5.472 \\
\hline & NPC & $<0.0001$ & & -0.6049 & -0.3366 & -0.8052 & -0.1656 \\
\hline & Neuron d7 & $<0.0001$ & $<0.0001$ & & 0.2683 & -0.2003 & 0.4393 \\
\hline & Neuron d14 & $<0.0001$ & 0.039 & 0.072 & & -0.4686 & 0.171 \\
\hline & Neuron d21 & $<0.0001$ & $<0.0001$ & 0.2226 & 0.0006 & & 0.6396 \\
\hline & Neuron d28 & $<0.0001$ & 0.5594 & 0.0006 & 0.4376 & $<0.0001$ & \\
\hline
\end{tabular}

\begin{tabular}{|c|c|c|c|c|c|c|c|}
\hline \multirow[t]{2}{*}{ GFAP } & \multicolumn{7}{|c|}{ Mean difference } \\
\hline & & iPSC & NPC & Neuron d7 & Neuron d14 & Neuron d21 & Neuron d28 \\
\hline \multirow{6}{*}{ 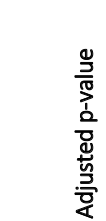 } & iPSC & & -3.56 & -8.869 & -7.388 & -9.101 & -10.08 \\
\hline & NPC & $<0.0001$ & & -5.308 & -3.828 & -5.541 & -6.522 \\
\hline & Neuron d7 & $<0.0001$ & $<0.0001$ & & 1.481 & -0.2322 & -1.214 \\
\hline & Neuron d14 & $<0.0001$ & $<0.0001$ & 0.0205 & & -1.713 & -2.695 \\
\hline & Neuron d 21 & $<0.0001$ & $<0.0001$ & 0.9903 & 0.006 & & -0.9814 \\
\hline & Neuron d28 & $<0.0001$ & $<0.0001$ & 0.0545 & $<0.0001$ & 0.1688 & \\
\hline
\end{tabular}

\begin{tabular}{|c|c|c|c|c|c|c|c|}
\hline \multirow[t]{2}{*}{ SYNPR } & \multicolumn{7}{|c|}{ Mean difference } \\
\hline & & iPSC & NPC & Neuron d7 & Neuron d14 & Neuron d21 & Neuron d28 \\
\hline \multirow{6}{*}{ 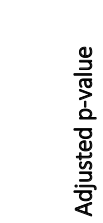 } & iPSC & & 0.6348 & -1.8 & -1.901 & -3.063 & -2.401 \\
\hline & NPC & 0.006 & & -2.435 & -2.535 & -3.698 & -3.036 \\
\hline & Neuron d7 & $<0.0001$ & $<0.0001$ & & -0.1004 & -1.263 & -0.6011 \\
\hline & Neuron d14 & $<0.0001$ & $<0.0001$ & 0.9739 & & -1.163 & -0.5007 \\
\hline & Neuron d21 & $<0.0001$ & $<0.0001$ & $<0.0001$ & $<0.0001$ & & 0.6619 \\
\hline & Neuron d 28 & $<0.0001$ & $<0.0001$ & 0.0016 & 0.0153 & 0.0006 & \\
\hline
\end{tabular}

\begin{tabular}{|c|c|c|c|c|c|c|c|}
\hline \multirow[t]{2}{*}{ DLG4 } & \multicolumn{7}{|c|}{ Mean difference } \\
\hline & & iPSC & NPC & Neuron d7 & Neuron d14 & Neuron d21 & Neuron d28 \\
\hline \multirow{6}{*}{ 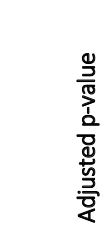 } & iPSC & & -1.733 & -3.29 & -3.667 & -4.361 & -4.241 \\
\hline & NPC & $<0.0001$ & & -1.557 & -1.934 & -2.628 & -2.508 \\
\hline & Neuron d7 & $<0.0001$ & $<0.0001$ & & -0.3771 & -1.071 & -0.9512 \\
\hline & Neuron d14 & $<0.0001$ & $<0.0001$ & 0.0006 & & -0.6935 & -0.5741 \\
\hline & Neuron d21 & $<0.0001$ & $<0.0001$ & $<0.0001$ & $<0.0001$ & & 0.1194 \\
\hline & Neuron d 28 & $<0.0001$ & $<0.0001$ & $<0.0001$ & $<0.0001$ & 0.521 & \\
\hline
\end{tabular}




\begin{tabular}{|c|c|c|c|c|c|c|c|}
\hline \multirow[t]{2}{*}{ SLC17A6 } & \multicolumn{7}{|c|}{ Mean difference } \\
\hline & & iPSC & NPC & Neuron d7 & Neuron d14 & Neuron d21 & Neuron d28 \\
\hline \multirow{6}{*}{ 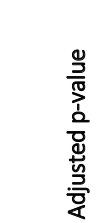 } & iPSC & & -5.373 & -6.327 & -5.852 & -7.203 & -6.673 \\
\hline & NPC & $<0.0001$ & & -0.9539 & -0.4792 & -1.83 & -1.299 \\
\hline & Neuron d7 & $<0.0001$ & $<0.0001$ & & 0.4747 & -0.8762 & -0.3455 \\
\hline & Neuron d14 & $<0.0001$ & 0.0554 & 0.0243 & & -1.351 & -0.8202 \\
\hline & Neuron d21 & $<0.0001$ & $<0.0001$ & $<0.0001$ & $<0.0001$ & & 0.5306 \\
\hline & Neuron d28 & $<0.0001$ & $<0.0001$ & 0.1209 & $<0.0001$ & 0.0059 & \\
\hline
\end{tabular}

\begin{tabular}{|c|c|c|c|c|c|c|c|}
\hline \multirow[t]{2}{*}{ SLC32A1 } & \multicolumn{7}{|c|}{ Mean difference } \\
\hline & & iPSC & NPC & Neuron d7 & Neuron d14 & Neuron d21 & Neuron d28 \\
\hline \multirow{6}{*}{ 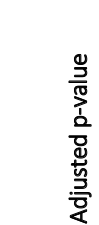 } & iPSC & & -6.254 & -8.48 & -8.563 & -9.491 & -9.004 \\
\hline & NPC & $<0.0001$ & & -2.226 & -2.309 & -3.237 & -2.75 \\
\hline & Neuron d7 & $<0.0001$ & $<0.0001$ & & -0.08287 & -1.011 & -0.5238 \\
\hline & Neuron d14 & $<0.0001$ & $<0.0001$ & 0.9937 & & -0.9278 & -0.4409 \\
\hline & Neuron d21 & $<0.0001$ & $<0.0001$ & $<0.0001$ & $<0.0001$ & & 0.4869 \\
\hline & Neuron d28 & $<0.0001$ & $<0.0001$ & 0.0164 & 0.0814 & 0.0289 & \\
\hline
\end{tabular}





\section{CHAPTER10}

SUMMARY, GENERAL DISCUSSION AND CONCLUDING REMARKS 



\section{Summary of main findings}

Humans are increasingly exposed to compounds through the environment, food and pharmaceuticals. Safety testing of these compounds is therefore indispensable and is required by law, with specific test guidelines for industrial chemicals, pesticides and pharmaceuticals. These tests are predominantly performed using laboratory animals. Obligatory test guidelines that require large numbers of animals include reproduction and developmental toxicity assessments. These tests are important, because the developing embryo may be more sensitive to compound exposure compared to adults. While animal testing has offered many valuable insights into the (developmental) toxicity of compounds, there is increasing concern that animal tests may fall short for the prediction of human safety. Besides this main scientific argument there are also serious ethical and economic reasons to rethink the manner in which compounds are assessed for their potential hazard. A dominant new approach that is being investigated in the toxicology field is the assessment of compounds using a combination of (human) cell cultures and non-mammalian organisms (such as worms, fish and flies), combined with computational approaches that can make predictions based on knowledge about human biology and physio-chemical properties of compounds. Using this approach, emphasis is laid on the mechanism(s) by which a compound is toxic instead of only studying whether a compound is toxic given a specific dose, which enhances prediction for human safety.

The area of research in this thesis is early brain development of the embryo, an area that is tested to a limited extent in the current test guidelines. Since human brain development is a highly complex process that is only partly mimicked in rodents, there is a high need for better models. In this thesis two in vitro models are investigated for their use in hazard assessment of compounds that can cause developmental neurotoxicity (DNT). Both models are based on embryonic stem cells, using cells from murine and human origin, respectively, which allow detailed observation of developmental processes during neural cell differentiation. These models can by no means completely replicate embryonic brain development. The goal is therefore to characterise the cell cultures in what they do and do not mimic, thereby defining their biological domain. This is mainly done through whole transcriptome analysis using RNA-seq and protein expression analysis using immunocytochemistry. Since both models are cell differentiation models, there is a focus on tracking cell types that emerge and disappear during neural differentiation.

This thesis consists of two parts. In the first part (chapter 2-6) the biological domain and capabilities of the murine neural embryonic stem cell test (mESTn) to assess neurodevelopmental toxicants is investigated. mESTn was previously introduced and improved in our lab and comprises a 13-day differentiation protocol of mouse embryonic stem cells (mESC) into a mix of neurons and glial cells. In chapter 2, 5 and 6 we show that during differentiation mESTn gives rise to a broad range of cell types along the ectodermal and neural cell lineage: stem cells, neural progenitor cells (NPC), neural crest cells, several subtypes of neurons, astrocytes and oligodendrocytes. Compared to in vivo development, mESTn mimics early neural differentiation of cells in the neural tube from the hindbrain to the thoracic region of the spinal cord between E6.5 and E12.5 of mouse development. This is determined by transcriptome analysis of genes encoding morphogenetic regulators, Hox genes and cell type markers. Using the same gene 
set, effects of a diverse set of compounds could be revealed, as shown in chapter 2 . Chapter 3 emphasises the importance of being familiar with basic culture ingredients that are involved in the same processes as a toxicity pathway of interest. Exposure scenario, timing and readout methods can have an influence on the experimental results, which is important to control well to produce sound science. Also oxygen tension can have a major effect on neural cell differentiation by modulating cell type proportions, which is investigated in chapter 4 . With regard to sensitivity to compounds, mESTn is able to distinguish structural analogues based on morphology, gene expression and protein expression, as is shown with valproic acid, 2-ethylhexanoic acid and 2-ethyl-methylpentanoic acid in chapter 5. It is also shown that for measuring gene expression to assess cell types, day 7 and 13 are the most suitable time points. A whole transcriptome analysis on these time points reveals the common and distinct effects of the selective serotonin-reuptake inhibitor fluoxetine and the serotonin-noradrenaline-reuptake inhibitor venlafaxine on mESTn, as described in chapter 6 . Besides analysis of the whole transcriptome, a cell lineage map of the ectodermal and neural differentiation pathways is presented. This map provides a first indication of which differentiation routes may be affected based on gene expression regulation of cell type specific markers. Specific receptors that are therapeutic targets of both fluoxetine and venlafaxine are regulated when they are expressed on day 13. Additionally, a common effect on oligodendrocyte markers by both compounds is revealed by the cell lineage map, which is an understudied effect of these compounds. This shows that mESTn may be a useful model for early neural differentiation to study effects of compounds on cell type marker expression and thereby potentially revealing new modes of action.

The second part of this thesis (chapter 7-9) describes the development and characterisation of a novel human embryonic stem cell (hESC)-based neural differentiation protocol called the human neural progenitor test (hNPT). The protocol comprises a two-step procedure based on existing protocols with some modifications as outlined in chapter 7 . In the first step, stem cells are differentiated to NPC that can be frozen for later use. In the second step NPC are differentiated into a neuron-astrocyte co-culture that present spontaneous electrical activity within three days of differentiation and lasting for at least four weeks, which is showing evidence of the complexity of the model. Spontaneous electrical activity is an important feature of neural development, and the speed with which these synaptic connections form in this model is beneficial in the light of fast toxicity testing. Several protocols tested for this second step resulted in different ratios of neurons and astrocytes. One protocol is chosen for toxicity testing, as presented in chapter 8 , based on the spontaneous electrical activity and gene and protein expression of cell type markers. The differentiation protocol is shortened into a test protocol that lasts for ten days, because by that time point the culture expresses important mature neuron and astrocyte markers and presents spontaneous electrical activity. Similar to chapter 2 and 6 , whole transcriptome data reveals the biological domain and the sensitivity to DNT compounds of hNPT. Dominant biological processes that are regulated in hNPT are neural differentiation, axon and dendrite development, synaptogenesis, synaptic signalling and neuron apoptosis. Of these processes, axon development, neuron apoptosis and synaptic signalling are sensitive to exposure to a selection of DNT compounds (acrylamide, chlorpyrifos, fluoxetine, methyl mercury and valproic acid). While the first two processes reveal common genes across compound exposure, the last process is differentially regulated by each compound. This indicates that 
hNPT may a useful model for both the detection of DNT compounds as well as investigating specific toxic mechanisms of DNT compounds.

In chapter 9, we show that human induced pluripotent stem cells (hiPSC) can be generated from peripheral blood mononuclear cells, which can be differentiated in a similar fashion to neurons as hESC. The hiPSC can also be differentiated into beating cardiac cells. Generation of neural and cardiac cells show that reprogramming to truly pluripotent hiPSC can be done successfully and that the neural differentiation protocol presented in chapter 7 is robust, since it works with both hiPSC and hESC. 


\section{General discussion}

\section{Neural differentiation of stem cells}

\section{Model considerations}

As the need for human cell-based models to assess DNT becomes increasingly clear, part of this thesis is dedicated to the development of a hESC-based neural differentiation protocol, the hNPT. Scientists are mastering the art of human stem cell differentiation at a fast pace, which facilitates the development of robust and reproducible protocols. This is important in the light of the use of in vitro tests for toxicological purposes. The protocol as presented in thesis is based on three protocols that are either commercially available or previously published by other research groups. The reproducibility and robustness of these protocols has been shown by successfully adopting these methods in our lab and by the differentiation of multiple H9 hESC cell banks (chapter 7 and unpublished data), as well as with hiPSC (chapter 9). Apart from robustness, (high) throughput possibilities are also crucial. Compared to other existing protocols, the 10-day differentiation protocol of the hNPT (chapter 8) that we proposed may sound relatively long compared to differentiation assays that only last for a few days [1-3], but is well within the range that other groups use for similar assays, which range between one to four weeks [4-11]. The first part of the protocol to produce a NPC bank is relatively labour-intensive, but NPC can be frozen and thawed at any time for the second part of the differentiation protocol. Additionally, this second part only needs medium refreshments twice a week, which makes this part suitable for high-throughput applications given the availability of the relevant equipment. Related to this, due to the labour-intensive nature of the first part of the protocol, we have chosen to not use this part for compound testing. This does not mean that it is not possible, as has been shown by Chen et al. [10], who could reveal specific effects of compounds at different stages of neural differentiation using a similar protocol as presented in this thesis. Adjustments to the first part of the protocol may allow for higher throughput to test effects of compounds on NPC generation and early development.

Having control over a cell culture is important for two reasons. First of all, being aware of the culture conditions is needed to interpret experimental results for DNT prediction based on the mechanisms represented in the model. This has been shown in chapter 3 , where the toxic mode of action of methotrexate affects the one-carbon pathway in MESTn, which is regulated by the basic culture ingredients folic acid and methionine. By changing the concentrations of these nutrients, toxicological outcomes may become different. It is important to realise that the artificial nature of culturing in vitro has consequences for the experimental results. Second, control over culture conditions allows for tweaking the culture system according to one's needs. For example, eight culture variations were tested in hNPT in chapter 7, which each produced (subtle) differences in cell type proportions, related gene expression and trends in spontaneous electrical activity. More profound differences were found in the mESC-based differentiations performed in different oxygen conditions in chapter 4 . Cardiac differentiation in $5 \%$ as opposed to $20 \%$ oxygen tension severely inhibited the development of cardiomyocyte beating in this test. Neural differentiation was both influenced by oxygen tension during the stem cell maintenance and neural differentiation, whereby the proportions of different cell types shifted in each of the four culture scenarios based on gene expression measurements. Being in control over the culture conditions, therefore, allows for choosing the optimal protocol given a research question. 


\section{Test set-up considerations}

Setting up a biologically relevant cell culture is one step, measuring effects of compounds on differentiation in these cultures is another. What is measured at what time point is, again, highly dependent on the culture protocol and the exposure scenario. Gene expression is both time and concentration dependent ([12-14] chapter 5,6,8). Previous studies in mESTc and mESTn have shown that measuring gene expression 24 hours after exposure to a compound provides a robust readout of altered biological processes in these tests [12,15]. In chapter 5 , we show that for measuring cell type distributions, day 7 and 13 (i.e. 96 or 240 hours of exposure) may be more suitable. The time point of measurement may also be dependent on the differentiation process of interest. For example, differentiation of stem cells into neural crest cells occurs early on in the differentiation (chapter 5) while differentiation into astrocytes and/or oligodendrocytes can only be measured later on (chapter $5,6,7,8$ ).

The timing of the readout can influence the interpretation of compound effects. As shown in chapter 3 , results may turn out different or even opposite depending on whether the gene expression is performed after 24 or 240 hours of exposure. This is related to the point mentioned above; one needs to be in control over the cell culture in order to know whether an observation represents a true biological effect or an artefact caused by the way the cells are being cultured. To complicate things even more, compounds can have multiple development-related modes of action. For example, valproic acid can both cause neural tube defects early in development $[16,17]$ and autism-like behaviour later in development [18]. Depending on the exposure scenario and biological domain of a test it may be possible to catch mechanistic pathways involved either or both of these effects.

With regard to readouts, the tandem of gene expression and protein expression measurements is a powerful combination to screen and confirm changes in cell type markers as a proxy for differentiation toxicity. Downregulation of gene expression of a cell type marker may indicate several things: inhibited differentiation of a cell type, specific toxicity to a cell type or decreased expression of that specific marker in a cell type, without changing the number of cells. Therefore it is essential to study the effect on protein level. Immunocytochemistry may give more insight in this on a qualitative or semi-quantitative level, for example the obvious downregulation of Gfap and GFAP in valproic acid exposed mESTn (chapter 5) or the changes in both GFAP and GFAP expression in each hNPT protocol (chapter 7). However, more subtle changes in gene expression are harder to measure on the protein level using this approach (e.g. chapter 3, 4). Application of flow cytometry may be able to provide a sensitive and quantitative measure to determine the effect of compounds (or culture methods) of cell type marker expression.

\section{Using in vitro neural cell differentiation for prediction of developmental neurotoxicity of compounds}

A central assumption in this thesis is that cell differentiation is an important feature of (neural) development, and that disturbances by compounds will be reflected in the expression of differ- 
entiation markers. While this is obviously true, this is certainly not the only developmental process that may be mimicked in vitro and may be used to study compounds-induced DNT. Other processes in human brain development on a cellular level include cell proliferation, migration, cell-cell interactions, apoptosis, neurite outgrowth, synaptogenesis, and more. These events occur in different (combinations of) cell types and in different developmental time windows, amongst others gastrulation, neurulation, network formation and neural patterning [19]. It is important to be aware that there is probably only a very limited part of neurodevelopment that can be mimicked in a single cell-based in vitro assay. That does not mean that it may not be possible to measure multiple of the above mentioned processes in a single culture. Indeed, there are in vitro tests under review for regulatory implementation that are alike mESTn in which migration from an embryoid body (EB) structure is measured alongside neural differentiation and other neurodevelopmental processes $[20,21]$. This may be possible to do as well with mESTn when having the appropriate analytical tools $[9,22,23]$. Likewise, it may be possible to quantitatively measure neurite outgrowth, axon guidance and synaptogenesis in hNPT on a protein level based on the RNA-seq results (chapter 8), which has been done before in primary rat cultures $[24,25]$ and human hiPSC-derived neurons $[4,26]$. Measuring different features in one culture system can enhance the mechanistic understanding of compound effects, but the relevance of the parameters should be tested vigorously using compounds with known modes of action [27].

Multiple other differentiation assays have been developed over the years, which each have their own focus on what they are supposed to mimic. mESC-based protocols have the advantage that they can be cultured relatively fast from mESC to a mix of maturing neurons and glial cells, while hESC-based tests typically need the same amount of time to only reach the NPC-stage. Comparable to mESTn in terms of culture method is the mESC-based differentiation assay developed by Zimmer et al. [28] that puts emphasis on various neurodevelopmental processes by tracking gene expression of various cell type markers [29], synaptic components, axon guidance and collagens. Sanchez-Martin et al. [30] focused on a selection of gene markers of neural differentiation, synapse-related processes and axon growth, while Visan et al. [31] focussed on a smaller array of cell type markers, but made quantitative measurements of neurons and astrocytes using flow cytometry. A hESC-based version of early differentiation was recently published with the advantage that not only neural differentiation but also other ectodermal lineages can be examined [32]. Analysing the morphology of neural rosettes analogous to the neural tube has shown a promising method to study genetic defects and the rescue potential of folic acid [33,34] or early neurotoxicants [35]. As already mentioned above, a multi-stage protocol, very similar to the first part of our hNPT protocol (from ESC to NPC), was proposed to measure DNT at different stages of neural differentiation (stem cells, EBs, rosettes, NPC, neurosphere) based on cytotoxicity and subsequent transcriptome analysis [10]. Other groups have also employed this combination of cytotoxicity measurements and subsequent transcriptomics on single early time points of differentiation [1 1,36-38]. However, most hESC or hiPSC-based differentiation protocols focus on the part from the NPC stage to neurons or neuron-glia co-cultures, similar to the protocol presented in this thesis (chapter 7 ). These cultures are grown in $2 \mathrm{D}$ structures $[39,40]$ or a secondary 3D structure $[20,21]$, which contain neurons and astrocytes. In these models there is a main focus on imaging-based methods to track synaptogenesis [4], neurite outgrowth $[4,26]$, differentiation, proliferation $[20,21,41]$ and migration $[20,21,42]$ as a measure of DNT. These models are considerably less complex than brain spheres containing 
neurons, astrocytes [43-45] and oligodendrocytes [46-48]. Microglia, the last major cell population in the brain that is least present in current in vitro cultures, have to be introduced separately in these brain spheres $[9,38,49]$, but organotypic cultures mimic neural differentiation to such an extent that also microglia can develop spontaneously in the culture [50]. These models, while more complex and much lengthier, allow for deeper mechanistic insight into the effect of compounds. Still, one has to keep in mind that even complex organoid structures may not (yet) be sufficiently complex to study the whole course of neural development. Whole non-mammalian organisms such as zebrafish, fruit flies and C. Elegans can aid in gaining insight in compound effects on later and more complex neurodevelopmental processes and may bridge cellbased and in vivo toxicology $[51,52]$. In conclusion, there are many differentiation models that each have their own advantages and disadvantages, and that can each fill a niche for a specific application in DNT research. Combining these models in a testing strategy can help to predict human-relevant DNT of compounds. Crucial for successfully building this testing strategy is to extensively characterise which processes and mechanisms are represented in each of the models, as we have explored for our assays in this thesis.

\section{Looking at stars in the city: cell type markers in whole transcriptome data}

In this thesis a transcriptomics approach was taken as the first step to comprehensively track neural differentiation in both mESTn and hNPT (chapter 2, 6, 8). This approach also aided in studying the effects of compounds on the differentiation track, both in terms of affected biological processes and cell types. The advantage of using RNA-seq as opposed to microarrays is that the data can keep being reinterpreted as knowledge about fundamental biology grows, because no prior knowledge is needed about the sequence of interest [53-55]. This is especially important in the case of the brain where much still needs to be discovered. The roles of multiple transcript variants and non-coding RNA are also only beginning to be elucidated, but they most likely play an important role in development $[56,57]$ and have already been shown to be affected by toxicants, for example by lead [58,59].

A disadvantage of transcriptome data is that the interpretation is currently still challenging due to its vast scale. A substantial part of the data interpretation is semi-quantitative; based on a p-value (and fold change) cut-off, lists are generated of differentially regulated genes and enriched pathways. Little is done with the magnitude of gene regulation in the toxicogenomics field, except by some tools such as GSEA [60], which is best at detecting trends in enriched pathways. The distinction between adaptive versus adverse responses through gene expression regulation is also challenging to make [61], although there are methods to flag cytotoxicity using a set of biomarkers, pathway enrichment [62] or deviation from the differentiation track [63]. Since the introduction of pathway enrichment tools, there has not been a major revolution in the analysis of transcriptomics data. The use of Al technologies may bring new breakthroughs in the field. For example, convolutional neural networks may be promising tools that can aid data interpretation by detecting patterns in visualisations of gene expression changes $[64,65]$. This tool, however, still has many hurdles to overcome and has not yet been applied in a toxicology context. What is crucially needed to make the implementation of these tools a success is to have good quality input data of multiple time points, concentrations and compounds. Third generation sequencers may aid massive generation of this data due to their higher sequencing speed, but still have to overcome the challenges of large error rates [66]. 
Until these technologies are more developed, a targeted approach can aid data interpretation done by humans, for example by selecting the most responsive biomarkers to toxic exposure in a whole transcriptome data set [63] or by selecting genes based on co-expression with other genes in the same pathway like the L1000 and S1500+ gene sets $[67,68]$. For the purpose of this thesis we chose to construct a cell lineage map to track neural differentiation of stem cells (chapter 6). This idea is not new; Kügler et al. [29] already compiled a list of cell type markers ten years ago with the main focus on stem cells, NPC, astrocytes and neurons, but not on neuron subtypes. In recent years, multiple open and commercial tools have been developed to assess cell types like LifeMap Discovery, which have a large database of embryonic development with associated tissues, cell types and selective markers. However, quantitative information is lost in these tools as only lists of differentially regulated genes are used as input. With the cell lineage map we aimed to keep the balance between a limited but redundant selection of genes while preserving the insight in the amount of gene regulation. Based on the first studies with mESTn and hNPT the cell lineage map can provide guidance in the selection of protein markers for immunostainings or flow cytometry to identify cell populations. The map can also be updated when markers behave similarly (e.g. stem cell markers, chapter 2), or expanded to more cell types. With the shift in focus in the DNT field towards cognitive disorders, the cell lineage map can be specifically expanded to include more neural and glial subtypes. Over the past few years, neuroscientists have been delineating the vast number of cell types in the developing and the adult brain using a single cell RNA-seq approach $[69,70]$. This opens up many opportunities for better characterisation of cell types in a cell culture [71], further improvements and fine-tuning of differentiation protocols towards specific brain regions and developmental windows [72-76], and the study of vulnerable cell types by exposure to toxic compounds [77-79].

\section{What developmental neurotoxicology can learn from neuroscience}

There seems to be a rise in cognitive disorders among children, which might be in part caused by exposure to compounds [80-84]. To investigate this notion, more advanced DNT testing is required, which is challenging in animals and even more challenging in cell-based assays. At the same time, because cognitive disorders are typically human, there may lie an opportunity here for human cell-based in vitro models to provide more insight into the relation between compound exposure and cognitive disorders. This requires the development and/or proper characterisation of advanced, human cell-based in vitro models and readouts that focus on these later developmental processes. Here, the DNT field can adopt promising, region specific stem cell-based culture protocols for neocortical [85], midbrain [86], hindbrain [87] and peripheral [88] neural cultures, and many more are being developed [89]. The increasing ease with which hiPSC are being produced is a promising development that can greatly enhance the use of these in vitro models to study patient-specific material and gene-environment interactions (chapter 9). Another focus point is to find readout technologies for synapses. Contributing gene mutations of many cognitive disorders lie in synaptic connectivity [90], therefore compounds acting on the same pathway as those genes may result in a similar phenotype [91]. In a toxicological context, Pistollato et al. [4] has shown a promising application of high content imaging of synapses of neurons exposed to compounds. However, this is only based on two synaptic markers that are only a subpopulation of the wide family of excitatory synapses [92,93], let alone the subfamilies of inhibitory synapses and further diversity caused by alternative splice 
variants [94]. The neuroscience field is only delineating synaptic and neuron diversity in recent years $[69,93,95,96]$, which will greatly enhance our understanding of the in vitro systems that we are working with, what their biological domain is and what we therefore can expect to find in these models in response to DNT compounds. The DNT field should keep a close eye on the developments in neuroscience and apply them readily, while also continuing to develop computational tools to integrate information of cell-based assays that can be translated to adverse outcomes.

\section{Defining the biological domain of in vitro neural differentiation models}

\section{Distinguishing chemical versus biological domain and the need for charac- terisation of both}

From the early days of the transition towards animal-free testing it was realised that a single in vitro model only represented a limited part of the in vivo situation. Initially, the focus was mainly put on attempting to describe the boundaries of an in vitro test by determining the chemical applicability domain. This was defined as to which compounds or compound classes an assay was or could be sensitive [97-99], based on the history of tested compound classes in the assay plus physicochemical limitations such as those related to compound solubility and volatility. This approach seems quite efficient, because it allows for fast determination of whether an in vitro assay is suited to test compounds of the same class (e.g. petroleum products, pesticide classes). However, a disadvantage of this reasoning is when false positives and false negatives are detected by an in vitro assay or even a battery of assays it can remain elusive why a compound is classified incorrectly. Projects that used a series of in vitroassays to predict developmental (neuro)toxicity of compounds and compound classes have shown that false negatives could be explained by missing biological pathways in the battery $[100,101]$. This fuelled another approach that has been gaining more attention in the last decade, which is defining the biological domain of an in vitro model, i.e. which part of biology is represented [19,102-105]. There are, theoretically, a finite number of biological processes in the human body, which should be able to be mapped based on the wealth of biological knowledge that is available to us [106]. The most important biochemical processes occurring in the cell have already been outlined [107] and by expanding on this knowledge it should be possible to define which biological processes are being mimicked in an in vitro test and, just as important, which are not. To some extent these concepts of chemical and biological domain may be regarded as two sides of the same medal, because they both attempt to define the boundaries of an in vitro assay. This is being increasingly acknowledged in the DNT field, stressing the importance of knowing the biological context of a cell culture (cell origin, cell complexity, place in in vivo (neuro)development) as well as the technical specifications, which is in fact the chemical applicability domain (robustness with chemicals training set, which compounds can be tested (e.g. volatile compounds)) $[51,108]$. This requires extensive characterisation of an in vitromodel and a considerate choice of compounds. 


\section{Defining the biological domain requires extensive characterisation}

It is clear that due to the reductionist nature of in vitro assays animal-free testing will require multiple tests to cover the whole biological space of human physiology. In the field of human brain development, timing is an extra dimension that needs to be taken into account, which makes it even more important to pinpoint what a single in vitro test is mimicking at which stage in development. This is also crucial in the light of defining the uncertainties of animal-free tests in terms of relevance and reliability, which is needed for validation of in vitro tests [109]. Part of this thesis is therefore focussed on attempts to define the biological domain of the two in vitro tests, i.e. which developmental processes and underlying mechanisms are mimicked in an assay and its related endpoints [19]. In mESTn attention was mainly focused on early morphogenetic regulators and cell types (chapter 2,6 ), alongside biological processes described by GOterms (chapter 6; [12]). In hNPT the main focus was on cell types and synaptic connectivity together with biological processes given by GO-terms (chapter 7, 8). For both tests a combination of whole transcriptome analysis and protein expression was chosen, but there are other approaches possible depending on the in vitro test that needs to be characterised. We have performed limited functional activity assessment in hNPT using an mwMEA, which was sufficient for our research question (i.e. do neurons in hNPT make functional connections, chapter 7). However, models that mimic functional network formation to measure compound effects on electrical activity should be optimised to enable a reliable readout for neurodevelopmental toxicity. Extensive characterisation also allows for the combination of complementary models to study compounds across development [110]. For example, neural crest cells are both present in mESTn and mESTc (chapter 4; [111]), and mESTn and hNPT both contain NPC, neurons and astrocytes (chapter $5,7,8$ ). In the future, more in vitro tests with complementary biological domains can be linked up with each other to create a testing battery, for example an endodermal differentiation test alongside mESTc and mESTn to cover early cell differentiation along the three germlines $[112,113]$ and regionally defined neural cultures with multiple cell types for later neural differentiation $[23,85,114,115]$.

\section{Choosing compounds: choose many or choose wisely}

After characterisation of its biological domain, it is important to challenge an in vitro model with a selection of compounds to test the applicability of the model for toxicological purposes. There are roughly two approaches to this applied so far, which have a different focus depending on the purpose of the in vitro assay in question. One is testing a large number of compounds that are known or suspected to cause DNT in rodents and/or humans, which focusses on the concentration at which a compound causes adverse effects in an assay [108]. This is a screening application to rank compounds by DNT-specific effects and potency, which allows for fast prioritisation of compounds that may require regulatory action to limit their exposure. The in vitro model does not need to be perfect but should reach sufficient predictivity (in a testing battery) given this set of DNT compounds. Another, more mechanism-based approach is applied in this thesis whereby a limited number of compounds with known effects is tested to investigate whether expected biological processes are present and the different cell types are responsive in the in vitro assay $[116,117]$. This approach focusses more on extensively assessing the 
boundaries of an individual in vitro model. A list of DNT compounds with known modes of action has been compiled [27] of which methyl mercury and valproic acid were also used in mESTn and hNPT.

What is not (extensively) tested in either of our in vitro assays are DNT negative compounds of which there is also a preliminary list available [27]. 'True' DNT negative compounds are hard to definitely classify as being negative, because at sufficiently high concentrations, every compound will elicit some kind of adverse response in the in vitro system. Irrelevant compound concentrations for testing can be precluded by determining the concentration range of a compound relative to internal exposures in vivo and apply that range in the in vitro test. Another guidance is to look at the selectivity of a compound as to the nature of the in vitro effect. For example, what is the order of magnitude difference between inhibition of cell differentiation and decrease in cell viability? And what is the order of magnitude difference between decreased cell viability of differentiated neurons versus undifferentiated stem cells? Constructing concentration-response curves of different endpoints and studying elicited gene expression changes can give more insight into this. Taking these different readout parameters in consideration, the proposed DNT negatives may serve as a tool to observe background noise and robustness of an assay $[27,118]$.

\section{In vitro neural differentiation models in risk assessment}

\section{Integrating in vitro models into testing strategies}

As has already been eluded to in previous sections, the two in vitrotests presented in this thesis can only cover a very limited part of neurodevelopment. Therefore, these assays should be placed in a larger framework with complementary tests that can together aid in compound prioritisation, hazard identification or risk assessment, depending on the regulatory framework. The tests may be of use in some of the frameworks that are currently being developed [51]. They can be used to test for one of the neurodevelopmental processes that have been defined by the OECD as part of Integrated Approaches to Testing and Assessment (IATA) for DNT [1 18]. They may represent one or more key events in an adverse outcome pathway (AOP) [102,119]. They may also be used to derive quantitative in vitro input from about rate-limiting key events in a DNT ontology [19]. Whether the in vitro assays are deemed useful is highly dependent on whether the complexity of the cell culture is in proportion to the information it needs to provide. It may be that either of the tests does not yet sufficiently mimic neural differentiation and more complex models may be needed that complement or replace these in vitro assays. It may also be that the tests turn out to be too complex for providing information just on a single key event or neurodevelopmental process. The same is true for the readout that we have developed in the form of the cell lineage map. The cell lineage map may offer a fast first indication of the cell types present in an in vitroassay of interest as well as perturbation of cell types by compounds. Whether this is sufficient, too complex or too simple is highly dependent on the overall purpose of the framework: is it a prioritisation tool, is it built for hazard identification or is it supposed to provide a full human risk assessment?

An interesting question is in which direction stem cell-based in vitroassays may evolve to contribute to a testing strategy. Will relatively simple models that mimic simple key events suffice or do we need to build complex 3D or organotypic cultures for the toxicological questions at 
hand? This is partly dependent on how fast different fields in toxicology and other disciplines will develop. In the future, (parts of) human physiology may be fully digitalised in what is called the Virtual Human [106]. These kind computational tools may require limited input from highthroughput in vitro assays and all the other steps toward human-relevant results may be calculated in silico [120-122]. On the other hand, the (developing) brain is still a poorly understood organ, which hampers capturing this organ in silico. Developing more complex in vitro models is therefore probably the more likely direction taken in the short term. It will also ultimately depend on which depth of information is regarded to be sufficient according to the toxicological community to make safe predictions for human toxicology.

\section{Animal-free methods in human risk assessment}

Regardless the framework of choice, there are other elements that are needed to translate results from individual in vitro assays to human-relevant risk assessment. To translate in vitro results to in vivo concentrations, quantitative in vitro to in vivo extrapolation (QIVIVE) is needed. The exposure scenario is fundamentally different in in vitro versus in vivo situations and therefore implementation of kinetic modelling will be key to determine how much of the compound cells in vitro are actually exposed to [123]. Another point of attention is that in most in vitro systems, there is no interaction with other parts of the body. Therefore, they lack information about effects of metabolism, the immune system, barrier effects (blood-brain barrier and placenta), hormones and connections with other organ systems (e.g. brain-gut [124,125]), all of which are also development dependent. These are all important factors that determine and potentially change the toxicity of a compound and may also play a key role in the mode of action of a compound in the target tissue. Whether these factors will be assessed in vitro or modelled in silico (which will be based on, ideally, human in vivo data) will again depend on how fast different technologies will evolve and which scientific question needs to be answered. For example, if the use of multiple organs or a whole body-on-a-chip becomes widespread, researchers may turn to these more complex in vitro systems, while if in silico approaches take a leap that only need input from high-throughput in vitro tests, this may become a dominant approach.

\section{Concluding remarks and future perspectives}

This thesis describes the characterisation and application of two animal-free in vitro tests based on embryonic stem cells for the assessment of compounds that are potentially toxic to the developing brain. mESTn mimics parts of very early neural cell differentiation of the neural tube and early hindbrain and spinal cord, and presents a wide array of different cell types along the ectodermal and neural cell lineage. hNPT mimics later developmental processes such as neuron and astrocyte differentiation, axon guidance and synaptic connectivity. These tests can, in combination with other animal-free tests, provide experimental data that can be used as part of a testing strategy to make predictions about if and how compounds may be harmful to normal neural development.

A number of recommendations for the future can be done based on the data in this thesis: 
- Use single cell RNA-seq to more extensively characterise these and other (stem) cellbased cultures, and validate findings using protein-based techniques such as immunocytochemistry and flow cytometry. Single cell RNA-seq may also be used for elucidating potential mechanisms of toxicity on specific cell types;

- Swiftly adopt and design protocols based on new neural differentiation methods, readout technologies and analysis tools for neural subtypes or brain regions that are being developed in the neuroscience field;

- Increase the use of hiPSC as a way forward to account for variation in the human population and the consequences this has for adverse outcomes caused by compounds;

- Further map neurodevelopment based on existing (neuro)biological data, determine which models are already available and which complementary tests are needed to mimic later and/or more complex processes such as the involvement of other cell types in brain development, development of different brain regions, and the effect of the developing blood-brain barrier;

- Taylor individual and combinations of in vitro assays to the regulatory purpose of the testing strategy (prioritisation, hazard assessment, risk assessment);

- Build computational tools that can integrate in vitro data into from multiple assays into a framework that can predict human-relevant adverse outcomes;

- Invest in making in vitro assays completely animal-free, also as with regard to culture ingredients. Beside the ethical argument that animal-derived ingredients should not be used in otherwise animal-free tests, the in vitro assay's reproducibility may be enhanced using non-animal reagents.

The toxicology field is currently in full transition moving from an animal-based black box towards a human-based, animal-free and mechanistic paradigm. One of the inherent features of the current situation is that there are many different opinions and initiatives posited on how to shape this future. On top of that, toxicology is a discipline that has many stakeholders involved, which makes it even more challenging to achieve consensus on the ideal way forward $[126,127]$. Academia, governmental institutions, the private sector and nongovernmental organisations each have their own questions and their own agenda, which can be overwhelming for the naive scientist. It is key to join these different perspectives into a common goal that accommodates the requirements of all these stakeholders, and will provide better and more efficient human safety testing of compounds, without the use of animals. 


\section{References}

[1] T.J. Zurlinden, K.S. Saili, N. Rush, P. Kothiya, R.S. Judson, K.A. Houck, E.S. Hunter, N.C. Baker, J.A. Palmer R.S. Thomas, T.B. Knudsen, Profiling the ToxCast Library with a Pluripotent Human (H9) Stem Cell LineBased Biomarker Assay for Developmental Toxicity, Toxicol. Sci. 174 (2020) 189-209. https://doi.org/10.1093/toxsci/kfaa014.

[2] Y. Pei, J. Peng, M. Behl, N.S. Sipes, K.R. Shockley, M.S. Rao, R.R. Tice, X. Zeng, Comparative neurotoxicity screening in human iPSC-derived neural stem cells, neurons and astrocytes, Brain Res. 1638 (2016) 57-73. https://doi.org/10.1016/j.brainres.2015.07.048.

[3] S. Kamata, R. Hashiyama, H. Hana-ika, I. Ohkubo, R. Saito, A. Honda, Y. Anan, N. Akahoshi, K. Noguchi, Y. Kanda, I. Ishii, Cytotoxicity comparison of 35 developmental neurotoxicants in human induced pluripotent stem cells (iPSC), iPSC-derived neural progenitor cells, and transformed cell lines, Toxicol. Vitr. 69 (2020) 104999. https://doi.org/10.1016/j.tiv.2020.104999.

[4] F. Pistollato, E.M. De Gyves, D. Carpi, S.K. Bopp, C. Nunes, A. Worth, A. Bal-Price, Assessment of developmental neurotoxicity induced by chemical mixtures using an adverse outcome pathway concept, Environ. Heal. A Glob. Access Sci. Source. 19 (2020) 23. https://doi.org/10.1186/s12940-020-00578-X.

[5] R. Taléns-Visconti, I. Sanchez-Vera, J. Kostic, M.A. Perez-Arago, S. Erceg, M. Stojkovic, C. Guerri, Neural differentiation from human embryonic stem cells as a tool to study early brain development and the neuroteratogenic effects of ethanol, Stem Cells Dev. $20 \quad$ (2011) 327-339. https://doi.org/10.1089/scd.2010.0037.

[6] J.A. Palmer, A.M. Poenitzsch, S.M. Smith, K.R. Conard, P.R. West, G.G. Cezar, Metabolic Biomarkers of Prenatal Alcohol Exposure in Human Embryonic Stem Cell-Derived Neural Lineages, Alcohol. Clin. Exp. Res. 36 (2012) 1314-1324. https://doi.org/10.1111/j.1530-0277.2011.01732.x.

[7] M. Hofrichter, L. Nimtz, J. Tigges, Y. Kabiri, F. Schröter, B. Royer-Pokora, B. Hildebrandt, M. Schmuck, A. Epanchintsev, S. Theiss, J. Adjaye, J.M. Egly, J. Krutmann, E. Fritsche, Comparative performance analysis of human iPSC-derived and primary neural progenitor cells (NPC) grown as neurospheres in vitro, Stem Cell Res. 25 (2017) 72-82. https://doi.org/10.1016/j.scr.2017.10.013.

[8] A.C. Feutz, C. De Geyter, Accuracy, discriminative properties and reliability of a human ESC-based in vitro toxicity assay to distinguish teratogens responsible for neural tube defects, Arch. Toxicol. 93 (2019) 23752384. https://doi.org/10.1007/s00204-019-02512-8.

[9] M. Brüll, A.-S. Spreng, S. Gutbier, D. Loser, A. Krebs, M. Reich, U. Kraushaar, M. Britschgi, C. Patsch, M. Leist, Incorporation of stem cell-derived astrocytes into neuronal organoids to allow neuro-glial interactions in toxicological studies, ALTEX. (2020). https://doi.org/10.14573/altex.1911111.

[10] H. Chen, H. Seifikar, N. Larocque, Y. Kim, I. Khatib, C.J. Fernandez, N. Abello, J.F. Robinson, Using a MultiStage hESC Model to Characterize BDE-47 Toxicity during Neurogenesis, Toxicol. Sci. 171 (2019) 221-234 https://doi.org/10.1093/toxsci/kfz136.

[11] J.-H. Oh, M.-Y. Son, M.-S. Choi, S. Kim, A. Choi, H.-A. Lee, K.-S. Kim, J. Kim, C.W. Song, S. Yoon, Integrative analysis of genes and miRNA alterations in human embryonic stem cells-derived neural cells after exposure to silver nanoparticles, Toxicol. Appl. Pharmacol. $299 \quad$ (2016) 8-23. https://doi.org/10.1016/J.TAAP.2015.11.004.

[12] P.T. Theunissen, J.L.A. Pennings, J.F. Robinson, S.M.H. Claessen, J.C.S. Kleinjans, A.H. Piersma, Timeresponse evaluation by transcriptomics of methylmercury effects on neural differentiation of murine embryonic stem cells, Toxicol. Sci. 122 (2011) 437-447. https://doi.org/10.1093/toxsci/kfr134

[13] P.T. Theunissen, J.F. Robinson, J.L.A. Pennings, E. De jong, S.M.H. Claessen, J.C.S. Kleinjans, A.H. Piersma, Transcriptomic concentration-response evaluation of valproic acid, cyproconazole, and hexaconazole in the neural Embryonic Stem Cell Test (ESTn), Toxicol. Sci. 125 (2012) 430-438. https://doi.org/10.1093/toxsci/kfr293.

[14] P.T. Theunissen, J.F. Robinson, J.L.A. Pennings, M.H. van Herwijnen, J.C.S. Kleinjans, A.H. Piersma, Compound-specific effects of diverse neurodevelopmental toxicants on global gene expression in the neural embryonic stem cell test (ESTn), Toxicol. Appl. Pharmacol. 262 (2012) 330-340. https://doi.org/10.1016/j.taap.2012.05.011.

[15] D.A.M. van Dartel, J.L.A. Pennings, P.J.M. Hendriksen, F.J. van Schooten, A.H. Piersma, Early gene expression changes during embryonic stem cell differentiation into cardiomyocytes and their modulation by monobutyl phthalate, Reprod. Toxicol. 27 (2009) 93-102. https://doi.org/10.1016/j.reprotox.2008.12.009.

[16] W. Löscher, H. Nau, Pharmacological evaluation of various metabolites and analogues of valproic acid Anticonvulsant and toxic potencies in mice, Neuropharmacology. 24 (1985) 427-435. https://doi.org/10.1016/0028-3908(85)90028-0.

[17] J. Jentink, M.A. Loane, H. Dolk, I. Barisic, E. Garne, J.K. Morris, L.T.W. de Jong-van den Berg, EUROCAT Antiepileptic Study Working Group, Valproic acid monotherapy in pregnancy and major congenital malformations., N. Engl. J. Med. 362 (2010) 2185-2193. https://doi.org/10.1056/NEJMoa0907328.

[18] A.M. Tartaglione, S. Schiavi, G. Calamandrei, V. Trezza, Prenatal valproate in rodents as a tool to understand the neural underpinnings of social dysfunctions in autism spectrum disorder, Neuropharmacology. 159 (2019). https://doi.org/10.1016/j.neuropharm.2018.12.024. 
[19] E.V.S. Hessel, Y.C.M. Staal, A.H. Piersma, Design and validation of an ontology-driven animal-free testing strategy for developmental neurotoxicity testing, Toxicol. Appl. Pharmacol. 1 (2018) 136-152. https://doi.org/10.1016/j.taap.2018.03.013.

[20] J. Baumann, K. Gassmann, S. Masjosthusmann, D. DeBoer, F. Bendt, S. Giersiefer, E. Fritsche, Comparative human and rat neurospheres reveal species differences in chemical effects on neurodevelopmental key events, Arch. Toxicol. 90 (2016) 1415-1427. https://doi.org/10.1007/s00204-015-1568-8.

[21] M. Barenys, K. Gassmann, C. Baksmeier, S. Heinz, I. Reverte, M. Schmuck, T. Temme, F. Bendt, T.C. Zschauer T.D. Rockel, K. Unfried, W. Watjen, S.M. Sundaram, H. Heuer, M.T. Colomina, E. Fritsche, Epigallocatechin gallate (EGCG) inhibits adhesion and migration of neural progenitor cells in vitro, Arch Toxicol. 91 (2016) 827837. https://doi.org/10.1007/s00204-016-1709-8.

[22] M.R. Schmuck, T. Temme, K. Dach, D. de Boer, M. Barenys, F. Bendt, A. Mosig, E. Fritsche, Omnisphero: a high-content image analysis (HCA) approach for phenotypic developmental neurotoxicity (DNT) screenings of organoid neurosphere cultures in vitro, Arch. Toxicol. 91 (2017) 2017-2028. https://doi.org/10.1007/s00204-016-1852-2.

[23] X. Zhong, G. Harris, L. Smirnova, V. Zufferey, R. de C. da S. e Sá, F. Baldino Russo, P.C. Baleeiro Beltrao Braga, M. Chesnut, M.-G. Zurich, H.T. Hogberg, T. Hartung, D. Pamies, Antidepressant Paroxetine Exerts Developmental Neurotoxicity in an iPSC-Derived 3D Human Brain Model, Front. Cell. Neurosci. 14 (2020). https://doi.org/10.3389/fncel.2020.00025.

[24] J.A. Harrill, T.M. Freudenrich, D.W. Machacek, S.L. Stice, W.R. Mundy, Quantitative assessment of neurite outgrowth in human embryonic stem cell-derived $\mathrm{hN2}{ }^{\mathrm{TM}}$ cells using automated high-content image analysis, Neurotoxicology. 31 (2010) 277-290. https://doi.org/10.1016/j.neuro.2010.02.003.

[25] J.A. Harrill, T.M. Freudenrich, B.L. Robinette, W.R. Mundy, Comparative sensitivity of human and rat neural cultures to chemical-induced inhibition of neurite outgrowth, Toxicol. Appl. Pharmacol. 256 (2011) 268-280 https://doi.org/10.1016/j.taap.2011.02.013.

[26] K.R. Ryan, O. Sirenko, F. Parham, J.H. Hsieh, E.F. Cromwell, R.R. Tice, M. Behl, Neurite outgrowth in human induced pluripotent stem cell-derived neurons as a high-throughput screen for developmental neurotoxicity or neurotoxicity, Neurotoxicology. 53 (2016) 271-281. https://doi.org/10.1016/j.neuro.2016.02.003.

[27] M. Aschner, S. Ceccatelli, M. Daneshian, E. Fritsche, N. Hasiwa, T. Hartung, H.T. Hogberg, M. Leist, A. Li, W.R. Mundy, S. Padilla, A.H. Piersma, A. Bal-Price, A. Seiler, R.H. Westerink, B. Zimmer, P.J. Lein, Reference compounds for alternative test methods to indicate developmental neurotoxicity (DNT) potential of chemicals: Example lists \& criteria for their selection \& use, in: ALTEX, 2017: pp. 49-74. https://doi.org/10.14573/altex.1604201.

[28] B. Zimmer, P. Kuegler, B. Baudis, A. Genewsky, V. Tanavde, W. Koh, B. Tan, T. Waldmann, S. Kadereit, M. Leist, Coordinated waves of gene expression during neuronal differentiation of embryonic stem cells as basis for novel approaches to developmental neurotoxicity testing, Cell Death Differ. 18 (2010) 383-395. https://doi.org/10.1038/cdd.2010.109.

[29] P. Kügler, B. Zimmer, T. Waldmann, B. Baudis, S. Ilmjärv, J. Hescheler, P. Gaughwin, P. Brundin, W. Mundy, A.K. Bal-Price, A. Schrattenholz, K.-H. Krause, C. von Thriel, M.S. Rao, S. Kadereit, M. Leist, Markers of murine embryonic and neural stem cells, neurons and astrocytes : reference points for developmental neurotoxicity testing, Altern. to Anim. Exp. ALTEX. 27 (2010) 16-42. https://doi.org/10.14573/altex.2010.1.16.

[30] F.J. Sánchez-Martín, Y. Fan, D.M. Lindquist, Y. Xia, A. Puga, Lead induces similar gene expression changes in brains of gestationally exposed adult mice and in neurons differentiated from mouse embryonic stem cells, PLoS One. 8 (2013) e80558-e80558. https://doi.org/10.1371/journal.pone.0080558.

[31] A. Visan, K. Hayess, D. Sittner, E.E. Pohl, C. Riebeling, B. Slawik, K. Gulich, M. Oelgeschläger, A. Luch, A.E.M. Seiler, Neural differentiation of mouse embryonic stem cells as a tool to assess developmental neurotoxicity in vitro, Neurotoxicology. 33 (2012) 1135-1146. https://doi.org/10.1016/j.neuro.2012.06.006.

[32] J. Tchieu, B. Zimmer, F. Fattahi, S. Amin, N. Zeltner, S. Chen, L. Studer, A Modular Platform for Differentiation of Human PSCs into All Major Ectodermal Lineages, Cell Stem Cell. 21 (2017) 399-410.e7. https://doi.org/10.1016/j.stem.2017.08.015.

[33] C. Valensisi, C. Andrus, S. Buckberry, N. Doni Jayavelu, R.J. Lund, R. Lister, R.D. Hawkins, Epigenomic Landscapes of hESC-Derived Neural Rosettes: Modeling Neural Tube Formation and Diseases, Cell Rep. 20 (2017) 1448-1462. https://doi.org/10.1016/j.celrep.2017.07.036.

[34] V. Sahakyan, R. Duelen, W.L. Tam, S.J. Roberts, H. Grosemans, P. Berckmans, G. Ceccarelli, G. Pelizzo, V. Broccoli, J. Deprest, F.P. Luyten, C.M. Verfaillie, M. Sampaolesi, Folic Acid Exposure Rescues Spina Bifida Aperta Phenotypes in Human Induced Pluripotent Stem Cell Model, Sci. Rep. 8 (2018) 2942. https://doi.org/10.1038/s41598-018-21103-8.

[35] N. Dreser, K. Madjar, A.K. Holzer, M. Kapitza, C. Scholz, P. Kranaster, S. Gutbier, S. Klima, D. Kolb, C. Dietz, T. Trefzer, J. Meisig, C. van Thriel, M. Henry, M.R. Berthold, N. Blüthgen, A. Sachinidis, J. Rahnenführer, J.G. Hengstler, T. Waldmann, M. Leist, Development of a neural rosette formation assay (RoFA) to identify neurodevelopmental toxicants and to characterize their transcriptome disturbances, Arch. Toxicol. 94 (2020) 151-171. https://doi.org/10.1007/s00204-019-02612-5

[36] A.K. Krug, R. Kolde, J.A. Gaspar, E. Rempel, N. V. Balmer, K. Meganathan, K. Vojnits, M. Baquié, T. Waldmann, R. Ensenat-Waser, S. Jagtap, R.M. Evans, S. Julien, H. Peterson, D. Zagoura, S. Kadereit, D. Gerhard, I. Sotiriadou, M. Heke, K. Natarajan, M. Henry, J. Winkler, R. Marchan, L. Stoppini, S. Bosgra, J. Westerhout, M. 
Verwei, J. Vilo, A. Kortenkamp, J. Hescheler, L. Hothorn, S. Bremer, C. Van Thriel, K.H. Krause, J.G. Hengstler, J. Rahnenführer, M. Leist, A. Sachinidis, Human embryonic stem cell-derived test systems for developmental neurotoxicity: a transcriptomics approach, Arch. Toxicol. $87 \quad$ (2013) 123-143. https://doi.org/10.1007/s00204-012-0967-3.

[37] S. Colleoni, C. Galli, J.A. Gaspar, K. Meganathan, S. Jagtap, J. Hescheler, D. Zagoura, S. Bremer, A. Sachinidis, G. Lazzari, A comparative transcriptomic study on the effects of valproic acid on two different hESCs lines in a neural teratogenicity test system, Toxicol. Lett. $231 \quad$ (2014) 38-44. https://doi.org/10.1016/j.toxlet.2014.08.023.

[38] M.P. Schwartz, Z. Hou, N.E. Propson, J. Zhang, C.J. Engstrom, V.S. Costa, P. Jiang, B.K. Nguyen, J.M. Bolin, W. Daly, Y. Wang, R. Stewart, C.D. Page, W.L. Murphy, J.A. Thomson, Human pluripotent stem cell-derived neural constructs for predicting neural toxicity, Proc. Natl. Acad. Sci. U. S. A. 112 (2015) 12516-12521. https://doi.org/10.1073/pnas.1516645112.

[39] F. Pistollato, D. Canovas-Jorda, D. Zagoura, A. Price, Protocol for the differentiation of human induced pluripotent stem cells into mixed cultures of neurons and glia for neurotoxicity testing, J. Vis. Exp. 2017 (2017) e55702. https://doi.org/10.3791/55702.

[40] J. Delp, S. Gutbier, S. Klima, L. Hoelting, K. Pinto-Gil, J.H. Hsieh, M. Aichem, K. Klein, F. Schreiber, R.R. Tice, M. Pastor, M. Behl, M. Leist, A high-throughput approach to identify specific neurotoxicants/ developmental toxicants in human neuronal cell function assays, ALTEX. 35 (2018) 235-253. https://doi.org/10.14573/altex.1712182.

[41] L. Buzanska, J. Sypecka, S. Nerini-Molteni, A. Compagnoni, H.T. Hogberg, R. Del Torchio, K. Domanska-Janik J. Zimmer, S. Coecke, A human stem cell-based model for identifying adverse effects of organic and inorganic chemicals on the developing nervous system, Stem Cells. 27 (2009) 2591-2601. https://doi.org/10.1002/stem.179.

[42] J. Baumann, M. Barenys, K. Gassmann, E. Fritsche, Comparative human and rat "neurosphere assay" for developmental neurotoxicity testing, Curr. Protoc. Toxicol. 1 (2014) 12.21.1-12.21.24. https://doi.org/10.1002/0471140856.tx1221s59.

[43] A.M. Pasca, S.A. Sloan, L.E. Clarke, Y. Tian, C.D. Makinson, N. Huber, C.H. Kim, J.Y. Park, N.A. O'Rourke, K.D. Nguyen, S.J. Smith, J.R. Huguenard, D.H. Geschwind, B.A. Barres, S.P. Pasca, Functional cortical neurons and astrocytes from human pluripotent stem cells in 3D culture, Nat. Methods. 12 (2015) 671-678. https://doi.org/10.1038/nmeth.3415.

[44] J. Kobolak, A. Teglasi, T. Bellak, Z. Janstova, K. Molnar, M. Zana, I. Bock, L. Laszlo, A. Dinnyes, Human Induced Pluripotent Stem Cell-Derived 3D-Neurospheres are Suitable for Neurotoxicity Screening, Cells. 9 (2020) 1122. https://doi.org/10.3390/cells9051122.

[45] O. Sirenko, F. Parham, S. Dea, N. Sodhi, S. Biesmans, S. Mora-Castilla, K. Ryan, M. Behl, G. Chandy, C. Crittenden, S. Vargas-Hurlston, O. Guicherit, R. Gordon, F. Zanella, C. Carromeu, Functional and mechanistic neurotoxicity profiling using human iPSC-Derived neural 3D cultures, Toxicol. Sci. 167 (2019) 249-257. https://doi.org/10.1093/toxsci/kfy218.

[46] D. Pamies, P. Barreras, K. Block, G. Makri, A. Kumar, D. Wiersma, L. Smirnova, C. Zhang, J. Bressler, K.M. Christian, G. Harris, G.L. Ming, C.J. Berlinicke, K. Kyro, H. Song, C.A. Pardo, T. Hartung, H.T. Hogberg, A human brain microphysiological system derived from induced pluripotent stem cells to study neurological diseases and toxicity, ALTEX. 34 (2017) 362-376. https://doi.org/10.14573/altex.1609122.

[47] J. Sandström, E. Eggermann, I. Charvet, A. Roux, N. Toni, C. Greggio, A. Broyer, F. Monnet-Tschudi, L. Stoppini, Development and characterization of a human embryonic stem cell-derived 3D neural tissue model for neurotoxicity testing, Toxicol. Vitr. 38 (2017) 124-135. https://doi.org/10.1016/j.tiv.2016.10.001.

[48] L. Ylä-Outinen, J. Heikkilä, H. Skottman, R. Suuronen, R. Äänismaa, S. Narkilahti, Human cell-based micro electrode array platform for studying neurotoxicity, Front. Neuroeng. 3 (2010) 111. https://doi.org/10.3389/fneng.2010.00111.

[49] C.M. Abreu, L. Gama, S. Krasemann, M. Chesnut, S. Odwin-Dacosta, H.T. Hogberg, T. Hartung, D. Pamies, Microglia Increase Inflammatory Responses in iPSC-Derived Human BrainSpheres, Front. Microbiol. 9 (2018) 2766. https://doi.org/10.3389/fmicb.2018.02766.

[50] P.R. Ormel, R. Vieira de Sá, E.J. van Bodegraven, H. Karst, O. Harschnitz, M.A.M. Sneeboer, L.E. Johansen, R.E. van Dijk, N. Scheefhals, A. Berdenis van Berlekom, E. Ribes Martínez, S. Kling, H.D. MacGillavry, L.H. van den Berg, R.S. Kahn, E.M. Hol, L.D. de Witte, R.J. Pasterkamp, Microglia innately develop within cerebral organoids, Nat. Commun. 9 (2018) 4167. https://doi.org/10.1038/s41467-018-06684-2.

[51] L.M. Carlson, F.A. Champagne, D.A. Cory-Slechta, L. Dishaw, E. Faustman, W. Mundy, D. Segal, C. Sobin, C. Starkey, M. Taylor, S.L. Makris, A. Kraft, Potential frameworks to support evaluation of mechanistic data for developmental neurotoxicity outcomes: A symposium report, Neurotoxicol. Teratol. 78 (2020) 106865. https://doi.org/10.1016/j.ntt.2020.106865.

[52] C. Rivetti, T.E.H. Allen, J.B. Brown, E. Butler, P.L. Carmichael, J.K. Colbourne, M. Dent, F. Falciani, L. Gunnarsson, S. Gutsell, J.A. Harrill, G. Hodges, P. Jennings, R. Judson, A. Kienzler, L. Margiotta-Casaluci, I. Muller, S.F. Owen, C. Rendal, P.J. Russell, S. Scott, F. Sewell, I. Shah, I. Sorrel, M.R. Viant, C. Westmoreland, A. White, B. Campos, Vision of a near future: Bridging the human health-environment divide. Toward an integrated strategy to understand mechanisms across species for chemical safety assessment, Toxicol. Vitr. 62 (2020). https://doi.org/10.1016/j.tiv.2019.104692. 
[53] B.A. Merrick, R.S. Paules, R.R. Tice, Intersection of toxicogenomics and high throughput screening in the Tox21 program: An NIEHS perspective, Int. J. Biotechnol. 14 (2015) 7-27. https://doi.org/10.1504/IJBT.2015.074797.

[54] B.A. Merrick, Next-generation sequencing data for use in risk assessment, Curr. Opin. Toxicol. 18 (2019) 1826. https://doi.org/10.1016/j.cotox.2019.02.010.

[55] A.H. Vo, T.R. Van Vleet, R.R. Gupta, M.J. Liguori, M.S. Rao, An Overview of Machine Learning and Big Data for Drug Toxicity Evaluation, Chem. Res. Toxicol. $33 \quad$ (2020) 20-37. https://doi.org/10.1021/acs.chemrestox.9b00227.

[56] J.A. Briggs, E.J. Wolvetang, J.S. Mattick, J.L. Rinn, G. Barry, Mechanisms of Long Non-coding RNAs in Mammalian Nervous System Development, Plasticity, Disease, and Evolution, Neuron. 88 (2015) 861-877. https://doi.org/10.1016/j.neuron.2015.09.045.

[57] T.R. Mercer, I.A. Qureshi, S. Gokhan, M.E. Dinger, G. Li, J.S. Mattick, M.F. Mehler, Long noncoding RNAs in neuronal-glial fate specification and oligodendrocyte lineage maturation, BMC Neurosci. 11 (2010) 1-15 https://doi.org/10.1186/1471-2202-11-14.

[58] A. Nan, L. Chen, N. Zhang, Z. Liu, T. Yang, Z. Wang, C. Yang, Y. Jiang, A novel regulatory network among LncRpa, CircRar1, MiR-671 and apoptotic genes promotes lead-induced neuronal cell apoptosis, Arch. Toxicol. 91 (2017) 1671-1684. https://doi.org/10.1007/s00204-016-1837-1.

[59] Z. Liu, R. Huang, R. Roberts, W. Tong, Toxicogenomics: A 2020 Vision, Trends Pharmacol. Sci. 40 (2019) 92103. https://doi.org/10.1016/j.tips.2018.12.001.

[60] A. Subramanian, P. Tamayo, V.K. Mootha, S. Mukherjee, B.L. Ebert, M.A. Gillette, A. Paulovich, S.L. Pomeroy, T.R. Golub, E.S. Lander, J.P. Mesirov, Gene set enrichment analysis: A knowledge-based approach for interpreting genome-wide expression profiles, Proc. Natl. Acad. Sci. U. S. A. 102 (2005) 15545-15550. https://doi.org/10.1073/pnas.0506580102.

[61] R.A. Currie, Toxicogenomics: The challenges and opportunities to identify biomarkers, signatures and thresholds to support mode-of-action, Mutat. Res. - Genet. Toxicol. Environ. Mutagen. 746 (2012) 97-103. https://doi.org/10.1016/j.mrgentox.2012.03.002.

[62] T. Waldmann, M. Grinberg, A. König, E. Rempel, S. Schildknecht, M. Henry, A.K. Holzer, N. Dreser, V. Shinde, A. Sachinidis, J. Rahnenführer, J.G. Hengstler, M. Leist, Stem cell transcriptome responses and corresponding biomarkers that indicate the transition from adaptive responses to cytotoxicity, Chem. Res. Toxicol. 30 (2017) 905-922. https://doi.org/10.1021/acs.chemrestox.6b00259.

[63] J.L.A. Pennings, P.T. Theunissen, A.H. Piersma, An optimized gene set for transcriptomics based neurodevelopmental toxicity prediction in the neural embryonic stem cell test, Toxicology. 300 (2012) 158167. https://doi.org/10.1016/j.tox.2012.06.016.

[64] G. López-García, J.M. Jerez, L. Franco, F.J. Veredas, Transfer learning with convolutional neural networks for cancer survival prediction using gene-expression data, PLoS One. 15 (2020) e0230536. https://doi.org/10.1371/journal.pone.0230536.

[65] S. Ma, Z. Zhang, OmicsMapNet: Transforming omics data to take advantage of Deep Convolutional Neural Network for discovery, (2018). http://arxiv.org/abs/1804.05283 (accessed September 22, 2020).

[66] E.L. van Dijk, Y. Jaszczyszyn, D. Naquin, C. Thermes, The Third Revolution in Sequencing Technology, Trends Genet. 34 (2018) 666-681. https://doi.org/10.1016/j.tig.2018.05.008.

[67] D. Mav, R.R. Shah, B.E. Howard, S.S. Auerbach, P.R. Bushel, J.B. Collins, D.L. Gerhold, R.S. Judson, A.L. Karmaus, E.A. Maull, D.L. Mendrick, B.A. Merrick, N.S. Sipes, D. Svoboda, R.S. Paules, A hybrid gene selection approach to create the S1500+ targeted gene sets for use in high-throughput transcriptomics, PLoS One. 13 (2018) e0191105. https://doi.org/10.1371/journal.pone.0191105.

[68] J. Lamb, The Connectivity Map: A new tool for biomedical research, Nat. Rev. Cancer. 7 (2007) 54-60. https://doi.org/10.1038/nrc2044.

[69] R. Yuste, M. Hawrylycz, N. Aalling, D. Arendt, R. Armananzas, G. Ascoli, C. Bielza, V. Bokharaie, T. Bergmann, I. Bystron, M. Capogna, Y. Chang, A. Clemens, C. de Kock, J. DeFelipe, S. Dos Santos, K. Dunville, D. Feldmeyer, R. Fiath, G. Fishell, A. Foggetti, X. Gao, P. Ghaderi, O. Gunturkun, V.J. Hall, M. Helmstaedter, S. HerculanoHouzel, M. Hilscher, H. Hirase, J. Hjerling-Leffler, R. Hodge, Z.J. Huang, R. Huda, Y. Juan, K. Khodosevich, O. Kiehn, H. Koch, E. Kuebler, M. Kuhnemund, P. Larranaga, B. Lelieveldt, E.L. Louth, J. Lui, H. Mansvelder, O. Marin, J. Martínez-Trujillo, H. Moradi, N. Goriounova, A. Mohapatra, M. Nedergaard, P. Němec, N. Ofer, U. Pfisterer, S. Pontes, W. Redmond, J. Rossier, J. Sanes, R. Scheuermann, E.S. Saiz, P. Somogyi, G. Tamás, A. Tolias, M. Tosches, M.T. Garcia, A. Aguilar-Valles, H. Munguba, C. Wozny, T. Wuttke, L. Yong, H. Zeng, E.S. Lein, A community-based transcriptomics classification and nomenclature of neocortical cell types, Nat. Neurosci. (2020) 1-13. https://doi.org/10.1038/s41593-020-0685-8.

[70] Z. Xue, K. Huang, C. Cai, L. Cai, C. Jiang, Y. Feng, Z. Liu, Q. Zeng, L. Cheng, Y.E. Sun, J. Liu, S. Horvath, G. Fan, Genetic programs in human and mouse early embryos revealed by single-cell RNA sequencing, Nature. 500 (2013) 593-597. https://doi.org/10.1038/nature12364.

[71] J. Kim, B.K. Koo, J.A. Knoblich, Human organoids: model systems for human biology and medicine, Nat. Rev. Mol. Cell Biol. (2020). https://doi.org/10.1038/s41580-020-0259-3.

[72] S.C. van den Brink, A. Alemany, V. van Baternburg, N. Moris, M. Blotenburg, J. Vivié, P. Baillie-Johnson, J. Nichols, K.F. Sonnen, A. Martinez-Arias, A. Van Oudenaarden, Single-cell and spatial transcriptomics reveal somitogenesis in gastruloids, Nature. (2020). https://doi.org/10.1038/s41586-020-2024-3. 
[73] J. V Veenvliet, A. Bolondi, H. Kretzmer, L. Haut, M. Scholze-Wittler, D. Schifferl, F. Koch, M. Pustet, S. Heimann, R. Buschow, L. Wittler, B. Timmermann, A. Meissner, B.G. Herrmann, Mouse embryonic stem cells selforganize into trunk-like structures with neural tube and somites, BioRxiv. (2020) 2020.03.04.974949. https://doi.org/10.1101/2020.03.04.974949.

[74] A. Spangler, E.Y. Su, A.M. Craft, P. Cahan, A single cell transcriptional portrait of embryoid body differentiation and comparison to progenitors of the developing embryo, Stem Cell Res. 31 (2018) 201-215 https://doi.org/10.1016/j.scr.2018.07.022.

[75] G. La Manno, D. Gyllborg, S. Codeluppi, K. Nishimura, C. Salto, A. Zeisel, L.E. Borm, S.R.W. Stott, E.M. Toledo, J.C. Villaescusa, P. Lönnerberg, J. Ryge, R.A. Barker, E. Arenas, S. Linnarsson, Molecular Diversity of Midbrain Development in Mouse, Human, and Stem Cells, Cell. 167 (2016) 566-580.e19. https://doi.org/10.1016/J.CELL.2016.09.027.

[76] E.E. Burke, J.G. Chenoweth, J.H. Shin, L. Collado-Torres, S.K. Kim, N. Micali, Y. Wang, C. Colantuoni, R.E. Straub, D.J. Hoeppner, H.Y. Chen, A. Sellers, K. Shibbani, G.R. Hamersky, M. Diaz Bustamante, B.D.N. Phan, W.S. Ulrich, C. Valencia, A. Jaishankar, A.J. Price, A. Rajpurohit, S.A. Semick, R.W. Bürli, J.C. Barrow, D.J. Hiler S.C. Page, K. Martinowich, T.M. Hyde, J.E. Kleinman, K.F. Berman, J.A. Apud, A.J. Cross, N.J. Brandon, D.R. Weinberger, B.J. Maher, R.D.G. McKay, A.E. Jaffe, Dissecting transcriptomic signatures of neuronal differentiation and maturation using iPSCs, Nat. Commun. 11 (2020) 462. https://doi.org/10.1038/s41467019-14266-z.

[77] B. Zhang, H. Li, L. Zhu, X. He, H. Luo, K. Huang, W. Xu, Single-cell transcriptomics uncovers potential marker genes of ochratoxin A-sensitive renal cells in an acute toxicity rat model, Cell Biol. Toxicol. (2020). https://doi.org/10.1007/s10565-020-09531-7.

[78] K.S. Hsu, B.C. Goodale, K.H. Ely, T.H. Hampton, B.A. Stanton, R.I. Enelow, Single-cell RNA-seq Analysis Reveals That Prenatal Arsenic Exposure Results in Long-term, Adverse Effects on Immune Gene Expression in Response to Influenza A Infection, Toxicol. Sci. $176 \quad$ (2020) 312-328. https://doi.org/10.1093/toxsci/kfaa080.

[79] Q. Zhang, W.M. Caudle, J. Pi, S. Bhattacharya, M.E. Andersen, N.E. Kaminski, R.B. Conolly, Embracing systems toxicology at single-cell resolution, Curr. Opin. Toxicol. 16 (2019) 49-57. https://doi.org/10.1016/j.cotox.2019.04.003.

[80] P. Grandjean, P.J. Landrigan, Neurobehavioural effects of developmental toxicity, Lancet Neurol. 13 (2014) 330-338. https://doi.org/10.1016/S1474-4422(13)70278-3.

[81] P. Grandjean, P.J. Landrigan, Developmental neurotoxicity of industrial chemicals, Lancet. 368 (2006) 2167 2178. https://doi.org/10.1016/S0140-6736(06)69665-7.

[82] T. Schettler, Toxic threats to neurologic development of children., Environ. Health Perspect. 109 (2001) 813816. https://doi.org/10.1289/ehp.01109s6813.

[83] EPA, America's Children and the Environment, 2019

[84] I. Hertz-Picciotto, L. Delwiche, The rise in autism and the role of age at diagnosis, Epidemiology. 20 (2009) 84-90. https://doi.org/10.1097/EDE.0b013e3181902d15.

[85] N. Gunhanlar, G. Shpak, M. van der Kroeg, L.A. Gouty-Colomer, S.T. Munshi, B. Lendemeijer, M. Ghazvini, C. Dupont, W.J.G. Hoogendijk, J. Gribnau, F.M.S. de Vrij, S.A. Kushner, A simplified protocol for differentiation of electrophysiologically mature neuronal networks from human induced pluripotent stem cells, Mol. Psychiatry. 23 (2018) 1336-1344. https://doi.org/10.1038/mp.2017.56.

[86] L.M. Smits, J.C. Schwamborn, Midbrain Organoids: A New Tool to Investigate Parkinson's Disease, Front. Cell Dev. Biol. 8 (2020) 359. https://doi.org/10.3389/fcell.2020.00359.

[87] J. Lu, X. Zhong, H. Liu, L. Hao, C.T.L. Huang, M.A. Sherafat, J. Jones, M. Ayala, L. Li, S.C. Zhang, Generation of serotonin neurons from human pluripotent stem cells, Nat. Biotechnol. 34 (2016) 89-94. https://doi.org/10.1038/nbt.3435

[88] E.S. Lippmann, C. E.williams, D.A. Ruhl, M.C. Estevez-Silva, E.R. Chapman, J.J. Coon, R.S. Ashton, Deterministic HOX patterning in human pluripotent stem cell-derived neuroectoderm, Stem Cell Reports. 4 (2015) 632-644. https://doi.org/10.1016/j.stemcr.2015.02.018.

[89] Y. Tao, S.C. Zhang, Neural Subtype Specification from Human Pluripotent Stem Cells, Cell Stem Cell. 19 (2016) 573-586. https://doi.org/10.1016/j.stem.2016.10.015.

[90] À. Bayés, L.N. van de Lagemaat, M.O. Collins, M.D.R. Croning, I.R. Whittle, J.S. Choudhary, S.G.N. Grant Characterization of the proteome, diseases and evolution of the human postsynaptic density, Nat. Neurosci. 14 (2011) 19-21. https://doi.org/10.1038/nn.2719.

[91] J.F. Robinson, J.A. Port, X. Yu, E.M. Faustman, Integrating genetic and toxicogenomic information for determining underlying susceptibility to developmental disorders, Birth Defects Res. A. Clin. Mol. Teratol. 88 (2010) 920-930. https://doi.org/10.1002/bdra.20708.

[92] F. Zhu, M. Cizeron, Z. Qiu, R. Benavides-Piccione, M. V. Kopanitsa, N.G. Skene, B. Koniaris, J. DeFelipe, E. Fransén, N.H. Komiyama, S.G.N. Grant, Architecture of the Mouse Brain Synaptome, Neuron. 99 (2018) 781 799.e10. https://doi.org/10.1016/j.neuron.2018.07.007.

[93] M. Cizeron, Z. Qiu, B. Koniaris, R. Gokhale, N.H. Komiyama, E. Fransén, S.G.N. Grant, A brainwide atlas of synapses across the mouse life span, Science (80-. ). 369 (2020) 270-275. https://doi.org/10.1126/science.aba3163. 
[94] S.G.N. Grant, Synapse diversity and synaptome architecture in human genetic disorders, Hum. Mol. Genet. 28 (2019) R219-R225. https://doi.org/10.1093/hmg/ddz178.

[95] E. Danielson, K. Perez De Arce, B. Cimini, E.-C. Wamhoff, S. Singh, J.R. Cottrell, A.E. Carpenter, M. Bathe, Molecular diversity of glutamatergic and GABAergic synapses from multiplexed fluorescence imaging, BioRxiv. (2020) 2020.06.12.148155. https://doi.org/10.1101/2020.06.12.148155.

[96] S.M. Guo, R. Veneziano, S. Gordonov, L. Li, E. Danielson, K. Perez de Arce, D. Park, A.B. Kulesa, E.C. Wamhoff, P.C. Blainey, E.S. Boyden, J.R. Cottrell, M. Bathe, Multiplexed and high-throughput neuronal fluorescence imaging with diffusible probes, Nat. Commun. 10 (2019) 1-14. https://doi.org/10.1038/s41467-019-123726.

[97] E.D. Kroese, S. Bosgra, H.E. Buist, G. Lewin, S.C. van der Linden, H. yen Man, A.H. Piersma, E. Rorije, S.H.W. Schulpen, M. Schwarz, F. Uibel, B.M.A. van Vugt-Lussenburg, A.P.M. Wolterbeek, B. van der Burg, Evaluation of an alternative in vitro test battery for detecting reproductive toxicants in a grouping context, Reprod. Toxicol. 55 (2015) 11-19. https://doi.org/10.1016/j.reprotox.2014.10.003.

[98] J. Louisse, M. Verwei, R.A. Woutersen, B.J. Blaauboer, I.M. Rietjens, Toward in vitro biomarkers for developmental toxicity and their extrapolation to the in vivo situation, Expert Opin. Drug Metab. Toxicol. (2012). https://doi.org/10.1517/17425255.2012.639762.

[99] K. Hayess, C. Riebeling, R. Pirow, M. Steinfath, D. Sittner, B. Slawik, A. Luch, A.E.M. Seiler, The DNT-EST: A predictive embryonic stem cell-based assay for developmental neurotoxicity testing in vitro, Toxicology. 314 (2013) 135-147. https://doi.org/10.1016/j.tox.2013.09.012.

[100] A.H. Piersma, S. Bosgra, M.B.M. van Duursen, S.A.B. Hermsen, L.R.A. Jonker, E.D. Kroese, S.C. van der Linden, H. Man, M.J.E. Roelofs, S.H.W. Schulpen, M. Schwarz, F. Uibel, B.M.A. van Vugt-Lussenburg, J. Westerhout, A.P.M. Wolterbeek, B. van der Burg, Evaluation of an alternative in vitro test battery for detecting reproductive toxicants, Reprod. Toxicol. 38 (2013) 53-64. https://doi.org/https://doi.org/10.1016/j.reprotox.2013.03.002.

[101] J.A. Harrill, T. Freudenrich, K. Wallace, K. Ball, T.J. Shafer, W.R. Mundy, Testing for developmental neurotoxicity using a battery of in vitro assays for key cellular events in neurodevelopment, Toxicol. Appl. Pharmacol. 354 (2018) 24-39. https://doi.org/10.1016/j.taap.2018.04.001.

[102] A. Bal-Price, K.M. Crofton, M. Leist, S. Allen, M. Arand, T. Buetler, N. Delrue, R.E. FitzGerald, T. Hartung, T. Heinonen, H. Hogberg, S.H. Bennekou, W. Lichtensteiger, D. Oggier, M. Paparella, M. Axelstad, A. Piersma, E. Rached, B. Schilter, G. Schmuck, L. Stoppini, E. Tongiorgi, M. Tiramani, F. Monnet-Tschudi, M.F. Wilks, T. Ylikomi, E. Fritsche, International STakeholder NETwork (ISTNET): creating a developmental neurotoxicity (DNT) testing road map for regulatory purposes, Arch. Toxicol. 89 (2015) 269-287. https://doi.org/10.1007/s00204-015-1464-2.

[103] T. Hartung, S. Bremer, S. Casati, S. Coecke, R. Corvi, S. Fortaner, L. Gribaldo, M. Halder, S. Hoffmann, A.J. Roi, P. Prieto, E. Sabbioni, L. Scott, A. Worth, V. Zuang, A modular approach to the ECVAM principles on test validity, ATLA Altern. to Lab. Anim. 32 (2004) 467-472.

[104] OECD, Guidance document on the validation and international acceptance of new or updated test methods for hazard assessment, Paris, 2005. https://doi.org/ENV/JM/MONO(2005)14.

[105] A.H. Piersma, J. Ezendam, M. Luijten, J.J.A. Muller, E. Rorije, L.T.M. Van Der Ven, J. Van Benthem, A critical appraisal of the process of regulatory implementation of novel in vivo and in vitro methods for chemical hazard and risk assessment, Crit. Rev. Toxicol. 44 (2014) 876-894. https://doi.org/10.3109/10408444.2014.940445.

[106] A.H. Piersma, J. van Benthem, J. Ezendam, Y.C. Staal, A.S. Kienhuis, The virtual human in chemical safety assessment, Curr. Opin. Toxicol. 15 (2019) 26-32. https://doi.org/10.1016/j.cotox.2019.03.009.

[107] Roche, Biochemical pathways, F. Hoffmann-La Roche Ltd. (2020). http://biochemicalpathways.com/\#/map/1 (accessed September 1, 2020).

[108] M. Behl, K. Ryan, J.H. Hsieh, F. Parham, A.J. Shapiro, B.J. Collins, N.S. Sipes, L.S. Birnbaum, J.R. Bucher, P.M.D. Foster, N.J. Walker, R.S. Paules, R.R. Tice, Screening for developmental neurotoxicity at the national toxicology program: The future is here, Toxicol. Sci. 167 (2019) 258-268. https://doi.org/10.1093/toxsci/kfy278.

[109] M. Paparella, S.H. Bennekou, A. Bal-Price, An analysis of the limitations and uncertainties of in vivo developmental neurotoxicity testing and assessment to identify the potential for alternative approaches, Reprod. Toxicol. 96 (2020) 327-336. https://doi.org/10.1016/j.reprotox.2020.08.002.

[110] P.T. Theunissen, J.L.A. Pennings, D.A.M. van Dartel, J.F. Robinson, J.C.S. Kleinjans, A.H. Piersma, Complementary detection of embryotoxic properties of substances in the neural and cardiac embryonic stem cell tests, Toxicol. Sci. 132 (2013) 118-130. https://doi.org/10.1093/toxsci/kfs333.

[111] R.H.G. Mennen, J.L.A.J. Pennings, A.H.A. Piersma, Neural crest related gene transcript regulation by valproic acid analogues in the cardiac embryonic stem cell test, Reprod. Toxicol. 90 (2019) 44-52. https://doi.org/10.1016/j.reprotox.2019.08.013.

[112] L. Ikonomou, D.N. Kotton, Derivation of endodermal progenitors from pluripotent stem cells, J. Cell. Physiol. 230 (2015) 246-258. https://doi.org/10.1002/jcp.24771.

[113] M.F. Taha, A. Javeri, T. Majidizadeh, M.R. Valojerdi, Both BMP4 and serum have significant roles in differentiation of embryonic stem cells to primitive and definitive endoderm, Cytotechnology. 68 (2016) 1315-1324. https://doi.org/10.1007/s10616-015-9891-8. 
[114] A.S. Monzel, L.M. Smits, K. Hemmer, S. Hachi, E.L. Moreno, T. van Wuellen, J. Jarazo, J. Walter, I. Brüggemann, I. Boussaad, E. Berger, R.M.T. Fleming, S. Bolognin, J.C. Schwamborn, Derivation of Human Midbrain-Specific Organoids from Neuroepithelial Stem Cells, Stem Cell Reports. 8 (2017) 1144-1154. https://doi.org/10.1016/j.stemcr.2017.03.010.

[115] I. Kelava, M.A. Lancaster, Dishing out mini-brains: Current progress and future prospects in brain organoid research, Dev. Biol. 420 (2016) 199-209. https://doi.org/10.1016/j.ydbio.2016.06.037.

[116] S. Kadereit, B. Zimmer, C. Van Thriel, J.G. Hengstler, M. Leist, Compound selection for in vitro modeling of developmental neurotoxicity, Front. Biosci. 17 (2011) 2442-2460. https://doi.org/10.2741/4064.

[117] T. Burgdorf, A.H. Piersma, R. Landsiedel, R. Clewell, N. Kleinstreuer, M. Oelgeschläger, B. Desprez, A. Kienhuis, P. Bos, R. de Vries, L. de Wit, T. Seidle, J. Scheel, G. Schönfelder, J. van Benthem, A.M. Vinggaard, C. Eskes, J. Ezendam, Workshop on the validation and regulatory acceptance of innovative 3R approaches in regulatory toxicology - Evolution versus revolution, Toxicol. Vitr. $59 \quad$ (2019) 1-11. https://doi.org/10.1016/j.tiv.2019.03.039.

[118] M. Sachana, A. Bal-Price, K.M. Crofton, S.H. Bennekou, T.J. Shafer, M. Behl, A. Terron, International regulatory and scientific effort for improved developmental neurotoxicity testing, Toxicol. Sci. 167 (2019) 45-57. https://doi.org/10.1093/toxsci/kfy211.

[119] J. Li, R. Settivari, M.J. LeBaron, M.S. Marty, An industry perspective: A streamlined screening strategy using alternative models for chemical assessment of developmental neurotoxicity, Neurotoxicology. 73 (2019) 1730. https://doi.org/10.1016/j.neuro.2019.02.010.

[120] N. Kleinstreuer, D. Dix, M. Rountree, N. Baker, N. Sipes, D. Reif, R. Spencer, T. Knudsen, A Computational Model Predicting Disruption of Blood Vessel Development, PLoS Comput. Biol. 9 (2013) e1002996. https://doi.org/10.1371/journal.pcbi.1002996.

[121] M.S. Hutson, M.C.K. Leung, N.C. Baker, R.M. Spencer, T.B. Knudsen, Computational Model of Secondary Palate Fusion and Disruption, Chem. Res. Toxicol. 30 (2017) 965-979. https://doi.org/10.1021/acs.chemrestox.6b00350.

[122] M.C.K. Leung, M.S. Hutson, A.W. Seifert, R.M. Spencer, T.B. Knudsen, Computational modeling and simulation of genital tubercle development, Reprod. Toxicol. $64 \quad$ (2016) 151-161. https://doi.org/10.1016/j.reprotox.2016.05.005.

[123] F.A. Groothuis, M.B. Heringa, B. Nicol, J.L.M. Hermens, B.J. Blaauboer, N.I. Kramer, Dose metric considerations in in vitro assays to improve quantitative in vitro-in vivo dose extrapolations, Toxicology. 332 (2015) 30-40. https://doi.org/10.1016/j.tox.2013.08.012.

[124] R.D. Heijtz, S. Wang, F. Anuar, Y. Qian, B. Björkholm, A. Samuelsson, M.L. Hibberd, H. Forssberg, S. Pettersson, Normal gut microbiota modulates brain development and behavior, Proc. Natl. Acad. Sci. U. S. A. 108 (2011) 3047-3052. https://doi.org/10.1073/pnas.1010529108.

[125] T.R. Catron, A. Swank, L.C. Wehmas, D. Phelps, S.P. Keely, N.E. Brinkman, J. McCord, R. Singh, J. Sobus, C.E. Wood, M. Strynar, E. Wheaton, T. Tal, Microbiota alter metabolism and mediate neurodevelopmental toxicity of 17ß-estradiol, Sci. Rep. 9 (2019). https://doi.org/10.1038/s41598-019-43346-9.

[126] M.J.W.A. Schiffelers, Animal testing, 3R models and regulatory acceptance: Technology transition in a riskaverse context, Utrecht University, 2016.

[127] P. Bos, Towards an animal-free human health assessment: starting from the current regulatory needs, ALTEX. 37 (2020). https://doi.org/10.14573/altex.1912041. 




\section{APPENDIX}

NEDERLANDSE SAMENVATTING

LIST OF PUBLICATIONS

DANKWOORD/ACKNOWLEDGEMENTS

CURRICULUM VITAE 


\section{Nederlandse samenvatting}

ledereen wordt blootgesteld aan chemische stoffen. Denk maar eens aan de schoonmaakmiddelen die je gebruikt, het voedsel dat je eet, de medicijnen die je slikt. Het testen van industriële chemicaliën, bestrijdingsmiddelen en (dier)geneesmiddelen op hun veiligheid is bij wet verplicht. Dit wordt sinds de jaren '50 voornamelijk gedaan met dierproeven. Een van de verplichte proeven is het testen van de veiligheid van een stof voor de voortplanting en de ontwikkeling van nakomelingen. Dit is belangrijk, omdat het embryo specifieke gevoeligheden heeft die een volwassene niet heeft. Bovendien kan blootstelling aan chemische stoffen tijdens de ontwikkeling een leven lang effect hebben.

Met de invoering van verplichte dierproeven kwamen er al snel regels voor de vermindering, verfijning en vervanging (3V's) van proefdieren. De laatste jaren is de nadruk steeds meer komen te liggen op de laatste $V$. Echter, een dierstudie kan niet zomaar één-op-één vervangen worden met een enkele proefdiervrije test. Een veel besproken manier om proefdieren te vervangen is een combinatie van het testen op (menselijke) cellen die worden opgekweekt tot (delen van) organen en het testen op lagere diersoorten (bijvoorbeeld vissen, wormen en fruitvliegen). De informatie die uit deze testen komt, moet vervolgens geïnterpreteerd worden met computermodellen om zo een voorspelling te doen voor de mens. Met andere woorden: een dierstudie wordt vervangen met een serie simpelere testen. Het voordeel van deze benadering is dat het ook mogelijk wordt om gedetailleerd te kijken hoe stoffen precies schadelijk zijn. Doordat er meer mechanistisch inzicht is in de manier waarop stoffen schadelijk zijn, kunnen mogelijk risico's bij de mens beter worden ingeschat.

Om de hele ontwikkeling van de mens na te bootsen zijn veel testen nodig. In dit proefschrift ligt de focus op de vroege hersenontwikkeling van het embryo. In de hierin beschreven studies wordt de toepasbaarheid onderzocht van twee soorten celkweken, ook wel in vitro testen genoemd, voor het voorspellen van de veiligheid van stoffen op de vroege embryonale hersenontwikkeling. Dit vakgebied heet de ontwikkelingsneurotoxicologie. De cellen die worden gebruikt in dit onderzoek zijn embryonale stamcellen. Deze stamcellen kunnen bijna alle andere cellen in het lichaam worden, in dit proefschrift dus hersencellen.

Hersenontwikkeling is een complex proces en deze twee in vitro testen beslaan maar een beperkt deel van deze ontwikkeling. Daarom moeten we bepalen welke ontwikkelingsprocessen wel en niet nagebootst worden in deze testen en waarvoor ze wel en niet voorspellend kunnen zijn. Dit noemen we ook wel het biologisch domein. Het biologisch domein onderzoeken we door de kijken naar de activiteit van genen. Op basis van de genactiviteit kan een inschatting worden gemaakt welke ontwikkelingsprocessen zich in de in vitro testen afspelen. Bovendien kan worden voorspeld wat voor typen hersencellen ontstaan uit de stamcellen, omdat de genactiviteit voor elke soort cel verschillend is. Naast het meten van genactiviteit hebben we ook kleuringen van eiwitten die specifiek een bepaald celtype laten zien om de resultaten van de genactiviteit te verifiëren. 
Het proefschrift bestaat uit twee delen. In het eerste deel (hoofdstuk 2-6) hebben we het biologisch domein en de toepassing van de muis neurale embryonale stamceltest (mESTn) onderzocht. Deze test is voorheen ontwikkeld voor het snel uitlezen van effecten van stoffen op de vroege hersen-ontwikkeling. In dit proefschrift bouwen we voort op de beschikbare kennis om het biologisch domein van de test te kunnen bepalen. Op basis van genactiviteit en eiwitkleuringen hebben we laten zien dat deze embryonale stamcellen zich ontwikkelen tot een mengel van hersencellen en andere steuncellen die in de hersenen voorkomen, vergelijkbaar met delen van de vroege hersenontwikkeling in de muis. We hebben ook kunnen aantonen dat sommige celtypes gevoeliger voor stoffen zijn dan andere. Dit biedt inzicht in hoe stoffen de vroege hersenontwikkeling zouden kunnen verstoren. Tot slot hebben we laten zien dat de manier van kweken invloed heeft op hoe de cellen zich ontwikkelen. Door bijvoorbeeld de cellen te kweken bij een laag zuurstofgehalte kunnen de verhoudingen tussen verschillende celtypes worden aangepast. Dit geeft de mogelijkheid om de test af te stellen op die celtypes waarop er getest moeten worden.

Uiteindelijk is het doel om alle proefdiervrije testen uit te voeren met menselijke cellen, omdat we deze testen doen voor het voorspellen van effecten van chemische stoffen op de mens. Het tweede deel van het proefschrift (hoofdstuk 7-9) beschrijft de ontwikkeling van een nieuwe in vitro test op basis van humane embryonale stamcellen (hESC) die zich ontwikkelen tot hersencellen en steuncellen: de humane neurale voorloperstest (hNPT). Bovendien vertonen de cellen spontane elektrische activiteit, wat een belangrijke aanwijzing is dat we inderdaad een stukje van de hersenontwikkeling nadoen. Het biologisch domein van deze cellen ligt daarmee ook verder in de hersenontwikkeling dan de mESTn. Analyse van alle genen in deze test toont aan dat de dominante biologische processen in deze test (uitgroei van hersencellen, communicatie tussen hersencellen en celdood) ook gevoelig zijn voor blootstelling aan chemische stoffen. Dat betekent dat deze test waarschijnlijk geschikt is voor het detecteren van ontwikkelingsneurotoxische stoffen. In dit deel van het proefschrift wordt ook aangetoond dat hetzelfde protocol werkt op een ander soort menselijke cellen, namelijk humane geïnduceerde pluripotente stamcellen (hiPSC). Dit zijn cellen uit het bloed van mensen die in het laboratorium zijn omgevormd van een gedifferentieerd celtype naar stamcellen. Ook deze cellen kunnen we dus goed gebruiken in testen van de effecten van chemische stoffen op de ontwikkeling van hersencellen.

De twee hierboven beschreven in vitro testen kunnen bijdragen aan het onderzoek naar de schadelijkheid van stoffen. Naast deze testen zijn er andere in vitro testen nodig die andere, aanvullende biologische domeinen hebben, die samen delen van de embryonale (hersen)ontwikkeling kunnen nabootsen. Het helemaal nabootsen is waarschijnlijk niet mogelijk met alleen maar testen in een petrischaaltje. Daarvoor moet de informatie uit al deze testen geïntegreerd worden door computermodellen om zo een beoordeling te kunnen doen voor de mogelijke schadelijkheid van stoffen. Dit zijn allemaal stappen richting een nieuwe soort risicobeoordeling van stoffen, voor mensen, zonder proefdieren. 


\section{List of publications}

\section{Peer-reviewed publications}

Victoria C. de Leeuw, Ellen V.S. Hessel, Aldert H. Piersma (2021). Exploring the biological domain of the neural embryonic stem cell test (ESTn): morphogenetic regulators, Hox genes and cell types, and their usefulness as biomarkers for embryotoxicity screening. Toxicology, 454: 152735. DOI: 10.1016/j.tox.2021.152735

Victoria C. de Leeuw, Conny T.M. van Oostrom, Sandra Imholz, Aldert H. Piersma, Ellen V.S. Hessel, Martijn E.T. Dollé (2020). Going back and forth: episomal vector reprogramming of peripheral blood mononucle-ar cells to induced pluripotent stem cells and subsequent differentiation into cardio-myocytes and neuron-astrocyte co-cultures. Cellular Reprogramming, 20(6): 300-310. DOI: 10.1089/cell.2020.0040

Victoria C. de Leeuw, Marieke van Nieuwland, Bas G. H. Bokkers, Aldert H. Piersma (2020). Culture conditions affect chemical-induced developmental toxicity in vitro: the case of folic acid, methionine and methotrexate in the neural embryonic stem cell test. Alternatives to Laboratory Animals, 48(4): 173-183. DOI: 10.1177/0261192920961963

Victoria C. de Leeuw, Conny T. M. van Oostrom, Remco H.S. Westerink, Aldert H. Piersma, Harm J. Heusinkveld, Ellen V.S. Hessel (2020). An efficient neuron-astrocyte differentiation protocol from human embryonic stem cell-derived neural progenitors to assess chemical-induced developmental neurotoxicity. Reproductive Toxicology, 98: 107-116. DOI: 10.1016/j.reprotox.2020.09.003

Regina H. Mennen, Victoria C. de Leeuw, Aldert H. Piersma (2020). Oxygen tension influences embryonic stem cells in culture and has lineage specific effects on neural and cardiac differentiation, Differentiation, 115: 1-10. DOI: 10.1016/j.diff.2020.07.001

Victoria C. de Leeuw, Jeroen L.A. Pennings, Hennie M. Hodemaekers, Paul F.K. Wackers, Conny T. M. van Oostrom, Ellen V.S. Hessel, Aldert H. Piersma (2020). Differential effects of fluoxetine and venlafaxine in the neural embryonic stem cell test (ESTn) revealed by a cell lineage map, NeuroToxicology, 76: 1-9. DOI: 10.1016/j.neuro.2019.09.014

Victoria C. de Leeuw, Ellen V.S. Hessel, Aldert H. Piersma (2019). Look-alikes may not act alike: Gene expression regulation and cell-type-specific responses of three valproic acid analogues in the neural embryonic stem cell test (ESTn), Toxicology Letters, 303: 28-37. DOI: 10.1016/j.toxlet.2018.12.005 


\section{Submitted publications}

Victoria C. de Leeuw, Conny T. M. van Oostrom, Paul F.K. Wackers, Jeroen L.A. Pennings, Hennie M. Hodemaekers, Aldert H. Piersma, Ellen V.S. Hessel. Neuronal differentiation pathways and compound-induced developmental neurotoxicity in the human neural progenitor cell test (hNPT) revealed by RNA-seq, submitted.

\section{Oral presentations}

Victoria C. de Leeuw. Using a cell linage map to study neurodevelopmental effects of two antidepressants in the neural embryonic stem cell test. David Ray Student Award Session, International Neurotoxicology Association (INA), 29 September - 3 October 2019, Mettmann, Germany.

Victoria C. de Leeuw. Cell-type specific effects of two valproic acid analogues in the neural embryonic stem cell test. PhD Speed presentation, Nederlandse Vereniging voor Toxicologie (NVT), 30 - 31 May 2018, Hilversum, the Netherlands.

Victoria C. de Leeuw. Immunohistochemical characterization of biomarkers in the neural embryonic stem cell test (ESTn) and their perturbation by chemical exposures. Young Scientist Round Table, European Teratology Society (ETS), 4 - 7 September 2017, Budapest, Hungary.

\section{Poster presentations}

Victoria C. De Leeuw, Conny T. M. van Oostrom, Paul F.K. Wackers, Jeroen L.A. Pennings, Hennie M. Hodemaekers, Aldert H. Piersma, Ellen V.S. Hessel. RNA-Seq reveals disturbance of key neurodevelopmental processes in the human neural progenitor test (hNPT) by diverse neurodevelopmental toxicants. 12-26 March 2021, Society of Toxicology (SOT), online.

*Victoria C. de Leeuw, Ellen V.S. Hessel, Aldert H. Piersma. Colinear Hox gene expression in the neural embryonic stem cell test (ESTn) defines its biological domain and reveals effects of compounds. NVT conference 10 - 11 June 2020, Ede, the Netherlands; World Congress on Alternatives and Animal Use in the Life Science 23 - 27 August 2020, Maastricht, the Netherlands.

*Victoria C. de Leeuw, Conny T. van Oostrom, Aldert H. Piersma, Harm J. Heusinkveld, Ellen V.S. Hessel. A robust protocol for the differentiation of stem cells to a neuronal-glial co-culture to assess developmental neurotoxicity. 15 - 19 March 2020, Society of Toxicology (SOT), Anaheim, CA, USA. 
*Victoria C. de Leeuw, Marieke van Nieuwland, Aldert H. Piersma. Folic acid and methionine levels affect neural differentiation and compound toxic potency in the neural embryonic stem cell test (ESTn). 15 - 19 March 2020, SOT, Anaheim, CA, USA.

Victoria C. de Leeuw, Conny T. van Oostrom, Aldert H. Piersma, Harm J. Heusinkveld, Ellen V.S. Hessel. The applicability of the human neuronal embryonic stem cell test in an ontology driven test strategy for DNT. INA, 29 September - 3 October 2019, Mettmann, Germany.

Victoria C. de Leeuw, Jeroen L.A. Pennings, Hennie M. Hodemaekers, Paul F.K. Wackers, Conny T. van Oostrom, Harm J. Heusinkveld, Ellen V.S. Hessel, Aldert H. Piersma. Using a cell linage map to study neurodevelopmental effects of two anti-depressants in the neural embryonic stem cell test. INA, 29 September - 3 October 2019, Mettmann, Germany.

Victoria C. de Leeuw, Jeroen L.A. Pennings, Hennie M. Hodemaekers, Paul F.K. Wackers, Conny T. M. van Oostrom, Ellen V.S. Hessel, Aldert H. Piersma. Using cell-type markers to elucidate neurodevelopmental effects of two anti-depressants in the neural embryonic stem cell test. NVT, 12 - 13 June 2019, Ede, the Netherlands.

Victoria C. de Leeuw, Ellen V.S. Hessel, Aldert H. Piersma (2018). Cell-type specific effects of using two valproic acid isomers in the neural embryonic stem cell test, Toxicology Letters, 295S: S69-S266. European Societies of Toxicology (Eurotox), 2 - 5 September 2018, Brussels, Belgium.

Victoria C. de Leeuw, Ellen V.S. Hessel, Aldert H. Piersma (2017). Immunohistochemical characterization of biomarkers in the neural embryonic stem cell test (ESTn) and their perturbation by chemical exposures. Reproductive Toxicology, 72: 28-30. ETS, 4 - 7 September 2017, Budapest, Hungary.

*Not presented due to cancelation of conference. 



\section{Proefschrift}

\section{Ingrediënten}

Marmercake
Paul
Elizabeth
Alexandra
Ganache
Tim
Watermeloencake
Jon
Erik
Astrid

Mousse
Heleen
Elsemieke
Merel
Ralien
Bollen en biggen
Els
Paul
Sigrid
Tim
Jelle

Worteltaart -
beslag
Jeroen
Marieke
Harm
Martijn
Bas
Remco
Hennie

\section{Bereidingswijze}

Verwarm de oven voor op $170{ }^{\circ} \mathrm{C}$. Zet alle spullen klaar die je nodig hebt, mise-en-place is cruciaal bij dit soort grote baksels.

Begin met de onderste van de drie cakes. Deze cake is de basis en is daarmee heel belangrijk voor het succes van de andere lagen. Maak het beslag en deel in tweeën. Meng door één deel kaneel met stukjes crispy en door het andere deel vanille-extract met stukjes karamel. Spatel de twee soorten deeg rustig door elkaar voor een mooi, gebalanceerd marmereffect. Roer op het laatste moment een royale hoeveelheid blauwe bessen en stukjes bladgoud mee, gewoon omdat het kan. Stort het beslag in de vorm en geef de lepel en de kom aan de gulzige keukenhulpjes. Maak, terwijl de cake aan het afkoelen is, de ganache van pure chocolade. Snijd de cake door en smeer een flinterdun laagje tussen de twee lagen. Meer is niet nodig, je moet het niet groter maken dan het is, niet gekker doen dan nodig. Dat siert de cake als geheel. Leg de twee helften cake op elkaar en werk hard en secuur de hele cake af met een dunne laag ganache. Zet weg, maar blijf af en toe omkijken.

De middelste cake is geïnspireerd door een paar meesterbakkers in hun discipline die je anders naar het taartenbakken laten kijken. Dat dingen soms kunnen, vaak kunnen, als je maar creatief en volhardend durft te zijn. Daarom wordt dit een watermeloencake. Maak drie cakes van een simpel génoisebeslag met een klein scheutje watermeloensiroop. Als het simpel kan, doe het, en doe het goed. Dan pas kom je tot de kern van de smaak. Voor de vulling heb je eigenzinnige medebakkers nodig. Neem een watermeloen en lepel er wat bolletjes uit. Pureer de rest van de watermeloen tot puree en maak er een mousse van met de rest van de ingrediënten. Zorg dat de mousse krachtig en eigenzinnig van smaak is. Smeer de mousse tussen en over de cakes. Rol fondant uit en leg deze over de taart, werk af zoals je geleerd hebt. Boetseer een paar biggetjes van fondant en leg die om en om met de bolletjes watermeloen rond de rand van de cake. Zing daarbij keihard "Ik houd van mij", want soms mag het wel eens even ongepast zijn. Span tot slot een rood lint om de taart. Knip de rafelige randjes ervan af. Misschien dat je dit later nog een keer moet herhalen, misschien ben je nu klaar. Mensen vinden het misschien maar niets, maar je weet van de meesterbakker: smaak is ook maar een mening.

De toplaag vereist wortels die komen uit een gebied onder Utrecht, tussen Bunnik en Houten. Ze zeggen dat de mensen die daar wonen bijzonder zijn. Of het door de wortels of door de mensen komt is voor dit recept niet belangrijk. Wat wel cruciaal is, is om hier heel precies en weloverwogen te werk te gaan. Rasp de wortels tot je precies 400 gram 
Paul

Sandra

Worteltaart -
vulling
Aldert
Ellen
Conny

Worteltaart -
bekleding
VTS
GZB

\section{Scherven \\ Anne \\ Charlotte \\ Lisanne \\ Anke}

\section{Decoratie}

Astrid

Charlotte

Gina

Kim

Coen

Stella

Erna

Laura

Christy

Alessandro

\section{Bloemen}

NVT committee

Proneri

\section{Muisje}

Proefdiervrij

Anne

Kwekerij

Sophie hebt, zowel te veel als te weinig is niet goed voor het resultaat, weet je van de chef. Maak een beslag van de overige ingrediënten, blijf proeven en feedback vragen tot je een goede basis hebt. Voeg de wortelrasp en walnoten toe. Die laatste staan bekend als supernootjes voor de hersenen. Wees wel bescheiden met de hoeveelheid, en vraag hulp aan de chef als je het nodig hebt. Meng tot slot stukjes gekonfijte gember erbij op smaak. Hier moet de intuïtieve bakker misschien bij helpen. Eigenlijk weet je wel zeker dat die erbij moet helpen, want dit komt nauw met de smaak die deze cake tot een succes maakt. Bak op $170{ }^{\circ} \mathrm{C}$ in het midden van de oven.

Zodra de worteltaart is afgekoeld kan je de marsepein uitrollen. Verdeel je aandacht goed als je de marsepein over je taart heen aanbrengt, zodat de laag dicht om de taart zit zonder dat er scheurtjes in komen. Leg de fondantlaag over de marsepein heen. Ook hier geldt dat het stevig om de taart heen moet zitten en er strak, gedegen en betrouwbaar uit ziet, zoals het hoort te zijn. Zorg dat je nu alvast een koffie gaat scoren, anders staat er een rij met allemaal gezellig en wijze mensen waardoor je in de knoei komt met je tijd.

Kook de tequila met limoen en Cointreau in samen met de suiker in tot er een karamelgeur van af komt. Stort op een stuk bakpapier en breek in scherven zodra het is uitgehard. Doe hetzelfde met de rode wijn. Drink er een klein glaasje bij, want het is al woensdag. Steek deze alvast in de bovenste cake. Leg om de scherven onbespoten eetbare bloemen. Zet bordjes en vorkjes alvast klaar en zet een muziekje op voordat de gasten komen. Goede organisatie is belangrijk voor de presentatie.

Maak tot slot de rest van de decoratie. Verlaag de oven naar $150^{\circ} \mathrm{C}$, chill een beetje, je bent er bijna. De macarons worden in vier batches gemaakt met verschillende kleurstoffen die passen bij de kleur van de vulling: champagnecrème, rosécrème, cappucinocrème en lichte whiskeycrème. Terwijl de macarons aan het bakken zijn, maak het beslag voor de mini-eierkoeken. Fire up die oven! en bak ze op $200{ }^{\circ} \mathrm{C}$. While everything is cooling down, make Italian meringue buttercream with a bit of honey and pipe this along the bottom of the top cake. Enjoy that moment of calmness and inner peace when you're adding each cube of butter to the batter. Plak de macarons en eierkoekjes speels op de bovenste cake. Boetseer van marsepein een muisje en zet op de bovenste laag als eerbetoon aan het beestje.

Serveer de taart op een mooie schaal en geef aan iedereen een stukje. Want laten we eerlijk zijn: een taart smaakt het best als je hem kan delen. De cakes zijn belangrijk en moeten goed zijn, maar de decoratie maakt het af. Geniet en dank al je chefs, souschefs, meesterpatissiers en commis de cuisine voor deze geweldige tijd. 



\section{Curriculum Vitae}

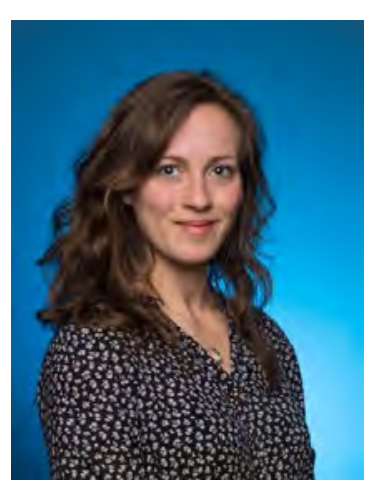

Victoria Cathérine de Leeuw was born on the 22 $2^{\text {nd }}$ of May 1993 in Haarlem, the Netherlands. After graduating cum laude from Gymnasium Felisenum in Velsen-Zuid in 2011, she studied BètaGamma at the University of Amsterdam. She did a major in Neurobiology with additional courses in broader themes like rhetoric and climate sciences, as well as an honours programme in biomedical sciences and interdisciplinary studies. She continued into a Master's programme at the University of Edinburgh in Integrative Neuroscience. Her first Master internship was in Computational Neuroscience under the supervision of Dr. Mark van Rossum at the department of Computational Neuroscience and Neuroinformatics about computational modelling to predict noise in a single neuron. Her second internship was on synapse degradation in an Alzheimer's mouse model at Prof. Dr. Seth Grant's lab in the Centre for Clinical Brain Sciences. She graduated with distinction in 2015.

After spending one year working as a Quality Assurance Officer at the pharmaceutical company Merck, Sharpe and Dohme (MSD) in Haarlem, she started her PhD project in 2016 at the Centre for Health Protection at the National Institute for Public Health and the Environment (RIVM) and the Institute for Risk Assessment Sciences (IRAS), Utrecht University, under the supervision of Prof. Dr. Aldert Piersma and Dr. Ellen Hessel. During her research, she completed the Postdoctoral Education in Toxicology to become a European Registered Toxicologist. She was also actively engaged in science communication through writing blogs and making a video and a theatre play about her research.

As of December 2020 Victoria continued to work in the Centre for Health Protection at RIVM as scientific resarcher, focussing on research in animal-free innovations for safety testing. 


